(1)

UNIVERSIDAD DE SALAMANCA

Facultad de Derecho

Departamiento de Derecho Público General

Doctorado en Procesos Políticos Contemporáneos

Tesis Doctoral

\title{
LA PROFESIONALIZACIÓN DE LAS CAMPAÑAS ELECTORALES EN BRASIL (1989-2006)
}

Doctorando:

Fenelon Martins da Rocha Neto

Directora:

Drª Flavia Freidenberg

Salamanca, diciembre de 2007 

ons

UNIVERSIDAD DE SALAMANCA

Facultad de Derecho

Departamiento de Derecho Público General

Doctorado en Procesos Políticos Contemporáneos

Tesis Doctoral

\section{LA PROFESIONALIZACIÓN DE LAS CAMPAÑAS ELECTORALES EN BRASIL (1989-2006)}

Doctorando:

Fenelon Martins da Rocha Neto

Directora:

Drª Flavia Freidenberg

Salamanca, diciembre de 2007 



\section{RESUMEN}

Esta investigación analiza la profesionalización de las campañas electorales, en concreto el impacto de los factores sistémicos (sistema electoral, sistema de partidos, cultura política y sistema de medios) y partidistas (el marco originario, organización interna y liderazgo) en esa profesionalización. La hipótesis central es que esos factores delimitan el nivel de profesionalización. Se analizan las dos principales campañas de cada una de las elecciones presidenciales brasileñas de 1989 a 2006. Se encuentra que factores como el sistema electoral con reglas rígidas, sobre todo para acceso a los medios, frenan la profesionalización; que un sistema de partidos débil y un sistema de medios competitivo desempeñan un papel opuesto, incentivando la profesionalización. La cultura política interfiere en la profesionalización y en el culto a la imagen, en especial por la presencia destacada del clientelismo. Los factores partidistas resultan decisivos en la organización de campaña: los partidos de masas como PT en sus comienzos limitan la presencia de consultores y la centralización del comando, el opuesto del que pasa con PRN, un partido profesional electoral. También los liderazgos individuales fortalecen la rápida profesionalización, puesto que son la misma referencia del partido. La investigación ofrece una propuesta de medición del nivel de profesionalización, con el análisis de 25 indicadores para cada una de las campañas, de ahí resultando un índice que revela el nivel profesional de cada campaña. Los índices registrados desde 1989 son de creciente profesionalización, en algunos casos comparables al patrón estadounidense, considerado el más profesional.

Palabras-Clave: Campaña electoral, campaña profesional, profesionalización de la política, Brasil. 


\section{ABSTRACT}

This investigation analyses the professionalization of the political campaigns, concretely the impact of the systematic (electoral system, parties system, political culture and the media system) and party's factors (the origin, the internal organization and leadership) in this professionalization. The main hypothesis is that these factor works as limits on the professionalization level. It is analyzed the main campaigns in the history of presidential elections in Brazil between the years 1989 and 2006, concluding that factors such as a complex of rigid rules applied to the electoral system, specially applying to limit the access to the media, works as a major brake to the increasing professionalization of the campaigns, a situation completely opposed to the role played by a system in which a weak party system or a competitive media system. The political culture interferes directly in the professionalization and the image cult, especially in a system in which clientelism has got so much presence. The parties' faithful results decisive in any campaign organization: mass parties such like PT, in its origins, limited the presence of consultants and centralized the command of the campaign, a way that was not taken by PRN, a real professional party. On the other hand, individual leaderships made it stronger the mentioned professionalization, as they are pretty much the main reference in the party. The investigation offers a proposed index on how to measure the professionalization level of a political campaign, analyzing 25 indicators in each one of the campaigns, resulting in a index that reveals the professional level of each campaign. The indexes registered since 1989 demonstrates a raising level of professionalism in each campaign, sometimes compared to the North-American standard, considered the most professional one.

Key-words: Electoral campaign, professional campaign, professionalization of politics, Brazil. 


\section{RESUMO}

Esta investigação analisa a profissionalização das campanhas eleitorais, em concreto o impacto dos fatores sistêmicos (sistema eleitoral, sistema de partidos, cultura política e sistema de mídia) e partidários (o marco originário, organização interna e liderança) em essa profesionalização. A hipótese central é que esses fatores delimitam o nível de profissionalização. São analisadas as duas principais campanhas de cada uma das eleições presidenciais brasileiras de 1989 a 2006. Conclui-se que fatores como o sistema eleitoral com regras rígidas, sobretudo para o acesso aos meios de comunicação, estancam a profissionalização; que um sistema de partidos débil e um sistema de meios competitivo desempenham um papel oposto, incentivando a profissionalização. A cultura política interfere na profissionalização e no culto à imagem, em especial pela presença destacada do clientelismo. Os fatores partidários resultam decisivos na organização de campanha: os partidos de massas como PT no seu começo limitam a presença de consultores e a centralização do comando, o oposto do que acontece com o PRN, um partido profissional eleitoral. Também as lideranças individuais favorecem à rápida profissionalização, posto que são a própria referência do partido. A investigação oferece uma proposta de medição do nível de profissionalização, com a análise de 25 indicadores para cada una das campanhas, daí resultando um índice que revela o nível profissional de cada campanha. Os índices registrados desde 1989 são de crescente profissionalização, em alguns casos comparáveis ao padrão norte-americano, considerado o mais profissional.

Palavras-Chave: Campanha eleitoral, campanha profissional, profissionalização da política, Brasil. 


\section{CONTENIDO}

PARTE I:

LA COMUNICACIÓN POLÍTICA Y LAS CAMPAÑAS ELECTORALES: HERRAMIENTAS Y DIMENSIONES DE ANÁLISIS

1. Los estudios de la comunicación política $\quad 13$

$\begin{array}{lr}\text { 1.1. Introducción } & 15\end{array}$

i) Primera Fase: una teoría de la propaganda 17

ii) Segunda Fase: los factores sociales y la teoría de los efectos mínimos 19

iii) Tercera Fase: la identificación partidista 20

iv) Cuarta Fase: la perspectiva cognitiva

1.2. La investigación en materia de comunicación política en España 26

1.3. Los estudios en comunicación política en América Latina 28

1.4. Los estudios de comunicación política en Brasil 31

2. Campañas Electorales: el recorrido hacia la profesionalización 35

\begin{tabular}{ll} 
2.1. & Introducción \\
\hline
\end{tabular}

2.2. Características de las campañas profesionalizadas $\quad 41$

2.3. Tres pasos hacia la profesionalización 44

2.4. Factores que influyen en la profesionalización 47

3. El objeto de estudio: el nivel de profesionalización de las campañas en Brasil $\quad 55$

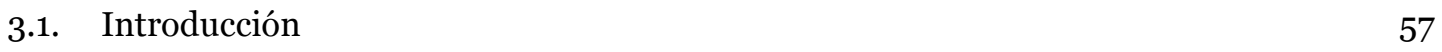

3.2. Una propuesta de medición del nivel de profesionalización $\quad 58$

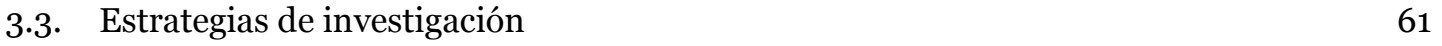

3.4. Las hipótesis de trabajo $\quad 69$

3.5. Datos: las técnicas de recolección y fuentes 71

PARTE II

ESCENARIO COMPETITIVO Y CAMPAÑAS ELECTORALES 79

4. Los factores sistémicos y partidistas:

la influencia sobre las campañas brasileñas $\quad 81$

$\begin{array}{lr}\text { 4.1. Introducción } & 83\end{array}$

4.2. Los factores sistémicos $\quad 84$

4.2.1. El Sistema Electoral: control de los medios, publicidad gratuita y campaña cara 86

4.2.2. El sistema de partidos: individualismo, fragmentación y electoralismo 96

4.2.3. Liderazgo y clientelismo: ante todo, el personalismo y el apartidismo 103

4.2.4. El Sistema de Medios: concentración y protagonismo como actor político 110

4.3. Factores partidistas 116

4.3.1. Origen de los partidos: cultura y pautas para la acción $\quad 117$

i) PT: base colectiva, horizontalidad y participación de la afiliación 122 
ii) PRN: personalismo en un partido que solo existe en el papel 124

iii) PSDB: el pragmatismo por en cima del discurso programático 126

$\begin{array}{ll}\text { 4.3.2. } & \text { La organización partidista } \\ & 128\end{array}$

i) Control personal y campaña profesional en PRN 130

ii) Liderazgos políticos y profesionalización, la doble faz de PSDB 132

iii) Cambios internos, menos democracia y más profesionalismo en PT 133

4.3.3. El liderazgo partidista: el carácter del candidato como imagen de la campaña 136

i) Collor, el héroe de película como producto del marketing 137

ii) Cardoso, Serra y Alckmin, la competencia técnica como posicionamiento 139

iii) Lula, el mítico héroe hijo del pueblo: discurso al corazón de la gente 141

PARTE III

ORGANIZACIÓN Y COMUNICACIÓN EN LAS CAMPAÑAS BRASILEÑAS: LA MEDICIÓN DE LA PROFESIONALIZACIÓN

$\begin{array}{ll}\text { 5. La dimensión organizativa } & 147\end{array}$

$\begin{array}{ll}\text { 5.1. Introducción } & 149\end{array}$

5.2. El comando de las campañas: centralización vs descentralización 151

$\begin{array}{ll}\text { 5.3. La presencia de los consultores } & 159\end{array}$

5.4. La planificación de campaña 166

5.3.1. Campañas de Largo Plazo $\quad 166$

$\begin{array}{ll}\text { 5.3.2. } & \text { Campañas de Medio Plazo } \\ & 171\end{array}$

5.3.3. Campañas de Corto Plazo 173

5.5. La financiación: grupos de interés vs voluntarios $\quad 175$

5.6. El monitoreo del elector: el uso de las encuestas y grupos focales 181

$\begin{array}{ll}\text { 5.7. Media training y entrenamiento de equipos } & 185\end{array}$

5.8. El uso de las nuevas tecnologías 189

5.9. La participación de la afiliación 193

6. La dimensión comunicacional 197

$\begin{array}{ll}\text { 6.1. Introducción } & 199\end{array}$

i) Los spots sueltos 200

ii) Los bloques $\quad 202$

6.2. El actor principal: mucha personalización y poco partidismo 207

6.3. El tema es el mismo candidato y su imagen 212

6.4. Profundidad de los mensajes: la superficialidad como patrón 216

6.5. El enfoque geográfico: mensajes sujetas al enfoque nacional 212

6.6. Segmentación de mensajes 224

6.7. El lenguaje simbólico como atajo 228

6.8. El predominio de la emoción como estrategia política 235

6.9. La sofisticación técnica $\quad 239$

$\begin{array}{ll}\text { 6.10. Los efectos cognitivos } & 244\end{array}$

6.11. Objetividad de los mensajes por en cima de todo 247

$\begin{array}{ll}6.12 & \text { La significativa negatividad de los mensajes } \\ & 251\end{array}$

$\begin{array}{lll}7 & \text { La cuantificación del nivel profesional } & 257\end{array}$

7.1. El índice de profesionalización en la dimensión organizativa 259

7.2. El índice de profesionalización en la dimensión comunicacional 263

7.3. El índice global de profesionalización de las campañas brasileñas 267

$\begin{array}{ll}\text { CONCLUSIONES } & 273\end{array}$

$\begin{array}{lr}\text { BIBLIOGRAFía } & 279\end{array}$ 


\section{ÍNDICE DE CUADROS}

$\begin{array}{lll}\text { 1.1 } & \text { Evolución de los estudios de la comunicación política en el siglo XX } & 17\end{array}$

2.1 Características de las Campañas Electorales, por fase 45

2.2 Factores que inciden sobre el nivel de profesionalización de las campañas, según autor $\quad 51$

3.1 Estructura de análisis de campaña profesional de Gibson y Römmele 62

3.2 Esquema de análisis de las campañas profesionales 66

3.3 Indicadores de Profesionalización en Campañas Electorales 67

3.4 El corpus de análisis de la investigación, por candidato (segundo/N) $\quad 74$

4.1 La cronología del voto en Brasil $\quad 89$

4.2 Sistema electoral y efectos sobre las campañas en Brasil 95

4.3 Número efectivo de partidos en la Cámara de los Diputados (1982-2006) 98

4.4 Número de diputados que cambiaron de partidos por legislatura (\%) 99

4.5 Representación partidista y votación presidencial en 1989 ( $1^{\text {a }}$ vuelta) 101

4.6 Sistema de partidos y efectos sobre las campañas en Brasil 102

$\begin{array}{lll}4.7 & \text { El prestigio y el poder de las Instituciones brasileñas (\%) } & 107\end{array}$

4.8 Cultura política y efectos sobre las campañas en Brasil 109

4.9 Índice de lectura de periódicos por clase socioeconómica en Brasil 112

4.10 Las redes de TV abiertas en Brasil 112

4.11 Sistema de medios y efectos sobre las campañas en Brasil 116

4.12 Elementos constitutivos de la dimensión origen de los partidos,

4.13 Los factores originarios en los partidos PRN, PSDB y PT 120

4.14 Representación del PRN en el Congreso Nacional 126

$\begin{array}{ll}4.15 \text { El cambio organizativo } & 129\end{array}$

5.1 Estructura de mando en las campañas brasileñas $\quad 152$

5.2 Los coordinadores generales de las campañas y sus vínculos 161

$\begin{array}{lll}5.3 & \text { Presencia y centralidad de los consultores } & 163\end{array}$

$\begin{array}{ll}5.4 & \text { La preparación de las campañas } \\ 5 \cdot 5 & 168\end{array}$

$\begin{array}{lll}5.5 & \text { Las donaciones privadas en las elecciones de } 1998 & 178\end{array}$

$\begin{array}{ll}\text { 5.6 La financiación de las campañas } & 179\end{array}$

5.7 Utilización de los recursos de monitoreo en las campañas 184

5.8 Los recursos de entrenamiento en las campañas brasileñas $\quad 188$

5.9 Las nuevas tecnologías en las campañas brasileñas 190

5.10 Capital vs voluntarios: el soporte de las campañas 194

7.1 Distribución de los índices de profesionalización de las campañas 269 


\section{ÍNDICE DE TABLAS}

6.1 Los formatos de los spots sueltos, por duración (en segundos) 201

6.2 Los formatos de los mensajes en los bloques, por duración (en segundos) 205

6.3 Tiempo medio de los spots en los bloques de programas (en segundo) 207

6.4 Personalismo $v$ s partidismo en los bloques de programas 209

6.5 Personalismo $v$ s partidismo en los en los spots sueltos 210

6.6 Temas $v s$ imagen en los bloques de programas y spots sueltos 213

6.7 Profundidad de los mensajes en los bloques de programas 219

6.8 Profundidad de los mensajes en los spots sueltos 220

6.9 El enfoque geográfico: nacional $v s$ local en los bloques 222

6.10 La segmentación de mensajes en los bloques de programas 225

$\begin{array}{ll}\text { 6.11 La segmentación de mensajes en los spots sueltos } & 228\end{array}$

6.12 Concreto $v s$ simbólico en los bloques de programas 230

6.13 Concreto $v$ s simbólico en los spots sueltos 232

6.14 El tono emocional de los mensajes en los bloques de programas $\begin{array}{ll}\text { y spots sueltos } & 237\end{array}$

6.15 La sofisticación técnica de los mensajes en los bloques de programas 241

6.16 La sofisticación técnica de los mensajes en los spots sueltos 243

6.17 Los efectos cognitivos en los bloques de programas y spots Sueltos 246

6.18 La propuesta única en los bloques de programas ( $\mathrm{n}^{\mathrm{o}}$ de bloques) 249

6.19 Objetividad de los mensajes, en los bloques y spots sueltos 250

6.20 La negatividad de los mensajes en los bloques de programas y spots sueltos $\quad 252$

7.1 El nivel de profesionalización en la organización de campañas 261

7.2 El nivel de profesionalización en la comunicación de las campañas $\quad 264$

7.3 El nivel global de profesionalización en las campañas brasileñas 268 


\section{ABREVIACIONES UTILIZADAS}

\section{Partidos Políticos:}

ARENA Aliança Renovadora Nacional

DEM Democratas

MDB Movimento Democrático Brasileiro

PAN Partidos dos Aposentados da Nação

PCB Partido Comunista Brasileiro

PC do B Partido Comunista do Brasil

PCO Partido da Causa Operária

PDT Partido Democrático Trabalhista

PFL Partido da Frente Liberal

PL Partido Liberal

PMDB Partido do Movimento Democrático Brasileiro

PMN Partido da Mobilização Nacional

PP Partido Progressista

PPB Partido Progressista Brasileiro

PPR Partido Progressista Reformador

PPS Partido Popular Socialista

PRN Partido da Reconstrução Nacional

PRONA Partido da Reedificação da Ordem Nacional

PSB Partido Socialista Brasileiro

PSC Partido Social Cristão

PSDB Partido da Social Democracia Brasileira

PSTU Partido Socialista dos Trabalhadores Unificado

PT Partido dos Trabalhadores

PTB Partido Trabalhista Brasileiro

PTR Partido Trabalhista Renovador

PV Partido Verde

PR Partido Republicano

\section{Otras siglas:}

TSE Tribunal Superior Electoral

TRE Tribunal Regional Electoral

Ibope Instituto Brasileño de Opinión Pública 
A Xica, Bruno y Mariana, que compartiron y sostenieron éste proyecto en todos los momentos, en las más diversas situaciones.

A Irene y Antonio Rocha, la semilla de todo lo que pueda cosechar. 
"O segredo da verdade é o seguinte: não existem fatos, só existem histórias".

João Ubaldo Ribeiro (escritor brasileño) 


\section{Agradecimientos}

La realización de esta tesis no sería posible sin la colaboración de una larga lista de personas y instituciones, a cuales soy deudor hoy y siempre. A todos soy muy agradecido. En esa larga lista de soportes, empiezo agradeciendo a mi directora, Flavia Freidenberg, que supo alargar y suavizar mis caminos, abriendo horizontes y estimulando a la realización de saltos más osados. En algunos momentos, Flavia me transformó en un hombre-bala, con dos diferencias: la primera, es que fue catapultado no bajo la limitada lona del circo, sino al espacio abierto de la comunicación política; la segunda, la directora asumió a la vez las funciones del cañonero que enciende la mecha y de la red que hace de la caída una delicia. Y tengo la viva sospecha (y la más ardiente esperanza) que el "salto" será del agrado del respetable público.

Agradezco al profesor Manuel Alcántara, coordinador del programa de doctorado, de quien aprendí muchas lecciones, dentro y fuera de las clases. Alcántara tiene la costumbre de decir que de la academia se puede pedir todo lo que no cueste dinero; pero más que el soporte académico, él ofrece el afecto que no se paga sencillamente porque no tiene precio. Dentro del programa de doctorado, agradezco a cada uno de los profesores que tuve la fortuna de encontrar en las aulas -Ivan Llamazares, Fátima García, Salvador Martí, Agustín Ferraro, Pilar Domingo, Pilar Gangas, Eva Anduiza, Ramón Máiz, Roberto Espíndola, Mónica Méndez Lago- y aquéllos con quien pudo compartir ideas y pasiones, como Araceli Mateos y Leticia Ruiz. Agradezco a las colaboraciones de Ángel Badillo, Patricia Marenghi, Mercedes García, Patricia Otero y Mar Rosón. Doy las gracias a los compañeros de programas, en especial Aquiles Magide, Hugo Picado, Martín Sacchi, Lucero Ramirez y Wladimir Gramacho, persistentes y decididos a seguir más allá, juntos. Y a Laureano Checa, amistad y apoyo que se mantienen a pesar de la distancia.

Quiero dejar manifiesto mi agradecimiento a la Universidad Federal de Piauí, en especial a mis compañeros del Departamento de Comunicación Social y a los rectores Pedro Leopoldino y Luís Santos Júnior. También a la Fundación Rotary Internacional, por la beca en el primero momento; gracias a Erlich Cordão, Décima Rosado (Rotary Teresina) y Alejando Iniestal (Rotary Salamanca), que funcionaron como estímulo, soporte y amparo en los primeros momentos de ese reto que ahora estoy a punto de 
superar. A la Capes, agencia del gobierno brasileño de estímulo a la investigación, por la beca fundamental a la conclusión de esa tesis. A Charles Silveira, Washington Bonfim y João Xavier, por el incentivo inicial. Y a Margareth Cabral, por la ayuda en muchos y cruciales momentos de esa trayectoria.

Tuve el apoyo decisivo de personas e instituciones, que me ayudaron en la lucha contra la corta memoria de Brasil, es decir, en la dura tarea de encontrar videos electorales que muchas veces ni siquiera los partidos tenían. Agradezco al Iuperj en la persona de Marcos Figueiredo; a GW Comunicação, en las figuras de Gilnei Rampazzo y Kátia Maia; a la TV Gazeta de Alagoas, sin la cual no tendría como analizar los videos de la publicidad de Collor; al Nilton Almeida, Soraya Alencar, Afonso Cozzolino, Silvio Mendes y Luciano Nunes Filho, atajos hacia algunos archivos que mantienen viva la memoria de las campañas brasileñas. Agradezco a todos los 13 profesionales de campaña que tuvieron la disposición de contestar mis preguntas sobre las disputas electorales en Brasil: Francisco Malfitani, Chico Santa Rita, Cláudio Humberto Rosa e Silva, Orlando Brito, Laerte Rímoli, Gilney Rampazzo, Elysio Pires, Carlos Brickmann, Fernando Lacerda, Eduardo de Godoy Pereira, Carlos Manhanelli, Luiz González y Marcos Coimbra. También a los diputados José Genoino y José Aníbal, por las informaciones de PT y PSDB, respectivamente.

Agradezco a Jonas Lemos, por el primer punto de apoyo en Salamanca, y a Maricarmen Herrera, por el último soporte; a Pavlova, generosidad y amistad por encima de todo; y a Eduardo Álvarez Lamas, solidaridad en forma de persona. Finalmente, a mi esposa Xica, decidida en multiplicar su cariño y su entrega por un proyecto que también es suyo, y a mis hijos Bruno y Mariana, comprensibles, dedicados y apasionados por un reto que se hizo de todos. A cada uno, mi más profunda gratitud.

Salamanca, diciembre de 2007. 
INTRODUCCIÓN 

Esta investigación analiza el proceso de profesionalización de las campañas electorales brasileñas desde el restablecimiento de las elecciones presidenciales por sufragio universal. Cuando se someten al veredicto popular, las campañas lo hacen según objetivos políticos cuyo éxito suele ser evaluado por el desempeño en número de votos y puestos públicos alcanzados. La profesionalización de las campañas se transformó en el recurso fundamental hacia el mejor desempeño en los comicios, tendencia que gana proporciones planetarias (Swanson y Mancini, 1996) y atrapa a los partidos y las candidaturas tanto a la derecha como a la izquierda. El soporte profesional cambia el modo de acción adoptado por las candidaturas, pero también se ajusta a las condiciones competitivas de cada sitio.

El propósito de esta investigación es analizar la profesionalización de las campañas, buscando conocer los factores que inciden sobre ese proceso a la luz de la experiencia brasileña. Se pretende mirar las campañas como resultado de un conjunto de factores sistémicos (sistema electoral, sistema de partidos, cultura política, estructura de los medios de comunicación) y partidistas (el marco originario de la organización, el modo de organización interna, el carácter del liderazgo) que inciden sobre las actividades y decisiones que toman los políticos y sus partidos para conseguir votos y maximizar sus posibilidades de triunfo electoral.

La principal motivación para la realización de este trabajo es la importancia atribuida en Brasil a las campañas, además de la evidente carencia en el país de estudios sobre la influencia de los factores del ambiente competitivo en las campañas-las reglas formales e informales que orientan en juego electoral- y sobre la misma profesionalización. Se entiende por profesionalización el esfuerzo técnico -es decir, un conjunto de acciones cientificamente sostenido- que asegura mayor eficacia a una campaña en la búsqueda del apoyo del elector y así de los objetivos políticos de las candidaturas (Norris, 2001 y 2004; Gibson y Römmele, 2001). Al enfocar a un electorado cada vez más desalineado, la profesionalización se apoya más en los medios que en las reclaciones interpersonales, con amplio dominio de la imagen (García Beaudoux et al, 2006).

Desde la primera elección presidencial de la actual fase democrática (1989) y la sorprendente victoria de Fernando Collor de Melo, la discusión sobre el papel de la 
comunicación política ${ }^{1}$ en general y las campañas electorales en particular pasaron a tener importante espacio en la academia. Pero los debates siempre estuvieron limitados fundamentalmente a dos enfoques: el primero, el poder de la publicidad electoral de televisión en la persuasión de los votantes, es decir, qué efectos tienen las acciones de comunicación electoral en la conformación del voto popular; segundo, el papel de los medios de comunicación de masas en la construcción de candidaturas, teniendo en cuenta sobre todo el protagonismo asumido por las empresas de comunicación en la victoria de Collor y en las dos de Cardoso. Como telón de fondo, esos estudios centran la discusión sobre la transformación de la política en una mercancía que se deja guiar por los principios del marketing comercial; es el debate sobre el establecimiento del imperio del marketing político en el cual las candidaturas se resumirían a productos construidos sobre todo en el imaginario de la gente, y la regla fundamental es un vale todo por el éxito electoral.

De este modo, hablar de marketing político significa hablar de profesionalización de los procesos políticos, que al fin y al cabo utilizan recursos técnicos con el propósito de alcanzar mayor eficacia (Mancini, 1995). Esa transformación está asociada a la pérdida de identificación del elector y el declinar de los partidos como correa de transmisión entre la gente y la política. Sin embargo, muchas veces las investigaciones hablan de ello como si fuera una situación puesta y acabada, como mucho una realidad que se instala en un sistema dado desde la experiencia ajena, importada sin más. Lo primero que hay que destacar es que la profesionalización no se da de igual modo en diferentes contextos, como han demostrado diversos estudios (Kaid y Holtz-Bacha, 1995; Swanson y Mancini, 1996; Dader, 1999; Espíndola, 2003). De hecho, las campañas electorales son producto de su tiempo y del lugar donde se desarrollan (Bowler y Farrell, 1992), generando diferencias sustantivas una a otra. Además, como algunos factores son especialmente influyentes en la conformación de esas campañas, cabe saber en concreto el tipo de influencia que cada factor impone y cómo se refleja en las acciones que buscan conquistar el voto del elector.

Esa consideración es el motor que impulsa esta investigación: si se tiene en cuenta que la profesionalización es el resultado de factores que integran el escenario competitivo, cabe saber cómo se da la influencia de esos factores y qué resultados producen estos últimos. Es decir, qué tipo de campaña sale de un determinado contexto competitivo. Desde el principio de la presente investigación se buscaba saber el nivel de

\footnotetext{
1 Comunicación política es “el intercambio de signos, señales, o símbolos de cualquier clase, entre personas físicas o sociales políticos, comunicadores, periodistas y ciudadanos con el que se articula la toma de decisiones políticas así como la aplicación de éstas en la comunidad" (Canel, 1999: 23-24). Las campañas aplican la comunicación política en el ámbito de las disputas por puestos de representación.
} 
profesionalización de las campañas electorales en Brasil a partir del análisis de la presencia de rasgos considerados caracterizadores de una campaña profesional, como mediatización, capital intensivo, presencia de consultores, uso de nuevas tecnologías, prioridad del lenguaje simbólico, sofisticación técnica de los mensajes y efectos coginitivos. La observación general es que las campañas electorales de Brasil son las más evolucionadas de América Latina (Queiroz, 2006), una percepción que se estableció desde las primeras elecciones presidenciales con la elección de Collor. Un análisis sencillo de los mensajes puede evidenciar la calidad técnica de la publicidad electoral, así como una mirada sobre la organización revela el alto nivel de la estructuración y gestión de campañas. Pero no basta una mera descripción. Es necesario explicar la razón de porque las campañas brasileñas son como son, objetivo asumible tanto para el caso de Brasil como de otros sistemas democráticos.

El caso brasileño presenta destacadas razones para un análisis más complejo del fenómeno de la profesionalización de campañas: es la segunda democracia electoral del planeta, con más de 120 millones de votantes en la disputa presidencial de 2006; es la más importante democracia de América Latina, además de contar con una economía razonablemente fuerte con un sistema de medios de comunicación con sustancial grado de independencia y un historial de elecciones que en las últimas cinco disputas ha elegido representantes de 3 distintos partidos sin cuestionamientos relevantes de las elecciones y sus resultados, ni de la legitimidad en el ejercicio del poder. El proceso electoral brasileño es también apuntado como uno de los más sofisticados de la región -en algunos aspectos, quizá del mundo- en cuanto al uso de técnicas modernas, desde el sistema de votación por ordenador hasta mecanismos propios de la más avanzada mercadotecnia.

Por ello, algunas preguntas se ponen en evidencia: ¿Cuál el grado de profesionalización de las campañas brasileñas? ¿Qué factores inciden sobre la conformación de mayor o menor grado de profesionalización? ¿Qué puntos de convergencia y discrepancia tienen las campañas brasileñas respecto a otros sistemas? ¿Cómo se puede medir el grado de profesionalización de las campañas? Estas son preguntas que responden a los tres objetivos de investigación analítica -conceptual, descriptivo y explicativo-.

Al intentar comprender y explicar la profesionalización de las campañas brasileñas, esta investigación apeló la perspectiva comparada, empezando con una mirada hacia los marcos teóricos de las campañas profesionales, especialmente los patrones del modelo estadounidense, siempre tomado en la literatura como los mayores níveles de profesionalización (Norris et al, 1999; Norris, 2001; Gibson y Rommële, 2001). Esa mirada permitirá la identificación de los rasgos principales del modelo patrón y luego 
buscarlos en las prácticas de campaña brasileñas; es una comparación que explicitará el nivel profesional en Brasil teniendo como parangón las prácticas presentes en Estados Unidos. Además, se hará una segunda comparación, ahora en el ámbito interno, permitiendo comprender la evolución de la misma profesionalización de una campaña a otra, entre partidos y incluso en un mismo partido. Las diferencias por tanto son a nivel diacrónico (un partido a lo largo del tiempo) y a nivel sincrónico (varias campañas/partidos en un mismo momento electoral).

La hipótesis central es que el conjunto de los factores sistémicos (sistema electoral, sistema de partidos, cultura política y sistema de medios) y partidistas (el marco originario, organización interna y liderazgo) determinan las condiciones de acción de cada campaña. Los factores sistémicos suelen producir impacto general sobre todas las candidaturas, como son las reglas establecidas para uma elección. Ello queda evidente en las presidenciales de 1994, cuando la limitación legal del uso de sofisticados recursos tecnológicos resultó en alguna pérdida en la calidad técnica de los mensajes electorales para televisión. No obstante, la influencia de los factores sistémicos es más amplia. La personalización es fortalecida por rasgos culturales (por ejemplo, el clientelismo operado por los liderazgos regionales), por un débil sistema de partidos y por una sociedad sustancialmente mediatizada. La presencia y centralidad de los consultores anda a la par con la poca importancia de los partidos y normas de la legislación, como el modelo de financiación que privilegía los grupos de interés. La consecuencia es el desplazamento de los partidos y candidaturas hacia una posición centrípeta y de estilo catch all donde los objetivos electorales se imponen como prioridad mayor.

Los factores partidistas también producen efectos, empezando por la estructura de campañas, donde los partidos de masas -caso del PT en su principio- garantizan el comando en manos de los afiliados y los partidos profesionales electorales (caso de PRN) contratan expertos del mercado para la gestión del proceso. La organización interna de los partidos profundiza esa situación, las relaciones horizontalizadas llevando a la constitución de comandos colectivos y menos profesionales, al revés de las relaciones verticales en que todo se resume al pequeño núcleo formado por y en torno al liderazgo o candidato. El origen partidista también influye sobre la profesionalización: en el caso de partidos fundados desde liderazgos colectivos (caso de PT y de PSDB), se establece una cultura del diálogo con las esferas inferiores de la organización partidista, caso muy distinto de los partidos con liderazgo individual, y todavía más el caso de liderazgos carismáticos, donde el historial del partido se vincula al mismo líder. Estos factores condicionan las estrategias de acción de las campañas tanto en el área organizativo como en el comunicacional: un líder carismático siempre 
fortalece la tendencia a la personalización y emocionalización de los mensajes, rasgos relacionados entre los caracterizadores de las campañas profesionales.

En el trabajo se explora el modo en que los factores sistémicos y partidistas inciden sobre las dos principales campañas de cada una de las cinco elecciones presidenciales, tomando en cuenta tanto las campañas exitosas como las derrotadas, además de partidos ubicados a la derecha (PRN), al centro (PSDB) y a la izquierda (PT). Estos son partidos que además cuentan con trayectoria muy distintas -el PT, un partido que nace colectivista y revolucionario; el PSDB, colectivista pero sin cuestionar el sistema; y PRN que tiene origen personalista y respetuoso del status quo vigente- y prácticas internas que incluyen el personalismo extremo (PRN) y la alta disciplina (PT). Las campañas analizadas por tanto son muy diversas en las condiciones para el desarrollo de las acciones de acercamiento al elector, como el desequilibrado soporte financiero o el acceso a los recursos tecnológicos. Diferencias tan sustantivas ofrecen la oportunidad de evaluar el impacto de los diversos factores endógenos y exógenos en el nivel profesional.

La recogida de los datos para la presente investigación se desarrolló en dos momentos. El primero, a través de entrevistas con 13 profesionales de campañas y dos ex dirigentes partidistas que participaron de los equipos de comando en diversas candidaturas analizadas. Las informaciones prestadas por estos profesionales y políticos cubren las diez campañas en áreas como coordinación de marketing, creación publicitaria, encuestas, estructuración de campaña, relación con los medios y telemarketing, además de la coordinación política ${ }^{2}$. El segundo momento se materializó en el análisis de la publicidad electoral en televisión de los dos principales candidatos de cada elección: Collor y Lula, en 1989; Cardoso y Lula, en 1994 y 1998; Lula y Serra, en 2002; y Lula y Alckmin, en 2006. Esa estrategia de investigación permite analizar de modo más detenido las dimensiones organizativa y comunicacional, conciliando las informaciones cualitativas de las entrevistas con las cuantitativas traducidas en las frecuencias de determinados recursos comunicacionales.

Los resultados del análisis suponen un paso más en el proceso de comprensión de las campañas electorales. Primero, por aportar un nuevo enfoque sobre la profesionalización de campañas no sólo en Brasil sino en América Latina, donde son pocos los estudios con esa orientación. Segundo, por aportar una propuesta específica

\footnotetext{
2 A través de contatos por correo electrónico, fueron entrevistados los siguientes profesionales de campaña: Carlos Brickmann, Carlos Manhanelli, Chico Santa Rita, Cláudio Humberto Rosa e Silva, Eduardo de Godoy Pereira, Elysio Pires, Fernando Lacerda, Francisco Malfitani, Gilney Rampazzo, Laerte Rímoli, Luiz González, Marcos Coimbra y Orlando Brito. También fueron contactados por teléfono los diputados José Genoino y José Aníbal, ex presidente de PT y PSDB, respectivamente.
} 
de medición del nivel profesional, operado a partir del análisis de 25 indicadores de profesionalización distribuidos entre las dimensiones organizativa (referente a la estructura de gestión y ejecución de la campaña) y comunicacional (respecto a los formatos y contenidos de los mensajes electorales en televisión); el sumatorio de los indicadores resultarán en un índice de campaña profesional que explicite el nivel de profesionalización de cada campaña. Finalmente, la investigación tiene especial relevancia por contribuir al debate sobre las reformas políticas que ocupa la actual legislatura en Brasil. Si las campañas son también un reflejo de un sumatorio de factores formales e informales, la comprensión del impacto de esos factores puede ser de gran valia para mejorar el debate y la definición de algunos puntos de las reformas buscadas. En suma, la comprensión de los procesos que afectan la conformación de las campañas puede contribuir a la construcción de un escenario competitivo (por lo menos en el campo normativo) que implique el perfeccionamiento de las competencias electorales y del mismo proceso democrático.

El trabajo está estructurado en tres partes. La primera concentra los aspectos teóricos y metodológicos concentrados en los capítulos 1, 2 y 3. El primer capítulo es un repaso de los estudios sobre comunicación política desde la Antiguidad hasta hoy, con atención especial a las aproximaciones teóricas que tratam de la comunicación política y de las campañas, desde la visión propagandística de la década de 1920 hasta el paradigma actual de los enfoques cognitivos. El apartado enfoca aún los estudios sobre el tema en España, América Latina y Brasil. En el capítulo 2, se hace un acercamiento teórico a la profesionalización de las campañas, asociando los cambios en las prácticas de campaña a las transformaciones sociales - por ejemplo, la centralidad de los medios- y en las instituciones políticas, como los partidos, en evidente declinio como representación de la ciudadanía. El capítulo 3 presenta el modelo teórico y metodológico de la propuesta de estudio de la profesionalización de las campañas brasileñas, con destaque para la elaboración de un índice capaz de medir el nivel profesional de cada campaña analizada.

En la segunda parte, compuesta por el capítulo 4, se analiza el impacto producido por los principales factores del ambiente competitivo en las campañas. En ella se hace la asociación entre esos factores y las campañas brasileñas en particular. La tercera parte está compuesta por tres capítulos con las evidencias empíricas. El capítulo 5 analiza la organización de las campañas, cuando son detalhadados 14 indicadores para cada una de las diez campañas estudiadas. El capítulo 6 es la evidencia empírica para la dimensión comunicacional, donde se analiza la ocurrencia y la intensidad de la ocurrencia de las características profesionales de los mensajes televisivos. El capítulo 7 
es la cuantificación de los indicadors, resultando en el Índice de Campaña Profesional. La tesis es complementada por las consideraciones finales a título de conclusiones. 

PARTE I:

La comunicación política y las campañas electorales:

herramientas y dimensiones de análisis 



\section{Los estudios de la comunicación política}

Resumen:

En este capítulo se hace un repaso de la evolución de los estudios de comunicación política, desde las primeras aportaciones de los filósofos griegos hace 25 siglos hasta las principales corrientes teóricas sobre el tema, desarrolladas desde la década de 1920. Los estudios ubicados en el siglo XX son mirados desde cuatro corrientes a la vez cronológica y de enfoque: la teoría hipodérmica, con enfoque propagandístico que atribuye alto poder a la comunicación de masas; la que enfatiza los factores sociales y destaca los efectos mínimos de la acción de comunicación política, aportación basada sobre todo en la Universidad de Columbia; el enfoque de la escuela de Michigan, que apunta a la identificación partidista como predictor en las decisiones del ciudadano; y la perspectiva cognitiva, con diversos enfoques, pero todos mirando la comunicación como un recursos de efecto de largo plazo. Además, el capítulo hace un repaso de los estudios desarrollados en España, América Latina y Brasil, destacando principalmente las aportaciones relacionadas con las campañas electorales. 



\subsection{Introducción}

Cuando se habla de la comunicación política en general se suele pensar en un fenómeno nuevo, que tendría sus bases a inicios de siglo XX, con un papel más destacado desde que la centralidad de la televisión y las concepciones del Marketing Político han impuesto el imperio de lo simbólico y de la imagen personal. Pero la Comunicación Política no sólo es una vieja práctica del ser humano, sino también uno de los objetos de estudio más antiguos de los pensadores. De hecho, la relación entre comunicación y política existe desde siempre, en los esfuerzos del hombre para relacionarse con el otro y a través de ese diálogo establecer un modo de predominio de sus visiones y intenciones; es la comunicación como instrumento de poder, que recibe la atención de los primeros filósofos ${ }^{1}$.

Desde las primeras reflexiones de Aristóteles, la comunicación política cumplió un largo recorrido hasta tomar conciencia de sí como disciplina en los años 1950 (Nimmo y Sanders, 1981) y consolidarse a mediados de los años 1970 como un importante y creciente campo de investigación capaz de ofrecer elementos fundamentales a la comprensión de los procesos políticos en general y de las campañas electorales en particular $^{2}$. La emergencia de ese campo como una ciencia se hace posible cuando unos medios permiten el libre flujo de información, centrándose en los intercambios comunicativas entre gobernantes y gobernados.

McQuail (1979) encuentra en los procesos electorales la identificación misma de la comunicación política, paradigma orientador de diversos trabajos, como el de Nimmo y Swanson (1990). Estos autores destacaban que la mayor parte de las investigaciones se dedicaban a estudiar el uso estratégico de la comunicación con el propósito de generar

\footnotetext{
1 Hace 24 siglos, Aristóteles apuntaba el parentesco entre los campos de la comunicación y de la política, en medio al énfasis que los estudios de la retórica tenían entre los griegos: la palabra era en el ágora una de las armas política más poderosas por la capacidad y la oportunidad de producir adhesiones que resultaban en decisiones importantes. Era el esfuerzo de persuadir, para Aristóteles una forma de convencer sobre un tema y motivar a que actúe según tal concepción. Para profundizar en el pensamiento de Aristóteles sobre la relación entre comunicación y política, ver Retórica y Política.

2 Desde Aristóteles hasta entrar en el siglo XX, las reflexiones sobre la relación entre elementos de la comunicación y de la político toman la atención de importantes pensadores a lo largo de la História. Entre ellos, Quinto Tulio Cicerón (Breviario de Campaña Electoral, en 64 a.C); Nicoló Maquiavel (El Principe, en 1513); Thomas Hobbes (The Elements of Law Natural and Politic, de 1640); John Locke (An essay concerning human understanding, en 1671); Jean Jacques Rousseau (Discours sur les sciences et les arts, de 1750); y también Alexis de Tocqueville (que en De la démocratie en Amérique, publicado en 1835/1840, habla de la formación de la opinión en la sociedad estadounidense).
} 
el conocimiento del público respecto las campañas. En ello relacionan enfoques como la teoría de la agenda-setting, los estudios de los usos y gratificaciones, los análisis sobre retórica y las aportaciones sobre los efectos de los mensajes políticos, hoy con destacada presencia en el campo.

Los investigadores suelen agrupar los estudios en tres grandes fases que atienden tanto a una evolución cronológica como de enfoques. Hay algunas diferencias en la agrupación, sobre todo en lo referente a la fase inicial, que algunos autores toman en cuenta las investigaciones anteriores a 1940 y otros no 3.

Es razonable tomar en cuenta las primeras aportaciones del período de entreguerras, sobre todo cuando una de las más importantes aportaciones de los últimos 30 años -la agenda-setting de McCombs y Shaw- reconoce sus orígenes en las contribuciones de Walter Lippmann. De ahí parece sensato dividir los estudios de comunicación política en cuatro grupos principales de trabajos empíricos (Cuadro 1.1). Aunque la primera fase no tenga una mirada específica siquiera indirecta sobre las campañas, esa fase inicial no puede ser desconsiderada por constituirse en el primer peldaño en la escalada hacia la afirmación científica del campo.

En la primera fase están los estudios enfocados especialmente en la propaganda política (la teoría hipodérmica), con las primeras aportaciones respecto a la opinión pública en el contexto de los medios de masas. Luego vienen los estudios que tiene como referencia la Universidad de Columbia, enfocando las relaciones sociales como determinantes del comportamiento político de la gente. El tercer momento, el más corto, es relativo a la Escuela de Michigan, que utiliza la identificación partidista como principal predictor de las decisiones políticas. Por último, emergen los estudios

\footnotetext{
3 Hay algunas diferencias en la agrupación, sobre todo en lo referente a la fase inicial. Martínez Pandiani (2000) sitúa el inicio de los estudios en los años 1920, rellenando las tres fases con diversas escuelas por período. Berrocal (1996) no toma en cuenta las investigaciones anteriores a 1940, considerando tan solo a partir de las aportaciones de la Escuela de Columbia. Además, analiza de forma autónoma la Escuela de Michigan, situada en los años 1960, y los estudios cognitivos, que empiezan en los años 1970 y alcanzan nuestros días. Wolf (1992), por su parte, presenta un esquema más fragmentado con nueve aportaciones teóricas de más destaque, aunque no exclusivamente sobre la comunicación política: la teoría hipodérmica; el enfoque empíricoexperimental; la teoría empírica de campo; el enfoque estructural-funcionalista; la Teoría Crítica de la escuela de Frankfurt; la teoría culturológica; los estudios Culturales; y las "teorías comunicativas". Wolf y Martínez Pandiani van más allá y subrayan una división extra que prevaleciera hasta los años 1970, enfrentando la mass communication research de matriz estadounidense con la europea Teoría Crítica de la escuela de Francfort. A pesar de tener como preocupación el impacto de la comunicación sobre la política y la sociedad, la Escuela de Frankfurt no es objeto de análisis en este trabajo por no desarrollar estudios específicos sobre las campañas electorales. Más bien es una teoría social crítica de las sociedades de masa y así con implicaciones políticas importantes. La literatura sobre el tema es demasiado amplia. Para una visión general de la Teoría Crítica desde varias percepciones, ver el número 1 de la revista Isegoría (Madrid: CSIC, 1990).
} 
cognitivos, con diversas aportaciones teóricas enfatizando no sólo el poder de los medios sino una nueva lógica de efectos de la comunicación: los efectos de largo plazo.

CUADRO 1.1

Evolución de los estudios de la comunicación política en el siglo XX

\begin{tabular}{|c|c|c|c|}
\hline Corriente & Periodo & Enfoques & Autores \\
\hline $\begin{array}{l}\text { Teoría de la } \\
\text { propaganda } \\
\text { (Teoría Hipodérmica) }\end{array}$ & $1920-1940$ & $\begin{array}{l}\text { Visión propagandística de la comunicación } \\
\text { (Teoría Hipodérmica). } \\
\text { El receptor es pasivo, vulnerable a los } \\
\text { mensajes emitidos con objetivos muy } \\
\text { específicos. }\end{array}$ & $\begin{array}{l}\text { Lippmann } \\
\text { Lasswell }\end{array}$ \\
\hline $\begin{array}{l}\text { Escuela de Columbia, } \\
\text { o de los efectos } \\
\text { mínimos }\end{array}$ & $1940-1960$ & $\begin{array}{l}\text { Los factores sociales son los principales } \\
\text { predictores del comportamiento político. } \\
\text { Las campañas producen efectos mínimos. } \\
\text { La comunicación funciona en dos etapas } \\
\text { (two steps flow), donde los líderes de } \\
\text { opinión tienen el papel de asimilar, filtrar y } \\
\text { distribuir la información. }\end{array}$ & $\begin{array}{l}\text { Lazarsfeld } \\
\text { Berelson } \\
\text { Katz } \\
\text { Hovland }\end{array}$ \\
\hline $\begin{array}{l}\text { Escuela de Michigan, } \\
\text { o de la identificación } \\
\text { partidista }\end{array}$ & $\begin{array}{l}\text { Década de } \\
1960\end{array}$ & $\begin{array}{l}\text { La política tiene poca importancia para la } \\
\text { gente, que toma sus decisiones según } \\
\text { relaciones partidistas de largo plazo. } \\
\text { Las campañas siguen sin gran importancia, } \\
\text { así también los medios. }\end{array}$ & $\begin{array}{l}\text { Campbell } \\
\text { Converse }\end{array}$ \\
\hline Efectos cognitivos & $\begin{array}{l}\text { Desde la } \\
\text { década de } \\
1970\end{array}$ & $\begin{array}{l}\text { La comunicación política produce efecto de } \\
\text { largo plazo, proceso en que los medios } \\
\text { ocupan protagonismo al jerarquizar hechos } \\
\text { y encuadrar la realidad. } \\
\text { Las campañas son permanentes y } \\
\text { ampliamente mediatizadas, exigiendo } \\
\text { sofisticada profesionalización. }\end{array}$ & $\begin{array}{l}\text { Blumler } \\
\text { McCombs Noële- } \\
\text { Neumann } \\
\text { Swanson } \\
\text { Mancini } \\
\text { Norris } \\
\text { Kaid }\end{array}$ \\
\hline
\end{tabular}

Fuente: Elaboración propia desde García Beaudoux, D’Adamo y Freidenberg (2007), Martínez Pandiani (2000) y Wolf (1992).

\section{i) Primera Fase: una teoría de la propaganda}

En la primera etapa, situada en el período de entreguerras, prevalece la creencia en una "sociedad de masas" donde los medios masivos acaparan un poder extraordinario: al llevar mensajes directamente al ciudadano, tendrían el poder de moldear opiniones y comportamientos. Uno de los marcos de ese período es Public Opinion, de Lippman, que en 1922 introduce el concepto de estereotipo como fundamental para el 
entendimiento de los consensos sociales y dedica atención a la relación entre los medios y la política, algo central en los estudios de la comunicación política actual4.

Posteriormente surge la primera teoría que intenta explicar los procesos de la comunicación política: la teoría de la aguja hipodérmica o de la bala mágica, que "presentaban a los medios inoculando mensajes a una audiencia que así quedaba inmunizada a la propaganda enemiga o narcotizada" (Sampedro 2000: 95). El surgimiento de la teoría se ajusta al momento histórico de experiencias políticas como los regímenes fascista y nazi en Italia y Alemania, que hacen de la propaganda y los emergentes medios masivos (el cine y la radio) soporte fundamental a la movilización de masas. En Italia y Alemania, la propaganda fue esencial en la estrategia de poder de esos regímenes que, por sus características de movimiento, necesitaban del más amplio apoyo, como un consenso plebiscitario de las poblaciones que no tenían la posibilidad de crítica o disenso (Mancini, 1995).

La Alemania nazi es el ejemplo más elocuente. Desde el RMVP5, Joseph Goebbels ${ }^{6}$ utilizó largamente la radio (incluso en los ambientes de trabajo) y desarrolló intensa política de incentivo al cine, creando su proprio "Hollywood" como soporte imprescindible a la acción de la propaganda7. Bajo la dirección del Ministro de Propaganda del III Reich se produjeron más de mil películas con fines de promoción política (Beevor, 2003).

Las acciones se pautaban por la idea de sociedad de masas, resultado de los cambios estructurales que llevó a la incorporación de las masas obreras y aumentó el poder de consumo de la clase media. En ese contexto, la teoría hipodérmica supone un sencillo modelo de estímulos y respuestas: los medios emiten un mensaje, generando determinadas reacciones en el receptor; la comunicación es tomada como un proceso asimétrico, en que cada individuo es un átomo aislado que reacciona aisladamente a los estímulos de los medios; y el receptor reacciona de modo particular, independiente de

\footnotetext{
${ }^{4}$ Como más tarde observaría McCombs (1996: 14), “Lippmann marcó una distinción importante entre el entorno (el mundo que realmente existe allí afuera) y el pseudo-entorno (nuestras percepciones privadas de aquel mundo)".

5 RMVP es como quedó conocido el Reischsministerium für Volksaufklärung und Propaganda, o "Ministerio para la educación del pueblo y la propaganda".

6 Goebbels fue uno de los más poderosos auxiliares de Adolf Hitler en el período de dominio nazista. Además de ministro de la propaganda de un régimen donde la imagen y las simbologías eran la fuente de legitimación y dominio, Geobbels era uno de los interlocutores más cercanos al führer. Sobre la comunicación en el régimen nazi, ver Rafael de España (2000), El cine de Goebbels, Madrid: Ariel; y Erwin Leiser (1974), Nazi Cinema, Londres: Secker \& Warburg.

7 Tan pronto llega al poder, Hitler por la mano de Goebbels concentra los esfuerzos de producción cinematográficos en algunas empresas bajo el incentivo del gobierno, resultando en películas con enfoque ideológico muy dirigido. Rafael España hace un interesante paralelo entre los métodos de producción de Hollywood y los utilizados por Goebbels en Alemania. Ver R. España (1998), “La guerra de celuloide: Goebbels vs. Hollywood, 1939-1941", en Film-Historia, vol. VIII, $\mathrm{n}^{\circ} 2-3$, pp.187-223.
} 
su entorno o su patrimonio sociocultural. Por ello, Wolf (1992: 18) define la teoría hipodérmica como una teoría "de la propaganda y sobre la propaganda", estableciendo una relación directa entre exposición a los mensajes y el comportamiento de la gente.

La teoría no encaja con la realidad: para que la teoría de la aguja hipodérmica funcione, los mensajes deberían no sólo llegar a los receptores sino llegar de modo uniforme, provocando reacciones iguales. Ocurre que no todos están expuestos a los medios y que tampoco se exponen del mismo modo.

\section{ii) Segunda Fase: los factores sociales y la teoría de los efectos mínimos}

En el período de posguerra surge lo que luego se denominaría mass communication research, que reúne a la vez la segunda fase (escuela de Columbia) y la tercera (escuela de Michigan). Las dos corrientes coinciden en la concepción de los medios con poca capacidad de influencia sobre el comportamiento político, además de un enfoque claramente empírico-experimental que centraliza su atención en los efectos de los mensajes comunicativos, en especial los efectos que los actores políticos buscan imprimir en la opinión pública sobre todo en el período de campañas electorales.

El marco inaugural de la segunda fase es People's Choise, de Lazarsfeld, Berelson y Gaudet (1944), estudio sobre las elecciones presidenciales estadounidenses de 1940, con la aplicación de los entonces novedosos estudios de panel como forma de constatar la evolución de la opinión de la gente y sus motivaciones en la decisión del voto. Instalada en la Universidad de Columbia, esa corriente se convirtió en el paradigma de los estudios de la comunicación política.

Los estudios de Columbia generan tres aportaciones principales. Una, respecto la metodología, asegura que las técnicas cuantitativas -capaces de estudiar grandes sectores de la realidad- ofrecen ventajas sobre los métodos cualitativos y a escala reducida. En cuanto a los procesos comunicativos, defienden 1) que la comunicación interpersonal produce mayor efecto sobre la actitud de la gente que los medios de masas y 2) de ahí, el poder de los medios es limitado, afectando al público en pequeña medida.

Los investigadores de Columbia destacan tres efectos producidos por las campañas: activación, refuerzo y conversión. El primero busca activar las predisposiciones latentes; el segundo intenta reforzar las predisposiciones y el tercero busca la conversión de las opiniones contrarias o sin una adhesión previa. La tarea más fácil es la de activación (o refuerzo), puesto que la gente está más propicia a aceptar lo que le es familiar; y la más difícil es llevar la gente a cambiar de posición política, de ahí en 
enfoque que aboga que las campañas electorales producen efectos mínimos sobre el comportamiento del elector. En otras palabras, los medios poco influyen en la conversión de los electores, las campañas funcionando más bien como instrumento de refuerzo de las opiniones previas, que por su parte están conformadas por los grupos de pertencia ${ }^{8}$.

Las investigaciones incorporan variables que buscan encontrar regularidades en la conducta de los individuos y de los grupos sociales, tales como valores, motivaciones, actitudes y percepciones. Señalan el papel especial jugado por los líderes de opinión en la búsqueda y redistribución de los mensajes en un flujo sistematizado en el modelo two step flow of communication (comunicación en dos etapas). Según los halazgos de Lazarsfeld y colegas, la influencia de los medios es indirecta, desde que los mensajes son filtrados por líderes de opinión que reciben las informaciones mediáticas, las seleccionan y reelaboran para entonces repasarlas a los sectores menos activos de la población. Debe resaltarse que las aportaciones de Columbia superan el paradigma propagandístico, pero no anula la visión de una audiencia de algún modo pasiva: el poder de influencia de los medios pasa a los líderes, que desempeñan un papel activo junto a una audiencia que sigue sobre todo receptiva -aunque la cercanía al líder resulte en modos de interacción que ofrecen posibilidades mayores que el simple consumo de mensajes a través de los medios de masa-.

\section{iii) Tercera Fase: La identificación partidista}

En comienzos de la década de 1960, los hallazgos de Columbia son cuestionados por investigadores de la Universidad de Michigan, como Angus Campbell (1980) o Phillip Converse (1964). Para los de Michigan, el principal factor explicativo del comportamiento electoral es la identificación partidista9. Abogan que la política no es importante en la vida de la gente y que la identificación partidista es forjada en bases afectivas a lo largo del proceso de socialización, funcionando como soporte de resistencias a las influencias puntuales.

Así, si bien divergen en cuanto a las influencias sociales, los investigadores de Michigan coinciden con Columbia respecto la escasa fuerza de los medios de masas, tomados tan sólo cómo más una de las fuentes que el elector utiliza para informarse sobre la política y las campañas. El proceso de petición de voto tiene poco efecto pues son las orientaciones previas de la gente que orientan las opciones políticas.

\footnotetext{
8 Para un visión general de las aportaciones y limitaciones de la Escuela de Columbia, ver el capítulo 3 de D'Adamo, García Beaudoux y Freidenberg (2007).

${ }^{9}$ Para una revisión sobre la teoría de la identificación partidista, ver Dalton y Watzenberg (1993).
} 
La tesis de la identificación partidista pierde fuerza en los años siguientes por el debate que realza el descenso del papel de los partidos como correa de transmisión entre la gente y la política, traducido en los altos índices de volatilidad electoral. Otros actores desarrollan el papel que antes cabía a las asociaciones partidistas, entre ellos (y de modo especial) los medios de comunicación, que van ampliando su centralidad en la interlocución con un elector cada vez más desalineado.

Esa realidad menos rígida lleva a nuevas aportaciones, como la teoría del voto retrospectivo basada en los estudios de la rational choice, relacionando el comportamiento electoral a la evaluación sobre la realidad: si el ciudadano la evalúa positivamente, vota por la continuidad; de lo contrario, vota por el cambio ${ }^{10}$. Entre las obras que dan soporte a la teoría de la elección racional quizá la más conocida sea Teoría económica de la democracia, de Anthony Downs, publicada en $1957^{11}$. Otros autores van aportar al concepto, pero siempre partiendo del marco fundamental de que el ciudadano realiza cálculos sobre los costes y beneficios de sus decisiones políticas.

Olson (1992) amplia la teoría entre otras cosas con la paradoja del free rider $^{12}$. Hirschman (1986) enfoca la participación política relacionándola con el acto de consumo, que busca alcanzar una satisfación. En el caso de la Teoría de Juegos, una variante de la rational choice, el individuo no solo evalua los costes y beneficios de su propia decisión, sino busca anticipar las decisiones que serán tomadas por otros individuos frente a las mismas ofertas políticas (Sanchéz-Cuenca, 2004).

Especialmente sobre los procesos electorales, la teoría económica trabaja los conceptos de voto retrospectivo y prospectivo. Las decisiones del elector tienen como base la información, donde las campañas desempeñan función fundamental. Pero la información en general no es completa y puede que siquiera sea verdadera. El desencuentro entre realidad y percepeción será una de las críticas a esa teoría. Además casos como el español estudiado por Maravall (2003) revelan que esto no es tan sencillo y que un gobierno mal evaluado (como el de González en 1992) puede ser premiado por aspectos como la baja confianza depositada en la oposición o la misma identificación partidista.

\section{iv) Cuarta Fase: la perspectiva cognitiva}

\footnotetext{
10 Dader (1998) relaciona los estudios del voto retrospectivo como una etapa intermedia o transitoria hacia las aportaciones de las corrientes de los efectos cognitivos.

${ }^{11}$ La edición en español aquí consultada es de 1973.

12 Según la paradoja del free rider, en un colectivo hay sectores que no se esfuerzan (coste) por ciertos objetivos (beneficios) por considerar que la acción desarrolla es mayor que los resultados esperados. Pero, como el beneficio es público, también reciben aquellos que no se movilizaron (Olson, 1965).
} 
El papel atribuido a las campañas cambia a partir de la década de 1970, pasándose a enfatizar la creciente presencia de los medios en los procesos políticos. Comienzan las teorías de los efectos cognitivos, un enfoque más complejo. El paradigma se establece en una nueva realidad caracterizada por partidos poco influyentes, electorado sin grandes referentes predictores y centralidad de los medios en la vida política. Tal combinación lleva, de una parte, a los estudios sobre el impacto de los medios y, de otra, a los enfoques de las campañas desde la visión del elector como consumidor, acercando la política a las estrategias del marketing.

Los enfoques dejan de ser sobre casos singulares, pasando a mirar todo el sistema de medios de comunicación y las estrategias de largo plazo; se adoptan metodologías integradas y complejas, con el análisis de datos sofisticados; en lugar de evaluar los cambios de actitudes y de opinión, se busca reconstruir el proceso por el cual los individuos cambian su representación de la realidad. Los efectos cognitivos no son puntuales sino acumulados, enfatizando el papel procesal de los mismos ${ }^{13}$.

El acercamiento a las estrategias del marketing comercial implica en la orientación hacia la imagen, donde el candidato se convierte en el producto a ser ofrecido al elector-consumidor. Así es que, según Kotler y Kotler (1999: 3), para tener éxito el candidato necesita entender los mercados -es decir, las circunscripciones en que actúan y a los electores y sus necesidades-. Los autores enfatizan la actuación de los medios en las campañas, afianzándose a la vez como vehículo de comunicación y unidad de negocios que hacen de la información una mercancía del mercado de la política.

La visión de la política desde las concepciones del marketing tienen en Philip Kotler uno de los autores seminales, cuando aboga la aplicación de las técnicas del campo comercial a las organizaciones sin ánimo de lucro ${ }^{14}$. Ese abordaje parte de una visión de la estrategia, pasa por aspectos de la organización y toma los medios de comunicación como soporte fundamental al desarrollo de las estrategias que visan la adhesión de un elector más y más desalineado ${ }^{15}$. En consecuencia, garantizan a los medios un lugar central en el acercamiento a ese elector cada vez más alejado de la política.

\footnotetext{
${ }^{13}$ Ver Wolf (1992), Crespo (2003) y D’Adamo, García y Freidenberg (2007).

${ }^{14} \mathrm{El}$ artículo seminal del marketing político es "Broadening the concept of marketing", de P. Kotler $y$ S. J. Levy (1969), publicado en el Journal of Marketing, vol. 33, $\mathrm{n}^{\circ} 1$, pp. 10-15. En 1975, Kotler publicaría un artículo más explícito respecto al uso del marketing en las campañas: "Overview of political candidate marketing", en Advances in Consumer Research, n 2, pp. 761-769.

${ }^{15}$ Se recuerda, el clásico marketing mix del marketing comercial es formado por los 4Ps -del inglés product, price, promotion y place [producto, precio, promoción y plaza o distribución]- en donde la promoción es esencialmente acción de comunicación, imprescindible a la realización de los objetivos. Ver Kotler (1978).
} 
El reconocimiento del destacado papel desempeñado por las acciones mediáticas abre a las nuevas prácticas y también a los nuevos estudios. Una de las primeras y más influyentes aportaciones de ese nuevo enfoque es la teoría del establecimiento de la agenda, o agenda-setting (McCombs y Shaw, 1972), resaltando la influencia de los medios en las percepciones de las personas sobre los temas políticos. Los autores afirman que los medios canalizan la percepción de la gente, encontrando en sus investigaciones que los principales temas destacados por el elector son los mismos destacados por los medios. Así es que las campañas hoy son en gran medida la pelea de los candidatos por la agenda mediática (McCombs, 2005).

En un primer enfoque, la agenda-setting señala que al establecer una determinada agenda, los medios no le dicen a la gente qué pensar sobre determinados temas, pero sí van a influir sobre qué temas pensar. Según la teoría del establecimiento de agenda, los medios dirigen la atención de la opinión pública hacia determinados temas ${ }^{16}$, determinantes en la construción de las imágenes mentales que van interferir en el comportamiento del ciudadano. Es decir, se encuentra correlación entre las prioridades que los medios otorgan a un tema y la opinión manifiesta por el público (D’Adamo, García Beaudoux y Freidenberg, 2000), lo que se conoce como el primer nivel del establecimiento de la agenda.

Diversos otros estudios en la secuencia del de McCombs y Shaw encuentran que el establecimiento de la agenda va más allá del definición de prioridades, pues el modo de presentación de las informaciones produce una percepción específica, el cómo pensar, que viene a ser el segundo nivel de la agenda-setting ${ }^{17}$. La importancia del tratamiento de la información es clave en construción de imágines mentales como etapa hacia la producción de opiniones y actitudes. Así es que el reflejo del encuadre se conoce como efecto framing (Scheufele, 1999), que se produce a partir de sutiles alteraciones en el trato de un objeto $^{18}$. En el proceso de encuadramiento, más importante que el peso relativo dado por los medios a determinados objetos es el modo como define las cosas, generando en la audiencia esquemas interpretativos que ordenan la información, de ahí

16 El establecimiento interesado de la agenda se puede dar también por la omisión, como en la campaña presidencial brasileña de 1989, cuando los temas más controversos relacionados al gobierno Cardoso desaparecieron de los medios, consonante con la estrategia de reelección del presidente (Miguel, 1999).

17 En el volumen coordinado por McCombs y Luna Pla (2003), son analizados los dos niveles del establecimiento de la agenda tomándose como objeto de análisis la realidad española. Canel, Llamas y Rey (pp. 31-55) estudian el primer nivel del establecimiento de la agenda en trabajo sobre la percepción de la gente de Pamplona respecto los problemas de la ciudad. En cuanto al segundo nivel, McCombs, López-Escobar y Llamas analizan los atributos transmitidos por los medios en torno a las elecciones españolas de 1996. Para una visión general y actualizada de la teoría, ver McCombs (2005).

18 Aquí se utiliza el término objeto como lo hace McCombs (2005: 138): “En todos esos casos: los temas de interés público, los candidatos políticos y otros temas que definan la agenda, se emplea el término objeto (...)". 
resultando en actitudes específicas en la gente. En una simplificación, ese proceso define el cierto y el errado, el bueno y el malo. El framing es el proceso capaz de llevar la audiencia a llegar a determinadas conclusiones de acuerdo con los encuadres de la información.

Otra aportación relacionada con el establecimiento de la agenda es el efecto priming (Iyengar, 1991), que reafirma el poder de influencia de los medios por la capacidad de ofrecer matrices que las personas adoptan para evaluar la realidad; es la attribución de responsabilidad -por ejemplo, a los liderazgos políticos, los candidatos- para la solución de los problemas. Tales consideraciones toman en cuenta que las personas no prestan atención a todo del entorno y que, al tomar decisiones, no realiza evaluaciones exahustivas de la realidad, usando los atajos cognitivos como son las informaciones disponibles. Las informaciones acumuladas (y encuadradas) en un momento anterior son rescatadas en la hora de la toma de decisión.

Esas teorías han sido especialmente utilizadas para el análisis de la acción de los medios en las campañas políticas, que realizan todos los esfuerzos para influir en la agenda mediática. Esa posibilidad se muestra más fuerte en campañas largas, como la de Estados Unidos, con mutua alimentación entre medios y mensajes electorales. La capacidad de interferir en la agenda mediática es uno de los factores que alimenta, por ejemplo, los mensajes negativos en las campañas de estadounidenses (Jamieson, 1992 y Rees, 1992) ${ }^{19}$.

A mediados de la década de 1970, surge la teoría de la espiral del silencio, también apuntando hacia los efectos de largo plazo, además de reconocer el papel central desempeñado por los medios, en especial la televisión, con sus altos índices de audiencia. Noellen-Neumann (2002), que formula la nueva teoría, afirma que los medios, al informar a los desinteresados sobre la política, crean climas de opinión que van a establecer un escenario a la manifestación de la misma. En tal contexto, las corrientes de opinión mayoritarias tienden a atraer nuevos simpatizantes en cuanto las corrientes minoritarias a ver reducidos el número de apoyos.

Los análisis reconocen la centralidad de la televisión, y desde ese medio a los spots electorales como canal fundamental a la comunicación con el elector. En la década de 1990, los spots eran considerados la principal fuente de información del elector estadounidense, por delante de los debates e incluso de los programas periodísticos (Berrocal, 1996). Aun cuando algunos estudiosos empiezan a preguntar si la era de la

\footnotetext{
${ }^{19}$ Sobre la relación entre la publicidad electoral brasileña y la agenda de los medios, ver el trabajo de Miguel (2004).
} 
TV está acabada ${ }^{20}$, el presupuesto de las campañas destinado a los anuncios televisivos pareciera indicar que ese recurso de comunicación sigue central en las estrategias de lo que inciden en ellas ${ }^{21}$.

El papel desempeñado por la televisión y el foco en la imagen hace surgir estudios orientados al análisis del impacto de la TV en la conformación de las nuevas campañas electorales. Uno de los primeros trabajos es el de Agranoff (1976), que habla del american style como traductor de esas nuevas campañas. El autor encuentra tres características fundamentales en el estilo americanizado: la personalización, la orientación hacia los medios y la presencia de consultores profesionales como operadores estratégicos y gestores de las campañas. Con posterioridad, se suman otros investigadores, atento al nuevo estilo de campañas ${ }^{22}$ y a la efectividad de la publicidad electoral 23 .

Las principales aportaciones de esos estudiosos se basan en la experiencia anglosajona y más aún estadounidense. La explicación es que las modernas técnicas de campaña basadas en el marketing político se desarrollan primero en Estados Unidos donde las condiciones fueron más favorables. Maarek (2005: 24-27) apunta tres razones principales para la primacía de los norteamericanos: el tipo de sistema electoral, especialmente la realización de elecciones primarias, que alargan las campañas además de desplazar importantes decisiones del partido al ámbito de la opinión pública; la tradición de celebrar elecciones -desde el inicio de la federación se hizo común el ciudadano elegir los dirigentes, del presidente al director de la escuela o shérif-; y rápida expansión de los medios de comunicación, desde el principio anclado en el sector privado, factor que profundiza la competencia sobre los temas públicos y genera mayor visibilidad sobre la política.

Así, la experiencia estadounidense ofrece oportunidad al estudio de los fenómenos de la comunicación política en general y de las campañas en particular. En Europa, Inglaterra va adelantarse a los demás países, también por recurrir con antelación a los nuevos recursos técnicos -como los sondeos para monitoreo de la opinión pública

\footnotetext{
20 Markus Prior (Post-broadcast democracy: How media choise increases inequality in political involviment and polarizes elections, Cambridge: Cambridge University Press, 2007) defiende que los nuevos medios quitan el protagonismo de la TV. Es la misma linea de la tesis doctoral de Natalie J. Stroud (Selective exposure to partisan information, University of Pensilvania, 2006).

${ }^{21}$ A pesar de incorporar nuevos canales, la campaña presidencial estadounidense de 2004 concentró la mayor parte de los recursos en las acciones de televisión: John Kerry y George W. Bush destinaron 620 millones de dólares a los mensajes en TV (Devlin, 2005). En 2006, la campaña de Hillary Clinton al Senado por Nueva York siguió estrategia idéntica: la publicidad en TV consumió 21 de los 29 millones de dólares gastados en la campaña (datos de www.nyt.com).

${ }^{22}$ Ver Trent y Friedenberg (2000), Blumler y Kavanagh (1999), Kaid (1981), Bowler y Farrell (1992) y Swanson y Mancini (1996).

${ }^{23}$ Ver Jamieson (1992), Norris (2001) y Devlin (2005).
} 
respecto la política (Negrini y Lilliker, 2002: 317-18)-. Son precisamente Estados Unidos e Inglaterra los dos sistemas que más sirven de referencia a los estudios comparados, con la natural ventaja estadounidense. Así se explica el importante retraso en las prácticas y los estudios de campañas en otros sistemas, sobre todos en aquellos que sufrieron la dura experiencia autoritaria incluso en la posguerra, como es el caso del sur de Europa y América Latina.

\subsection{La investigación en materia de comunicación política en España}

La redemocratización de España restablece la abierta comunicación entre gobernantes y gobernados; vuelven las elecciones como proceso de selección de los representantes populares y, con ellas, las campañas. El cambio trae junto los estudios sobre la comunicación política en general y la comunicación electoral, en específico. Así es natural el paralelo del interés académico hacia las campañas y el inicio de la democracia, en la segunda mitad de la década de 1970, aunque la afirmación como importante campo de investigación va se dar en los primeros años de la década siguiente ${ }^{24}$.

En una de las publicaciones pioneras, López Guerra (1977) aborda las campañas desde las teorías de la propaganda en sociedades de masas, enfoque seguido por Arceo Vacas (1982). Lo más representativo es el análisis de las elecciones de 1979 en Castilla-León, realizado por Llera Ramo (1982), autor que sigue los estudios sobre la relación entre campaña, opinión pública y voto. Muñoz Alonso (1984) contribuye con la fase de consolidación de los estudios de comunicación política al coordinar la publicación de un conjunto de análisis sobre las históricas elecciones de 1982, consideradas como la consolidación de la misma democracia; y Del Rey (1989) hace un primero abordaje general sobre el tema. Sin embargo, no es hasta la década de 1990 que se va a poner el campo de la comunicación política en un destacado puesto de la producción académica española, cuando también las campañas electorales reciben importante atención.

La oleada de nuevos estudios abraza diversos intereses: algunos de ellos enfocan los aspectos generales de la comunicación política (Muñoz y Rospir, 1995; Dader, 1998; Canel, 1999) y otros miran hacia el proceso de construcción de la opinión pública (Monzón, 1996; Muñoz Alonso et al, 1992). La relación entre medios y política es el tema de diversos trabajos, con enfoque especial sobre el establecimiento de la agenda. Uno de los trabajos más destacados es el que cuenta con la participación del mismo

\footnotetext{
24 Se recuerda que los estudios universitarios en Comunicación e Información, que van formar los investigadores del área, empiezan en España en comienzo de la década de 1970 (Herrero y (Herrero y Connolly-Ahern, 2004: 155).
} 
McCombs - uno de los padres de la teoría de la agenda-setting - y investigadores de la Universidad de Navarra ${ }^{25}$. Entre los trabajos que miran la comunicación desde una perspectiva del marketing política está el de José Luís Sanchis (1996), uno de los pioneros de la moderna comunicación política en España, al que se suma el reciente relato de Campmany (2005) sobre las estrategias del PSOE de cara a las generales de 2004. Luque (1996) y Martín Salgado (2002) contribuyen con estudios sobre las bases conceptuales del marketing político.

Las campañas electorales reciben más atención en los últimos años a través de trabajos que revelan la madurez de ese campo de estudio. Fernandez Mellizo-Soto (2001) aborda la efectividad de las campañas en un estudio sobre las generales de 1993. Luego, Berrocal (2003) reúne una serie de enfoques sobre los diversos elementos del esfuerzo de acercamiento al elector, pero con énfasis en los procesos televisivos ${ }^{26}$. Se debe destacar aún el trabajo de Martínez y Méndez Lago (2000), en que analizan las elecciones europeas de 1999; los de García Luengo (2006 y 2005), con mayor atención a la teoría del malestar mediático; los trabajos del Grupo de Investigaciones sobre Campañas Electorales, GICE ${ }^{27}$; el de Capdevila Gómez (2004), sobre las estrategias retóricas en los spots televisivos; el de Molins y Oñate (2006), así como las contribuciones de Sampiedro (2000, 2003 y 2005) especialmente en los estudios sobre el uso de nuevas tecnologías, con énfasis al último que trata de la movilización del 13M y sus efectos en el resultado de las generales de 2004. Del Rey Morató (2007) sigue esa línea en su más reciente estudio en que investiga el papel de la internet en las campañas contemporáneas.

El interés en las campañas electorales se amplia: en enfoque normativo ocupa la atención de investigadores como Soller-Sanchez (2001), así como el comportamiento del elector genera diversas investigaciones, tanto en el ámbito de las competencias generales (Mateos y Moral, 2006; Lago Peñas, 2005), en las elecciones autonómicas y municipales (Delgado Sotillos, 2000; Font, 2002) o en perspectiva comparada, como lo hace Anduiza (1999) al explicar la abstención en Europa. Molins y Oñate (2006) desarrollan un análisis multinivel del comportamiento electoral español.

Los estudios siguen en deuda en cuanto a la profesionalización de las campañas en España. Diversos estudios enfocan aspectos de la profesionalización, como es el caso de

\footnotetext{
${ }^{25}$ Ver McCombs y Luna Plá (2003)

${ }^{26}$ En ese volumen, según el interés de la presente investigación, merece especial atención el texto de Teresa Sádaba ("Los anuncios de los partidos en televisión. El caso de España, 1993-2000", capítulo 6, páginas 163-205).

27 Desde la Universidad de Murcia, el GICE reúne investigadores de diversas instituciones, como Ismael Crespo, Antonia Martínez, Eva Anduiza, Mónica Méndez Lago, Paulo Oñate y Irene Delgado. Sus trabajos más conocidos son los tres volúmenes sobre las campañas y sus efectos (Crespo, 2002, 2003 y 2004) en que analizan las generales españolas de 2000.
} 
los citados trabajos de Sanchis (1996) y Campmany (2005), que ofrecen los pasos para la planificación y ejecución de las campañas (en el caso de Sanchis) o revelan las etapas de desarrollo de una campaña concreta (caso de Campmany). También se puede citar los trabajos de Sádaba (2003) y Capdevila Gómez (2004), que analizan una de las principales herramientas de las campañas profesionales, los spots electorales. Los diversos trabajos sobre la mediatización de la política hablan de un tema central de las campañas profesionales. Sin embargo, hace falta un enfoque que revele el nivel profesional de las campañas españolas, abordaje solo encontrado de modo más directo en contribuciones como la de Dader (1998), que advierte la limitación de ese proceso, constreñido por factores propios del sistema político nacional.

\subsection{Los estudios en comunicación política en América Latina}

En el escenario latinoamericano, los estudios de la comunicación política presentan destacado estadio de madurez, con trabajos consistentes en la mayor parte de los países, pero fundamentalmente en Brasil, Argentina y México. En el ámbito más general, merece destaque la Fundación Konrad Adenauer, vinculada al Partido Democristiano alemán, en su sucursal de Buenos Aires, muy activa a través del Centro Interdisciplinar de Estudios sobre el Desarrollo Latinoamericano (Ciedla). A partir del apoyo de Konrad Adenauer/Ciedla, se han publicado relevantes estudios que posibilitan una mirada hacia las campañas electorales en América Latina, tanto en enfoques específicos de los diversos países como también en análisis comparados.

Las investigaciones han enfocado diversos aspectos, desde la legislación que determina el juego electoral hasta el papel del marketing político y los recursos comunicativos utilizados en las recientes campañas. Ese abordaje se completa con publicaciones en forma de manual de campañas electorales o de análisis de las disputas electorales en la región. Entre los trabajos colectivos realizados por la fundación alemana, destacan el Manual de marketing y comunicación política, editado por Carlos Fara (2000), y Trastienda de una elección (2000), los dos enfocando las presidenciales argentinas de 1999, cuando el aparato del marketing político se hizo tan visible.

A través del Ciedla se viabilizó el desarrollo de trabajos como Los partidos políticos en las constituciones y legislaciones, de Stefan Jost (1998), quienes confronta los objetivos partidistas y la relación con los medios de comunicación en 17 países de América Latina además de Alemania y España. Pero el trabajo más relevante en el campo de las campañas es el doble volumen editado por Frank Priess y Fernando Tuesta Soldevilla (1999) bajo el título Campañas electorales y medios de comunicación en América Latina, donde ofrecen un conjunto de datos, tendencias e impactos 
producidos por los medios en elecciones presidenciales y legislativas. Joseph Thessing y Priess reciben el apoyo de la fundación en la organización de Globalización, democracia y medios de comunicación (1999), analizando aspectos como la ética en la comunicación política.

Las contribuciones de la Fundación Konrad Adenauer y del Ciedla, sin embargo, son a la vez el refuerzo a los estudios de la política y reflejo del esfuerzo previo de diversos investigadores. En Argentina, los estudios de la moderna comunicación política pueden ser encontrados aún en la década de 1980 en publicaciones como Votando imágenes, de Hugo Haime (1988). Muraro (1991) aportaría un temprano enfoque sobre el papel del marketing político en las campañas actuales, así como Carlos Fara (1997 y 2006) se firmará como un referente sobre las modernas técnicas de campaña, no solo en la publicación de trabajos sobre el tema sino también por la actuación como consultor político.

Otro investigador pionero es Eliseo Verón, hace tres décadas analizando las campañas, aunque primero desde la realidad francesa y en los últimos años incluyendo un enfoque latinoamericano ${ }^{28}$. Cabe destacar los estudios sobre marketing político desarrollados por Martínez Pandiani, campo donde Borrini (2003) también ocupa lugar de relevancia. Además, hay que enfatizarse las investigaciones dirigidas por García Beaudoux y D'Adamo, con especial destaque al trabajo producido en colaboración con Slavinsky (2006), en que analizan tanto los formatos como los efectos de las acciones de comunicación en las presidenciales argentinas de 2003.

El proceso de modernización de las campañas en Argentina y México es el tema del estudio comparado realizado por Mendé (2003) que apunta hacia la creciente profesionalización en los dos países, con la incorporación de nuevas técnicas y la presencia de consultores. Si en Argentina la redemocratización es un marco fundamental para el desarrollo de los estudios de campañas, en México las investigaciones se han incrementado desde las elecciones de 1988, cuando el dominio del PRI revela importantes fracturas. Verdad que los primeros trabajos enfocan más la cobertura periodística, con énfasis en el tratamiento de los medios respecto el polémico conteo de los votos ${ }^{29}$. Posteriormente, crece el enfoque sobre los procesos electorales, especialmente la modernización de las campañas, enfatizándose el uso de las técnicas del marketing político y la presencia de consultores.

28 En 2003, Verón publicó con Fausto Neto Lula Presidente (São Paulo: Racker), un análisis del tratamento televisivo respecto las presidenciales brasileñas de 2002. Otra de las importantes contribuciones recientes del autor es El cuerpo de la imagen (Buenos Aires: Normal, 2001).

${ }^{29}$ Ver Así se calló el sistema, de Pablo Arredondo, Gilberto Fregoso y Raúl Trejo (1991). Ver también "Medios de comunicación y procesos electorales. El caso de telenoticieros mexicanos", de Pablo Arredondo (en Comunicación y Sociedad, $n^{\circ} 8$ ). 
El enfoque profesional y el soporte del marketing queda explícito en autores como Valdez Zepeda (2006 y 2004), Martínez Silva (198) y Arbesú (1998), todos enfocando la modernización y la centralidad de la mercadotecnia en las campañas actuales. Winocur (2002) trabaja sobre el papel de la radio en las campañas electorales, en cuanto Gil García y Almazán (2004) relacionan los esfuerzos de campaña con las formas de financiamiento. Entre las instituciones universitarias de México, sobresalen los núcleos de investigadores de la Universidad Nacional de México y de la Universidad de Guadalajara. También ofrecen importante soporte a los investigadores las publicaciones afianzadas por el Instituto Federal Electoral y el Instituto Electoral de Estado de México (revista Apuntes Electorales).

Otros países de la región, como Chile, Ecuador, Perú y Uruguay, también cuentan con importantes estudios sobre las campañas, aunque no en el mismo nivel de los dos anteriores pero sin duda reveladores de la atención que la academia dedica al tema. En el caso uruguayo, Costa Bonino (1994) hace mucho investiga los nuevos modos de las campañas, con análisis que tienen como base las referencias del marketing político, en cuanto Casas Zamora (2003) relaciona el desarrollo de las campañas al soporte financiero. En Chile merece destaque Verdugo Hidalgo (2003), que compara las estrategias comunicativas del partido democristiano chileno con las del Partido Popular español. En Ecuador, Rabeneick estudias las últimas campañas ecuatorianas del siglo pasado; y en Perú, además del sobresaliente trabajo de Tueste Soldevilla, se subrayan las investigaciones de Rospligliosi (2000), Trelles Cruz (2006) y Roberts y Arce (1998).

Finalmente, vale recordar que la mirada hacia las campañas en América Latina se concreta desde otros espacios, como en el ya citado trabajo de Swanson y Mancini (1996), donde hay dos capítulos sobre la comunicación electoral de la región, uno sobre Argentina y otro sobre Venezuela. Espíndola (2003) realizó estudio sobre las campañas en el Cono Sur, donde pone acento en la limitación al proceso de profesionalización en los países de la región debido al tipo de cultura política. El corto pero denso trabajo de Espíndola es uno de los pocos que enfoca la profesionalización misma de las campañas en la región, puesto que el proceso de modernización en general es tratado sectorialmente -algunos miran hacia la mediatización; otros para los signos de modernización; otros aun para la presencia de consultores-. Otros trabajos que miran de modo más amplio hacia la profesionalización son el de García Beaudoux, D’Adamo y Slavinsky (2006) y el de Priess y Soldevilla (1999).

Los diversos estudios, sin embargo, revelan que la idea de estandarización de las campañas electorales no es adecuada a la región. Hay coincidencias en la creciente presencia de consultores, como revela Espíndola (2000) para los países del Cono Sur o bien Mendé (2003) para Argentina y México; también en la amplia mediatización, que 
alcanza tantos grandes como pequeños centros urbanos; y en los costes cada vez más elevados. Por otra parte, las diferencias están presentes no solo de un país a otro sino dentro de un mismo Estado -sobre todo entre los grandes centros urbanos y regiones más alejadas-. La cultura política determina importantes cambios en las acciones de campañas, así como las reglas del sistema políticos ${ }^{30}$.

\subsection{Los estudios de comunicación política en Brasil}

Las primeras publicaciones importantes sobre comunicación y política en Brasil son de la década de $1960 \mathrm{y}$, además de enfocar la propaganda política, son trabajos internacionales traducidos al portugués. El primero de esos trabajos es $A$ mistificação das massas pela propaganda política [La mistificación de las masas por la propaganda política], la versión brasileña del conocido trabajo de Serge Tchakhotine ${ }^{31}$, en el que son analizadas las técnicas psicológicas para el convencimiento de las masas. El libro, traducido por el exilado político Miguel Arraes y publicado en 1967, analiza el simbolismo de la propaganda política tomando como ejemplo los casos del nazifascismo europeo y de la Unión Soviética estalinista en la década de 1930. A esa publicación seguiría la traducción de Le propagande politique, del francés Jean-Marie Domenach ${ }^{32}$, donde clasifica las categorías históricas de la propaganda política.

Los estudios autóctonos van surgir en fines de la década de 1970 y especialmente desde mediados de la década de 1980, centrándose en las relaciones entre política y medios, con detenida atención al papel de los medios tanto en el soporte del poder establecido (por parte de los grandes periódicos y las redes de televisión) como en la resistencia a la dictadura, a través de las radios piratas ${ }^{33}$ y de los periódicos nanicos, como era conocida la prensa alternativa ${ }^{34}$. Son de esa fase los trabajos de Machado (1986) sobre las radios libres como voz de la "otra realidad" que la prensa grande no enseñaba, bien

\footnotetext{
30 Sobre las diferencias en las 12 campañas presidenciales realizadas en América Latina entre fines de 2005 y diciembre de 2006, ver entrevista de la británica BBC con profesionales de campaña: http://news.bbc.co.uk/hi/spanish/latin america/newsid 6213000/6213996.stm.

${ }^{31}$ El título original, Le viol des foules par la propagande politique, fue publicado en Francia en primer edición de 1939 por la editorial Gallimard. En Brasil, la edición es de la editorial Civilização Brasileira.

32 En portugués, edición de la editorial Difusão Européia do Livro (s.f.). Edición en español, $L a$ propaganda política, Buenos Aires: Editorial Universitaria de Buenos Aires, 1966.

${ }^{33}$ Emisoras que funcionaban sin autorización legal, en general en precarias condiciones técnicas.

${ }^{34}$ El término "nanico" (en portugués de Brasil un sinónimo de enano, pequeño), era una referencia al patrón de presentación de la prensa alternativa, el formato tabloide, a diferencia de los periódicos empresariales, en general en formato estándar.
} 
cómo la investigación en postgrado de José Luiz Braga ${ }^{35}$ sobre el papel político del Pasquim, el más importante periódico de la resistencia.

A continuación surge A História Secreta da Rede Globo, de Daniel Herz (1987), que explicitó las relaciones históricas y hondas de la TV Globo con el régimen militar, volviéndose uno soporte del otro. De esa fase pionera se destacan los trabajos de Pedrinho Guareschi (Comunicação e Poder, de 1985) y de Ciro Marcondes Filho, que organiza un volumen (Política e imaginário nos meios de comunicação, de 1986) sobre la influencia de los medios en la construcción del imaginario colectivo, y otro $(O$ Capital da Notícia), en que maneja el concepto de información como mercancía que es negociada por las empresas de comunicación en el mercado de las simbologías y de la política.

La campaña de 1982, todavía bajo el régimen militar pero con algún grado de libertad en una dictadura que agonizaba, y especialmente la campaña de Tancredo Neves a la elección indirecta a la Presidencia de la República (septiembre de 1984 a enero de 1985), amplían los estudio de la comunicación política en las contiendas electorales. Es representativo de ello el trabajo de Ronald Kuntz y Joseh Luyten (1982), donde analizan aspectos de la estrategia política, construcción del discurso y producción de identidad visual para las candidaturas. El trabajo es un primer acercamiento al marketing político como recurso de las campañas, luego seguido por otras publicaciones como Marketing Político e Governamental, de Torquato do Rego (1985), y $O$ que é propaganda ideológica (1986) de Jahr Garcia. Otros que sobresalen en esa fase son Figueiredo (1985), Marques de Melo (1985) y Brickmann (1994), que asocian aportaciones teóricas con la nueva práctica de la comunicación estratégica y relaciones con los medios.

La redemocratización va a ofrecer nuevas oportunidades a los estudiosos, en especial con la elección presidencial de 1989, en la que vence Fernando Collor de Mello. La disputa se desarrolló en medio de sofisticados recursos de comunicación, organización y técnicas de monitoreo, revelando un nuevo formato de campaña. Resulta en una oleada de estudios sobre las campañas, con el particular destaque de Antonio Fausto Neto, que sigue una referencia en el tema ${ }^{36}$. El autor analiza el papel jugado por los medios tanto en el ascenso como en la caída de Collor, que renunció tras diversos escándalos de corrupción.

\footnotetext{
${ }^{35}$ La tesis doctoral de Braga, presentada en la Sorbone, se convierte en $O$ Pasquim e os anos 70 (Brasilia: Editora UnB, 1991).

${ }^{36}$ Entre los textos de Fausto Neto que producen un nuevo acercamiento al análisis de las campañas, dos merecen ser destacados: O presidente da televisão, de 1990, en donde analiza la ascensión de Collor desde la acción del medio TV; y Como se cassa um presidente: o impeachment da televisão, en que analiza la caída del presidente desde la misma perspectiva. En 2003, publica con Verón un análisis del papel de la televisión en la elección de Lula.
} 
Desde comienzos de la década de 1990 los estudios de las campañas han presentado gran evolución, adoptando mayor rigor metodológico. Ahí destaca el grupo de investigadores situados en Bahía, liderados por Antonio Albino Rubim, creador del concepto de "idade mídia" (media age) 37, fortaleciendo la visión de los medios como agentes políticos. Otro núcleo prolífico está en la Universidade de Brasilia, donde Lima (2001) construyó el concepto de Cenario de Representación de la Política [escenario de representación de la política] o CR-P, en que los medios son centrales en ese nuevo modo de representación política, en que las empresas mediáticas actúan como agentes interesados en la construcción de escenarios sobre los cuales los actores políticos van actuar. Aun en Brasilia, Porto (2004) y Miguel (1999, 2003 y 2004) centran la atención en los efectos de los medios. En Rio de Janeiro, el de Iuperj $3^{8}$ contribuye con análisis enfocando sobre todo en los efectos de la publicidad electoral en la opinión pública.

En la Universidade Metodista de São Paulo el interés prioritario está en el marketing y la publicidad política (Queiroz, 2006), al paso que la Universidade de São Paulo alcanza diversos abordajes, a través de las aportaciones de investigadores como Matos (1994) y Capelato (1998), además del citado Marcondes Filho. En Rio Grande do Sul, han surgido importantes trabajos en las universidades Federal, PUC y Unisinos ${ }^{39}$. Como reflejo de eses estudios, la Intercom ${ }^{40}$ se ha convertido en un espacio para los trabajos sobre la comunicación política, desde que en ella funciona un grupo sobre el tema y la Compós abriga un núcleo de estudio centrado en la relación entre comunicación y política ${ }^{41}$.

37 El término "idade mídia" (media age, o edad de los medios) es un juego de palabras que hace referencia a la vez al poder de los medios y a la oscuridad de la Edad Media.

${ }^{38}$ Ver www.iuperj.br.

39 La Unisinos, en São Leopoldo (Rio Grande do Sul), cuenta con dinámico núcleo de investigadores ya reconocidos como Fausto Neto y Braga, con egresados respectivamente de la Universidade Federal do Rio de Janeiro y de la Universidade de Brasilia.

40 Intercom es la asociación de estudios interdisciplinares de la comunicación. Reúne investigadores de todo el país con interés en los distintos campos de la comunicación y cuenta con un núcleo específico para los estudios de comunicación política. Ver en www.intercom.org.br.

41 La Compós (www.compos.org.br) es la asociación que reúne los programas de postgrado en Comunicación. Desde 1993 cuenta con un Grupo de Trabajo sobre Comunicación y Política. 



\section{Campañas Electorales: el recorrido hacia la profesionalización}

Resumen:

El capítulo enfoca la evolución de las campañas hacia el modelo profesional, proceso que se inicia en los años 1950 y se consolida desde principios de la década de 1990. La profesionalización se desarrolla en un escenario de declive de las lealtades hacia los partidos o grupos sociales y teniendo en cuenta la creciente mediatización, con especial centralidad de la televisión como gran medio de comunicación de masas. Las campañas profesionales se caracterizan por la presencia de expertos en el comando de las acciones, reemplazando al personal partidista, y por la lógica del marketing comercial que hace del político un producto donde la imagen es la referencia fundamental en el acercamiento al elector. Es además un proceso altamente mediatizado, con sofisticados recursos tecnológicos y, en consecuencia, elevados presupuestos. El capítulo enfoca aún las variables independientes que intervienen en el la profesionalización, donde se destacan el sistema electoral, el sistema de partidos, la cultura política y la estructura de los medios de comunicación. Respecto los partidos, señala como importante factor en la profesionalización el origen del partido, la organización interna y el papel desempeñado por el líder. 



\subsection{Introducción}

El término campaña tiene origen en el lenguaje militar y hace referencia a una acción concentrada en un tiempo y lugar, con objetivos precisos. También la campaña electoral desde sus comienzos cuenta con esa idea de empresa especial con un objetivo específico cuya operacionalización está constreñida a un tiempo establecido, el periodo inmediatamente anterior a las urnas. La idea de empresa especial sigue presente, pero la limitación en el tiempo no encaja por entero con las prácticas actuales de campaña, aunque las principales definiciones hablan de un tiempo específico.

Las campañas son fundamentalmente un esfuerzo de comunicación, el medio por el que ellas comienzan, se desarrollan y acaban (Trent y Friedenberg, 2000: 14). La esencia comunicativa de esa empresa es destacada desde Lazarsfeld et al (1944), quien la define como el conjunto de acciones de comunicación enderezadas a influir en el comportamiento del votante; y como espacios de debate e instrumento de participación y movilización. Chafee (1981) sigue el mismo tono, pero subraya el factor estratégico al describir las campañas como esfuerzos organizados de recursos comunicativos que buscan alcanzar un propósito político. Norris (2001) destaca el objetivo de influir sobre el elector a través de la persuasión y la movilización, además de la función de información, necesaria a la construcción de una percepción que va a ser la base de las decisiones del ciudadano respecto la disputa.

Ellas funcionan como puertas de entrada a la democracia, desempeñando importante papel práctico y simbólico (Rospir, 1999). Es a la vez "una realidad jurídica y una realidad política y social” (Soler, 2001: 28). Por la visión jurídica, es un período de tiempo limitado (15 días en España; alrededor de 60 días en la primera vuelta, para el caso de Brasil), además de un conjunto de normas que regulan la participación de partidos y ciudadanos. En la realidad política y social, como señala Soler, las actividades enderezadas a la captación de votos (entre ellas la publicidad de las opciones políticas en oferta en el mercado político) abrazan un espacio temporal más amplio que la estricta definición jurídicaํ.

\footnotetext{
1 Según la legislación española, se entiende como campaña al “conjunto de actividades lícitas llevadas a cabo por los candidatos, partidos, federaciones, coaliciones o agrupaciones en orden a la captación de sufragios" (Soler, 2001). Esta definición legal toma como campaña el período oficial destinado a la explícita petición de voto, que en España ocupa los 15 días hasta el penúltimo día antes de la votación. Pero, aunque la legislación establezca plazo para la petición de voto, todo el tiempo los partidos actúan con miradas hacia la opción electoral del ciudadano.
} 
Las acciones de comunicación de campaña actúan como un conjunto de inputs informativos que funcionan como en un mosaico: cada registro que el elector recibe es una pequeña pieza del gran panel político; ese registro se suma a la imagen más amplia sobre la política y los políticos que va a ser rescatado por el votante en el momento de decidir cómo se comportará en la elección. Ello implica pensar las campañas como proceso estratégico, que se ajustan a los conceptos del marketing y a la idea de campañas permanentes (Nimmo, 1999) donde la imagen es una construcción de largo plazo y base de la decisión del elector ${ }^{2}$. Significa decir que muchos factores intervienen en su recorrido, desde factores del sistema político (sistema de partidos, reglas electorales, sistema de medios) hasta elementos coyunturales (la percepción sobre la realidad), pasando por la cultura cívica (prácticas patrimonialistas, personalismo) e incluso factores particulares como las relaciones internas del partido y el carácter del candidato.

El proceso de largo plazo resalta el papel jugado por los medios, responsables directos por el que Lima (2001) llama de "Escenario de Representación de la Política", en que parte sustantiva de la campaña acontece con antelación, en las construcciones mediáticas. En el análisis de las presidenciales brasileñas de 1989, el autor afirma que la victoria de Collor estaría "definida" seis meses antes de la votación, desde la conformación de escenarios realizada por los medios según establecimiento de la agenda y encuadre claramente enderezados ${ }^{3}$ (Lima, 1993), en especial en el caso de la televisión y más aún de TV Globo, la principal operadora del esfuerzo mediático a favor del candidato.

El concepto de CR-P, sin embargo, no debe ser tomado como menosprecio a la campaña oficial, cuando los candidatos realizan mítines y ocupan espacio en los medios. Ese período se ajusta a los escenarios construidos con antelación: es la coronación de todo el previo recorrido, ahora con más intensidad y entonces con los actores definitivos, puesto que la fase no oficial muchas veces cuenta con postulaciones que de hecho no se confirman. El CR-P es otro modo de hablar de campaña permanente, que mira al periodo oficial como la fase para consolidar posicionamientos políticos construidos con anterioridad.

Tanto cuanto el resultado de las urnas, las campañas son importantes para la salud de la democracia (Swanson y Mancini, 1996), por las consecuencias prácticas y también por su papel simbólico. Entre las varias funciones que las campañas desempeñan,

\footnotetext{
${ }^{2}$ El término “campaña permanente" es utilizado por primera vez por Sidney Blumenthal (1980), quién vincula la expresión a la acción mediática que los políticos desarrollan mucho antes de la campaña formal.

${ }^{3}$ Sobre el CR-P en la campaña de 1989, ver especialmente Lima (1993).
} 
cuatro se destacan: legitimación del sistema político, información de los votantes, persuadir al elector a optar por una cierta alternativa electoral y selección de elites. Las dos últimas son muchas veces cuestionadas: la persuasión sería un fin, no una función (Crespo, 2003); en cuanto a la selección de elites, muchas veces no queda claro que se está para elegir un equipo que va gestionar la cosa pública (Vallés y Bosch, 1997) o el equipo que se presenta con antelación no es la que se efectiva como gestora ${ }^{4}$.

La legitimación se materializa a través del voto y de otros modos de participación que establecen la relación más cercana del ciudadano con la política. Norris et al (1999) resaltan el "compromiso cívico" como resultado de la participación: el elector se siente responsable por el proceso, el resultado y por los rumbos de la política y sus consecuencias. En sentido contrario, Capella y Jamieson (1997) apuntan el creciente desinterés resultado de procesos electorales crispados, donde los partidos se empeña en campañas negativas y los medios en coberturas que además de enfatizar la negatividad no resalta los aspectos de fundo, básicamente informando quien está por delante en la carrera electoral, como en una carrera de caballos $^{5}$. La suma de superficialidad periodística con la negatividad resultaría en el malestar del elector (la videomalaise o media malaise $)^{6}$.

La información es básica para que las campañas cumplan sus objetivos. Con el afán de llevar al ciudadano los ejes de su candidatura, los contrincantes buscan informar al elector para que así pueda confrontar propuestas y referencias personales, y reunir los elementos necesarios a la toma de decisión sobre el voto. El valor de la información genera la pelea por la agenda política, cada sector buscando no solo garantizar espacio a los temas que considera importantes sino establecer el enfoque estratégicamente más ventajoso. Sin embargo, esa función no está restricta al espacio periodístico, alcanzando incluso programas de naturaleza ficcional, como pasa en Brasil con las telenovelas (Porto, 1995).

Paletz (1997: 208-18) enumera cuatro modos de relación de las campañas con los medios, según el grado de control que los candidatos tienen sobre el contenido vehiculado:

\footnotetext{
${ }^{4}$ En la campaña de 2002, la publicidad electoral de Lula empezaba con una imagen panorámica sobre la equipe de trabajo. Importantes personalidades que eran presentadas -como el ex ministro João Sayad o la ex alcaldesa Marta Suplicy- no participaron del gobierno que asumió en enero de 2003.

${ }^{5}$ En la literatura anglosajona, el horseracism (Blumler y Gurevitch, 1995).

${ }^{6}$ Norris (2001) refuerza el papel de información y movilización de las campañas, aunque reconoce que aumenta el escepticismo hacia la política, sobre todo desde comienzos de la década de 1970, con el escándalo Watergate.
} 
1) las intervenciones de iniciativa explícita de los medios: prescinden de la voluntad o incluso de la participación de los candidatos. Se refieren a los comentarios periodísticos y tratamientos humorísticos sobre la campaña, sin ningún control del contenido por parte de los candidatos o partidos;

2) las coberturas con iniciativa prioritaria de los medios: cuentan con la participación de los candidatos -como en la cobertura de los hechos de campaña-, pero son los medios que definen qué es (y cómo es) noticia;

3) las acciones de iniciativa prioritaria de los candidatos o partidos: son las acciones en que los medios tienen alguno poder de intervención, pero los candidatos detienen el mayor control del contenido. Es lo que pasa en los debates o en los discursos de asambleas de nominación de candidaturas; y

4) las intervenciones de exclusiva iniciativa y control de los candidatos: los medios funcionan tan sólo como intermediarios. Es el caso de la publicidad electoral, en que el mensaje es vehiculado como el candidato lo desea.

Ese último modo de acción tiene gran importancia al ofrecer la oportunidad del candidato llevar su mensaje según las más precisas intenciones estratégicas, lo que acaba por afianzar la centralidad de los spots electorales en la política actual. Los spots son "mensajes políticos televisivos en campaña, eminentemente persuasivos, construidos por los propios partidos y no mediatizados por los medios de comunicación" (Sádaba, 2003: 166)7. Como recurso comunicativo, presentan ventajas sobre otros mensajes: mayor alcance (llegan a una audiencia muy por encima de los anuncios de periódicos, por ejemplo), tienen más viveza por contener movimientos, así generando más impacto en el público que lo ver; la posibilidad de segmentación en muy amplia8; y otorgan credibilidad al candidato, pues la presencia en la tele hace que el candidato cuente (Trent y Friedenberg, 2000) ${ }^{9}$.

Tanto en la realidad de Estados Unidos como en el caso brasileño, la publicidad electoral ocupa un lugar destacado en las acciones de campaña. En Brasil, los spots electorales -garantizados a los candidatos por la Justicia Electoral según criterios de

\footnotetext{
7 Cuando habla en "no mediatizado" Sábada quiere decir sin intervención en el contenido por parte de los medios, poniéndose de acuerdo con Paletz (1997).

8 Esto tiene validez especialmente para el caso estadounidense y otros sistemas que ofrecen la posibilidad de compra de espacios, donde se puede programar un anuncio según el público al que se desea alcanzar. En España, la exhibición es siempre un uno mismo horario y tan solo en las emisoras estatales, limitando la segmentación. En Brasil, además de bloques de programas en horarios fijos, la legislación permite a los partidos la exhibición de spots sueltos que vuelven posible alguna segmentación, aunque muy distante de la realidad estadounidense.

9 Trent y Fridenberg también destacan puntos negativos de los spots: los altos costes (en Estados Unidos, algunas campañas destinan más del $70 \%$ del presupuesto a los gastos con la publicidad en televisión); y el privilegio de la estética, favoreciendo a los candidatos con telegenia por en cima del contenido de sus discursos.
} 
representatividad- se vuelven elemento central en la disputa sobre todo por ser importante paso en el equilibrio de las condiciones competitivas al garantizar voz a los pequeños partidos (Miguel, 2004). Además, los spots desempeñan un importante papel informativo, que en el caso estadounidense es apuntado por los electores como la más importante fuente sobre la contienda electoral, por delante de los debates e incluso de los programas periodísticos (Berrocal, 1996).

Los espacios publicitarios en TV son uno de los aspectos más importantes del proceso de profesionalización que hoy caracteriza la política, especialmente por la amplia visibilidad que posibilita. Además, como principal medio de comunicación de masa, la televisión se convierte en recurso esencial para que el candidato pueda dialogar con sectores tan alejados de la política. Así es que el spot electoral se vuelve uno de los rasgos de las campañas estadounidense, y luego también ocupan un papel protagónico en otros sistemas.

\subsection{Características de las campañas profesionalizadas}

La profesionalización de las campañas es un fenómeno que se vincula a la declinación de los partidos y a la centralidad de los medios (en especial la televisión) en el quehacer político. Los cambios se notan desde la década de 1950, cuando el general Dwight Eisenhower utilizó los servicios de profesionales del mercado comercial para desarrollar las estrategias electorales en su primera elección (1952). La agencia BBDO y el publicitario Thomaz Rosser Reeves fueron los nombres que quedaron asociados a la entonces revolucionaria serie de 49 spots que llevaban la etiqueta "Eisenhower Answers America”. Eran spots donde personas corrientes grababan preguntas al candidato republicano sobre temas diversos, en un formato que actualmente suena amateur, pero que cambió la historia de la comunicación electoral (Berrocal, 2003b).

La idea de profesionalización está muy lejos de aquellas acciones pioneras, hoy asociada al uso de nuevas tecnologías y nuevos canales de distribución de mensajes, además de planificación de largo plazo y altísima mediatización (LeDuc et al, 2001; Norris, 2004; Gibson y Römmele, 2001). Ahora, una campaña profesional es mucho más que tener bajo contrato un par de expertos en comunicación política, medios o encuestas; es algo más complejo, relacionado no sólo a los recursos comunicacionales sino también a los aspectos organizativos.

Algunos autores hablan de "profesionalización de la política" desde otra perspectiva, en concreto, desde el fenómeno del político profesional que vive de y para la política, a ella dedicándose de manera estable y a tiempo completo. Sartori (1992) identifica tres 
tipos de políticos según el nivel de entrega: el político no profesional (que prioriza las actividades particulares extra-política), el semiprofesional (que se divide entre las dos tareas) y el profesional (dedicado a la política a tiempo completo) ${ }^{10}$. Aunque ubique la mayoría de los políticos en la categoría semiprofesionales, reconoce una creciente profesionalización -es decir, cada vez más políticos tienen dedicación estable a la política-, apuntando como uno de los rasgos de esa profesionalización la capacidad de mantenerse en la política.

Esa percepción de la profesionalización, sin embargo, adopta una mirada desde dentro, distinto del enfoque de la profesionalización de las campañas, que mira de fuera hacia dentro, desde la presencia de personas ajenas a la vida política partidista en la conducción de esa misma política. La profesionalización es una respuesta de las candidaturas a las nuevas condiciones de ejercicio de la política que cambiaron los soportes anteriores (Blumler y Gurevitch, 1995)

El término "profesionalización" no es aceptado por todos. Negrine y Lilleker (2002) lo consideran una etiqueta por demás abarcadora, quizá quitando parte del sentido que debería sostener. Señalan que el término busca acentuar especialmente una diferencia entre el hoy y el ayer, donde las diversas etiquetas se preocupan casi tan sólo en destacar las diferencias en los arreglos contemporáneos de comunicación política respecto las prácticas de un pasado lejano en una exagerada simplificación del proceso $^{11}$.

La crítica de Negrine y Lilleker mira a la profesionalización como un fenómeno estanco, fruto de la década de 1990 y sin vínculos con una trayectoria histórica de las prácticas de campaña. Sin embargo las campañas profesionales traducen un proceso evolutivo de incorporación de nuevos recursos, culminando con el uso de herramientas recientes tales como Internet, correo directo y datafone, como también métodos para el monitoreo del sentimiento del elector (Gibson y Römmele, 2001). Cuando se habla hoy de campañas profesionales se vincula el término a nuevas formas de planificación y

\footnotetext{
${ }^{10}$ Esa clasificación parte de las aportaciones de Max Weber (ver Escritos Políticos, Madrid: Alianza, 1991), que en 1918 hablaba de político profesional puro y político no profesional puro. Sartori (1992: 202) advierte que hoy la mayor parte de los políticos son semiprofesionales, conciliando actuación política con dedicación a intereses particulares.

11 Para evidenciar la inadecuación del término, los autores resaltan la presencia de profesionales del mercado en las campañas desde la década de 1930, cuando George Gallup ya aplicaba encuestas con fines políticos, y como lo ha hecho después para Eisenhower, orientando los temas de los discursos para que estuviesen más ajustados al sentimiento popular. Añaden otros datos: en 1957, las empresas de relaciones públicas que trabajaban con campañas sumaban ya 41 en estados Unidos, número que salta a los 60 en 1972, cuando entonces casi todas ya ofrecían especialización en el área; en las elecciones de 1962, por encima de dos tercios de los candidatos al Senado de Estados Unidos tenían el soporte de encuestas, índice todavía más elevado entre los candidatos a los gobiernos estaduales.
} 
dirección de las campañas, presencia de expertos y a un conjunto de técnicas y tecnologías utilizadas en la interacción con el elector.

Así como a Negrini y Lilleker no les gusta el término, otros autores adoptan nombres distintos para identificar las nuevas prácticas de campañas. Algunos las identifican como moderna (Bowler y Farrell, 1992), otros postmoderna (Norris, 2001; LeDuc et al, 2001) en cuanto hay aquellos que la etiquetan con un american style o "americanizadas" (Swanson y Mancini; Negrine y Papatranassopoulos, 1996). Denver y Hands (2000) identifican como "posfordista", en cuanto Maarek (2005) utiliza el término-paraguas "Marketing Político" para resumir la esencia de las nuevas prácticas pautadas pela lógica del producto. Gibson y Römmele (2001) usan la categoría “campañas profesionalizadas" por la comprensión de que uno de los rasgos más destacados es la presencia de expertos externos a los partidos, imponiendo maneras de acción con importantes efectos sobre el quehacer de las campañas ${ }^{12}$.

Más allá de la etiqueta, los autores coinciden en que hay una cierta estandarización en las campañas en todo el mundo, sobre todo la amplia mediatización, alto grado de personalización, presencia de expertos del mercado en el comando, uso de las técnicas de la mercadotecnia y (por todo esto) el comprometimiento de elevada suma en recursos financieros. La mayoría de las prácticas identificadas con las campañas profesionalizadas pueden ser encontradas en los más distintos sistemas, desde las democracias consolidadas (Europa y América del Norte) hasta las jóvenes democracias como son la mayor parte de América Latina.

La causa de esa expansión encuentra dos explicaciones principales: una apunta hacia la americanización de las campañas alrededor del planeta, a través de la emulación de las técnicas proselitistas de Estados Unidos (Swanson y mancini (1996); otra ve los cambios como resultado del proceso de modernización de las sociedades e involucra diversos sectores, entre ellos los relacionados a la comunicación de masas y sus relaciones con la política (Norris et al, 1999; Norris, 2001; y Kaid y Holtz-Bacha, 1995). La hipótesis de americanización está relacionada con un proceso de "convergencia unidireccional” en el cual otros países adoptan técnicas experimentadas en Estados Unidos; cuando mucho, promueven la adaptación, ajustando las técnicas al contexto local. Por otra parte, la modernización explica la estandarización como consecuencia del proceso de cambio estructural en curso en la sociedad como un todo, donde política y medios de comunicación no son casos aparte (Plasser et al, 2000: 125-26).

\footnotetext{
12 Este es el término aquí utilizado sobre todo teniendo en cuenta que todas las caracterizaciones de las campañas contemporáneas hacen referencias a ese aspecto profesional, desde la harbemasiana idea de "scientificization" adotada por Swanson y Mancini (1996) hasta la sofisticación estratégica indicada por Norris (2001) y Denver et al (2003), pasando aun por la énfasis dada a la presencia de los consultores en el mando de las campañas, destacada por Bowler y Farrell (1992).
} 


\subsection{Tres pasos hacia la profesionalización}

Las campañas profesionales son el resultado de la evolución de los procesos electorales, con cambios en el modo de acercamiento al elector, la participación del ciudadano en la política, la organización de las campañas, estrategias y los recursos comunicativos utilizados. Precisamente eses cambios son las referencias para identificar las fases evolutivas, que la mayor parte de los autores divide en tres generaciones.

Hasta entrada la segunda mitad del siglo XIX, las campañas poco contaban puesto que de hecho no había competencia electoral, verificándose situaciones como el caso de una circunscripción inglesa en que un único nombre se ha presentado para el único escaño por más de dos décadas (Caramani, 2003). Sin competencia, las campañas eran innecesarias; era suficiente los acuerdos entre los grupos de elites. La industrialización y urbanización producen cambios con fuertes consecuencias. Se amplia el derecho al voto; surgen los partidos de masa y las divisiones políticas que se reflejan en el palco electoral. Con los cambios, las campañas pasan a ser parte importante del proceso político: hay que establecer una nueva relación con el electorado como forma de garantizar buenos resultados.

La primera generación de campañas ${ }^{13}$ está situada de fines del siglo XIX al inmediato posguerra ${ }^{14}$. Es la fase de fuerte identificación partidista con segmentos sociales, lo que asegura la relación estable con el ciudadano (ver Cuadro 2.1). La organización está en la misma estructura partidista, planificada según objetivo específico e inmediato (ad hoc), desarrollada en el corto plazo. La comunicación es directa entre candidato y elector, a través de mítines, caminadas y acciones puerta-a-puerta.

La prensa del partido es la principal herramienta mediática -solamente en el final del periodo la radio pasa a tener papel político relevante-. El enfoque local favorece a los mensajes fragmentados, cada sitio recibiendo oferta discursiva propia; las sucursales partidarias tienen el poder de seleccionar candidatos y de conducir la campaña. El elector ocupa un lugar activo, participando de reuniones y mítines, o incluso haciendo parte de la estructura ejecutiva de las acciones electorales. Los ciudadanos también son militantes, lo que caracteriza esta fase como de personal intensivo (labor intensive) y de bajo coste, pues la participación es voluntaria.

\footnotetext{
13 Norris et al (1999) llama a esta etapa de premoderna; Farrell y Webb (2004), de fase 1. A la segunda generación llaman respectivamente de etapa moderna y fase 2.

${ }^{14}$ Las características de cada etapa de campaña aquí resumidas son basadas sobre todo en LeDuc et al (2001), Norris (2001), Kaid y Holtz-Bacha (1995) y Gibson y Römmele (2001). También sirve de referencia Mancini (1995).
} 
CUADRO 2.1

Características de las Campañas Electorales, por fase

\begin{tabular}{|c|c|c|c|}
\hline & $1^{\text {a }}$ Generación & $2^{a}$ Generación & $3^{a}$ Generación \\
\hline $\begin{array}{l}\text { Período de } \\
\text { predominio }\end{array}$ & $\begin{array}{l}\text { Fines del siglo XIX hasta } \\
\text { los años } 1950\end{array}$ & $\begin{array}{l}\text { Del inicio de los } 1960 \\
\text { hasta fines de los } 1980\end{array}$ & Desde los años 1990 \\
\hline $\begin{array}{l}\text { Espacio de } \\
\text { actuación }\end{array}$ & Local & Nacional & Nacional/Local \\
\hline $\begin{array}{l}\text { Tiempo de la } \\
\text { campaña }\end{array}$ & Corto (ad hoc) & Largo Plazo & Permanente \\
\hline Organización & $\begin{array}{l}\text { Descentralizada, local; } \\
\text { Coordinación del liderazgo } \\
\text { partidista; } \\
\text { Uso del personal interno y } \\
\text { trabajo voluntario }\end{array}$ & $\begin{array}{l}\text { Centralizada, nivel } \\
\text { nacional; } \\
\text { Coordinación del partido } \\
\text { con soporte de expertos } \\
\text { del mercado }\end{array}$ & $\begin{array}{l}\text { Centralizada, pero con } \\
\text { operacionalización } \\
\text { descentralizada; } \\
\text { Coordinación de } \\
\text { profesionales contratados }\end{array}$ \\
\hline Medios & $\begin{array}{l}\text { Prensa del partido y, luego, } \\
\text { la radio }\end{array}$ & Televisión & $\begin{array}{l}\text { Multimedios (Internet, TV } \\
\text { pagada, correo dirigido) }\end{array}$ \\
\hline $\begin{array}{l}\text { Forma de } \\
\text { comunicación }\end{array}$ & $\begin{array}{l}\text { Predominio de la } \\
\text { comunicación directa; } \\
\text { Cobertura periodística }\end{array}$ & $\begin{array}{l}\text { Predominio de la } \\
\text { comunicación indirecta; } \\
\text { Publicidad electoral }\end{array}$ & $\begin{array}{l}\text { Amplia segmentación; } \\
\text { Comunicación directa } \\
\text { desde multicanales }\end{array}$ \\
\hline $\begin{array}{l}\text { Eventos de } \\
\text { campaña }\end{array}$ & $\begin{array}{l}\text { Reuniones públicas locales } \\
\text { (mítines), viajes por el país }\end{array}$ & $\begin{array}{l}\text { Gestión de los medios, } \\
\text { conferencias de prensa; } \\
\text { Debates en TV }\end{array}$ & $\begin{array}{l}\text { Mayor gestión de medios; } \\
\text { Rutinas políticas ajustadas } \\
\text { a los medios }\end{array}$ \\
\hline $\begin{array}{l}\text { Foco de la } \\
\text { campaña }\end{array}$ & $\begin{array}{l}\text { El partido, el programa y la } \\
\text { ideología }\end{array}$ & $\begin{array}{l}\text { El candidato, sin importar } \\
\text { el programa o la ideología }\end{array}$ & $\begin{array}{l}\text { El candidato, sin importar } \\
\text { el programa o la ideología }\end{array}$ \\
\hline $\begin{array}{l}\text { Vínculo con el } \\
\text { elector }\end{array}$ & $\begin{array}{l}\text { Directo, basado en lealtad } \\
\text { política y sentimiento de } \\
\text { clase }\end{array}$ & $\begin{array}{l}\text { Indirecto, basado en la } \\
\text { imagen mediatizada }\end{array}$ & $\begin{array}{l}\text { Mediatizado, pero } \\
\text { buscando interacción a } \\
\text { través de nuevos medios }\end{array}$ \\
\hline Electorado & $\begin{array}{l}\text { Vínculos sociales y } \\
\text { partidarios estables }\end{array}$ & $\begin{array}{l}\text { Desalineación social y } \\
\text { partidario }\end{array}$ & $\begin{array}{l}\text { Desalineación social y } \\
\text { partidaria }\end{array}$ \\
\hline Gastos & Bajo & Alto & Muy alto \\
\hline Uso del marketing & Bajo o inexistente & Mediano & Amplio \\
\hline $\begin{array}{l}\text { Evaluación de } \\
\text { efectos }\end{array}$ & $\begin{array}{l}\text { Improvisación. } \\
\text { Escasos Sondeos. }\end{array}$ & $\begin{array}{l}\text { Encuestas de opinión } \\
\text { pública a gran escala }\end{array}$ & $\begin{array}{l}\text { Uso en gran escala de las } \\
\text { técnicas para monitorear el } \\
\text { sentimiento del elector }\end{array}$ \\
\hline
\end{tabular}

Fuente: Sistematización en base a LeDuc et al (2001), Norris (2004), Farrell (1996), Swanson y Mancini (1996), Gibson y Römmele (2001), Plasser et al (1999) y Negrine y Lilleker (2002).

La segunda generación está situada entre mediados de la década de 1950 y la de 1980, caracterizándose sobre todo por la presencia de la televisión como medio de comunicación de referencia. El nuevo medio determina un cambio radical en el modo de la política relacionarse con el elector, desde entonces con marcada personalización: si antes, con el radio y el periódico el partido podía tener "voz", con la televisión esa voz pasa a tener una cara (Berrocal 2003b) capaz de traducir sentimientos y emociones (Canel, 1999). El nuevo medio, de masa por excelencia, vuelve la mediatización la esencia misma de la política, estableciendo lo que unos llaman de "videopolítica" (Sartori, 2002) o de "democracia de audiencia" (Manin, 1997); la imagen construida a 
través de los medios pasa a ser la credencial fundamental en la relación con el ciudadano y referencia en sus decisiones sobre la política.

Esa etapa coincide con acentuado descenso del papel de los partidos, factor que se asocia a la alta volatilidad electoral. El alcance de la TV produce campañas de ámbito nacional, con mensajes unificados y organización centralizada. El nuevo medio también exige nuevos conocimientos, lo que obliga a la contratación de expertos (profesionales del marketing, publicitarios, relaciones públicas) que ocupan cada vez más espacios en la organización. Las campañas se vuelven más caras sobre todo por los altos costes de producción y divulgación de los mensajes, además de la contratación de los mismos consultores y el pago de los militantes.

Por último, la tercera generación surge al comienzo de la década de 1990 y se pauta especialmente por nuevos condicionantes tecnológicos que establecen nuevas formas de interacción con el elector. La TV abierta aunque sigue como principal canal de información de la gente ya no reina absoluta, perdiendo parte del protagonismo especialmente para medios que posibilitan una relación más segmentada, alcanzando diversos públicos. Ganan espacios la televisión pagada, el videomail y principalmente la Internet, que vuelve posible recursos como el mail directo y la comunicación casi individualizada. Los cambios producen un fuerte impacto en la política y "existen pocas dudas de que las campañas políticas se hayan transformado por la diversificación de medios informativos y también por la amplia adopción de técnicas de marketing político" (Norris, 2001: 24).

La personalización es, más que nunca, la tónica de la política aunque con importante diferencia: la campaña es pensada nacionalmente, pero ejecutada de forma local, con mensajes específicos para cada público. La profesionalización alcanza dimensión nunca antes vista, con especialistas para los más diversos campos -encuestas, publicidad, relaciones públicas, tecnología, recaudación de fondos, producción de eventos, etc-; los profesionales asumen el comando de las acciones, respondiendo básicamente al líder o candidato, ya que la organización partidista apenas tiene relevancia. También pasan a personificar la propia campaña, saliendo de los bastidores y ganando las pantallas y portadas de los medios como estrellas del proceso. La diversidad de acción hace explotar los costes de las campañas (de capital intensivo), que además son permanentes.

Las campañas profesionales profundizan algunos aspectos de la fase anterior, como la participación de los expertos, y a la vez recupera (en dimensión más sofisticada) elementos como la relación más directa con el ciudadano. El comando sigue siendo nacional, pero descentralizando parte de la operacionalización, incluyendo acciones 
regionalizada o locales como estrategia de segmentación (Norris, 2001). La concepción del "producto político" tiene una dimensión nacional anclada en grandes temas, aunque también adopte mensajes locales, con el uso de distintos canales (TV pagada, correo dirigido, Internet). La comunicación es cada vez menos partidista, merced un electorado cada vez más desalineado.

La tercera generación de campañas encarna la lógica del marketing, es decir, del político como producto. Se deja pautar por la planificación estratégica, con organización en moldes profesionales, multicanales de distribución de los mensajes, altos costes, mensajes en formatos comerciales y propaganda negativa. Un modelo que encuentra su representación más exacta en Estados Unidos. Para ser considerada profesional, sin embargo, una campaña no necesita repetir el estricto guión estadounidense.

En estudio sobre los cambios en las campañas en el Cono Sur, Espíndola (2003) apunta coincidencias y discrepancias en Argentina, Chile y Uruguay respecto el patrón americano, diferencias pautadas por las especificidades de cada sistema. Al estudiar los cambios en Reino Unido, Denver et al (2003) consideran que las campañas británicas están más profesionalizadas desde el principio de la década de 1990 por utilizaren "estrategias profesionales", es decir, la planificación estratégica, orientada por los principios del marketing y teniendo como soporte los conocimientos de expertos. Encuentran que el "modelo inglés" guarda sus características propias conducentes con su sistema y cultura política. Resultados similares son encontrados por Holtz-Bacha y Kaid (1995) respecto Alemania; Cohen y Wolfsfeld (1995) para Israel; Johnston y Gerstlé (1995), en Francia y Sádaba (2003) y Dader (1999), para el caso español.

\subsection{Campañas profesionales y variables independientes}

Los estudiosos del comportamiento electoral suelen tomar los procesos de comunicación de campaña como determinantes en la toma de decisión por el votante. Esos análisis pueden encontrar explicación en las campañas tanto para la apatía electoral como para el mayor interés por la política (Anduiza y Bosch, 2004).

Unos destacan en las campañas la función de información, que produce los efectos cognitivos fundamentales en la decisión del ciudadano; generan reacción cívica en la ciudadanía y una postura más proactiva del votante ${ }^{15}$. La información cumple el papel de estimular a la participación, además de permitir a la gente contrastar propuestas,

\footnotetext{
${ }^{15}$ Ver especialmente Norris et al (1999).
} 
evaluar los candidatos y orientar su decisión. Otros autores encuentran en las campañas la fuente de la apatía y del malestar hacia la política, consecuencia directa del formato profesional que tiene entre sus características la publicidad negativa y la cobertura periodística centrada en la superficialidad ${ }^{16}$. Los mensajes negativos a la vez que atrapan la atención de los electores, producen un malestar que resulta en creciente rechazo de la política, en una especie de deslegitimación del sistema político. La cobertura que los medios dan a las campañas -superficial y a la vez enfocando temas personales sobre todo negativos- refuerza el malestar.

Es cierto que las campañas producen efectos sobre el comportamiento electoral, pero también es cierto que son conformadas por elementos del ambiente competitivo: las campañas son una variable dependiente, el resultado de su contexto. El impacto del contexto sociopolítico sobre las prácticas de campañas está fundamentado por diversos estudios ${ }^{17}$ que resaltan distintos factores causales en la conformación del esfuerzo de adhesión a las ofertas electorales. Es más: sí hay coincidencia en que las campañas están cada vez más profesionales, se reconoce que la profesionalización no es igual. Es decir, la variable dependiente Campaña Profesional cambia según el impacto de diversos factores componentes del ambiente competitivo, implicando en mayor o menor nivel de profesionalización.

Cada sistema guarda sus características particulares que al fin y al cabo hacen las campañas muy distintas de un país a otro. Un ejemplo de las diferencias es la publicidad electoral, central en las campañas de Estados Unidos así como en sistemas como el brasileño. En esos dos países, la mayor parte del presupuesto es destinado a la publicidad, en especial la publicidad en televisión: en Brasil, los costes con los mensajes televisivos se ponen alrededor del 60\% del presupuesto (Miguel, 2004), índice que en Estados Unidos puede situarse incluso por en cima de las tres cuartas partes de los costes (Trent y Friedenberg, 2000: 7) ${ }^{18}$.

En un sistema como el de España, sin embargo, la publicidad formal tiene peso relativo. El corto período de tiempo y la limitación de los spots a los espacios de las televisiones estatales reduce el impacto de ese tipo de recurso de comunicación haciendo incluso que algunas candidaturas locales prescindan del derecho de vehicular

\footnotetext{
${ }^{16}$ Ver Cappela y Jamieson (1997), Fridkin y Kenney (2004) y Side et al (2003).

17 Entre ellos, Bowler y Farrell (1992), Kaid y Holtz-Bacha (1995), Swanson y Mancini (1996), Kaid, Gerstlé y Sanders (1991) y Norris et al (2001).

${ }^{18}$ En Brasil, los costes con la publicidad en la radio y televisión incluyen tan solo la producción de los spots sueltos y bloques de programas, pues los espacios para emisión son garantizados por la legislación, sin costes añadidos. Por el espacio ocupado por los partidos, las emisoras tienen compensación fiscal, que el 2004 sumó casi 200 millones de reales (algo cercano a 100 millones de dólares).
} 
spots electorales ${ }^{19}$. También se hace necesario notar que, pese la destacada importancia estratégica de los spots tanto en Estados Unidos como en Brasil, hay significativas diferencias entre las campañas en eses dos sistemas, tanto en los formatos cuanto en los contenidos. De hecho, experiencias como las de Brasil, Estados Unidos y España ofrecen evidencias de como las campañas pueden ser diferentes, aunque todas presenten elementos considerados del marco profesional. Las diferencias son el resultado de los factores propios que intervienen en las acciones enderezadas a la conquista del elector.

Kaid y Holtz-Bacha (1995) presentan quizá la esquematización más aceptada para explicar las variables que influyen en la conformación de las campañas, cuando apuntan tres elementos fundamentales: el sistema político, la estructura del sistema de medios de comunicación (incluyendo las condiciones establecidas para acceso a los medios) y la cultura política. Los condicionantes del sistema político (las reglas electorales en especial) definen entre otras cosas la intensidad de la comunicación electoral realizada por los partidos y los formatos admitidos, así como la existencia o no de comunicación electoral pagada. Por otra parte, la estructuración de los medios influye en los modos de información sobre la política, así como la cultura incluye la relación de la gente con la política y aspectos como la costumbre de ver televisión y, por lo tanto, exponerse a los mensajes electorales.

Por otra parte, LeDuc et al (2001) relacionan cuatro variables: el ambiente regulador, el sistema de medios, el sistema de partidos y el electorado. El marco regulador incluye el sistema electoral, la regularidad de elecciones y las reglas del juego electoral, mientras el sistema de medios toma en cuenta la estructuración (control público vs privado) y el nivel de desarrollo, donde incluyen la industria de la consultoría. En cuanto al sistema de partidos, miran tanto hacia la estructura del sistema en su todo como la organización interna y la relación con la militancia. Por último, el electorado: este ítem puede ser entendido como la cultura política, puesto que los autores lo relacionan con el comportamiento de los votantes y aspectos como la relación que mantienen con la política en general y el nivel de lealtad con los partidos.

Swanson y Mancini (1996) relacionan cinco elementos que consideran esenciales al entendimiento de las campañas: sistema electoral, sistema de partidos, regulación de las campañas, cultura política y sistema de medios. Sistemas electorales mayoritarios tienden a ser más personalistas (y así más propensos a la profesionalización), al paso que sistemas proporcionales se vuelven más partidistas o programáticas. En el sistema

\footnotetext{
19 Un ejemplo fue la candidatura del PSOE a la alcaldía de Salamanca, en las elecciones de 2007: los socialistas decidieron no utilizar spots teniendo en cuenta el bajo alcance de las emisoras locales. Al final el PSOE eligió uno concejal menos que en 2003 (11 contra 12, de 25 concejales totales). En sistemas como el brasileño, tal decisión muy probablemente tendría efectos catastróficos.
} 
de partidos, el multipartidismo exige mayor diferenciación e identificación con la asociación, en cuanto el bipartidismo cobra mayor uso de la comunicación con el propósito de atraer al elector desalineado. Respecto la financiación de campañas y la cultura política, subrayan la importancia de aspectos como las prácticas clientelistas y los movimientos sociales. Sobre los medios, observan que los sistemas privados ofrecen mayor posibilidad de profesionalización por la competencia que se establece.

Al comparar las prácticas en Estados Unidos y Europa, Plasser, Scheucher y Senft (1999) ${ }^{20}$ destacan seis factores con influencia más directa en la conformación de las campañas: sistema electoral, sistema de partidos, regulación de la competencia electoral, sistema de medios, cultura política y grado de modernización de la sociedad. Los sistemas electorales generan distinto impacto se son mayoritarios o proporcionales, centrado en el candidato o en el partido, con pocas o muchas elecciones (más elecciones, más incentivos a la profesionalización). En el sistema de partidos, enderezan la atención hacia el grado de institucionalización y el número efectivo de partidos. En cuanto a la regulación de la competencia electoral, subrayan el modo de financiación (público o privado; con o sin límites), las posibilidades de acceso a los medios y la duración de la campaña, añadiendo en este último punto la existencia o no de primarias (que también favorecen a la profesionalización). Evalúan si los sistemas de medios son públicos, privados o mixtos, además de su nivel de modernización y la autonomía que desfrutan.

Los autores observan aun el grado de homogeneidad o fragmentación de la cultura política, sobre todo se es jerarquizada o competitiva, con alta o baja participación, así como el grado de confianza del ciudadano en los procesos políticos. Por último, respecto la modernización de las sociedades, toman como relevantes para la profesionalización el grado de movilidad social, de industrialización y de informatización (Plasser, Scheucher y Senft, 1999: 91).

Gibson y Römmele (2001) hacen un acercamiento más estrechamente relacionado a la profesionalización de las campañas desde una perspectiva de la organización de los partidos, algo distinto de LeDuc et al y de Swanson y Mancini, que abordan las características y dimensiones de los procesos electorales actuales, o de Plasser y colegas, que hablan desde la percepción de los consultores (Cuadro 2.2). El abordaje de Gibson y Römmele es una visión que intenta analizar los condicionantes internos y externos que hacen que un partido tenga mayor o menor grado de profesionalización, donde relacionan las variables ideológicas, orientación hacia la maximización del voto,

20 Plasser y colegas entrevistan consultores de 16 países de Europa sobre la aceptación y el uso de las técnicas del marketing político estadounidense. 
disponibilidad de recursos financieros y los choques internos (por ejemplo, cambio de liderazgo) y externos (como derrotas electorales).

CUADRO 2.2

Factores que inciden sobre el nivel de profesionalización de las campañas, según autor

\begin{tabular}{|c|c|}
\hline Autor & Variables \\
\hline Kaid y Holtz-Bacha (1995) & $\begin{array}{ll}\text { - Sistema Político } \\
\text { - Estructura de los Medios } \\
\text { - Cultura Política }\end{array}$ \\
\hline LeDuc, Niemi y Norris (2001) & $\begin{array}{l}\text { - Ambiente regulador } \\
\text { - Sistema de medios } \\
\text { - Sistema de partidos } \\
\text { - Electorado }\end{array}$ \\
\hline Swanson y Mancini (1996) & $\begin{array}{l}\text { - Sistema Electoral } \\
\text { - Sistema de Partidos } \\
\text { - Regulación de las campañas } \\
\text { - } \text { Cultura política } \\
\text { - Estructura de los medios }\end{array}$ \\
\hline $\begin{array}{l}\text { Plasser, Scheucher y Senft } \\
\text { (1999) }\end{array}$ & $\begin{array}{l}\text { - Sistema electoral } \\
\text { - } \text { Sistema de partidos } \\
\text { - } \text { Sistema de medión la campaña } \\
\text { - Cultura política } \\
\text { - Grado de modernización de la sociedad }\end{array}$ \\
\hline Gibson y Römmele (2003) & $\begin{array}{l}\text { - Ideología partidista } \\
\text { - Disponibilidad de recursos } \\
\text { - Orientación hacia maximización del voto } \\
\text { - Choques externos } \\
\text { - Choques internos }\end{array}$ \\
\hline
\end{tabular}

Fuente: Elaboración propia.

El conjunto de variables de los trabajos relacionados en la Tabla 1.2 no presenta grandes discrepancias, más bien coinciden en líneas generales, con variaciones que se relacionan sobre todo al objetivo de cada investigación. Las variables elegidas por Swanson y Mancini de cierto modo coinciden con Kaid y Holtz-Bacha, con la diferencia de que ese último trabajo utiliza un término (sistema político) para tres variables (sistema electoral, sistema de partidos y regulación electoral) utilizadas en el primero. Plasser y colegas repiten la misma situación, además de añadieren la variable "grado de modernización de las sociedades", lo que no se puede considerar de todo cierto: el grado de mediatización en Brasil o España (con alto nivel en el consumo de televisión y amplia personalización de la política), por ejemplo, se revela más acentuado que en 
Suecia $^{21}$, a pesar de la inequívoca superioridad sueca en cuanto al desarrollo social y tecnológico.

Si hay algo a reparar en las variables independientes elegidas por Kaid y Holtz-Bacha se refiere al sistema político, que puede tener algunos de sus elementos -en especial el sistema electoral y el sistema de partidos- analizados por separado, por el alto impacto que producen. El sistema electoral es considerado uno de los más impactantes en los formatos de campaña, por establecer las directrices generales de competencia y las reglas del juego de cada contienda (Lago Peñas, 2003). Por implicaciones tan sustantivas merece un análisis más detenido. La asociación del proceso de profesionalización con la pérdida de relevancia de los partidos (García et al, 2006) también es suficiente para asegurar al sistema de partidos un lugar destacado en el análisis de las campañas profesionales.

Se añade como más un factor las preocupaciones de Gibson y Römmele con la vida interna de los partidos, que pueden hacer que la idea de profesionalización sea más o menos acogida. Por supuesto, el modo de acción de un partido "está determinado tanto por la situación externa en la cual estos actúan como por la dinámica intraorganizativa” (Freidenberg, 2003: 63). Implica decir que tanto factores endógenos como exógenos influyen en el trabajo del partido; determinan la manera como las organizaciones y sus candidatos actúan en el momento de las campañas electorales. Los factores del ambiente competitivo son las pistas que de forma macro guían la acción de los partidos. Por otra parte, la experiencia histórica del partido funciona en la micro esfera partidista, como experiencia y referencias que se establecen modos de acción, identidad y cultura política. $\mathrm{O}$, haciendo eco a las palabras de Freidenberg, los factores internos y externos son determinantes a la construcción de las estrategias de los partidos -entre ellas, las estrategias de campaña-.

El reconocimiento de la importancia de los factores internos a los partidos no significa concordar con el énfasis dada a los elementos partidistas en el análisis de Gibson y Rommele, que de hecho quitan importancia a factores externos que también son relevantes. En la valorización de la vida interna de los partidos no se va a tomar cuenta, por ejemplo, de la ideología, uno de los elementos causales del diseño analítico de los dos autores, que consideran que los partidos de derecha son más proclives a la profesionalización. Algunas experiencias pueden indicar otra realidad, como el caso de España, donde el socialista PSOE se encamina hacia la profesionalización antes que

\footnotetext{
${ }^{21}$ Para analizar la cercanía de las campañas de Suecia con las de Estados Unidos, ver Nord (2006), además de Stromback y Dimitrova (2006), que enfocan la cobertura periodística en los dos países. Sobre el grado de mediatización de los países de Europa (con datos sobre el consumo de la tele y lectura de periódicos), ver LeDuc et al (2001) que ofrece cuadro comparativo de 26 sistemas.
} 
partidos a la derecha hiciesen lo mismo ${ }^{22}$. Este esfuerzo de profesionalización ${ }^{23}$ contribuye a que los socialistas lograsen sorprendentes resultados desde la primera votación de la naciente democracia y luego alcanzasen el poder. Solamente en mediados de la década de 1980 la AP (después PP) sigue la estela de la profesionalización en la conocida travesía al centro que culminó en dos elecciones de José María Aznar para la presidencia del gobierno.

Otros ejemplos parecen indicar que el factor ideológico no suele ser un determinante tan fundamental. En Francia, aunque Römmele y Gibson (2001) apunten el conservador Giscard D'Estaing como el primero a profesionalizar la política gala ${ }^{24}$, el referencial de transformación en general citado es el socialista François Mitterrand (Verón, 2004b), que tras dos derrotas desarrolló extraordinario cambio hacia la profesionalización en las elecciones de 1981, con la temprana presencia de consultores y una nueva estructura y modo de acción en la campaña 25 .

En Brasil, el proceso de profesionalización se establece con el retorno a la democracia, se verificando el uso de novedosos recursos técnicos y estratégicos ya en la primera presidencial (1989), donde el liberal Fernando Collor establece un nuevo parámetro de práctica de campaña. Esta profesionalización es seguida por Cardoso en 1994 y 1998; y por Lula, cuyo partido contaba con algunos elementos de la profesionalización desde la primera disputa presidencial, en una sofisticación técnica que alcanza la cúspide en la actual década, muy por encima de siglas a la derecha de PT.

En resumen, las variables que parecen fundamentales sobre el nivel de profesionalización de las campañas son cuatro, dos de ellas directamente vinculadas a los aspectos formales del sistema político: 1) el sistema de partidos, enfocando los modos de organización de los partidos (incluso la cultura interna y la fuerza del liderazgo de carácter carismático) y la relación que mantienen con los votantes; y 2) el sistema electoral, ahí incluyendo las reglas que regulan las campañas. A ellas se juntan

\footnotetext{
22 El primero momento de profesionalización, aun en la segunda mitad de los años 1970, es cuando el partido busca al elector medio, adoptando posición menos extremada (rompe con el marxismo) y personifica su identificación en Felipe González. Sobre la trayectoria del PSOE hacia el poder, ver Méndez Lago (2000), Guerra (1984) y Santos Juliá (1997), además de Maravall (2003).

${ }^{23}$ Sanchis (1996) sostiene que el primero paso hacia la profesionalización fue dado por la UDC de Adolfo Soarez, también en los primeros momentos de la transición, cuando contrató un grupo de expertos con el mismo Sanchis a la cabeza. Pero él no deja de reconocer que el PSOE ya en aquél entonces adoptaba estrategias conducentes con el que hoy se conoce como campaña profesional.

${ }^{24}$ La primacía de D'Estaing es destacada especialmente por lanzar mano de la asesoría del consultor estadounidense Joe Napolitan en 1974, aunque la profesionalización misma se va a ver en 1981, cuando Mitterrand pone en la calle (y en la televisión) una campaña planificada con mucha antelación, con nuevos modos de acción comunicativa e incluso cuidado cambio en su modo de presentación que ha acercado el socialista a un público antes hostil.

${ }^{25}$ Una visión general sobre las campañas francesas puede ser encontrada en Gauthier, Gosselin y Mouchon (1998). No se puede olvidar el trabajo de Kaid, Gerstlé y Sanders (1991).
} 
3) la estructura del sistema de medios, no sólo por implicar en mayor o menor mediatización, sino por la relación con la madurez de la industria que reúne los expertos de campaña y por el reflejo que ello resulta en el formato y contenido de los mensajes electorales; y 4) la cultura política, que indica patrones de comportamiento del ciudadano hacia la política.

Pensar las campañas desde esas cuatro variables parece ofrecer mayor precisión en cuanto a la realidad de América Latina además de constituirse en esquematización que puede ser más abarcador, capaz de ajustarse al análisis de otras sociedades, en contextos sociopolíticos distintos. Esa elección excluye, por ejemplo, la variable modernización de Plasser y colegas, que de hecho se revela en los indicadores medidos, como la sofisticación técnicas de los mensajes electorales y el uso de técnicas de monitoreo. 


\section{El objeto de estudio: el nivel de profesionalización de las campañas en Brasil}

\section{Resumen:}

Este capítulo detalla la propuesta de investigación que mira hacia la profesionalización de las campaña electorales brasileñas. Enfoca primero los estudios que analizaron la profesionalización de campañas, con destaque para el de Gibson y Römmele (2001), que sin embargo se presentan limitados por una visión intrapartidista. Ofrece un nuevo modelo de analisis que toma dos dimensiones como fundamentales a la evoluación del nivel de profesionalización de campañas: la dimensión organizacional, que mira al modo de estructuración de las campañas y la utilización de diversos recursos técnicos; y la dimensión comunicacional, puesto que el modo de comunicación con el elector es también traductor de profesionalización. El apartado describe la estrategia de investigación, que se pauta en entrevistas con consultores brasileños, soporte bibliográfico y de documentos y en el análisis de mensajes electorales de las principales candidaturas a la presidencia, desde 1989. Trabaja con la hipótesis de que hay importante grado de profesionalización de las campañas brasileñas, pero con limitaciones resultados del contexto competitivo tanto formal como informal. 



\subsection{Introducción}

La constatación de que cada sistema presenta campañas con características particulares evidencia el impacto de los diversos factores internos y externos sobre las campañas. Pero no dice sobre el papel específico de cada uno en la conformación de las prácticas de campaña. Esa constatación lleva a importantes cuestionamientos sobre la realidad brasileña: ¿Cuál es el grado de profesionalización de las campañas electorales en Brasil? ¿Qué rasgos principales presentan? ¿Cómo se puede medir el grado de profesionalización de las campañas? ¿Qué factores son fundamentales para que las campañas tengan el grado de profesionalización que tienen? Y, finalmente, ¿̇cuáles son los efectos que las campañas tienen sobre la democracia?

Más allá de describir los rasgos centrales de la publicidad electoral en las campañas brasileñas, se busca medir el grado de profesionalización de dichas campañas en comparación con el modelo estadounidense. Se va a comparar también el nivel de profesionalización de una campaña a otra de un mismo partido y en relación a otros partidos que compiten en un momento dado. Así se producirá una doble comparación, la primera con un elemento extraño a la realidad brasileña (el modelo americano) y la segunda dentro del propio sistema nacional, comparando no sólo a partir de la evolución de las campañas de una elección a otra sino el modo de hacer campaña de uno partido a otro, en concreto, los dos principales partidos de las cinco elecciones presidenciales desde 1989, lo que permitirá también la percepción sobre el modo de hacer campaña en general y en cada partido, apuntando y explicando los cambios encontrados.

La comparación permite evidenciar similitudes y diferencias (Sartori, 1994) y ofrece especial ventaja metodológica en el estudio de la comunicación electoral en las disputas presidenciales, por evidenciar la interferencia de los factores políticos (Negrine y Papathanassopoulos, 1996: 46-47). Para esos últimos, la comparación posibilita mayor claridad sobre el proceso comunicacional por tres razones: primero, permite explorar patrones y problemas en nuestro propio ambiente espacial y temporal, contribuyendo a que se evalúe hasta que punto ellos son comunes o inexistentes, así como entender las razones de ser así; segundo, la comparación permite la generalización de suposiciones, o la comprensión del que sea excepcional en un determinado sistema; y, tercero, puede revelar como la comunicación política es organizada en un nivel macro social. 
La comparación con el modelo americano es por tanto hacer referencia a un modelo que además de real es una idealización: es el modelo profesional en su nivel pleno, por ello capaz de facilitar la comprensión de hasta tan cerca del patrón llegan las prácticas de campañas verificadas en Brasil. Por su parte, la comparación dentro del mismo sistema es un modo de verificar la consistencia de los hallazgos tanto de uno partido a otro como en el mismo partido según sus condiciones históricas.

Se tendrá en cuenta las características del modelo americano como la matriz, de ahí observándose cual de los rasgos principales existentes en ese modelo se dan en las prácticas de campañas electorales de Brasil. En las evidencias de similitudes y diferencias se podrá ofrecer una visión más clara sobre el nivel de profesionalización de las campañas brasileñas.

\subsection{Una propuesta de medición de Campañas Profesionales}

Las campañas electorales han cobrado destacada atención de los investigadores brasileños en las últimas décadas, pero los enfoque han priorizado el análisis de los discursos políticos (Melo, 1994) o la interacción entre medios y campañas, buscando evidenciar la intencionalidad de los medios como actores políticos ${ }^{1} \mathrm{o}$ resaltando los vehículos como herramienta de acción sobre la opinión pública (Figueiredo, 2000; Aldé, 2004; Cervi y Fuks, 2005). La amplia producción y la calidad de los trabajos explicita la extraordinaria evolución de los estudios en las últimas dos décadas. Pero no oculta la larga laguna respecto a uno de los rasgos fundamentales de las campañas electorales, el proceso de profesionalización. El tema, cuando mucho, ha sido tratado por consultores - como los relatos personales de Mendonça (2001), Santa Rita (2001) y Pinto (1989) - en abordajes carentes de un rigor metodológico, casi restringiéndose a percepciones particulares, recetas de manuales y consejos para se lograr la victoria.

Las investigaciones se han olvidado tanto de los cambios experimentados en la organización de las campañas como de los formatos utilizados, uno y otro traductores del grado de profesionalización ${ }^{2}$. Otro olvido importante es el que relaciona los modos de desarrollo de las campañas con el ambiente competitivo, es decir, con el sistema político que establece las pistas sobre las cuales van recorrer las acciones de los partidos y candidatos con vista a la conquista del elector. Las lagunas se notan incluso

\footnotetext{
1 Algunos autores que tratan de ese enfoque son Rubim (1999); Fausto Neto (1990 y 1994); Lima (2001) y Miguel (1999 y 2003)

2 Aquí cabe exceptuarse Queiroz (2006), a pesar de ofrecer una visión más bien histórica, sin profundizar sobre como se desarrollan las prácticas actuales, tampoco las relaciona con el ambiente competitivo formal o informal.
} 
respecto a la televisión, el medio fundamental de las campañas electorales de los últimos 50 años. Como subraya Albuquerque (2003) refiriéndose a la realidad brasileña, la TV es la gran ausente en los estudios sobre la comunicación política, puesto que la mayor parte de los estudiosos parten de un prejuicio despreciativo sobre el medio, sin observar que la misma esencia técnica de la tele produce importantes consecuencias en la comunicación de la política3 ${ }^{3}$.

Se puede decir que el proceso mismo de profesionalización no ha sido analizado como tal en el contexto político de Brasil. Aunque a menudo se diga que las campañas brasileñas son lo que hay de más avanzado en América Latina -como lo hace Queiroz (2006)-, ese tipo de afirmación se basa en la presencia de expertos que salen de Brasil a prestar asesoría a candidatos en otros países de la región, o en la sencilla información de que la comunicación electoral brasileña presenta alta sofisticación técnica. Faltan evidencias empíricas que indiquen la intensidad de la profesionalización, así como las razones que ponen a Brasil por delante de los otros sistemas del continente; o que hacen de las prácticas de campañas de Brasil distintas de las encontradas en democracias consolidadas.

Este trabajo tiene por objetivo evidenciar la intensidad de la profesionalización y las razones de porque las campañas electorales de Brasil presentan tal nivel profesional. La investigación se muestra relevante teniendo en cuenta dos constataciones: primero, el reconocimiento de la creciente modernización de las campañas alrededor del planeta, con cierta estandarización de las prácticas hacia la mediatización, que da paso a la personalización y al uso de técnicas sofisticadas y, de ahí, a la participación de expertos y la utilización de grandes volúmenes de dinero; segundo, que la tendencia a la modernización no significa que todas las campañas son iguales.

Hay grandes diferencias en el nivel de profesionalización de campaña de un país a otro, como ya han evidenciado diversos trabajos (Swanson y Mancini, 1996; Kaid y HoltzBacha, 1995; Espíndola, 2003; Plasser y Plasser, 2002); y las diferencias no pueden ser explicadas de modo sencillo, por ejemplo, separando las democracias maduras de las jóvenes -se esto fuera cierto, Suecia sería tan referencia en los estudios de las modernas prácticas de campañas cuanto Estados Unidos-. Tampoco es suficiente dividir por el sistema de gobierno, indicando que el presidencialismo favorece a la profesionalización, puesto que más personalista $-\mathrm{y}$ el personalismo es uno de los factores que cobran la presencia de los expertos (Maarek, 2005)-.

3 Según Albuquerque (2003), la excepción sería Antonio Fausto Neto, que ha valorado las implicaciones políticas de los factores funcionales de la televisión. 
Lo que se pretende en esta investigación es describir, analizar, comparar y explicar el nivel de profesionalización de las prácticas de campaña en Brasil y los principales factores que intervienen en esa profesionalización. Si las campañas cambian según el tiempo y el lugar, se pretende evaluar la evolución de las campañas brasileñas a la vez que se relacionan los elementos que actúan para que las prácticas desarrolladas en un momento dado y por un dado candidato/partido presenten determinados rasgos y evolucionen (o no) en el tiempo. En resumen, se busca conocer los factores que llevan a la profesionalización de las campañas.

La elección de la experiencia brasileña se fundamentas en diferentes razones. Primero, por ser a la vez una joven democracia y, segundo, por contar con un sistema con alta mediatización de la política. Además Brasil es asociado a la vez con prácticas modernas y antiguas: de una parte, es muchas veces ser asociado con importante grado de profesionalización, exportando expertos para campañas no sólo en otros países de América Latina como también para otros continentes como África e incluso Europa 4. Por otro lado, mantiene un sistema que guarda referencias clásicas de las prácticas latinoamericanas, como el clientelismo (Carey y Reinhardt, 2003; Leal, 1997).

La compleja y heterogénea realidad de Brasil ofrece la oportunidad para evaluar el impacto de determinados factores, sea de la cultura política, sea de las reglas formales que orientan el juego electoral. Súmese a todo ello el hecho del país, en las cinco elecciones desde 1989, alzar a la presidencia políticos/partidos de tres vertientes ideológicas distintas: Fernando Collor (PRN), a la derecha; Fernando Henrique Cardoso (PSDB), al centro; y Lula da Silva (PT), a la izquierda. Y que en todas esas campañas se verificó el uso de recursos profesionales.

Serán precisamente esas cinco campañas da actual fase democrática $(1989,1994,1998$, 2002 y 2006) el foco de la investigación. Serán analizadas las estructuras organizacionales adoptadas por las principales candidaturas, así como los formatos en la comunicación y aspectos del contenido de los anuncios electorales. En cuanto al organizacional, se tomará como referencia las informaciones bibliográficas y otras fuentes, además de entrevistas realizadas con integrantes de las campañas para la concretización de esa investigación.

\footnotetext{
${ }^{4}$ Entre los profesionales de campaña brasileños con actuación en otros países, se puede destacar Duda Mendonça, con campañas en Angola y Argentina; João Santana, con actuación en Argentina; Luiz Gonzalez, con campañas en Portugal y Paraguay; Carlos Augusto Manhanelli, com actuación en Equadror; Fernando Lacerda, con trabajos en Venezuela; Eduardo Godoy, con campañas en El Salvador; y Einhardt Jácome, que ya respondió por la comunicación electoral del Partido Social-Democrata de Portugal en 1999 y 2005. Pero la actuación en el área política que merece más destaque es la del instituto lbope, que con sucursales en todo el continente realiza sondeos desde el Cono Sur hasta México.
} 


\subsection{Estrategias de investigación}

Para hacer posible la medición, se hace necesaria la definición de un conjunto de indicadores que permiten evaluar la ausencia o presencia de las principales características de las campañas profesionales y, en ese último caso, la intensidad de dichas características. Eses indicadores van a representar las dimensiones capaces de traducir la profesionalización: la dimensión comunicativa y la organizativa. Esas dos dimensiones son las dos caras de una misma moneda, porque el modo de organización de las campañas (centralizada, con muchos recursos financieros, presencia de expertos) es tan revelador de la profesionalización cuanto determinados modos de mensajes (simbólicas, orientada hacia la imagen, centrada en la persona).

En la definición de la estrategia, una de las referencias que se toma aquí es la estructura de análisis de campañas profesionales desarrollada por Gibson y Römmele (2001), puesto que es uno de los pocos esfuerzos de medición de nivel de profesionalización encontrado en la literatura. Sin embargo no se lo toma como el modelo a ser aplicado en el análisis de las campañas profesionales en Brasil teniendo en cuenta lo antes expuesto: es un análisis desde dentro de los partidos, con la intención de explicar por qué uno partido más que otro se vuelve más proclive a los cambios hacia la profesionalización; más que todo ofrece una lectura de las tendencias que llevan hacia la profesionalización. Pero si las variables son suficientes para explicar una tendencia, no lo son para indicar el grado de profesionalización de las campañas, sobre todo en sistemas donde los partidos cuentan tan poco.

Los dos autores eligen cuatro dimensiones de donde sacan los indicadores de medición: 1) la referente a las herramientas y estrategias, 2) la que focaliza en el estilo o modelo de campaña, 3) la que traduce las relaciones con el elector y 4) la atinente a la distribución de poder en la estructura de la campaña. De ahí elaboran un conjunto de diez indicadores que van a integrar lo que consideran el índice general de profesionalización.

Para concretar el intento de construcción de un índice, los autores eligen dos grupos de ocurrencias relacionados a las variables independientes. El primero, que llaman de "variables principales", incluye aspectos como la ideología (para los autores, cuanto más a la derecha está el partido, más posibilidad de profesionalización), el alto nivel de recursos disponibles (más dinero, más profesional), estructura de campaña centralizada (más profesional, más centralización) y si el partido tiene como objetivo la maximización de votos, es decir, si es un partido catch-all, en los términos de Kirchheimer (1980) que amplia la necesidad de esfuerzos profesionales por alcanzar públicos diversos y sin vínculos con el partido. El otro grupo de fenómenos es 
denominado "variables de eventos", donde incluyen los choques externos al partido (de modo más concreto, la pérdida de elección o victorias marginales) y los choques internos (relacionados al cambio de liderazgo o la presencia de sectores radicales). De la interacción de esas variables presentan el diseño de las relaciones de causalidad representado en la Cuadro 3.1.

CUADRO 3.1

Estructura de análisis de campaña profesional de Gibson y Römmele

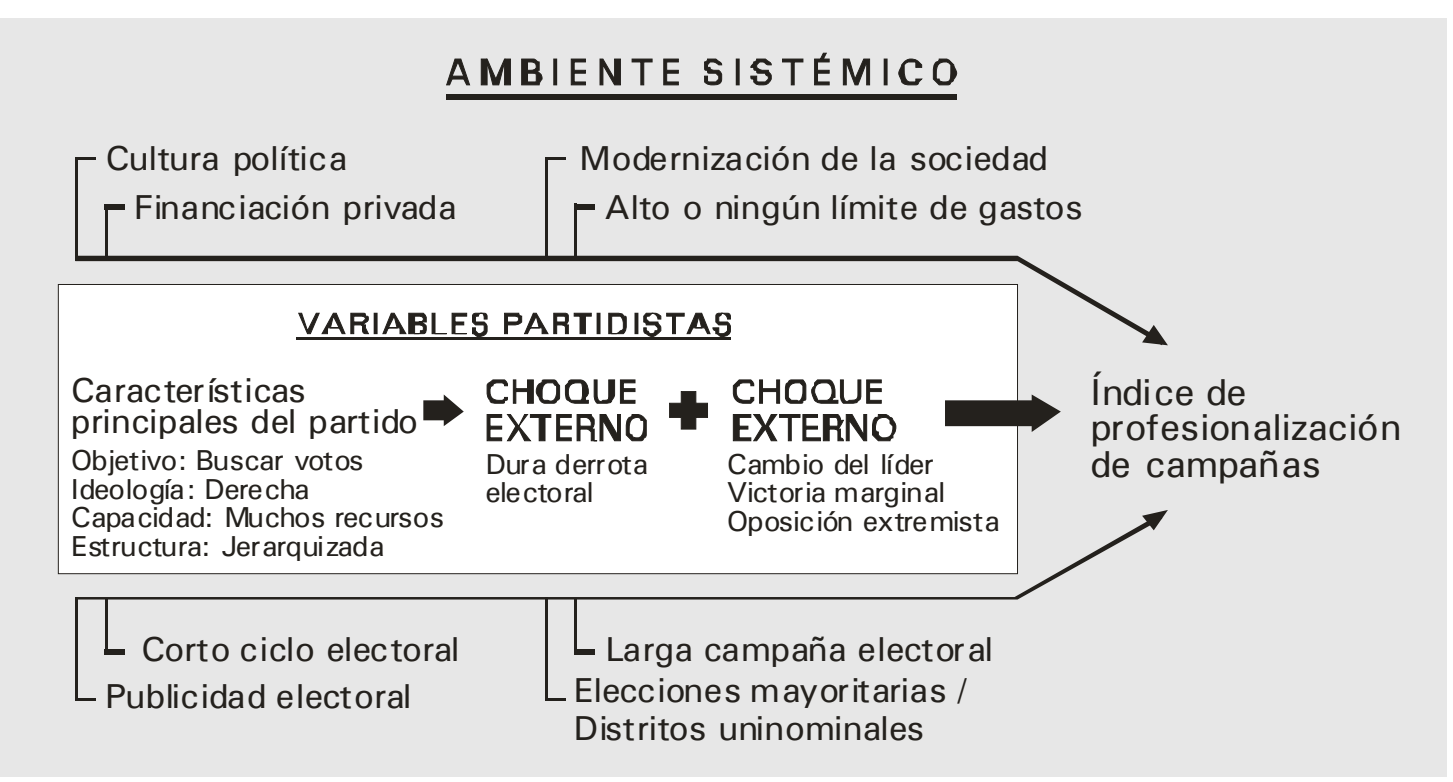

Fuente: Gibson y Römmele (2001: 38), tradución libre del autor.

En lo que se refiere a la variable dependiente "nivel de profesionalización", cada uno de los diez indicadores recibe una valoración que llevará a la construcción del índice: en caso de ocurrencia del indicador, se suma el valor 1; su ausencia significará la atribución del valor cero. La suma total indicará el nivel de profesionalización que los autores pretenden constatar, donde cuanto más cerca de diez más profesional será la campaña. Los siguientes son los indicadores efectivos de profesionalización elegidos por Gibson y Römmele (2001: 39):

1. Uso del tele marketing para contactar miembros del propio partido y integrantes de los grupos blanco;

2. Uso de correo dirigido para se comunicar con miembros del partido y integrantes de grupos-blanco; 
3. Uso de consultores externos en medios y relaciones públicas;

4. Uso de bases de datos informatizadas;

5. Uso de sondeos de opinión pública sobre la intención de voto;

6. Monitorización de las encuestas respecto de la oposición;

7. Presencia de sistema interno de comunicación por Internet;

8. Enviar correos electrónicos a una lista de suscripción con actualización regular de las noticias;

9. Comando de campaña formado por outsiders; y

10. Campaña permanente.

A pesar de constituirse en un importante intento de medición, los indicadores de Gibson y Rommele presentan algunas inadecuaciones que quizá se justifiquen por el enfoque estrictamente partidista. Primero por no incluir ningún elemento relacionado al modo de comunicación con el elector respecto el principal canal de comunicación electoral -la televisión-. Relaciona a la posibilidad de mejor comunicación en el ámbito interno de las campañas (uso de intranet), pero este aspecto está más en el campo de la organización que en el modo de relación de la campaña con el elector, que es recordado tan sólo cuando hacen referencia a la distribución de correos electrónicos a miembros y no miembros del partido. Es un enfoque por demás limitador de la acción comunicativa en las campañas profesionales, un marco no sólo por la intensidad en la exhibición de los mensajes sino por los formatos y el uso de canales específicos.

Además, los indicadores valoran excesivamente los recursos tecnológicos utilizados en las campañas -correspondiendo a la mitad de la lista, en los indicadores 1, 2, 4, 7 y 8-, casi como se la profesionalización fuera tan solo el uso de recursos técnicos. Aunque de gran importancia, los factores tecnológicos revelan sólo una de las caras de las campañas profesionales, traduciendo un nivel organizativo y también la capacidad financiera disponible. No es que los aspectos organizativos sean de poca importancia, muy al contrario; pero no es posible la medición efectiva del grado de profesionalización sin la evaluación de la presencia o ausencia de otros rasgos de las campañas profesionales, como son los formatos de comunicación utilizados fundamentalmente en el campo de la televisión.

Diversos autores hablan de esos aspectos que son de naturaleza técnica pero que se vinculan a los cambios en la acción comunicativa en búsqueda de mayor efectividad, como cuando enfatizan el papel de la comunicación simbólica, la emocionalización (Rees, 1992), la centralidad de la persona y de la imagen en los spots publicitarios (Berrocal, 2003b), la sofisticación técnica y la segmentación de los mensajes (Norris, 2001). Es la suma de los aspectos organizativos y de los elementos comunicacionales 
caracterizadores del modo de acción que van decir efectivamente el grado de profesionalización. Es decir, no se puede desconsiderar como indicador de profesionalización el uso de ciertos recursos comunicacionales con el intento de optimizar la respuesta del elector hacia una oferta política específica.

También parece muy relevante la centralización del comando así como el propósito de unificar estrategias y discurso con el objetivo de maximizar votos. Entre los eventos, la pérdida de elecciones y el cambio de liderazgo tienen efectivamente fuerte impacto en el movimiento hacia la profesionalización -como bien demuestran el caso de PT en Brasil, del PSOE en España, del PS francés y del Partido Laborista inglés-, sin revelar la misma profesionalización.

Otro problema en los indicadores de Gibson y Römmele: los indicadores "uso de encuestas y sondeos" y "monitorización de la oposición” parecen poder ser resumido a un sólo indicador, quizá "uso de instrumentos para monitorizar el contexto político". Además, hace falta aún un indicador que dimensione los esfuerzo de interacción entre campaña y elector, característica que diferencia las diversas etapas de las campañas (Norris et al, 2001). De hecho, la ausencia más destacada en el listado de indicadores se relaciona con las acciones de comunicación, tanto respecto a la forma cuanto al contenido de los mensajes publicitarios: si están centrados en temas, o si usan lenguaje simbólico, si está centrado en el candidato, en el partido o el programa. Son aspectos relevantes para la traducción del grado de evolución de las campañas, acorde con autores como Sábada (2003), Swanson y Mancini (1996) y Kayd y Holtz-Bacha (1995).

Aunque sea comprensible parte de esas ausencias para un análisis que tiene el foco en la organización partidista, no lo es para el presente trabajo que busca una visión más amplia capaz de traducir el desarrollo de campañas profesionalizadas, considerándolas resultados de factores sistémicos, estructurales y culturales, y encontrando en los elementos organizativos y comunicacionales las formas de manifestación del nivel de profesionalización. Además, no se puede olvidar que los procesos comunicacionales siempre han sido centrales en las campañas y lo son todavía más en las campañas contemporáneas con bajo contacto personal, en que las referencias partidistas suelen ser puestas en un plan inferior.

La elección de la dimensión comunicativa parece obvia, desde que se considera a las campañas como un esfuerzo de comunicación (Trent y Friedenberg, 2000) y teniendo en cuenta que los cambios en los procesos comunicacionales -sea desde un enfoque de forma y contenido, sea aún por el uso de nuevos canales o tecnologías de comunicación- son centrales en todas las comparaciones acerca de las distintas fases de evolución de las campañas. En esto no se va a encontrar divergencias significativas 
entre los autores, aunque se pueda percibir algunas discrepancias en cuanto a los recursos usados. Desde que Agranoff (1976) utilizó el término "estilo americano" de campaña ciertos modos de acción comunicativa son observados como traductores de un nuevo estilo de campaña electoral. Con el establecimiento de la fase profesional, en principio de la década de 1990, los recursos comunicacionales (nueva forma y contenido) son destacados como traductores de esa profesionalización de campaña. De ahí la natural elección de esa dimensión como elemento necesario a la medición del grado de profesionalismo.

Incluir la dimensión comunicativa hace más preciso el intento de medición de la profesionalización, huyendo de generalizaciones o dispersiones. El abordaje aquí adoptado se vuelve a la vez más amplio y específico que el modelo de Gibson y Römmele. Más amplio por mirar más allá de los factores relacionados a la organización y más específico por elegir un grupo con mayor número de indicadores que refinan el análisis de las campañas profesionales, pudiéndose ofrecer mayor precisión en la medición del grado de profesionalización de cada una.

Los efectos de las campañas no serán considerados en el desarrollo de este trabajo, aunque se reconozca la importancia de los estudios en esta área. Las investigaciones coherentes con la perspectiva cognitiva evidencian la comunicación política como un proceso de dos vías, donde dos actores -candidatos y electores- dialogan y establecen un pacto fundado en el intercambio de intenciones (Figueiredo et al, 1996). Aquí se va a mirar hacia una vía de ese diálogo: a pesar de la importancia de los estudios sobre el impacto de las acciones comunicativas, los efectos no son objeto de este estudio sencillamente porque no cabe utilizarlos como traductores del nivel de profesionalización, aquí analizado desde la conformación operativa que delinea la estructura organizativa y las acciones de comunicación según las intenciones estratégicas en el seno de la campaña. No cabe evaluar la manera como el elector recibe, interacciona y reacciona con/a los mensajes. En resumen, lo que se objetiva es analizar la profesionalización sí como un proceso que puede ser asociado con la dinámica de modernización de las sociedades cotejando con las características identificadas dentro del llamado estilo americanizado.

Desde ahí se puede establecer un esquema de relación causa-efecto en que las variables independientes integran el ambiente competitivo que impacta y da forma a las campañas profesionales. En el escenario competitivo por lo tanto se destacan cuatro factores causales: el sistema electoral, el sistema de partidos, la estructura del sistema de medios y la cultura política. El sistema electoral contempla las reglas formales que necesitan ser observadas por los competidores, reglas que definen el modo de competencia (mayoritaria o proporcional, grandes o pequeñas circunscripciones, listas 
abiertas o cerradas) y los límites de actuación de las campañas (acceso a los medios, financiación, duración).

La relación de causa y efecto va a generar un diseño de investigación caracterizado en el Cuadro 3.2: en él los factores organizativos y comunicaticionales se revelan en prácticas que están ajustadas a las condiciones del medioambiente competitivo (es decir, reciben la influencia de las variables independientes). Esas prácticas son los indicadores cuya presencia (e intensidad) o ausencia va a decir el grado de profesionalización de una campaña.

CUADRO 3.2

\section{Esquema de análisis de las campañas profesionales}

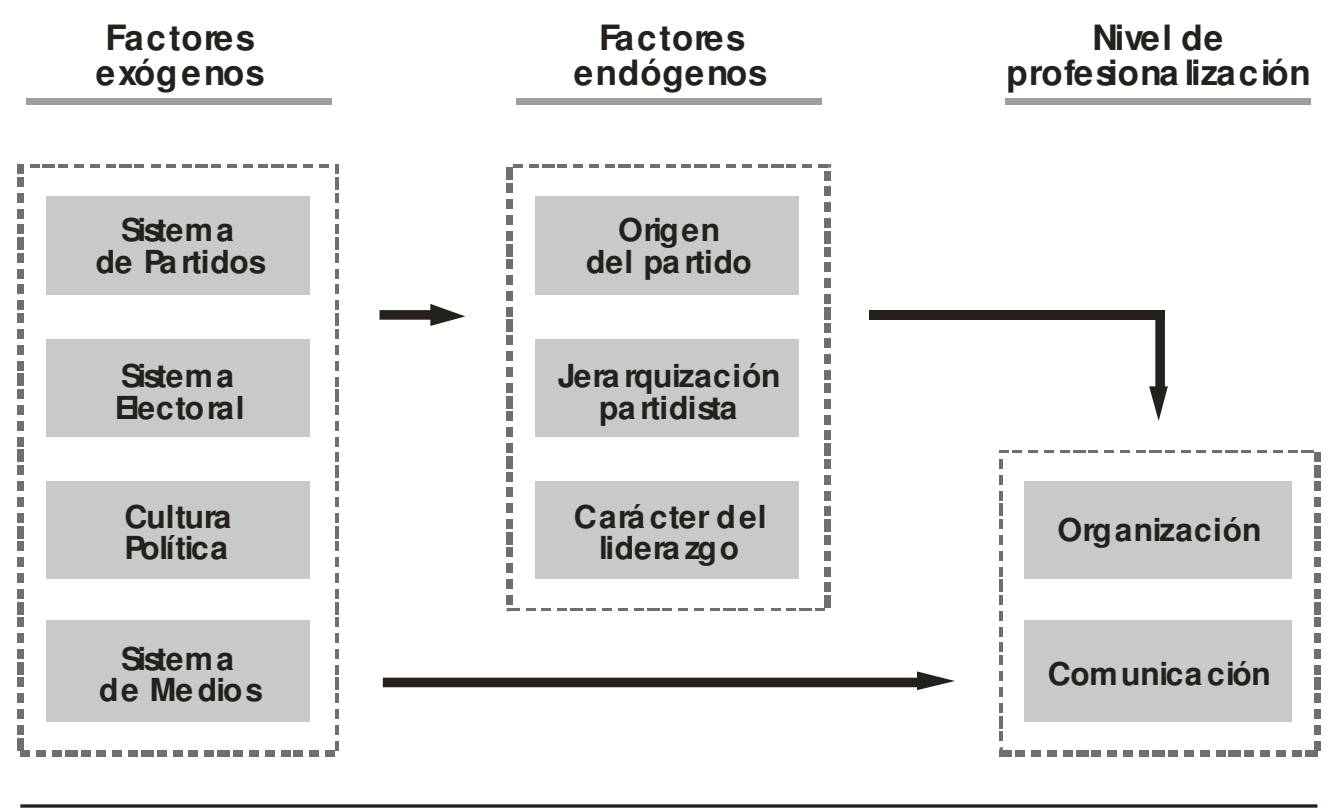

Fuente: Elaboración propia

El reto principal ahora es tener claro los indicadores más relevantes en el campo organizativo y comunicacional con el intento de buscar mayor fiabilidad al modelo, haciendo que la medición indique con la mayor precisión posible el grado de profesionalización de las campañas. Eses indicadores forman la parte más relevante para las campañas del amplio escenario medioambiental, el contexto competitivo en que las candidaturas están inseridas e interfieren en el proceso de profesionalización. 
CUADRO 3.3

Indicadores de Profesionalización en Campañas Electorales

\begin{tabular}{|c|c|c|c|}
\hline & \multicolumn{3}{|c|}{ Intensidad } \\
\hline & 0 & 1 & 2 \\
\hline \multicolumn{4}{|l|}{ Dimensión ORGANIZATIVA } \\
\hline Centralización del comando & Descentralizado & Parcial & Total \\
\hline $\begin{array}{l}\text { Presencia de consultores externos en } \\
\text { áreas de comando }\end{array}$ & $\begin{array}{l}\text { Poco o nada } \\
\text { representativo }\end{array}$ & $\begin{array}{l}\text { Participación } \\
\text { mediana }\end{array}$ & $\begin{array}{l}\text { Participación con } \\
\text { alta importancia }\end{array}$ \\
\hline Planificación & Corto plazo & Medio plazo & Permanente \\
\hline Fuente de financiación & Voluntarios & Mixto & Grupos de interés \\
\hline $\begin{array}{l}\text { Uso de sondeos, encuestas y grupos } \\
\text { focales }\end{array}$ & Bajo / Inexistente & Mediano & Intensivo \\
\hline $\begin{array}{l}\text { Media training y entrenamiento de } \\
\text { equipe }\end{array}$ & Bajo / Inexistente & Mediano & Alto \\
\hline Páginas webs interactivas & Bajo / Inexistente & Uso mediano & Amplio uso \\
\hline $\begin{array}{l}\text { Uso e-mail para enviar noticias y para } \\
\text { contacto con votantes }\end{array}$ & $\begin{array}{l}\text { Esporádico / } \\
\text { Inexistente }\end{array}$ & Frecuente & Muy frecuente \\
\hline $\begin{array}{l}\text { Sofisticados sistemas internos de } \\
\text { comunicación / Intranet }\end{array}$ & Sin sistema & $\begin{array}{l}\text { Parte de la } \\
\text { estructura }\end{array}$ & Toda la estructura \\
\hline Uso de nuevos recursos como SMS & Bajo / Inexistente & Mediano & Alto \\
\hline Bancos de datos informatizadas & Bajo / Inexistente & Medianas & Muchas \\
\hline Uso del tele marketing & Bajo / Sin uso & Mediano & Amplio \\
\hline Uso de satélite & Bajo / Inexistente & Mediano & Alto \\
\hline Militancia predominante & Voluntaria & Mezclada & Pagada \\
\hline \multicolumn{4}{|l|}{ Dimensión COMUNICATIVA } \\
\hline Mensajes Personalizados & Poca & Mediana & Alta \\
\hline Mensajes enfocados en la imagen & Poca & Mediana & Alta \\
\hline $\begin{array}{l}\text { Profundización sobre los asuntos } \\
\text { enfocados en los mensajes }\end{array}$ & Baja & Mediana & Alta \\
\hline $\begin{array}{l}\text { Nacionalización de los enfoques de } \\
\text { los mensajes }\end{array}$ & Baja & Mediana & Alta \\
\hline Segmentación de mensajes & Baja & Mediana & Alta \\
\hline $\begin{array}{l}\text { Uso de abordaje simbólico y } \\
\text { reduccionista }\end{array}$ & Bajo & Mediano & Alto \\
\hline $\begin{array}{l}\text { Uso de tono emocional en los } \\
\text { mensajes electorales }\end{array}$ & Bajo & Mediano & Alto \\
\hline Sofisticación de los efectos técnicos & Baja & Mediana & Alta \\
\hline Efectos con intención cognitiva & Poco & Mediano & Alto \\
\hline Objetividad & Baja & Mediana & Alta \\
\hline Uso de propaganda negativa & Bajo & Mediano & Alto \\
\hline \multicolumn{4}{|l|}{ SUMA } \\
\hline Índice & & & \\
\hline
\end{tabular}

La búsqueda de precisión eleva el número de indicadores a 25, 14 de ellos traduciendo la dimensión organizativa y 11 relativos a los aspectos comunicacionales. Con el intento de refinar la capacidad de dimensionar el nivel de profesionalización, será establecida 
una graduación para la ocurrencia de los indicadores. Esta decisión aleja el modelo aquí presentado del propuesto por Gibson y Römmele (2001), que tan sólo anota la existencia o inexistencia del indicador, implicando en la suma "1" para la ocurrencia o en el valor "o", cuando no se verifica tal fenómeno. El esquema de aquellos autores no considera la intensidad de tales ocurrencias, reduciendo la capacidad de precisión.

La opción por adoptar mecanismo que permitar considerar la intensidad de los fenómenos toma en cuenta que los indicadores, como las campañas profesionales, pueden presentar niveles muy diversos. Uno ejemplo es el uso de anuncios negativos, verificados en todos los sistemas analizados en el volumen coordinado por Kaid y Holtz-Bacha (1995) aunque en niveles distintos según el país. El mismo tipo de verificación se puede encontrar en indicadores como personalización de mensajes, o participación de consultores políticos del mercado, sin vínculo partidista.

El diseño investigativo aquí elaborado establece tres grados de intensidad, favoreciendo a una mayor precisión cuanto al nivel de profesionalización, conforme el Cuadro 3.3. Cada uno de los 25 indicadores del nivel de profesionalización de las campañas va a recibir valoración “o”, “1” o “2”, donde el valor “o” representará la inexistencia o la baja ocurrencia del fenómeno; el valor "1" será imputado a los casos en que la campaña presenta una intensidad mediana del indicador evaluado; y el "2" será considerado cuando el fenómeno se presenta de modo muy significativo. Las campañas serán más profesionales cuanto más presentes (y con más intensidad) estén los indicadores. La valoración posibilitará la construcción del índice de profesionalización de las campañas, desde una media que variará del valor o al 2, según la siguiente fórmula:

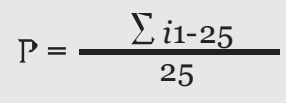

El índice de profesionalización es representado por "P", que es resultado de la suma de los valores identificados para cada uno de los 25 indicadores "i”, que variará del resultado mínimo de cero punto (valor mínimo de "o" para todos los indicadores evaluados) hasta 50 (valor máximo de 2 también para cada uno de los indicadores). Por su parte, la suma es dividida por 25 (el número de indicadores evaluados), ofreciendo un índice final que variará en la escala de o,o a 2,0. Cuanto más cerca de 2 mayor será la profesionalización de la campaña. Para una clasificación más objetiva, se utilizarán tres grupos de indicadores, contemplando los 21 resultados posibles del intervalo, cada 
grupo con siete valores con una décima: las medias de o,o hasta 0,6 significan bajo nivel de profesionalización; de 0,7 hasta 1,3 representan una campaña de profesionalización mediana y de 1,4 hasta 2,0 traducen una campaña con alto nivel profesional. Esos resultados serán matizados con las condiciones medioambientales de la contienda electoral, permitiendo no sólo notarse el grado de profesionalización traducido en el índice, sino también explicar las razones que hacen las campañas como son.

\subsection{Las hipótesis de trabajo}

Por supuesto, hay importantes diferencias en las campañas brasileñas respecto los marcos característicos del modelo estadounidense, así como algunos aspectos son comunes a las dos realidades. Los factores propios del ambiente competitivo suponen en un modo distinto de acción electoral. Así, mirando el contexto competitivo brasileño y las variables que condicionan el juego electoral, se puede extraer algunas hipótesis principales:

H1. Las campañas brasileñas presentan importante grado de profesionalización con el foco en la planificación, alto nivel de mediatización, amplio soporte financiero, uso de instrumentos de evaluación de escenarios y sofisticación en cuanto al lenguaje y a la técnica comunicativa, además del destacado papel desempeñado por los consultores.

Desde fines de la transición democrática los recursos profesionalizantes se van consolidando como importantes en el proceso político brasileño, que se hacen todavía más presentes con el aumento de la competencia. Hoy ni siquiera las disputas por alcaldías de municipios medianos o incluso la lucha por un puesto de concejal prescinde del recurso profesional: las encuestas son recurso ampliamente utilizado, la planificación de largo plazo y especial atención a los medios como generadores de referencialidades y mediadores en la relación entre sociedad y política. La publicidad electoral tiene importante papel en las disputas, manifiesta en la sofisticación de los mensajes electorales de los candidatos.

La hipótesis general H1 no acaba los presupuestos respecto de las campañas brasileñas, que es conformada desde un conjunto de rasgos institucionales (formales e informales) referentes a factores como el sistema político, la cultura política y la organización de los medios de comunicación de masas. De ahí se puede relacionar otras hipótesis:

H2. La industria de comunicación -en especial la televisión y el sector de la publicidad- tiene un papel destacado en la madurez de las campañas en 
Brasil, con el uso de recursos técnicos de alta sofisticación y el establecimiento de una cultura visual asociada al lenguaje simbólico y fragmentado.

La industria de la comunicación de Brasil es reconocida por su calidad, estando entre las más competentes tanto en el campo televisivo como en la producción publicitaria. El conocimiento del campo comunicacional contribuyó en la rápida madurez de la comunicación política, aportando recursos propios del mercado comercial, tales como lenguaje simbólico, simplificación de los mensajes y estrategias adecuadas al acercamiento a los diversos públicos. El estadio avanzado de los medios profundiza la centralidad de la personalización y atención a la construcción de imágenes, fundamental a la producción de escenarios de representación de la política.

A pesar de ello, la profesionalización encuentra sus limitaciones merced de rasgos específicos del sistema brasileño. De ahí, surgen otras hipótesis:

H3. La legislación es un importante limitador en el uso de las técnicas disponibles y ampliamente usadas en las acciones del marketing y de la publicidad comercial, contribuyendo a la limitación de la misma profesionalización.

Una de las más importantes características de la campaña profesional, la segmentación de mensajes, encuentra fuerte limitación en las campañas brasileñas por las reglas electorales. La mayor parte de la publicidad electoral está concentrada en bloques de programas con horarios de exhibición fijos e incluso los spots sueltos están limitados a horarios establecidos por la justicia electoral, ajustados a la disponibilidad de espacio de las emisoras de televisión y radio, lo que impide la adecuada programación de mensajes para públicos específicos. Otra limitación es que las TVs por cable, donde se hace más evidente la segmentación, no vehiculan la publicidad electoral.

H4. La cultura política favorece la personalización, aspecto importante de las campañas profesionales, pero a la vez exige acercamiento físico del candidato, en contra la tendencia de la profesionalización.

La cultura política fortalece el papel de los liderazgos regionales en la organización y estrategias de los candidatos, bien como en la elaboración del contenido -otra vez el enfoque negativo de la publicidad es desestimado por un elector reacio a los mensajes de ataque-.

Además, algunos aspectos de la comunicación profesional presentes en las campañas brasileñas deben ser explicados de modo distinto del enfoque de la literatura internacional. Es el caso de la personalización: 
H5. La personalización de la política, siempre mirada como reflejo de la perdida de importancia de los partidos, en Brasil no caracteriza la fase profesional puesto que ha sido un rasgo presente en cualquier modelo o fase de campaña.

De hecho, los partidos nunca han tenido gran importancia en la política brasileña (Mainwaring, 2001; Carey y Reinhardt, 2003) y la personalización siempre ha sido un rasgo central en la política. En la historia del país, los partidos apenas pasan del papel de formalizadores de candidaturas.

H6. Personas vinculadas a los partidos o al liderazgo siguen con destacado papel en el comando de las campañas, a pesar de la creciente presencia de expertos.

La profesionalización cobra presencia de los expertos, pero la regla en Brasil es que tales profesionales del mercado no se adueñan de las campañas, en general respondiendo a la coordinación política vinculada al partido o sobre todo al candidato.

\subsection{Datos: las técnicas de recolección y fuentes de datos}

La operacionalización de los indicadores de profesionalización se realiza desde tres procedimientos: 1) entrevistas con 13 profesionales de campaña de referencia nacional y dos ex presidentes partidistas, como forma de identificar la organización de las campañas presidenciales brasileñas de la actual fase democrática; 2) consulta de publicaciones periódicas, bibliografías y documentos (libros, artículos, periódicos, informes de la Justicia Electoral) relacionados con aspectos de la organización; y 3) análisis de los 80 bloques de programas electorales y 155 spots cortos. Ese cuerpo de análisis de la publicidad electoral es una significativa muestra correspondiente a cerca de una quinta parte del todo que ha sido exhibido por los dos principales candidatos de cada una de las cinco presidenciales brasileñas desde 1989.

Las entrevistas, fueron realizadas mediante contacto directo (vía teléfono o por correo electrónico), con preguntas sobre la forma de organización, el proceso de decisión interno y especialmente informaciones relacionadas al uso de recursos tecnológicos en la estructura de las campañas. Fueran entrevistados del área de coordinación y planificación de marketing a Chico Santa Rita, Luíz González, Francisco Malfitani, Elysio Pires y Eduardo Godoy Pereira; del área de producción de videos, a Gilnei Rampazzo; del sector de organización de estructuras de campañas, Carlos Manhanelli; de las encuestas, Marcos Coimbra; del área de telemarketing, Fernando Lacerda; y del campo de relación con los medios, Cláudio Humberto Rosa e Silva, Orlando Brito, 
Laerte Rímoli y Carlos Brickmann. Además, fueron entrevistados el ex presidente de PT, diputado José Genoíno, y el ex presidente de PSDB, José Aníbal. Las preguntas no se limitaron al campo de actuación de cada entrevistado, mas bién a los diversos aspectos de las campañas ${ }^{5}$

Las fuentes complementarias tienen a la vez la función de aportar datos raramente puestos a la disposición pública por las campañas -como los gastos de una candidatura, cuantificables a través de los documentos del Tribunal Superior Electoral o del análisis de investigadores como Samuels (2001) - y llenar lagunas en el proceso de entrevistas, especialmente en el caso de aquellos que no se disponen a atender la solicitud de la investigación. En ese último aspecto, los archivos de periódicos fueron de gran valía para la investigación. Todas esas informaciones permitieron la identiticación de los rasgos fundamentales de las campañas y así la ubicación de cada una en cuanto las características de las campañas profesionales.

De ese modo, la identificación de una campaña como permanente está vinculada a la preocupación permanente de los partidos y los políticos con el desempeño electoral, dentro del entendimiento de que toda la acción política, en cualquier tiempo, tiene como foco final la conquista del voto ${ }^{6}$. Para ello se observa la planificación de largo plazo, traducida en la contratación de expertos con mucha antelación, o el funcionamiento regular de núcleos de trabajo preocupados con la imagen y las alianzas con otros partidos o actores sociales relevantes. La campaña permanente tiene un foco específico en la visibilidad, de ahí la atención a los medios, donde el manjeo de la agenda mediática permite a la construcción de un escenario de representación de la política capaz de generar efectos cognitivos con amplia respuesta política al momento de las elecciones (Lima, 2001).

Identificar una campaña como de capital intensivo tiene como principal indicador los costes declarados a la justicia electoral, cotejándose con los costes de otras campañas como las estadounidenses y de otros paísses. Se sabe que este es un dato siempre problemático en el caso de Brasil, donde escándalos de corrupción revelan la práctica sistemática de contabilización solamente parcial. El falseamiento de los números

\footnotetext{
${ }^{5}$ Entre los coordinadores de las campañas evaluadas, tres se negaron a ser entrevistados. Duda Mendonça, coordinador de la campaña de Lula en 2002, y Nizan Guanaes, coordinador de la campaña de José Serra en 2002 y Fernando Henrique en 1998, no contestaron a los varios intentos, ni por teléfono ni por correo electrónico. Se recusan hablar sobre el tema, conforme información prestada por asesores. João Santana, coordinador de Lula en 2006, dijo no concordar con el enfoque "americanista" de la investigación, que considera "superado". Pero la investigación utilizó las declaraciones publicadas (en livros o entrevistas) por eses consultores. Otra importante laguna es la del coordinador general de la campaña de Fernando Henrique en 1994, Geraldo Walter, fallecido en 1998, cuando estaba a la cabeza de la campaña de reelección, puesto luego ocupado por Guanaes.

${ }^{6}$ Ver Soler (2001) y Nimmo (1999).
} 
relativos a los gastos es particularmente evidente en las campañas de Collor 1989 y en la de Lula 2002, ampliamente divulgado por la prensa en el rastrillo de sonantes escándalos; pero la doble contabilidad es una práctica distendida en la política brasileña. Un estudio de la Universidade Federal de Pernambuco reveló que, además de gastos elevados con la financiación de los apoyos políticos y las acciones de campaña, los candidatos recaudan altos valores también para la formación de soporte financiero particular, mas allá de la campaña misma (Figueiredo, 1994).

La centralización de organización se revela en la estructuración de cada comando, y especialmente en el papel jugado por los consultores externos en cada una de las analizadas en la investigación. Se evalua además el papel del líder y/o candidato en ese comando, explicitando en que nivel se da el acercamiento de cada estructura al estilo profesional. El papel de los consultores será el parámetro utilizado para valorar otros dos indicadores -el que respecta a la participación de consultores externos más allá del comando y hasta que punto eses profesionales asumen la condición de estrella de la campaña misma-. Las entrevistas, documentos y bibliografía van revelar el uso (y con que intensidad) del correo electrónico, los instrumentos de monitoreo de la campaña, la presencia de intranet para comunicación dentro da la organización, uso del satélite para distribución de mensajes y comunicación con sectores del electorado, páginas web interactivas y presecia de servicios como el telemarketing.

En cuanto a los indicadores de la dimensión comunicacional, será resultado del análisis de los bloques de programas y spots sueltos selecionados. El corpus de análisis incluye dos tipos de mensajes, puesto que la legislación brasileña admite bloques de programas (como en Francia e Inglaterra) y spots sueltos, semejantes al patrón de anuncios electorales de Estados Unidos -a diferencia que Brasil no se permite la compra de espacio-. De cada campaña fueron seleccionados 5 programas electorales, que en los años de 1989, 2002 y 2006 fueron analizados 10 bloques de programas de cada candidatura, 5 de la primera vuelta y 5 de la segunda. Esa ampliación se hizo para evidenciar similitudes y discrepancias entre las acciones de campaña entre la primera y la segunda vuelta, puesto que muchas veces pasar de una vuelta a otra resulta en cambios también de estrategias. La misma preocupación fue adoptada para el caso de los spots sueltos, con muestreo incluyendo piezas de primera y segunda vuelta, para el caso de 1989, 2002 y 2006.

La selección de los bloques de programas incluye dos programas exhibidos en la fase inicial de la publicidad electoral en televisión, uno de la fase intermedia y dos del final del período, salvo en el caso de la segunda vuelta de Collor, en que el muestreo tuvo que 
estar restricto a cinco de los seis primeros programas del período7. Para los spots sueltos, fueron analizados el mayor número posible, con la preocupación de contar con un muestreo de por lo menos diez anuncios por campaña. Los 80 bloques de programas suman 643 minutos y 42 segundos de mensajes electorales, en cuanto los 155 spots cortos resultan en 56 minutos y 15 segundos de mensajes, en una suma total de 699 minutos y 57 segundos de publicidad. La distribución de mensajes electorales analizados queda así distribuida, segundo el número de unidades y el tiempo por candidatura:

Cuadro 3.4

El corpus de análisis de la investigación, por candidato (segundo/N)

\begin{tabular}{|c|c|c|c|c|c|}
\hline \multirow{2}{*}{ Año } & \multirow{2}{*}{ Candidato } & \multicolumn{2}{|c|}{$1^{\text {a }}$ Vuelta } & \multicolumn{2}{|c|}{$2^{a}$ Vuelta* } \\
\hline & & Bloques & Spots** & Bloques & Spots** \\
\hline \multirow{2}{*}{1989} & Collor & 1.401 & & 2.997 & \\
\hline & Lula & 1460 & & 2.989 & \\
\hline \multirow{2}{*}{1994} & Cardoso & 2.263 & & & \\
\hline & Lula & 990 & & & \\
\hline \multirow{2}{*}{1998} & Cardoso & 3.546 & 315 & & \\
\hline & Lula & 1.421 & 285 & & \\
\hline \multirow{2}{*}{2002} & Lula & 1.554 & 330 & 2.987 & 270 \\
\hline & Serra & 3.059 & 465 & 2.982 & 300 \\
\hline \multirow{2}{*}{2006} & Lula & 2.151 & 360 & 2.981 & 510 \\
\hline & Alckmin & 2.866 & 360 & 2.975 & 180 \\
\hline \multirow{2}{*}{ Total *** } & (en segundos) & 20.711 & 2.115 & 17.911 & 1.260 \\
\hline & (en minutos) & $345: 11$ & $35: 15$ & $298: 31$ & $21: 00$ \\
\hline
\end{tabular}

Fuente: elaboración propia

* No hubo segunda vuelta en 1994 y 1998.

* En 1989 y 1994 la legislación no permitía los anuncios en formato de spots sueltos.

*** A causa del muestreo disponible, el tiempo carece de rigurosa exactiud. En las segundas vueltas la suma debría ser de 3.000 segundos (5 programas de 10 minutos). Pero la diferencia no se considera comprometedora: en el caso de mayor discrepancia entre el tiempo exacto y la suma del muestreo la diferencia es de 25 segundos, 5 segundos por programa o menos al $1 \%$. Muchas veces, esa diferencia era tan sólo el proposital fade out para separar de los mensajes del adversario.

La clasificación de los mensajes electorales se produjo según la tipificación consagrada en la literatura especializada (Trent y Friedenberg, 2000; Kaid, 1999; Sádaba, 2003; García Beaudoux et al, 2006). Pero la característica de la comunicación electoral brasileña, con bloques de programas ininterrumpidos que pueden llegar a más de 10 minutos para un único candidato, exige procedimiento metodológico especial buscando

\footnotetext{
7 Una de las principales dificultades de la investigación fue construir el muestreo, especialmente en relación a las campañas de Collor y a la de Cardoso 1994. De la segunda vuelta de Collor, solo fue posible la íntegra de los seis primeros programas.
} 
la definición de unidades de análisis más pequeñas y pasibles de clasificación. En la campaña de 1998, por ejemplo, el candidato de PSDB, Fernando Henrique Cardoso, acaparaba más de 11 minutos de propaganda electoral continuos, exhibidos dos veces al día, así como Serra en 2002 tenía derecho a 10 minutos y 30 segundos.

De hecho, ese tiempo es compuesto por una serie de inserciones más pequeñas, como se el bloque de publicidad electoral se tratara de un telediario o de un documental. El formato "telediario" es mantenido por los principales candidatos, exceptuándose aquellos de los pequeños partidos, que por el criterio de proporcionalidad a la representación parlamentar quedan con poco tiempo y adoptan formatos distintos, a veces limitándose al simple pronunciamiento del candidato. En general, el tiempo es dividido en diversos formatos con cierto grado de autonomía: un clip con el jingle del candidato, efectos visuales que funcionan como separación entre temas, reportagens sobre temas o eventos, hablas del candidato o de personalidades que apoyan la candidatura etc. Así, los 80 bloques de programas analizados resultaron en 610 unidades de análises.

La división de los bloques en unidades menores observa criterios como el cambio de tema o la mudanza de formato que no guarde explícita continuidad con el fragmento anterior. Así si un candidato habla sobre empleo y luego aparece un reportaje sobre sus propuestas para generar oportunidades de trabajo, los fragmentos serán considerados como una sola unidad. Pero se al pronunciamiento sobre empleo sigue un reportaje sobre el mitin realizado por el candidato el día anterior, los dos fragmentos serán considerados unidades autónomas, como se dos spots distintos. También serán consideradas unidades autónomas si una mensaje en formato de comercial separa la habla y el reportaje, aunque las dos enfoquen el mismo tema. El análisis será realizado desde el conjunto de micro unidades formado por las 610 fragmentos de los bloques de programas y los 155 los spots cortos (en estos casos, cada uno formando una unidad autónoma) exhibidos a lo largo de la programación ${ }^{8}$.

Serán considerados mensajes personalistas aquellos que enfocan más en la persona del candidato que en el partido, ideología o coalición partidista que da soporte a la candidatura. El equilibrio entre mensajes enfocados en el partido y en la persona indicará una personalización mediana, al paso que se considerará alta personalización si hay explícita superioridad del enfoque sobre el candidato que sobre el partido,

\footnotetext{
${ }^{8}$ Desde 1962 la legislación brasileña garantiza a los partidos espacio gratuito para vehiculación de la publicidad electoral en radio e televisión, emitidos en bloques de programas donde la participación de los partidos atiende al criterio de representación parlamentar. Desde 1996, para las campañas municipales, y desde 1998, para las elecciones generales, la legislación garantiza también el derecho a la inserción de spots cortos, que pueden tener formato de 15, 30, 45 o 60 segundos (ver www.tse.gov.br).
} 
ideología o coalición. Lo mismo tipo de criterio será utilizado en la evaluación de los mensajes cuanto al enfoque hacia la imagen, en contrapunto al foco en las propuestas. Los mensajes que buscan establecer del candidato una visión positiva, pero sin vincular ese posicionamiento a propuestas elaboradas, serán consideradas destinadas a la formación de una imagen, pautada mucho más por sensaciones que por argumentos consistentes. La falta de clara superioridad de un enfoque indicará el equilibrio, con valoración "2" en la conformación del índice.

Los spots que tratan de temas serán evaluados en cuanto al alcance y la profundidad del tema abordado. Por una parte se evaluará si el tema es tratado con profundidad y con datos concretos o si al revés recibe referencias superficiales e incluso alegóricas, apelando más bien a los estereotipos generales que a la realidad del tema. Por otra parte, se evaluará el alcance de los temas, es decir, si adoptan mensajes de ámbito nacional y genérico o contemplan grado de segmentación, sea con enfoque local o particularizado con el objetivo de alcanzar un segmento de público.

Como uno de los rasgos más destacados de las campañas profesionales, se va a analizar la presencia del lenguaje simbólico o reduccionista en los spots. Será considerado simbólico el mensaje que, sea sobre la persona o sobre temas, recurra al tratamiento que apela a referencias poco tangibles, más en el campo sensitivo que de la racionalidad; es decir, un lenguaje más bien metafórico que concreto, estableciendo un posicionamiento desde valores distendidos pero genéricos. Es simbólico el spot de Lula 1989 cuando pone un chico de ojos vendados tocando la tele imágenes de los candidatos. "Este no", dije al tocar la tele que emite imagen del adversario; "este sí", dije cuando toca en la tele con Lula. El simbolismo está sobre todo en que ese spot reproduce un anuncio comercial de una muy conocida marca de jamón. Por otra parte, es reduccionista el mensaje que toma un caso muy particular para tratar de un tema general, didácticamente tomando aquella pequeña parte como traductora de una realidad muy más compleja.

El tono emocional estará centrado en un claro intento de movilizar la gente desde el sentimentalismo, sea por revuelta o pena. Este tipo de spot muchas veces recurría a la dramatización, como en un spot de Lula 2002 en que habla del problema de la salud pública desde la dramatización de dos realidades distintas: una, del chico enfermo que tiene padres ricos que rápidamente le garantiza en atención es hospital privado; otro, del chico hijo de padres pobres que necesitan esperar demorada (y a veces fatal) cola 
hasta merecer la atención médica. El "clima" del mensaje es fundamental en el propósito de pasar un mensaje o sensación respecto la realidad9.

Los aspectos técnicos serán observados desde dos indicadores. El primero se refiere a la sofisticación técnica, es decir, al uso de efectos visuales especiales, tanto de los recursos de computación gráfica (efecto de ordenador, como el Morph ${ }^{10}$ ) como a la sofisticación de producción escénica. Uno de los ejemplos de efectos de ordenador es el spot de Collor 1989 en que el "tren de la modernidad" va derrumbando las barreras del desempleo, da violencia y de la inflación. Todo ha sido producido en el ordenador, algo ultra innovador para el período. Ejemplo de sofisticación técnica es el amplio escenario utilizado tanto en el programa de Cardoso 1998 como el de Lula 2002, donde además de exigir muchos gastos en producción, se exige equipamientos como grúas (caso de Cardoso) o trillo para la movilidad de la cámara (caso de Lula).

El segundo enfoque técnico es el que se refiere a los efectos con intención cognitiva. Son efectos que a veces pueden no exigir tanta sofisticación técnica, pero exige personal calificado y tiempo de finalización (o, en otros términos, dinero) para su realización. Son considerados efectos con propósito cognitivo aquellos en que el ritmo normal de captación de imagen es alterado en la edición (más lento en el slow motion, más rápido en la edición fragmentada), además del uso de recursos como la saturación sonora para producción de un clima dado. La edición lenta (slow motion) en general es utilizada para fortalecer una intención de emocionalización, buscando envolver emocionalmente el elector. Los clips y noticias sobre mítines suelen recurrir a ese tipo de edición. Por otra parte, la edición fragmentada suele ser utilizada para pasar una idea de dinamismo, sobre todo cuando se habla de las realizaciones del candidato, como en las campañas de Lula y Alckmin en 2006.

Se verificará también la presencia de mensajes segmentados, tanto la utilización de spots para medios complementarios (como televisión a cable o emisiones regionalizadas) como el contenido diferenciado, destinado a un segmento de público y vehiculado en horarios específicos. Por último, se analizará el tono negativo de las campañas, otro rasgo muy destacado en la literatura sobre las campañas profesionales (Rees, 1992). Serán considerados negativos los mensajes que hacen ataque directo al adversario, o aquellas en que se comparan los dos candidatos, pero imputando términos de fuerte y explícita descalificación al concurrente. También serán clasificados

\footnotetext{
${ }^{9}$ Ese spot repite la misma situación de un spot exhibido por el Partido Laborista inglés en la campaña de 1992, conforme la descripción de Rees (1992).

${ }^{10}$ El Morph es un efecto producido por programa de ordenador que transforma una imagen en otra. Ese efecto quedó conocido desde su utilización en el videoclip de la canción Black and White, de Michael Jackson, en que la imagen del cantante sufre diversas transformación, asumiendo la faz de otras personas.
} 
como negativos los mensajes que atacan personas o instituciones explícitamente vinculadas al adversario, o los mensajes indirectos pero con blanco explícito en el concurrente $^{11}$. En la realidad brasileña, los ejemplos de publicidad negativa no siempre son sutiles, como revela la campaña de 1989: Collor exhibió ataques personales a Lula, así como el candidato de PT enfocó tanto el desequilibrio emocional del candidato, su falta a la verdad y el descalabro administrativo. En 2002, Serra posicionó Ciro Gomes como mentiroso y desequilibrado, así como en 2006 tanto Lula como Alckmin trocaron acusaciones directas.

Del mismo modo que en las clasificaciones anteriores, serán consideradas de alta negatividad las campañas en que la publicidad de ataque presenta amplia superioridad sobre los spots positivos, en cuanto números cercanos indican el equilibrio y así mediana negatividad.

\footnotetext{
11 Un ejemplo de enfoque negativo indirecto es el clásico Spot de la Margarita, en la campaña de Lyndon Johnson 1964, que asocia el riego de la guerra nuclear al adversario, Goldwater. Para la descricpción de la pieza, ver Maarek (2005).
} 
PARTE II:

Escenario competitivo y campañas electorales 



\section{Los factores sistémicos y partidistas: la influencia sobre las campañas brasileñas}

\section{Resumen:}

En este capítulo se exploran las variables independientes que inciden sobre el nivel de profesionalización de las campañas brasileñas. Se presenta la complejidad del sistema electoral, con reglas muy abiertas a la participación política y características particulares, como el sistema de lista abierta con grandes circunscripciones; y con uno de los más largos espacios a la publicidad electoral, que además es gratuita, contribuyendo al personalismo y a participación de candidaturas que apenas cuentan. En cuanto al sistema de partidos, es uno de los más fragmentado y desinstitucionalizado, lo que quita referencia a las organizaciones y fortalece otra vez el personalismo de los candidatos. Con amplia libertad de creación y manutención de partidos, el sistema brasileño siquiera exige umbral de representación o cuenta con reglas de fidelidad, combinación que lleva a otro rasgo, el transfuguismo, y a la centralidad de los liderazgos regionales en las coaliciones. La cultura política está anclada en la identidad nacional que se apoya en una visión estatista, autoritaria y clientelista, implicando en posicionamientos específicos en las campañas. Por fin, el sistema de medios es técnicamente moderno y bajo el control privado, aunque históricamente vinculado al poder público, fuente de renta de las empresas. Los medios también ofrecen a las campañas una cultura audiovisual que sigue las directrices del campo del marketing y la publicidad comercial. 



\subsection{Introducción}

En estudio sobre los sistemas de Europa occidental, Caramani (2003) indica que las campañas electorales se establecen como prácticas imprescindibles a la vida política en paralelo a los cambios sociopolíticos que producen la efectiva competencia por el voto. El marco inicial de los cambios es la reforma británica de 1838 que inspirará reformas semejantes en otros países del continente, marcadas sobre todo por la inclusión electoral. Desde la segunda mitad del siglo XIX, la necesidad de influir sobre la opción política del elector van transformando las campañas en el instrumento fundamental de acercamiento al votante, en la búsqueda de la adhesión. El resultado es que ya desde las primeras décadas del siglo $\mathrm{XX}$, las elecciones ocupan prominente papel simbólico y práctico en la construcción de gobiernos y en la misma legitimación del sistema político. Y, sobre todo con la ampliación del sufragio, no hay elección legítima sin un distendido y abierto debate sobre las ofertas electorales, la etapa correspondiente a las campañas.

En Brasil, la competencia electoral se establece de modo más lento y con diversas rupturas, como son las dictaduras del Estado Nuevo y del período militar posterior a 1964, cuando fueron limitadas (o suprimidas del todo) las elecciones por sufragio popular. Hasta llegar a la competitividad actual, el país experimentó diversos modos de elección de los representantes (Fleischer, 1988b), del mismo modo que enfrentó una larga y penosa maduración de las prácticas que hoy culminan con un proceso ampliamente democrático y de considerable estabilidad. El recorrido resultó en la institucionalización de un conjunto de prácticas formales e informales que hoy dan forma al sistema político.

En lo informal, la cultura política que se establece desde el Imperio se firma sobre la base del personalismo donde los partidos desempeñan casi tan sólo el papel legal para la presentación de candidaturas (Paiva, 1985). El particularismo se firma como una institución hasta hoy presente, operado desde el uso del poder público a través de los liderazgos regionales, que desempeñan importante papel en la operacionalización de la política tanto en la fase de campaña como en la constitución y gestión de los gobiernos. Aún al margen de lo formal, los medios de comunicación ostentan claro vínculo político, en el principio a través de los periódicos doctrinarios vinculados a grupos o campañas específicas y luego como empresas casi siempre pendientes de los recursos oficiales. 
En cuanto a lo formal, las reglas del juego cambiaron sustancialmente a lo largo del tiempo, con destacado reflejo sobre el modo de acción política, en especial sobre las campañas, hasta poco pendientes de una legislación producida para cada nueva disputa. Por su parte, el sistema de partidos brasileño es uno de los más jóvenes en una región en la que la regla es la juventud de los partidos, a pesar de algunas excepciones que confirman la regla como es el caso de Argentina y Uruguay, con siglas centenarias (Alcántara, 2004). Los partidos brasileños, débiles, en general están pendientes de los liderazgos que tienen papel decisivo en la efectiva fuerza política que cada organización puede presentar en el juego por el poder.

Los aspectos formales e informales también alcanzan la vida interna de los partidos. De un lado, están las reglas de funcionamiento que establecen relaciones jerarquizadas o más bien participativas de los miembros. Por otro, tienen influencia la cultura de la organización, asociada a su historial; y la presencia de liderazgos que suelen influir en las prácticas partidistas. En las campañas electorales, tanto un factor como el otro genera consecuencias, interviniendo en la conformación misma de las campañas.

Así, la conformación de las campaña se da desde dos conjunto de factores: los sistémicos, con influencia más bien generalizada, alcanzando de modo semejante a todos los actores; y los partidistas, cuya influencia es resultado de las condiciones específicas de cada organización. Los factores sistémicos son el sistema electoral, el sistema de partidos, la cultura política y el sistema de medios. En cuanto a los factores partidistas, se refieren al marco fundacional de los partidos, la organización interna y el papel desempeñado por el liderazgo.

\subsection{Los factores sistémicos}

Brasil es un Estado federativo con amplia autonomía de los entes federados. Es una sociedad de enormes contradicciones, resultando en importantes clivajes: conviven un medio rural arcaico con un evolucionado sector urbano de amplia industrialización; 90\% de la población se concentra en el 35\% del territorio correspondiente a los estados de la orilla del atlántico; y la distribución de renta es una de las más desiguales del mundo, con disparates que crean el modelo Belindia ${ }^{1}$ (Salàs Darrocha, 2004). Institucionalmente también presenta situaciones curiosas. Un ejemplo es el mismo sistema de gobierno, que el autor catalán identifica como presidencialismo de corte parlamentario, donde el Congreso Nacional bicameral (Cámara de los Diputados y

El llamado "modelo Belindia" enfatiza las desigualdades en un país donde se puede encontrar a la vez el desarrollo y calidad de vida de Belgica y la distendida pobreza de India. 
Senado con atribuciones equivalentes) tiene mucha fuerza pero no puede cesar al presidente, ni al revés.

La visión sobre las relaciones institucionales no es uniforme. Limongi y Figueiredo (1995) resaltan el alto poder del presidente, incluso la capacidad de legislar, aunque bajo poder de veto. Por otra parte, Amorim Neto (2006) y Pereira y Müller (2006) apuntan en dirección opuesta, encontrando que el poder del presidente es limitado. Carey y Reinhardt (2003) resaltan la influencia desempeñada por los liderazgos regionales, especialmente los gobernadores de los estados, que suelen tener más influencia sobre el comportamiento de la representación parlamentaria en el Congreso que el partido al que los representantes se vinculan; un poder a veces capaz de poner en jaque el mismo Ejecutivo central. Los intereses particulares -sobre todo la atención a las bases que garantizan la elección del congresista- son más determinantes que la relación partidista e incluso la vinculación política con el gobierno central. Ese rasgo, por su parte, mantiene estrecha relación con las prácticas clientelistas. La necesidad de aprobación popular como fuente de estabilidad política también afianza a los medios un lugar importante como actor político, influyendo en la construcción de los escenarios de representación de la política (Lima, 2001).

Es cierto que el Ejecutivo concentra muchas posibilidades de acción, pero episodios recientes de la política brasileña demuestran que hay sustantivas limitaciones en ese poder, muchas veces vinculados a la fortaleza o debilidad popular del presidente. El escándalo del mensalão ${ }^{2}$ muestra la dificultad de gobernabilidad y la dependencia del apoyo del Congreso; pero revela también que ese apoyo no es buscado necesariamente a través de los partidos, sino de relaciones directas con el diputado o senador a cambio de beneficios particulares más allá de las acciones de interés de sus bases políticas: muchos de los beneficios son personales, algo que parece institucionalizado.

Las características del sistema brasileño guardan algunas similitudes con otros países de América Latina, como el régimen presidencialista, partidos débiles y fuerte influencia de las prácticas patrimonialistas. También hay características muy particulares, como el altísimo transfuguismo que muchas veces transforman los partidos en simple abrigo legal para la participación en la política. De hecho, el nivel de institucionalización de las asociaciones partidistas está muy por debajo de la media de la región (Mainwaring, 1997). El sistema electoral brasileño adopta el voto preferencial de lista abierta, único en la región. Por otra parte, el sistema de medios es el más

\footnotetext{
${ }^{2}$ El escándalo del mensalão fue el principal escándalo de corrupción del gobierno Lula y se relaciona al pago de una mesada a los parlamentares aliados para que aprobasen los mensajes del Ejecutivo. Resultó en la renuncia de diversos acusados, además de la casación del mandato de otros, entre ellos el diputado José Dirceu, ex ministro, articulador político y brazo derecho de Lula.
} 
evolucionado de toda la América Latina, con referencia internacional en áreas como la teledramaturgia y la creación publicitaria.

Si las instituciones formales e informales condicionan las estrategias y decisiones de los actores, por supuesto todos esos factores producen impacto en la vida política. Y las campañas brasileñas son el reflejo de ese conjunto de factores.

\subsubsection{El Sistema Electoral: control de los medios, publicidad gratuita y campañas caras}

Los sistemas electorales tienen destacado impacto sobre la vida política, en especial sobre el sistema de partidos y la representación (Cox, 2004). Son una variable "potencialmente influyente" con efectos sobre las relaciones de poder y así sobre la gobernabilidad (Nohlen, 2000: 159). Los sistemas electorales implican en condiciones específicas de competitividad, generando diferenciadas posturas de los actores y orientando sus actitudes. De ese modo, interfieren en la conformación de las campañas, esfuerzo de acercamiento al elector que se ajusta a ese contexto, generando actitudes calculadas y traducidas en la coordinación estratégica y el voto estratégico3.

Se debe tener en cuenta que los sistemas electorales son el resultado del embate entre las elites políticas, cuya correlación de fuerza define los rumbos del sistema; en el cual esas elites buscan resguardar sus posiciones de privilegio (Colomer, 2004). La realidad histórica de Brasil es de continuos arreglos en las reglas electorales, buscando asegurar la posición de privilegio de las fuerzas en el poder.

En 1822, Brasil se hace independiente de Portugal en un proceso que es distinto de los demás países latinoamericanos por lo menos por dos aspectos. Primero, por no haber completa ruptura con la metrópoli colonial; quién asume el poder es precisamente el heredero de la corona portuguesa, don Pedro I, y en menos de nueve años abdica al trono brasileño por el de Lisboa, donde asume como Pedro IV4. Segundo, por mantener la monarquía, en cuanto sus vecinos se independizaban cambiando hacia la República como claro rechazo al sistema del colonizador (Velasco, 2003).

La independencia no elimina rasgos absolutistas, donde el imperador ejercía dos de los cuatro poderes definidos en la Constitución de 1824 -el poder ejecutivo y el moderador, este con la función de arbitrar conflictos, al que recurrió por ejemplo para

\footnotetext{
${ }^{3}$ Para una visión general, ver Cox (2004). Para una visión desde España, ver Lago Peñas (2003).

${ }^{4}$ Al abdicar al trono en favor de su hijo, en 1831, Pedro I genera un impasse: el sucesor tenía entonces tan sólo cinco años y Brasil será gobernado por regentes hasta 1840, cuando se anticipa la mayoridad del príncipe. Pedro II es coronado y empieza el segundo Imperio.
} 
cerrar el Parlamento5-. Brasil también es original en el Segundo Imperio (1840-1889) al adoptar el parlamentarismo, que dura casi medio siglo. A lo largo del Imperio, las condiciones de competencia política cambian varias veces. Brasil experimenta todos los modelos electorales conocidos hasta entonces: adoptó el voto distrital uninominal con mayoría absoluta, luego transformado en distritos de mayor magnitud (primero con tres y luego con cinco representantes), experimenta el sistema de lista abierta y la votación en doble vuelta, así como implanta la "ley del tercio", asegurando al partido mayoritario la indicación adicional de un tercio de los representantes (Fleischer, 1988b).

En la monarquía, la "fórmula mixta" hacía convivir elección directa con modelos indirectos (Paiva, 1985). Estaba vigente el sufragio censitario con exigencia de renta mínima para votantes y votados 6 , además de vedar el voto a las mujeres, esclavos, hombres menores de 25 años, los mendigos y criados domésticos (Valença, 1999). El segundo Imperio registra la realización regular de elecciones, aunque ello no traduzca regularidad legal, desde entonces se estableciendo una característica del sistema brasileño: los seguidos cambios en las reglas del juego.

La evolución de los procesos electorales es una larga y lenta marcha y contramarcha hasta el sufragio universal y la estabilidad normativa. En un contexto histórico, el sistema brasileño es asociado con baja participación, resultado de las diversas limitaciones legales. La proclamación de la República introduce nuevas condiciones de competición, donde los cambios más importantes son la elección directa y la ampliación del sufragio con la extinción de la exigencia de renta mínima y la reducción de la edad electoral a los 21 años7.

La revolución de 1930, que pone fin a la República Vieja e inaugura la República Nueva, abre una serie de cambios importantes, como la implantación del voto femenino (1932) y luego la reducción de la edad electora hacia los 18 años, además de establecer el voto obligatorio (ver Cuadro 4.1). El gobierno provisorio de Getúlio Vargas, de característica populista y discurso sintonizado con la expansión urbana y la industrialización que daban al obrerismo papel de actor relevante, influyó directamente en el texto de la Constitución de 1934 para la creación de los “diputados clasistas" o "diputados

\footnotetext{
${ }^{5}$ Los otros dos poderes eran el Legislativo, con un Senado con miembros nombrados y la Asamblea General con diputados electos; y el Judiciario, con una Corte Suprema y tribunales inferiores.

6 En principios del Imperio, se exigía renta mínima de $\$ 100$ mil réis para el votante, además de $\$ 200$ mil para los candidatos a la cámara baja y de $\$ 400$ mil a los postulantes al Senado. En el Segundo Imperio, los valores van respectivamente a $\$ 200, \$ 400$ y $\$ 800$ mil réis. Ver Valença (1999) y www.tse.gov.br.

7 A pesar de ampliado con el nuevo régimen, el derecho al voto sigue muy limitado, pues vedado a las mujeres, mendigos y analfabetos, eses últimos correspondiendo a dos tercios de la población en fines del siglo XIX, según datos de IBGE (www.ibge.gov.br).
} 
corporativistas" - semejantes al existente en Italia-, correspondientes a un cuarto de los puestos de la cámara baja (Fleischer, 1988b).

El autogolpe de Vargas, en 1937, establece la dictadura del Estado Nuevo, promulga una nueva constitución -de inspiración fascista- y define algunas pocas reglas electorales, que nunca serán utilizadas, ya que las elecciones y los partidos fueron excluidos del escenario político hasta 1945. Con la democratización y una nueva Constitución, vuelve el voto directo y secreto; es uno de los períodos más libres de la política nacional. Pero las conquistas serían sepultadas por la dictadura de 1964, que conservaría elecciones para el Congreso, para las Asambleas Estaduales y las alcaldías de la mayoría de los municipios, pero bajo reglas muy duras y francamente comprometedoras del proceso electivo.

En los 21 años de régimen militar, Brasil experimentó mucho: introdujo elecciones indirectas para la Presidencia, modificando por tres veces la composición del colegiado encargado de "elegir" el presidente; adoptó la fidelidad partidaria; creó, extinguió y recreó el recurso de la sublegenda para disputas mayoritarias (senador y alcalde), a través de la cual un partido podía presentar más de un candidato para el mismo puesto, siendo elegido la legenda (no necesariamente el candidato) que lograse más votos; estableció el voto vinculado; modificó la duración de mandatos de alcaldes para hacer coincidir con las elecciones generales y luego tornó a modificar esa duración, ahí entonces para "desencontrar" las elecciones locales y generales ${ }^{8}$.

El proceso de apertura -iniciado en los primeros momentos del gobierno Geisel (197379) - sería marcado por una serie de artificios políticos, entre ellos el "paquete de abril", en 1977, que creó los "senadores biónicos"9. Uno de los momentos cumbres de la fase de transición son las elecciones de 1982, con el restablecimiento de la elección de los gobernadores por el voto popular, todavía que marcadas por el cambio de las reglas en la última hora con el propósito de perjudicar la oposición ${ }^{10}$. La larga transición por fin

\footnotetext{
${ }^{8}$ Ver Fleischer (1988) y Paiva (1985).

${ }^{9} \mathrm{El}$ "paquete de abril" es un conjunto de medidas adoptados por el presidente Ernesto Geisel en abril de 1977, luego de cerrar el Congreso. El principal objetivo era alterar la composición del colegiado responsable pela elección del presidente de la República. Con ello, el colegiado pasó a ser integrado por los congresistas y representantes de las asambleas estaduales en proporción que desconsideraba el criterio de población o electorado, favoreciendo a los pequeños estados, donde el poder central tenía más fuerza. Los senadores biónicos (un por estado) indicados por el presidente también participaban de ese restricto colegio electoral (Carey y Reinhardt, 2003). El término "biónico" es una referencia a la artificialidad e ilegitimidad del mandato.

10 Uno de los cambios fue el voto vinculado, que impedía el elector de votar en candidatos de partidos distintos. Así, al escoger el voto en el gobernador de un partido, tendría que votar en nombres del mismo partido para los demás cargos en contienda: senador, diputado federal diputado estadual, alcalde y concejal. La intención del gobierno era impedir la reaglutinación de la oposición, fragmentada con la adopción del multipartidismo. El efecto inmediato de esa decisión fue la fusión del PMDB de Ulysses Guimarães con el PP del moderado Tancredo Neves, unificando los dos principales grupos de oposición al régimen. Ver Fleischer (1988).
} 
terminaría con la elección (aún indirecta) para la presidencia de un nombre vinculado a la oposición, Tancredo Neves. Tancredo murió sin tomar posesión del cargo, pero la democratización de Brasil fue llevada adelante por su vicepresidente, José Sarney, sostenido por actores con origen tanto en el viejo régimen como en su oposición. Ya en 1985 fueron restablecidas las elecciones en las capitales y legalizados los partidos comunistas, además de establecer el derecho al voto a los analfabetos. En 1988, la nueva Constitución restableció la elección directa para la presidencia.

\section{CUADRO 4.1}

\section{La cronología del voto en Brasil}

\begin{tabular}{|c|c|}
\hline 1824 & $\begin{array}{l}\text { Derecho de voto a los varones mayores de } 25 \text { años. Los casados o oficiales militares tienen } \\
\text { ese derecho a partir de los } 21 ; \text { y los clérigos y graduados desde cualquier edad. Exigencia } \\
\text { de renta mínima. Mujer y esclavo no votan }\end{array}$ \\
\hline 1842 & Se establece el registro electoral anterior a la elección \\
\hline 1875 & Creado el carné de identificación del elector \\
\hline 1881 & Elección directa para Asamblea General, Senado y Asambleas provinciales \\
\hline 1882 & Se exige la alfabetización en el registro de nuevos electores \\
\hline 1889 & Elección directa. Acaba la exigencia de renta. Edad electoral reducida a 21 años \\
\hline 1932 & $\begin{array}{l}\text { Derecho de voto a las mujeres. Creada la Justicia Electoral. Elección para la Cámara de los } \\
\text { Diputados por sistema mixto, parte mayoritario, parte proporcional }\end{array}$ \\
\hline 1933 & Se introduce el sobre oficial para la papeleta \\
\hline 1934 & Se reduce a 18 años la edad electoral. El registro electoral pasa a obligatorio \\
\hline 1937 & Dictadura del Estado Nuevo. Suspendidas las elecciones \\
\hline 1945 & $\begin{array}{l}\text { Vuelve la democracia. Adopción de la representación proporcional en la Cámara de los } \\
\text { Diputados, Asambleas Estaduales y cámaras municipales }\end{array}$ \\
\hline 1947 & Casado el registro del Partido Comunista Brasileño (PCB) \\
\hline 1955 & Por primera vez se usa la papeleta oficial en las elecciones presidenciales \\
\hline 1962 & Se extiende el uso de la papeleta oficial a las elecciones para la Cámara Baja \\
\hline 1964 & Golpe militar. El Congreso es cerrado \\
\hline 1965 & $\begin{array}{l}\text { Suspendidas las elecciones presidenciales. Extintos los partidos. Instituido el bipartidismo } \\
\text { controlado }\end{array}$ \\
\hline 1966 & Suspendidas las elecciones para gobernador de estado y alcalde de capital \\
\hline 1980 & Vuelve el sistema multipartidista. Creados 5 nuevos partidos \\
\hline 1982 & Vuelven las elecciones directas para los gobernadores de los estados \\
\hline 1985 & $\begin{array}{l}\text { Vuelve la democracia. Elecciones en las capitales de estado y los municipios considerados } \\
\text { áreas de seguridad nacional. Derecho de voto al analfabeto }\end{array}$ \\
\hline 1986 & Informatización del registro electoral \\
\hline 1988 & La nueva constitución adopta el voto facultativo a los jóvenes con 16 y 17 años \\
\hline 1989 & Vuelve la elección presidencial directa, ahora en doble vuelta \\
\hline 1996 & Se usa la urna electrónica por primera vez en 57 municipios de Santa Catarina \\
\hline 1998 & Se introduce la posibilidad de reelección de los ocupantes de cargos ejecutivos \\
\hline 2000 & Universalización del voto electrónico \\
\hline
\end{tabular}

Fuente: Elaboración propia con Nicolau (2004), Fleischer (1988b), Paiva (1985) y www.tse.gov.br. 
Con la redemocratización, los cambios -a veces intempestivos- continuaron, pero las reglas electorales pasaron a tener la regularidad mínima necesaria a la adecuada convivencia democrática. Lo más relevante es que, con la instalación de la llamada "Nueva República" (1985) y especialmente con la Constitución de 1988, Brasil pasó a contar con los requisitos fundamentales del régimen poliárquico, con reglas fijas en cuanto a la duración del mandato, amplio derecho al sufragio, casi ninguna limitación a la participación electoral y comunicación abierta y competitiva, con espacio para el contrario como nunca antes el país pudo disfrutar.

Desde principios de la década de 1990, Brasil cuenta con una legislación electoral que se puede decir fija, aunque hasta 1997 hubiese la necesidad de aprobación de una ley complementaria para cada contienda ${ }^{11}$. Sin embargo, excluyéndose la reelección, resultado de enmienda constitucional aprobada también en 1997, los cambios establecidos por las leyes complementarias han sido accesorios (Nogueira, 1999), como la extinción del candidato nato ${ }^{12}$ o la exclusión del voto blanco del cálculo del coeficiente electoral, factor que favorecía a los grandes partidos. Incluso las alteraciones sobre el acceso de los partidos a los medios de comunicación -como la reducción del tiempo total de 120 para 90 minutos diarios, y durante 45 días, en contra los 60 de antes- no implicaron en modificación sustantiva en las condiciones de competición.

Lo evidente es que los cambios en la legislación electoral que se produjeron desde la primera mitad de la década de 1980 fueron en el sentido de la inclusión ciudadana y la democratización del proceso. Las directrices legales establecidas por la Asamblea Constituyente (1987-88) son la base de la legislación actual, donde se destaca el restablecimiento de las elecciones directas para la presidencia de la República. Pero una de las alteraciones a producir más impacto fue la introducción de la disputa en dos vueltas en las competiciones por cargos ejecutivos ${ }^{13}$. La segunda vuelta abre a la posibilidad de ejercicio de la primera opción de voto en la primera ronda, con opciones

\footnotetext{
${ }^{11}$ En 30 septiembre de 1997 el Congreso Nacional aprobó la Ley Ordinaria n 9.504/97, la llamada "Ley Electoral", desde entonces reguladora de las elecciones, aunque algunas interpretaciones de la Corte Electoral respeto esa Ley y enmiendas del Congreso sobre temas como el financiamiento de los partidos implicaron en algunos cambios en el escenario competitivo. Ver la ley en www.tse.gov.br.

${ }^{12}$ Los diputados federales y estaduales, así como los concejales, tenían el derecho automático de ser candidato a la reelección, no necesitando someter la candidatura a la deliberación de las instancias partidistas. Era un recurso que tenía importancia en el bipartidismo, en razón de las peleas entre corrientes acomodadas en un mismo partido y del grande número de candidatos para limitado número de escaños. Con el pluripartidismo el candidato nato perdió el sentido de ser.

${ }^{13}$ La mayoría calificada exigida es la mayoría absoluta: si ningún candidato alcanza $50 \%$ más un de los votos atribuidos a un candidato, se realiza una segunda vuelta entre los dos más votados. La regla del segundo turno tiene validez también para las elecciones de gobernador de los estados y los alcaldes de las ciudades con más de 200 mil electores; en los municipios con menos de 200 mil votantes la decisión se da por mayoría simple. Ver ley $\mathrm{n}^{\circ}$ 9.504/97, en www.tse.gov.br.
} 
más bien estratégicas en la segunda. Además, tiende a mayor fragmentación partidista, sobre todo con altos umbrales de mayoría calificada, como es el caso de Brasil (Martínez, 2004).

El sistema electoral brasileño combina fórmula proporcional con mayoritaria, según el cargo, en una compleja legislación que abre varias posibilidades a la concertación. El voto es obligatorio para los mayores de 18 años y facultativo a los analfabetos, los mayores de 65 años y mayores de 16 pero menores de 18 años. La acción de los actores políticos se hace muy compleja delante de las posibilidades que se abren:

1. La ley permite la formación de coaliciones tanto en las elecciones mayoritarias como en las proporcionales.

2. Se permiten diversas posibilidades de coalición entre partidos y circunscripciones, aunque en las elecciones de 2006 se prohibió que un partido con alianza formal en la disputa por la presidencia estableciese alianza distinta en los estados;

3. En las proporcionales, los partidos o coaliciones presentan listas abiertas que pueden contar con número de candidatos 50\% a 100\% superior al número de puestos en disputa, según el número de partidos coalicionados; $\mathrm{y}$

4. Hay a la vez el voto de leyenda en las elecciones proporcionales -que suma para la coalición, sin necesariamente beneficiar a los candidatos del partido votado-, instituto que se relaciona con el alto índice de analfabetismo: sobre todo con el voto electrónico, ese recurso facilitaría el voto de la gente menos esclarecida (Salàs Darrocha, 2004: 104).

En las elecciones generales, el sistema mayoritario es adoptado para la presidencia de la República (así como para los gobernadores, en los estados) y para el Senado, con segunda vuelta en las disputas ejecutivas donde ningún candidato logre alcanzar la mayoría absoluta de los votos válidos ${ }^{14}$. La primera vuelta ocurre siempre en el primero domingo de octubre y la segunda en el último, lo que presupone tres o cuatro semanas entre las dos elecciones. Los mandatos son de cuatro años, con posibilidad de una reelección para los ocupantes de puestos ejecutivos ${ }^{15}$.

\footnotetext{
14 Son considerados votos válidos para efecto de la contabilidad electoral los sufragios atribuidos a un candidato. Es decir, el conteo no lleva en cuenta el voto nulo o blanco.

15 Para el Congreso, el mandato de los diputados es de cuatro años, sin limites de reelección; y de ocho años para el senado, también si limites de reelección. En el Senado, a cada cuatro años se alterna la renovación de un y dos tercios de la representación.
} 
Las peculiaridades ganan colores más fuertes por algunas características del sistema electoral, como las circunscripciones muy amplias; la existencia del voto preferencial o sistema uninominal de lista abierta en las disputas proporcionales; y inexistencia de umbral mínimo de representación. Cada estado corresponde a uno distrito, variando del mínimo de ocho al máximo de 70 escaños en la Cámara Baja, además de los tres senadores por unidad federativa. El desvío resultante es extraordinario: la diferencia entre el estado más suprarepresentado (Roraima) y el más subrepresentado (São Paulo) es de 27 veces.

El sistema de lista abierta acentúa la personalización de la política, además de contribuir a la competencia dentro de los partidos (Carey y Reinhardt, 2003). Por éste sistema, el elector puede elegir su candidato entre todos los presentados, sin posibilidad de ordenación por parte del partido. El total de votos dados a los candidatos de un partido o coalición se suma a los votos de legenda dados a los diversos partidos coalicionados, de ahí estableciendo la proporcionalidad de escaños a que tienen derecho. Son considerados elegidos los candidatos con más votos personales, lo que genera la pelea entre los integrantes del mismo partido o coalición.

En la actualidad, los cambios en las reglas electorales se resumen básicamente a las resoluciones que el Tribunal Superior Electoral ${ }^{16}$ edita respecto cada elección, con decisiones que son más de naturaleza administrativa. Por supuesto que la ley no es estática y algunas alteraciones se van introduciendo, incluso con una nueva ley aprobada en mayo de 2006 modificando artículos de la Ley Electoral de 1997 respecto el financiamiento de las campañas. Ese cambio, con el intento de volver más transparente la entrada y salida de los recursos de campaña, es una reacción al escándalo del mensalão, que evidenció la promiscuidad entre partido, donantes y sectores de campaña como las empresas de marketing político, donde la doble contabilidad ha sido regla. Desde mediados de los años 1990 las alteraciones más importantes fueron la posibilidad de reelección (desde 1998), la introducción de spots electorales cortos exhibidos sin horario fijo (desde 1996) y la reducción del tiempo de publicidad electoral (también desde 1998).

Además de eso, en general las reglas siguen iguales:

1. Los mítines son permitidos en los tres meses que anteceden a la votación, además de la segunda vuelta, cuando hay;

\footnotetext{
${ }^{16}$ En Brasil la administración electoral es responsabilidad del Poder Judicial, con una corte específica, el Tribunal Superior Electoral. EI TSE tiene sus desdoblamientos en los estados en los Tribunales Regionales Electorales, TREs.
} 
2. No se admite candidatura independiente, necesitando que un partido sea valedor de cualquiera presentación;

3. La financiación de las campañas es privada y ilimitada, desde que dentro del presupuesto presentado por el partido en el registro de las candidaturas. El sector público participa con el fondo partidista y la gratuidad de los espacios para exhibición de los mensajes electorales;

4. Es vedada la compra de espacios en radio y TV;

5. El espacio publicitario gratuito destinado a cada candidatura es proporcional a la representación parlamentar del partido o coalición.

Hoy, el principal problema parece más relacionado al sistema mismo que a la regulación específica de cada elección. Un de los debates más candentes en Brasil es respeto la financiación de las campañas, sobre si debe ser pública o privada. Aunque los principales grupos políticos con asiento en el Congreso aboguen la necesidad de una profunda reforma del sistema electoral, las divergencias son tantas que es posible que ninguna reforma sustantiva se materialice en la presente legislatura. Más allá de la financiación privada, las campañas brasileñas carecen de transparencia, lo que favorece al abuso del poder económico. Según cálculos del Orden de los Parlamentarios de Brasil, en los últimos 15 años fueron utilizados ilegalmente cerca de 3.000 millones de dólares en las campañas ${ }^{17}$. El valor, sin embargo, es subestimado pues el cálculo toma en cuenta tan solo los recursos involucrados en los escándalos relacionados con las campañas, a ejemplo del mensalão, responsable por casi mitad de las financiaciones irregulares listadas.

Son diversos los efectos directos producidos por el sistema electoral brasileño sobre las campañas (Cuadro 4.2), empezando por el refuerzo al personalismo, un rasgo histórico que encuentra soporte en otras variables -partidos débiles; centralidad de la TV; clientelismo operacionalizado por los liderazgos regionales-. En el ámbito de las reglas electorales, el voto preferencial con lista abierta contribuye a consolidar la faz personalista de la política en Brasil: hay disputa intrapartidista y los elegidos consideran el mandato suyo, no del partido; el discurso de los candidatos es fundamentalmente personalista ${ }^{18}$. Aunque esa característica alcance las elecciones

\footnotetext{
17 Ese valor en dólar corresponde a los 5.800 millones de reales contabilizados por la Orden de los Parlamentarios y divulgados el 14 de mayo de 2007. La conversión al dólar aquí se hace para se utilizar una referencia más universal. Los datos están disponibles en la página Web del periódico Folha de S. Paulo: http://www1.folha.uol.com.br/folha/brasil/ult96u92368.html.

${ }^{18}$ Carey y Reinhardt (2003).
} 
proporcionales, tiene reflejo sobre la íntegra del sistema, incluyendo las disputas presidenciales, donde las alianzas pasan por los políticos antes que por los partidos ${ }^{19}$.

La doble vuelta condiciona las estrategias, tanto en la formación de coaliciones ${ }^{20}$ como en la elaboración de los discursos políticos. La necesidad de nuevos arreglos políticos entre las dos vueltas hace que en general el tono de los mensajes en la primera ronda sea más moderado, dejando espacio a las futuras adhesiones; y la negatividad tiende a crecer en la etapa final, cuando se lleva a cabo un decisivo juego de todo o nada y sin prórroga. La financiación privada y ilimitada tiene dos caras: de un lado fortalece los grandes partidos y las posiciones más afines con el grande capital (en la contramano de la democratización posibilitada por la gratuidad de los mensajes en radio y TV); de otro, profundiza la posibilidad de profesionalización, con la contratación de expertos del mercado, aspecto que lleva a campañas más caras.

Otro factor que amplia la necesidad de expertos es la larga fase de campaña formal: para 3 meses de mítines y 45 días de anuncios solamente en la primera vuelta, hace falta profesionales que aseguren a los mensajes el atractivo capaz de mantener la atención del elector. Ello también profundiza la mediatización, puesto que la dinámica de campaña tan larga necesita de la resonancia en los medios de comunicación, algo que se logra de modo adecuado con la asesoría de expertos en medios.

La misma posibilidad de espacios gratuitos en radio y TV lleva que las campañas brasileñas cuenten siempre con candidatos de pequeños partidos: incluso en las dos últimas elecciones, con sustancial reducción del número de concurrentes, se registró la participación de partidos sin representatividad como PCO o PSTU ${ }^{21}$. Otras organizaciones -sin claro matiz ideológico, más bien con perfil electoralistapresentaron candidaturas en elecciones anteriores, como en 1989, cuando 14 de las 21 candidaturas se vinculaban a partidos que nunca han alcanzado $5 \%$ de la votación para el Congreso (entre ellos el elegido Fernando Collor); en 1994, de los ocho postulantes cuatro eran de partidos irrelevantes; y en 1998, tan solo tres de los 12 candidatos estaban asociados a partidos que cuentan en el Congreso Nacional ${ }^{22}$.

\footnotetext{
${ }^{19}$ Es siempre ilustrativo el ejemplo del ex presidente José Sarney que en 2002 apoyó explícitamente la candidatura de Lula, a pesar de su partido estar formalmente coalicionado con el PSDB de Serra.

20 Ver Martínez (2004), especialmente la "Introducción” (pp. 9-21).

${ }^{21}$ El Partido de la Causa Operaria (PCO) y el Partido Socialista de los Trabajadores Unificados (PSTU, antiguo PRT) son asociaciones de extrema izquierda que tanto en 2002 como en 2006, valiéndose del espacio gratuito de propaganda electoral, presentaron candidaturas con el fin de llevar al público sus pronunciamientos de claro contenido ideológico. En las elecciones en los estados, muchas candidaturas también son presentadas con el propósito de proyección personal o como estrategia combinada con otras candidaturas.

${ }^{22}$ La noción de relevancia toma en cuenta el hecho del partido alcanzar en por lo menos una elección de la actual fase democrática el umbral de $5 \%$ de los votos para la Cámara Baja.
} 
La facilidad para presentación de candidaturas y la garantía del espacio de publicidad electoral hace que en los estados sean comunes las candidaturas presentadas con el propósito de proyección personal o como estrategia combinada con otras candidaturas. Un ejemplo de ese último caso fue la campaña para el gobierno de Maranhão, en 2006: Edson Vidigal (PSB), del bloque de oposición al grupo del ex presidente José Sarney, se presentó en estrategia combinada con Jackson Lago (PDT), en confronto con Roseanna Sarney (PFL), hija del ex presidente. En toda la campaña, Vidigal utilizó dura publicidad negativa contra Roseanna con el propósito de desgastar la candidata de PFL y beneficiar Lago, que se volvió depositario de los votos perdidos por la pefelista.

CUADRO 4.2

Sistema electoral y efectos sobre las campañas en Brasil

\begin{tabular}{|c|c|}
\hline Característica & Efecto \\
\hline \multirow{2}{*}{$\begin{array}{l}\text { Sistema Mayoritario (doble } \\
\text { vuelta con alto umbral: } \\
50 \% \text { ) }\end{array}$} & - Tendencia a la moderación de discurso en la primera vuelta \\
\hline & - Tendencia a la negatividad en la segunda \\
\hline \multirow{2}{*}{$\begin{array}{l}\text { Voto preferencial (lista } \\
\text { abierta) }\end{array}$} & - Personalismo y acuerdos a revelía de los partidos \\
\hline & - Disputa intrapartidista y discurso no-partidista \\
\hline \multirow{3}{*}{$\begin{array}{l}\text { Financiación privada e } \\
\text { ilimitada }\end{array}$} & - Campañas caras \\
\hline & - Mayor posibilidad de contratación de expertos del merado \\
\hline & - Fortalece los partidos/candidatos afines al gran capital \\
\hline \multirow{2}{*}{$\begin{array}{l}\text { Campaña de larga } \\
\text { duración }\end{array}$} & - Mediatización \\
\hline & - Mayor necesidad de expertos \\
\hline \multirow[t]{3}{*}{$\begin{array}{l}\text { Espacios gratuitos en } \\
\text { radio y TV }\end{array}$} & $\begin{array}{l}\text { - Multiplicación de candidaturas (participación de pequeños } \\
\text { partidos y outsider) }\end{array}$ \\
\hline & - El más importante estímulo a las coaliciones partidistas \\
\hline & - Espacio para candidaturas combinadas o de proyección \\
\hline \multirow{2}{*}{$\begin{array}{l}\text { Bloques de programas y } \\
\text { spots sueltos }\end{array}$} & - Lenguaje periodística en los bloques \\
\hline & - Lenguaje publicitario en los spots \\
\hline
\end{tabular}

Fuente: Elaboración propia

Además, la distribución de espacios de radio y TV produce efectos sobre los formatos de la publicidad electoral. En los bloques de programas, es común el lenguaje más cercano al periodismo, como es evidente sobre todo en las campañas a la reelección de Cardoso (1998) y en la de Serra (2002), así como en parte de la comunicación televisiva de Lula en 2002. Por otra parte, los spots sueltos adoptan estructura común a los anuncios comerciales, con el uso de recursos simbólicos, lenguaje fragmentado y predominio de las sensaciones sobre las informaciones concretas. 
4.2.2. El sistema de partidos: individualismo, fragmentación y electoralismo

Brasil cuenta hoy con un sistema de partidos que dura ya 27 años, el más largo de su historia republicana. La actual durabilidad, sin embargo, no significa fortaleza de los partidos, que siguen los rasgos históricos que hacen de las organizaciones partidistas brasileñas casi meros legitimadores de candidaturas (Paiva, 1985) y posicionan el país como uno de los sistemas de partidos más débiles de América Latina (Mainwaring, 1997) en que las personas al frente de las siglas tienen más importancia que las mismas siglas (Samuels, 1999).

Luego de la independencia, los partidos apenas contaban. En el segundo Imperio, Brasil adopta un sistema de cara bipartidista, inspirado en el modelo inglés, donde los Conservadores y los Liberales alternaban el control de los gabinetes ${ }^{23}$. La República no cambia la centralidad de los liderazgos, mas bien refuerza. Antes de la actual fase, los partidos alcanzan alguna relevancia en el período 1946-64, algunos autores encontrando en la identificación partidista importante factor predictor del comportamiento electoral de esa etapa ${ }^{24}$. El golpe de 1964 reemplaza las diversas siglas por extraño bipartidismo en el que el partido oficial (Arena) convivía con un constreñido partido de oposición (MDB) cuya acción era limitada por legislación coercitiva, como los Actos Institucionales que permitían la casación de los derechos políticos por un simple discurso o incluso sin cualquier justificativa. En 1979, según la estrategia de apertura "gradual y segura" iniciada en 1973 por Ernesto Geisel, el gobierno João Figueiredo aprueba una nueva ley de partidos y en comienzos de 1980 surgen las primeras siglas del sistema actual.

Los cambios que resultan en el actual sistema empezaron todavía en el período militar, en un esfuerzo estratégico que, fiel al principio de "dividir para reinar" (Fleischer, 1988b), rescataba el pluripartidismo con el objetivo de fragmentar las oposiciones, cada vez más fuertes dentro del MDB. El fin del riguroso bipartidismo era una reivindicación de las fuerzas demócratas: tan pronto entra en vigor la nueva ley, surgieron los cinco primeros partidos (PMDB, PDS 25, PDT, PTB y PT, todos existentes hasta hoy). Con la redemocratización surgen otras siglas, como $\mathrm{PSB}, \mathrm{PFL}^{26}, \mathrm{PCB}^{27}$, $\mathrm{PC}$ do $\mathrm{B}$ y $\mathrm{PSDB}^{28}$,

\footnotetext{
${ }^{23}$ Un tercer partido, el Republicano, tendría alguna influencia en las últimas dos décadas del Imperio, encabezando la lucha que culminaría en el cambio hacia la República, en 1989 (Paiva, 1985).

${ }^{24}$ Ver Lavareda (1991), Nicolau (2004) y Singer (1999).

${ }^{25}$ EI PDS, partido gubernista del final del período militar, cambió el nombre varias veces: ha sido PTR y PPB, y desde 2003 es Partido Progresista (PP).

${ }^{26}$ El Partido de la Frente Liberal (PFL) fue creado en 1985 de la excisión del PDS, teniendo como base el grupo que no aceptó la candidatura Paulo Maluf a la presidencia y apoyó la postulación de Tancredo Neves. En marzo de 2007, el PFL cambió el nombre para Demócratas (DEM).

27 Desde principios de los años 1990, el PCB cambió para PPS, Partido Popular Socialista.
} 
además de casi dos decenas de otros partidos que explicitan la amplia fragmentación y la debilidad del sistema brasileño (Mainwaring, 1999).

Fenómenos como la elección de Fernando Collor ${ }^{29}$ y el alto grado de volatilidad electoral (Figueiredo, 1995; Melo, 2000) serían elementos traductores de tal irrelevancia. Otros resultados electorales de los últimos años ayudan a evidenciar tal debilidad, donde el inexpresivo desempeño de Ulysses Guimarães en las presidenciales de 1989 es uno de los casos más sonantes: a pesar de comandar el mayor partido del país y contar con 21 de los 23 gobernadores estaduales, Guimarães terminó su participación en la primera vuelta electoral en distante $6^{\circ}$ lugar, con tan solo 4,7\% de los votos (Albuquerque, 1995). Es revelador que, desde 1989, solamente en 2006 el partido con mayor número de escaños en la Cámara Baja en el momento de la elección, PT, lograra elegir el presidente -aun así sin lograr elegir el mayor número de congresistas para la legislatura siguiente, hecho que cabe al PMDB, que ni siquiera formalizara apoyo a cualquier candidato-.

En las últimas cinco elecciones generales, ningún partido ha logrado alcanzar el 25\% de los votos para cualquiera de las casas del Congreso, hecho que pone acento sobre todo en tres características del sistema: el alto número de partidos, la baja concentración de votos y la alta volatilidad electoral (Salàs Darrocha, 2004). Alcántara (1999) también subraya el fenómeno de la alta volatilidad y añade como explicación de ese cuadro el papel desempeñado por el Estado, históricamente por encima de los partidos; el peso de la política regional, que orienta la vida política nacional; y la fuerza -con influencia negativa- de los liderazgos personalistas como José Sarney y Fernando Collor, que actúan en paralelo a los partidos. El autor considera que se debe relacionar aun la contribución de la Constitución de 1988 al fortalecimiento del pluripartidismo, puesto que consagra un sistema de partidos por demás abierto, casi enteramente libre, siquiera contemplando cláusulas de barrera de representación.

La inexistencia práctica del umbral mínimo de representación y la inexistencia de cualquier regla de fidelidad son grandes incentivadores de la fragmentación partidista, con elevado número de partidos efectivos: en la elección de 2006 ese número llegó a 9,3 (Cuadro 4.3), claro complicador de la gobernabilidad. En la misma elección se requirió un desempeño mínimo de $5 \%$ de los votos para la Cámara Baja, distribuidos en por lo menos un tercio de los 27 estados, con desempeño mínimo de $2 \%$ en cada uno de

\footnotetext{
${ }^{28}$ El Partido de la Socialdemocracia Brasileña (PSDB) fue creado en 1988, resultado de la división de PMDB en los debates de la Asamblea Nacional Constituyente.

${ }^{29}$ Fernando Collor disputó la presidencia por el Partido de la Renovación Nacional (PRN), creado especialmente para esa contienda desde el Partido de la Juventud, sigla que antes del fenómeno Collor siquiera tenía representante en el Congreso Nacional. Ver Albuquerque (1995), Conti (1999).
} 
ellos. No obstante, las penalizaciones previstas son casi nulas: según la ley, los partidos que no alcanzan ese umbral pueden mantener la representación, quedando la restricción a formar grupos parlamentarios. La posibilidad de que esos pequeños partidos perdieran el derecho a fondos públicos hasta ahora no se cumple ${ }^{30}$, manteniéndose la mayoría de los incentivos a la formación y conservación de partidos y así a la fragmentación. De los 21 partidos que eligieron representantes para la Cámara Baja en la última elección, 7 lograron alcanzar el umbral31.

CUADRO 4.3

Número efectivo de partidos en la Cámara de los Diputados (1982-2006)

\begin{tabular}{l|ccccccc}
\hline & 1982 & 1986 & 1990 & 1994 & 1998 & 2002 & 2006 \\
\hline NP* $^{*}$ & 5 & 12 & 19 & 18 & 18 & 19 & 21 \\
\hline NEP* & 2,4 & 2,8 & 8,7 & 8,1 & 7,1 & 8,5 & 9,3 \\
\hline
\end{tabular}

Fuente: Krause y Campos (2006) para los datos hasta 2002 y TSE (www.tse.gov.br) para 2006.

* NP es el número de partidos con representación en la Cámara de los Diputados y NEP es el número efectivo de partidos, calculado según la fórmula (de Taagepera y Shugart, 1987) NEP $=\sum \mathrm{ep}^{2}$, donde "ep" corresponde al porcentual de votos de cada partido.

En cuanto a la fidelidad partidista, hasta la elección de 2006 no había nada que obligase un político a mantenerse vinculado a una sigla, quedando libre para cambiar sin la pérdida del mandado, considerado una conquista personal sobre todo por las disputas en lista abierta en que el partido no tiene la posibilidad de ordenar las candidaturas. Además de fortalecer el personalismo, ese sistema siempre resultó en fuerte estímulo a la competencia interna, debilitando todavía más la organización (Carey y Reinhardt, 2003). Sin posibilidad de penalidades, los políticos son libres para cambiar de partido incluso antes de la toma de pose para el cargo elegido -algo que suele pasar- y hace del transfuguismo uno de rasgos característicos del sistema brasileño ${ }^{32}$.

Los números hablan por sí: entre 1985 y 1989, 686 diputados o suplentes en el ejercicio del mandato cambiaron de partidos. Hay diversos casos de parlamentares que se

\footnotetext{
30 Al juzgar recurso de presentado por grupo de pequeños partidos, el Supremo Tribunal consideró las penas inconstitucionales, en la práctica manteniendo sin ningún efecto la cláusula de barrera. Por todo el año de 2007, el Congreso ha discutido una nueva legislación sobre el tema, pero sin grandes avances hacia el acuerdo entre los partidos.

${ }^{31}$ Eses partidos fueron el PMDB, PT, PSDB, PFL, PDT, PSB e PP.

32 El 27 de marzo de 2007, el Tribunal Superior Electoral decidió que el mandato es del partido, no del candidato, y que el cambio de sigla es pasible de la pérdida del mandato. En octubre, el Supremo Tribunal Federal, la corte constitucional de Brasil, confirmó el fallo del TSE. Pero los cambios anteriores al 27 de marzo no sufrirán ninguna punición. Ver en www.tse.gov.br.
} 
desplazaron más de una vez en un mismo mandato: en cuatro legislaturas analizadas por Melo (2000), 95 congresistas cambiaron de partido dos veces, otros 19 diputados migraron tres veces y 4 cambiaron cuatro veces o más (Cuadro 4.4). En la suma total se registraron 812 cambios de partido en las cuatro legislaturas.

CUADRO 4.4

Número de diputados que cambiaron de partidos por legislatura (\%)

\begin{tabular}{|c|c|c|c|c|c|}
\hline \multirow{2}{*}{$\begin{array}{l}\text { Tipo de } \\
\text { diputado }\end{array}$} & \multicolumn{4}{|c|}{ Legislatura } & \multirow{2}{*}{ Total (N) } \\
\hline & $1983 / 1987$ & $1987 / 1991$ & $1991 / 1995$ & $1995 / 1999$ & \\
\hline No migrante & 68,8 & 72,5 & 67,7 & 73,1 & (1.643) \\
\hline Migrante & 31,3 & 27,5 & 32,3 & 26,9 & (686) \\
\hline Total $(\mathrm{N}) *$ & (528) & (560) & (620) & (621) & (2.329) \\
\hline
\end{tabular}

A pesar de los diversos cambios verificados en el sistema de partidos en el último siglo, Krause y Campos (2006) señalan que es posible percibir en todas las configuraciones del sistema de partidos brasileño características comunes en cuanto al perfil, el desarrollo y los procedimientos empleados por las organizaciones políticas. La síntesis del sistema estaría en la característica general más destacada por la amplia mayoría de los analistas: los partidos cuentan poco y están lejos de desempeñar un papel protagónico. La visión general respecto la poca relevancia de los partidos encuentra excepciones en trabajos como el de Meneguello (1998), que subraya la importancia de los partidos en el funcionamiento del gobierno, especialmente desde la actuación en el Parlamento. Pero no deja de señalar lo poco que aporta en la relación con diversos sectores sociales y especialmente en las campañas. Así se puede resumir el caso brasileño33:

1. Partidos débiles, con baja capacidad de representación de la sociedad, en que son reemplazados por otros actores, como las iglesias y asociaciones patronales y de trabajadores;

2. Alta fragmentación partidista: resultado de las facilidades para creación y manutención de partidos, la fragmentación se hace más problemática por

${ }^{33}$ Características sistematizadas desde Krause y Campos (2006), Meneguello (1998), Mainwaring (1994 y 1997). 
producir un cuadro donde diversos partidos alcanzan alguna relevancia en el funcionamiento del Congreso, como revela el número de partidos efectivos que en la elección de 2006 resultó superior a nueve, en la Cámara de los Diputados;

3. Inexistencia de cláusulas de barrera de representación: en 2006, tres partidos (PAN, PT do B y PRB) han elegido un único representante para la Cámara de los Diputados, sumando tan solo $0,3 \%$ de la votación nacional, sin que eso implique en la pérdida del escaño. Lo mismo pasa con PMN, que con $0,9 \%$ de los votos eligió tres diputados;

4. Inexistencia de fidelización partidista: no hay ningún mecanismo que genere la efectiva vinculación de los elegidos a los partidos por los cuales se presentaron. Como los elegidos se sienten dueños del mandato, y delante de la falta de punición para los cambios, el resultado es el alarmante transfuguismo;

5. Baja identificación partidista o ideológica, traducida en el acentuado nivel de volatilidad del elector. La identificación es más bien con las personas;

6. Débil estructura organizativa nacional, donde el éxito electoral está basado sobre todo en la fuerza de los liderazgos locales y regionales, tradicionalmente dependientes del acceso a los recursos y empleos públicos;

7. Corto ciclo de vida de los partidos: el actual sistema, con 27 años es el más largo de la República, lo que denuncia la corta vida de las asociaciones partidistas. Además, los seguidos cambios de nombres en partidos como PP (ex PDS), DEM (ex PFL) y PPS (ex PCB), así como las muchas fusiones (como de PL con Prona, resultando en el PR, ya en 2007) refuerzan esa tendencia: los cambios de nombre y fusiones insinúan un cambio de partido, aunque siga el mismo;

Especificamente en relación a las campañas y la capacidad de orientar la opción de voto del ciudadano, las limitaciones de los partidos brasileños quedan manifiesta en varios momentos. Quizá uno de los más expresivos fue en las primeras presidenciales de la actual etapa democrática, cuando Fernando Collor disputó y venció por un partido -el PRN- formado especificamente para dar soporte a su postulación. En el momento crucial de la campaña, el PRN contaba tan sólo con 20 de 494 diputados y dos entre 75 senadores, todos afiliados al partido cuando la candidatura de Collor ya mostraba robustos señales de viabilidad con los buenos índices de intención de voto expresados por las encuestas desde fines de 1988. El Cuadro 4.5 demuestra que la fuerza de los partidos no se tradujo en el resultado de los candidatos a la presidencia. Hay casos de resultados muy superiores al poder electoral del partido (además de Collor, la campaña de Lula) o aún muy por abajo (casos de Ulysses Guimarães y especialmente Aureliano 
Chaves, respectivamente de PMDB y PFL, al tiempo las dos principales organizaciones partidista del país).

CUADRO 4.5

Representación partidista y votación presidencial en 1989 ( $1^{\text {a }}$ vuelta)

\begin{tabular}{|c|c|c|c|c|c|c|}
\hline \multirow[b]{2}{*}{ Candidato } & \multirow[b]{2}{*}{ Partidos } & \multicolumn{3}{|c|}{ Congreso* } & \multicolumn{2}{|c|}{ Presidencia } \\
\hline & & $C D$ & SF & $\%$ & Nominal & $\%$ \\
\hline Fernando Collor & PRN, PST y PSL & 20 & 2 & 3,9 & 20.607936 & 30,5 \\
\hline Lula & PT, PC do B y PSB & 19 & 0 & 3,3 & 11.619 .816 & 17,2 \\
\hline Leonel Brizola & PDT & 28 & 3 & 5,4 & 11.166 .016 & 16,5 \\
\hline Mário Covas & PSDB & 50 & 10 & 10,5 & 7.786 .939 & 11,5 \\
\hline Ulysses Guimarães & PMDB & 178 & 31 & 36,7 & 3.204 .853 & 4,7 \\
\hline Aureliano Chaves & PFL & 91 & 13 & 18,2 & 600.730 & 0,9 \\
\hline Otros* * & -- & 108 & 16 & 21,8 & 12.627 .047 & 18,7 \\
\hline Total & & 494 & 75 & 100 & 67.613.337 & 100 \\
\hline
\end{tabular}

Fuente: Elaboración propia a partir de Albuquerque (1995), para el número de parlamentares, y luperj

(www.iuperj.br), para la votación.

* En la columna Congreso, "CD" es la representación en la Cámara de los Diputados y "SF", en el Senado Federal.

El porcentual apuntado en la columna es sobre la suma de las dos casas parlamentarias.

** La fila Otros incluye los votos dados a 15 diferentes candidatos representando 17 partidos.

Se tiene siempre como atenuante que la campaña de 1989 fue una campaña "soltera", es decir, con votación exclusiva para la presidencia, lo que disminuye el empeño de los liderazgos locales y regionales en relación a los representantes del partido. Pero la elección general de 1994 -con votación "casada" para presidente, senador, diputado federal, gobernador de estado y diputado estadual- explicita el divorcio entre partido y candidaturas. El resultado más ilustrativo es el de Orestes Quércia, candidato de PMDB: Quércia obtuvo 4,4\% de los votos presidenciales, en cuanto su partido eligió la mayor bancada del Congreso (21,5\% de la Cámara y 25,9\% del Senado). En la misma elección, Eneas Carneiro, del Prona, obtuvo sorprendentes 7,4\% de la votación presidencial, pero su partido no ha elegido siquiera un representante para el Parlamento. Espiridião Amin, del entonces PRP (hoy PP), no pasó de 2,7\% de los votos, aunque su partido sumó 9,5\% de los escaños en el Congreso.

Los resultados indican dos caras de la misma moneda: primero, que los partidos cuentan poco; segundo, que la personalización es marca fundamental de las campañas brasileñas, sea por la relación con los liderazgos regionales y locales (lo que explica parte del extraordinario desempeño parlamentario del PMDB de 1994), sea también 
por la mediatización de la política, determinante en la conformación de imágenes públicas, uno de los principales factores del éxito de Collor en 1989.

En la conformación misma de la acción las campañas, los partidos no cuentan como un factor decisivo en las opciones del electorado, lo que implica sobre todo en la personalización de los mensajes y énfasis en la imagen del candidato. Es el resultado directo de la baja institucionalización de las organizaciones partidistas (Cuadro 4.6). Esto queda evidente en las presidenciales desde 1989, donde tan solo en la primera campaña de Lula la referencia partidista fue un discurso relevante. En el caso de Collor, un outside con un partido electoralista, la referencia al PRN es casi nula en toda la campaña. El discurso de Collor es más bien salvacionista, un rasgo no exclusivo suyo pues se encuentra en todas las campañas, que suelen tener un carácter plebiscitario, según la visión de Moisés (1997).

La fragmentación partidista asociada a la necesidad de mayoría absoluta en las disputas presidenciales hace que los mensajes sean orientados hacia los amplios segmentos, sin un claro clivaje. Tan solo Lula en la primera vuelta de 1989 ofrece algo de discurso clasista, hablando para los trabajadores y en contra las elites, enfoque que será atenuado en la segunda vuelta, ya en busca de apoyos ampliados que puedan volver posible la absoluta.

CUADRO 4.6

Sistema de partidos y efectos sobre las campañas en Brasil

\begin{tabular}{|c|c|}
\hline Característica & Efecto \\
\hline \multirow[t]{3}{*}{ Baja institucionalización } & - Discurso apartidista y desideologizado \\
\hline & - Reforzo del personalismo; foco en la imagen \\
\hline & - Posicionamiento electoralista \\
\hline Fragmentación & - Estrategias orientadas a las grandes coaliciones de actores \\
\hline \multirow{2}{*}{$\begin{array}{l}\text { Ausencia de reglas de } \\
\text { fidelización }\end{array}$} & - Reforzo del apartidismo y del personalismo \\
\hline & - Enfoque orientado hacia los liderazgos \\
\hline \multirow{2}{*}{$\begin{array}{l}\text { Ausencia de cláusula de } \\
\text { barrera }\end{array}$} & - Multiplicación de candidatos \\
\hline & - Estímulo a los outsiders \\
\hline Débil organización nacional & - Personalismo y refuerzo de los liderazgos regionales \\
\hline
\end{tabular}

El cuanto a la ausencia de reglas de fidelización implica en valorización de los liderazgos regionales personalistas, como quedó claro en la campaña de Lula en 2002: 
en la segunda vuelta, los primeros programas electorales presentaban la ex gobernadora de Maranhão (ya electa senadora en la primera vuelta), Roseanna Sarney. Vale notar que Roseanna era entonces filiada al PFL, partido que oficialmente apoyaba el adversario de Lula. Ese apoyo explícito no produjo ningún tipo de sanción. También los liderazgos regionales son reforzados por la debilidad de la estructura organizacional de los partidos: la estructura partidista orbita en torno de los liderazgos que se ponen al frente del partido en cada estado, no al revés. Un ejemplo de ello es el DEM (ex PFL) de Piauí: a pesar de en 2006 logra elegir 4 diputados estaduales y dos federales, el partido que hace poco era el mayor del estado, ahora siquiera encuentra liderazgos que hablen en su nombre, puesto que los diputados migraron para otras siglas como PTB y PSB 34 . Los liderazgos que cambian se llevan juntos la estructura política que controlan a modo personal; y el partido anterior en la práctica deja de existir.

\subsubsection{Liderazgo y clientelismo: ante todo, el personalismo y el apartidismo}

La cultura política es un conjunto de valores comunes que orientan el comportamiento de la gente respecto los temas políticos, resultado de una historia compartida entre ciudadanos, a través de la socialización que hace aprender e interiorizar elementos que van dar significado a los objetos políticos (Almond y Verba, 1992). La cultura política tiene un papel crucial para el funcionamiento de la democracia ${ }^{35}$, existiendo fuerte relación entre la cultura y la importancia de las instituciones ${ }^{36}$.

Entre los rasgos comunes al brasileño, los estudios sobre la identidad nacional suelen destacar el carácter pacato y de cierto modo complacente que explicaría una historia sin episodios sangrientos o enfrentamientos importantes37. Esa visión del "hombre cordial” ${ }^{8}$ también es asociada con una postura estatista que otorga al poder público la capacidad de gestionar los destinos del país y la responsabilidad de suprir el ciudadano con el esencial. Es una postura que marca la relación de la gente con la política, donde

\footnotetext{
${ }^{34}$ El cambio en el DEM está asociada a la necesidad que los políticos tienen del soporte estatal: cambian de un partido de oposición a uno del bloque gobiernista para seguir con acceso a los beneficios. Sobre ese tipo de práctica, ver Carey y Reinhardt (2003).

35 Moisés (1995: 97) afirmar que “la cultura política es insuficiente per se para generar las condiciones necesarias a la emergencia del régimen democrático, [pero] ello no autoriza considerarla innecesaria al proceso para su consolidación"

${ }^{36}$ Sobre el papel de la cultura política en la democracia, ver el buen resumen de Mateos (2004).

37 Entre los autores que tratan del tema están Varnhagen, Capistrano de Abreu, Gilberto Freyre, Nélson Werneck Sodré, Caio Prado Jr., Florestan Fernandes, Sérgio Buarque de Holanda y Fernando Henrique Cardoso. Para una discusión general y sustantiva de la identidad brasileña, ver el trabajo de Reis (1999). Para una visión crítica de esa construcción identitaria, ver Chauí (2000).

${ }^{38}$ El término es de Sérgio Buarque de Holanda (1995), que así sintetiza el carácter del brasileño.
} 
el personalismo y el favor ocupan lugar destacado, profundizando el personalismo y el apartidismo.

Al analizar la cultura política brasileña, Moisés (1997) parte precisamente de un grupo de autores considerados pioneros en la dicusión sobre el carácter y la identidad nacional39. Según esos autores, la cultura política nacional se caracteriza por un conjunto rígido de patrones político-culturales que tiene continuidad a lo largo del tiempo donde combinan rasgos heredados de la tradicción ibérica (valores autoritarios, jerárquicos y plebiscitarios) con una visión "estatista” y antiliberal resultantes del proceso de la formación del Estado. "Las imágenes que traducen esta cultura política son conocidas: clientelismo, populismo, actividad de complacencia frente a las autoridades, manipulación, apatía política $\mathrm{y}$, finalmente, antipartidismo $\mathrm{y}$ antinstitucionalismo" (Moisés, 1997: 78).

Con la redemocratización, Moisés encuentra cambios sutiles, donde enfatiza la dinámica interacción entre las elites políticas y el público de masas en la formación de concensos mínimos. También subraya la tendencia plebiscitaria en las presidenciales de la actual fase democrática, sobre todo en las regiones más desarrolladas, donde "los electores usan el voto cómo arma para sancionar positiva o negativamente la gestión de los gobiernos; en particular, su capacidad para gestionar adecuadamente la grave situación económica a la que se ha enfrentado el país en las últimas décadas" (Moisés, 1990: 62). Hay en la ciudadanía un profundo descrédito hacia la política y los políticos. Pero hay también una enorme dependencia de la política.

En una línea semejante, Rennó Jr. (1999) enfatiza la convivencia de elementos institucionales formales (como las elecciones) con el particularismo de las relaciones sociopolíticas, donde coincide con O’Donnell (1996) en que los sistemas latinoamericanos no se encuadran en la teoría de la poliarquía y debe añadir nuevos elementos a su concepto. Advierte que el escepticismo hacia la política, resultante de la ineficacia estatal, si no fortalece la postura autoritaria fragiliza la opción democrática.

Las prácticas política apuntan hacia una institucionalización informal pautada especialmente en las relaciones personales donde el sistema de trueque clientelar tiene centralidad. Es una vieja herencia con raíces hincadas en el período colonial y se consolida en la fase del Imperio, cuando los terratenientes recibían la patente de coroneles de la Guardia Nacional de ahí asumiendo en el entonces Estado unitario la representación del poder central en el espacio local (Leal, 1997; Graham, 1997). Los

\footnotetext{
39 Moisés se refiere, además de Sérgio Buarque de Holanda, a Oliveira Viana, Alberto Torres y Gilberto Freyre, cuya producción a cerca del carácter nacional está situada en la primera mitad del siglo XX.
} 
coroneles disfrutaban de amplio poder, con la autoridad para hacer y deshacer en nombre de la Corona.

Con la proclamación de la República, el Estado se vuelve federal pero no acaba el poder de los coroneles, que pasan a representar el poder político regional, generando la mutua dependencia entre los políticos nacionales y esos liderazgos: al apoyo recibido en cada provincia, se retribuía con los recursos públicos, especialmente empleo. Está formalizado así el coronelismo como una de las marcas de la política brasileña, que es una manifestación del poder privado -sobre todo agrario- que se relaciona con un régimen político de base representativa. Esa relación es también un compromiso, un trueque de favor; es un doble trueque (Costa, 1978). O, como destaca Leal (1997), es una "relación de reciprocidad" en la que

"por una parte, [están] los jefes municipales y los 'coroneles' que conducen montones de electores como quien lleva tropa de burros; por otra, la situación política dominante del Estado, que dispone del erario, de los empleos, de los favores y de la fuerza policial; que posee, en resumen, el cofre de las gracias y el poder de la desgracia" (Leal, 1997: 63-64).

La capacidad de conducir electores es la esencia del poder de los coroneles. Costa (1978) destaca que el tipo de liderazgo que caracteriza el coronel es el hecho de que él dirige autoritariamente un lote considerable de "votos de cabestro". Su poder viene de la calidad de ser propietario, responsable de un conjunto de trabajadores que gravitan en torno a sus dominios sobre los cuales ejercen el poder a través de su prestigio personal, manteniéndolos en una relación de dependencia en la que el "voto de cabestro" es una de las monedas de cambio.

Las prácticas políticas de las últimas décadas registran importantes perfeccionamientos tanto formales como informales, pero los liderazgos regionales siguen con destacado poder, como bien resalta Alcántara (1999) al apuntar esta como una de las razones de la debilidad del sistema de partidos brasileño. Elecciones como la de Collor e incluso las dos de Lula evidencian la importancia de los liderazgos regionales más allá de los partidos. Un ejemplo elocuente es el del ex presidente y hoy senador José Sarney, que en 2002 apoyó Lula a pesar de su partido, el PMDB, tener una coalición formal con el PSDB de José Serra. En las estrategias por la conquista del poder, Lula no sólo recibió como buscó el apoyo de caciques políticos de inequívoco matiz conservador y dudosa reputación, entre ellos el mismo Sarney y Antonio Carlos Magalhães, ambos en otros 
tiempos soporte de la dictadura militar, y hasta el presente señores del clientelismo y del nepotismo ${ }^{40}$.

La relación de los liderazgos regionales con el poder central sigue la lógica del coronelismo donde el control de masas de votantes se vuelve la moneda que da acceso a los puestos y verbas públicas; una parte de los beneficios -sobre todo en servicios públicos que deberían ser de acceso universales, como la atención a la salud- son repasados al ciudadano leal al "coronel" como se fuera un premio por la fidelidad. Por su origen basada en el poder agrario, en general el coronelismo es asociado a la vez al pasado y a los estados periféricos. Sin embargo, las prácticas se muestran vivas en la política contemporánea y en centros bastante referenciales, como demuestra estudio de Rennó Jr. (1999) para el nada agrario Distrito Federal. Peixoto (2000) resalta la persistencia de algunas de las más importantes características del coronelismo: el mandonismo, el familiarismo, el nepotismo, el falseamiento del voto y la desorganización de los servicios públicos locales. Y advierte que las relaciones de favor pueden ser encontradas en los escenarios del Brasil urbano, como la ciudad de São Paulo.

El particularismo pone el clientelismo en el centro de las relaciones políticas, involucrando no solo los liderazgos sino también el mismo elector que siempre espera un beneficio particular como incentivo a la toma de decisión sobre el voto. Tal práctica ha incentivado la industria de los regalos electorales, como camisetas, equipos de fútbol, balones, gorras, reloj, puerta llaves y sopote térmicos para cervezas ${ }^{41}$. Además, los liderazgos esperan soporte financiero (por supuesto, sin registro contable formal) para el desarrollo de las campañas en su área de influencia. Parte de ese dinero se destina al propio líder, práctica que hacen las campañas todavía más caras (Figueiredo, 1994).

Aspectos de la relación del brasileño con las instituciones y la percepción del poder de esas instituciones pueden ser encontrados en la encuesta del instituto Data Folha, divulgada en enero de 2004. En ella (Cuadro 4.7), queda explícito primero la diferencia entre el prestigio institucional (es decir, la importancia que la gente da a las instituciones) y el poder (la capacidad de influir en la vida del país). Esto es particularmente visible en el caso de los clubes de fútbol, el segundo en la lista de

\footnotetext{
40 Sarney y Magalhães han conquistado nuevos mandatos en 2006. Sarney sigue en el Parlamento. Magalhães se murió en julio de 2007, reemplazado en el escaño por el mismo hermano, su suplente y seguidor de las viejas prácticas oligarcas.

${ }^{41}$ Con el propósito de cohibir la acción del poder económico, en 2006 se prohibió la distribución de regalos. Aun así, el elector sobre todo en las regiones más pobres siguen esperando beneficios particulares de los candidatos.
} 
prestigios pelo cuarto en cuanto al poder, exactamente a la inversa de la presidencia de la República y sus ministerios. La encuesta también explicita el poder atribuido a la prensa y a las iglesias, sobre todo la católica.

CUADRO 4.7

El prestigio y el poder de las Instituciones brasileñas (\%)

\begin{tabular}{lccccccc}
\hline & \multicolumn{3}{c}{ Poder $^{*}$} & \multicolumn{3}{c}{ Prestigio* * } \\
\cline { 2 - 7 } & Mucho & Ningún & & Mucho & Ningún \\
\hline Medios de Comunicación & 74 & 3 & $1^{\circ}$ & 73 & 4 & $1^{\circ}$ \\
\hline Clubes de fútbol & 58 & 11 & $4^{\circ}$ & 66 & 8 & $2^{\circ}$ \\
\hline Iglesia Católica & 56 & 8 & $5^{\circ}$ & 59 & 7 & $3^{\circ}$ \\
\hline Presidencia de la República & 63 & 6 & $2^{\circ}$ & 56 & 8 & $4^{\circ}$ \\
\hline Bancos y Financieras & 61 & 7 & $3^{\circ}$ & 56 & 10 & $5^{\circ}$ \\
\hline Fuerzas Armadas & 51 & 10 & $8^{\circ}$ & 49 & 11 & $6^{\circ}$ \\
\hline Iglesia Universal & 49 & 17 & $9^{\circ}$ & 46 & 19 & $7^{\circ}$ \\
\hline Empresas estatales & 44 & 9 & $11^{\circ}$ & 42 & 10 & $8^{\circ}$ \\
\hline Poder Judicial & 55 & 8 & $6^{\circ}$ & 42 & 12 & $9^{\circ}$ \\
\hline Congreso Nacional & 55 & 8 & $6^{\circ}$ & 38 & 14 & $10^{\circ}$ \\
\hline Sindicatos obreros & 38 & 13 & $12^{\circ}$ & 38 & 15 & $11^{\circ}$ \\
\hline Partidos Políticos & 46 & 12 & $10^{\circ}$ & 34 & 20 & $12^{\circ}$ \\
\hline Funyyyyyy
\end{tabular}

Fuente: Data Folha (www.datafolha.com.br). Encuesta realizada en las cinco más grandes capitales brasileñas.

* A los encuestados, el cuestionario establecía: “Yo voy citar algunas instituciones nacionales y me gustaría que usted me dijera, de cada una, si tiene mucho, poco o ningún poder de influencia en Brasil".

* * El entrevistador cita la misma lista de instituciones para la evaluación del encuestado cuanto al prestigio de cada una de ellas.

Es curioso notar la percepción de la gente sobre la Iglesia Universal del Reino de Dios, a quien se le atribuye mucho poder. La Universal es una iglesia evangélica creada en Brasil, hoy presente en más de 50 países. Funciona como una especie de franquicia: el pastor líder de cada templo gana según lo que recauda. Tiene fuerte actuación políticopartidista ${ }^{42}$, con alto poder de transferencia de voto por la táctica posible en el sistema brasileño de concentración de votos en un solo candidato dentro de amplas alianzas (Oro, 2003). Una de sus estrategias fundamentales es ocupar importantes espacios de comunicación, lo que llevó a ser propietaria de tres redes de televisión (una de señal abierto -Record-y dos otras en señal cerrado), además de un centenar de emisoras de radio (Lima, 2001).

\footnotetext{
42 Hasta 2005, la Universal actuaba en el PL, con amplio control del partido. Entonces decidió crear su propio partido, el PRB que tiene entre sus miembros el vicepresidente de la República, José Alencar.
} 
Según encuesta del instituto Data Folha, Universal es la novena institución en poder y séptima en prestigio, a pesar de ser tan sólo la cuarta mayor entre las iglesias evangélicas en un país donde los evangélicos suman el 22\% de la población, en contra 64\% de católicos 43 . Quizá esa percepción sea por la explícita actuación políticopartidista de la iglesia -con reconocida influencia en la indicación del vicepresidente José Alencar- y por su atención a los esfuerzos de comunicación que hacen de la TV Record una red de gran influencia, en muchos momentos se posiciona como la emisora con la segundo mayor audiencia, por detrás de TV Globo.

La encuesta revela una vez más la debilidad de los partidos políticos tanto en prestigio como en la percepción del poder que ejerce, aunque se les vea con más poder $\left(10^{\circ}\right.$ puesto) que prestigio $\left(12^{\circ}\right)$. El Congreso Nacional también padece del mismo descrédito, aunque en mejor posición que los partidos: $10^{\circ}$ en prestigio y $6^{\circ}$ en poder. La presidencia de la República se destaca sobre todo por el segundo puesto en poder, un poco por encima de la banca. La disparidad entre presidencia y las otras instituciones políticas (Congreso y Partidos) es también una traducción de la centralidad del puesto presidencial en el imaginario brasileño (Lima Júnior, 1999), lo que debe ser asociado también a la percepción sobre el ejercicio personalizado y centralizado de la política. Finalmente, la percepción del poder de instituciones como iglesias y la banca evidencia el papel de otros actores en la política y, como destaca Rennó Jr. (1999), la relación entre formalidad e informalidad en la cultura política brasileña.

Los indicadores de la encuesta reflejan diversos rasgos de la cultura política del brasileño, empezando por la centralidad de los medios de comunicación en la vida nacional: son los primeros no sólo en poder sino también en prestigio, traduciendo el papel de los medios como actor fundamental. Ello es resultado de la amplia presencia de los medios en la vida del país merced del alto nivel de consumo de información mediatizada, sobre todo a través de la televisión, como se verá en el próximo apartado. Es más: en la relación con la TV, el brasileño mezcla ficción con la realidad, haciendo de las telenovelas brasileñas un fenómeno de comunicación único en que los personajes del culebrón son temas de noticias como se fuera de verdad44. Esa relación imaginaria

\footnotetext{
${ }^{43}$ Datos de encuesta realizada por el instituto DataFolha en abril de 2007, antes de la visita del papa Benedicto XVI a Brasil. La encuesta está disponible en www.datafolha.com.br.

${ }^{44}$ La telenovela es el producto más característico de la TV brasileña, mereciendo importante atención de los estudios académicos que intentan explicar la influencia que desempeñan en la vida del brasileño. Entre los trabajos sobre el tema, vale mencionar el de Wolton (1996) en que destaca la interactividad (es decir, para el espectador la ficción se mezcla con la realidad) como uno de los rasgos de la televisión brasileña, la primera del mundo a lograrlo, incluso antes de las nuevas tecnologías. Ver aun Marcondes Filho (1988) y Bucci (1996). En cuanto a la ficción televisiva y las campañas electorales, ver Porto (1995).
} 
alcanza la vida política a punto de actores de TV ocuparen espacios en las campañas políticas prestando apoyo a los candidatos no como persona, sino como personaje.

Porto (1995: 64) presenta un ejemplo elocuente de la relación de la televisión con la política más allá de la visión tradicional que enfoca el agendamiento y el encuadre desde los espacios periodísticos: en 1994, el programa de televisión del Partido Popular empieza con la reproducción de escenas de la novela Renascer, de TV Globo, en que el personaje José Inocencio habla de la necesidad de cambios en el Congreso. A la habla del personaje de ficción, sigue el pronunciamiento del presidente del partido, que se apropia del discurso ficcional: "Esa indignación de José Inocencio, de la novela Renascer, es nacional. Ella toma cuenta de todo el país". Es como si el personaje ofreciese la legitimación al discurso del político real. Por supuesto, la interacción con la televisión asegura al medio un lugar especial el la política.

Como en Estados Unidos, las estrategias de campaña en Brasil toman en cuenta el papel desempeñado por la televisión, pero en dimensión mayor. Es más: se verifica una disputa particular por el apoyo de la TV Globo -como revelaron los esforzos de Lula da Silva ya en 1994 (Dimenstein y Souza, 1994) - como paso fundamental a la viabilidad de las candidaturas.

CUADRO 4.8

Cultura política y efectos sobre las campañas en Brasil

\begin{tabular}{ll}
\hline Característica & Efecto \\
\hline Particularismo & - Voto como moneda de cambio \\
\cline { 2 - 2 } & $\begin{array}{l}\text { - Centralidad de los liderazgos regionales en las estrategias de } \\
\text { campaña }\end{array}$ \\
\cline { 2 - 2 } & - Discurso apartidista y desideologizado \\
\hline Estatismo (Fisiolojismo) & - Clientelismo \\
\cline { 2 - 2 } & - Visión plebiscitaria de la elección; voto como arma \\
\hline Autoritarismo & - Discurso de autoridad, imagen de mando \\
\hline Apartidismo & - La política son las personas \\
\hline $\begin{array}{l}\text { Televisismo (TV como } \\
\text { medio protagónico) }\end{array}$ & - Mediatización centrada en la TV \\
\cline { 2 - 2 } & - Valorización de la TV como actor \\
& - Protagonismo de Globo, su por casi monopolio \\
\hline
\end{tabular}

Fuente: Elaboración propia 


\subsubsection{El Sistema de Medios}

La prensa brasileña nació estatal, con el primer número de A Gazeta do Rio de Janeiro publicado el 10 de septiembre de 1808, bajo los auspicios de la Corona Real que acabara de llegar a Rio de Janeiro, huida de las tropas napoleónicas que invadieron Portugal. Antes de la publicación de A Gazeta, hubo muchas tentativas de publicación de periódicos en la entonces colonia portuguesa, todas desmanteladas por la fuerza de los representantes de Lisboa que sencillamente prohibía la instalación de imprenta fuera de la metrópoli (Sodré, 1978) ${ }^{45}$. Si bien el inicio es estatal, el desarrollo de la prensa es de matiz privado, en especial en el caso de la televisión: Brasil fue uno de los pioneros en ese campo, inaugurando en 18 de octubre de 1950 la primera emisora de América Latina -la TV Tupi de São Paulo- a expensas de Assis Chateubriand, magnate de la comunicación con amplio dominio del sector entre la década de 1930 y comienzo de los años 1960 (Moraes, 1994) y que en el momento controlaba vasta red de periódicos, revistas y emisoras de radio.

Desde antes de la mitad del siglo XX, el sistema de comunicación presenta importante concentración, que se va a ampliar sobre todo después de la década de 1960, en un fenómeno que no es sólo brasileño, sino mundial, pero que en Brasil cuenta con el impulso del modelo concentrador del gobierno militar. La apertura de los canales de TV pagada, en los años 1990, no redujo esa tendencia, mas bien la reforzó, pues los controladores de los nuevos canales en general son los mismos que dominan los medios tradicionales (Lima, 2001).

Además de la centralización, hay dos otras características destacadas por Lima: por una parte, la presencia de grupos familiares y, por otra, la presencia de elites políticas locales o regionales. En el sector de radio y televisión, el dominio está en manos de ocho familias, tres de ámbito nacional y cinco con actuación regional. A esas se suman otras ocho familias con importante control en áreas como periódicos y revistas. En total, esos grupos familiares controlan 90\% del sector de comunicación brasileño ${ }^{46}$. La centralización en el campo televisivo es todavía más acentuado, pocas familias controlando la casi totalidad del contenido vehiculado a razón del modelo de formación de redes en que las emisoras locales que retransmiten la programación nacional casi no tienen espacio para programación propia. Un ejemplo es TV Globo, que deja bajo la responsabilidad de las emisoras afiliadas menos de una hora y media diaria en la programación, aun así con vigilancia justificada por la etiqueta de "control de calidad".

\footnotetext{
45 Las limitaciones impuestas llevaron Hipólito da Costa, tres meses antes de $A$ Gazeta, a iniciar la publicación desde Londres del Correio Braziliense, enviado clandestinamente a Brasil. El Correio es para muchos el primero periódico brasileño.

${ }^{46}$ Ver el capítulo 5 de Lima (2001)
} 
Otro agravante es que hay una triple concentración: además de estar la mayor parte del sector de la comunicación de masas en manos de una docena de familias, y la televisión como vehículo monopolizador de la atención de la audiencia nacional -tanto que concentra tres quintas partes del total de inversiones publicitarias en Brasil-, la tercera concentración se completa con el hecho de que una sola emisora acapara más de la mitad de eses espectadores y tres cuartas partes de las inversiones destinada a las televisiones (Azevedo, 2006).

La centralidad de la TV no es caso único de Brasil, pero el país presenta datos más contundentes. La televisión cubre 100\% de los 8,8 millones quilómetros cuadrados del territorio, tiene audiencia diaria alrededor de 120 millones de espectadores, cerca de dos tercias partes de la población; es la única fuente de información para la mayor parte de los brasileños ${ }^{47}$; y cuenta con alto índice de consumo televisivo: según datos de encuesta del instituto Ibope, divulgados en febrero de 2007, en el año de 2006 el brasileño se puso delante de la pequeña pantalla una media de 5 horas y 4 minutos al diario ${ }^{48}$. El índice es semejante al encontrado por el Ateliê Aurora, grupo de investigación de la Universidade Federal de Santa Catarina ${ }^{49}$. La media brasileña es una hora superior a la media de países como España. Por otra parte, los periódicos registran circulación diaria alrededor de los 7 millones de ejemplares ${ }^{5}$. El instituto Ipsos Marplan revela que el hábito de lectura de periódico no alcanza siquiera una quinta parte de la población ${ }^{11}$, disparidad en parte explicada por la baja renta y el aún alto índice de analfabetismo ${ }^{52}$.

Ni siquiera los estados más ricos cambian esa tendencia, el hábito de lectura quedando alrededor de un tercio de la población de estados como Rio de Janeiro y São Paulo. Además, el hábito de lectura de periódicos está concentrado especialmente en la elite, los integrantes de las clases A y B, según datos de TGI (ver el Cuadro 4.9). El índice de lectura en la gran mayoría de la población -las clases D y E- es muy pequeño. Es sobre todo esa parte de la población que recurre a la televisión como medio de información y entretenimiento, garantizando a la tele un poder extraordinario en la construcción de los escenarios de representación de la política, en los términos definidos por Lima (2001).

\footnotetext{
47 Ver Lima (2001) y Miguel (2004).

${ }^{48}$ Ver página Web de Ibope: www.ipobe.com.br.

${ }^{49}$ Ver página Web del grupo de investigación: http://www.aurora.ufsc.br/index.htm.

${ }^{50}$ En una media de 4,5 lectores por periódico, las ediciones diarias alcanzan cerca de 32 millones de personas.

${ }^{51}$ Ver www.ipsos.com.br.

52 Según datos de IBGE (www.ibge.gov.br), un tercio de los brasileños son analfabetos funcionales. Es decir, saben firmar el nombre pero son incapaces de comprender incluso pequeños textos.
} 
CUADRO 4.9

Índice de lectura de periódicos por clase socioeconómica en Brasil

\begin{tabular}{lc}
\hline Clase socioeconómica & Índice de la lectura diaria \\
\hline A y B & 180 \\
\hline C & 89 \\
\hline DE & 38 \\
\hline
\end{tabular}

Fuente: Azevedo (2006: 95).

Obs: 100 = Población en general. Un índice mayor que el 100 significa que las personas de una clase son más propensas a leer periódicos al diario que la población en general; y menor que 100 significa que son menos propensas.

Si es evidente el poder de la televisión, también es evidente la tercera forma de concentración, es decir, la posición casi monopolista de TV Globo en el sector de televisión (Cuadro 4.10). El grupo de la familia Marinho controla los principales canales por cable y en TV abierta -el área más importante en términos comercial y político, por alcanzar la mayor parte de la población- TV Globo desfruta de amplia ventaja: en el horario de mayor audiencia, de 18 a las 22 horas, la emisora en general alcanza índices superiores al 50\% de la audiencia (Lima, 2001). A efecto comparativo, es un índice superior a la suma de la audiencia media de las dos principales cadenas de televisión españolas53. Otro factor a ser tomado en cuenta es que uno de los programas más vistos de la emisora es su principal telediario, Jornal Nacional, también alrededor del 50\%.

CUADRO 4.10

Las redes de TV abiertas en Brasil

\begin{tabular}{lcccccc}
\hline & $\begin{array}{l}\text { Emisoras } \\
\text { en que } \\
\text { tiene } \\
\text { sociedad }\end{array}$ & $\begin{array}{l}\text { Emisoras } \\
\text { afiliadas }\end{array}$ & $\begin{array}{l}\text { Emisoras } \\
\text { que } \\
\text { reproducen } \\
\text { el señal de } \\
\text { la red }\end{array}$ & $\begin{array}{l}\text { Alcance } \\
\text { total de los } \\
\text { aparatos } \\
\text { de TV }\end{array}$ & $\begin{array}{l}\text { Audiencia } \\
\text { media } \\
\text { todos } \\
\text { horarios }\end{array}$ & $\begin{array}{l}\text { Participación } \\
\text { el en total de } \\
\text { la verba } \\
\text { publicitaria }\end{array}$ \\
\hline TVs & 32 & 113 & 1.276 & $99,96 \%$ & $58 \% *$ & $75 \%$ \\
\hline Rede Globo & 10 & 97 & 542 & $78,60 \%$ & $21 \%$ & - \\
\hline SBT & 12 & 68 & - & $61,70 \%$ & $5 \%$ & - \\
\hline Bandeirantes & 21 & 47 & - & $44.20 \%$ & $10 \%$ & - \\
\hline Record ** & - & - & - & $37,90 \%$ & - & - \\
\hline Rede TV & - & 24 & - & $5,50 \%$ & $5 \%$ & - \\
\hline CNT*** & & & & & & \\
\hline
\end{tabular}

Fuente: Lima (2001: 100).

* En el horario de 18 a 22h, el más importante de la televisión, Globo alcanza una media de $61 \%$ de la audiencia.

* * Los datos de Record incluyen las redes Record, Mulher y Familia. En los últimos meses, SBT ven perdiendo audiencia para Record, las dos emisoras alternándose en la segunda posición tras Globo.

*** La CNT ahora se llama JB TV.

${ }^{53}$ De los 30 programas más vistos en julio de 2007 en la ciudad de Sao Paulo (el mayor mercado de Brasil), 27 son emitidos por Globo. La lista incluye dos de la TV Record (en las posiciones 21 y 22) y uno de SBT (en la posición 30). Ver http://epocaestado.wordpress.com/2007/09/02/top-30listados-30-programas-mais-vistos-em-julho-sao-paulo/. 
La alta centralidad de la televisión interfiere en la vida política más allá del refuerzo de la personalización de la política que en Brasil es anterior a la mediatización. El sistema televisivo está en el centro de las estrategias de todos los políticos, que dedican especial atención a TV Globo, que por encima del casi monopolio de la audiencia disfruta de amplio historial de relación (y interferencia directa) con la política. Herz (1987) señala el soporte que el empresario Roberto Marinho recibió de la dictadura militar en la instalación de su emisora, en 1965. A continuación, Globo y el régimen militar se vuelven uno dependiente del otro, sobre todo desde 1969, cuando la TV inicia las transmisiones por satélite y en directo para todo el ancho territorio nacional. La naciente televisión de Marinho necesitaba de soporte oficial especialmente en verbas publicitarias y el gobierno necesitaba de la legitimación, donde la televisión cumple a perfección ese papel de llevar el discurso oficial a todos los rincones. Desde ahí la emisora asume el papel de dar dimensión y unidad nacional al discurso de interés de la dictadura, a través del sistema de afiliación que hace de las emisoras locales poco más que retransmisoras de la programación nacional, reproducida sin siquiera contar con la posibilidad de interpretación propia de los acontecimientos más importantes del país.

La relación de Globo con el poder se mantiene a lo largo del tiempo, en algunos momentos con implicaciones muy visibles incluso para el ciudadano corriente. La trayectoria de la empresa es un historial de manipulación de la política, como destaca Colling (2004). En 1982, fue acusada de participar de un intento de fraude a las elecciones para el gobierno de Rio de Janeiro, delante de la perspectiva de victoria de Leonel Brizola, nombre de izquierda vinculado a la resistencia al régimen militar 54 . Dos años más tarde, Globo ignoró casi por completo la mayor movilización cívica de la historia brasileña, las Diretas Já [Directas ya], campaña por el retorno de las elecciones directas para la presidencia. Enseguida se pone como avaladora de la candidatura de Tancredo Neves y poco después se convierte en la gran articuladora de la candidatura de Fernando Collor al Palácio do Planalto, en 1989: a Collor garantiza la visibilidad necesaria a un candidato desconocido y aún encuadra la cobertura periodística según los interés de la candidatura, culminando con la manipulación del último debate presidencial en la segunda vuelta, que muchos ven como decisivo en la elección del ex gobernador de Alagoas, puesto que la elección se encontraba muy reñida55.

\footnotetext{
54 En este episodio, conocido como el escándalo Proconsult, Globo tiene la función de divulgar los datos del conteo de votos, pero datos falsos contabilizados por la empresa Proconsult, que resultaría en la derrota de Brizola y en la victoria del candidato apoyado por el gobierno federal, aun bajo mando del general Figueiredo. Pero el conteo paralelo realizado por los partidos desenmascara la burla.

${ }^{55}$ La cobertura del debate presentada por la emisora en el Jornal Nacional pode ser definida como la edición de los mejores momentos de Collor con los peores de Lula (Lima, 2001). Para más informaciones sobre ese tema, ver Colling (2004), Conti (1999) y Fausto Neto (1990 y 1994).
} 
El historial de manipulación seguiría en la adhesión al Plan Real -y a la candidatura de Fernando Henrique Cardoso-, en 1994 (Dimenstein y Souza, 1994). Cuatro años más tarde volvería a apoyar Cardoso escandalosamente, casi excluyendo la cobertura de las elecciones de sus programas noticiosos. Se puede decir que fue un agendamiento al revés, contribuyendo a la reelección del presidente cuya estrategia pasaba por la ausencia de debate de la política (Miguel, 1999). La cobertura de 2002 es considerada la que mejor atiende a los criterios de noticiabilidad (Miguel, 2003), aunque algunos autores consideren que la amplia cobertura dada a las elecciones tendría la intención de favorecer al candidato gobiernista, el no tan conocido José Serra (PSDB), en desventaja en la contienda contra el ya muy conocido Lula (Rubim, 2004b).

En 2006, Globo realiza una cobertura que se divide entre el encantamiento y la denuncia. El encantamiento se podía notar especialmente en la "Caravana del Jornal Nacional", un autobús-reportaje que recurrió el país de sur a norte enseñando una realidad distinta y rica de bellezas escondidas en los rincones del Brasil profundo. Las reportajes de la Caravana se ajustaban a perfección al posicionamiento del presidente Lula, que hablaba de inclusión de un Brasil históricamente olvidado. Por otra parte, las denuncias se relacionaban a la divulgación de los escándalos de corrupción en el gobierno, por supuesto contrarios a los interés de PT y Lula. La opción de 2006 fue como si las empresas de la familia Marinho ofreciesen el Brasil pujante de la comunicación oficial, pero sin callar del todo respecto los escándalos puestos en la agenda política por la oposición.

El papel central ocupado por Globo en el sistema de medios brasileño la convierte en el que se llama de agenda setter ${ }^{6}$. Es decir: tiene la capacidad de agendar a los agendadores, tanto en relación a los medios como en lo que respecta a las instituciones políticas. En Brasil funcionan las emisoras estatales bajo control del gobierno central, amplificada por las emisoras controladas por los estados, pero además de un foco más educativo, esas emisoras registran poca audiencia. La emisora gubernamental de hecho pasa a ser Globo, sin la cual ningún gobierno alcanza buena respuesta popular, fundamental en una democracia de masas y todavía más en un país que es casi 18 veces el territorio de España; un medio imprescindible a cualquiera que busque el éxito en una campaña de ámbito nacional 57 .

\footnotetext{
${ }^{56}$ En la literatura estadounidense, los agenda setters son instituciones que a modo de gatekeeper o guardabarreras encargados de la selección de noticias hacen destacar unos temas sobre otros, influyendo en la agenda de los mismos medios. "En el caso norteamericano se han denominado agenda setters o seleccionadores de agenda a nuevas figuras muy influyentes del ámbito público e institucional como son: The New York Times, la Casa Blanca, las revistas científicas y resultados de encuestas nacionales" (Rodríguez Díaz, 2004: 53).

${ }^{57}$ Además de la bibliografía aquí citada, un buen trabajo sobre el papel de TV Globo y la interferencia de Roberto Marinho en la política brasileña es el documental "Brazil: Beyond Citizen Kane" (Brasil -
} 
El énfasis en la televisión no desproveen de importancia los medios impresos. Ellos desempeñan papel político relevante y los estudios indican una cierta uniformidad en la mayoría de los medios, con pequeñas variaciones entre ellos: el silencio de 1998 respecto la campaña que llevaría a la reelección de Cardoso no es solo de Globo sino de casi todos los medios (Miguel, 1999), así como la adhesión a Collor en 1989 fue general y entusiasmada (Conti, 1999). En 2002, los medios impresos cambian de estrategia respecto 1998, como lo hizo Globo, y dedican mucho espacio a la contienda electoral. Es cierto que la uniformidad no es tanta, pues Folha de S. Paulo presente una cobertura más neutral y $O$ Estado de $S$. Paulo adopta enfoque más favorable a la candidatura de José Serra (Aldé, 2004).

El sistema de medios en Brasil presenta un elevado nivel de profesionalización en cuanto a los procesos de producción y competencia por el mercado. La teledramaturgia es una de las más sofisticadas del mundo, tanto que la exportación de telenovelas es una de las principales fuentes de divisas de Globo. La prensa cuenta con sofisticados parques gráficos y la industria de la publicidad es bastante sofisticada, lo que puede ser traducido por las seguidas premiaciones en el festival de Cannes: Brasil es uno de los tres países más premiados en el festival francés, por debajo de Inglaterra y en competencia directa con Estados unidos por la segunda posición ${ }^{5}$.

El profesionalismo se refleja en el campo político, donde los consultores electorales disfrutan de prestigio internacional, participando de campañas en diversos países, incluso en Europa. La sofisticación del sistema exige profesionales calificados no sólo para atender al marketing comercial sino también al marketing político. Y esta condición a la profesionalización está presente en Brasil. En los formatos, la política incorpora el lenguaje simbólico y fragmentado de la publicidad comercial, familiar no sólo a los profesionales involucrados en los procesos de producción de anuncios de productos sino parte del hábito de consumo de medios por la gente corriente.

El punto más negativo quizá sea el sistemático y explícito envolvimiento de los principales vehículos con la política partidista, especialmente una tendencia gobiernista -cualquiera que sea el gobierno, sea con el PSDB antes o el PT ahora- que sigue siendo una de las principales fuentes de recursos de las empresas de comunicación. Esa realidad de dependencia del presupuesto de los gobiernos para la publicidad es todavía más fuerte en los escenarios regionales, donde el poder estatal en general es el mayor anunciante. Además, como recuerda Lima (2001), gran parte de las empresas de

Más allá del Ciudadano Kane), dirigido y producido por Simon Hartog, una realización de la productora independiente Large Door Ltd., de 1992 y exhibido por el Channe/ 4 de Londres el 10 de mayo de 1993.

58 Ver el rankink de galardonados en la página web de la Asociación Brasileña de Agencias de Publicidad, ABAP: www.abap.com.br. 
comunicación regionales están bajo control de los políticos y sus familias -y así, la publicidad oficial es mucha veces tan sólo un modo de transferencia del dinero público hacia las cuentas privadas-.

El Cuadro 4.11 sintetiza las implicaciones del sistema de medios sobre las campañas, una influencia que favorece a la profesionalización por la cultura de consumo establecida, por la experiencia profesional que aporta y por la disponibilidad de recursos que son comunes a la industria de la comunicación en general.

CUADRO 4.11

Sistema de medios y efectos sobre las campañas en Brasil

\begin{tabular}{ll}
\hline Característica & Efecto \\
\hline Predominio del privado & - Competencia y mayor mediatización \\
\cline { 2 - 2 } & - Medios con actores políticos de gran influencia \\
\hline Centralidad de la TV & - Televisiones como medios centrales \\
\cline { 2 - 2 } & - Protagonismo de Globo, por su casi monopolio \\
\hline - Mayor importancia de los spots, por la cultura de ver TV \\
\hline $\begin{array}{l}\text { Fuerte industria de la } \\
\text { publicidad }\end{array}$ & - Sofisticación técnica y lenguaje simbólica \\
\cline { 2 - 2 } & - Lógica del marketing (política como producto) \\
\cline { 2 - 2 } & - Mayor espacio para la participación de los expertos \\
\hline
\end{tabular}

Fuente: Elaboración propia

\subsection{Factores partidistas}

Los partidos funcionan según un conjunto de reglas formales y informales "que establecen el tipo de interacción que debe darse en el interior del mismo y en relación con el entorno" (Alcántara y Freidenberg, 2003: 15). Esas reglas se relacionan tanto con el historial del partido (su origen, el modo en que fue creado, sus experiencias previas, la tradición de pactar etc), como con las normas que establecen formas de participación de la afiliación y la presencia de liderazgos que desde la posición de autoridad y/o carisma ejercen la influencia sobre las formas de actuación particular de la organización.

Tres factores internos principales influyen en la definición de las estrategias del partido y en el modo de actuación: el origen, que incluye la constitución y consolidación del partido; el modo de organización interna, estableciendo los procesos decisorios y los 
espacios de participación de los miembros; y el papel del liderazgo, sobre todo la presencia (o no) de liderazgo carismático59. Tales aspectos producen importantes diferencias en el momento de la organización de una campaña así como la elaboración de estrategias y construcción del discurso.

El caso brasileño de PRN, PSDB y PT ofrecen evidencias de cómo esos factores llevan las campañas a distintos caminos. Es todavía más revelador el caso del PT, que se reinventó desde mediados de los años 1990 para alcanzar nuevas condiciones competitivas que van favorecer el proceso de profesionalización y el desarrollo de campañas con mayor eficacia en cuanto a la conquista del elector y también el apoyo de destacados actores de la política nacional.

\subsubsection{El origen de los partidos: cultura y pautas para la acción}

El momento fundacional condiciona la vida de los partidos (Duverger, 2002) y puede ofrecer muchos elementos para explicar las estrategias que esos actores políticos diseñan y ejecutan (Freidenberg, 2003). Es amplia la literatura que habla del origen de los partidos y la influencia que produce el factor originario en la trayectoria de la organización partidista. El mismo Duverger enfoca la creación de los partidos desde dos abordajes generales: la motivación interna y la externa. La primera incluye las organizaciones que surgen en el seno de las elites parlamentarias, donde se puede relacionar PSDB en el caso brasileño. La segunda dice respecto a los partidos que son creados por grupos de la sociedad civil sin vínculos directos con el parlamento -donde PT es un caso ejemplar-. El autor francés destaca la tendencia del primero caso a la consolidación de estructuras centralizadas, en cuanto en el segundo tiende a construir relaciones más horizontales.

Panebianco (1990) perfecciona el modelo de Duverger al señalar tres factores originarios: el modo como se inicia y se desarrolla la organización partidista; la existencia o no de organizaciones patrocinadoras en su creación; y la presencia o ausencia de liderazgo carismático, lo que implica en diferenciada dinámica al acopio de apoyos, sobre todo en la fase inicial. En cuanto al momento de construcción, el autor italiano observa que se puede se por penetración territorial (el partido tiene un centro que controla la expansión hacia la periferia), por difusión territorial (que implica en la presencia de fuerzas locales que se fusionan formando una estructura nacional) o por un modelo mixto que combina las dos fórmulas.

\footnotetext{
59 Para una visión general sobre el tema, ver Panebianco (1990), especialmente capítulo 4. Para una síntesis de los abordajes teóricos, ver el capítulo 2 de Freidenberg (2003).
} 
La existencia de organizaciones externas patrocinadoras en la formación de nuevos partidos es un modelo clásico en todo el mundo, donde sobresalen las internacionales partidistas: en América Latina uno de los casos es el PRD panameño, que cuenta en la formación con el soporte de la Internacional Socialista. Pero otras organizaciones han garantizado las condiciones para la creación de nuevos partidos, como la Iglesia Católica (caso del Partido Conservador de Colombia, aún en el siglo XIX; y el PAN mexicano), sindicatos (caso del Partido Justicialista argentino), movimientos sociales (el caso del Movimiento Patchakutick-Nuevo País, soportado por la confederación indigenista ecuatoriana) y organizaciones empresariales (como es ejemplo el boliviano Unión Cívica Solidaridad) ${ }^{60}$.

La presencia de liderazgos carismáticos ${ }^{61}$ en la formación de los partidos garantiza una dinámica particular donde el líder es la misma referencia de la organización. Además de asegurar apoyos pautados en la lealtad, el líder quita autonomía a la organización, puesto que encarna todas las decisiones a él vinculando el futuro del partido. El líder provisto de carisma es la representación misma del partido, muchas veces la vida de la organización limitándose a la presencia del liderazgo.

En un análisis específico sobre el origen de los partidos latinoamericanos, Alcántara (2004) desarrolla interesante modelo que incluye tres variables para la dimensión originaria: fecha de creación del partido; el momento de la constitución; y la naturaleza de la organización (Cuadro 4.12). Esas variables se dividen en 11 subvariables, que además son acompañadas por 22 características adicionales capaces de ofrecer clasificación más exhaustiva sobre el momento fundador de los partidos en América Latina.

El modelo de Alcántara, además de enfocar la realidad latinoamericana, es más completo por analizar desde el carácter originario al modo cómo se da la creación del partido. La primera variable "fecha de origen" hace la demarcación temporal, lo que es el primer revelador del grado de institucionalización. Así es que en América Latina se encuentran partidos como los colombianos Partido Conservador y Partido Liberal, creados a la mitad del siglo XIX, y el argentino Unión Cívica Radical, de 1890. En el caso de Brasil, la ausencia de estructuras nacionales de los partidos anteriores a 1964 y el completo cambio del sistema en fines de la dictadura militar resultan en partidos jóvenes incluso para los patrones de América Latina.

\footnotetext{
60 Ver diversos casos de patrocinio por organizaciones externas en Alcántara (2004: 61-63).

61 Panebianco (1990: 267-269) señala que el líder carismático, además de los aspectos personales que garantizan ascendencia sobre los seguidores, presenta particularidades como una naturaleza revolucionaria, el personalismo que reduce la importancia de la organización y la permanente inestabilidad resultado de las disputas entre seguidores.
} 


\section{Elementos constitutivos de la dimensión origen de los partidos, según Alcántara}

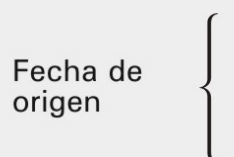

Partidos surgidos antes de 1925

Partidos surgidos entre 1925 y 1950

Partidos surgidos entre 1950 y 1975

Partidos surgidos después de 1975
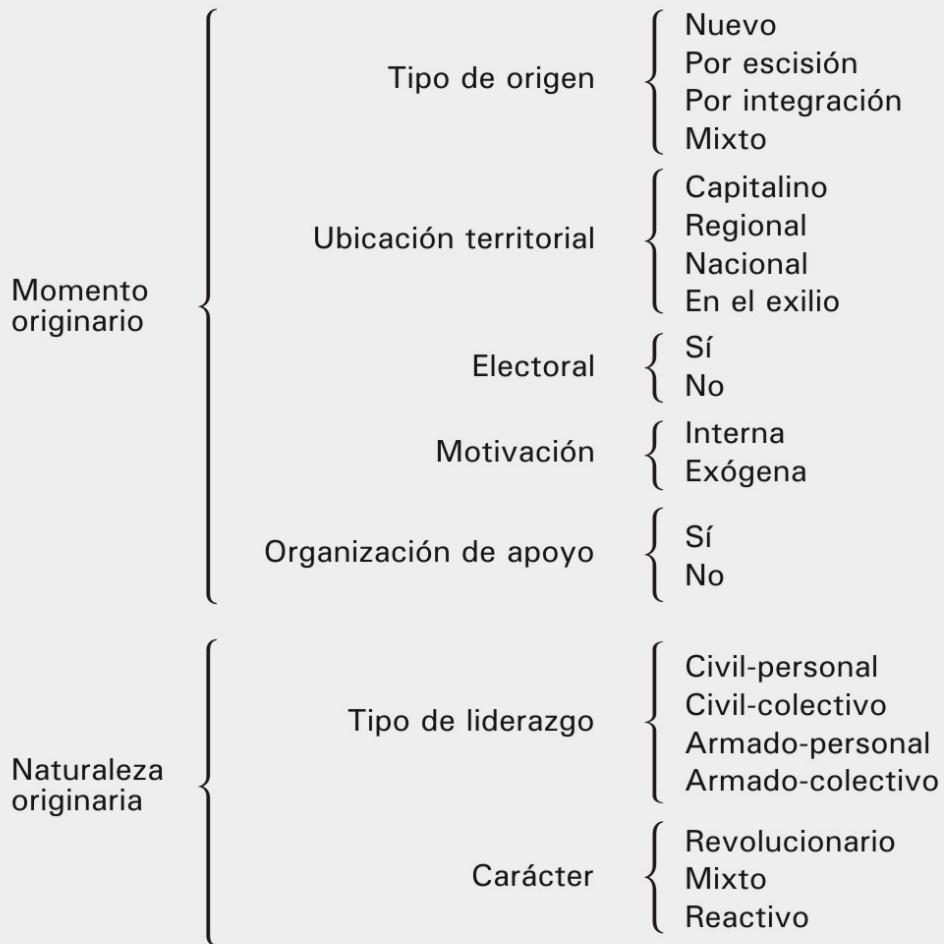

Fuente: Alcántara (2004: 44)

La segunda variable "momento originario" relaciona cinco subvariables y ofrecen una visión sobre las condiciones políticas en los primeros momentos de la organización. Así, se puede analizar el tipo de origen (partido nuevo, resultado de escisión o integración, o proceso mixto), la base territorial inicial (capitalino, regional, nacional o en el exilio), si privilegió o no el objetivo electoral, si tuvo motivación interna o externa y aún si contó en la formación con el soporte financiero de organizaciones externas.

En cuanto a la naturaleza originaria, Alcántara analiza en la formación del partido el tipo de liderazgo (civil o armado, personal o colectivo) y el carácter mismo de la nueva organización, es decir, si tiene un carácter contestatario, cuestionando el sistema, o si es más bien colaborador, que reafirma las características vigentes. El carácter indica se el partido nació con enfoque revolucionario (es decir, defendiendo cambios radicales en 
el orden vigente) o si es reactivo, caso en que el partido se propone a luchar por la interrupción de procesos de cambios o el restablecimiento de un orden anterior.

Tomándose el diseño de Alcántara como parangón, el caso de los partidos brasileños aqui analizados revelan uniformidad tan solo en dos de las clasificaciones: la fecha de creación y la motivación (Cuadro 4.13). Respecto esta última, todos presentan una motivación interna. En cuanto a la fecha de creación, todos son jóvenes organizaciones, creadas después de 1975, en concreto, después de 1979, cuando entra en vigor la nueva Ley Orgánica de los Partidos que de hecho instauró un nuevo sistema de partidos ${ }^{62}$. PT es el más antiguo, surgiendo en la primera oleada de partidos del nuevo sistema ${ }^{63}$. PSDB surgió en 1988, como una escisión de PMDB luego de los duros embates en la Asamblea Nacional Constituyente. Y PRN nació en comienzos de 1989, como soporte legal a la candidatura de Fernando Collor ${ }^{64}$.

CUADRO 4.13

Los factores originarios en los partidos PRN, PSDB y PT

\begin{tabular}{|c|c|c|c|}
\hline Fecha de origen & Después de 1975 & & PRN, PT y PSDB \\
\hline \multirow[t]{9}{*}{ Momento originario } & \multirow[t]{2}{*}{ Tipo de origen } & Nuevo & PRN y PT \\
\hline & & Por escisión & PSDB \\
\hline & \multirow[t]{2}{*}{ Ubicación territorial } & Nacional & PRN y PSDB \\
\hline & & Regional & PT \\
\hline & \multirow[t]{2}{*}{ Electoral } & $\mathrm{Si}$ & PRN \\
\hline & & No & PSDB y PT \\
\hline & Motivación & Interna & PRN, PSDB y PT \\
\hline & \multirow[t]{2}{*}{ Organización de apoyo } & Sí & PT \\
\hline & & No & PRN y PSDB \\
\hline \multirow[t]{4}{*}{ Naturaleza } & \multirow[t]{2}{*}{ Tipo de liderazgo } & Civil-personal & PRN \\
\hline & & Civil-colectivo & PSDB y PT \\
\hline & \multirow[t]{2}{*}{ Carácter } & Revolucionario & PT \\
\hline & & Neutro & PRN y PSDB \\
\hline
\end{tabular}

Fuente: Para PSDB y PT, Alcántara (2004). Para PRN, elaboración propia.

\footnotetext{
62 La Ley Orgánica de los Partidos fue aprobada en diciembre de 1979, extinguiendo Arena y MDB y restableciendo el pluripartidismo. Ver Meneguello (1998).

63 PT fue creado formalmente en 10 de febrero de 1980, aunque la organización misma del partido empieza en 1979: una asamblea del 13 de octubre aprobó una Declaración Política que es considerada la declaración de principios del futuro partido. Además de PT, en 1980 surgen PMDB, PDS, PDT y PTB. Ver Meneguello (1989 y 1998).

${ }^{64}$ A pesar de creado desde el registro legal del Partido de la Juventud, el PRN de hecho un nuevo partido: nuevo líder, nueva base política, nuevo discurso. El Partido de la Juventud es tan sólo el atajo legal utilizado por Collor para hacerse controlador de una legenda y así poder presentarse a las presidenciales sin el riesgo de competencia interna que encontraba en PMDB, su anterior partido.
} 
Si PSDB es una escisión, PRN y PT son partidos nuevos. Pero las similitudes entre estas dos siglas acaban allí. PRN es claramente un partido con objetivo esencialmente electoral, basado en un liderazgo civil-personal, en cuanto PT -igual que PSDB- nació con objetivos más allá del campo exclusivamente electoral, además de contar con la referencia del liderazgo civil-colectivo. A pesar de la posición de Lula como incuestionable líder de PT sobre todo en la cohesión y consolidación a lo largo de la década de 1980, la creación del Partido de los Trabajadores no se resume al líder metalúrgico, muy al contrario de $\mathrm{PRN}$, que tuvo en Collor la razón misma de la organización. En PSDB, la referencia del liderazgo es todavía más diluida, aunque se pueda apuntar como principales estrellas los entonces senadores Mário Covas y Fernando Henrique Cardoso, ambos de São Paulo.

De los tres partidos, el PT es el único que nació con una ubicación regional, vinculado a los grandes centros urbanos donde el movimiento sindical se presentaba más fuerte; tiene como base principal el cinturón industrial de São Paulo, con destacada centralidad de los liderazgos metalúrgicos -Lula a la cabeza- y luego otras fuertes categorías de trabajadores, como los funcionarios de la banca y de las universidades. PRN y PSDB surgen con una distribución territorial nacional, a partir de las asociaciones con los liderazgos esparcidos por los estados. En el caso del partido socialdemócrata, esa base estaba en el mismo grupo fundador, constituyendo por parlamentares de las diversas regiones del país; en cuanto al PRN, la nacionalización se da a través de la adhesión de los liderazgos -en general de corte conservador y clientelista - a la candidatura de Collor, ya en principios de 1989 revelándose más viable que cualquiera otra del centro-derecha.

Aún en ese momento de origen, el PT se diferencia de los dos otros por contar con el soporte financiero de una organización externa. PSDB y PRN son partidos que se mantienen desde la estructura propia de sus miembros fundadores (sobre todo parlamentares, en caso del primer) y referencia de su liderazgo (caso del segundo). El PT, sin embargo, cuenta con el soporte explícito del movimiento sindical, con destaque para la Central Única de los Trabajadores (CUT), cuya acción se confunde con la del partido y al revés. La fuerza de los liderazgos vinculado a los trabajadores se revela en la composición de la primera dirección del nuevo partido: 12 de los 17 puestos estaba en manos de sindicalistas (Singer, 2001), lo que pone PT como el único entre los grandes partidos brasileños resultado de un movimiento externo a las elites políticas (Roma, 2006; Meneguello, 1989).

Otro factor que repite esa separación entre los tres partidos es en relación al carácter inicial: PRN y PSDB son partidos neutros, que no ofrecen ninguna resistencia al sistema vigente, tampoco actúan con el propósito de restablecer un orden anterior; PT, 
por su parte, se presenta como un partido que se puede clasificar como revolucionario, puesto que plantea cambios radicales. Los primeros documentos de PT alimentan la lucha de clase, combaten el capitalismo y defienden al socialismo. La postura actual del partido, mucho más cercana a una visión socialdemócrata, es el resultado de cambios internos que se producen principalmente después de la derrota de 1994.

Las características originarias resultan importantes en la operacionalización de las campañas, puesto que dicen del modo de organización de los partidos y los procesos de toma de decisión, además de la centralidad del comando. La juventud de los partidos indica la baja institucionalización y la poca relevancia del discurso partidista, aunque en ese enfoque se pueda encontrar algo distinto en el caso de PT, partido que ha logrado llevar a cabo una estrategia partidista en contra de la tendencia general de un sistema que Samuels (1999) destaca por la sobresaliencia de los candidatos.

\section{i. PT: base colectiva, horizontalidad y participación de la afiliación}

Importantes particularidades del PT están en sus comienzos: el partido es el resultado de un proceso de abertura de la sociedad brasileña en fines de la década de 1970, favorecido por la convergencia de diversas corrientes sociales, entre ellos intelectuales, políticos de izquierda egresados del MDB, sectores progresistas de la Iglesia Católica y especialmente el movimiento sindical. La seña de esa convergencia fueron las grandes huelgas de los metalúrgicos del $\mathrm{ABC}^{65}$ de 1978, revelando las debilidades del régimen militar y produciendo apoyos sin precedentes al movimiento de los operarios, mientras daba a conocer al país un nuevo líder operario: Luís Inácio Lula da Silva, sencillamente conocido como Lula66. Las huelgas también consolidaron el llamado Nuevo Sindicalismo ${ }^{67}$, que a continuación resultará en la creación de la Central Única de los Trabajadores, CUT.

\footnotetext{
${ }^{65}$ La región del $A B C$ está en cinturón industrial de la ciudad de São Paulo y es así llamada por las tres ciudades de referencia: Santo André, São Bernardo y São Caetano. A veces es llamada de $A B C D$, por la ciudad de Diadema, creada como escisión de São Bernardo. Es precisamente São Bernardo el centro de las huelgas y considerada la cuna de PT.

66 Lula es un apodo común a la mayor parte de las personas llamadas Luís, como en España es común Pepe para quien se llama José. En comienzos de la década de 1980 Lula incorporó formalmente el apodo a su registro civil, puesto que en aquello entonces el elector necesitaba escribir en nombre o el número del candidato en la papeleta -y la justicia prohibía el uso de apodos-. Lo mismo pasó en la década de 1960 con José Sarney, que incorporó el apodo Sarney a su registro civil.

${ }^{67}$ El Nuevo Sindicalismo es un movimiento operario más pragmático, caracterizado por el alejamiento del control estatal presentes entre los liderazgos "pelegos" (conservadores y en general vinculados al gobierno militar) y del juego ideológico de los liderazgos vinculados a los partidos comunistas que, a pesar de clandestinos, seguían muy influyentes en ese campo de actuación política Ver Santana (1999) y Mendonza y Oliveira (2001).
} 
El PT desde el principio se reveló un amplio frente de corrientes ideológicas que buscaban una nueva alternativa política, reuniendo desde sectores más cercanos a la socialdemocracia hasta grupos clandestinos que participaron de la lucha armada contra la dictadura, como los leninistas Partido Comunista Brasileño Revolucionario (PCBR) y Alianza Popular; también contaba con grupo radicales como la trotskista Convergencia Socialista y miembros defensores de un indefinido socialismo, a ejemplo de muchos de los grupos vinculados a la iglesia católica y incluso sectores del Nuevo Sindicalismo ${ }^{68}$. En su creación, PT se propone a dar dignidad y nobleza a la lucha de los trabajadores, mirando hacia la participación parlamentaria como un nuevo espacio para las conquistas de los trabajadores (D’Araújo, 1990).

El partido nace con relaciones horizontales, con procesos decisorios propios, más allá de la exigencia de la legislación. La fundación del partido es un ejemplo de como la participación de la afiliación estaba en la cultura originaria de PT. Oficialmente el partido fue creado el 10 de febrero de 1980 , en un Congreso Nacional, conforme exigencia de la Ley Orgánica de los Partidos aprobada en 1979. Sin embargo, la creación misma y las directrices de la nueva organización quedaron definidas en un proceso de discusión muy más amplio y exhaustivo ocurrido en octubre de 1979, cuando de hecho se elaboraron los documentos que fueron confirmados en la reunión de febrero. La instancia formal exigida por la ley era el espacio de oficialización de las discusiones precedentes que se traducían en duros debates internos ${ }^{69}$.

El documento de fundación enfatiza la participación de los miembros:

“El PT lucha para que todo el poder económico y político venga a ser ejercido directamente por los trabajadores. Única manera de poner fin a la explotación y a la opresión. En consecuencia, construirá una estructura interna democrática, apoyada en las decisiones colectivas y colegiadas, que garanticen, efectivamente, su dirección política y su programa a partir de las decisiones de sus bases ${ }^{70}$.

El origen descentralizado va a tener importante impacto en las campañas, especialmente las dos primeras. En 1989 el discurso de Lula -sobre todo el del primer

\footnotetext{
68 Sobre las corrientes ideológicas que forman PT, ver Azevedo (1995) y Meneguello (1989).

69 Las normas de la justicia electoral brasileña establecen una rígida estructura jerárquica en que el comité local responde al regional (en nivel estadual), que por su parte sigue las directrices del comité nacional.

70 Los principales documentos de la historia del Partido de los Trabajadores están disponibles en la Fundación Perseo Abramo: www.fpa.org.br
} 
turno- tiene fuerte dosis ideológica, en mucho traduciendo los principios establecidos en los documentos fundacionales, en los que destacan la lucha de clase y la construcción del socialismo, un socialismo no muy claro, a pesar del evidente rechazo al socialismo real del este europeo (D’Araújo, 1990). En 1994, los primeros intentos de ampliación de las alianzas electorales genera un encarnizado debate: de un lado, la "derecha" del partido alimentando la alianza con sectores del PMDB o incluso una coalición formal con PSDB; de otro las tendencias ${ }^{71}$ más radicales rechazaban cualquiera asociación con lo que consideraban fuerzas burguesas. El confronto llega indefinido al $9^{\circ}$ Encuentro Nacional de PT, de mayo de 1994, menos de 5 meses antes de la elección. El encuentro determinó la victoria de las fuerzas radicales, no sólo restringiendo las alianzas a los partidos de izquierda sino imponiendo un discurso más ideológico y menos electoralista, rescatando propuestas que los sectores más moderados cercanos a Lula les gustaría olvidar (Dimenstein y Souza, 1994).

Las divergencias respecto las presidenciales de 1994 profundizan las diferencias de visión sobre las campañas y el mismo proyecto de poder del partido. Los sectores de izquierda pugnaban por un partido marcadamente ideológico en cuanto los moderados miraban a las perspectivas de efectiva elección de Lula desde la ampliación de alianzas, incluyendo actores que los radicales consideraban representantes de la burguesía. A continuación PT cambia de rumbo, de cierto modo sepultando algunos de los marcos originarios, pero dando paso fundamental a la profesionalización pretendida por el grupo moderado en lo cual Lula pontificaba y sigue pontificando (Paiva, 2005).

\section{ii. PRN: personalismo y centralización en un partido que apenas existe}

Como al PT, se puede considerar al PRN como un partido nuevo. Si bien el Partido de los Trabajadores es consecuencia de un movimiento social, la creación de PRN está asociada a cuatro hechos: 1) la amplia personalización de la política en Brasil, rasgo histórico muy anterior a la mediatización; 2) la repercusión popular del nombre de Fernando Collor, en la secuencia del posicionamiento antipolítica y anticorrupción que encarnaba desde los primeros momentos como gobernador de Alagoas; y 3) las dificultades encontradas por Collor dentro del PMDB para viabilizarse como candidato a la presidencia. Súmese a ello las facilidades de la legislación brasileña para el cambio de partido, así también para crear o rebautizar siglas.

71 Desde la fundación, los documentos internos de PT llaman de "tendencias" a los grupos que actuaban dentro del partido, caracterizando un bies ideológico en la actuación. Para más informaciones sobre la actuación de las corrientes ideológicas en el seno de PT, ver Documento de Reglamentación de las Tendencias, disponible en la página web de la Fundación Perseu Abramo: www.fpa.org.br. 
El proyecto de Collor de presentarse a las presidenciales de 1989 encuentra en fines de 1988 fuerte resistencia dentro de PMDB, partido al cual se vinculara en 1985 con miradas hacia la disputa del gobierno estadual en 1986. Un año antes de las primeras presidenciales de la nueva etapa democrática, el aún gobernador de Alagoas manifestó la intención de enfrentarse en la convención pemedebista a Ulysses Guimarães, un histórico del partido y de las luchas por la redemocratización. La casi nula resonancia de la reivindicación hizo ver que no tenía muchas posibilidades dentro de PMDB, lo que lleva Collor a buscar abrigo en otra organización: en febrero de 1989 anuncia la creación del PRN teniendo como base el Partido de la Juventud, sigla hasta entonces sin ninguna expresión política (Meneguello, 1998).

La base del Partido de la Juventud fue tan sólo un atajo legal para garantizar la legalidad de la nueva sigla. Sin embargo, Collor era el mismo partido: las adhesiones no se daban a un proyecto de partido, tampoco a una propuesta de nación o de gobierno; los miembros que llegaban a PRN lo hacían por la figura del Caçador de Marajás, o más bien por la perspectiva de poder que otros candidatos del espectro centro-derecha no ofrecían. Así es que la vida del partido es un paralelo a la trayectoria del candidato y si la ascensión de Collor hace existir al partido, la derrota del presidente es la caída de la organización.

Antes de trasmutarse en PRN, el Partido de la Juventud no tenía siquiera un representante en el Congreso Nacional. Tan pronto Collor lanzó el nuevo partido, y teniendo en cuenta la viabilidad electora que enseñaba, 21 diputados y 2 senadores se pasaron a la nueva sigla (Cuadro 4.14). En 1990, con el presidente elegido, el PRN pasa a 31 diputados y a 3 senadores, aunque seguía siendo un número muy poco expresivo, correspondiendo a un 6,3\% y 3,7\% de Cámara y Senado, respectivamente. En las elecciones de 1990, el partido del presidente (ya desgastado por medidas impopulares) logró elegir solamente 40 diputados, un 7,9\% de la cámara baja. El continuado desgaste de Collor se refleja en la migración de los representantes del partido, que en 1993 después de la caída del presidente- descienden a 10. En la elección de 1994, el partido consigue solamente 1 diputado y un año más tarde ya no tendría ningún representante en el Congreso.

El PRN no resiste a la primera elección sin el liderazgo carismático de Collor, quien era la síntesis del partido. Los afiliados nunca han contado para nada, sencillamente porque el partido nunca ha tenido afiliados: cuando mucho presentaba entre sus miembros a aliados de Collor que tan sólo buscaban el abrigo más cercano al líder y a la perspectiva de poder que él ofrecía. En la campaña de 1989, el líder y su entorno decidían los rumbos estratégicos y la forma de ejecución, sin la necesidad de consultas más allá del comando central alrededor del candidato. El mando de la campaña era 
confiado a aquellos en quienes Collor y su entorno quisieran y muchas veces el depositario de las tareas más importantes fueron profesionales contratados con ese fin específico.

CUADRO 4.14

Representación del PRN en el Congreso Nacional*

\begin{tabular}{lcccccc}
\hline & & 1989 & 1990 & 1991 & 1993 & 1995 \\
\hline Deputados** & $(\mathrm{n})$ & 21 & 31 & 40 & 10 & 1 \\
\cline { 2 - 7 } & $\%$ & 4,2 & 6,3 & 7,9 & 2,0 & 0,2 \\
\hline Senadores & $(\mathrm{n})$ & 2 & 3 & 3 & 5 & 1 \\
\cline { 2 - 7 } & $\%$ & 2,7 & 3,7 & 3,7 & 6,2 & 1,2 \\
\hline
\end{tabular}

Fuente: Meneguello (1997: 64-65).

* Porcentual basado en la composición de la Cámara, de 495 diputados en 1989 y 1990:

503 diputados en 1991 y 1993; y 513 desde 1995. La composición del Senado era de 69 senadores en 1989 y 1990; y de 81 desde 1991.

* * Los números indicados en las columnas 1991 y 1995 corresponden a los diputados que asumieron sus escaños en eses años, pero elegidos en el año anterior.

\section{iii. PSDB: el pragmatismo por en cima del discurso programático}

El Partido de la Socialdemocracia Brasileña (PSDB) fue creado a fines de junio de 1988, acto final de las divergencias históricas en el seno de PMDB que alcanzaron el límite en los debates de la Asamblea Nacional Constituyente (1987-1988). El grupo de parlamentarios que formaron la representación inicial del partido fueron básicamente del ala identificada con el Movimiento de Unidad Progresista (MUP) que aún a mediados de la década de 1970 fortaleció los vínculos del MDB con los movimientos populares, dando a la moderada oposición al régimen militar una actuación más allá del campo parlamentario (Cabrera, 1995).

Según los documentos iniciales del partido, los fundadores del PSDB buscaban una alternativa distinta de la ruta conservadora que el PMDB revelara tanto en las políticas adoptadas por sus gobernadores elegidos en 1982 y 1986 como las implantadas en el curso del gobierno José Sarney, a quien el partido respaldaba formalmente ${ }^{72}$. Además, la Constituyente consolidó la faz conservadora de PMDB, que contribuyó con la mayor

\footnotetext{
72 En el manifiesto de fundación, de junio de 1988, PSDB se posiciona como un partido que busca un nuevo modelo de Estado, pero sin ruptura, puesto que proponía reformas que garantizasen la mayor eficiencia del sector público. Entre las tesis abrazadas esta la adopción del parlamentarismo como camino hacia la estabilidad política. Documentos disponibles en www.psdb.org.br.
} 
parte del Centrão, grupo que entre otras cosas avaló la fijación del mandato de 5 años para Sarney73. Ello generaba conflicto con el grupo que luego crearía el PSDB, con un discurso de modernización de la sociedad y empeñados en dejar en la nueva Constitución una marca social74.

Esa faz ideológica presente en el discurso inicial del nuevo partido es cuestionada por investigadores como Roma (2002). A pesar de las diferencias de fondo en el seno de PMDB - principalmente en relación al sistema de gobierno, que produjo divergencias tan profundas en la Asamblea Constituyente-, serían factores pragmáticos los decisivos para la formación del partido, en especial los determinados por las disputas internas en PMDB de São Paulo, donde el partido era dominado por el ex gobernador Orestes Quércia, sin muchas alternativas para el grupo de los entonces senadores Mávio Covas y Fernando Henrique Cardoso. En cierto modo, había una motivación electoral ya de cara a las municipales de 1988, sobre todo en relación a la candidatura a la alcaldía de São Paulo, puesto que el grupo que resultó en el PSDB no aceptaba las alternativas ofrecidas por Quércia.

A pesar de ser socialdemócrata, el PSDB es distinto de los clásicos partidos socialdemócratas europeos, puesto que no presenta una relación importante con los sindicatos; tiene como base el parlamentos, desde el inicio contando con nombres influyentes en la política nacional 75 , revelándose más como un partido de cuadros que de masas, en la clasificación de Duverger (2002). El principal núcleo en el origen estaba situado en el estado de São Paulo -orbitando en torno de Covas y Cardoso- contaba con el soporte de intelectuales como Bolivar Lamounier, Bresser Pereira y Paulo Renato Souza que ofrecen una imagen técnica a la nueva organización.

Además, el partido nace con orientación profesional, empezando por la definición de una identidad visual. Los colores son el azul y el amarillo, ambos parte de la bandera nacional; y el símbolo es el tucano, ave característica de la fauna tropical brasileña que pasa a identificar la sigla y a sus miembros: hoy en la política brasileña, tucano es sencillamente un integrante de PSDB o alguien identificado con el partido. Los cuidados en el lanzamiento hacen evidente la tendencia profesional que hace del partido un producto: hay una marca visualmente definida y un calculado posicionamiento que ubica PSDB en la franja centro-izquierda, distinta de PMDB y de otras legendas.

\footnotetext{
73 El Centrão era un grupo parlamentario que en la Constituyente daba soporte a las propuestas conservadoras, con fuerte vínculo con el gobierno Sarney. De los 304 signatarios del manifiesto del Centrão, 128 integraban el PMDB, 115 el PFL, 31 eran de PDS, 5 de PDT y otros 25 de PTB, PL, PDC e PSC. Para más informaciones ver Lamounier (1989).

${ }^{74}$ Ese grupo también se empeñó por la institución del parlamentarismo, propuesta que no tuvo éxito.

75 En su fundación, PSDB contaba ya con 41 diputados federales y 8 senadores (Roma, 2006).
} 
Todos esos factores van a tener reflejo en las campañas del partido, incluso en la de 1989, cuando Mário Covas logró ser el cuarto más votado: posiblemente era, por detrás de Collor, la campaña mejor estructurada en términos de comunicación, aunque carente de apoyos de actores políticos fundamentales pues el grueso de los conservadores estaban con el candidato de PRN y los movimientos sociales y fuerzas de izquierda se dividían entre Lula y Brizola. La vertiente técnico-programática va ser notada en las campañas presidenciales, además de una postura profesoral principalmente en caso de Fernando Henrique Cardoso (1994 y 1998) y de José Serra (2002). Las referencias a la competencia técnico-administrativa estará presente en todas las campañas de 1994 a 2006, ya sea presentando Fernando Henique Cardoso como "padre del Real", ya sea de José Serra como "mejor ministro de Sanidad del mundo" o aún de Geraldo Alckmin como el gobernador que hizo de São Paulo un estado mejor que los demás.

Es evidente que la personalización se revela más fuerte que el partidismo, tanto que publicaciones del propio PSDB reconocen que en elecciones como las de 1994 la gente no votó en el partido sino en la persona de Cardoso, alabado por la creación y implantación del plan Real (Madeira, 2004). Todo ello porque por encima de la imagen programática, el partido es sobre todo pragmático, pues adopta estrategias que objetivan resultados electorales concretos.

\subsubsection{La organización partidista}

Comprender los cambios organizativos en los partidos puede ser la clave para explicar otros procesos (Panebianco, 1990). Y la organización de los principales partidos brasileños involucrados en las últimas elecciones presidenciales es parte de la explicación del modo de operacionalización de las campañas. Son partidos con perfiles distintos, aunque todos se encaminen hacia una actuación que privilegia el desempeño electoral, todos ellos apropiándose de elementos que acercan al perfil catch-all de Kirchheimer (1980).

Kirchheimer relaciona cinco características del partido catch-all: 1) marcada desideologización; 2) mayor abertura a la influencia de los grupos de interés; 3) pérdida de relevancia de los afiliados; 4) mayor poder organizativo de los líderes; y 5) pérdida de identificación entre partido y electorado. Panebianco añade una sexta característica: la creciente profesionalización de las organizaciones partidistas ${ }^{76}$. Además, desde las

\footnotetext{
${ }^{76}$ Panebianco advierte que el catch-all party suele ser identificado como el partido que busca todos los públicos, algo imposible. De hecho Kirchheimer relaciona el partido catch-all con el intento de agregar los más amplios públicos sin intereses conflictivos (Panebianco, 1990: 489).
} 
aportaciones de Duverger (2002) respecto el partido de masas y de Kirchheimer sobre el partido catch-all, el autor italiano ofrece categorización que considera más ajustada a la realidad contemporánea: el partido burocrático de masas y el partido profesionalelectoral.

En el partido de masas clásico, la burocracia desempeña papel crucial en el vínculo entre la organización y los afiliados y, desde ahí, con los grupos sociales de referencia77. En el nuevo partido de masas, los afiliados siguen en puestos centrales, pero sin presencia absoluta, puesto que algunas tareas en la organización partidista son transferidas a no afiliados. La burocracia partidista ejerce papel central en la organización, alimentando los estrechos lazos con la afiliación (Cuadro 4.15). El comando es fuerte y colegiado, cuenta con clara orientación ideológica y la financiación de las actividades proviene de los afiliados.

CUADRO 4.15

El cambio organizativo

\begin{tabular}{l|l}
\hline Partido burocrático de masas & Partido profesional-electoral \\
\hline $\begin{array}{l}\text { a) Papel central de la burocracia (competencia } \\
\text { político-administrativa). }\end{array}$ & $\begin{array}{l}\text { a) Papel central de los profesionales } \\
\text { (competencias especializadas) }\end{array}$ \\
\hline $\begin{array}{l}\text { b) Partido de afiliación con fuertes lazos } \\
\text { organizativos de tipo vertical que se dirige } \\
\text { sobre todo a un electorado fiel. }\end{array}$ & $\begin{array}{l}\text { b) Partido electoralista, con débiles lazos } \\
\text { organizativos de tipo vertical y que se dirige } \\
\text { ante todo al electorado de opinión. }\end{array}$ \\
\hline $\begin{array}{l}\text { c) Posición de prominencia de la dirección del } \\
\text { partido; dirección colegiada. }\end{array}$ & $\begin{array}{l}\text { c) Posición de prominencia de los } \\
\text { representantes públicos; dirección } \\
\text { personificada. }\end{array}$ \\
\hline $\begin{array}{l}\text { d) Financiación por medio de las cuotas de los } \\
\text { afiliados y mediante actividades colaterales. }\end{array}$ & $\begin{array}{l}\text { d) Financiación a través de los grupos de } \\
\text { interés y por medio de fondos públicos. }\end{array}$ \\
\hline $\begin{array}{l}\text { e) Acentuación de la ideología. Papel central de } \\
\text { los creyentes dentro de la organización. }\end{array}$ & $\begin{array}{l}\text { e) El acento recae sobre los problemas } \\
\text { concretos y sobre el liderazgo. El papel central } \\
\text { lo desempenan los arribistas y los } \\
\text { representantes de los grupos de interés dentro } \\
\text { de la organización. }\end{array}$ \\
\hline
\end{tabular}

Fuente: Panebianco (1990: 492).

Por otra parte, al utilizar el término "partido profesional-electoral" en lugar de catchall, Pabenianco busca subrayar la importancia de los aspectos organizativos en la acción de acercamiento al elector por esos partidos, diferente del partido de masas que tiene como referencia la representación social. El partido profesional-electoral se

77 Ver las descripciones de Duverger (2002) y Michels (1991) y las consideraciones de Panebianco (1990). 
caracteriza por una visión electoralista en donde los profesionales asumen la centralidad en la relación con el elector. La dirección es personalista y la financiación tiene como base los grupos de interés y los fondos públicos. Además, la ideología da paso a los problemas concretos y a la figura del líder, referencia fundamental en la afirmación política de la organización.

Entre los partidos protagonistas de las campañas presidenciales desde 1989 en Brasil, hay una importante similitud: la centralización del comando de campaña, aunque se verifiquen modos distintos de operacionalización de esas campañas. En el caso de PRN, partido creado con un objetivo estrictamente electoral y vinculado a un liderazgo personal, las decisiones son tomadas de modo directo, sin la necesidad de satisfacción a ninguna otra instancia sino el núcleo creado por y al rededor del candidato. PSDB, a pesar de presentar relaciones jerarquizadas, la referencia colectiva del liderazgo hace necesario el diálogo con las bases. En el caso del Partido de los Trabajadores, cuyo origen está en el movimiento sindical y cuenta con diversas corrientes ideológicas en su interior, las decisiones son fundamentalmente colegiadas, factor que dificulta el proceso decisorio y frena la profesionalización de las campañas. Es más: por su carácter originario revolucionario, la acción de PT en primeras las campañas estaba constreñida por las prioridades estratégicas más allá de la elección -otro factor que dificultó el camino hacia la profesionalización-.

Hay otras diferencias: el PRN se ajusta al perfil profesional-electoral, en cuanto el primer PT (de las campañas de 1989, 1994 y 1998) es un partido burocrático de masas con perfil clásico sobre todo en la primera elección, cuando el discurso clasista está claramente presente y además cuenta con el apoyo fundamentalmente anclado en ciertos sectores sociales. El PT de las dos últimas campañas cambia y abre espacio a la profesionalización, quitando parte del papel desempeñado por la burocracia partidista. En el caso de PSDB, tiene semejanzas al segundo PT, con alguna atención a los afiliados pero con actuación soportada por profesionales que ya actúan en el seno del partido desde su fundación.

\section{i) Control personal y campaña profesional en PRN}

El Partido de la Reconstrucción Nacional es el típico partido profesional-electoral, donde la identificación partidista apenas existe, resumiendo su referencia a una persona. Creado con el fin específico de dar soporte legal a una candidatura de alguien que se presenta como outsider -en concreto la candidatura de Fernando Collor de Melo- se caracteriza como máquina electoral bajo el mando directo del candidato. Es por ello un partido cuya trayectoria se vincula a la carrera política del mismo Collor, 
fenómeno meteórico tanto en la ascensión como en la caída. Así es que el PRN cuenta con un historial de escaso éxito electoral, restricto básicamente a la elección del presidente de la República en 1989.

En la disputa presidencial de 1989, el PRN se presenta sin lazos organizativos significativos: no hay miembros y la estructura directiva es el núcleo de amigos y profesionales del entorno del candidato. A pesar de creado desde la base legal del Partido de la Juventud, hay que subrayar que el mismo PJ apenas existía legalmente, sin referencia en términos de imagen o de representación social y política. Además, de la organización anterior (si se puede decir que había una organización anterior) lo único que queda en la nueva fase es el presidente, Daniel Tourinho. Pero Tourinho apenas cuenta como referencia del partido y menos aún de la candidatura Collor, absolutamente anclada en la imagen del Caçador de Marajás y orbitando en torno del núcleo estratégico y ejecutivo que el candidato formó en bases profesionales.

En la campaña de 1989, las cuatro características del partido profesional-electoral son seguidas con precisión: los profesionales ocupan un papel central, incluso porque no hay afiliados; la organización es claramente vertical, con un discurso que no es diseccionado a un público específico, mas bien buscando alcanzar el mayor número posible de electores; la publicidad electoral está centrada en los grandes problemas nacionales y en la persona del liderazgo, que se presentaba como la solución, como el héroe que va a salvar la patria y la relación con los grupos de interés, es la base de la financiación.

Collor estructura un núcleo central de campaña aún antes crear el PRN, preocupado sobre todo en crear una imagen personal reconocida en ámbito nacional y que sirviera de base a los propósitos electorales. Es el mismo núcleo que seguirá comandando la campaña después, ya en la nueva sigla: funciona de modo vertical, las decisiones del mando central encaminadas a las otras esferas para mera ejecución. Las acciones son orientadas por las demandas populares, diagnosticadas por encuestas continuas y analizadas por profesionales responsables en el diseño estratégico. El público blanco es siempre la mayor parte del electorado, haciendo que los grandes temas nacionales sean los que interesan al candidato. No es casual que la moralización sea el grande tema de Collor desde la toma de posesión en el gobierno de Alagoas: la marca final del gobierno Sarney es la secuencia de escándalos de corrupción, a los cuales el candidato de PRN asegura tener soluciones, presentando como credencial su lucha contra los marajás del servicio público alagoano.

Todo se resume a la imagen del candidato. Incluso las adhesiones no son al partido, sino a la candidatura Collor. La relación de los diversos actores son con el político, ya 
sean empresarios en búsqueda de un candidato confiable, ya sean los liderazgos regionales que intentan ponerse bajo el paraguas de una candidatura viable y capaz de atender a sus demandas clientelistas. La interlocución con esos actores es enteramente centrada en el pequeño núcleo formado en torno al candidato y la operacionalización de la campaña se realiza arriba, donde el mando central distribuye tareas que deben ser ejecutadas en los diversos niveles políticos. Así se puede decir que la estructura de poder en el PRN se resumen a un nombre: Collor.

ii) Liderazgos regionales y profesionalización, la doble faz de PSDB

Los fundadores de PSDB fueron, sobre todo, líderes con experiencia en elecciones y en la actuación parlamentaria. De ahí se explica que el diseño organizativo se oriente hacia una dinámica que favorece a los dirigentes y representantes parlamentarios, sin interferencia significativa de los miembros partidistas. A pesar de ello, las reglas formales son bastante democráticas: según establece el estatuto del partido, la estructura organizativa es rígida, con reglas explícitas de funcionamiento interno que establece funciones específicas a cada instancia de poder; la verticalización y la jerarquía son aseguradas por las reglas, con claras medidas disciplinarias, pero con sustantivo espacio a la participación de los miembros partidistas. Entre la letra del estatuto y la práctica, sin embargo, hay una importante distancia (Roma, 2006).

En el cotidiano del partido, los líderes son la clave de la organización, sin necesidad de verificar la jerarquía o la disciplina, tampoco presentan medidas efectivas que derivan en la punición de los miembros que actúen en contra las directrices y intereses partidistas. En 2006, la alianza de PSDB con el PFL del senador Antonio Carlos Magalhães hizo que parte de los tucanos de Bahia votasen en el candidato del PT como estrategia para no fortalecer al cacique de la derecha en el estado. En 2002, el grupo del senador Tasso Jereissati en Ceará votó para presidente a Ciro Gomes (PPS), reforzando la alianza local, en perjuicio del candidato del partido, José Serra. La autonomía de los afiliados se da precisamente por el rasgo de PSDB como partido de líderes: cada líder decide las estrategias propias en su instancia de poder, sin la interferencia de las esferas superiores. O dicho de otro modo, las decisiones en el ámbito local sencillamente no consideran a las estrategias nacionales.

A pesar del estatuto democrático, el núcleo nacional suele decidir las estrategias nacionales, en general sin tener en cuenta el pensamiento de las bases partidistas: las estrategias son establecidas desde arriba y desde el núcleo formado por el candidato según sus elecciones personales. Es sin duda un funcionamiento que abre paso a la profesionalización, con la participación de personas que pueden no tener vínculos con 
el partido o que hace poco estaban en campo opuesto. Esa práctica reduce el estímulo a la participación de los miembros partidistas, puesto que de hecho cabe al líder la efectiva decisión sobre el rumbo a seguir. Así es que las reuniones son poco frecuentes, exceptuándose el período de las campañas, cuando el miembro es otra vez valorizado.

El mismo papel del núcleo central puede cambiar según quien va presentarse a las elecciones. En 2006, la estructura de campaña planificada para el caso de José Serra ser candidato fue sustantivamente modificada a partir de la definición de Geraldo Alckmin como el nombre del partido. Antes de ser un núcleo de la confianza de la dirección general del partido, debe ser de la estrecha confianza del candidato. Es revelador el caso de Antonio Lavareda, analistas de encuestas que trabajaba con PSDB desde 1994 y contaba con la estricta confianza del presidente del partido, el senador Tasso Jereissati. A pesar de ello, Alckmin prefirió recurrir a otros profesionales de su entorno personal.

En ese sentido, PSDB guarda diversas características del partido profesional-electoral: los profesionales son estratégicamente importantes, aunque la coordinación general de campaña sea siempre de alguien del partido y vinculado al candidato; los lazos organizativos formales no se materializan en la práctica; se verifica la personalización del comando; los discursos se orientan por los problemas concretos (minuciosamente diagnosticados por encuestas y grupos focales) y la financiación está basada esencialmente en los grupos de interés.

iii) Cambios internos, menos democracia y más profesionalización en PT

La estructura de poder del Partido de los Trabajadores es innovadora para los patrones brasileños, al conciliar el proceso de deliberación con el centralismo democrático e incorporar diversas instancias de participación de los miembros ${ }^{78}$. La deliberación se da de modo descentralizado mientras el centralismo se pauta por la disciplina partidista y la jerarquía en la toma de decisión (Roma, 2006). El proceso es especialmente incluyente, donde los "núcleos de base" tienen papel importante en la relación del partido con los movimientos sociales. No es casual que la participación de

\footnotetext{
78 Roma (2006) relaciona entre las innovaciones de PT los "núcleos de base" (instancia de participación por local de moradía, sector de actuación, categoría funcional, etc), la contribución obligatoria de los afiliados, la idea del mandato como perteneciente al partido, la aceptación de las de tendencias internas y la elección directa de los dirigentes partidistas.
} 
los miembros esté por en cima de los 90\%, donde los comités municipales son la instancia de mayor participación, seguidos de los núcleos de base ${ }^{79}$.

Además, la descentralización no resta importancia a instancias nacionales, donde el Encuentro Nacional desempeña un papel importante como traductor de las decisiones generales debatidas desde abajo. Junto con la amplia participación hay la verticalización de las instancias, lo que hace aplicable las medidas disciplinarias. Y de hecho el incumplimiento de decisiones resulta en puniciones. Una de las más sonantes fue aún en 1985, cuando tres diputados dejaron el partido por desobedecer a la decisión de no votar en la elección indirecta que elegiría Tancredo Neves. En 1991 y 1992 fueron expulsadas las tendencias Causa Operaria y Convergencia Socialista, respectivamente. En 2005, en el debate sobre los escándalos del gobierno Lula, diversos miembros se vieron constreñidos a abandonar el partido, la mayor parte fundando el PSOL.

Esta distendida democracia interna ofrece una importante ventaja, desde el momento en que el partido pauta su actuación a partir de la legitimidad asegurada por las bases, capaces de traducir el sentimiento de gran parte de la sociedad. Sin embargo, las diversas instancias de decisión y un comando central colegiado - con la participación de representantes de las tendencias- resulta en complicadores en el momento de ejecución de las campañas. La diversidad ideológica vuelve casi imposible los consensos sobre muchos temas, además de retardar decisiones que sobre todo en las campañas cobran rapidez. Los intentos de profesionalización estancaban en los grupos más extremados, así como las propuestas y discursos eran guiados por las decisiones del Encuentro Nacional del partido, sin atención a la oportunidad electoral de cada propuesta. Esto queda en evidencia en la campaña de 1989, con propuestas polémicas (como el no pago de la deuda externa) y un discurso de tono clasista (críticas directas a los empresarios, calificados de explotadores de clase obrera).

El papel de la burocracia partidista en las campañas se manifiesta en el hecho de que todas las campañas tuvieron como coordinador general el presidente del partido, seguido por el Directorio Nacional. La coordinación de la publicidad electoral y de relación con los medios era responsabilidad de profesionales contratados, pero con limitaciones: hasta 1998, el coordinador de publicidad contratado era sobre todo un profesional vinculado al partido - caso de Paulo de Tarso en 1989 y 1994, y de Tony Contrim, en la elección de 1998-. La asesoría de prensa de las tres primeras campañas de Lula estaban bajo la responsabilidad de Ricardo Kotscho, respetado periodista, pero vinculado a PT desde su fundación -tanto que ocupó asesoría en la presidencia da República en el primero mandato de Lula-. En 2002, Kotscho dividió la función con

79 Datos de encuesta de la Fundación Perseu Abramo, vinculada al PT, disponibles en Roma (2006 159). 
André Singer, otro nombre desde siempre vinculado a PT, y que en 2006 asumiría en solitario la tarea de relación con los medios. En cuanto a la coordinación de la publicidad electoral, hay importante cambio en 2002 y 2006, cuando profesionales del mercado sin vínculo con el partido asumen el puesto.

Las características organizativas de PT en las tres primeras presidenciales son semejantes a la estructura de los partidos burocrático de masas: la burocracia partidista tiene papel central tanto en la planificación cuanto en la ejecución de las campañas; son fuertes los lazos organizativos con la afiliación, lo que revela un electorado fiel; la dirección es colegiada, desempeñando papel prominente; el discurso preserva el tono ideológico y la financiación es basada en la afiliación y actividades colaterales.

Después de 1994, el PT pasa por importantes cambios internos que resultan en la reducción del número de tendencias: además de la expulsión de algunos de los grupos más radicales de la izquierda del partido, hay el esfuerzo de fortalecimiento del grupo más cercano a Lula, el Campo Mayoritario -que se vuelve hegemónico y se hace capaz de imponer una directriz general al partido-. Las decisiones en las campañas pierden la característica colegiada. En 1998 los cambios empiezan a ser sentidos, cuando por la primera vez el núcleo de campaña es todo de personas de la confianza del candidato. Sin embargo, aún se mantienen rasgos del viejo PT, como el hecho de la coordinación de comunicación seguir en manos de profesionales vinculados al partido.

La profesionalización de PT se observa en las municipales de 2000, cuando consultores del mercado pasan a coordinar las campañas en los principales centros, como la de Marta Suplicy en São Paulo ${ }^{80}$. Desde entonces el partido se abre hacia nuevas alianzas, abandonando la directriz de otras elecciones que restringía las coaliciones a los partidos de izquierda. El discurso se pone más moderado y el partido es presentado como sinónimo de competencia administrativa, en el casi olvido de los temas claramente ideológicos. A partir de 2002, la estructura sufre grandes cambios. Aunque la burocracia partidista siga centralizando el poder de decisión, los profesionales de mercado ocupan importante espacio en el núcleo central, al tiempo que declinan (especialmente en 2006) los lazos con la afiliación. El tono ideológico, que disminuye desde 1994, en 2006 apenas se nota, en cuanto la financiación está soportada por los grupos de interés como otro partido cualquiera.

80 En entrevista al autor, el diputado y ex presidente de PT José Genoino apunta las municipales de 2000 como la primera campaña profesionalizada del partido. 


\subsubsection{El liderazgo partidista: el carácter del candidato como imagen de la campaña}

Así como las instituciones son fundamentales para la política, también tienen importancia los políticos, en especial en regiones como América Latina en que la personalización ocupa un lugar central y actores como los partidos no repiten la institucionalización encontrada en otros sitios, como los países de Europa. Desde esa perspectiva, Alcántara (2006: IX) subraya que "el reconocimiento del papel que desempeñan los políticos en el devenir de la propia política es una reivindicación necesaria acorde con los tiempos que corren en América Latina”.

Entre los políticos, los que ocupan la función de liderazgo influyen de modo más intenso en la política en general y en las campañas en particular, puesto que el líder ejerce doble papel: uno hacia dentro de la organización y otro hacia afuera (Nareta, 2001). En las campañas, el papel del líder en el escenario interno se refleja en la misma organización, como en el caso de Collor, en el cual todo partía desde el candidato. En cuanto al campo externo, el liderazgo es tanto más influyente cuanto más carismático sea. Incluso en partidos con matiz programático, como PT, el candidato con algo de carisma acaba por acaparar importante centralidad del foco de los mensajes, que se centran en su persona y algunos signos a él vinculados (en caso de Lula, cambio, esperanza, origen humilde y conocimiento de la realidad de la gente).

Por supuesto, el liderazgo no es un estado concreto, sino un fenómeno relacional que cambia según aspectos asociados a la trayectoria del político y las demandas del elector. Hoy Collor no tendría la receptividad de 1989 con el discurso de entonces sencillamente porque la imagen de moralizador y cambio no encajan más; y las demandas del elector son distintas. Es decir, votar por el liderazgo pasa por un proceso de evaluación que a su vez es un factor de difícil predicción por que incluyen aspectos como confianza y afectividad que pueden cambiar con un simple suceso ${ }^{81}$. Además, la evaluación pasa por aspectos no-políticos, como la apariencia exterior o el origen, este último uno de los soportes del posicionamiento de Lula sobre todo en 2002, en que fue presentado casi como un héroe que supera todas las adversidades hasta realizar la tarea para la cual está destinado ${ }^{82}$.

\footnotetext{
81 Las elecciones de 1989 y 2002 ofrecen dos ejemplos. En 1989, el candidato Afif Domingues (PL) presentaba importante crecimiento en las encuestas desde el posicionamiento de "constituyente nota 10", afirmando que votara por los interés de los trabajadores. La tendencia de alza se transforma en pérdida de popularidad cuando los adversarios revelan que Afif estuvo ausente en la votación de temas fundamentales a los trabajadores. En 2002, Ciro Gomes (PPS) desciende de la segunda hacia la cuarta posición en las encuestas tan pronto los medios revelan que datos biográficos por él presentados en la publicidad electoral eran falsos.

82 Sobre la comparación de la imagen de Lula en la campaña de 2002 con el mito del héroe griego, ver Rocha (2004).
} 
De hecho, el liderazgo es un producto social resultado de interferencia de una serie de variables, desde las características personales hasta las circunstancia políticas ${ }^{83}$. El liderazgo tiene destacada relevancia en los sistemas democráticos, sobre todo teniéndose en cuenta la progresiva personalización que hace que en las elecciones la escoja política del elector recae sobre el candidato mejor valorado o con características consideradas especiales.

i) Collor, el héroe de película como producto del marketing

Si el liderazgo es un producto social moldeado por las circunstancias, Collor se convierte en el héroe que se traduce en la esperanza de un Brasil envuelto en la crisis y la frustración. La Nueva República ${ }^{84}$, instalada con la redemocratización en 1985, era depositaria de las esperanzas nacionales, esperándose cambios en las políticas económica y social (sobre todo el combate a la inflación y la generación de empleo) y en el campo moral (traducida en la lucha contra la corrupción). A finales del mandato de Sarney, sin embargo, la inflación seguía descontrolada, los problemas sociales se habían agravado y la corrupción parecía mayor que nunca. Collor asume la fantasía de héroe para ofrecer la perspectiva de un Brasil Nuevo -término que utilizaría en los discursos de campaña y sería el slogan de su gobierno- y enciende otra vez las esperanzas del país.

La imagen del candidato es construida como producto que se ajusta al momento político. Así es que se posiciona como un nombre distanciado de los partidos y casi un antipolítico, a pesar de tener origen en una familia política y en los partidos tradicionales ${ }^{85}$. Con el soporte de los grandes medios, logró presentar al Brasil un personaje de ficción que se apropia de las demandas de la ciudadanía. Personaje carismático, arrebató las masas como una especie de Indiana Jones vendido en cada mensaje electoral (Melo, 1994). En la campaña, el candidato valiente y carismático era lo que contaba; lo demás -partido o programa de gobierno- no pasaban de meros accesorios.

83 Natera (2001) presenta las principales aportaciones sobre la construcción y actuación de los liderazgos. Sobre el liderazgo populista, tan presente en América Latina, ver Freidenberg (2007).

${ }^{84}$ El término fue acuñado por Tancredo Neves en su primero discurso luego de la elección por el Colegio Electoral, el 15 de enero de 1985, con el propósito de firmar la idea de una nueva fase en la vida política nacional. A pesar de fallecer antes de asumir la presidencia, su vicepresidente José Sarney siguió utilizando el término.

${ }^{85}$ Collor fue integrante de Arena, después de PDS y de PMDB. También era nieto e hijo de político, además de tener ocupado el puesto de diputado federal, alcalde de la ciudad de Maceió y gobernador de Alagoas. A pesar de eso, trabajaba la imagen de antipolítico, posicionándose como novedad de a política, aunque no fuera. 
Los spots electorales presentan Collor como valiente y determinado, imagen que tiene cómo credencial el trabajo contra los marajás de Alagoas. Es decir, como una inequívoca credencial de que era valiente lo bastante para enfrentar el descalabro de corrupción que tomaba cuenta del país. En el foro interno de la campaña, ejercía el comando personal y autoritario, distribuyendo tareas entre los auxiliares, en seguida cobrando el cumplimiento de las atribuciones en un perfil cercano al ejecutivo de empresas.

La imagen de valiente refuerza el discurso personalista: las propuestas se resumen casi al mismo candidato y las referencias a su imagen de Indiana Jones, dispuesto a enfrentar a quien sea con el objetivo de transformar el país. Algunos mensajes electorales presentan el candidato mirando hacia la cámara y enseñando la muñeca cerrada, en señal de disposición de lucha; otras veces, aparece caminando rápido, traduciendo la prisa y el dinamismo que el país cobraba. Es un héroe de película, que utiliza toda la potencialidad de la televisión para reforzar la percepción construida en los dos años anteriores.

Uno de los elementos traductores de las estrategias es el jingle, que ocupa especial importancia en las campañas por ofrecer el posicionamiento y la posibilidad de construcción de un clima emocional capaz de involucrar la gente ${ }^{86}$. Un ejemplo referencial en la historia política brasileña es el jingle de Jânio Quadros, en 1960, que utilizaba tan solo el símbolo de la campaña -la escoba, instrumento utilizado para limpiar la suciedad- y el nombre del candidato ${ }^{87}$. Una nueva solución no muy distante, el jingle de Collor se resume a su propia persona y a la esperanza de cambio que inspira, traducida en la lucha contra los “marajás". Sencillamente, es esta la letra del jingle:

"!Oh, Collor! Chegou a hora de acabar com os marajás. iOh, Collor! Vamos botar tudo de novo no lugar. iOh, Collor! Dia 15 o Brasil vai colorir. E vai dar Collor do Oiapoque ao Chuí. Chegou a hora" 88 .

86 Sampaio (2003) destaca el poder de comunicación de los jingles, por la capacidad de ser internalizado: la gente escucha, memoriza y lo repite mentalmente después. Sobre los jingles políticos, ver también Mendonça (2001).

87 El jingle de Jânio Quadros decía sencillamente: “Varre, varre, varre vassourinha/ Varre, varre a bandalheira/ Que o povo já está cansado de sofrer desta maneira/ Jânio Quadros é a esperança deste povo abandonado" [en español, "Barre, barre, barre escobita/ Barre, barre la pandillaje/ que el pueblo ya está cansado de sufrir de esa manera/ Jânio Quadros es la esperanza de esa gente abandonada"].

88 En una traducción libre: “'Oh, Collor! Llegó la hora de acabar con los maharajás. ¡Oh, Collor! Vamos poner todo otra vez en su sitio. ;Oh, Collor! En el día 15 Brasil va colorir. Y va dar Collor 
ii) Cardoso, Serra y Alckmin, la competencia técnica como posicionamiento

Los tres candidatos de PSDB de las campañas de 1994 a 2006 tienen un perfil semejante, un vínculo con la vida intelectual (en el caso de Cardoso y Serra, profesores de universidad), conocimiento técnico y administrativo (Cardoso como creador del Real; Serra como ministro de Sanidad aplaudido en todo el mundo, especialmente en la lucha contra el Sida ${ }^{89}$ y Alckmin por sonantes realizaciones como gobernador de São Paulo, además de médico). Cada uno a su modo, los tres se presentan como cambio.

Cardoso es vendido en 1994 como el cambio en curso, es decir, como el hombre que acabara de implantar el Real y reunía las credenciales para consolidar ese importante cambio en la economía del país90; otra vez en 1998 se apega a la necesidad de consolidación del Real, ahora ofreciendo como plato principal la generación de empleo. En 2002, Serra se presenta como el "cambio seguro" y hace del empleo casi tema único de la campaña, puesto que era el principal problema de aquel momento; pero el intento no se reveló verosímil sobre todo delante de un adversario como Lula, que presentaba la idea de cambio con más credibilidad porque oposición ${ }^{91}$. En la publicidad electoral de 2006, Alckmin es la alternativa al gobierno Lula, posicionado por el tucano como un descalabro administrativo, discurso que no obtiene la resonancia esperada sobre todo junto al segmento popular.

Los tres utilizan un tono tecnicista, con declaraciones a veces extensas y postura profesoral, manifiesta sobre todo en los pronunciamientos de Serra en 2002. Además Serrra y Alckmin ocupan demasiado tiempo en largos discursos en tono duro, casi como un presentador de telediario, sin ofrecer una idea de complicidad con el elector o calor humano. Es como si siempre hablara el técnico, el administrador que desea dejar evidente el conocimiento sobre el tema que trata.

Ese tipo de postura contrasta con Collor, que hablaba a cada uno de los espectadores con un "mi gente" o la frase "ahora somos nosotros, yo y tu" para reforzar una idea de

del Oiapoque al Chuí. Llegó la hora". El Oiapoque y el Chuí son, respectivamente al norte y al sur, los puntos extremos del territorio brasileño.

${ }^{89}$ La publicidad electoral explotó el hecho de Serra haber recibido el premio de Naciones Unidas por su lucha contra el Sida, incluyendo la quiebra de las patentes de medicinas administrada a los paciente seropositivos.

90 Sobre la idea de "cambio en curso", ver Rocha (2004).

91 En 2002, la publicidad de Serra afirma que "el nombre del cambio" es el empleo y que José Serra es el hombre cierto para realizar ese cambio. Serra se apega a la idea de "cambio sin atropellos" como un intento de ocupar el posicionamiento referencial de Lula, candidato de oposición. Sobre esa fracasada estrategia de Serra, ver Almeida (2004). 
cercanía al elector; o de Lula, que desde la primera campaña utilizaba un lenguaje coloquial, tratamiento cercano y, desde 1998, un tono simpático que es sencillamente una charla con viejos amigos. Ese tipo de cercanía no se encuentra en el lenguaje tecnicista de los candidatos de PSDB, ninguno con carisma suficiente que garantizase una postura que podría ser traducida como "uno de nosotros".

En la publicidad tucana, los jingles son personalista, pues así exige la cultura política brasileña, pero añaden un tono programático que los hacen más técnicos que emocionales. Se encuentra un poco más de calor humano en los jingles de Cardoso. En 1994, el tema musical afirma que "está en nuestras manos hacer Fernando Henrique presidente", una frase que pone el elector dentro de la campaña. Sin embargo, en el mismo jingle el refrán es más distante: "levanta la mano, levanta la mano/ Fernando Henrique es el Brasil que va vencer" 92 . El discurso distanciado de la gente es agravado por la legislación que permitía tan solo la aparición del candidato. Así, el video asociado a la música reúne imágenes de trabajo en plan cerrado o tan sólo manos que se levantan. En 1998, Cardoso adopta tono semejante, incluso manteniendo la mano como símbolo. La diferencia está en los videos que ponen imágenes de gente corriente como un esfuerzo de acercamiento más directo al elector 93 .

En 2002, Serra radicaliza y además de hacer del empleo su tema casi solitario utiliza el principal jingle como soporte de la propuesta de creación de puestos de trabajo. El tema musical es presentado por cantantes conocidos -como Elba Ramalho, Xitãozinho \& Xororó y el grupo KLB- y el símbolo pasa a ser el carné del trabajador. El tema explota el lunes como un día de felicidad, precisamente porque en Brasil es conocido como "el peor día de la semana" por la vuelta al trabajo. Como el trabajo es el sueño de la gente, el jingle dice:

"Hoje é segunda-feira/ dia de alegria.

Num mundo de medo

Quem tem um emprego

Adora esse dia.

\footnotetext{
92 El jingle en la íntegra, en Portugués: “Está na sua mão, na minha mão, na mão da gente/ fazer de Fernando Henrique o nosso presidente./ Levanta a mão, levanta a mão/ Fernando Henrique é o Brasil que vai vencer".

93 El jingle de 1998 dice: Levanta a mão e vamos lá,/ o Brasil tá caminhando e não pode parar./ Quero avançar, seguir em frente/ reeleger Fernando Henrique presidente./ Ele plantou a semente do futuro./ É o pulso firme nesse tempo turbulento./ Está fazendo o Brasil pra todo mundo,/ mais felicidade é construção que leva tempo" [en español, "Levanta la mano y vamos allá, el Brasil está caminando y no puede parar. Él plantó la semilla del futuro. Es pulso firme en esos tiempos turbulentos. Está haciendo el Brasil para toda la gente, pero felicidad es construcción que lleva tiempo"].
} 
Poder olhar pra frente

Ter uma profissão

Zé Serra presidente é

Trabalho, trabalho, trabalho, trabalho, trabalho, trabalho

Pra gente" 94.

El tono programático refuerza la percepción sobre la capacidad técnica, aun más cuando al fin del tema musical añade: "el nombre del cambio es empleo y el hombre para hacer ese cambio es José Serra”.

Geraldo Alckmin sigue la misma línea de eficiencia técnica y un lenguaje formal y poco emotivo. La mayor parte de las veces, habla en una mesa de trabajo, enfatizando el papel del administrador. En cuanto a los jingles, empieza la campaña con un tema musical que posiciona el candidato como un hombre de origen humilde ("un brasileño, un mozo simple venido del interior... que trabajó para se hacer doctor"), pero luego se destaca el jingle asociado a las realizaciones en el gobierno de São Paulo: siempre que hablaba de un programa administrativo realizado como gobernador, el tema musical repetía el refrán "ahora Geraldo va llevar para el Brasil”. Aunque el refrán fuese acompañado de imágenes de gente corriente, la parte más sustantiva de los videos eran siempre las obras, presentadas desde panorámicas y edición fragmentada con el intento de evidenciar dinamismo. Casi como se Alckmin fuera un hombre-máquina.

iii) Lula, el mítico héroe hijo del pueblo: discurso al corazón de la gente

A pesar de ser PT el único gran partido que busca el voto partidista en la política brasileña (Samuels, 1999), Lula siempre ha sido el centro de las campañas no sólo por la cultura personalista de la política brasileña sino por un carácter carismático que hizo del líder petista la referencia del Partido de los Trabajadores y en punto de convergencia de las diversas tendencias que formaron la organización. Además del carisma, la preocupación de no enfrentarse a ninguna de las tendencias siempre ha sido cultivada por Lula, incluso cuando esas tendencias impusieron fragorosa derrota as las

\footnotetext{
${ }^{94}$ En español: "Hoy es lunes, día de alegría. En un mundo de miedo quien tiene un empleo adora ese día. Poder mirar hacia delante, tener una profesión. 'Zé' Serra presidente es trabajo, trabajo, trabajo, trabajo para nosotros".
} 
intenciones del mismo líder del partido, como pasó en el Encuentro Nacional de 1994, ya a la víspera de la campaña ${ }^{95}$.

Las tendencias que se enfrentaban dentro de PT nunca cuestionaron la posición referencial de Lula, figura que siempre ha sido más grande que el partido. Esa posición destacada se refleja en las campañas, cuyo discurso es ajustado a la imagen e historial del candidato, enfatizándose su origen de trabajador, de emigrante del Nordeste que sufrió las dificultades en los grandes centros urbanos y del sindicalista que dedicó la vida a luchar por mejores condiciones de vida para la gente. La centralidad de Lula y su trayectoria particular se manifiesta en el programa que PT exhibió en abril de 2002, cuando el mismo candidato habló del dolor de la pérdida de su primera mujer en la víspera del alumbramiento. Entre lágrimas, Lula admite que una mejor atención en los hospitales podría haber evitado la tragedia. Ese drama es rescatado en la publicidad electoral.

El tono utilizado por Lula en la publicidad electoral siempre ha sido personal y intimista, firmando una idea de cercanía. En la campaña de 1989, la orientación hacia la ideologización del debate hace que los discursos sean más vinculados al sindicalista que conoce la realidad del trabajador; está siempre a denunciar los "poderosos" que explotan el trabajador. En las campaña siguientes, la referencia al trabajador queda encubierta por un discurso más abarcante, que se ajusta al ciudadano de a pie, sin recurrir al discurso clasista. Y el tono se pone más y más intimista, resultando cariñoso incluso cuando trata de temas negativos como el paro.

En 1998, uno de los spots sueltos exhibidos por la campaña de Lula trataba precisamente del desempleo. En close, faz serena y voz suave, el candidato apela: "tu que tienes desempleado en tu familia, da una oportunidad para tu propio". Entonces habla de la necesidad de cambiar y arremata: "yo necesito de tu voto". En 2002, el primero programa electoral da una muestra de como el hombre Lula guía la imagen del político: antes de pronunciar la primera habla de la campaña, el candidato camina por es escenario poblado por la equipe responsable por el programa de gobierno. Lula habla al pie del oído con el entonces diputado (hoy senador) Aloizio Mercandante en gesto cómplice y sólo entonces empieza a hablar para la cámara. Es un gesto que dice más del hombre que del político.

\footnotetext{
95 En ese Encuentro de mayo de 1994, que definió las directrices de PT de cara a las presidenciales de octubre, los sectores más radicales lograron salir victoriosos y aprobar propuestas como el no pago de la deuda externa, en contra las pretensiones del grupo más cercano a Lula. Ver Dimenstein y Souza (2004).
} 
El Lula cercano está presente en los jingles de las cinco campañas. En el tema musical de 1989 -que es utilizado hasta 2006- hay referencia al partido, pero indirecta, al hablar de la estrella, símbolo de PT. El foco principal es de hecho el candidato:

\author{
"Lula lá, brilha uma estrela \\ Lula lá, cresce a esperanza \\ Lula lá, o Brasil crianza \\ Na alegria de se abraçar \\ Lula lá, com sinceridade \\ Lula lá, com toda a certeza pra você \\ Um primeiro voto \\ Pra fazer brilhar nossa estrela \\ Lula lá, muita gente junta \\ Valeu a espera" ${ }^{96}$.
}

En 1994 y 1998, se refuerza el vínculo Lula/pueblo. El de 1998 es todavía más explícito: "Lula sou eu, Lula é a gente, coração brasileiro"97. El jingle de 2002 rescata el enfoque partidista ("pone esa estrella en el pecho, no tenga miedo o pudor"), pero sin dejar de enfocar la persona del líder y de buscar mezclarlo con el pueblo:

"Bote essa estrela no peito,

Não tenha medo ou pudor.

Agora eu quero você,

Te ver torcendo a favor.

A favor do que é direito,

Da decência que restou.

A favor de um povo pobre,

Mas nobre trabalhador.

É o desejo dessa gente

Querer um Brasil mais decente.

Ter direito à esperanza

\footnotetext{
${ }^{96}$ En una tradución libre: “Lula allá, brilla una estrella/ Lula allá, crece la esperanza/ Lula allá, el Brasil niño/ En la alegría de se abrazar/ Lula allá, con sinceridad/Lula allá, con toda la certeza para ti / Un primero voto/ Para hacer brillar nuestra estrella/ Lula allá, mucha gente junta/ Valió la espera". Como se ya ha dicho, el "lá" [allá] es una referencia a un objetivo mayor, a un sueño alcanzado.

97 En español: “Lula soy yo, Lula es nosotros, corazón brasileño”
} 


\author{
E uma vida diferente. \\ É só você querer. \\ É só você querer, \\ Que amanhã assim será. \\ Bote fé e diga Lula, \\ Bote fé e diga Lula, \\ É Lula" 98 .
}

Finalmente, en 2006 la campaña de PT resalta el trabajo de Lula por el pueblo, su vínculo con la gente de a pie y junta el destino de los dos. Así, el tema musical es categórico: "É Lula de novo com a força do povo" [Es Lula otra vez, con la fuerza del pueblo]. La campaña otra vez es la imagen del candidato.

98 En español, "Ponga esa estrella en el pecho,/ no tengas miedo o pudor./ Ahora yo quiero a ti,/ verte vibrando a favor./ A favor del que es derecho,l de la decencia que quedó./ $A$ favor de un pueblo pobre,/ pero noble trabajador./ Es el deseo de esa gente / querer un Brasil más decente./ Tener derecho a la esperanza / y una vida diferente./ Basta que tu quieras/ Basta que tu quieras, que mañana así será./ Tenga fe y digas Lula/ tenga fe y digas Lula/ es Lula". 
PARTE III

\section{Organización y Comunicación en las campañas brasileñas}





\section{Las dimensiones organizativas}

\section{Resumen:}

El capítulo trae las evidencias de las dimensiones organizativas en las diez campañas analizadas, enfocando los indicadores que traducen la profesionalización en la estructuración de las campañas. Son analizados el nivel de centralización de los comandos, la presencia de los consultores del mercado, el plazo de planificación, el tipo de financiación (si voluntaria o por grupos de interés), el uso de encuestas y grupos focales, el entrenamiento de candidatos y militantes, la participación de la afiliación y el uso de nuevas tecnologías. El análisis revela grados distintos de profesionalización en algunos de esos indicadores según la campaña, pero queda clara la evolución por la cual pasan, sobre todo el uso de las nuevas tecnologías. Los consultores tienen destacada presencia, aunque sin el protagonismo encontradas en experiencias como la estadounidense. También se verifica fuerte presencia del capital como camino hacia el éxito: los grupos de interés son los financiadores de todas las campañas victoriosas. 



\subsection{Introducción}

Las campañas electorales brasileñas alcanzan un nivel muy alto de organización, especialmente si se las compara con otros países de América Latina. En Brasil es posible observar un fuerte desarrollo de la industria de la consultoría política, compuesta por profesionales experimentados en un mercado de comunicación maduro y competitivo (Queiroz, 2006b); profesionales que además cuentan con formación técnica específica en ese campo, a través de los cursos de publicidad y marketing o expertos en comunicación institucional y relaciones públicas. Esta realidad no escapa al marketing político, el cual también presenta un alto nivel de sofisticación en los diversos sectores técnicos vinculados a la planificación, producción publicitaria, encuestas o las relaciones con los medios ${ }^{1}$. Estos últimos son una parte fundamental del proceso político contemporáneo, ocupando lugar central en la política brasileña de las últimas décadas y configurando la Idade Media -o la Edad de los Medios- que ha descrito Rubim (2000).

Esta configuración es resultado del desarrollo que se efectúa de modo acelerado desde la década de 1980, cuando se establecen nuevas condiciones competitivas tras la redemocratización. Los cambios se pueden apreciar en los rasgos organizativos y comunicacionales de las campañas electorales de ámbito nacional, a pesar de una legislación que impone restricciones a los candidatos y partidos. Sin embargo, la profesionalización que se va a concretar en las dos últimas décadas del siglo XX es -en realidad- la consecuencia lógica de la evolución en las prácticas de campañas que tienen sus primeras manifestaciones en el imperio, cuando el Partido Republicano utiliza novedosas técnicas de propaganda y recursos de acercamiento al elector ${ }^{2}$. La fase de la República Populista ${ }^{3}$ es un peldaño importante en la evolución. En ese período están

\footnotetext{
${ }^{1}$ Para una visión general sobre la evolución del marketing político en Brasil, ver Queiroz (2006).

2 El lanzamiento del Partido Republicano, en 1870, fue acompañado por cuidada estrategia tanto en la organización como en las acciones de comunicación. En ello tuvieron un papel fundamental Prudente de Moraes y Campos Sales, quienes después serían los primeros presidentes elegidos de Brasil. Entre las novedodas acciones desarrolladas, los republicanos formaron una red de 74 periódicos, asociaban los mensajes doctrinarios con el personalismo y utilizaron un rudimentario catastro de electores con los cuales establecían comunicación dirigida. Algunas de esas estrategias de propaganda también son utilizadas por los republicanos durante sus mandatos en la presidencia. Para un mayor conocimiento, ver Romanini (2006), Corte Real (2004) y el relato del mismo Campos Sales (1998), edición facsimilar del Senado).

${ }^{3}$ La República Populista es el período entre la 1945 y 1964, cuando destacan líderes populistas y carismáticos (Getúlio Vargas, Juscelino Kubitschek, Jânio Quadros y João Goulart). Es uno de los períodos más democráticos de Brasil, interrumpido por el golpe de 1964.
} 
dos de las más ricas experiencias de campañas en Brasil: las de Juscelino Kubitschek (1955) y de Jânio Quadros (1960), con la formación de estructuras organizativas diferenciadas y el uso de técnicas de comunicación con algún grado de sofisticación. Kubitschek hace de la radio y del cine uno de sus diferenciales, además de realizar toda la campaña con un avión DC-3 adaptado a las necesidades del candidato4. Quadros adoptó una comunicación folclórica y populista, pero minuciosamente planificada. Como simplificación de los mensajes, utilizó un símbolo que traducía su propuesta de cambio: la escoba, reproducida en carteles, panfletos, bottons, porta-llaves y en el jingle hasta hoy considerado un ícono entre las campañas brasileñas (Grossi, 2006).

El período de dictadura militar (1964-1985) frena la evolución, pero el retorno de las disputas por los gobiernos estaduales en 1982 trae de vuelta las campañas como etapa fundamental de la vida política nacional. La candidatura presidencial de Tancredo Neves (1984-85) es otro marco de esa evolución: aunque indirecta, la campaña de Neves tuvo la preocupación de establecer una comunicación con la ciudadanía no sólo para que el sentimiento del pueblo influyese en el comportamiento del restricto colegio electoral sino también para la búsqueda de legitimidad en un mandato indirecto. La campaña utilizó importantes herramientas del moderno marketing político, tanto en el cuidado posicionamiento como en la elección de símbolos y colores (Oliveira, 2006).

La madurez llega con las elecciones directas de 1989, sobre todo con la campaña de Fernando Collor, guiada por las directrices del marketing: planificación de largo plazo, alta mediatización, amplia personalización, uso de encuestas y grupos focales y movilización de altísimas sumas de recursos financieros ${ }^{5}$. Desde entonces se estableció un nuevo patrón técnico con la amplia adopción de recursos consagrados en el marketing comercial y usados por la política en muchos otros sistemas democráticos, principalmente en América del Norte. Si desde la década de 1940 las encuestas forman parte de la política brasileña ${ }^{6}$, es a partir de las primeras elecciones presidenciales de la actual fase democrática que los partidos y candidatos van hacer de los sondeos un recurso ordinario, además de adoptar otros mecanismos de evaluación del escenario electoral, como los grupos focales.

\footnotetext{
${ }^{4}$ EI DC-3 contaba con despacho que llevaba incluso una pequeña biblioteca con diversificado acervo, influyendo desde datos sobre la realidad nacional hasta publicaciones sobre propaganda política. Contaba aun con espacio para los invitados políticos y periodistas. Para más detalles sobre la innovadora campaña de 1955 de Juscelino, ver Picolin (2006) y la autobiografía de Kubitschek (Meu caminho para Brasília: a escalada política. Rio de Janeiro: Bloch, vol. II).

${ }^{5}$ Sobre la campaña de Collor, especialmente sobre la relación con los medios y el sector empresarial, ver Conti (1999). Para una visión desde dentro, ver Rosa e Silva (1993).

${ }^{6}$ El pionero en Brasil en las encuestas electorales fue el Ibope, instituto creado en Brasil en la estela del éxito del Gallup en Estados Unidos. Ver trayectoria del instituto en www.ibope.com.br.
} 
La redemocratización consolida la industria de la consultoría que apenas estaba presente en las elecciones de gobernador en 1982 y 1986. Hoy el sector reúne un gran número de empresas que viven de la política. La Asociación Brasileña de Consultores Políticos, ABCOP, creada en 1991, reúne 107 profesionales que dirigen empresas con dedicación integral al negocio de la consultoría política, actuando en áreas tan distintas como planificación, relación con los medios, creación de jingles, encuestas, entrenamiento, estructuración de comités electorales, telemarketing y correo dirigido ${ }^{7}$.

\subsection{El comando de las campañas: centralización vs. descentralización}

La centralización del proceso de toma de decisión es uno de los indicadores del nivel de profesionalización de las campañas. En el caso de las campañas brasileñas, ese rasgo revela que están a medio camino de la efectiva profesionalización. Según la literatura, el comando de una campaña profesional atiende a dos características fundamentales: la centralización en un núcleo nacional y la presencia de expertos sin vínculo partidista (Norris , 2004; Gibson y Römmele, 2001). En una composición ideal, los expertos integran ese núcleo directivo, respondiendo básicamente al candidato o liderazgo partidista, apenas tomando en cuenta a los afiliados. El núcleo debe ser nacional -dirigido por un consultor estrella- y tiene la función de hacer toda la coordinación estratégica y gerencial, determinando el rumbo de la candidatura. A ese núcleo central se vinculan otros profesionales de las diversas áreas de consultoría, instrumentalizando el comando general de las informaciones y herramientas necesarias al buen curso de la campaña.

En las prácticas de campaña encontradas en Brasil, la centralización nacional es verificada en todas las campañas, con algún grado de descentralización que sigue las orientaciones del núcleo central. En cuanto a ese comando nacional, sin embargo, se divide entre una representación política y una profesional, aunque se note una evolución desde 1989 hasta 2006 para el caso de PT (Cuadro 5.1). El coordinador político suele ser en la práctica el gestor de la campaña, respondiendo más que nadie por la organización misma y la operacionalización de las tareas. Esa organización suele ser jerarquizada, con diversos subcoordinadores -afiliados o no- responsables por

\footnotetext{
7 Datos de Carlos Augusto Manhanelli, presidente de la ABCOP y director de la Manhanelli \& Asociados ( $w w w . m a n h a n e l l i . c o m . b r$ ), empresa con dedicación exclusiva a la consultoría política. Manhanelli fue entrevistado en dos momentos (diciembre de 2006 y junio de 2007), por correo electrónico. Vale añadir que importantes profesionales del sector -como Duda Mendonça y Nizan Guanaes- no están afiliados a la asociación de consultores políticos, sino a la que reúne los profesionales de publicidad.
} 
áreas como recaudación y gastos, movilización, definición de la agenda del candidato y la organización de los mítines a lo largo del país.

Todos los coordinadores sectoriales responden a la coordinación general, incluso el coordinador de marketing y comunicación. Este último es -quizás- el único que puede disfrutar de cierta autonomía para actuar, gestionando aquella parte de la campaña referida a la visibilidad, a la producción y distribución de los mensajes electorales, además de gestión de los datos de encuestas y grupos focales (producidos por empresas especializadas) que van orientar las acciones de comunicación. Por su parte, el coordinador general responde al candidato, incluso porque suele ser de su estrecha confianza. Vale notar la excepción del PT, donde el coordinador general siempre es el presidente del partido, aunque se puede decir que solamente en 1989 y 1994 esos coordinadores no eran la primera opción de Lula. Otra particularidad es el papel del tesorero o recaudador de las campañas, que nunca es un profesional: por la práctica de contabilidad paralela entre candidatos y donantes, el tesorero es alguien del círculo personal del candidato, que habla y se compromete con los donantes como si fuera el candidato.

CUADRO 5.1

\section{Estructura de mando en las campañas brasileñas}

\begin{tabular}{ll}
\hline Estructura Nacional & $\begin{array}{l}\text { Adoptada por todas las campañas desde 1989. } \\
\text { El comando nacional establece las directrices; los núcleos } \\
\text { regionales operacionalizan las acciones teniendo esas directrices } \\
\text { como referencia. }\end{array}$ \\
\hline $\begin{array}{l}\text { Centralización de las } \\
\text { decisiones }\end{array}$ & $\begin{array}{l}\text { Centralización en un núcleo cerrado alrededor del líder o } \\
\text { candidato: es caso sobre todo de la campaña de Collor, pero las } \\
\text { decisiones quedan en manos de un grupo cerrado también en } \\
\text { todas las campañas de PSDB y las dos últimas de PT } \\
\text { Centralización, pero bajo comando colegiado: caso de PT hasta } \\
\text { 1998. }\end{array}$ \\
\hline Comando central dividido en dos ramas: el político y el de \\
marketing, pero con predominio del político. \\
El comando político toma en cuenta aspectos partidistas (sobre \\
todo en caso de PT y algo en caso de PSDB) pero es marcado \\
especialmente por la cercanía al candidato. \\
El comando del marketing es la principal cara profesional de las \\
campañas, en todas las campañas de PSDB, en las de PT desde \\
2002 y especialmente en la campaña de Collor.
\end{tabular}

Fuente: elaboración propia.

De las diez organizaciones de campañas analizadas, todos los casos indican la centralización del comando a nivel nacional, verificándose la descentralización de 
operaciones de modo controlado, tanto cuando los operadores regionales son los líderes políticos tradicionales (como pasó con Collor, las campañas de PSDB y las dos últimas de Lula) o asociaciones del movimiento popular, especialmente los sindicatos (como en las tres primeras campañas de Lula). Pero si la literatura considera la centralización organizativa una característica de la profesionalización, en Brasil ese elemento representa una profesionalización a medias, puesto que en ninguna de las diez campañas se ha generado un comando enteramente profesional, conciliando la presencia de representantes políticos y expertos en campañas con el selecto grupo que toma las decisiones fundamentales.

Incluso en la campaña de Collor, la más profesional en términos de organización, las tareas estaban divididas. La coordinación general siempre estuvo en manos del mismo Collor (secundado por Renan), aunque la estructura organizativa básica fuera formada ya en 1987, con la presencia de profesionales. Ese grupo estaba compuesto por el periodista Claudio Humberto, con la tarea de establecer las buenas relaciones con los medios; Marcos Coimbra (socio-presidente del instituto Vox Populi de opinión pública), el principal analista de las encuestas; Marcos Antonio Coimbra y Leopoldo Collor de Mello (hermano del candidato), responsables por las articulaciones con el sector empresarial en general y con la rama de la comunicación, en particular, puesto que Leopoldo siempre tuvo actuación en el campo de la televisión, con estrecha relación con las organizaciones Globo.

Ese grupo se amplia en la fase de campaña oficial, pasando a tener cuatro principales bases profesionales (no política) de operacionalización: además del Instituto Vox Populi, que realizaba y analizaba las encuestas, estaban la ZLC, empresa de consultoría económica radicada en São Paulo, con acceso a los grandes empresarios y también responsable de la planificación económica; la Setembro Propaganda, agencia de publicidad actuando en el diseño de los mensajes políticos, incluso de los mensajes exhibidos en TV en la fase de precampaña, y la CAP Software, responsable del desarrollo de programas de ordenador utilizados en la gestión de los datos. Específicamente para el diseño y producción de los programas de la fase electoral, la campaña contrató a Chico Santa Rita, uno de los pioneros del marketing político en Brasil, y a Belisa Ribeiro, periodista y ex empleada de TV Globo, con historial de participación en campañas electorales, como la elección de Moreira Franco al gobierno de Rio de Janeiro en 1986. El recaudador fue un antiguo amigo de Collor, el empresario alagoano Paulo César Farias.

La autonomía del equipo no era plena, tanto que en la segunda vuelta el núcleo duro básicamente los que estaban con Collor desde 1997 y especialmente el candidato- 
decidieron ampliar la publicidad negativa luego de una encuesta que apuntaba la posibilidad real de victoria de Lula. Se decidió entonces apelar al discurso ideologizado pautado en la estrategia del miedo contra el "radicalismo de Lula"8 y el uso de la polémica declaración de una ex novia del petista ${ }^{9}$. Ese episodio, quizá la página más sucia de las campañas presidenciales en Brasil, determinó el alejamiento de Belisa Ribeiro del núcleo central de marketing, ya que estaba en contra de esa decisión. En ese caso, Santa Rita coge las riendas de la tarea decidida en el estricto círculo personal del candidato $^{10}$. Esas acciones de los últimos días resultaron decisivas, complementadas por un soporte mediático favorable a Collor, como quedó claro en la tendenciosa edición que TV Globo hizo sobre el último debate.

Las campañas de PSDB utilizaron estructuras organizativas semejantes a las de Collor: los profesionales fueron parte importante del comando, especialmente en la comunicación y el marketing, pero el núcleo partidista y las personas de confianza del candidato tuvieron un protagonismo innegable. Así, el coordinador efectivo de la campaña de Cardoso en 1994 fue Sérgio Motta, vinculado al núcleo paulista de PSDB y viejo amigo e incluso socio de aventuras empresariales del candidato. El coordinador de publicidad electoral fue Geraldo Walter, publicista paulista. Junto a él estaban otros nombres conocidos de la publicidad, como Nizan Guanaes y Einhardt Jácome.

Ya en la presidencia y mirando con antelación hacia la campaña de reelección en 1998, Cardoso contó con el soporte de dos coordinadores efectivos: Motta como operador general de la organización y el diputado Luís Eduardo Magalhães -afiliado al PFL e hijo del cacique Antonio Carlos Magalhães- como articulador político en el Congreso. La muerte de los dos coordinadores, en abril de 1998, no cambió la relación: otros

8 Figueiredo (1994), que fue consejero de Collor en la campaña de 1989, revela la participación directa del candidato en la ideologización de la campaña. En acciones complementarias -en los mitines y principalmente en el boca a boca de reuniones por todo Brasil-, Lula era calificado de comunista, término que asumió mayor importancia ya que la segunda vuelta que tuvo lugar pocos días después de la caída del muro de Berlin. Además, los rumores esparcidos por la campaña de Collor respecto a que Lula cambiaría la bandera nacional por una de color rojo y dividiría los bienes de la gente: quien tuviese casas de dos pisos, se quedaría sólo con uno, y cosas por el estilo.

${ }^{9}$ En el mensaje, exhibido los días 13 y 14 de diciembre, Miriam Cordeiro, la ex novia de Lula y madre de su hija mayor, dice que el petista -viudo en la época de la relación- cuando supo que estaba embarazada la incentivó a hacer un aborto, prohibido en Brasil, y luego la abandonó puesto que decidió mantener el embarazo. Lula evitó seguir ese tipo de ataque y tan sólo ocupó espacios de su propio programa, teniendo la hija al lado, para decir que ella no era fruto del odio más bien del amor. Pronto se descubrió que la declaración de Miriam fue pagada por la campaña de Collor (Dimenstein y Souza, 1994).

10 “En contra esas dos decisiones tomadas por Fernando Collor, Lula y sus asesores no tuvieron la habilidad tampoco la competencia para luchar. En el segundo debate [de la segunda vuelta] transmitido por un pool de emisoras de TV -el último acto de la campaña según los plazos de la legislación electoral-, Collor pasó como un tractor por encima de Lula. El candidato de PT estaba totalmente desnortado" (Figueiredo 1994: 62-63). 
políticos asumieron las dos funciones ${ }^{11}$. Euclides Scalco, fundador de PSDB y amigo de Cardoso, fue elegido para la coordinación general y Eliseu Padilha asumió las articulaciones políticas y contactos con grandes empresarios. Junto a Scalco, estará el secretario-general de la Presidencia, Eduardo Jorge, íntimo colaborador de Cardoso que pidió licencia en el cargo para actuar exclusivamente en la campaña. La tercera base de la campaña fue Guanaes, al frente de la coordinación de marketing y comunicación en sustitución a Walter, también fallecido meses antes.

Así como la anterior participación de Luís Eduardo Magalhães, la presencia de Padilha en el núcleo central de la campaña reveló que más que las relaciones partidistas contaban las relaciones de confianza con el candidato: Padilha era afiliado al PMDB, partido que oficialmente abdicó de lanzar candidato o de formalizar apoyo a cualquier candidatura. Pero desde la posición de ministro de Transportes del primer mandato de Cardoso, se granjeó la confianza del presidente, reafirmada en las articulaciones que estancaron la candidatura propia de $\mathrm{PMDB}^{12}$. Tampoco Magalhães era de PSDB, pero por lo menos era afiliado a uno de los partidos que participaban de la coalición.

En las campañas de Serra y Alckmin, otra vez el mando se divide. El coordinador de la campaña de Serra fue Pimenta da Vieiga, otro fundador y ex presidente del partido además de haber integrado el gabinete de Cardoso, donde fue compañero del ahora candidato. Pero es un comando que, a diferencia de Motta en 1994 e incluso de Scalco y Jorge en 1998, no tenía tanta autonomía en la gestión: el estilo Serra es demasiado centralizador, acercándose más al perfil de Collor. El candidato reservaba para sí la palabra final en muchas de las decisiones, carácter que se va a reflejar sobre todo en la coordinación de marketing, bajo la batuta de Nizan Guanaes (el mismo de la campaña de reelección de Cardoso) que cedió ante la decisión del candidato de hacer largas declaraciones sobre asuntos diversos: fueron 11 spots con este formato en los cinco programas de la primera vuelta.

Los nombres que integran el staff de campaña revelan el factor político en la designación del coordinador general, en cuanto el área del marketing y comunicación mantiene el carácter profesional. A pesar de tener una relación histórica con las candidaturas de PSDB, Guanaes sólo se integró a la campaña de Serra en abril de 2002, después de una bullada aventura en la promoción de la precandidatura de Roseanna

\footnotetext{
11 Sérgio Motta falleció de un cáncer. Luís Eduardo Magalhães sufrió un infarto.

12 El ex presidente Itamar Franco buscó viabilizarse como candidato del PMDB, pero no logró el apoyo interno necesario, en parte por la acción de Padilha. Ver revista Veja número 1550, de 10/06/1998, páginas 42-48 (disponible en www.veja.com.br).
} 
Sarney, que intentaba acreditarse como candidata de $\mathrm{PFL}^{13}$. Los límites en la autonomía de la coordinación de marketing, sin embargo, no reduce los instrumentos profesionales utilizados por la campaña, como la contratación de una sofisticada empresa como realizadora de los vídeos -la GW Comunicação, de Brasília-, o la implementación del soporte de Internet para viabilizar la interacción a través de la página Web del candidato e informes diarios de encuestas y grupos focales sobre la reacción del público respecto de la publicidad electoral y otros temas.

Con Geraldo Alckmin, el mando sigue dividido: Sérgio Guerra, senador de PSDB, toma las riendas de la coordinación política y Luís González asume el área de marketing. Pero la distribución de poder es al revés: González, un hijo de español que ya había trabajado como coordinador de la campaña de Alckmin para el gobierno de São Paulo cuatro años antes, reunía más poder en el mando real de la campaña; los coordinadores políticos centraban su atención en las articulaciones en búsqueda de adhesiones de liderazgos a lo largo de Brasil, sin tanta importancia en los rumbos generales de la campaña. Esa realidad encontrada en el núcleo tucano de 2006 tiene que ver menos con la profesionalización que con el factor amistad, puesto que el coordinador de marketing era un viejo conocido del candidato. La definición de los analistas de encuestas también pasa por el factor amistad: Antonio Lavareda, el antiguo colaborador de PSDB y PFL, da un paso al costado en esta campaña; las encuestas cualitativas y análisis estratégicos son realizadas por Orjan Olsen, experimentado profesional pero ante todo un nombre de la confianza personal de González y del candidato.

En el caso de PT, el papel del partido fue fundamental en la estructuración de las dos primeras campañas y, de forma más sutil, en 1998, dando paso en 2002 y 2006 a relaciones en que la estructura del partido va a ser en parte desplazada por los consultores del mercado. En términos de jerarquía, la nacionalización del mando se repite en las cinco campañas; la ampliación de la campaña en el nivel local y regional corresponde a los núcleos regionales (partidos de la coalición y instituciones del movimiento social, hasta 1998; también los liderazgos políticos independientes del partido, en las dos últimas), siguiendo las directrices del núcleo central.

En 1989, el coordinador fue Wladimir Pomar, fundador del partido y con activa participación en las luchas contra la dictadura. Además de coordinar toda la parte operativa de la campaña, tenía la preocupación respetar las directrices aprobadas en el

\footnotetext{
${ }^{13}$ Con un aparatoso empuje publicitario, Roseanna creció en las encuestas, en el primer trimestre de 2002, acercándose al liderazgo de la carrera presidencial en un empate técnico con Lula. Pero las pretensiones de la gobernadora de Maranhão colisionaron a raíz de un escándalo de corrupción que involucraba directamente a su marido, Jorge Murad (Carvalho, 2004).
} 
Congreso Nacional del PT. Contaba con la supervisión del Directorio Nacional, formado por representantes de las diversas tendencias integrantes del partido en aquél entonces. Las mismas directrices y vigilancia alcanzan al coordinador de marketing, Paulo de Tarso Santos, profesional reconocido en el mercado, pero que toma las riendas de la publicidad de PT por sus vínculos históricos con el partido. La autonomía es limitada y muchas veces la decisión sobre la exhibición de un mensaje pasa por una extenuante discusión interna, lo que da cuenta de la importancia de la plenaria interna en PT.

Esta situación se repite en 1994, a pesar de un intento de profesionalización de la estructura, conforme revela un documento interno elaborado por el periodista Ricardo Kotscho a inicios de la década de 1990. El documento advirtió sobre la necesidad del partido de abrir su política de alianzas, además de realizar un proyecto profesional que volviese su imagen más aceptable; para eso sugiere la contratación de equipo profesional para la dirección de la comunicación y del marketing de las campañas (Dimenstein y Souza, 1994), pero fue olvidado por la división interna, especialmente con la victoria de las tendencias radicales en $9^{\circ}$ Encuentro Nacional de mayo de 1994, rescatando el partidismo y la ideología que los más cercanos a Lula deseaban poner aparte. El diputado Rui Falcão asumió la coordinación general y Paulo de Tarso Santos otra vez sería el responsable de la producción de la publicidad electoral. Como en la disputa anterior, Santos se sometía a las decisiones del núcleo central lleno de discrepantes tendencias.

Después de la derrota de 1994, el PT cambia. Los grupos más moderados no sólo vuelven a tener el control del partido, sino que emprenden cambios sustantivos en el funcionamiento interno. En este sentido, el cambio más importante era la reducción de espacio a las tendencias. Los moderados cercanos a Lula querían lograr la hegemonía. La tendencia Articulación se une a otras tendencias y forman el "Campo Mayoritario", pasando a tener el control del Directorio y la Ejecutiva Nacional, las dos instancias más altas de la jerarquía del partido. El trabajo de reorganización del PT concentró la atención de los principales liderazgos en 1996 y 1997; la elección de 1998 quedó en segundo plano y la estructura de campaña sólo se estableció a fines del primer semestre, poco más de tres meses antes de la votación, pero por la primera vez los aliados directos de Lula dominan todos los puestos fundamentales. La coordinación general estuvo a cargo de José Dirceu, ya como presidente del partido, secundado por Luís Gushiken, otro viejo compañero del candidato. La coordinación de comunicación pasó a mano de Tony Cotrim, vinculado al partido, pero que estará allí por ser una persona de confianza de José Dirceu. 
De ese modo, también por primera vez las decisiones pasan a ser tomadas en un círculo cerrado: el núcleo duro integrado por fieles aliados de Lula y Dirceu ${ }^{14}$. Esa estructura centralizada se profundiza y en 2002 se vuelve también profesional: Dirceu y Gushiken están otra vez al frente de las articulaciones políticas y estratégicas, pero con Duda Mendonça en la coordinación del marketing electoral ${ }^{15}$. El cambio se revelaba radical, sobre todo teniendo en cuenta el historial de Mendonça, ex asesor de Paulo Maluf, uno de los íconos de la derecha brasileña. El cambio fue profundo también en los procesos de toma de decisiones, como ya se evidenciaba 15 meses antes de la campaña un reportaje de la revista Veja sobre los cambios en las relaciones internas del partido y en la imagen de Lula:

\begin{abstract}
"La vida interna del PT también cambió mucho. Esa transformación produjo una novedad en la estructura del partido: el reconocimiento de la existencia de los caciques. Sí, porque en el PT todo siempre fue decidido en interminables asambleas. Ahora, ganó importancia la decisión de una cúpula, exactamente como pasa en el PFL. Un ejemplo de ello son los procedimientos para la aprobación de los programas de TV. Los publicistas siempre necesitaron presentar sus propuestas ante un comité. El actual publicista, Duda Mendonça, sólo necesita rendir cuentas a algunos jefes" 16 .
\end{abstract}

La opción profesional que se instala en 2002 también estará presente en 2006. Ahora ya no será Mendonça, sino con João Santana. En las dos últimas campañas, el PT mantiene la definición de estrategias y coordinación política en un núcleo partidista, pero cediendo un importante grado de autonomía al sector de comunicación y marketing. Ya no estarán los colegiados que debían aprobar los programas que son exhibidos cada día: dentro de las estrategias generales, el responsable de la propaganda electoral realiza su trabajo - cuando mucho- reportándose al comando general de la campaña en una relación mucho más fluida. Además, tiene siempre en sus manos los números de las encuestas y grupos focales que van orientando el rumbo de los mensajes (y de la misma campaña) según los objetivos de optimización de los resultados electorales.

\footnotetext{
${ }^{14}$ Sobre la coordinación de PT y PSDB en 1998, ver revista Veja n 1550, del 10/06/1998, páginas 42-48 (disponible en http://veja.abril.com.br/100698/p_042.htmh.

15 Sobre el proceso de decisión de los mensajes del PT de cara a las elecciones de 2002 con Duda Mendonça, ver revista Veja $\mathrm{n}^{\circ} 1707$, del 4/07/2001.

${ }^{16}$ Revista Veja no 1707, del 04/07/2001, p. 38)
} 


\subsection{La presencia de los consultores}

La presencia de los consultores políticos en las campañas es un indicador fundamental de profesionalización (Trent y Fridenberg, 2000; Norris et al, 1999), resultado de la combinación de diversos factores donde son sobresalientes la declinación del papel de los partidos y la alta mediatización de la sociedad, exigiendo nuevos modos de acercamiento a un elector menos politizado. De la mano de ese proceso, el debate se vuelve más personalizado y se impone la lógica del político como producto, basado en la percepción, en la imagen. Y los expertos se ponen en el centro mismo de ese cambio. Respecto la realidad brasileña, el apartado anterior revela la presencia de los consultores políticos en todas las campañas presidenciales analizadas. Si bien la autonomía de la cual gozan estos expertos no es la misma de los consultores en Estados Unidos, en Brasil ya se puede asumir como un cambio que no es reversible.

El "asalto" de los consultores al centro de las campañas brasileñas puede ser considerado reciente pero avasallador: tienen presencia apenas visible en las elecciones de 1982 y 1986 (gobernador y senador), pero desde la campaña de Fernando Collor, fueron alzados casi a la condición de Midas, puesto que una rigurosa planificación convirtió un inexpresivo político en presidente de la República. Desde entonces, los profesionales de campaña han cobrado más y más espacio, verificándose por lo menos un registro de profesionales extranjeros en el núcleo estratégico de las disputas nacionales.

Fue precisamente en la campaña de Collor cuando los profesionales extra partido tuvieron mayor presencia, no sólo porque el PRN no contaba para nada sino también (y sobre todo) por el amplio uso de recursos técnicos y tecnológicos novedosos que exigían los expertos; los profesionales eran centrales en la organización de la campaña. El éxito de Collor fue atribuido principalmente al soporte profesional reunido, constituyendo un equipo de consultores en encuestas, finanzas, medios, publicidad y organización de eventos. En la mayoría de los estados, el núcleo nacional era secundado por un soporte encargado no sólo de la conducción de las cuestiones esencialmente políticas, sino también en temas de la estrategia de visibilidad e imagen.

Un ejemplo de esa estructura es el estado de Río de Janeiro: cuando Chico Santa Rita comandaba el núcleo nacional, en Río las acciones de marketing tenían el soporte de Elysio Pires, contratado especialmente con ese fin, como una especie de sucursal que controlaba el espacio regional y garantizaba la aplicación de las estrategias nacionales. Ese tipo de estructura va a ser encontrada en las campañas de Cardoso y Serra, pero en menor intensidad, puesto que en los estados en general eran los liderazgos políticos los controladores de la campaña, la mayoría prescindiendo del apoyo profesional. En el 
caso de las campañas de Lula, la estructura nacional también contaba con el refuerzo de apoyos regionales, pero que se preocupaban más de la movilización y casi sin espacio para los profesionales contratados.

Cabe notar, sin embargo, que a pesar de la imprescindible participación de los consultores en la planificación y ejecución de campañas, hay un límite para esa presencia: ningún consultor estuvo a cargo de la coordinación general de ninguna de las diez campañas analizadas. De hecho, los coordinadores de comunicación y marketing ocupan una función que responde a la vez al candidato y al coordinador general, papel que siempre está en manos de un personaje de cuño político, con vínculos partidistas y/o con el candidato (Cuadro 5.2). Incluso en el caso de la campaña de Collor, que empieza con un núcleo profesional y se vincula a un partido sin mayor base de afiliados, el mando central se pone en manos del mismo candidato y del entonces diputado Renan Calheiros: lo que más importaba era la relación de confianza personal, independiente del factor partidista, aunque Calheiros hubiera migrado al PRN junto con Collor e incluso se convirtiera en su líder en la Cámara Baja.

En las campañas de PSDB, la estructura de mando era una mezcla de confianza personal y factor partidista. Todos los coordinadores de las campañas tucanas son miembros de PSDB, pero asumen el puesto fundamentalmente por el vínculo con el candidato, siendo depositarios de su más estrecha confianza. Es revelador el caso de Sérgio Motta, coordinador de la primera campaña de Cardoso: Motta era de PSDB, pero sin disfrutar de una posición revelante en el partido; su credencial era la antigua amistad con el candidato. En el PT, el factor que determina la conformación del comando general es el criterio partidista: los coordinadores fueron siempre los presidentes del partido, aunque ocupando interinamente el puesto, como Wladimir Pomar, en 1989, y Rui Falcão, en 1994, cuando el presidente titular, el mismo Lula, pidió licencia para tener más tiempo para la campaña. En las otras tres, los presidentes titulares fueron los coordinadores.

Las limitaciones a los consultores van más allá. Si en las campañas estadounidenses hay consultores con más de 30 años de destacada trayectoria, en Brasil la realidad es muy distinta: la profesión de consultor parece ser una actividad de alto riesgo, quizá por la asociación con sus asesorados. Ningún consultor participó como coordinador principal del marketing en más de dos campañas. Chico Santa Rita coordinó la campaña de Collor en 1989 y la Orestes Quércia, en 1994. Desde entonces perdió la condición de estrella no sólo por la carga de la asociación con Collor, sino también por 
el fiasco electoral de Quércia ${ }^{17}$. Desde entonces, nunca más participó en ninguna elección nacional18. Nizan Guanaes integró el equipo de la campaña de Cardoso en 1994, pero en posición secundaria. Alcanza la coordinación general en 1998, así como en la campaña de Serra en 2002, pero ya en el gobierno Lula las empresas de su esposa fueron involucradas en denuncias de evasiones tributarias, hecho que atribuye a los vínculos que tuvo con la campaña de PSDB. Desde entonces, decidió no volver a participar en campañas electorales, concentrado atención a la agencia de publicidad África, que preside ${ }^{19}$.

CUADRO 5.2

\section{Los coordinadores generales de las campañas y sus vínculos}

\begin{tabular}{|c|c|c|c|}
\hline & & Coordinador General & Credenciales \\
\hline \multirow[t]{2}{*}{1989} & Collor & Renan Calheiros & $\begin{array}{l}\text { Vínculo personal con Collor: era diputado de } \\
\text { Alagoas y de la estrecha confianza del candidato }\end{array}$ \\
\hline & Lula & Wladimir Pomar* & Función partidista: Presidente del PT \\
\hline \multirow[t]{2}{*}{1994} & Cardoso & Sérgio Motta & $\begin{array}{l}\text { Vínculo personal, aunque miembro del partido: era } \\
\text { amigo y ex socio de Cardoso }\end{array}$ \\
\hline & Lula & Rui Falcão* & Función partidista: Presidente del PT \\
\hline \multirow[t]{2}{*}{1998} & Cardoso & $\begin{array}{l}\text { Euclides Scalco y } \\
\text { Eduardo Jorge }\end{array}$ & $\begin{array}{l}\text { Vínculo personal con el candidato, a pesar de } \\
\text { integrantes históricos del partido }\end{array}$ \\
\hline & Lula & José Dirceu & $\begin{array}{l}\text { A pesar de vinculado a Lula, ocupa el puesto por } \\
\text { ser presidente del PT }\end{array}$ \\
\hline \multirow[t]{2}{*}{2002} & Lula & José Dirceu & Función partidista: Presidente del PT. \\
\hline & Serra & Pimenta da Veiga & $\begin{array}{l}\text { Fundador de PSDB y integrante del núcleo duro del } \\
\text { partido, al cual Serra también pertenece. }\end{array}$ \\
\hline \multirow[t]{2}{*}{2006} & Lula & $\begin{array}{l}\text { Ricardo Berzoini y } \\
\text { Marco Aurélio Garcia** }\end{array}$ & $\begin{array}{l}\text { Berzoini y Garcia ocupan el puesto en su condición } \\
\text { de presidente de PT }\end{array}$ \\
\hline & Alckmin & Sérgio Guerra & $\begin{array}{l}\text { Asume la coordinación por una mezcla de factores: } \\
\text { el vínculo con el candidato y por ser de Nordeste, } \\
\text { donde Alckmin necesitaba crecer }\end{array}$ \\
\hline
\end{tabular}

Fuente: Elaboración propia.

* En las campañas de 1989 y 1994, Lula pide licencia de la presidencia del partido. Asumen el puesto los vicepresidentes, Wladimir Pomar, en 1989, y Rui Falcão, en 1994.

* En 2006, la posición de presidente de PT lleva Ricardo Berzoini a la coordinación general de campaña. En mediados de la primera vuelta, al tener su nombre involucrado en escándalos, Berzoini deja el puesto. Fue sustituido por el asesor de relaciones internacionales de la presidencia, Marco Aurélio García, que pasa a la condición de coordinador hasta terminada la campaña, cuando Berzoini vuelve.

17 Quércia, ex gobernador de São Paulo, fue candidato de PMDB en 1994, recibiendo una votación correspondiente tan sólo a una cuarta parte de los sufragios obtenidos por su partido en la disputa por los escaños de la Cámara de los Diputados. Ese desempeño, sin embargo, debe ser asociado más a la concentración de los apoyos de los actores políticos vinculados al PMDB en torno a la candidatura de Cardoso (PSDB).

${ }^{18}$ En 2005, Santa Rita coordinó la campaña por el "no" en el plebiscito sobre el control en la venta de armas, logrando salir victorioso. En elecciones, ha participado de campañas en países de América Latina y para gobiernos estaduales y puestos legislativos en Brasil.

19 Por esa decisión, Nizan Guanaes reusó conceder una entrevista para esta investigación. A través de la asesoría de comunicación informó que no habla más sobre política, sólo sobre publicidad comercial. 
En el caso de Mendonça, los escándalos en el gobierno de Lula quitaron brillo quien quizás ostenta el currículo con el mayor número de campañas: más de un centenar. Las investigaciones revelaron que parte del contrato del publicista fue cubierta con recursos públicos, además de enviar parte de las ganancias para cuentas secretas en paraísos fiscales en el exterior. Mendonça es el ejemplo más acabado del profesional de campaña, con servicios prestados a partidos de los más diversos matices ideológicos. En las disputas presidenciales, asesoró al ultra conservador Paulo Maluf (1989) y al izquierdista Lula (2002). En las disputas por los gobiernos estaduales, estuvo al lado de nombres de perfiles tan distintos como Maluf y Miguel Arraes (PSB), o Dante de Oliveira (PMDB) y Jorge Viana (PT). En las campañas por las alcaldías, sólo en São Paulo trabajó para Maluf, Celso Pita (PP) y Marta Suplicy (PT). A pesar de esa trayectoria, en 2006, se vio obligado a restringir su actuación a algunas campañas estaduales.

Paulo de Tarso Santos, responsable de las dos primeras campañas de Lula, fue atropellado por los cambios en PT. Si Duda Mendonça es el prototipo del consultor sin ideología, Santos es el negativo de esa foto: ocupó la coordinación precisamente por sus vínculos partidistas y preocupación por un discurso ideológico, aunque plásticamente bien elaborado. Identificado con el partido, hoy ocupa espacios secundarios en las campañas. Tony Cotrim tuvo una única experiencia con Lula en 1998. Luís González, el coordinador de Alckmin, participó en otras campañas presidenciales (Ulysses Guimaráes, en 1989; Cardoso, en 1994), pero en posiciones de menor importancia. Lo mismo pasó con Santana, el coordinador de Lula en 2006, que fue auxiliar de Mendonça en diversas campañas.

La literatura destaca como rasgo de las campañas profesionales la presencia de consultores estrellas, que llegan a disputar con el mismo candidato la referencia principal de la campaña (Norris et al, 1999). Esa no es una característica de Brasil. De hecho, tan sólo en 2002 se vio una disputa de egos entre Nizan Guanaes y Duda Mendonça (Cuadro 5.3). Desde que asumieron las campañas, los dos consultores ocuparon sistemáticamente los medios hablando sobre la disputa y aprovechando para exponer el posicionamiento del candidato, además de sus propias visiones sobre la política, la disputa y la publicidad. En un reportaje de mayo de 2002, la revista Veja casi reduce la disputa presidencial al enfrentamiento entre los dos publicistas ${ }^{20}$. En las demás, los profesionales siempre tuvieron posición discreta. Un ejemplo es la campaña

\footnotetext{
20 El reportaje "O duelo das feras" [el duelo de las fieras] apunta Mendonça y Guanaes como los dos principales profesionales del marketing político y quienes maracarán el ritmo (y del resultado) de la campaña presidencial de aquél año. Ver revista Veja, $\mathrm{n}^{\circ} 1.750$, del 8/5/2002. Archivo disponible en http://veja.abril.com.br/080502/p_042.htm/.
} 
de 2006, en que el victorioso João Santana concedió una sola entrevista (al periódico Folha de S. Paulo) y ya después de la elección acabada. En el caso de Gónzalez, no hubo entrevistas ni antes ni después.

CUADRO 5.3

\section{Presencia y centralidad de los consultores}

\begin{tabular}{ll}
\hline Comando general & $\begin{array}{l}\text { Ningún consultor ocupa la dirección deel comando general de la } \\
\text { campaña, ni siquiera en el caso de Duda Mendonça, en 2002. } \\
\text { Esta instancia está siempre en manos políticas o de alguien de la } \\
\text { estrecha confianza personal del candidato. }\end{array}$ \\
\hline Vínculo partidista & $\begin{array}{l}\text { Es tomado en cuenta en las tres primeras campañas de PT; } \\
\text { Se nota la permanencia de nombres asociados al partido en el } \\
\text { caso de PSDB; } \\
\text { No tiene ninguna importancia en el caso de PRN y en el segundo } \\
\text { PT. }\end{array}$ \\
\hline Autonomía & $\begin{array}{l}\text { Limitada al campo específico del marketing electoral, es decir, de } \\
\text { los mensajes electorales (programas y spots). }\end{array}$ \\
\hline Consultores estrellas & $\begin{array}{l}\text { El estrellato de los consultores sólo se verifica en 2002, con dos } \\
\text { de los más egocéntricos profesionales (Duda Mendonça y Nizan } \\
\text { Guanaes). Pero no dice tanto: en esa campaña Guanaes tuvo } \\
\text { menor autonomía que en 1998. }\end{array}$ \\
\hline Consultores extranjeros & $\begin{array}{l}\text { Sin relevancia: se resume a un caso, el de James Carville en la } \\
\text { elección de Cardoso (1994), y tan sólo como concejero. }\end{array}$ \\
\hline
\end{tabular}

Fuente: elaboración propia.

Sin embargo, se debe añadir que la visibilidad de los consultores no significa autonomía en el trabajo. Nizan Guanaes no tuvo en 2002 la misma autonomía desfrutada en 1998, a pesar de posicionarse como la segunda estrella por detrás tan sólo de José Serra ${ }^{21}$. Por el contrario, otros más discretos tuvieron la posibilidad de trabajar según la planificación inicial (caso de Santana) o según sus convicciones, sin interferencias significativas del sector político (caso de González) que presionaba por cambios en la comunicación electoral de Geraldo Alckmin. La autonomía de los dos coordinadores de 2006 sólo es comparable a la de Mendonça en 2002, cuando pudo dictar el tono de los mensajes electorales, teniendo contenido a un obediente Lula, muy distante del rebelde candidato que en 1989 se negaba incluso a sonreír.

\footnotetext{
${ }^{21}$ El publicista Mauro Salles, que participó del núcleo estratégico tanto de las campañas de Cardoso como de Serra, reconoce que Guanaes no tuvo en 2002 la autonomía que disfrutó en 1998, cuando ocupó la coordinación del marketing de la reelección de Cardoso. En la campaña de Serra, otras personas del núcleo central participaban en las decisiones, en cuanto que en la Cardoso Guanaes tenía poder absoluto en esas decisiones. Ver entrevista de Salles en el portal de la Asociación Brasileña de la propaganda: www.abp.com.br.
} 
Otro aspecto que debe ser tomado en cuenta es la baja participación de extranjeros en las campañas brasileñas. De hecho, hay un único registro: el de James Carville en la campaña de Cardoso en la elección, en 1994. Carville es el principal estratega de la sorprendente victoria de Bill Clinton en 1992, que dejó algunas lecciones de marketing (por ejemplo, la política más allá de los telediarios nocturnos) y una frase célebre: "es la economía, estúpido”22. En el equipo de Cardoso, el consultor estadounidense no ocupó una posición de mando, sino la función de consejero, con análisis críticos sobre el posicionamiento inicial y el desarrollo de la campaña -que centró su atención especialmente en un tema: el Real-. Es una realidad muy distinta a la observada en países como Argentina, Chile y Uruguay, donde hay registro de diversos extranjeros en el mando de campañas electorales (Espíndola, 2003).

Por supuesto, la presencia de los consultores repercute en altos costes. La facturación es un secreto del sector, pero sin duda es muy elevada, como revelaron las investigaciones del escándalo del mensalão, especialmente sobre los recursos movilizados por Duda Mendonça y Marcos Valerio, dos profesionales dedicados a la política y vinculados a las campañas y al gobierno del PT. En declaraciones a la Comisión de Investigación del Congreso sobre el mensalão, Mendonça reveló que en 2002 las campañas que realizó para el PT (la presidencial, algunos gobiernos de estado y puestos del Congreso) aportaron a sus empresas un total de 25 millones de reales (cerca de 10 millones de euros o casi 14 millones de dólares, convertidas por el cambio actual ${ }^{23}$ ). Es más: casi la mitad de esos recursos (11,9 millones de reales, o 4,6 millones de euros) no fue oficialmente contabilizada ${ }^{24}$.

Los costes tan sólo con el equipo de producción de la publicidad electoral en una campaña presidencial suelen estar muy por encima de los 10 millones de euros declarados por Mendonça, valor que supera todos los costes de un partido en la disputa por el poder central en Portugal o España ${ }^{25}$. En 2006, la campaña de Lula a la reelección desembolsó cerca de 22 millones de reales (más de 12 millones de dólares o 8,6 millones de euros) tan sólo con la producción de la publicidad electoral, las

\footnotetext{
22 La frase traduce el enfoque básicamente monotemático de la primera campaña de Clinton, centrada en los temas económicos.

23 La conversión, tan sólo para efecto de referencia, tiene como base la cotización del Banco Central de Brasil del día 15 de octubre de 2007. En esa fecha, 1 euro correspondía a 2,56 reales; y 1 dólar a 1,80, valores que serán tomados para conversiones en otros momentos del presente trabajo, excepto en citaciones bibliográficas que ya incluyen otros parámetros. Ver cotizaciones en http://www5.bcb.gov.br/pec/conversao/Resultado.asp?idpai=convmoeda.

${ }^{24}$ Informaciones publicadas en el periódico Folha de $S$. Paulo del 14/08/2005. El archivo digital está disponible en http://clipping.planejamento.gov.br/Noticias.asp?NOTCod $=214126$.

${ }^{25}$ Ver datos en la columna Panorama Político, de Teresa Cruvinel, O Globo, el 20/02/2006, pag. 2.
} 
encuestas y acciones de telemarketing, según declaraciones al TSE ${ }^{26}$. Con el agravante de que, a diferencia de los sistemas parlamentarios como España, los gastos de una campaña presidencial en Brasil no incluyen los recursos financieros de las elecciones de los congresistas, también muy costosas sobre todo en el caso de los senadores. En un esfuerzo por calcular el valor de las campañas en Brasil, Samuels (2001) encuentra números extraordinarios: los gastos declarados de todos los candidatos en las generales de 1998 (presidente, gobernadores, congresistas y diputados estaduales) sumaron 3.500 millones de dólares ${ }^{27}$. Pero el investigador estadounidense reconoce la contabilidad paralela y evalúa que el valor real está situado en una larga franja entre 7.000 y 35.000 millones de dólares.

Segundo datos de los políticos, los equipos de comunicación y marketing suelen consumir cerca de $60 \%$ del presupuesto de las campañas. Si eso es cierto, se puede evaluar las ganancias del sector de consultoría teniendo en cuenta que la campaña de Lula de 2006 ha contado con un presupuesto declarado por encima de los 40 millones de euros ${ }^{28}$. El coordinador de la campaña de Lula para la reelección, João Santana, declaró haber cobrado 13,7 millones de reales (valor por encima de los 5 millones de euros) por sus servicios ${ }^{29}$. Además, se debe tener en cuenta que profesionales como Duda Mendonça y Santana coordinan diversas campañas a la vez, una en el nivel nacional y otras en la esfera de los estados, acumulando ganancias. Los valores finales dispendidos por las candidaturas y las ganancias de los consultores siguen siendo un misterio porque los datos no son todos revelados, como admitieron dirigentes de PT y el mismo Mendonça en las investigaciones de los escándalos de desviación de recursos en el gobierno Lula ${ }^{30}$.

Aunque persisten las dudas sobre el presupuesto real, la contabilidad declarada ya es suficiente para evidenciar el alto coste de las campañas en Brasil. También para evidenciar que parte importante de los recursos se destinan a actividades profesionales.

\footnotetext{
${ }^{26}$ Ver datos en www.tse.gov.br.

27 Samuels convierte los gastos en dólares por la cotización media del año de 1989, con 1 dólar para cada 1,16 real.

28 El valor declarado para la campaña de Lula fue de 104,3 millones de reales, correspondiente a 40,7 millones de euros. Geraldo Alckmin declaró gastos de 82 millones de reales (32 millones de euros). Sobre los gastos de cada campaña, ver www.tse.gov.br. Ver aún los interesantes cálculos de Paulo Moreira Leite (http://blog.estadao.com.br/blog/paulo/?m=200611): oficialmente Lula gastó en 2006 casi 1,87 real (cerca de 73 céntimos de euro) por voto conquistado.

${ }^{29}$ Entrevista de João Santana a Fernando Rodrigues, publicada por el periódico Folha de $S$. Paulo del 11/11/2007. Disponible en http://noticias.uol.com.br/ultnot/2006/11/05/ult23u261.jhtm.

30 Ver el Jornal do Senado, edición del 22/08/2005, disponible en www.senado,gov.br.
} 


\subsection{La planificación de campaña}

Si se mira el plazo de planificación como traductor de profesionalización, la mayor parte de las campañas presidenciales brasileñas serán clasificadas como profesionales: seis de las diez candidaturas analizadas tuvieron preparación de largo plazo, con dos planificadas en plazo mediano y otras dos en el corto plazo (Cuadro, 5.4). Pero hay que se añadir que la panificación de largo plazo no siempre se refleja en la constitución de un amplio equipo de profesionales de campaña contratados en el mercado, pudiendo ocurrir como en la preparación de Lula para la campaña de 1994, cuando la estructura del mismo PT y entidades asociadas fueron el soporte para la preparación de la Caravana de la Ciudadanía ${ }^{31}$ y el registro en video de los viajes del candidato petista.

\subsubsection{Campañas de Largo Plazo:}

Como estructura profesional, la campaña de Collor es otra vez la que más se destaca, con un equipo constituido más de dos años antes de las elecciones. El equipo contaba con analistas de encuestas, encargados de las relaciones con medios y articulación con los actores políticos y sociales, en especial el contacto con empresas que garantizasen la mediatización necesaria (empresas de comunicación) o el soporte financiero para el necesario recorrido al continental territorio brasileño. Desde 1987 Collor ya asumía posiciones públicas según las demandas de los electores reveladas por las encuestas, convirtiéndose en el actor que se apropia del discurso latente en la mente de la gente, conforme la afirmación de Figueiredo (1994).

Collor no hablaba claramente como candidato puesto que la legislación brasileña impide campaña anticipada ${ }^{32}$; pero se comportaba como candidato, además de tener en los medios de comunicación su nombre asociado a la sucesión presidencial. Las encuestas mostraban que necesitaba hacerse conocido. Cuatro años antes de que Clinton pusiese en la agenda de los candidatos estadounidenses el tour por los talkshows, Collor ocupó espacios mediáticos a la época inusuales para los políticos, como el Casino do Chacrinha (TV Globo), programa de entretenimiento destinado al segmento popular, y A Praça é Nossa (red SBT), humorístico muy popular. También en

\footnotetext{
${ }^{31}$ La Caravana de la Ciudadanía fue una serie de viajes de Lula por las regiones más pobres de Brasil, con el objetivo de reforzar la idea de acercamiento del candidato con la realidad brasileña. En esos viajes, Lula conversaba con la gente sobre los problemas de cada sitio. Cada paso de la Caravana era registrado en vídeo, inclyendo entrevistas con personas del pueblo.

32 La regla prohibiendo la campaña antes del período oficial sigue en vigor, pero es letra muerta: todos los aspirantes se movilizan y se portan como candidatos. Además, los medios hablan abiertamente de las candidaturas, incluso con encuestas sobre la futura disputa, mucho antes del plazo legal. Sobre la legislación actual, ver Ley 9.504/97 (disponible en www.tse.gov.br).
} 
el carnaval de Río de Janeiro de 1989, desfiló en la pasarela de la samba, aprovechando que tres escuelas presentaban enredo de crítica a la corrupción: fue ovacionado 33 .

Esta fase estará marcada por acciones impactantes con el objetivo de producir la visibilidad necesaria. En ello están las colas de funcionarios en la entrada de las reparticiones públicas de Alagoas, tan sólo para registrar la presencia en el puesto de trabajo, exigido por el gobernador. Un pseudoevento de amplia resonancia fue una caja llena de documentos "comprobando corrupción" en el gobierno Sarney, que Collor fue personalmente a entregar en la secretaría del Ministerio de Justicia, exigiendo aclaración de los hechos y el castigo de los responsables. La buena repercusión de los hechos se hace visible en las portadas de los periódicos y más aún en las encuestas: a fines de 1988 el gobernador ya se encontraba en la tercera posición, por detrás de Leonel Brizola y Luís Ignacio Lula da Silva. La repercusión popular captó la atención (y a continuación el apoyo) de diversos sectores políticos, sobre todo de los caciques conservadores que controlaban gran parte de votos en los rincones del interior de Brasil, como Antonio Carlos Magalhães, en Bahia, o Adauto Bezerra, en Ceará. También despertó el interés de las grandes empresas, cuyo apoyo se materializó en la financiación de las acciones de campaña.

La temprana planificación permite a Fernando Collor disponer del tiempo suficiente para evaluar las dificultades que tendría en el seno de PMDB y decide entonces la creación de un nuevo partido. En febrero de 1989 lanzó el manifiesto de fundación de PRN y ya el 30 de marzo lograba exhibir el primer programa de radio y TV del nuevo partido, con 20 minutos de duración en el horario de más audiencia ${ }^{4}$. Tras negociaciones especiales, otros dos pequeños partidos abrieron espacios para Collor en sus programas: PTR, el 27 de abril, y PSC, el 14 de mayo. En todos ellos, el candidato mostraba sus obras en Alagoas, sobre todo la lucha contra los marajás, y no se cansaba de criticar al gobierno Sarney. El resultado fue notable, pues al inicio de abril las encuestas ya lo presentaban por delante de Brizola y Lula35.

La postura del candidato que es pero hace que no lo es se convierte en patrón en la política brasileña, distinto de la realidad estadounidense, en que el anuncio de la candidatura es seguido por la apertura del comité electoral y las acciones por

\footnotetext{
${ }^{33}$ Ver Conti (1999), Melo (1994), Fausto Neto (1994) y la entrada Fernando Collor en FGV (2000).

34 La legislación brasileña, contempla espacios para la exhibición de mensajes políticos para los partidos, independiente del período electoral; y asegura espacio para la propaganda electoral destinada a los candidatos en los 45 días anteriores a la elección. En teoría, los espacios dado a los partidos son para enfocar aspectos programáticos, pero casi siempre utilizados con objetivos electorales, como en el caso de Collor.

${ }^{35}$ Ver Instituto Ibope ( $w w w . i b o p e . c o m . b r$ ) y Data Folha (www.datafolha.com.br).
} 
recaudación de fondos ${ }^{36}$. Esta simulación es evidente en las candidaturas de Cardoso en 1998 y Lula en 2006, cuando eran a la vez presidente y candidato. En la letra de la ley, la legislación es vigilante e impide, además de las candidaturas fuera del plazo formal, que candidatos participen de actos gubernamentales o que los actos oficiales sean asociados a intenciones electorales. Así, los ocupantes de cargos públicos se portan como gestores públicos hasta el último día exigido por la ley, aunque todo el tiempo estén trabajando para la elección. Los actos oficiales más que otros intereses miran hacia la candidatura.

CUADRO 5.4

La preparación de las campañas

\begin{tabular}{ll}
\hline Planificación & Candidaturas \\
\hline Largo plazo & Tienen planificación de largo plazo las campañas de Collor en \\
(6 campañas) & 1989, la Cardoso en 1998, las de Lula en 1994, 2002 y 2006 y \\
& la de Serra, en 2002. \\
& En las campañas de Lula en 1994 y la Serra en 2002, la \\
planificación de largo plazo se verán perjudicadas: la primera, por & el cambio de legislación y divergencias internas en el partido; la \\
& segunda, por los conflictos del candidato con aliados dentro y \\
& fuera del partido. \\
\hline Mediano & En ese caso están las campañas de Lula en 1989 y de Cardoso \\
(2 campañas) & en 1994. En el caso de Lula, es una campaña guiada menos por \\
& los objetivos electorales que por las estrategias generales del \\
partido, en esa la época orientado hacia la lucha de clase. \\
Cardoso prepara su campaña en medio las indecisiones del \\
partido y la planificación del Real.
\end{tabular}

Los dos -Cardoso y Lula- hicieron de la presidencia una plataforma de campaña mucho antes de la campaña misma. Cardoso tuvo que desarrollar articulaciones políticas para cambiar la ley, resultando una enmienda constitucional que autoriza una reelección a los ocupantes de los puestos ejecutivos. Lula ni siquiera tuvo esa preocupación. Los dos desarrollaron programas gubernamentales con fines más bien electorales más que mostrar efectivas intenciones de implementar políticas públicas duraderas. En ese sentido, es referencial el caso de Lula y el programa Hambre Cero,

\footnotetext{
${ }^{36}$ Un ejemplo es la candidatura de Hilary Clinton, que anunció la postulación y la apertura formal del comité de campaña en enero de 2007, un año antes de las primeras elecciones primarias y casi dos antes de la votación final, marcada para inicio de noviembre de 2008.
} 
base del discurso de inclusión social abrazado en la fase oficial de la campaña de 2006. Desde el gobierno, tanto Lula como Cardoso manejaron una amplia estructura profesional: encuestas, asesores de marketing, relaciones con los medios, todo como si fueran acciones del gobierno aunque al fin y al cabo se mezclaban las intenciones del presidente y del candidato.

Un caso ejemplar es el de João Santana, el coordinador de la campaña de reelección de Lula, contratado para asesorar al presidente (sí, al presidente, no al candidato) un año antes de que comenzara la campaña oficial. Él sustituía a Mendonça, bombardeado por los escándalos de desviación de los recursos públicos. El 24 de agosto de 2005, el presidente fue claro: "Si yo voy a ser el candidato, tu vas a hacer mi campaña", dijo Lula al publicista" 37. De hecho, desde entonces Santana pasó a hacer lo que su antecesor ya hacía: trabajar por la reelección del presidente, enfocando todo el actuar del gobierno hacia el mismo objetivo.

Lula tuvo otras dos campañas de larga planificación: la de 1994 y la de 2002. En la primera, el soporte fue la estructura del partido; en la segunda, la base de actuación fue claramente profesional, con la implantación de las nuevas estrategias ya en las municipales de 2000, como admitió el diputado José Genoíno ${ }^{38}$. La planificación de 1994 empieza aún en la amargura que dejó la derrota de 1989, cuando el grupo cercano al líder petista vislumbró la posibilidad real de llegar al poder. Sin embargo, la evaluación de la derrota ante Collor apuntaba hacia la necesidad de ampliar el abanico de apoyos políticos y sociales, incluso el soporte de sectores de las elites económicas antes tan criticados por el PT y su candidato. A ello apunta el plan de profesionalización elaborado por Ricardo Kotscho, que ya hablaba de la necesidad de cambios en el área del marketing y producción de los mensajes electorales.

Lula pasó más de dos años de gira por todo el país, visitando los rincones más lejanos y registrando todo en video. La base de la campaña de comunicación estaba ya armada si no hubiesen tenido lugar dos sucesos: el primero, el cambio de legislación que prohibió para la campaña siguiente el uso de imágenes exteriores -precisamente el resultado más importante de la Caravana de la Ciudadanía-; segundo, la derrota de los moderados en el $9^{\circ}$ Encuentro Nacional de PT, lo que impuso al candidato del partido propuestas más radicales, no deseadas por los más cercanos a Lula, además de una política de alianza muy estrecha.

\footnotetext{
37 Ver entrevista de João Santana al periódico Folha de S. Paulo, el día 5/11/2006, disponible en http://noticias.uol.com.br/ultnot/2006/11/05/ult23u261.jhtm.

${ }^{38}$ Entrevista al autor en mayo de 2007. Ver aún entrevista de César Benjamin al periódico O Povo, el 27/01/2006 (disponible en http://www.noolhar.com/opovo/paginasazuis/521156.htm/.
} 
El resultado concreto es que la planificación de largo plazo se reveló improductiva. Más allá del resultado del $9^{\circ}$ Encuentro, los esfuerzos de formalización de alianzas con el PSDB resultaron inoficiosos, puesto que el principal nombre del partido -Fernando Henrique Cardoso- logró viabilizarse como la alternativa del centro-derecha, especialmente tras la implantación del plan Real. La reforma económica de Cardoso fue otro suceso que cambió la estrategia petista, que primero estuvo concentrado en criticar el plan de estabilización y después -tras la positiva respuesta popular respecto del control de la inflación- giró su estrategia hacia intentar posicionarse como los más aptos para dar el mejor rumbo a la estabilización iniciada con el Real.

En 2002 tuvo mejor suerte. Primero, la planificación contó con la participación de profesionales. Segundo, el cuadro de crisis económica no cambió y Lula pudo recoger a su favor el descontentamiento popular en el fin del periodo de Cardoso. La planificación -de hecho- empezó en 1995, durante la primera etapa de los cambios internos que no pudieron ser traducidos en una campaña profesional en 1998 porque los cambios sólo quedaron concluidos en inicio de aquél año. Pero sí ya se pudo notar en las municipales de 2000, especialmente en la lucha por alcaldías importantes como en São Paulo, Porto Alegre, Belo Horizonte y Recife. El PT que se presentó a las elecciones de aquél año fue un partido con una nueva estrategia de alianzas (mucho más amplia que antes), un discurso más moderado y una organización de campaña que cabía en los moldes profesionales, centralizada en torno a expertos del mercado. Los cambios hacen surgir el PT color rosa ${ }^{39}$.

La sexta campaña con planificación de largo plazo es la de José Serra en 2002, que se vio afectada por diversos sucesos. Desde el Ministerio de Sanidad, que ocupó en el segundo mandato de Cardoso, el histórico tucano trabajó para ser el candidato del oficialista, desarrollando acciones que posicionaban al ministro como trabajador y eficiente, además de ser reconocido internacionalmente por la quiebra de las patentes de las medicinas y el alabado programa de combate del SIDA40. Pero el camino no estaba libre y Serra tuvo primero que enfrentarse a otros nombres dentro del mismo PSDB -como el senador Tasso Jereissati- y después en los partidos aliados, en concreto el PFL, con César Maia (alcalde de Rio de Janeiro) y Roseanna Sarney (gobernadora de Maranhão).

\footnotetext{
39 Referencia a la portada de la revista Veja $\mathrm{n}^{\circ} 1670$, del 11/10/2000, que adopta ese titular para referirse al cambio de PT (archivo disponible en http://veja.abril.com.br/111000/p_034.html). El rosa es sindicado como la moderación en contrapunto al rojo, asociado a un historial de posiciones radicales.

40 El programa de combate al SIDA se caracteriza sobre todo por la distribución de medicinas para los seropositivos. El coste de las medicinas fue rebajado por la quiebra de las patentes, puesto que se dejó de pagar royalties a los laboratorios. El programa fue reconocido por Naciones Unidas como uno de los eficaces en el mundo.
} 
Para limpiarse el camino, Serra utilizó métodos duros, generando la reacción tanto dentro como fuera del partido (Almeida, 2004; Carvalho, 2004). El marido de Roseanna estuvo involucrado en una operación de blanqueo de dinero y el entorno de Jereissati fue también investigado, ambas acciones atribuidas a Serra. Como resultado de lo anterior, el ministro logró ser el candidato de PSDB, pero sin el apoyo formal del PFL y también con escisiones importantes: José Sarney, el padre de Roseanna, decidió no seguir en su partido, el PMDB - que formalizó alianza con el PSDB-y apoyó Lula; Jereissati votó por Ciro Gomes, candidato de PPS.

La estructura profesional no logró llevar el tucano hacia la victoria. Llegó a la segunda vuelta, pero entonces vio a los principales partidos apoyando Lula, resultado no sólo del cambio de imagen del PT y de su candidato, sino también de la indisposición creada por Serra en el recorrido hasta la candidatura presidencial.

\section{4.2. Campañas de Medio Plazo:}

Las dos campañas con planificación de mediano plazo tienen justificaciones distintas. La de Lula en 1989 se verá cercada por los mismos objetivos del partido, priorizando la lucha ideológica y la crítica al modelo capitalista, apuntado como salvaje; la de Cardoso en 1994, estará marcada por la indefinición en el rumbo del partido. En el caso del PT, no había ninguna duda sobre la candidatura del histórico líder metalúrgico, pero la perspectiva de competencia real por la presidencia no parecía factible: la campaña de 1989 era entendida más como una táctica en la estrategia de fortalecimiento de la lucha de clases.

El tono clasista se puso de manifiesto en el documento final del $6^{\circ}$ Encuentro Nacional del partido, anterior a la campaña ${ }^{41}$, que asume las elecciones como una etapa más en la tensión entre las clases trabajadoras y la burguesía "al servicio del capital internacional". Ve en una eventual victoria petista un modo de acelerar la polarización política capaz de generar un ambiente "revolucionario" o por lo menos "prerevolucionario" que tensione las relaciones de clase. El documento es categórico:

"En contra del proyecto de las clases dominantes, el PT reafirma su opción para solventar la crisis desde el punto de vista de los trabajadores, que es la instauración

\footnotetext{
${ }^{41}$ El $6^{\circ}$ Encuentro del Partido de los Trabajadores (São Paulo, 31 de mayo al 3 de junio de 1989), además de oficializar la candidatura Lula, aprobó el documento-directriz 0 Momento Atual e as nossas tarefas [El momento actual y nuestras tareas]. La íntegra del documento está disponible en http://www.pt.org.br/pt25anos/anos80/documentos/89_momento_atual_tarefas.pdf.
} 
de un gobierno democrático-popular, antiimperialista, antimonopolista, contra el pago de la deuda externa, que realice la reforma agraria y que promocione el desarrollo social sobre nuevas bases, y en el cual los trabajadores detengan la hegemonía y puedan avanzar hacia el socialismo"42.

Las líneas estratégicas político-ideológicas del partido están por encima de la competencia electoral. Además, el PT tarda en formalizar una estructura mínima que pueda hacer funcionar una campaña tan compleja como suelen ser en Brasil, con uno de los más grandes electorados del planeta y un territorio grande y lleno de diversidades43. Es decir, si las estrategias del partido están definidas desde muy temprano -en general, las motivaciones clasistas de 1989 son las mismas de las elecciones municipales de 1988- la organización necesaria para las acciones electorales esperan el periodo oficial: antes de la formalización de candidatura, la campaña de Lula no contaba con estructura, sino con sucursales regionales del PT y algunas entidades del movimiento social, en efecto transformadas en comités electorales.

Las condiciones de operación eran precarias. La planificación seguía los análisis políticos internos y atendía a las estrategias establecidas en difíciles debates que involucraban tendencias internas con muy diversas visiones del proceso. Los recursos eran reducidos, impidiendo que se contratase encuestas de orientación de las estrategias. Según el diputado José Genoíno, "era todo hecho en base a corazonadas"44. A diferencia del PT en 1989, el PSDB de 1994 tarda en definir su candidato pero pronto contará con una amplia estructura. Hasta entrada la segunda mitad de 1993, el partido aún alimentaba la esperanza de armar una alianza con el PT, en una coalición en que los tucanos ofrecerían el vicepresidente de Lula. La designación de Fernando Henrique Cardoso en el ministerio de Hacienda va a cambiar el rumbo sucesorio. Cardoso alimenta el sueño de presentarse a las presidenciales, pero enfrentaba el problema de la poca relevancia popular y las dificultades de formar una coalición electoralmente competitiva capaz de enfrentar a Lula, entonces líder en las encuestas.

Las intenciones de Cardoso empezaron a explicitarse en diciembre de 1993, cuando el presidente Itamar Franco exige que dimitan todos los integrantes del gabinete que

\footnotetext{
${ }^{42}$ Ver documentos históricos de PT en Fundación Perseu Abramo: www.fpa.org.br.

${ }^{43}$ Brasil tiene un territorio correspondiente a 17,5 Españas. El electorado en 1989 era de 82 millones de votantes, pasando a 94 millones en 1994, a 106 millones en 1998, a 115 millones en 2002 y 125 millones de electores en 2006.

${ }^{44}$ Entrevista citada.
} 
serían candidatos en las siguientes elecciones 45 . Cardoso recibió trato distinto: con la excusa de estar a cargo de un área demasiado delicada -la economía-, podría quedarse hasta inicio de abril. En ese período pudo llevar adelante no sólo la planificación del Real, sino que también pudo gestionar las articulaciones -especialmente con el PFL y parte del PMDB- que le permitieron formar una gran alianza de centro-derecha. Cuando dejó el ministerio, el Real ya había dado los primeros pasos: en marzo Cardoso anunció una fase de transición hacia el cambio definitivo de moneda, que ocurriría en julio. Era el tiempo suficiente para quedar en el inconciente popular como el "padre del Real" y presentar esa credencial en la campaña.

Cuando salió, ya se comportaba como candidato y contaba con respaldo para gestionar las estrategias electorales, incluyendo encuestas orientándose sobre las principales preocupaciones de la gente y las expectativas sobre la política. Además del apoyo de importantes actores políticos y sociales, desde su época en el ministerio ya contaba con asesoría profesional, una realidad que lo diferenciaba de la competencia. La planificación de plazo mediano se apropió del éxito del Real y llevó a cabo una campaña con alto nivel profesional y condiciones de organización muy favorables.

\subsubsection{Campañas de Corto Plazo:}

En 1998, el PT no tenía dudas: Lula sería candidato otra vez. Sin embargo, no tuvo tiempo para planificación de la campaña. Desde 1995, el partido consumía energía en la reorganización interna, resultando en la limitación de las tendencias y concentración de poder en torno de un gran grupo -el Campo Mayoritario- identificado con el líder petista. La reorganización interna creó las condiciones para la profesionalización, pero faltaba un elemento fundamental: recursos financieros. En junio, cuando la candidatura de Lula fue oficializada y logró acercarse a Cardoso en las encuestas electorales, el PT no contaba siquiera con un comité estructurado. Como mucho, podría presentar un staff de campaña enteramente partidista y aún sin un nombre en el área de comunicación y marketing 46 .

Es recién en esta fecha que se establece una efectiva planificación de campaña, que a continuación va recibir el refuerzo de Tony Cotrin para la producción de la publicidad electoral. En esa elección, los recursos eran casi tan escasos como en las anteriores,

\footnotetext{
45 A pesar de que la legislación establece un plazo de 6 meses para que los candidatos abandonen las funciones ejecutivas, el presidente Itamar Franco estableció el 20 de diciembre como fecha límite para la dimisión de los ministros. Deseaba entrar en el nuevo año con el nuevo equipo constituido.

${ }^{46}$ Ver revista Veja número 1550, de 10/06/1998, páginas 42-48 (disponible en www.veja.com.br).
} 
pero la planificación tardó demasiado: es, junto con la de 1994, la peor campaña de comunicación del PT. Al punto que no sacó ni siquiera partido del tono emocional ya experimentado con éxito en 1989. La estructura de 1998 pudo por lo menos presentar un núcleo central uniforme, todos los principales integrantes sintonizados con el candidato, sin los incómodos representantes de las tendencias minoritarias que en otras disputas tanto dificultaban la operacionalización de la organización electoral. Esta era la principal cosecha de las reformas iniciadas casi cuatro años antes.

En el caso de Ackmin 2002, otra campaña con planificación de corto plazo, los problemas financieros ni de lejos se asemejan a los de Lula 1998; pero sí la escasez de tiempo. A pesar de haber sido siempre citado como uno de los "presidenciables" del PSDB, de hecho Geraldo Alckmin no se preparó para ser candidato: como casi todo el país, creía que José Serra no abdicaría de la candidatura presidencial. Sin embargo, en marzo Serra sorprendió a todos al anunciar su decisión de no ser candidato a presidente, sino al gobierno de São Paulo, abriendo el camino a la candidatura de Alckmin. Lo que se vio enseguida fue un festival de improvisaciones más afectos a los aficionados que a los profesionales.

Sin ninguna planificación, los primeros pasos del candidato tucano estuvieron llenos de tropezones. La agenda no funcionaba y el nivel de improvisación quedó en evidencia en los frecuentes retrasos de la agenda 47 . Los eventos de fines de marzo y comienzo de abril carecían de las mínimas condiciones operacionales, incluyendo la falta de estructura de transporte, fundamental en un país de dimensiones continentales. El lanzamiento efectivo se dio en spots partidistas exhibidos en marzo y abril, avalando la imagen de Alckmin como realizador de grandes obras e importantes programas sociales en el gobierno de São Paulo. No obstante, la estrategia no logró -tampoco lo hará en la publicidad del período electoral- hacer de Alckmin un candidato popular, percibido como alguien sintonizado con el pueblo.

El poco tiempo de planificación de la campaña se revela en un hecho prosaico: el nombre por el cual el candidato sería llamado en la publicidad electoral, es decir, con que marca sería vendido al elector. Para los estrategas, el apellido Alckmin sonaba muy elitista, sobre todo cuando tenía por delante un candidato cuyo nombre de pila es Luís Inácio da Silva pero conocido por el apodo que normalmente cabe a todo Luís -Lula-, su nombre público. Esa costumbre responde a la tradición brasileña de referirse a las personalidades públicas -entre ellas artistas, políticos, jugadores de fútbol- no por su

\footnotetext{
${ }^{47}$ Ver revista Veja número 1951, del 12 de abril de 2006 (disponible en www.veja.com.br).
} 
apellido, sino por el nombre, como una señal de acercamiento al pueblo ${ }^{48}$. Como intento de ofrecer un nombre fácil, cercano y nada elitista, el primer material publicitario aparece con un sorprendente "Geraldo presidente". Es posible que la estrategia fuese acertada, pero el tiempo la condenaba: Alckmin siempre fue identificado por su apellido, el cambio hacia su nombre de pila volvía al nacionalmente poco conocido ex gobernador de São Paulo un nombre enteramente desconocido.

La dificultad de la estrategia también se revela en los ajustes realizados en la publicidad en la radio y televisión: el Geraldo de los primeros spots se transforma en Geraldo Alckmin, con nombre y apellido, en un esfuerzo para unir la marca de antes con la identificación pretendida. La confusión se hace notar en el material gráfico (pegatinas, carteles, bottons) en el medio de la campaña con las dos identificaciones, de cierto modo quebrando la unidad visual de la candidatura y generando confusión. Así es que en ningún momento Alckmin logra revertir la amplia ventaja que Lula disfrutaba.

\subsection{La financiación: la fuerza de los grupos de interés}

Los grupos de interés son los grandes soportes financieros de las campañas electorales en Brasil, un sistema que incluye el uso indirecto de recursos públicos y especialmente la posibilidad de donación del sector privado. El sector público participa de dos modos. Primero, a través del fondo partidista, que fuera del período oficial de campaña garantiza importante soporte para la acción política (y electoralista) de los partidos. Segundo, con la gratuidad del espacio de radio y TV para los candidatos, lo que en Estados Unidos corresponde a la mayor parte del presupuesto de las campañas. El valor del espacio cedido a los partidos en una campaña, si fuera facturado, tendría un valor superior a los 300 millones de euros. Las empresas de comunicación no reclaman por las "pérdidas": como compensación, reducen de los encargos fiscales una cuenta correspondiente a 80\% del impuesto que pagarían si el tiempo ocupado por los partidos hubiese sido comercializado en el mercado publicitario. En 2006, según datos divulgados por la agencia fiscal brasileña, las empresas de comunicación dejaron de

\footnotetext{
48 Por supuesto, hay excepciones, como los presidentes militares -todos identificados por el apellido desde la caserna- e incluso algunos nombres de la izquierda, como (Leonel) Brizola y (Miguel) Arraes. Pero en general funciona la identificación por el nombre, como Fernando Henrique (Cardoso), Juscelino (Jukitscheck), Jânio (Quadros), Tancredo (Neves) y Getúlio (Vargas), o también por el apodo, como en el caso de Jango, como era conocido João Goulart, y también el mismo Juscelino, identificado por JK, y Getúlio, también identificado por Gegê.
} 
pagar cerca de 75 millones de euros. A eso se suman otros 38 millones de euros correspondientes al fondo público de los partidos 49 .

Si la cuenta del sector público es alta, sustancialmente mayor es la que paga el sector privado: la renuncia fiscal de las empresas de comunicación correspondió al 12,5\% de los valores declarados por todas las candidaturas de 2006, pero esa proporción es ciertamente muy distinta si se toma como referencia la investigación de Samuels (2001), indicando que una elección general en Brasil involucra valores que son por lo menos dos veces el valor declarado por los partidos ${ }^{50}$. Según el autor estadounidense, la inversión hace de las campañas brasileñas la segunda más cara del planeta, incluso cuando se toma en cuenta tan sólo los valores oficiales, muy por debajo de la realidad. Es decir, sólo en Estados Unidos las campañas son más caras. En tan sólo tres meses de campaña, tanto Lula cómo Alckmin gastaron más que los partidos de Tony Blair y Angela Merkel en las campañas de Inglaterra y Alemania, los presupuestos más grandes de las campañas europeas.

Lula informó a la justicia electoral un valor correspondiente a 40,7 millones de euros, un 57\% mayor que el presupuesto de los democristianos alemanes y un $36 \%$ por encima de los laboristas ingleses. Alckmin declaró gastos de 32 millones de euros, $7 \%$ más que los gastos del partido de Blair y 23\% que el de Merkel ${ }^{51}$. Hay un agravante que merece la pena ser resaltado otra vez: la comparación entre Brasil y los dos sistemas europeos no toma en cuenta que tanto en el caso inglés como en el alemán, el coste ya incluye la elección de los integrantes del parlamento, que en Brasil y Estados Unidos implica una cuenta aparte.

Esos recursos tienen origen fundamentalmente en las grandes empresas, que depositan sus interés en una u otra candidatura. Las empresas fueron el soporte financiero de por lo menos siete de las diez campañas analizadas. El "por lo menos" es por la práctica del "caja dos", una contabilidad paralela, no declarada a la justicia electoral. De las otras tres campañas -las tres primeras de Lula-, hay serias sospechas del uso no declarado de recursos de grandes empresas en 1994 y 1998. Según César Benjamin, que participó en la coordinación de las campañas petistas de 1989 y 1994, ya en la segunda disputa presidencial se rumoreaba sobre las donaciones para la “caja dos” del PT, hecho que se

\footnotetext{
49 La renuncia fiscal respecto los espacios para los partidos en 2006 sumó 191 millones de reales, además de otros 98 millones del fondo partidista, cuya destinación final no es clara. Ver datos en http://veja.abril.com.br/blogs/reinaldo/2006/12/horrio-eleitoral-gratuito-uma-ova-r.htm/.

50 El cálculo de Samuels, realizado para las elecciones de 1998, toma en cuenta todas las campañas, no solo las presidenciales. Los valores declarados oficialmente suman 3.500 millones de dólares, pero el valor real estaría entre 7.000 y 35.000 millones de dólares.

51 Ver comparación en revista Época $\mathrm{n}^{\circ}$ 446, del 04/12/2006 (archivo digital disponible en http://revistaepoca.globo.com/Revista/Epoca/0,,EDG75860-6009,00.html).
} 
confirmó en 1995 y fue uno de los motivos para que saliera del partido5². En 1998, la tesorera de la campaña petista, Clara Ant, se empeñó en buscar apoyo financiero de las grandes empresas como forma de reunir las condiciones para la operacionalización de una estructura que pecaba de reducida.

Las primeras campañas de Lula tuvieron en las entidades del movimiento social un soporte fundamental en estructura para la acción política o incluso en recursos financieros directos. En 1994 Lula fue fotografiado realizando mítines con los coches de sonido de sindicatos de trabajadores, apoyo material que no aparece en la contabilidad. En esa misma campaña, el PT ha intentado que la justicia electoral considerase legal las donaciones de asociaciones sindicales, pero la prohibición se mantuvo. Después de ser fotografiado en los coches de sonido de sindicatos, Lula fue categórico: "Entre la ley y la cosa justa y legítima, yo siempre he dicho que el justo y legítimo es mucho más importante. Lo que yo considere que no es crimen, voy continuar practicando" 53 . La práctica revela la participación disimulada de los grupos de interés de los trabajadores en las campañas del PT.

Sin embargo, el gran salto del Partido de los Trabajadores hacia las donaciones de los grupos de interés empieza en las municipales de 2000 y se consolida en las presidenciales de 2002. Aún antes de las elecciones de 2000, Lula dijo con todas las letras que no entraría en una nueva campaña sin una estructura altamente profesional; no deseaba competir en el marco de precariedad de antes. Al serle recordada la necesidad de mucho dinero para concretar tal objetivo, dijo sin medias palabras: "Hágase lo que sea necesario", frase que es considerada la señal para una relación más amplia con el gran empresariado, responsable de la mayor parte de las donaciones y también usuarios sistemáticos de las donaciones no contabilizadas 54 .

La caja dos es una realidad no sólo de la política sino principalmente de las empresas brasileñas. Según datos del Instituto Brasileño de Planificación Tributaria, el dinero que cada año gira en la contabilidad paralela es cercano a los 400 mil millones de euros, cuyo primer resultado es la evasión fiscal de un 39\% de la carga tributaria de Brasil55. El segundo resultado son las donaciones no contabilizadas, práctica que lleva a muchas empresas a donar para más de un candidato, algo que agrada a los partidos

\footnotetext{
52 Ver el periódico O Povo del 03/10/2005, cuaderno Páginas Azuis (archivo digital disponible en http://www.opovo.com.br/opovo/paginasazuis/521156.htm/.

${ }^{53}$ Ver "Caixa 2 do PT se intensificou em 2002", de Josias Souza, en el periódico Folha de S. Paulo del 14/08/2005 (http://clipping.planejamento.gov.br/Noticias. asp? NOTCod $=214126$ ).

${ }^{54}$ Ver el citado reportaje de Josias Souza.

${ }^{55}$ Ver "Caixa 2 gira un tri por ano, diz estudo", de Sandra Balbi, en el periódico Folha de S. Paulo del 14/08/2005 (disponible en http://clipping.planejamento.gov.br/Noticias.asp?NOTCod=214106).
} 
pues necesitan de dinero para la "compra" de apoyos electorales y la financiación de prácticas ilegales como la institucionalizada "boca de urna".

Según un estudio del consultor político Gualdencio Torquato, profesor de la Universidad de São Paulo, ese tipo de ación representa el segundo mayor coste del presupuesto, por detrás tan sólo de los recursos destinados a la publicidad electoral ${ }^{5}$. Los cálculos fueron realizados en el contexto de las elecciones de 2002 y el coste total estimado es de 70 millones de reales (cerca de 27 millones de euros) estaba por encima de los valores declarados por los dos principales candidatos al reconcluir la campaña. Del presupuesto estimado por Torquato, 15 millones (casi 6 millones de euros) o el $21,4 \%$ del total tiene como objetivo esos tipos de gastos sin registro contable. No es de extrañar que las campañas del PT en los diversos niveles movilizaron entre 2002 y 2004 un valor calculado entre los 200 y 300 millones de reales o entre 78 y 117 millones de euros ${ }^{57}$. Una verdad indesmentible: la caja dos está presente en todas las campañas, independiente del partido.

Quizá -iquizá!- la única de las diez campañas analizadas que tiene como base los recursos de los voluntarios es la primera del PT, aún así fortalecida en gran medida por el dinero de empresas que en la segunda vuelta optaron por Lula como antítesis a la alternativa Fernando Collor. Eso no significa que las primeras campañas de Lula estuvieron basadas en el capital; no, la base eran los voluntarios, sobre todo en 1989. Pero es notorio que la participación de las donaciones de personas físicas en la política brasileña es muy distinta de la realidad americana. Además, hasta 1998, aunque algunas empresas aportasen recursos para Lula, miraban preferentemente hacia sus concurrentes. Un ejemplo es el Banco Itaú, una de las principales compañías financieras del país: en aquel año, el banco donó 84 mil dólares para Ciro Gomes, 151 mil para Lula y 2,24 millones para Cardoso (Samuels, 2001). Todo cambia a partir de 2002, cuando las grandes empresas son el soporte financiero de la campaña petista; en 2006, la banca antes tan refractaria se convierte en la principal fuente de recursos de la campaña del PT.

Los datos de Samuels para 1998 revelan que los diez principales donantes privados destinaron 32,7 millones de dólares a candidaturas en diversos niveles (Cuadro 5.5). Valle recordar que esos son los valores declarados, porque parte sustantiva de los recursos van a parar a la caja dos de las campañas; se evalúa que por lo menos 10 millones de reales (o 8,6 millones de dólares de la época, por la conversión de Samuels)

\footnotetext{
${ }^{56}$ Ver "Começa o show dos milhões", de David Friedlander y Thomas Traumann, en revista Época $\mathrm{n}^{\circ}$ 213, del 17/06/2002 (Disponible en http://epoca.globo.com/edic/213/brasil2002a.htm).

57 Datos del periódico Folha de S. Paulo del 14/08/2005.
} 
dejaron de ser contabilizados en la campaña de reelección de Cardoso. Otro factor que dificulta la identificación del origen del dinero es que la legislación admite que las donaciones realizadas directamente a los partidos oculten la fuente; corresponde al partido decidir a cuál campaña (local o nacional) se destinará ese dinero. En 2006, 17\% de la contabilidad de Lula y $12 \%$ de los recursos de Alckmin llegaron de fuentes ocultas $5^{8}$.

CUADRO 5.5

Las donaciones privadas en las elecciones de 1998

\begin{tabular}{lcc|ccc}
\hline El dinero invertido & \multicolumn{5}{c}{ Políticos que cada empresa ayudó a elegir } \\
\hline Donadores & Valor & Diputados & Senadores & Gobernadores & Presidente \\
\hline Banco Itaú & 5,0 & 24 & 5 & 3 & 1 \\
\hline Odebrecht & 4,8 & 28 & 3 & 5 & 1 \\
\hline Copesul & 4,5 & 9 & 3 & 2 & 1 \\
\hline Andrade Gutierrez & 3,3 & 5 & 3 & 4 & 1 \\
\hline Votorantim & 3,0 & 12 & 2 & 1 & 1 \\
\hline Ipiranga & 2,8 & 18 & 3 & 3 & 1 \\
\hline Inepar & 2,7 & 5 & 1 & 3 & 1 \\
\hline Bradesco & 2,2 & - & - & 1 & 1 \\
\hline Unibanco & 2,2 & 18 & - & 1 & 1 \\
\hline Vale do Rio Doce & 2,2 & 4 & - & & 1 \\
\hline $\begin{array}{l}\text { Fuente: Samuels (2001) y Revista Época } \mathrm{n}^{\circ} \text { 213, del 17/06/2002. } \\
*\end{array}$
\end{tabular}

El poder del dinero en las campañas puede ser medido por un estudio de la ONG Transparencia Brasil: en las elecciones generales de 2006, los candidatos elegidos (poco más de $12 \%$ del total de postulantes) concentraron $56 \%$ de los recursos en gastos en la campaña59. En otra investigación, Transparencia Brasil saque importantes revelciones a través de una encuesta junto a las empresas donantes: primero, que muchas de las donaciones son realizadas bajo coacción de los sectores políticos; segundo, que las donaciones se traducen en beneficios a los donantes, después de la elección. Al convertirse en principal donante de las campañas, los grandes empresarios adquieren una amplia capacidad de presión. Y el dinero es destinado según los intereses de cada donante.

\footnotetext{
${ }^{58}$ Ver revista Época $\mathrm{n}^{\circ} 446$, del 04/12/2006.

59 Una sistematización de los estudios de la Transparencia Brasil sobre corrupción en Brasil están en Abramo (2004). Los estudios más recientes y el observatorio sobre financiación de campaña están el la página web de la ONG: www.transparenciabrasil.org.br.
} 
Siguiendo con el ejemplo del Banco Itaú, el dinero destinado por el grupo financiero a los candidatos presidenciales fue la mitad del total donado en aquella elección. Al final, el banco pudo celebrar el hecho de ayudar a elegir 24 diputados federales, 5 senadores, 3 gobernadores y el presidente, conforme el Cuadro 5.5. El segundo mayor donante, la constructora Norberto Odebrecht, contribuyó con 4,8 millones de dólares en la elección de 48 diputados, 3 senadores, 3 gobernadores y del presidente. Esa representación es posible de interpretar como una puerta abierta del poder para los intereses de la empresa.

En definitiva, solamente la campaña de Lula en 1989 tuvo la participación voluntaria como base financiera, a través de donaciones directas a la campaña o de la participación en eventos para recaudar recursos (Cuadro 5.6). En esa elección se pusieron de moda las "cenas de apoyo a Lula”. Ese tipo de evento es una tradición en la política estadounidense, operando como una importante fuente de recursos, especialmente en la fase inicial. Pero hay dos destacadas diferencias respecto el caso del PT: primero, ese tipo de evento era realizado en todo el país y sin la participación del candidato, al contrario de Estados Unidos, donde la posibilidad de contacto con el postulante a la Casa Blanca se convierte en el principal incentivo del encuentro; segundo, el valor de las invitaciones, que muchas veces correspondía al doble o triple de una cena normal de un restaurante mediano, en contra la realidad norteamericana en que los invitados pagan miles de dólares para estar cerca del candidato por algunos minutos. La diferencia fundamental está en que los eventos estadounidenses se enfocan a grandes empresarios y las acciones de Lula apuntaban a profesionales de clase media.

Cuadro 5.6

La financiación de las campañas

\begin{tabular}{ll}
\hline Fuente de recursos & Candidaturas \\
\hline $\begin{array}{l}\text { Grupos de interés } \\
\text { (7 campañas) }\end{array}$ & $\begin{array}{l}\text { Es el gran soporte de las campañas en Brasil. } \\
\text { Todas las } 5 \text { campañas victoriosas (más las de Serra 2002 y } \\
\text { Alckmin 2006) financiaron la extraordinaria estructura } \\
\text { organizativa con los recursos de grandes donadores privados, } \\
\text { sobre todo aquellos que prestan servicios al Poder Público. }\end{array}$ \\
\hline $\begin{array}{l}\text { Voluntarios y grupos } \\
\text { de interés }\end{array}$ & $\begin{array}{l}\text { Lula 1994 y 1998: contaba con una importante participación de } \\
\text { (2 campañas) } \\
\text { movilización de los partidistas y simpatizantes), pero con }\end{array}$ \\
\hline Voluntarios & sustantivas donaciones de empresas. \\
(1 campañas) & $\begin{array}{l}\text { Campaña de Lula 1989, basada en la movilización de los } \\
\text { partidistas y simpatizantes. }\end{array}$ \\
\hline Fuente: elaboración propia. &
\end{tabular}


Las campañas de Lula en 1994 y 1998 pueden ser calificadas como un término medio entre el voluntarismo de la primera y la relación con los grupos de interés, en las últimas. En las dos campañas de la década pasada, hay una importante participación de los partidistas y simpatizantes pero también contó con los recursos de grupos de interés, cubriendo parte sustantiva de los gastos. Las otras siete campañas -entre ellas las dos últimas de Lula- estuvieron basadas en la financiación de los grandes grupos. Otra vez cabe destacar la campaña de Collor en 1989, lejos la más cara campaña de toda la historia democrática brasileña.

\subsection{El monitoreo del elector: el uso de las encuestas y grupos focales}

El uso de encuestas como instrumento de acompañamiento de la política no es nuevo en las campañas brasileñas. Los primeros sondeos sobre temas políticos fueron realizados ya en la década de 1940, con la creación del Ibope, instituto de opinión pública inspirado en la experiencia de George Galup en Estados Unidos. En la década siguiente, en la campaña presidencial de 1955, Juscelino Kubitschek pudo contar con información sobre la evolución de su candidatura gracias a las encuestas del instituto. Pero la popularización de ese recurso como instrumento para orientación de las estrategias de campaña se da con el proceso de redemocratización en la década de 1980, en concreto desde 1982, cuando empieza a ser utilizada de modo amplio no sólo por partidos, son también por los medios de comunicación. Con las presidenciales de 1989 ganan extraordinaria importancia tanto las encuestas cuantitativas como otros recursos de monitoreo del sentimiento del elector, por ejemplo: los grupos focales.

En la campaña para el gobierno de Río de Janeiro en 1982, Leonel Brizola contó con los servicios del analista de encuestas Homero Icaza Sánchez, que por mucho tiempo trabajó para TV Globo analizando la reacción del público frente a las producciones exhibidas por la emisora. Sánchez es una de las caras del proceso profesional que maduró en la industria de la comunicación y a continuación migró hacia la política. También en Globo se utilizaban los análisis cualitativos, con grupos focales que orientaban a la emisora en la definición de las telenovelas. Como consecuencia de la popularización de las encuestas, a fines de los años 1980 surgieron varios institutos de opinión pública en todo el país. Un ejemplo es IPOP, el Instituto Piauiense de Opinión Pública, que en 1988 trabajó para la candidatura de Heráclito Fortes (PMDB) a la alcaldía de Teresina realizando encuestas semanales.

En las presidenciales de 1989, sólo la limitación financiera impedía la amplia utilización de las encuestas como instrumento de orientación de las campañas, puesto 
que el recurso ya contaba con una amplia aceptación en el mundo político. Éste es el caso de la campaña del PT, que se guió más por los instintos que los instrumentos técnicos, según revela José Genoino, ex presidente del partido ${ }^{60}$. Las estrategias del PT en aquella elección no contaban con las encuestas orientando las decisiones, en primer lugar porque las directrices eran fruto del enfoque basado en la lucha de clases, pero principalmente- porque la escasez de recursos impedía la contratación de sondeos. Solamente en la fase final de la disputa -más que nada en la segunda vuelta- la campaña de Lula va contar con datos de encuestas, casi siempre datos generales, sin detalles más allá de la "fotografía del momento" en la carrera electoral; datos, además, obtenidos de modo subrepticio, filtrados por simpatizantes de la candidatura entonces ya un verdadero movimiento social- instalados en institutos de investigación, medios o incluso en asociaciones empresariales ${ }^{61}$.

En 1994 y 1998, otra vez la escasez de recursos en las campañas de Lula resultó en el bajo uso de las encuestas como instrumento estratégico. Es cierto que los sondeos estuvieron más presentes que en la primera campaña, pero aún en un nivel muy bajo, sobre todo cuando comparado con la competencia, ampliamente respaldada por datos estadísticos que incluso orientaban a diario la toma de decisiones respecto importantes temas, el posicionamiento previo y el desarrollo de la campaña. Si el PT aún encontraba dificultades para contratar sondeos de opinión pública, en la competencia eran comunes tanto las encuestas como los grupos focales, permitiendo una visión detallada del proceso electoral.

Es particularmente ilustrativo el caso de Collor, que dos años antes de la campaña ya era orientado por los sondeos del instituto Vox Populi y los análisis de Marcos Coimbra. Consciente de la necesidad de volverse conocido, el poítico se concentró en producir sus mensajes y concentrar sus acciones mediáticas según las demandas del elector; todos los pasos del candidato eran guiados por las encuestas que indicaban cuál era la posición más interesante para aumentar su popularidad. El esfuerzo por ajustar el discurso al sentimiento de la mayoría hace que Figueiredo (1994) identifique al Caçador de Marajás como el actor que se apropia del discurso latente en la mente de la gente. Es decir, Collor fue el candidato que se supo ajustar a la demanda del elector, no al revés.

Un ejemplo de la preocupación por el sentimiento popular tuvo lugar en 1987, en el calor de las discusiones de la Asamblea Nacional Constituyente: conocedor del amplio

\footnotetext{
60 Entrevista al autor en mayo de 2007.

61 Ver declaraciones de César Benjamin, uno de los coordinadores de la campaña de PT en 1989 y 1994, en entrevista al periódico O Povo del 03/10/2005.
} 
desgaste del gobierno de Sarney, Collor fue el único de los 23 gobernadores de PMDB en no apoyar la propuesta de un mandato de 5 años para el entonces presidente; quería que la constituyente lo fijara en 4 años ${ }^{62}$. También por orientación de los sondeos, hace de la lucha contra la corrupción una de sus principales banderas, traducida en el combate a los Marajás del servicio público. La estrategia tiene una amplia repercusión, culminando con un Globo Repórter ${ }^{63}$ enteramente dedicado a la lucha de Collor contra los altos sueldos de los funcionarios, o la portada de la revista Veja ${ }^{64}$ con el gobernador, cuando se popularizó la etiqueta Caçador de Marajás.

Exceptuando las tres primeras campañas de Lula, desde Collor en 1989 las encuestas son un recurso ordinario en las campañas brasileñas (Cuadro 5.7). Hoy toda candidatura -incluso para la alcaldía de ciudades medianas- cuenta con las encuestas como instrumento estratégico, tanto en la definición del posicionamiento inicial como en las evaluaciones del curso de la campaña para mantener o corregir el rumbo. Y en ese campo el partidismo es mínimo: quizá con la excepción del caso de Antonio Lavareda, con estrechos vínculos con el grupo central de PSDB y PFL/DEM, no hay ningún instituto de investigación vinculado a un partido. El ejemplo más claro es el Vox Populi de Coimbra: trabajó para Collor en 1989, después para Cardoso en 1994 y 1998, para Ciro Gomes en la primera vuelta de 2002 y para Lula en la segunda vuelta de aquel año y otra vez para Lula en las dos fases de la campaña de 2006.

Las cuatro campañas del PSDB analizadas contaron con un amplio soporte de encuestas, base de todas las decisiones importantes. Lo mismo pasa con las dos últimas de Lula, cuando la profesionalización se impuso a partir de los cambios internos del PT y el extraordinario presupuesto que pasó a manejar. Además, los datos cuantitativos eran complementados por análisis cualitativos, especialmente los resultantes de los grupos focales, otra técnica popularizada desde la campaña de Collor.

Hasta 1989, los grupos focales eran patrimonio casi exclusivo de las tesis universitarias y la industria de la comunicación, en pruebas para productos de consumo o evaluación de programas televisivos y anuncios publicitarios. La campaña de Collor utiliza los grupos focales desde la fase de preparación estratégica. La gran novedad de la campaña del Caçador de Marajás fue la utilización de esa técnica en la evaluación diaria de la publicidad electoral, lo que se evidencia en el caso de un spot exhibido con el propósito de orientar el elector a votar: en la papeleta de la primera vuelta, el nombre del

\footnotetext{
62 Ver Rosa e Silva (1993) y el verbete Fernando Collor en Fundaçao Getúlio Vargas (2000).

${ }^{63}$ El Globo Repórter es un programa semanal de reportaje de TV Globo, comparable al 60 Minutes en la cadena CBS de Estados Unidos o al Informe Semanal, en la TVE 1 española, pero con audiencia alrededor de los $40 \%$.

64 Veja es la principal revista de información de Brasil.
} 
candidato de PRN aparecía en el medio de un listado de 21 competidores; en concreto, era el noveno puesto desde abajo hacia arriba, resultando difícil de identificar, sobre todo para el elector de poca escolaridad, que componía el grueso de sus votantes.

CUADRO 5.7

Utilización de los recursos de monitoreo en las campañas

\begin{tabular}{l|l}
\hline Técnica & Utilización \\
\hline Encuestas & Ampliamente utilizada en la campaña de Collor, que creó la referencia. \\
Cuantitativas & $\begin{array}{l}\text { Está presente en todas las campañas victoriosas, además de las de } \\
\text { Serra y Alckmin. } \\
\text { Baja utilización en las tres primeras campañas de Lula, sobre todo en la } \\
\text { de 1989, a falta de recursos financieros. }\end{array}$ \\
\hline Cualitativas / & Altísimo uso en la campaña de Collor y alta utilización en las cuatro \\
Grupos Focales & $\begin{array}{l}\text { En la práctica, inexistente en las campañas de Lula en } 1989 \text { y poco } \\
\text { utilizada en 1994 y 1998, por la escasez de recursos. }\end{array}$ \\
\hline
\end{tabular}

Fuente: elaboración propia.

Los publicistas idearon una fórmula que se plasmó en un anuncio que daba mejores coordenadas para identificar el sitio donde estaba el nombre de Collor. En él utilizan la frase "é para frente que se anda" [es para adelante que se anda], cada sílaba indicando un nombre más arriba hasta llegar a la casilla del candidato. El anuncio fue exhibido una sola vez: la evaluación en los grupos focales reveló que la gente no lo comprendía; la cuenta hacia arriba no siempre coincidía con el cuadrillo del candidato. Fue sustituido por otro que decía sencillamente "vote redondo", haciendo referencia al número 20 correspondiente a Collor y que en la papeleta constaba dentro del cuadro por delante del nombre del Caçador de Marajás. Además de un número redondo por ser decenas completas, el 20 contaba aún con la ventaja de contener el cero, visualmente redondo. Las pruebas con grupos de electores revelaron mayor efectividad de ese anuncio que el primero.

La presencia de los instrumentos de monitoreo del electorado está cada vez más presente, alcanzando un nivel extraordinario, como revela el mismo coordinador de marketing de la campaña de Lula 2006, João Santana, en entrevista al periódico Folha de $S$. Paulo. El texto de apertura de la entrevista da una clara idea del papel de los recursos de monitoreo: 
"Cada 24 horas, el instituto Vox Populi entrevistaba 700 electores para la campaña del PT en todo el país. A la vez, también a diario, ocho grupos de 12 personas eran entrevistados por cerca de una hora y media por especialistas -las llamadas encuestas cualitativas-. Las 'cualis' eran transmitidas en vídeo, en directo, a través de Internet por medio de una conexión segura hacia el ordenador de Santana.

En 77 días [de campaña], el publicista de Lula conoció la opinión, por tanto, de 53.900 entrevistas cuantitativas y 7.392 cualitativas -más que la mayoría de las tesis universitarias que intentan comprender lo que piensan los electores brasileños-". (Folha de S. Paulo, 5/11/2006)

La presencia de tales recursos técnicos son esenciales en las campañas, tanto en el nivel nacional como regional y local. En ese campo, las campañas electorales de Brasil parecen indicar un nivel de profesionalización por encima de la mayoría de las disputas latinoamericanas y europeas. Duda Mendonça (2001) revela que utilizó los grupos focales incluso para acompañar la evolución de los debates televisivos. En general, acompañaba al candidato al plató de televisión mientras un auxiliar seguía el debate junto a uno o más grupos focales, repasando por teléfono la evaluación del grupo sobre las intervenciones del político. Las reacciones podían cambiar la postura del candidato en el debate. Hubo un caso en que la respuesta a una pregunta no quedó suficientemente clara para el grupo. En el intervalo entre bloques de preguntas, el consultor orientó el candidato, que ante una nueva cuestión, hizo referencia a la pregunta anterior, reformulando la respuesta de un modo más claro para la audiencia.

A pesar de implicar en grandes sumas de dinero, no es de extrañar que ningún partido levante la mano para criticar el uso de ese tipo de recurso en el proceso de competencia electoral. De hecho, son instrumentos de gran utilidad, capaces de aportar a los estrategas informaciones preciosas que pueden ayudar a decidir la disputa.

\subsection{Media training y entrenamiento de equipos}

Los recursos de entrenamiento son utilizados de modo irregular, aunque estén presentes en las campañas desde hace bastante tiempo. El entrenamiento de equipo para la acción electoral fue una innovación introducida en la campaña de Fernando Collor que sigue en uso, pero en intensidad menor. En cuanto al entrenamiento de los 
candidatos, es común que enfrenten sesiones de media training ${ }^{65}$, incluso en el caso de candidatos que llegan a las presidenciales como etapa cumbre de una carrera profesional que en otro momento exigió conocimientos específicos sobre, por ejemplo, el modo de presentarse en la TV. En búsqueda del mejor desempeño ante los medios, ellos se someten a la dirección de expertos al momento de grabar la publicidad electoral o antes de una entrevista o debate televisivo ${ }^{66}$. Quizá el caso de Lula en 1989 sea excepcional: el candidato se negaba a utilizar el teleprompter ${ }^{67}$, además de rehusar algunas orientaciones del director de la publicidad que pedía que el candidato se distendiera e incluso esbozase alguna sonrisa. Esta negativa contribuyó a formarle una imagen "pesada".

En 1994 Lula comienza a aceptar la orientación del director y desde entonces fue acumulando experiencia en el trato con las cámaras de televisión. Aún así, en la campaña de 2002 Duda Mendonça sometió el experimentado Lula a una especie de laboratorio para el principal debate contra José Serra, en la segunda vuelta, en TV Globo ${ }^{68}$. La gran artimaña de Mendonça fue que el laboratorio serviría a la vez para preparar el candidato y crear un contrato de lectura con el votante: el debate ofrecería un formato distinto del tradicional, sin sitio fijo para los candidatos, que tenían la posibilidad de moverse por un círculo rodeado por una platea ocupada por ciudadanos encargados de hacer las preguntas. En los días anteriores al enfrentamiento entre candidatos, el programa electoral de PT adoptó una mecánica semejante a la del debate, Lula desplazándose por un plató lleno de ciudadanos que le preguntaban sobre un tema específico. Además de acostumbrar al candidato al espacio, Mendonça permitió que el elector asociase el escenario con el mismo Lula.

La preparación para los debates televisivos es antigua en las campañas brasileñas, siendo utilizados ampliamente en las disputas por los gobiernos de los estados en 1982. La preparación pasa por el tipo de respuesta a los temas principales que deberán ser tratados así como por la forma de presentarse. El mismo Mendonça (2001) explicita las preocupaciones en esa preparación, especialmente cuando las contiendas son muy

65 El media training [entrenamento para los medios] es un recurso popularizado en las campañas estadounidenses en que los políticos reciben entrenamiento para enfrentar a los medios. Los entrenamientos pueden ser para un pronunciamiento sobre un tema específico, como en los spots electorales, o la preparación para debates y entrevistas. Tiene una especial preocupación respecto la forma en que los candidatos se presentan ante las cámaras de TV.

66 Las informaciones de ese apartado se obtuvieron en las entrevistas realizadas por el autor y otras fuentes, como Mendonça (2001), Rosa y Silva (1993) y declaraciones como las de César Benjamin a la prensa.

${ }^{67}$ El Teleprompter, también conocido como $P T$, es un aparato localizado por delante de la cámara que permite reproducir un texto para ser leído por quien se encuentra delante de ella. La ausencia de papeles genera la sensación de que se trata de una declaración sin preparación previa.

${ }^{68}$ Sobre el debate entre Lula y Serra en 2002, ver el análisis de Fausto Neto e Verón (2003). 
disputadas y el debate puede tener un papel decisivo en el resultado electoral. La elección de 1989 ofrece dos distintas preocupaciones con el duelo entre los candidatos: después de un mal desempeño en el primer enfrentamiento televisivo de la segunda vuelta, Collor dedicó las últimas 24 horas antes del segundo debate a repasar los temas y mantener la apariencia descansada. Lula, al revés, enfrentó una maratón de mítines en el mismo día del suceso, llegando al debate agotado y sin la brillantez del encuentro anterior. Perdió el debate y la elección.

El entrenamiento del candidato incluye la preparación para toda situación de contacto con el público, directo o mediatizado. La gesticulación de Collor en toda la campaña fue estudiada: el caminar acelerado produciendo la idea de dinamismo; la mano cerrada insinuando fuerza y valentía; los discursos vibrantes y las grabaciones en estudio mezclando la valentía con el tono cercano y suave del "yo y tú" presente en una serie de mensajes de la segunda vuelta. Cardoso también tuvo el mismo tipo de orientación, además de recibir en 1994 las "clases de pueblo" para no parecer artificial en el contacto con la gente (Dimenstein e Souza, 1994). El Cardoso que enfrenta la disputa de 1994 también es distinto del Cardoso que nueve años antes disputó (y perdió) la alcaldía de São Paulo: el candidato a la alcaldía hablaba en escenarios de poca luz, sin un texto elaborado y un gestual poco consciente; el Cardoso candidato a presidente utilizaba las filmaciones en plan cerrados, incluso utilizando el close up, más ajustados al lenguaje televisivo, fortaleciendo la personalización. También utilizaba gestos medidos y rostro maquillado. La dirección del candidato era tarea del mismo Geraldo Walter, como en 1998 sería de Nizan Guanaes. Ningún spot era aprobado hasta que cada movimiento de la cara y el tono de hablar tradujesen toda la intención estratégica deseada; si era necesario, la grabación se repetía una decena de veces.

Lula, por su parte, pasa por un largo aprendizaje que se revela de una campaña a otra: el Lula de habla firme y tono denunciador que se encuentra en 1989 es distinto del Lula sereno y dulce que se ve desde 1998; el político con un programa casi revolucionario da paso al hombre del pueblo que, por conocer el pueblo y hablar con el corazón, es capaz de llevar a cabo importantes transformaciones. Hoy Lula es uno de los más preparados en el trato con la cámara, ajustando el tono y los gestos a cada situación y capaz de hacer de un discurso formal una charla con la audiencia.

El Lula intimista y dulce es resultado de la suma del cambio estratégico y de mucho entrenamiento. En 2002, no sólo Lula sino todo un amplio grupo de políticos y técnicos del PT y partidos aliados se convirtieron en actores para la grabación de la apertura de los programas electorales de la primera vuelta. En ella, el candidato camina por el escenario, simula decir algo al oído de Aloízio Mercadante y entonces empieza a hablar. 
Cuando termina el texto, leído en el teleprompter, el grupo que "trabaja" en el programa de gobierno sigue escenificando y, de pie, aplaude el candidato. Todo como si fuera natural, aunque fue el resultado de muchos ensayos.

En el caso de Serra, los entrenamientos no redujeran el tono duro y tecnicista del candidato tucano de 2002. La dirección de las grabaciones era responsabilidad del mismo Guanaes que tan buenos resultados logró con Cardoso. Mejor suerte tuvo Luís González con Geraldo Alckmin, en 2006: a pesar de ser mucho más contenido en los gestos y con una timidez a veces confundida con frialdad, Alckmin pudo presentar momentos vivos, con energía en el modo de hablar y calidez en el contacto con la gente. En esa campaña, las sesiones de entrenamiento del candidato delante de las cámaras de TV fueron agotadoras.

En cuanto al entrenamiento de la militancia, ese recurso fue utilizado sobre todo por Collor (ver Cuadro 5.8). Uno de los símbolos de la modernización organizativa inaugurada por Collor fue un vídeo orientando el trabajo de boca de urna que empezaba con un saludo del mismo candidato a los involucrados en la tarea. Este vídeo, didáctico y de sofisticada producción, fue distribuido en todo el país, una demostración de la profesionalización y de la centralización de comando de la campaña, además de la disponibilidad de recursos. El trabajo de boca de urna realizado por Collor se distinguía también por contar con personas contratadas, un cambio que se impone de ahí en delante: ahora, en la práctica, todas las actividades realizadas a boca de urna son pagadas, realidad que en 2006 se consolidó incluso en la esfera petista.

CUADRO 5.8

Los recursos de entrenamiento en las campañas brasileñas

\begin{tabular}{ll}
\hline Tecnología & Utilización \\
\hline Media trainning & $\begin{array}{l}\text { A excepción de Lula en 1989, muy utilizado por todas las campañas: el } \\
\text { candidato es dirigido en su gesticulación y el tono que utiliza según la } \\
\text { intención estratégica de cada mensaje. }\end{array}$ \\
\hline $\begin{array}{l}\text { Entrenamiento } \\
\text { de equipos }\end{array}$ & $\begin{array}{l}\text { Alta utilización en la campaña de Collor, quedando como uno de los } \\
\text { marcos de profesionalización. } \\
\text { En las demás campañas, la orientación de partidarios y simpatizantes es a } \\
\text { través de manuales y cartillas con las directrices de la campaña. }\end{array}$ \\
\hline
\end{tabular}

Fuente: elaboración propia.

Las demás candidaturas actuaron de modo menos explícito y también menos intenso, sobre todo porque la boca de urna está prohibida por la legislación brasileña, aunque institucionalizada y practicada ampliamente. A causa de la prohibición, no hay vídeos 
desde 1994. A pesar de ello, todas las candidaturas adoptan algún tipo de orientación para partidarios y simpatizantes. El recurso más tradicional es la elaboración de cartillas y manuales de campañas en que son reproducidas las principales metas del candidato, los cuidados respecto a la legislación y formas de dar mayor visibilidad y movimiento a la campaña. En todas las campañas, el PT y PSDB elaboraron manuales, casi todos incluyendo las orientaciones de como se debe utilizar la marca del candidato en reuniones, coches y comités.

\subsection{El uso de las nuevas tecnologías}

Si la incorporación de las nuevas tecnologías es un rasgo de la profesionalización de campañas (Norris, 2001), la profesionalización de las campañas brasileñas se revela con el creciente uso de los nuevos recursos técnicos. Un ejemplo que ilustra bien tal relación es la Internet, que ya en 1998 -primera campaña desde el surgimiento de la Internet comercial en Brasil- fue utilizada de modo relevante, aunque no en la misma medida que en la campaña de 1996 en Estados Unidos, cuando las paginas web se convierten en una importante ventana para la interacción del candidato con el elector.

Por supuesto, la Internet estuvo ausente en las dos primeras campañas presidenciales, puesto que no estaba popularizado su uso entre los ciudadanos de estratos medios. Incluso en 1998 la utilización es incipiente, puesto que el alcance del nuevo medio es muy limitado. A fines de la década de 1990, tan sólo un $3 \%$ de los brasileños estaban conectados, a pesar de que Brasil era el país latinoamericano con mayor presencia en el ciberespacio. A fines de 2006, el índice era cinco veces mayor, alcanzando el 15\% de la población por encima de los 15 años, posicionando al país en el $11^{\circ}$ puesto en el número de usuarios. Según datos de Internet World Stats, Brasil tenía en junio de 2007 un total de 39 millones de usuarios, superando la cantidad estimada de lectores de periódicos ${ }^{69}$.

A pesar del reducido público, la Internet formó parte de las estrategias de comunicación de Cardoso y Lula, en 1998 (Cuadro 5.9). Cardoso dispuso en su página web diversas informaciones, desde noticias, agenda de viajes y programa de gobierno, además de solicitar las críticas y sugerencias del elector. En la página de Lula, se podía encontrar informaciones sobre la campaña, detalles de las propuestas y ataque a la administración y proyectos de Cardoso (Steffen, 2004). Para los patrones actuales, es

69 Para el ranking de Brasil, ver datos de la empresa comSkore Networks (archivo disponible en http://cidadebiz.oi.com.br/noticias/imprimir.php?artigo_id=38425). Para los datos de Internet World Stats para América del Sur, ver http://www.internetworldstats.com/stats 15.htm. 
una subutilización del recurso, pero es una realidad sustancialmente distinta a la observada en la campaña de 1994, cuando las candidaturas solamente ofrecían como posibilidad de interacción una línea telefónica con llamada gratuita, como en el caso de Cardoso.

\section{CUADRO 5.9}

Las nuevas tecnologías en las campañas brasileñas

\begin{tabular}{|c|c|}
\hline Tecnología & Candidatura \\
\hline \multirow[t]{3}{*}{ Web } & $\begin{array}{l}\text { Sin uso en } 1989 \text { y } 1994 \text {, puesto que no existía todavía como medio de } \\
\text { masas. }\end{array}$ \\
\hline & $\begin{array}{l}\text { Uso mediano en 1998: las campañas de Cardoso y Lula empiezan a } \\
\text { utilizar la web como medio de información, pero sin interactividad. }\end{array}$ \\
\hline & $\begin{array}{l}\text { En } 2002 \text { y } 2006 \text {, todas las campañas utilizan páginas web como } \\
\text { instrumento de interacción con el elector. En 2006, las campañas también } \\
\text { utilizan Orkut y Youtube. }\end{array}$ \\
\hline e-Mail & $\begin{array}{l}\text { No estaba disponible hasta 1994, tiene baja utilización en } 1998 \text {, tanto por } \\
\text { Cardoso como por Lula. Desde } 2002 \text { es ampliamente utilizado en la } \\
\text { comunicación con partidarios y no partidarios (en este caso, a través de la } \\
\text { adquisición de bancos de datos informatizados a empresas } \\
\text { especializadas). }\end{array}$ \\
\hline Intranet & $\begin{array}{l}\text { Es parte fundamental de la estructura de las campañas de Lula y Alckmin } \\
\text { en } 2006 \text {. En 2002, tiene un uso mediano, y bajo o inexistente en las } \\
\text { anteriores. }\end{array}$ \\
\hline SMS & $\begin{array}{l}\text { Aparece recién en 1998, apenas existe en 2002. Gana relevancia } \\
\text { mediana en las campañas tanto de Lula como de Alckmin, en } 2006 .\end{array}$ \\
\hline \multirow[t]{2}{*}{$\begin{array}{l}\text { Banco de datos } \\
\text { informatizado y } \\
\text { correo dirigido }\end{array}$} & $\begin{array}{l}\text { La comunicación directa sigue siendo una materia pendiente en las } \\
\text { campañas brasileñas. Collor la utiliza en mediana intensidad, así como las } \\
\text { campañas de PT y PSDB en } 2002 \text { y } 2006 \text {. }\end{array}$ \\
\hline & $\begin{array}{l}\text { Baja utilización en las tres primeras campañas de Lula y en las dos de } \\
\text { Cardoso. }\end{array}$ \\
\hline \multirow[t]{3}{*}{ Telemarketing } & Bajo uso por Lula de 1989 a 1998, a causa de los pocos recursos. \\
\hline & $\begin{array}{l}\text { Cardoso, Serra, Alckmin y las campañas de Lula desde } 2002 \text { hacen uso } \\
\text { mediano, con estudiada definición de público, resultando en mayor } \\
\text { efectividad. }\end{array}$ \\
\hline & $\begin{array}{l}\text { Intensa utilización tan sólo en la campaña de Collor: como novedad, tuvo } \\
\text { un fuerte impacto. }\end{array}$ \\
\hline Satélite & $\begin{array}{l}\text { Bajo uso: la distribución de los mensajes se hace en cadena por las } \\
\text { emisoras de TV. Uso esporádico en conferencias cerradas. }\end{array}$ \\
\hline
\end{tabular}

Fuente: elaboración propia.

Es a partir de 2002, sin embargo, que este medio se convierte en uno de los recursos más importantes, sobre todo por la capacidad de hablar con segmentos específicos. En aquella elección, los tres principales candidatos -Lula, Serra y Ciro Gomes- buscaron establecer un diálogo permanente con el elector, en una comunicación en los dos sentidos, diferente de la relación unilateral de la publicidad en radio y TV. A través de la 
página web era posible la distribución de noticias, del programa de gobierno y de piezas publicitarias; y de recibir sugerencias, además de despejar dudas.

Era sólo el primer paso. En 2006 las páginas web serán más sofisticadas, con la distribución de jingles y de los mensajes publicitarios producidos para TV. Las páginas disponían de ringtones para móvil e imágenes para que los usuarios del Orkut explicitaren el apoyo a una u otra candidatura. Tanto Lula como Alckmin grabaron mensajes destinadas al público del Orkut, y puestos a acceso del público en la página web de cada candidato. Lula también grabó un mensaje para los brasileños que viven en el exterior, que también fue distribuído a través de la Internet. Otra herramienta del ciberespacio ampliamente utilizada por los dos candidatos fueron los sites donde se puede subir videos (por ejemplo, Youtube), donde estaban disponibles diversos mensajes de la campaña.

Otro recurso esencial fueron los correos electrónicos, inexistentes en las dos primeras campañas y con baja utilización en 1998 tanto por Cardoso como por Lula. En 2002, pasan a tener un destacado uso, tanto en la comunicación con los afiliados -el mail-list del partido- como en el contacto con no partidarios. Tiene especial utilización en la comunicación con grupos específicos, como los periodistas, concejales, alcaldes, abogados y profesores universitarios. Sobre todo en 2006, funcionó como instrumento de comunicación para redes ciudadanas, estimuladas tanto al interior de la campaña de Lula como en la de Alckmin.

La intranet pasa a ser parte de cualquier organización de campaña desde 2002, alcanzando un papel fundamental en 2006. Su extendido uso se fundamenta en la seguridad que posibilita el flujo de las informaciones estratégicas. Antes funcionaban las redes internas de ordenadores, sin interacción en línea y tampoco contaban con tranquilizadores mecanismos de seguridad. El uso de la Intranet en las campañas brasileñas está asociado a la disponibilidad de la tecnología y a los recursos de cada campaña. En 2002, tanto Lula como Serra contaban con un amplio soporte financiero, pero la estructura de comunicación interna en línea era tan sólo mediana, limitada a los condicionantes del mercado. En 2006, el dinero no era un problema mayor para su implementación y la intranet formó parte del corazón de las campañas de PT y PSDB, conectando los diversos sectores del núcleo central e incluso empresas contratadas para funciones estratégicas, como los institutos de opinión pública -cómo bien revela la entrevista de João Santana, el coordinador de Lula en 2006, respecto la transmisión de las evaluaciones de los grupos focales ${ }^{70}-$.

\footnotetext{
70 Folha de S. Paulo, 5/11/2006.
} 
Los recursos de los mensajes cortos por móvil -los SMS, sigla en inglés para Short Message Service-, que ya demostraron su eficacia en muchas situaciones y particularmente en el 13-M español ${ }^{71}$, no tuvieron un uso extendido en la campaña de 2006. En 2002, apenas existía en el mercado de telefonía, por lo que no recibió mayor atención de parte de las candidaturas. En la última elección, se verifican tentativas de formación de redes ciudadanas al estilo 13-M, pero con resultados muy distintos. Lo que funcionó fueron algunas acciones desde la organización de campaña, con mensajes destinadas a determinados grupos del registro de usuarios de las operadoras de telefonía.

Los bancos de datos informatizados, la base para una efectiva comunicación dirigida, tienen presencia desde las primeras presidenciales, aunque en un nivel muy distante de la realidad estadounidense y de muchos países europeos. Collor utilizó los correos postales dirigidos en mediana intensidad, pero en condiciones muchas veces poco precisas: los destinatarios de los mensajes eran sacados de las listas de usuarios de empresas de energía o de telefonía, por lo que los mensajes eran casi siempre genéricos. Lula no utilizó correo dirigido con mucha intensidad; en las tres primeras campañas, fue baja la utilización de ese tipo de recurso, a pesar de adoptar mensajes específicos en algunos casos, como aquellos destinados al segmento universitario. En 2002 y 2006, lo hace en intensidad mediana, como lo hicieron Serra y Alckmin. En sus dos campañas, Cardoso también usa ese recurso con baja intensidad.

Vale notar que los panfletos son el recurso más utilizado para la segmentación de mensajes, con la distribución en general por área geográfica o, como en el caso de categorías funcionales, en los locales de concentración de esos profesionales: si el mensaje es para los metalúrgicos, la distribución es en la entrada de las fábricas; si el foco es el sector universitario, la distribución se da en los campi. Uno otro modo de segmentación -en general con criterio geográfico- es el telemarketing. Acaparó bastante atención en las estrategias de Collor, teniendo un importante impacto (sobre todo por la novedad). En las tres primeras campañas de Lula, es casi inexistente, sobre todo por el alto costo de la contratación de ese servicio. El uso es mediano en las cuatro campañas de PSDB, así como en las dos últimas de Lula.

La contratación de servicios de satélite es de hecho irrelevante. Hay por lo menos dos motivos principales. El primero, es que no hay en Brasil la preocupación por enviar spots para una TV regional distante -como es común en Estados Unidos-, puesto que la legislación determina la uniformidad del programa, y éste es emitido por una determinada emisora de televisión responsable de distribuir el señal para todas las

\footnotetext{
${ }^{71}$ Para una discusión más profundizada sobre el paradigmático caso español, ver Sampedro (2005).
} 
demás, obligadas a retransmitir en directo. Otro factor que limita el uso del satélite es la baja frecuencia de eventos como las teleconferencias, poco utilizados incluso en la comunicación con el público partidista, puesto que en la cultura política brasileña prima el contacto físico, el acercamiento al candidato.

\subsection{La participación de la afiliación}

En cuanto a la participación ciudadana, las campañas brasileñas ofrecen un gran bloque de seis candidaturas centradas en el dinero (capital intensivo), tres basadas en los partidarios y simpatizantes y una que concilia el soporte financiero con una importante movilización de la gente (Cuadro 5.10). En el primer bloque están las cuatro campañas del PSDB, la de Collor y la de Lula en 2006. La conciliación entre capital y voluntarios es posible en la campaña petista de 2002, que contaba con mucho dinero pero también alimentaba el sueño del cambio en miles de brasileños, en buena parte involucrados en la campaña tan sólo por ese sueño. En las tres primeras campañas de Lula, sin embargo, el soporte fundamental era la militancia. De hecho, ésta era el alma de la candidatura.

De las tres campañas de personal intensivo, es particularmente relevante la de Lula 1989, que se transformó en un verdadero movimiento, sólo comparable en las últimas décadas a la movilización por el restablecimiento de las elecciones directas. Los apoyos surgían de diversos estratos, con participación decisiva de la clase media, además de los segmentos sindicales y universitarios. Esos tres grupos son tradicionalmente vanguardistas y están relacionados con las grandes movilizaciones callejeras. Así, los partidarios y simpatizantes eran la base de la campaña, tanto en el aspecto financiero como de agitación: las "cenas de apoyo" a Lula y otros eventos aportaban recursos y la gente participaba sin ningún costo en las movilizaciones en las calles de ciudades grandes y medianas. Además, el material de campaña -pegatinas, carteles, banderas, gorras- que los militantes usaban en los eventos era comprado al partido, lo que lo convertía en una forma más de financiación a través del aporte de la ciudadanía. Las campañas de 1994 y 1998 también están basadas en la militancia voluntaria, pero sin la misma euforia ciudadana, sobre todo por la división de una clase media que en gran medida estaba contenta con los efectos del plan Real.

En 2002, Lula logra sumar la euforia por el cambio y el soporte financiero de grandes donantes que apostaban por el nuevo Lula, más moderado. Es una campaña que cuenta a la vez con voluntarios y personal contratado. Los militantes del núcleo duro que apoyaba a Lula -PT, PC do B y PSB- siguen participando por creer en un proyecto 
distinto de país. Sin embargo, algunos de los nuevos aliados, sobre todo los vinculados a los liderazgos tradicionales y de historial clientelista -como José Sarney, Antonio Carlos Magalhães y Oreste Quércia- verán pagada su participación gracias a los recursos para operacionalización de la campaña y por los compromisos de distribución de puestos públicos e influencia en el gobierno. Los "cabos electorales"72 son fundamentales en la transferencia de los votos, principalmente en el escenario rural, además de implicar una parte importante del presupuesto: $21,4 \%$, en una campaña nacional, según el ya citado cálculo del consultor Gaudencio Torquato73.

\section{CUADRO 5.10}

Capital vs voluntarios: el soporte de las campañas

\begin{tabular}{ll}
\hline Soporte de campaña & Candidatura \\
\hline Capital intensivo & $\begin{array}{l}\text { El dinero es el motor de las campañas de Collor, las cuatro de } \\
\text { PSDB y la de Lula 2006. }\end{array}$ \\
\hline Capital y personal & $\begin{array}{l}\text { Es el caso de la campaña de Lula 2002, con fuerte soporte } \\
\text { financiero pero con amplia participación voluntaria. }\end{array}$ \\
\hline Personal intensivo & $\begin{array}{l}\text { La participación ciudadana es el alma de las tres primeras } \\
\text { campañas de Lula. }\end{array}$ \\
\hline
\end{tabular}

Fuente: elaboración propia.

En 2006 la campaña de Lula repitió lo visto en 2002 respecto al soporte financiero y las relaciones con liderazgos clientelares. En esa campaña, el dinero se transforma en el motor de la carrera por los votos, incluso para viejos afiliados al PT que participan de las movilizaciones con remuneración directa (por la movilización misma) o indirecta (caso de quienes ocupan puestos en el gobierno). Es la misma realidad encontrada en campañas como la de Collor en 1989, o de las cuatro candidaturas tucanas desde 1994. En todas ellas, hay pago incluso a los integrantes de las actividades a boca de urna, la gente que actúa el día de votación junto a las secciones electorales.

El trabajo de boca de urna es importante en un sistema como Brasil por dos motivos: primero, porque como el voto es obligatorio, muchos electores llegan al puesto de votación sin tener un candidato definido; segundo, por el bajo nivel de escolaridad de la población, que hace que muchos sencillamente no sepan votar, fenómeno que se incrementa en las elecciones generales donde el elector necesita registrar el número de

\footnotetext{
72 Los "cabos electorales" son los jefes políticos -alcaldes, concejales- que controlan una determinada cantidad de voto, cuya transferencia negocian con los candidatos.

${ }^{73}$ Ver "Começa o show dos milhões", reportaje de David Friedlander y Thomas Traumann, en revista Época $\mathrm{n}^{\circ} 213$, del 17/06/2002.
} 
hasta seis candidatos 74 . Y los candidatos que buscan la victoria y cuentan con los medios necesarios, pagan a esos militantes eventuales.

${ }^{74}$ En las generales, el elector necesita registrar en la urna electrónica un número correspondiente a cada candidato, por separado: presidente, gobernador, un o dos senadores, diputado federal y estadual. 



\section{Las dimensiones comunicacionales}

\section{Resumen:}

El capítulo presenta un análisis del uso práctico de los recursos comunicacionales en las campañas brasileñas, a partir de los diversos indicadores de profesionalización de la dimensión comunicacional. El análisis registra no sólo la ocurrencia de esos indicadores sino el nivel de esa ocurrencia y las razones que hacen que se encuentren distintos niveles de una campaña a otra. En general, se encuentra una evolución técnica en las prácticas comunicacionales, culminando con la alta sofisticación de las últimas elecciones. También se encuentra la tendencia a la adopción de lenguaje más acorde a los rasgos de las campañas profesionales, tales como personalización, preponderancia de la imagen sobre el contenido, uso de la simbología, simplificación de los mensajes y significativa presencia de publicidad negativa. Sin embargo, algunos rasgos se alejan del patrón profesional, como la casi inexistente segmentación, resultado del contexto competitivo en que la legislación impone límites considerables. 



\subsection{Introducción}

Si la organización es una de las caras de las campañas profesionales, la otra cara es la comunicación. En búsqueda de mayor efectividad de las campañas, los profesionales de la política adoptan ciertos recursos comunicacionales como atajo hacia el elector cada vez menos identificado con partidos o agrupamientos sociales. El uso de tales recursos, por su efectividad y amplia presencia, se convierten en traductores de la profesionalización misma. Así, los mensajes de las campañas contemporáneas se orientan hacia algunas características: el foco en la imagen, haciendo del político la traducción misma de las expectativas del elector; la superficialidad ajustada al sentimiento de un ciudadano poco atento a las discusiones profundas; el enfoque simbólico que apenas traduce una intención general; o recursos visuales sofisticados que implican un efecto cognitivo más bien afecto a las sensaciones que a la consistencia de los discursos y propuestas.

Los mensajes de las campañas profesionales, más que el contenido, buscan crear un clima, generando una relación más emocional que racional (Rees, 1995). La sofisticación técnica hace parte del proceso que es más de encantamiento que de convencimiento; los efectos van a generar el clima deseado y a ofrecer una lectura compatible con la estrategia de cada candidato. Además, la literatura subraya que junto al enfoque general se recurre a la segmentación, que insinúa una individualización capaz de hacer al elector sentirse único (LeDuc et al, 2001; Norris, 2000). Lo fundamental es que el candidato sea percibido según características que produzcan buenas sensaciones, es decir, con un posicionamiento que ofrezca no sólo una característica distinta sino más bien una ventaja competitiva ${ }^{1}$.

Muchas de esas características están presentes en las campañas brasileñas, aunque se puedas encontrar rasgos propios tanto en la forma como en el contenido. Las diferencias empiezan con el doble modo de presentación de los mensajes electorales: una parte en bloques de programas con horario fijos y otra en spots sueltos exhibidos a lo largo de la programación. Los spots sueltos, en general, siguen el formato de la publicidad comercial, en mensajes cortos y lenguaje simbólico que hace posible la diferenciación de esos mensajes en medio de otros anuncios, puesto que son exhibidos

\footnotetext{
Aquí se utiliza el concepto de posicionamiento de Ries y Trout (1989), tan caro al marketing tanto en la esfera comercial como política. Para esos autores, el posicionamiento es la percepción que el público tiene del producto y que para tener éxito necesita que sea a la vez una visión diferenciada y ventajosa a los ojos de ese público. Sobre la política, Ries y Trout son fieles a la idea de que "la realidad es la percepcíón" (pag. 7).
} 
junto a mensajes comerciales de productos tales como yogurt, refrescos, coches o jabón. Se verifica una tendencia a los anuncios de 15 segundos, quizá una forma de optimizar el espacio que cada candidatura tiene derecho, limitado por las reglas que establecen criterios de proporcionalidad $^{2}$. Es decir, en lugar de 1 anuncio de 60 segundos, 4 de 15 segundos o como mucho 2 de 30.

\section{i) Los spots sueltos}

De los 155 spots sueltos analizados, 98,7\% llevaban esos dos formatos más cortos, con mayor presencia de los spots de 15 segundos: $54,8 \%$, contra $43,8 \%$ de los vídeos con 30 segundos (Tabla 6.1). La suma del tiempo de los spots sueltos fue de 3.375 segundos, lo que significa una media de 21,8 segundos por pieza exhibida. Además de una media cercana a los 20 segundos, la preferencia por el spot de 15 segundos revela una pequeña diferencia respecto el patrón norteamericano donde es cierto que el anuncio corto se estableció como la referencia desde los años 1970, pero con predominio del formato de 30 segundos (Devlin, 1995). Esa opción de las campañas en Brasil, común a todas las candidaturas desde 1998, se justifica por una decisión estratégica que multiplica la visibilidad del candidato, además de permitir alcanzar públicos distintos, sobre todo aquellos electores poco interesados en ver anuncios electorales, puesto que el espectador apenas tiene tiempo para cambiar de canal en el momento que aparece un anuncio tan corto.

Los anuncios cortos son utilizados particularmente para refuerzo de una estrategia o posicionamiento, lo que se revela en la producción de "serie de anuncios", es decir, una secuencia de pequeños spots con un mismo enfoque o idea; en la mayor parte de las veces, incluso con la misma estructura de presentación. Eso se puede verificar desde 1998, cuando la campaña de Lula utilizó una serie de cinco anuncios con textos semejantes y el mismo presentador, con la intención de revertir la perspectiva de derrota ya en la primera vuelta. Los cinco filmes, todos de 15 segundos, tenían el objetivo único de generar dudas entre la oferta programática de Lula y Cardoso y sugerir la necesidad de una segunda vuelta, cuando sería posible un debate más profundo ${ }^{3}$. Luego de peguntar quien tiene la razón sobre un asunto específico, si Lula o

\footnotetext{
2 En las presidenciales, la proporcionalidad es definida por la representación de los partidos en la Cámara de los Diputados. Ver la "Ley Electoral", la ley ordinaria n 9.504, del 30 de septiembre de 1997. Disponible en www.tse.gov.br.

3 Esa estrategia tiene en cuenta que Cardoso se negó a participar de los debates en la televisión en la primera vuelta. Sí lo haría si hubiese segunda vuelta. Esa estrategia, con el propósito de no desgastarse en los debates de primera vuelta con diversos adversarios a la vez, fue utilizada por Collor en 1989, por el mismo Cardoso en 1994 y también por Lula en 2006.
} 
Cardoso, el vídeo protagonizado por el conocido periodista Juarez Soares añade: "tu votas a Lula, vamos a la segunda vuelta y veremos quien tiene la razón”.

TABLA 6.1

Los formatos de los spots sueltos, por duración (en segundos)

\begin{tabular}{|c|c|c|c|c|c|c|c|c|c|c|c|}
\hline \multicolumn{2}{|c|}{ Campaña* } & \multirow{3}{*}{$\frac{\text { Vuelta }}{1^{\mathrm{a}}}$} & \multicolumn{2}{|c|}{$15^{\prime \prime}$} & \multicolumn{2}{|c|}{$30 "$} & \multicolumn{2}{|c|}{$45^{\prime \prime}$} & \multicolumn{2}{|c|}{$60^{\prime \prime}$} & \multirow{2}{*}{$\begin{array}{c}\text { Total } \\
\mathrm{n}\end{array}$} \\
\hline & & & $\mathrm{n}$ & $\%$ & $\mathrm{n}$ & $\%$ & $\mathrm{n}$ & $\%$ & $\mathrm{n}$ & $\%$ & \\
\hline \multirow{2}{*}{$\begin{array}{l}\infty \\
\stackrel{\infty}{9}\end{array}$} & Cardoso & & 9 & 60,0 & 6 & 40,0 & & & & & 15 \\
\hline & Lula & $1^{\mathrm{a}}$ & 10 & 66,6 & 5 & 33,3 & & & & & 15 \\
\hline \multirow{4}{*}{ ญ్ } & \multirow{2}{*}{ Lula } & $1^{\mathrm{a}}$ & 8 & 53,3 & 7 & 46,6 & & & & & 15 \\
\hline & & $2^{a}$ & 8 & 61,5 & 5 & 38,5 & & & & & 13 \\
\hline & \multirow{2}{*}{ Serra } & $1^{\mathrm{a}}$ & 2 & 12,5 & 12 & 75,0 & 1 & 6,2 & 1 & 6,2 & 16 \\
\hline & & $2^{a}$ & 10 & 66,6 & 5 & 33,3 & & & & & 15 \\
\hline \multirow{5}{*}{ 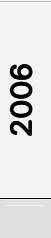 } & \multirow{2}{*}{ Lula } & $1^{\mathrm{a}}$ & 18 & 85,7 & 3 & 14,3 & & & & & 21 \\
\hline & & $2^{a}$ & 10 & 45,4 & 12 & 54,5 & & & & & 22 \\
\hline & \multirow{2}{*}{ Alckmin } & $1^{\mathrm{a}}$ & 2 & 15,4 & 11 & 84,6 & & & & & 13 \\
\hline & & $2^{a}$ & 8 & 80,0 & 2 & 20,0 & & & & & 10 \\
\hline & TOTAL & & 85 & 54,8 & 68 & 43,8 & 1 & 0,6 & 1 & 0,6 & 155 \\
\hline
\end{tabular}

Aún en 1998, Cardoso también utilizó anuncios en serie con tres mensajes reforzando los puntos de su programa de gobierno. Los spots empezaban siempre con un texto patrón, con el mismo tratamiento visual y la narración anunciando puntos del programa de gobierno: "el presidente Fernando Henrique tiene propuestas para la educación”, decía uno; el otro repetía que Cardoso tenía propuestas para la generación de empleo y el tercero enfocaba sobre las acciones para la sanidad. La serie de mensajes buscaba diferenciarlo del oponente por tener más preparación además de un plan de gobierno minuciosamente elaborado.

En 2002, otra vez la publicidad de Lula utilizó ese recurso, en una serie de spots en que repite ideas generales asociadas al cambio. En esos mensajes el candidato aparece hablando en close, siempre apuntando al futuro que deseaba construir: "cada real aplicado, un nuevo empleo generado", afirmaba el candidato de PT, para enseguida resaltar la confianza en un nuevo Brasil. Los spots cerraban siempre con el eslogan "llegó la hora, Brasil. Ahora es Lula". En 2006, un conjunto de anuncios de 15 segundos resaltaba los hechos administrativos del gobierno petista. En ellos, aparecía un cubo colorido que giraba por efecto de ordenador; a cada nueva faz presentaba datos o imágenes relacionadas a las acciones de gobierno. En otra serie de 2006 conocida como "Adivinha" [Adivina], actores que pasaban por gente corriente hacen preguntas como 
“quién es el presidente que más realizó por el área social”. Enseguida el mismo actor pregunta: ¿Adivinó? La contestación aparece en forma de jingle: "Yo quiero Lula de nuevo, con la fuerza del pueblo. Para que Brasil se quede contento, yo quiero Lula presidente".

También la comunicación de José Serra utilizó los anuncios sueltos en serie. Aún en la primera vuelta asoció la generación de empleo -su tema central- con diversas áreas. En una estructura patrón, personalidades conocidas hablaban de la necesidad de generar empleo en sectores como la industria, la agricultura o la pequeña empresa. Personas distintas introdujeron cada tema, pero todos los vídeos cerraban siempre destacando el nombre del candidato, complementados por un fragmento del jingle que señalaba “José Serra es trabajo, trabajo, trabajo, trabajo, trabajo para nosotros". Alckmin hizo lo propio en 2006 al exhibir mensajes que presentaban sus obras como gobernador de São Paulo, cerrando los anuncios con un fragmento del jingle que sencillamente ofrecía la perspectiva de nacionalización de tantos logros: "ahora Geraldo va a llevar [las obras] para Brasil".

\section{ii) Los bloques de anuncios}

En el caso de los bloques de programas, el patrón está lejos de los 15 segundos de los spots sueltos, puesto que el tiempo es definido por las reglas del juego electoral: según la Ley Electoral de 1997, un tercio del tiempo total es dividido en igualdad entre los candidatos y los otros dos tercios son distribuidos según la representación parlamentaria. En general, los candidatos dan un tratamiento a los bloques más cercano al periodismo que a la publicidad. Hay casos en que los bloques son presentados como si fueran pequeños telediarios, como es el ejemplo de la campaña de Cardoso en 1998 y parte de los espacios de Lula y Serra en 2002. En el caso de Cardoso, el programa exhibido por las tardes ${ }^{4}$ se llamaba "Buenas Tardes, Brasil", una referencia poco sutil al programa periodístico "Buenos Días, Brasil”, que Globo lleva al aire todos los días en el inicio de la mañana. Como el programa real, el simulacro contaba con presentador en un vistoso plató e invitados que eran entrevistados como si se tratara de un telediario real. Serra repite ese modelo, en cuanto Lula recurre al formato de debates en que el "debatidor" es el mismo candidato y los que preguntan "personas del pueblo".

\footnotetext{
${ }^{4}$ Los bloques de publicidad electoral en TV van al aire en dos horarios: a las 13 horas y a las 20 h30.
} 
En ese formato, los bloques cuentan con viñetas de apertura del programa ${ }^{5}$, reportajes y spots que funcionan como anuncios autónomos -como los anuncios exhibidos en medio del telediario real- separando las partes del programa. Al final, el bloque es formado por un conjunto de spots (vídeoclips, reportajes, “comerciales”). Las partes del bloque cuentan con tiempos distintos: puede ser un simple efecto de tres segundos con el nombre del candidato o el refrán del jingle, funcionando como cortinas que tienen como propósito hacer la separación entre temas o reportajes. Esos pequeños vídeos pueden ser encontrados especialmente en la campaña de 1989, que tiene como una de las características la alta fragmentación de los bloques.

Del mismo modo se pueden encontrar largos reportajes como si fueran pequeños documentales, como en la campaña de Lula en 2002, cuando el día 29 de agosto trató del problema de la generación de empleo: para hablar del paro, el vídeo toma como punto de partida la crisis de los astilleros del Estado de Río de Janeiro; el reportaje dura 4 minutos y 10 segundos. En la segunda vuelta de 2002, la campaña de Lula ofrece un caso excepcional en el programa que simula el debate presidencial, que en la práctica convierte el bloque de 10 minutos en tan solo dos largos spots. En la primera parte, Lula contesta preguntas de la platea sobre el proyecto "Mi Primer Empleo" - una idea de estímulo a las empresas para contratación de jóvenes sin experiencia- y en la segunda el programa presenta diversas declaraciones del público sobre la experiencia de hacer preguntas a Lula y la percepción de la gente ya no sobre las respuestas, sino sobre el mismo candidato. La suma de los dos vídeos es de más de 8 minutos, quedando el bloque cerrado con una breve viñeta de apertura y el jingle al final.

También hay largos pronunciamientos de los candidatos, especialmente en el caso de la campaña de Serra en 2002. En el bloque del día 12 de septiembre sobre las propuestas para generar empleo, el candidato hace dos declaraciones, separadas por un reportaje y un anuncio suelto. El primer pronunciamiento tiene 2 minutos 14 segundos, un tiempo muy largo para los patrones de la televisión brasileña. El segundo es más corto, pero también algo largo, con 1 minuto y 9 segundos. Alckmin ocupó importante parte del tiempo de sus programas con declaraciones, pero fragmentadas en

\footnotetext{
5 El término viñeta tiene en Brasil sentido distinto del utilizado en España, donde identifica las pequeñas historietas de los periódicos, en general con sentido de humor. En países como Colombia y casi toda América Central, la viñeta es de hecho el anuncio publicitario en TV, que así se diferencia del spot, término que -como en Brasil-identitifica el anuncio de radio. El término viñeta electrónica o sencillamente viñeta es utilizado en Brasil para identificar vídeos cortos que funcionan como característica de programas televisivos o de parte de eses programas. La suma del visual con el sonido característico funciona como una señal de identidad. Hay las viñetas principales -que identifican el programa- y las "viñetas temáticas" o "de separación", que separan blocos específcos o anticipan la llegada de determinados asuntos, como las noticias de deportes. En la publicidad electoral brasileña, los candidates suelen tener una viñeta que caracteriza su bloque publicitario. Aunque no sea tan común, se pueden encontrar viñetas de separación entre los mensajes, como es ejemplo la campaña de Lula en 1989, que utilizó diversas viñetas intercaladas entre los spots.
} 
intervenciones de menor tamaño, puesto que estaban dividas con informaciones en forma de reportajes y gráficos.

A diferencia de los spots sueltos, emitidos en reiteradas ocasiones con la intención de fijar un mensaje, el bloque de un día suele no ser el mismo del otro. Fiel al principio del periodismo de ofrecer novedades, cada día el programa presenta una nueva cara, aunque pueda ser una especie de variación sobre el mismo tema. De hecho los programas hablan siempre de los temas centrales de la campaña, para así generar una percepción específica del candidato, recursos que respetan el principio de la propuesta única de venta ${ }^{6}$ tan utilizada en la publicidad comercial. El caso de Serra en 2002 es esclarecedor de ese tipo de estrategia: aunque los programas tuviesen siempre una nueva cara, el tema de fondo era casi siempre el empleo, una vez enfocado desde la expansión industrial o la importancia de la exportación, otra vez incluso desde el área de la sanidad pública.

Por supuesto, no todo es inédito en esos programas. Hay repeticiones, empezando por las viñetas electrónicas que funcionan como firma de identidad del candidato. La aparición de la viñeta de apertura es un modo de decir "acabó el programa del otro y ahora empieza el mío". También se repiten algunos reportajes, los vídeoclips para los jingles y mensajes producidos como si fueran anuncios comerciales destinados a separar los temas y reportajes o a reforzar una cierta idea. Esos recursos que aportan dinámica a la publicidad también cumplen la función de quebrar la monotonía, fundamental en una campaña que ocupa 45 días en los medios.

En cuanto al tiempo de duración de las partes autónomas que componen los bloques de programas la mayoría tiene más de 60 segundos, tiempo que tanto puede ser utilizado para ofrecer un abordaje más exhaustivo sobre un tema, o incluso para generar una idea de cercanía, como en el caso de los vídeoclips producidos para los jingles de campaña, donde es común la imagen del candidato en contacto con el pueblo o en los mítines llenos de simpatizantes. Los spots de los bloques con más de 60 segundos fueron el 36,9\% de las 610 unidades clasificadas (Tabla 6.2). En el segundo puesto están los spots de hasta 15 segundos (21,3\%), donde se revela la preocupación plástica de las campañas brasileñas y el simulacro de telediarios, pues la mayor parte de las inserciones cortas son las viñetas de apertura o de separación entre mensajes. De los 102 spots clasificados como viñetas, 82 están entre los 130 mensajes con menos de 15 segundos.

\footnotetext{
${ }^{6}$ La propuesta única de venta (en inglés, Unique Selling Proposition, o USP) es un concepto creado por Ted Bates en la década de 1940. Se refiere a la necesidad de que los mensajes centren atención en una sola idea. Ver Maarek (2005). Ver también el item 6.11 de éste capítulo, a la página 247.
} 
En general, las viñetas de los bloques tienen una preocupación exclusivamente estética, como es ejemplar el caso de la campaña de Lula en 1989, que utilizaba rigurosas imitaciones de la identidad visual de TV Globo7. Sin embargo, hay casos en que esas características presentan más que una intención estética, como se puede notar en la campaña del mismo Lula en 2002. En aquél año, la apertura del bloque petista tenía claro posicionamiento político al ofrecer respuesta a una de las más recurrentes críticas al PT y Lula -que no estarían preparados para gobernar o no contaban con cuadros técnicos suficientes-. En la viñeta, el candidato caminaba por una amplia sala de trabajo con reconocidas personalidades de la vida política nacional, responsables de la elaboración de su programa de gobierno. Al final de la caminata, el candidato siempre anunciaba el tema que tendría la atención prioritaria del bloque, complementado por la relación de personalidades que contribuyeron a la elaboración de las propuestas relacionadas con el tema a destacar.

TABLA 6.2

Los formatos de los mensajes en los bloques, por duración (en segundos)

\begin{tabular}{|c|c|c|c|c|c|c|c|c|c|c|c|c|c|}
\hline \multicolumn{2}{|c|}{ Campaña } & \multirow[t]{2}{*}{ Vuelta } & \multicolumn{2}{|c|}{$<15^{\prime \prime}$} & \multicolumn{2}{|c|}{$16-30 "$} & \multicolumn{2}{|c|}{$31-45^{\prime \prime}$} & \multicolumn{2}{|c|}{$46-60 "$} & \multicolumn{2}{|c|}{$>60^{\prime \prime}$} & \multirow{2}{*}{$\begin{array}{l}\mathrm{T} \\
\mathrm{n}\end{array}$} \\
\hline & & & $\mathrm{n}$ & $\%$ & $\mathrm{n}$ & $\%$ & $\mathrm{n}$ & $\%$ & $\mathrm{n}$ & $\%$ & $\mathrm{n}$ & $\%$ & \\
\hline \multirow{4}{*}{$\begin{array}{l}\text { ̊ } \\
\text { o̊ } \\
\stackrel{2}{-}\end{array}$} & \multirow[t]{2}{*}{ Collor } & $1^{\mathrm{a}}$ & 11 & 34,4 & 7 & 21,9 & 5 & 15,6 & 2 & 6,2 & 7 & 21,9 & 32 \\
\hline & & $2^{a}$ & 11 & 18,0 & 14 & 23,0 & 10 & 16,4 & 4 & 6,6 & 22 & 36,0 & 61 \\
\hline & \multirow[t]{2}{*}{ Lula } & $1^{\mathrm{a}}$ & 22 & 55,0 & 6 & 15,0 & 1 & 2,5 & 1 & 2,5 & 10 & 25,0 & 40 \\
\hline & & $2^{a}$ & 25 & 40,3 & 11 & 17,7 & 6 & 9,7 & 5 & 8,1 & 15 & 24,2 & 62 \\
\hline \multirow{2}{*}{ ১ু } & Cardoso & $1^{\mathrm{a}}$ & 3 & 7,9 & 6 & 15,8 & 10 & 26,3 & 3 & 7,9 & 16 & 42,1 & 38 \\
\hline & Lula & $1^{\mathrm{a}}$ & 6 & 25,0 & 7 & 29,2 & 4 & 16,6 & 1 & 4,7 & 6 & 25,0 & 24 \\
\hline \multirow{2}{*}{ o } & Cardoso & $1^{a}$ & 1 & 2,0 & 15 & 30,6 & 11 & 22,5 & 2 & 4,1 & 20 & 40,8 & 49 \\
\hline & Lula & $1^{\mathrm{a}}$ & 13 & 38,2 & 4 & 11,8 & 6 & 17,6 & 4 & 11,8 & 7 & 20,6 & 34 \\
\hline \multirow{4}{*}{ ণิ } & \multirow{2}{*}{ Lula } & $1^{\mathrm{a}}$ & 3 & 14,3 & 2 & 9,6 & 2 & 9,5 & 2 & 9,5 & 12 & 57,1 & 21 \\
\hline & & $2^{a}$ & 2 & 7,7 & 9 & 34,6 & 2 & 7,7 & - & - & 13 & 50,0 & 26 \\
\hline & \multirow{2}{*}{ Serra } & $1^{\mathrm{a}}$ & 6 & 10,7 & 13 & 23,2 & 12 & 21,4 & 5 & 8,9 & 20 & 35,8 & 56 \\
\hline & & $2^{\mathrm{a}}$ & 4 & 10,8 & 7 & 18,9 & 4 & 10,8 & 9 & 24,3 & 13 & 35,2 & 37 \\
\hline \multirow{5}{*}{ ঠ্ণ } & \multirow{2}{*}{ Lula } & $1^{a}$ & 4 & 13,8 & 5 & 17,2 & 5 & 17,2 & 2 & 6,9 & 13 & 44,9 & 29 \\
\hline & & $2^{a}$ & 7 & 19,4 & 5 & 13,9 & 5 & 13,9 & 5 & 13,9 & 14 & 38,9 & 36 \\
\hline & \multirow{2}{*}{ Alckmin } & $1^{a}$ & 6 & 18,8 & 5 & 15,6 & - & & 1 & 3,1 & 20 & 62,5 & 32 \\
\hline & & $2^{a}$ & 6 & 18,2 & 1 & 3,0 & 1 & 3,0 & 8 & 24,2 & 17 & 51,6 & 33 \\
\hline & TOTAL & & 130 & 21,3 & 117 & 19,2 & 84 & 13,8 & 54 & 8,8 & 225 & 36,9 & 610 \\
\hline
\end{tabular}

\footnotetext{
7 Varias viñetas de Lula en 1989 emulan el visual y el sonido de las viñetas de TV Globo, utilizando incluso la sonoridad cercana: Rede Globo y Rede Povo (Red Pueblo). La referencia a Globo es explícita en cada inicio de programa, cuando añade al fin de cada característica electrónica "aqui você vê o que não vê nas outras tevês" [aquí tu ves lo que no ves en las otras teles]. Otras que emulan los efectos visuales de Globo son el "Vale a pena ver de novo" [vale la pena ver otra vez] y "Povo Repórter" [Pueblo Repórter], referencias as los programas "Vale a pena ver de novo" y "Globo Repórter" de la misma emisora. Además, hay la viñeta conocida como "Plim-Plim", utilizada por PT con igual sonoplastia, tan sólo para separar temas o reportajes del programa electoral de 1989.
} 
Fuente: elaboración propia.

Es interesante notar el aumento del tiempo medio de los spots desde las elecciones de 1989. Hasta 1994, todas las campañas analizadas presentaron una duración media de spot menor que 60 segundos, evidenciando la opción por la fragmentación de los bloques de programas en muchas mensajes, aunque en ocasiones sobre un mismo tema. La fragmentación es particularmente notable en el caso de la primera vuelta de Lula en 1989, cuando los spots presentan una media de tan solo 36,5 segundos, resultado del amplio uso de viñetas como recurso estético para la separación entre otros mensajes y producir la idea de dinamismo. Además, en 1989 las viñetas eran lo que la campaña de Lula tenía de más sofisticado: carente de recursos, la casi totalidad de las demás mensajes utilizaban recursos técnicos simples. En la segunda vuelta, la campaña de Lula presenta medias más elevadas, 48,2 segundos, pero siguiendo por debajo de los 50 segundos. En 1994 el petista presentaría un tiempo promedio de 41 segundos, casi el mismo de la primera vuelta de la primera presidencial.

La campaña de Cardoso en 1998 va a romper esa tendencia de las dos primeras disputas, presentando una media ya de 72 segundos por spot; sin embargo Lula sigue con medias bajas -en aquél año, de 41,8 segundos (Tabla 6.3). En 2002, con la campaña claramente profesionalizada, los spots de Lula presentan una media de 74 segundos en la primera vuelta y de 114 en la segunda. La media de la segunda vuelta de 2002 está un poco fuera del patrón pero es reflejo de la estrategia de comunicación petista que en la fase final presentó programas simulando el debate presidencial en que no sólo trataba de un único tema sino que reducía el bloque a dos o tres spots. En ese caso, el dinamismo exigido por la televisión está en la conducción por parte del presentador y de las intervenciones del público que pregunta sobre el tema del día -en el caso analizado, el tema era "Mi primer empleo", una de las propuestas más exploradas en la publicidad del candidato de PT-.

En 2006, la campaña de Lula mantiene el patrón cercano a la primera ronda de 2002, con media de 74 y 82 segundos para la primera y segunda vueltas, respectivamente. Lo mismo pasa con Alckmin, aunque con tiempo medio alrededor de 90 segundos por spot. En cualquiera de los casos, el tiempo medio de los spots exhibidos en los bloques de programas es sustancialmente superior a los anuncios sueltos: la media para las diez campañas analizadas es un spot de 63 segundos, casi el triple del "spot patrón" de los anuncios con exhibición a lo largo de la programación de las televisiones. Incluso los vídeos de 1989 son alrededor del doble del tiempo de los spots sueltos, media que en 2002 es más de tres veces superior. 
TABLA 6.3

Tiempo medio de los spots en los bloques de programas (en segundo)

\begin{tabular}{|c|c|c|c|c|c|}
\hline Año & Candidato & Vuelta & Tiempo & $\mathrm{N}^{0}$ spots & Media \\
\hline \multirow{4}{*}{1989} & \multirow[t]{2}{*}{ Collor } & $1^{a}$ & 1.401 & 32 & 43,8 \\
\hline & & $2^{a}$ & 2.997 & 61 & 49,1 \\
\hline & \multirow[t]{2}{*}{ Lula } & $1^{a}$ & 1460 & 40 & 36,5 \\
\hline & & $2^{a}$ & 2.989 & 62 & 48,2 \\
\hline \multirow{2}{*}{1994} & Cardoso & $1^{a}$ & 2.263 & 38 & 59,5 \\
\hline & Lula & $1^{a}$ & 990 & 24 & 41,2 \\
\hline \multirow{2}{*}{1998} & Cardoso & $1^{\mathrm{a}}$ & 3.546 & 49 & 72,3 \\
\hline & Lula & $1^{a}$ & 1.421 & 34 & 41,8 \\
\hline \multirow{4}{*}{2002} & \multirow[t]{2}{*}{ Lula } & $1^{a}$ & 1.554 & 21 & 74,0 \\
\hline & & $2^{a}$ & 2.987 & 26 & 114,9 \\
\hline & \multirow[t]{2}{*}{ Serra } & $1^{\mathrm{a}}$ & 3.059 & 56 & 54,6 \\
\hline & & $2^{a}$ & 2.982 & 37 & 80,6 \\
\hline \multirow{4}{*}{2006} & \multirow[t]{2}{*}{ Lula } & $1^{\mathrm{a}}$ & 2.151 & 29 & 74,2 \\
\hline & & $2^{a}$ & 2.981 & 36 & 82,8 \\
\hline & \multirow[t]{2}{*}{ Alckmin } & $1^{\mathrm{a}}$ & 2.866 & 32 & 89,6 \\
\hline & & $2^{a}$ & 2.975 & 33 & 90,2 \\
\hline Total & & & 38.622 & 610 & 63,4 \\
\hline
\end{tabular}

Fuente: elaboración propia.

En 2006, la campaña de Lula mantiene el patrón cercano a la primera ronda de 2002 , con media de 74 y 82 segundos para la primera y segunda vueltas, respectivamente. Lo mismo pasa con Alckmin, aunque con tiempo medio alrededor de 90 segundos por spot. En cualquiera de los casos, el tiempo medio de los spots exhibidos en los bloques de programas es sustancialmente superior a los anuncios sueltos: la media para todas las diez campañas analizadas es un spot de 63 segundos, casi el triple del "spot patrón" de los anuncios con exhibición a lo largo de la programación de las televisiones. Incluso los vídeos de 1989 son alrededor del doble del tiempo de los spots sueltos, media que en 2002 es más de tres veces superior.

\subsection{El actor principal: mucha personalización y poco partidismo}

La preponderancia del candidato sobre el partido se revela en el enfoque de los mensajes electorales: más del 85\% de los spots exhibidos en los bloques de programas resaltan las referencias personales, frente al $8 \%$ de los mensajes que miran hacia los partidos (Tabla 6.4). Otros 6,6\% dividen el protagonismo entre el gobierno -sin referencia a partido o persona-, el discurso ideológico o aún mensajes meramente 
estéticos, sin cualquier referencia personal o partidista, como son algunas de las viñetas exhibidas en la publicidad de PT en 1989, que sencillamente se preocupaban en ofrecer una sofisticada presentación, sin citar nombre del candidato, partido o coalición ${ }^{8}$. De hecho, todas las viñetas de la primera campaña de Lula emulan los recursos visuales de TV Globo, apropiándose de una idea de modernidad además de hacer el contrapunto entre la Red Globo, comprometida con los poderosos, y la Red Pueblo, que estaría al lado de la gente.

El personalismo es todavía más intenso en los spots sueltos, donde tan sólo 3,2\% de los spots sostienen el discurso en la referencia partidista, en contra del 93,6\% que se encuentra enfocado en la persona (Tabla 6.5). Es decir, de los 155 anuncios sueltos, 145 hablan de personas, en cuanto tan sólo 5 se refieren a los partidos, además de 4 que enfocan en los gobiernos. Un mensaje tiene foco ideológico -en concreto, un vídeo de la segunda vuelta de la campaña de José Serra en que utiliza la retórica del miedo en un viejo discurso contra el radicalismo de las izquierdas-. Se debe anotar aún que la referencia partidista en general es empleada con un enfoque negativo: el único partido que utilizó la organización partidista como soporte discursivo a favor es PT. En 2002, el partido exhibe con ese enfoque dos spots sueltos y tres en los bloques; en 1998 fueron tres spots dentro de los bloques. Pero el partidismo tiene especial importancia en la primera campaña de PT, así como tendrá para la publicidad de Collor en la segunda vuelta del mismo año.

Es importante destacar que sólo en una situación el partidismo fue superior al personalismo: precisamente en la campaña de Lula en 1989, y aún así solamente en la primera vuelta, cuando las estrategias electorales eran básicamente las estrategias del partido, con significativo enfoque clasista y ideológico. Los discursos centrados en la persona de Lula, y sin referencia partidista, son el 37,5\% de los mensajes, en contra de un $47,5 \%$ de mensajes centrados en la organización y otros $5 \%$ ideológicos. Pero en la segunda vuelta, cuando el candidato de PT tiene como principal objetivo la suma apoyos que garantice la mayoría absoluta de votos -es decir, cuando prevalece un discurso del tipo atrápalo todo-, el partidismo se resume a menos de $5 \%$ de los mensajes. Los mensajes personalistas superan la barrera del $85 \%$.

La preocupación partidista de la primera vuelta de la campaña de Lula en 1989 está tan presente que las declaraciones de personalidades -una forma de personalización en sí

\footnotetext{
${ }^{8}$ En una de esas viñetas de pasaje, efectos de ordenador superponen dos círculos con el mapa de Brasil en medio: cuando los círculos se unen se oye el "plim.plim", sonido característico de TV Globo -la televisión del plim-plim-. Esa característica es una situación distinta de otras de esa misma campaña, que usan los grafismos de Globo pero acompañadas de narración que anuncia el programa del Frente Brasil Popular, citando los partidos que hacen parte de la coalicón, y así clasificadas como partidista.
} 
misma, puesto que la persona que habla es la credencial del discurso pronunciado- en general son "casadas". Es decir, casi siempre a una personalidad que pronuncia un discurso partidista o ideológico acompaña otra que destaca la figura de Lula9. Un ejemplo es el spot que une el escritor Ariano Suassuna al popular actor Odilon Wagner: la revolución racionalmente vislumbrada por el escritor en la estela de los compromisos ideológicos de PT es enseguida atenuada por la sonrisa y el discurso personalista (y moderado) que el actor pronuncia en defensa del candidato que tiene el corazón del pueblo.

TABLA 6.4

Personalismo vs partidismo en los bloques de programas

\begin{tabular}{|c|c|c|c|c|c|c|c|c|c|c|c|c|c|}
\hline \multicolumn{2}{|c|}{ Campaña* } & \multirow[t]{2}{*}{ Vuelta } & \multicolumn{2}{|c|}{ Persona } & \multicolumn{2}{|c|}{ Partido } & \multicolumn{2}{|c|}{ Gobierno } & \multicolumn{2}{|c|}{ Ideológico } & \multicolumn{2}{|c|}{ Otros } & \multirow{2}{*}{$\begin{array}{c}\text { Total } \\
\mathrm{n}\end{array}$} \\
\hline & & & $\mathrm{n}$ & $\%$ & $n$ & $\%$ & $\mathrm{n}$ & $\%$ & $\mathrm{n}$ & $\%$ & $\mathrm{n}$ & $\%$ & \\
\hline \multirow{4}{*}{ 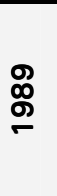 } & \multirow{2}{*}{ Collor } & $1^{a}$ & 28 & 87,5 & & & 4 & 12,5 & & & & & 32 \\
\hline & & $2^{a}$ & 44 & 72,1 & 16 & 26,2 & & & 1 & 1,6 & & & 61 \\
\hline & \multirow{2}{*}{ Lula } & $1^{\mathrm{a}}$ & 15 & 37,5 & 19 & 47,5 & & & 2 & 5,0 & 4 & 10,0 & 40 \\
\hline & & $2^{a}$ & 53 & 85,5 & 3 & 4,8 & & & 1 & 1,6 & 5 & 8,0 & 62 \\
\hline \multirow{2}{*}{ \$ } & Cardoso & $1^{\mathrm{a}}$ & 32 & 84,2 & & & 4 & 10,5 & 2 & 5,3 & & & 38 \\
\hline & Lula & $1^{\mathrm{a}}$ & 23 & 95,8 & & & 1 & 4,2 & & & & & 24 \\
\hline \multirow{2}{*}{$\stackrel{\infty}{\infty}$} & Cardoso & $1^{\mathrm{a}}$ & 49 & 100 & & & & & & & & & 49 \\
\hline & Lula & $1^{\mathrm{a}}$ & 30 & 88,2 & & & 4 & 11,8 & & & & & 34 \\
\hline \multirow{4}{*}{ ণิ } & \multirow{2}{*}{ Lula } & $1^{\mathrm{a}}$ & 17 & 80,9 & & & 4 & 19,1 & & & & & 21 \\
\hline & & $2^{\mathrm{a}}$ & 20 & 76,9 & 3 & 11,5 & 3 & 11,5 & & & & & 26 \\
\hline & \multirow{2}{*}{ Serra } & $1^{\mathrm{a}}$ & 56 & 100 & & & & & & & & & 56 \\
\hline & & $2^{\mathrm{a}}$ & 31 & 83,8 & 6 & 16,2 & & & & & & & 37 \\
\hline \multirow{5}{*}{ ஜ̊ํํ } & \multirow{2}{*}{ Lula } & $1^{\mathrm{a}}$ & 25 & 86,2 & & & 4 & 13,8 & & & & & 29 \\
\hline & & $2^{a}$ & 36 & 100 & & & & & & & & & 36 \\
\hline & \multirow{2}{*}{ Alckmin } & $1^{\mathrm{a}}$ & 31 & 96,9 & & & 1 & 3,1 & & & & & 32 \\
\hline & & $2^{\mathrm{a}}$ & 31 & 93,9 & 2 & 6,1 & & & & & & & 33 \\
\hline & TOTAL & & 521 & 85,4 & 49 & 8,0 & 25 & 4,1 & 6 & 1,0 & 9 & 1,5 & 610 \\
\hline
\end{tabular}

Fuente: elaboración propia.

El personalismo presente en las campañas se ajusta al perfil de cada candidato: Collor es el "hombre valentía" capaz de barrer la corrupción. En las primeras campañas, Lula es el trabajador que conoce la realidad de los otros trabajadores ("uno de nosotros") y lucha en defensa de los explotados; luego, en las últimas campañas, se convierte en el mítico hijo del pueblo que hará un nuevo Brasil para todos. Cardoso es presentado

\footnotetext{
${ }^{9}$ En eses casos, el spot será clasificado como partidista o personalista según el enfoque considerado predominante.
} 
como la competencia al servicio de un país estable, lo mismo que Serra, que además tiene como gran meta el empleo. Alckmin también se posiciona como la eficiencia provada (en el gobierno de São Paulo) capaz de restablecer el orden que no ve en el gobierno Lula.

En cuanto al énfasis en los partidos encontrada en 1989 tanto en Lula como en Collor exige una explicación adicional, puesto que el PRN sencillamente no existía para la campaña de Collor, tampoco en el imaginario de la gente. El partidismo abrazado por los dos candidatos sigue estrategias opuestas. Por una parte, Lula destaca la fortaleza programática y la lucha del Partido de los Trabajadores, así como los logros de las administraciones petistas -que en aquél momento incluía entre otras la ciudad de São Paulo-; por otra, Collor utiliza ese discurso precisamente para criticar PT, entonces identificado con el radicalismo y una idea de desorden. Además, como las estrategias guían los mensajes, es revelador notar que el partidismo (o contra-partidismo) de Collor se encuentra solamente en la segunda vuelta. En la primera, él no habla de partidos, haciendo del presidente Sarney o del gobierno central los blancos de sus críticas más duras. En la segunda, los ataques al Partido de los Trabajadores son una de las armas más poderosas para debilitar el posicionamiento de Lula: los 16 mensajes con enfoque partidista se destinan a criticar al PT o a la coalición, enfatizando el radicalismo, la unión de aliados imposibles de conciliar (como Lula y Brizola) o el caos administrativo en ciudades bajo el mando petistas.

TABLA 6.5

Personalismo vs partidismo en los en los spots sueltos

\begin{tabular}{|c|c|c|c|c|c|c|c|c|c|c|c|}
\hline \multicolumn{2}{|c|}{ Campaña* } & \multirow[t]{2}{*}{ Vuelta } & \multicolumn{2}{|c|}{ Persona } & \multicolumn{2}{|c|}{ Partido } & \multicolumn{2}{|c|}{ Gobierno } & \multicolumn{2}{|c|}{ Ideológico } & \multirow{2}{*}{$\begin{array}{c}\text { Total } \\
\mathrm{n}\end{array}$} \\
\hline & & & $\mathrm{n}$ & $\%$ & $\mathrm{n}$ & $\%$ & $\mathrm{n}$ & $\%$ & $\mathrm{n}$ & $\%$ & \\
\hline \multirow{2}{*}{ क } & Cardoso & $1^{a}$ & 15 & 100 & & & & & & & 15 \\
\hline & Lula & $1^{\mathrm{a}}$ & 15 & 100 & & & & & & & 15 \\
\hline \multirow{4}{*}{ ญิ } & L & $1^{\mathrm{a}}$ & 14 & 93,3 & 1 & 6,6 & & & & & 15 \\
\hline & Luia & $2^{a}$ & 13 & 100 & & & & & & & 13 \\
\hline & Serra & $1^{\mathrm{a}}$ & 16 & 100 & & & & & & & 16 \\
\hline & Serra & $2^{a}$ & 13 & 86,6 & 1 & 6,6 & & & 1 & 6,6 & 15 \\
\hline \multirow{5}{*}{ ஜ̊ } & L Lla & $1^{\mathrm{a}}$ & 18 & 85,7 & 1 & 4,8 & 2 & 9,5 & & & 21 \\
\hline & Luia & $2^{a}$ & 21 & 95,5 & 1 & 4,5 & & & & & 22 \\
\hline & Alomin & $1^{\mathrm{a}}$ & 12 & 92,3 & & & 1 & 7,7 & & & 13 \\
\hline & ласкитіт & $2^{a}$ & 8 & 80,0 & 1 & 10,0 & 1 & 10,0 & - & - & 10 \\
\hline & TOTAL & & 145 & 93,6 & 5 & 3,2 & 4 & 2,6 & 1 & 0,6 & 155 \\
\hline
\end{tabular}

Fuente: elaboración propia

* El uso de los spots sueltos en las presidenciales empieza con la elección de 1998. 
El enfoque crítico hacia el PT vuelve con Serra y Alckmin, pero en menor intensidad y en general de modo más sutil. El antipetismo de Alckmin se refiere a la participación de dirigentes del partido de Lula en escándalos corrupción, explicitando el puesto partidista ocupado por los involucrados, pero sin mayores comentarios sobre el partido. En cuanto a Serra, intenta lanzar dudas sobre la moderación de PT, presentando declaraciones de dirigentes del partido y del mismo Lula en las que hablan de la necesidad de ser moderados para ganar las elecciones, camino necesario para alcanzar el poder y entonces implementar las políticas públicas ansiadas por las izquierdas. Además, Serra intenta rescatar (sin éxito) el miedo al radicalismo del Partido de los Trabajadores, a esas fechas apenas recordado. En la estrategia del miedo, es ilustrativo un jingle en que indirectamente asocia PT a las viejas referencias de la izquierda: la bandera roja y los cambios radicales, además de la "incompetencia" administrativa del partido. El discurso presenta tono claramente ideológico, travestido de patriotismo, insinuando que la victoria de Lula significará incluso el cambio de la bandera, una retórica semejante a la utilizada por Collor en 1989. El jingle decía:

\begin{abstract}
"Pegue uma bandeira verde e amarela
Bote um adesivo e vem lutar por ela

Seja prá melhor, pra andar pra frente

Muda meu País, mas não muda de bandeira

A onda é verde e amarela, ela não é vermelha

Olho na incompetência que o perigo ronda

Se levanta meu País e não entra em qualquer onda

A onda é verde e amarela, vem Brasil lutar por ela" ${ }^{10}$.
\end{abstract}

Cabe aún destacar la presencia en los spots el enfoque sobre el gobierno, tanto entre oficialistas como opositores. En 1989, la campaña de Collor se posiciona como cambio en ataques frontales al gobierno Sarney y a la corrupción. En 1994, la campaña de Cardoso en algunos momentos hace referencia al Real como una exitosa acción de gobierno, sin citar explícitamente al candidato: la asociación es indirecta, puesto que la nueva moneda es la base del discurso de esa campaña; además, el presidente Itamar

\footnotetext{
${ }^{10}$ El jingle, exhibido en los bloques y también como spot suelto, tiene la siguiente traducción: "Coge una bandera verde-amarrilla/ Ponte una pegatina y ven a luchar por ella/ Que sea para mejor, para andar hacia delante/ Cambia mi país, pero no cambies de bandera/ La onda es verde-amarrilla, ella no es roja/ Ojo en la incompetencia que el peligro ronda/ Levántate, mi país, y no toma una onda cualquiera / La onda es verde-amarilla, ven Brasil a luchar por ella".
} 
Franco -apoyo claro a Cardoso- disfrutaba de altos índices de aprobación popular ${ }^{11}$. La campaña petista también habla del gobierno, pero en tono negativo, en una crítica que busca indirectamente vincular malos resultados administrativos al candidato gobiernista. La misma estrategia será utilizada en 1998 y 2002, aunque en esa última con un poco más de intensidad (19,1\% de los mensajes en primera vuelta y 11,5\% en la segunda) pero tono suave. Los candidatos a la reelección (Cardoso en 1998 y Lula en 2006) adoptan una estrategia semejante: el gobierno pasa a ser personificado; en un, es el gobierno Fernando Henrique, en el otro, es el Gobierno Lula, estrategia que profundiza la personalización de los anuncios electorales.

\subsection{El tema es el mismo candidato y su imagen}

Los mensajes electorales enfatizan más la imagen del candidato que los temas mismos que van a formar las propuestas de campaña. Quizá de modo sorprendente, eso se evidencia de manera más fuerte entre los spots de los bloques de programas, donde dos tercios de los mensajes están centrados en la imagen del candidato; en los spots sueltos el foco en la imagen está en un poco más de la mitad de los vídeos analizados. En la suma de los dos tipos de mensajes, las que enfocan prioritariamente la imagen del candidato representan dos tercias partes del total (67.7\%), en contra un 32,3\% de los anuncios temáticos (Tabla 6.6).

La sorpresa en relación a los bloques es que en ellos los mensajes suelen tener más tiempo: una media de 63 segundos en contra los 21 segundos para los anuncios sueltos. Los spots sueltos suelen ser más objetivos en cuanto al posicionamiento central de cada campaña, al paso en que los bloques, a pesar de un formato que se acerca al periodismo, tienen la preocupación de ser agradables, casi un show destinado al entretenimiento de la gente. Es una preocupación que toma en cuenta las desconfianzas del elector hacia la publicidad electoral, que ocupa 45 minutos seguidos de la programación normal de la tele ${ }^{12}$. Así, es natural que los bloques busquen ser atractivos, justificando la importante presencia de mensajes que priorizan la belleza visual y una cierta ligereza, como son los vídeoclips para los jingles de los candidatos.

\footnotetext{
11 Según un sondeo del instituto Data Folha, en octubre de 1994, el presidente Itamar Franco registraba una evaluación de $40 \%$ entre óptimo y bueno; un $46 \%$ regular y tan sólo $10 \%$ de malo y pésimo. Hay un $5 \%$ de encuestados que no superon contestar. Ver www.datafolha.com.br.

12 Sondeos revelan el descontedo de la mayor parte de los electores con el horario electoral y registran redución de la audiencia de TV durante la publicidad electoral. En 2002, la audiencia del primer programa exhibido fue de $42 \%$, más de diez puntos abajo de la audiencia media en el mismo horario. Los sondeos también revelan que el elector presta más atención a la publicidad electoral en los primeros días y en los últimos, con audiencia todavía menor en la fase intermedia. Ver datos del instituto lbope en www.ibope.com.br. Ver también el reportaje de la BBC Brasil del día 18 de agosto de 2006, disponible en http://www.bbc.co.uk/portuguese/reporterbbc/story/2006/08/060818_horario_politicodg.shtm/.
} 
Destinados a encantar y movilizar, los vídeoclips en general carecen de contenido concreto pero están llenos de contenido simbólico -son bonitos, pasan la idea de cercanía entre candidato y el elector y buscan expresar emoción y confianza en la candidatura-. Todas las campañas utilizan vídeoclips, que se convierten en uno de los marcos propios de las campañas brasileñas. En total, fueron 86 mensajes con ese formato, correspondiendo al 14,1\% de los 610 spots de los bloques. Las viñetas, también con intención prioritariamente estética, tienen importante presencia: 102 casos, un 16,7\%. Tan sólo esos dos tipos de mensajes con intención sobre todo plástica y emocional suman un $30,8 \%$ de los spots de los bloques ${ }^{13}$.

TABLA 6.6

Temas vs imagen en los bloques de programas y spots sueltos

\begin{tabular}{|c|c|c|c|c|c|c|c|c|c|c|c|c|}
\hline \multicolumn{2}{|c|}{ Campaña* } & \multirow{3}{*}{ Vuelta } & \multicolumn{5}{|c|}{ Bloques de programas } & \multicolumn{5}{|c|}{ Spots sueltos* } \\
\hline & & & \multicolumn{2}{|c|}{ Imagen } & \multicolumn{2}{|c|}{ Tema } & \multirow{2}{*}{$\frac{\text { Total }}{\mathrm{n}}$} & \multicolumn{2}{|c|}{ Imagen } & \multicolumn{2}{|c|}{ Tema } & \multirow{2}{*}{$\begin{array}{c}\text { Tota } \\
\mathrm{n}\end{array}$} \\
\hline & & & $\mathrm{n}$ & $\%$ & $\mathrm{n}$ & $\%$ & & $\mathrm{n}$ & $\%$ & $\mathrm{n}$ & $\%$ & \\
\hline \multirow{4}{*}{$\begin{array}{l}\text { क } \\
\infty \\
\text { ద }\end{array}$} & \multirow{2}{*}{ Collor } & $1^{\mathrm{a}}$ & 27 & 84,4 & 5 & 15,6 & 32 & & & & & \\
\hline & & $2^{a}$ & 55 & 90,2 & 6 & 9,8 & 61 & & & & & \\
\hline & \multirow{2}{*}{ Lula } & $1^{\mathrm{a}}$ & 30 & 75,0 & 10 & 25,0 & 40 & & & & & \\
\hline & & $2^{a}$ & 55 & 88,7 & 7 & 11,3 & 62 & & & & & \\
\hline \multirow{2}{*}{ హั } & Cardoso & $1^{a}$ & 19 & 50,0 & 19 & 50,0 & 38 & & & & & \\
\hline & Lula & $1^{\mathrm{a}}$ & 13 & 54,2 & 11 & 45,8 & 24 & & & & & \\
\hline \multirow{2}{*}{ ळ్ } & Cardoso & $1^{\mathrm{a}}$ & 27 & 55,1 & 22 & 44,9 & 49 & 10 & 66,7 & 5 & 33,3 & 15 \\
\hline & Lula & $1^{a}$ & 24 & 70,6 & 10 & 29,4 & 34 & 4 & 13,3 & 11 & 86,7 & 15 \\
\hline \multirow{4}{*}{ ญ̊ } & \multirow{2}{*}{ Lula } & $1^{a}$ & 14 & 66,7 & 7 & 33,3 & 21 & 8 & 53,3 & 7 & 46,7 & 15 \\
\hline & & $2^{a}$ & 16 & 61,5 & 10 & 38,5 & 26 & 12 & 92,3 & 1 & 7,7 & 13 \\
\hline & \multirow{2}{*}{ Serra } & $1^{a}$ & 21 & 37,5 & 35 & 62,5 & 56 & 10 & 62,5 & 6 & 37,5 & 16 \\
\hline & & $2^{a}$ & 27 & 73,0 & 10 & 27,0 & 37 & 9 & 60,0 & 6 & 40,0 & 15 \\
\hline \multirow{5}{*}{ ஜ̊ } & \multirow{2}{*}{ Lula } & $1^{a}$ & 17 & 58,6 & 12 & 41,4 & 29 & 12 & 57,1 & 9 & 42,9 & 21 \\
\hline & & $2^{a}$ & 26 & 72,2 & 10 & 27,8 & 36 & 7 & 31,8 & 15 & 68,2 & 22 \\
\hline & \multirow{2}{*}{ Alckmin } & $1^{\mathrm{a}}$ & 23 & 71,9 & 9 & 28,1 & 32 & 5 & 38,5 & 8 & 61,5 & 13 \\
\hline & & $2^{a}$ & 19 & 57,6 & 14 & 42,4 & 33 & 3 & 30,0 & 7 & 70,0 & 10 \\
\hline & TOTAL & & 413 & 67,7 & 197 & 32,3 & 610 & 80 & 51,6 & 75 & 48,4 & 155 \\
\hline
\end{tabular}

Fuente: elaboración propia

* El uso de los spots sueltos en las presidenciales empieza con la elección de 1998.

Además de ello, muchos de los mensajes que tienen la intención de posicionar el candidato sobre un tema específico suelen ser desviados para el enfoque personalista, donde el candidato pasa a ser de hecho la referencia para el tema. Dos mensajes de Lula

${ }^{13}$ Excluyedos los vídeoclips y viñetas electrónicas, los demás mensajes con enfoque en la imagen son un $33,8 \%$ del total, un poco por encima del $32,3 \%$ de los mensajes temáticos. 
son muy representativos de ello. El primero, del 29 de agosto de 2002, es cuando el programa enfoca el problema de la sanidad pública. El tema pasa a ser explorado desde la experiencia particular del candidato, que narra como perdió su primera mujer, embarazada y en las vísperas de alumbrar. La diferencia de Lula hacia los oponentes es sutilmente tratada en el texto de introducción al tema, en boca del presentador:

"Todos sabem que o mais sério problema da saúde no Brasil é a má qualidade do atendimento e do serviço nos postos de saúde e hospitais públicos. Existem pessoas que sabem disso apenas através de relatórios e pesquisas. Outras, através dos jornais e da televisao. Mas existem aqueles que, como o Lula, conhecem isso muito mais de perto. Vejam um trecho de um documentario sobre a vida de Lula feito em maio deste ano"14.

Luego es exhibido el documental. La narrativa emocional de Lula -que llega a llorares complementada con dos comentarios. El primero del mismo candidato, cuando dijo estar seguro de que si su mujer hubiera recibido mejor atención en el hospital habría sobrevivido. A continuación, el presentador cierra el mensaje diciendo que "quien pasó por eso no olvida jamás”. En éste caso, el tema sanidad está traducido en la imagen del candidato, hombre del pueblo, que sabe de la realidad de los hospitales no sólo por los datos de los informes y sondeos - una insinuación malévola a José Serra, ex ministro de Sanidad-, sino por sentir y sufrir en la piel la precariedad de la atención dada a la gente corriente. La vivencia personal se sobrepone a las propuestas concretas o datos estadísticos.

Otro mensaje que sirve como ejemplo de ese recurso es el de Lula el 7 de septiembre de 2006, el día de la independencia de Brasil. La idea de independencia es asociada a la actuación del presidente: el hombre reconocido, el hombre que pelea con los líderes mundiales para garantizar a Brasil un sitio importante en el escenario internacional, el presidente que fortalece las empresas nacionales como modo de generación de empleo. Como en el mensaje sobre sanidad, la idea de independencia -algo que no se puede vincular solamente al pasado sino que es reafirmada cada día, como señala el mensajeestá centrado en la imagen de Lula y su actuación como presidente.

\footnotetext{
${ }^{14}$ En español: “Todos saben que el más serio problema de la sanidad en Brasil es la mala calidad del atendimiento y del servicio en los puestos de salud y hospitales públicos. Hay personas que saben de ello tan sólo a través de informes y sondeos. Otras, a través de los periódicos y de la televisión. Pero hay aquellos que, cómo Lula, conocen eso muy de cerca. Vea una parte de un documental sobre la vida de Lula realizado en mayo de éste año".
} 
Todas las candidaturas utilizan ese tipo de recursos. Collor centró casi toda la campaña de 1989 en su experiencia personal, incluso la imagen de joven y fuerte como atributo que fortalece la idea de cambio; pero sobre todo enfocó la propuesta de moralización desde su lucha contra los marajás y la valentía que los mensajes suelen destacar en el candidato, a veces incluso con palabras poco elegantes. El tema de la estabilidad económica, tan presente en 1994, tiene el mismo tipo de personalización: de una parte, la campaña de Cardoso lo vende como el más preparado, de otra recuerda ser el "padre del Real” y así el nombre adecuado para llevar adelante el plan económico y la estabilidad anhelada. En 2002, la campaña de Serra utilizó el testimonio de Luiz Carlos Oliveira, un portador del virus HIV, para afianzar la propuesta de empleo en la misma figura del candidato. La declaración de Oliveira vincula la imagen de Serra como ex ministro de Sanidad para destacar las posibilidades que se abren en el área del empleo:

"Eu acho que o Fernando Henrique, com o Real, derrubou a inflaçao e deu uma arrumada na economia. Eu vejo no José Serra uma nova etapa. Com ele o Brasil vai dar um grande salto social. Se ele fizer pelo emprego o que ele fez como ministro da saúde, eu tenho certeza que a vida dos brasileiros vai melhorar muito. Porque é graças ao programa de combate à AIDS que o José Serra fez, que eu estou aqui: vivo, feliz, pra ver tudo isso"15.

El foco en la imagen está muy presente en la campaña de 1989, aunque en la primera vuelta la publicidad de Lula destinó una cuarta parte de los spots a los temas. La disputa de 1994 presenta uniformidad y alto índice de mensajes temáticos, lo que se puede asociar en parte a la regla específica de aquella elección, que restringió los programas electorales a las declaraciones de los candidatos e imágenes producidas en el estudio o exhibición de fotos. Tanto Cardoso como Lula presentan medias superiores al 40\% de mensajes enfocando los temas. En la elección siguiente, la campaña de Cardoso seguiría con alto índice de mensajes temáticos, un rasgo que parece asociado a PSDB, desde el origen valorando la imagen de partido con personal técnico calificado y preparado para gobernar. Pero Lula vuelve al nivel de la primera vuelta de 1989.

En 2002, los mensajes de Lula presentan una tendencia a enfocar temas, aunque con tratamiento que siempre lleva a la personalización, como el citado documental en que

\footnotetext{
${ }^{15}$ En una traducción libre: "Yo creo que Fernando Henrique, con el plan Real, derrumbó la inflación e hizo un arreglo en la economía. Yo veo en José Serra una nueva etapa. Con él, Brasil va a emprender un gran salto social. Si él hace por el empleo lo que hizo como ministro de sanidad, estoy seguro que la vida de los brasileños va a mejorar muchísimo. Porque es gracia al programa de combate al Sida que realizó José Serra que yo estoy aquí: vivo, feliz, para ver todo eso".
} 
el candidato habla de la muerte de su primera esposa; casi todo es llevado para la dramatización que amplia el tono emocional. En esa campaña la idea de brasilidad es explorada en gran medida. Uno de los ejemplos de eso es el vídeoclip con el himno nacional, en una alegre versión del grupo afro Ilé Ayié, uno de los más conocidos del carnaval de Bahia. En el vídeoclip, exhibido por primera vez en el día de la independencia, las imágenes presentan un Brasil pujante, de gente trabajadora y naturaleza poderosa. En otro spots, la campaña petista habla del cambio desde un grupo de mujeres embarazadas: en ese vídeo, una narración del cantautor Chico Buarque observa que las madres pueden no tener como elegir aspectos como el color de los ojos de los hijos que están por llegar, pero seguro que pueden elegir el país donde ellos vivirán. El cambio es enseguida asociado a Lula. En cuanto a la campaña de José Serra, la primera vuelta mantiene la tendencia de PSDB a destinar un poco más de espacio a los enfoques temáticos. En la segunda vuelta, los bloques de programas tucanos privilegian la imagen del candidato, pero siguen significativamente temático en los spots sueltos, con $40 \%$ de los mensajes.

En 2006, la campaña de Lula tiene importante enfoque temático en la primera vuelta: 41,4\% de los spots de los bloques y 42,9\% de los spots sueltos. En los dos casos, se destacan los mensajes retrospectivos sobre las realizaciones de gobierno -cabe recordar, un gobierno en gran medida personalizado en la publicidad-. En la segunda vuelta, el retrospectivo pierde fuerza y los mensajes centrados en la imagen son más de dos tercias partes en los bloques. En los spots sueltos, siguen los temas, pero con un enfoque más dirigido a atacar el opositor. Por su parte, Alckmin rompe el enfoque temático de los tucanos: poco conocido en gran parte del país, es obligado en la primera vuelta a dedicar importante espacio de los bloques a la propia imagen (casi $72 \%$ de los mensajes). Aún así mantiene el rasgo de PSDB, con índices significativos de mensajes temáticos: en los bloques, $28 \%$ y $42 \%$ en la primera y segunda vuelta, respectivamente; en los spots sueltos, $61 \%$ y $70 \%$.

\subsection{Profundidad de los mensajes: la superficialidad como patrón}

En un sistema en que las campañas suelen ser personalistas y enfocadas en la imagen, no sorprende que la publicidad electoral sea sobre todo superficial, sin profundizar en los mensajes. Así son las campañas brasileñas, en las que casi tres de cada cinco anuncios electorales son mensajes con enfoque general, cuando mucho de diagnóstico sin ofrecer propuestas. Por supuesto, esa postura está de acuerdo con lo que Rees (1995) considera fundamental respecto a los mensajes de las campañas 
profesionalmente eficaces ${ }^{16}$ : como estrategia de posicionamiento es imprescindible que el candidato trate los asuntos que son de amplio interés de la gente en el momento de la campaña, pero lo mejor es que lo haga desde un enfoque superficial que no genere dudas o discusiones polémicas y, en consecuencia, pérdida de apoyos. Es decir, cuanto más profundizado sea el mensaje, mayor será la posibilidad de producir reacciones en desacuerdo.

Para el análisis de la profundidad en el tratamiento de los temas en los mensajes electorales, esta investigación utilizó tres clasificaciones. En la primera están los spots de abordaje general, cuando lo más hondo que alcanzan es un ligero diagnóstico sobre el asunto tratado. Casi todas las viñetas -excepto las de Lula en 2002, que ofrecen un posicionamiento muy claro- están en esa clasificación, así como los vídeoclips y otros mensajes que destacan la imagen del candidato o apenas ofrecen una idea sin ninguna base de argumento. Aquí están relacionados también los spots de pronunciamientos superficiales de los candidatos. Se pueden destacar dos: uno, de la campaña de Cardoso en 1998. En un tono solemne, el spot anuncia "Compromisos del presidente Fernando Henrique", para enseguida aparecer el mismo candidato hablando en close up, de manera firme y postura imperial:

"Comigo a inflação não volta. Comigo, não tem pacote. Comigo as coisas são claras: eu protejo o Real para proteger o seu salário, seu poder de compra ${ }^{17}$.

A continuación la narración en off añade: vote 45 (el número de Cardoso). En 2002, la campaña de Lula utilizó el mismo tipo de discurso al intentar de modo muy genérico descalificar las críticas de oposición y presentar la "propuesta" de presidente-candidato que se resume a la promesa de trabajar por el pueblo:

“A responsabilidade de quem governa é uma. A de quem é só candidato, é outra. Eles podem prometer tudo. Eu, apenas uma coisa: governar ainda melhor. E isso, eu garanto, eu farei" 18 .

\footnotetext{
16 Rees (1995) no utiliza el término “campaña profesional”, más bien hace referencia al estilo americanizado, relacionando las características que hacen esas campañas más eficaces.

17 En español: "Conmigo la inflación no vuelve. Conmigo las cosas son claras: yo protejo el Real para proteger tu sueldo, tu poder de compra".
} 
Esos spots no pasan de una intención, sin siquiera una propuesta tal como lo hace Lula en un programa sobre sanidad, también en 2002, cuando promete mejorar los hospitales públicos, distribuir medicinas para la gente carente y enfatizar la prevención de enfermedades. En este caso, el spot es clasificado como un mensaje que ofrece una propuesta, pero sin profundizar en la propuesta misma. Es decir, está clara la opción por la mejoría de los hospitales públicos, la prevención y la distribución de medicinas, pero no hay ningún indicio de como se la pondría en práctica: no hay información sobre los recursos que viabilizarán las propuestas, tampoco cómo se dará la mejoría de los hospitales -si a través de la reforma, del aumento del número de camas hospitalarias, la contratación de personal o modernización de los aparatos-.

Un caso de mensaje profundizado es el que exhibe la campaña de Lula en 2002, cuando enfoca el problema del desempleo a partir de la decisión de Petrobrás -la petrolera estatal brasileña- de contratar en el extranjero la construcción de una nueva plataforma marítima de extracción del crudo, con perjuicios para los astilleros nacionales. Al enfocar el tema, Lula lo hace detallando el valor del contrato, el número de puestos de trabajo que podría generar y la decisión de priorizar la industria nacional. El spot incluye entrevistas con obreros y empresarios, en un reportaje con poco espacio a las declaraciones generales y sin base.

En el conjunto de los mensajes electorales analizados, la profundización no ocupa la preocupación de las campañas. Un caso que se aparta un poco del patrón es la campaña de 2006, especialmente la segunda vuelta de Lula, con 27,8\% de mensajes con enfoque profundizado (Tabla 6.7). Ese número contrasta con la segunda vuelta, cuando los asuntos tratados alcanza detallados tan sólo 3,4\% de los mensajes. En el mismo año, la campaña de Alckmin registra un importante índice de mensajes profundizadas: $19,4 \%$ y 18,2\% para primera y segunda vuelta, respectivamente, casi el doble del promedio general para los bloques de programas. El uso de mensajes detalladas está asociado a la intención de los estrategas en construir la imagen de Alckmin cómo político realizador: muchas de las acciones del tucano en el gobierno de São Paulo o incluso como médico, son detalladas con spots a veces largos. Hay vídeos que presentan las acciones en áreas como educación o atención a la gente carente. También hay spots que enfocan la actuación del médico a partir de las declaraciones de los pacientes que en otro tiempo fueron atendidos por el profesional de la medicina.

18 En una tradución libre: “La responsabilidad de quien gobierna es una. La de quien es sólo candidato, es otra. Ellos pueden prometer todo. Yo, solamente una cosa: gobernar todavía mejor. $Y$ eso, yo garantizo, lo haré". 
Hay campañas que se caracterizan por la superficialidad, como las de 1989 y 1994, cuando los asuntos profundizados en las dos candidaturas alcanzaron un 6,7\%: fueron 13 spots así clasificados, entre los 195 para las dos vueltas. En 1998, la campaña de Cardoso mantiene el bajo índice para ese tipo de mensaje, aunque la de Lula suba al 17\%. En 2002, la campaña petista mezcla un mediano uso de mensajes detallada en la primera vuelta (19\%) con bajo, en la segunda (tan sólo $7,7 \%$ ). Incluso la campaña de José Serra, que se utiliza de largos pronunciamientos, en general lo hace desde un abordaje en que hay propuesta, pero sin profundización.

TABLA 6.7

Profundidad de los mensajes en los bloques de programas

\begin{tabular}{|c|c|c|c|c|c|c|c|c|c|}
\hline \multirow{2}{*}{\multicolumn{2}{|c|}{ Campaña* }} & \multirow[t]{2}{*}{ Vuelta } & \multicolumn{2}{|c|}{$\begin{array}{c}\text { Enfoque } \\
\text { general o } \\
\text { Diagnóstico }\end{array}$} & \multicolumn{2}{|c|}{$\begin{array}{l}\text { Propuesta } \\
\text { sin } \\
\text { profundidad }\end{array}$} & \multicolumn{2}{|c|}{$\begin{array}{c}\text { Propuesta } \\
\text { profundizada }\end{array}$} & \multirow{2}{*}{$\begin{array}{c}\text { Total } \\
\text { n }\end{array}$} \\
\hline & & & $\mathrm{n}$ & $\%$ & $\mathrm{n}$ & $\%$ & $\mathrm{n}$ & $\%$ & \\
\hline \multirow{4}{*}{$\begin{array}{l}\text { ̊ } \\
\text { O } \\
-\end{array}$} & \multirow{2}{*}{ Collor } & $1^{a}$ & 23 & 71,9 & 9 & 28,1 & & & 32 \\
\hline & & $2^{a}$ & 40 & 65,6 & 19 & 31,1 & 2 & 3,3 & 61 \\
\hline & \multirow{2}{*}{ Lula } & $1^{\mathrm{a}}$ & 22 & 57,5 & 12 & 30,0 & 6 & 15,0 & 40 \\
\hline & & $2^{a}$ & 39 & 62,9 & 18 & 29,0 & 5 & 8,1 & 62 \\
\hline \multirow{2}{*}{ ఫ } & Cardoso & $1^{\mathrm{a}}$ & 24 & 63,2 & 13 & 34,2 & 1 & 2,6 & 38 \\
\hline & Lula & $1^{\mathrm{a}}$ & 17 & 70,8 & 6 & 25,0 & 1 & 4,2 & 24 \\
\hline \multirow{2}{*}{$\stackrel{\infty}{\sigma}$} & Cardoso & $1^{\mathrm{a}}$ & 20 & 40,8 & 27 & 55,1 & 2 & 4,1 & 49 \\
\hline & Lula & $1^{\mathrm{a}}$ & 18 & 52,9 & 10 & 29,4 & 6 & 17,7 & 34 \\
\hline \multirow{4}{*}{ ญ్ } & \multirow{2}{*}{ Lula } & $1^{\mathrm{a}}$ & 15 & 71,4 & 3 & 14,3 & 3 & 14,3 & 21 \\
\hline & & $2^{\mathrm{a}}$ & 15 & 57,7 & 9 & 34,6 & 2 & 7,7 & 26 \\
\hline & \multirow{2}{*}{ Serra } & $1^{\mathrm{a}}$ & 16 & 28,6 & 32 & 57,1 & 8 & 14,3 & 56 \\
\hline & & $2^{a}$ & 20 & 24,1 & 13 & 35,1 & 4 & 10,8 & 37 \\
\hline \multirow{5}{*}{ ஜ্ণ } & \multirow{2}{*}{ Lula } & $1^{\mathrm{a}}$ & 18 & 62,1 & 10 & 34,5 & 1 & 3,4 & 29 \\
\hline & & $2^{a}$ & 17 & 47,2 & 9 & 25,0 & 10 & 27,8 & 36 \\
\hline & \multirow{2}{*}{ Alckmin } & $1^{\mathrm{a}}$ & 16 & 50,0 & 4 & 12,5 & 12 & 19,4 & 32 \\
\hline & & $2^{a}$ & 13 & 39,4 & 14 & 42,4 & 6 & 18,2 & 33 \\
\hline & TOTAL & & 333 & 54,6 & 208 & 34,1 & 69 & 11,3 & 610 \\
\hline
\end{tabular}

En el total, ese tipo de mensaje con algo de propuesta pero sin profundidad suma un $34,1 \%$ de los spots de los bloques, en cuanto los enfoque generales tienen una media del $54,6 \%$. Entre los spots sueltos, los mensajes con propuesta sin profundización registra promedio algo por debajo del encontrado en los bloques: 27,7\% (Tabla 6.8). Además los anuncios cuyo tema recibe un tratamiento profundizado son todavía menos: tan sólo $5,2 \%$, lo que resultada en un índice de mensajes generales de un $67,1 \%$. Sumándose bloques y anuncios sueltos, 57,1\% de los 765 spots analizados presentan un enfoque 
general que enfatiza una intención o una simple sensación, como bien representan los vídeoclips y viñetas electrónicas. La media de mensajes con propuestas pero sin profundización es de $32,8 \%$ y los vídeos cuyos asuntos reciben tratamiento detallado suman $10,1 \%$ del total.

TABLA 6.8

Profundidad de los mensajes en los spots sueltos

\begin{tabular}{|c|c|c|c|c|c|c|c|c|c|}
\hline \multicolumn{2}{|c|}{ Campaña* } & \multirow[t]{2}{*}{ Vuelta } & \multicolumn{2}{|c|}{$\begin{array}{c}\text { Enfoque } \\
\text { general o } \\
\text { Diagnóstico }\end{array}$} & \multicolumn{2}{|c|}{$\begin{array}{l}\text { Propuesta } \\
\text { sin } \\
\text { profundidad }\end{array}$} & \multicolumn{2}{|c|}{$\begin{array}{c}\text { Propuesta } \\
\text { profundizada }\end{array}$} & \multirow{2}{*}{$\begin{array}{c}\text { Total } \\
\mathrm{n} \\
\end{array}$} \\
\hline & & & $\mathrm{n}$ & $\%$ & $\mathrm{n}$ & $\%$ & $\mathrm{n}$ & $\%$ & \\
\hline \multirow{2}{*}{ ळ } & Cardoso & $1^{a}$ & 9 & 60,0 & 5 & 33,3 & 1 & 6,7 & 15 \\
\hline & Lula & $1^{\mathrm{a}}$ & 15 & 100 & & & & & 15 \\
\hline \multirow{4}{*}{ ণั } & \multirow{2}{*}{ Lula } & $1^{\mathrm{a}}$ & 14 & 93,3 & 1 & 6,7 & & & 15 \\
\hline & & $2^{\mathrm{a}}$ & 12 & 92,3 & 1 & 7,7 & & & 13 \\
\hline & \multirow{2}{*}{ Serra } & $1^{\mathrm{a}}$ & 8 & 50,0 & 8 & 50,0 & & & 16 \\
\hline & & $2^{a}$ & 5 & 33,3 & 6 & 40,0 & 4 & 26,7 & 15 \\
\hline \multirow{4}{*}{ ஜํํ } & \multirow{2}{*}{ Lula } & $1^{\mathrm{a}}$ & 14 & 66,7 & 7 & 33,3 & & & 21 \\
\hline & & $2^{a}$ & 16 & 72,7 & 6 & 27,3 & & & 22 \\
\hline & \multirow{2}{*}{ Alckmin } & $1^{\mathrm{a}}$ & 7 & 53,8 & 3 & 23,1 & 3 & 23,1 & 13 \\
\hline & & $2^{a}$ & 4 & 40,0 & 6 & 60,0 & & & 10 \\
\hline & TOTAL & & 104 & 57,1 & 43 & 27,7 & 8 & 5,2 & 155 \\
\hline
\end{tabular}

Los datos referentes a la superficialidad de los mensajes no parece indicar una tendencia hacia la profesionalización, si se toma la superficialidad como caracterizador de esa misma profesionalización, como subraya Rees (1995). De hecho, tres campañas se han destacado en un abordaje más ligero: la de Collor en 1989 y las dos últimas de Lula. En la primera disputa presidencial, la publicidad electoral exhibida por la campaña de Collor es de una extraordinaria superficialidad. En la primera vuelta no hay siquiera un único mensaje con propuesta profundizada. En la campaña de Lula en el mismo año, se verifica un alto número de spots de abordaje general, pero también hay mensajes con profundización de los asuntos, equilibrando un poco los anuncios. Ese rasgo es retomado por Lula en 2002 y 2006, cuando incluso temas complejos reciben tratamiento ligero, sobre todo con el uso del caso particular como representación del todo. El recurso, tan común en el periodismo de TV de inspiración estadounidense, en una manera de reducir los temas a las sensaciones y así mantener el asunto en la superficialidad de las apariencias que más que informar encanta el espectador. 


\subsection{El enfoque geográfico: mensajes sujetos al enfoque nacional}

El enfoque geográfico de los mensajes electorales de las campañas brasileñas está más cerca de las características de las campañas modernas que de las profesionales. Según señala Norris (2004), los discursos de campaña evolucionan de los temas y apelaciones locales de la fase premoderna a los enfoques nacionales de la etapa moderna, para en la fase actual de campañas postmodernas - profesionales, para esta investigación- utilizar discursos centrados en grandes temas nacionales pero con matizaciones locales que buscan atender demandas más directas del elector. En la realidad estadounidense, el enfoque nacional/local se viabiliza por la posibilidad de comprar espacios en emisoras nacionales y locales.

La caracterización está muy distante de la situación vivida por las campañas brasileñas, donde los mensajes son uniformes y transmitidos para todo el país a una sola vez, en un pool que une todas las cadenas de televisión abiertas, públicas o privadas. Por el sistema adoptado desde que se restablecieron las elecciones presidenciales, las grandes cadenas de TV fijan una rotación por la cual cada una es responsable por la emisión de la publicidad de los candidatos en determinados días del período electoral; las demás cadenas retransmiten vía satélite para las emisoras afiliadas alrededor de Brasil, haciendo que todo el país vea el mismo programa a un sólo tiempo ${ }^{19}$.

Los números son muy reveladores de la nacionalización de los mensajes electorales ${ }^{20}$ : por encima del 90\% de los spots de los bloques de programas presentan un contenido enderezado al público en general, de ámbito nacional. Los mensajes regionales (que enfocan una región del país o más de uno estado) suman 4,3\%, en cuanto los spots con abordaje local suman solamente 3,9\% (Tabla 6.9). Situación tan distintas del patrón profesional es el reflejo claro de la legislación que establece reglas tan rígidas de acceso a los medios. Sin posibilidades de distribución diferenciada de los anuncios electorales, las candidaturas son casi obligadas a ofrecer un enfoque el más amplio que pueda con el intento de producir respuestas igualmente amplias.

De todos los candidatos, lo único que presenta un índice significativo de mensajes regionales o locales es Geraldo Alckmin, en la primera vuelta de 2006, con un 28,1\%, donde $15,6 \%$ son anuncios que pueden ser caracterizados como regionales (sobre todo enderezados a los estados de Nordeste) y 12,5\% son mensajes locales, especialmente

\footnotetext{
19 En las disputas estaduales y municipales, se realiza el mismo procedimiento en el ámbito del estado o municpio.

20 Son considerados nacionales los mensages que ofrecen un enfoque que no está atrapado a la realidad local o regional. Así, incluso mensajes que toman casos locales para representar cuestiones o propuestas de ámbito general son consideradas nacionales.
} 
sobre y para el estado de São Paulo. Eso se da por la difícil posición de Alckmin, poco conocido en Nordeste y necesitando consolidar su posición en São Paulo so pena de siquiera pasar a la segunda vuelta. En el caso de São Paulo, la atención de los mensajes se justifica por ser el mayor electorado del país, responsable por 22,2\% del electorado de 2006. Además, es el estado de referencia del candidato de PSDB, donde fue gobernador. En cuanto al Nordeste, la segunda mayor de las cinco regiones de Brasil por delante está tan sólo el Sureste, que incluye São Paulo-, era donde el tucano cosechaba sus peores resultados en las encuestas de intención de voto. La regionalización era casi un acto de desesperación de un candidato que tenía poco horizonte por delante.

TABLA 6.9

El enfoque geográfico: nacional vs local en los bloques

\begin{tabular}{|c|c|c|c|c|c|c|c|c|c|}
\hline \multicolumn{2}{|c|}{ Campaña* } & \multirow[t]{2}{*}{ Vuelta } & \multicolumn{2}{|c|}{ Nacional } & \multicolumn{2}{|c|}{ Regional } & \multicolumn{2}{|c|}{ Local } & \multirow{2}{*}{$\begin{array}{c}\text { Total } \\
\mathrm{n}\end{array}$} \\
\hline & & & $\mathrm{n}$ & $\%$ & $\mathrm{n}$ & $\%$ & $\mathrm{n}$ & $\%$ & \\
\hline \multirow{4}{*}{$\begin{array}{l}\text { : } \\
\text { Ф } \\
-\end{array}$} & \multirow{2}{*}{ Collor } & $1^{a}$ & 28 & 87,5 & 4 & 12,5 & & & 32 \\
\hline & & $2^{a}$ & 50 & 82,0 & 3 & 4,9 & 8 & 13,1 & 61 \\
\hline & \multirow{2}{*}{ Lula } & $1^{\mathrm{a}}$ & 38 & 95,0 & 1 & 2,5 & 1 & 2,5 & 40 \\
\hline & & $2^{\mathrm{a}}$ & 58 & 93,6 & 2 & 3,2 & 2 & 3,2 & 62 \\
\hline \multirow{2}{*}{ హి } & Cardoso & $1^{\mathrm{a}}$ & 38 & 100 & & & & & 38 \\
\hline & Lula & $1^{\mathrm{a}}$ & 24 & 100 & & & & & 24 \\
\hline \multirow{2}{*}{$\stackrel{\infty}{\sigma}$} & Cardoso & $1^{\mathrm{a}}$ & 49 & 100 & & & & & 49 \\
\hline & Lula & $1^{\mathrm{a}}$ & 34 & 100 & & & & & 34 \\
\hline \multirow{4}{*}{ ণั } & \multirow{2}{*}{ Lula } & $1^{\mathrm{a}}$ & 21 & 100 & & & & & 21 \\
\hline & & $2^{a}$ & 25 & 96,2 & & & 1 & 3,8 & 26 \\
\hline & \multirow{2}{*}{ Serra } & $1^{\mathrm{a}}$ & 53 & 94,6 & 2 & 3,6 & 1 & 1,8 & 56 \\
\hline & & $2^{a}$ & 33 & 89,2 & 1 & 2,7 & 3 & 8,1 & 37 \\
\hline \multirow{5}{*}{ ஜ్̊ } & \multirow{2}{*}{ Lula } & $1^{a}$ & 29 & 100 & & & & & 29 \\
\hline & & $2^{a}$ & 31 & 86,1 & 3 & 8,3 & 2 & 5,6 & 36 \\
\hline & \multirow{2}{*}{ Alckmin } & $1^{\mathrm{a}}$ & 23 & 71,9 & 5 & 15,6 & 4 & 12,5 & 32 \\
\hline & & $2^{a}$ & 26 & 78,8 & 5 & 15,1 & 2 & 6,1 & 33 \\
\hline & TOTAL & & 560 & 91,8 & 26 & 4,3 & 24 & 3,9 & 610 \\
\hline
\end{tabular}

La rigidez del acceso a los medios hace que el discurso regional se convierta en un riesgo, pues a la vez que favorece a una región se olvida de las demás. Un recurso utilizado por las campañas es la producción de mensajes con doble enfoque, a la vez nacional y regional; o biográfico y regional. El mismo Alckmin es un ejemplo, cuando en mensajes sobre sus propuestas o realizaciones incluía declaraciones elogiosas de 
populares. El detalle es que los populares -moradores de São Paulo pero con origen en Nordeste- eran identificados por el nombre y el estado de origen. El enfoque principal de eses spots no es regional, pero la regionalización se da de modo sutil, capaz de generar la simpatía de los votantes de la región sin perder el foco nacional.

Hay también casos de mensajes que reciben un enfoque local pero como forma de puntuar la realidad nacional. Como ejemplo se puede otra vez citar el mensaje sobre los astilleros de Río de Janeiro, utilizado por Lula en 2002 para tratar de un tema nacional, el alto índice de paro y la falta de apoyo a la industria nacional. A pesar de la particularización, el enfoque es claramente nacional -y así el anuncio ha sido clasificado-. Quién hizo explícito uso del discurso local fue Collor en la segunda vuelta de 1998 como estrategia para fortalecer los vínculos con los estados. Sobre todo en los primeros programas de la segunda fase, la comunicación electoral presentaba el mitin del candidato en el estado o hacía referencia a la ventaja que alcanzó en la primera ronda. A continuación, el mismo Collor agradecía: "Gracias, Pernambuco", decía para añadir la necesidad de siguieren juntos hacia la victoria en la votación final.

Aún en 1989, el muestreo analizado incluye dos mensajes locales en la campaña de Lula en la segunda vuelta. Las dos son referencias al caos administrativo en Alagoas, una forma de debilitar el oponente. En 1994 y 1998, los enfoques locales y regionales en la práctica desaparecen. En 2002, Serra registra 8,1\% de mensajes locales, de hecho enfoques sobre administraciones de PT. Un ejemplo es el spot a través del cual critica duramente el gobierno petista del estado de Río Grande del Sur, acusado por una parte de radicalismo que aleja los inversores y, de otra, de participación en prácticas corruptas y asociación con el crimen organizado. La reacción de la campaña de Lula fue un otro mensaje local, presentando los logros de Río Grande del Sur desde la llegada de PT al poder estadual.

En cuanto a los spots sueltos, no cambia la tendencia sino más bien la refuerza: todos tienen un enfoque nacional, excepto un único caso. La excepción es un anuncio de Alckmin que habla de la votación de la primera vuelta en São Paulo, en que se puso por delante de Lula. En el anuncio, el contenido recuerda que São Paulo es el estado que mejor conoce a los dos candidatos, puesto que el origen político de ambos. Un intento de reafirmar el concepto "quien conoce vota/no vota".

El abordaje geográfico no resulta necesariamente en un proceso de segmentación, entendida como un esfuerzo de comunicación más directa con un público algo delimitado con el propósito de hacer ese mismo público decantarse por una oferta electoral específica. En la comunicación con enfoque geográfico encontrada en las campañas brasileñas, muchas veces el objetivo no es establecer un diálogo particular 
con un segmento del electorado situado en un estado o región, sino generar un posicionamiento sobre el candidato, partido u opositor. Ello se pone más evidente cuando el enfoque es negativo, como lo hizo Lula en 1989, cuando enfocaba los problemas administrativos producidos por el gobierno Collor en el estado; Collor hace lo propio al atacar la gestión de Luiza Erundina (PT) en São Paulo.

El citado mensaje de Serra en que ataca al gobierno de PT en Río Grande del Sur tampoco es un esfuerzo de establecer un diálogo amistoso con los gauchos, más bien intentando rescatar la percepción negativa más general respecto la capacidad administrativa de PT. En cambio, el PT hace de la respuesta a Serra un modo de conquista del electorado del estado, uno donde Lula presentaba baja intención de votos. Al contestar los ataques, el mensaje exhibido por la campaña de PT destaca el papel del Río Grande en la historia del país y la valentía de la gente del estado.

\subsection{Segmentación de mensajes}

La segmentación es uno de los rasgos de las campañas profesionales por ofrecer (Norris, 2004), pero ese rasgo está lejos de ser una característica de las campañas brasileñas. Otra consecuencia fundamentalmente del rigor de la legislación en cuanto al acceso de los candidatos a los medios, imponiendo limitaciones que reducen sobremanera la posibilidad de un diálogo particularizado por lo menos en los mensajes del horario electoral de los candidatos. Con el fin de buscar una comunicación más clara con determinados grupos de electores, las campañas brasileñas suelen emplear otros recursos de comunicación más allá de la radio y la televisión, donde los mensajes son iguales para todo el país. Los recursos más comunes entre las acciones complementarias son los panfletos, los correos dirigidos, uso del telemarketing y el espacio mediático sobre todo de los periódicos capaces de alcanzar determinados segmentos, como es el caso de la prensa regional.

En el modelo estadounidense, los mensajes televisivos segmentados son una realidad desde la campaña de John Kennedy, cuando por la primera vez se produjo spots para grupos de minorías, entre ellos los hispánicos (Maarek, 2005). En las últimas campañas, la relación con los diversos públicos se ha convertido en una de las principales preocupaciones estratégicas. Uno de los hechos reveladores de de esa preocupación son los diversos spots en español exhibidos tanto por demócratas como por republicanos en las últimas presidenciales estadounidenses. Esas estrategias son facilitadas por el sistema norteamericano, que además de permitir la libre compra de espacios publicitarios - de hecho, el límite de uso de la tele es el poder de compra de publicidad por cada candidato- cuenta desde la década de 1960 con cadenas de TV por 
cable con alcance nacional ${ }^{21}$. Muchas de esas cadenas son claramente enderezadas a públicos con perfil muy definido, como las que transmiten sólo noticias, las que tienen programación deportiva, foco en la música o emiten en español. Por el registro de clientes, se hace posible la definición de una rigurosa estrategia de segmentación de mensajes con optimización de los recursos disponibles.

El control de acceso a los medios en Brasil no permite ese tipo de estrategia en la publicidad de televisión, obligando las candidaturas al uso de medios complementarios o la exhibición en el espacio de publicidad televisiva de mensajes muchas veces no tan evidentes en cuanto su intención de alcanzar un determinado grupo de electores. El resultado es que casi nueve de cada diez mensajes llevados al aire en los bloques de programas no ofrecen ningún tipo de segmentación (Tabla 6.10). En 12,8\% de esos mensajes hay segmentación clara o disimulada. La segmentación disimulada (que representa $8,9 \%$ del total de spots por bloque), es cuando se busca alcanzar un determinado grupo de electores, pero sin un abordaje directo y explícito.

TABLA 6.10

La segmentación de mensajes en los bloques de programas

\begin{tabular}{|c|c|c|c|c|c|c|c|c|c|}
\hline \multicolumn{2}{|c|}{ Campaña* } & \multirow[t]{2}{*}{ Vuelta } & \multicolumn{2}{|c|}{ Clara } & \multicolumn{2}{|c|}{ Disimulada } & \multicolumn{2}{|c|}{ Ausente } & \multirow{2}{*}{$\begin{array}{c}\text { Total } \\
\mathrm{n}\end{array}$} \\
\hline & & & $\mathrm{N}$ & $\%$ & $\mathrm{n}$ & $\%$ & $\mathrm{n}$ & $\%$ & \\
\hline \multirow{4}{*}{$\begin{array}{l}\infty \\
\stackrel{9}{\circ} \\
\stackrel{-}{-1}\end{array}$} & \multirow{2}{*}{ Cardoso } & $1^{\mathrm{a}}$ & & & 4 & 12,5 & 28 & 87,5 & 32 \\
\hline & & $2^{a}$ & 9 & 14,8 & 3 & 4,9 & 49 & 80,3 & 61 \\
\hline & \multirow{2}{*}{ Lula } & $1^{\mathrm{a}}$ & 1 & 2,5 & 5 & 12,5 & 34 & 85,0 & 40 \\
\hline & & $2^{a}$ & 2 & 3,2 & 3 & 4,9 & 57 & 91,9 & 62 \\
\hline \multirow{2}{*}{ ஓ } & Cardoso & $1^{\mathrm{a}}$ & & & 4 & 10,5 & 34 & 89,5 & 38 \\
\hline & Lula & $1^{\mathrm{a}}$ & & & & & 24 & 100 & 24 \\
\hline \multirow{2}{*}{$\stackrel{\infty}{\circ}$} & Cardoso & $1^{a}$ & & & & & 49 & 100 & 49 \\
\hline & Lula & $1^{\mathrm{a}}$ & 2 & 5,9 & 5 & 14,7 & 27 & 79,4 & 34 \\
\hline \multirow{4}{*}{ ญ̊ } & \multirow{2}{*}{ Lula } & $1^{\mathrm{a}}$ & & & 3 & 14,3 & 18 & 85,7 & 21 \\
\hline & & $2^{a}$ & 1 & 3,9 & 3 & 11,5 & 22 & 84,6 & 26 \\
\hline & \multirow{2}{*}{ Serra } & $1^{\mathrm{a}}$ & 2 & 3,6 & 4 & 7,1 & 50 & 89,3 & 56 \\
\hline & & $2^{a}$ & 1 & 2,7 & 8 & 21,6 & 28 & 75,7 & 37 \\
\hline \multirow{5}{*}{ ஜ̊ํํ } & \multirow{2}{*}{ Lula } & $1^{\mathrm{a}}$ & & & 2 & 6,9 & 27 & 93,1 & 29 \\
\hline & & $2^{\mathrm{a}}$ & 1 & 2,8 & 3 & 8,3 & 32 & 88,9 & 36 \\
\hline & \multirow{2}{*}{ Alckmin } & $1^{\mathrm{a}}$ & 3 & 9,4 & 4 & 12,5 & 25 & 78,1 & 32 \\
\hline & & $2^{a}$ & 2 & 6,1 & 3 & 9,1 & 28 & 84,8 & 33 \\
\hline & TOTAL & & 24 & 3,9 & 54 & 8,9 & 532 & 87,2 & 610 \\
\hline
\end{tabular}

${ }^{21}$ Sobre la evolución de la televisón por cable en Estados Unidos y la abertura del sector en Brasil, ver el trabajo de Hoineff (1991). 
La ya citada serie de spots de la campaña de Lula en 1998 que intenta reforzar las dudas sobre los candidatos ofrece tanto ejemplos de segmentación clara como disimulada. Todos los spots son mensajes dirigidos al elector que no tiene todavía una firme opción de voto. En cuatro de los cinco spots protagonizados por el periodista Juarez Soares, el texto pronunciado no deja explícito el destino, como en el vídeo en que toma los altos intereses como excusa para estimular las dudas:

"Olha só: Como é que é isso? O Lula diz que tem que baixar os juros. O Fernando Henrique aumenta. Quem é que está com a razão? A gente tem que colocar os dois cara-a-cara pra saber. No dia 4, vote no Lula, 13. Aí vem o segundo turno, debate, você vê quem é o melhor e decide”22.

Con el intento de llevar la disputa hacia la segunda volta, la estrategia de campaña focaliza en el elector menos convencido, pero en ese caso desde un abordaje no explícito, sin una apelación que haga referencia clara a los indecisos, lo que queda evidente en la expresión "a gente tem que colocar os dois cara-a-cara" [nosotros tenemos que ponerlos cara a cara], que de tan abarcante incluye en mismo presentador del vídeo, que es todo menos indeciso. El mensaje expone elementos que ayudan a ampliar la indecisión y de ahí a generar la opción por el candidato que puede provocar la segunda vuelta y así la ampliación del debate. Es distinto lo que pasa en el quinto vídeo de la serie, en que hay un abordaje directo, puesto que el presentador habla claramente del indeciso y con él busca un diálogo sin tapujos:

"Você está indeciso, né? Votar pra presidente é um negócio muito sério, tem que pensar muito pra votar no melhor. Então faz o seguinte: dia 4, vote no Lula, 13. Aí vem o segundo turno, tem o debate, você vê quem é o melhor e decide" 23 .

\footnotetext{
${ }^{22}$ En español: “Mira bién, ¿Cómo puede ser? Lula dijo que hay que rebajar los intereses. Fernando Henrique los aumenta. ¿Quién tiene la razón? Nosotros tenemos que ponerlos cara a cara para saberlo. El día 4 vota Lula, 13. Entonces viene la segunda vuelta, debate, tu ves quien es el mejor y decide".

${ }^{23}$ En español: "Estás indeciso, ¿verdad? Votar para presidente es algo muy serio, hay que razonar muchísimo para votar mejor. Entonces haces así: el día 4 vota en Lula, 13. Entonces viene la segunda vuelta, hay debate, tu ves quien es el mejor y decide".
} 
No queda duda sobre el segmento que el mensaje desea alcanzar, sobre todo al propio indeciso, de quien se pide la atención en la primera frase: "Você está indeciso, né?" [Estás indeciso, civerdad?]. Aún en 1998, Lula utiliza la estrategia de segmentación en anuncios dirigidos a las mujeres y a las personas que tienen desempleados en la familia, anuncios que son exhibidos tanto en los bloques como en los espacios publicitarios a lo largo de la programación. En 2002, Serra utiliza a la diputada Rita Camata -su candidata a vicepresidente- para fortalecer los vínculos con las mujeres, en mensajes que empiezan con un "tú que eres mujer, tú que eres madre" y evidencian a que grupo de elector están dirigidos.

Anque esté presentes en casi todas las campañas, la publicidad con segmentación clara sólo tiene alguna relevancia en los bloques de programas de la segunda vuelta de Collor, en 1989, cuando los mensajes destinados a fortalecer los vínculos con grupos específicos representan casi 15\% de los spots. Estos anuncios de explícita segmentación son en los que el candidato agradece la votación lograda en determinado estado y luego reafirma la necesidad de continuar juntos hasta la victoria. Es de notar que las segundas vueltas suelen tener mayor número de mensajes segmentados que las primeras. La media de segmentación explícita, un 2,3\% en la primera ronda electoral, pasa al 6,3\% en la segunda. Los anuncios de segmentación disimulada son casi iguales en dos fases: un $8,7 \%$ en la primera y $9 \%$ en la segunda.

En los anuncios sueltos, que ofrecen una pequeña posibilidad de flexibilización de horarios, los mensajes segmentados se hacen más presentes, donde representan un $9 \%$ del total (Tabla 6.11). Además hay otros 20\% de vídeos en que los contenidos son clasificados como segmentación disimulada. Pero también en ese caso, la amplia mayoría siguen siendo los mensajes carentes de segmentación, con $71 \%$ del total. La segmentación explícita también es algo más significativa en las segundas vueltas: 13,3\% en contra un $6,3 \%$ de la primera ronda. En todo caso, ese crecimiento no reduce el protagonismos de los enfoques generales.

Quizá el factor que lleve a un pequeño aumento de los mensajes segmentados sea la necesidad de fortalecer la campaña junto a públicos en los que la candidatura tiene posición muy fuerte (para preservarla) o bien muy débil (con el propósito de reverter la amplia desventaja). En el primero caso están los mensajes de Collor en 1989, así como en el segundo se destacan los anuncios de Lula en 1998. Parece evidente como factor decisivo en la opción por spots no segmentados el hecho de que la publicidad electoral sea exhibida con poca flexibilización en los horarios y sin ninguna opción en la regionalización de los mensajes. 
TABLA 6.11

La segmentación de mensajes en los spots sueltos

\begin{tabular}{|c|c|c|c|c|c|c|c|c|c|}
\hline \multicolumn{2}{|c|}{ Campaña* } & \multirow[t]{2}{*}{ Vuelta } & \multicolumn{2}{|c|}{ Clara } & \multicolumn{2}{|c|}{ Disimulada } & \multicolumn{2}{|c|}{ Ausente } & \multirow{2}{*}{$\begin{array}{c}\text { Total } \\
\mathrm{n}\end{array}$} \\
\hline & & & $\mathrm{N}$ & $\%$ & $\mathrm{n}$ & $\%$ & $\mathrm{n}$ & $\%$ & \\
\hline \multirow{2}{*}{$\stackrel{\infty}{\circ}$} & Cardoso & $1^{\mathrm{a}}$ & 1 & 6,7 & 2 & 13,3 & 12 & 80,0 & 15 \\
\hline & Lula & $1^{\mathrm{a}}$ & 3 & 20,0 & 7 & 46,7 & 5 & 33,3 & 15 \\
\hline \multirow{4}{*}{ ণิ } & \multirow{2}{*}{ Lula } & $1^{\mathrm{a}}$ & & & 3 & 20,0 & 12 & 80,0 & 15 \\
\hline & & $2^{\mathrm{a}}$ & 3 & 23,0 & 5 & 38,5 & 5 & 38,5 & 13 \\
\hline & \multirow{2}{*}{ Serra } & $1^{\mathrm{a}}$ & 1 & 6,2 & 4 & 25,0 & 11 & 68,8 & 16 \\
\hline & & $2^{a}$ & 2 & 13,3 & 1 & 6,7 & 12 & 80,0 & 15 \\
\hline \multirow{5}{*}{ ஜ̊ } & \multirow{2}{*}{ Lula } & $1^{\mathrm{a}}$ & 1 & 4,8 & 7 & 33,3 & 13 & 61,9 & 21 \\
\hline & & $2^{a}$ & 2 & 9,1 & 2 & 9,1 & 18 & 81,8 & 22 \\
\hline & \multirow{2}{*}{ Alckmin } & $1^{\mathrm{a}}$ & & & & & 13 & 100 & 13 \\
\hline & & $2^{a}$ & 1 & 10 & & & 9 & 90 & 10 \\
\hline & TOTAL & & 14 & 9,0 & 31 & 20,0 & 110 & 71,0 & 155 \\
\hline
\end{tabular}

Fuente: elaboración propia

\subsection{El lenguaje simbólico como atajo}

Una de las lecciones de la campaña de Eisenhower en 1952 fue que los mensajes necesitan tener un lenguaje accesible, lo que llevó a los estrategas a simplificar los discursos del general (Maarek, 2005). Las décadas siguientes enseñarían que, además de simplificar, el uso del lenguaje simbólico ayuda en la fijación de los mensajes, sobre todo cuando la simbología también contiene alta dosis de emoción; sencillamente porque es más fácil ganar la adhesión del elector con una sonrisa o referencias del imaginario de la gente que con un árido discurso de difícil interpretación (Rees, 1995). El simbólico es un camino más corto hacia el elector, el atajo que puede hacer decantar las preferencias del ciudadano hacia un candidato.

El lenguaje símbolo tiene destacado papel en la comunicación publicitaria, desde que se utiliza de referencia afectiva, como instrumento de acercamiento y encantamiento. Ese proceso es posible porque los símbolos, además del sentido objetivo y visible, contienen un sentido oculto y más profundo que está presente en el imaginario de las personas; el símbolo funciona como puente entre esos dos campos -el visible y el ocultoatribuyendo sentido más amplio y más preciso a los mensajes (Nasser, 2004). Es por esa fuerza simbólica que los mitos son tan presentes como forma de expresión de un conjunto de ideas e idealizaciones. O, dicho de otra, forma, los símbolos son la mejor forma de expresar una idea o sentimiento. 
En cuanto puente entre dos opuestos, el símbolo contiene el oculto y el revelado, "el conocido y el desconocido, el inmanente y el trascendente" y así ejerce la función de ir más allá, según Nasser (2004: 110) 24. Los mensajes simbólicos despiertan el interés del receptor al activar conexiones internas de naturaleza psicológica que producen ciertas actitudes en el público (López-Vázquez, 2007). De ello se valle la publicidad, incluso la publicidad electoral que, al utilizar esos atajos hacia el alma de la gente, busca producir una satisfacción simbólica en el elector, lo que generará reacciones positivas y afectivas capaces de conseguir la adhesión a una oferta política específica.

Un spots clásico que utiliza la simbología para posicionar sobre un tema es el anuncio de la niña de la margarita, en la campaña de Lyndon Johnson en las presidenciales estadounidenses de 1964: el acto de deshojar la flor, tan conocido de la gente, hace referencia a un juego de suerte o azar, que puede ser aceptable para juguetes de niños, no para el grave problema de la amenaza nuclear. Muchas veces, el humor pasa a ser uno de los caminos utilizados incluso para tratar de temas complejo, como lo hizo George W. Bush en 2004, al utilizar la fábula del Caperucita Roja: en ese vídeo, el adversario de Bush, John Kerry, era presentado como Caperucita y los enemigos de Estados Unidos -asociados con la guerra de Irak- eran el lobo en piel de cordero; desde la asociación con la fábula, Kerry era presentado como ingenuo, por tanto incapaz de estar a la altura del puesto en disputa.

La publicidad electoral en las presidenciales brasileñas ha utilizado los recursos simbólicos con importante intensidad, representando cerca de la mitad de los mensajes exhibidos en los bloques de programas (Tabla 6.12) y casi un tercio de los spots sueltos (Tabla 6.13). Los atajos simbólicos son utilizados desde la primera disputa presidencial, precisamente la que presenta la más alta media de simbolismo en los mensajes, a pesar de la segunda vuelta de la campaña de Collor, cuando ese tipo de anuncio no alcanza los 40\% del total. En la primera ronda, 62\% de los mensajes del Caçador de Marajás utilizan el lenguaje simbólico, en tanto en la campaña de Lula el índice se pone en cuatro quintas partes en las dos fases.

La campaña de Collor ofrece un conjunto de ejemplos de anuncios simbólicos. En uno de ellos, utilizado en las dos vueltas, un tren -pronto bautizado por la prensa como el tren de la modernidad, así reforzando el posicionamiento del candidato del cambioavanza por los carrilles y va destruyendo obstáculos que se ponen en el camino. Los obstáculos son placas que contienen referencias negativas como el paro y la corrupción. En otro, busca sensibilizar al elector propenso a votar en blanco con la exhibición de un mensaje en que la bandera brasileña va perdiendo los colores en cuanto la narración

\footnotetext{
${ }^{24}$ La conceptualización de Nasser (2004) es basada sobre todo en el pensamiento de Carl Jung,
} además de aportaciones de Jacques Derridá. 
hace asociaciones negativas. "A quien vota en blanco no importa que devasten nuestro verde", advierte el anuncio, para enseguida el verde de la bandera desaparecer. Luego es el amarillo y el azul, en un mensaje que insinúa que esas pérdidas nacionales será reales en caso de una victoria del opositor. Los colores vuelven a aparecer cuando el spot destaca que "El día 17 no puede dar blanco. Porque Brasil va colorir".

TABLA 6.12

Concreto vs simbólico en los bloques de programas

\begin{tabular}{|c|c|c|c|c|c|c|c|c|c|}
\hline \multicolumn{2}{|c|}{ Campaña* } & \multirow[t]{2}{*}{ Vuelta } & \multicolumn{2}{|c|}{ Concreto } & \multicolumn{2}{|c|}{ Reducionista } & \multicolumn{2}{|c|}{ Simbólico } & \multirow{2}{*}{$\begin{array}{c}\text { Total } \\
\mathrm{n}\end{array}$} \\
\hline & & & $\mathrm{n}$ & $\%$ & $\mathrm{n}$ & $\%$ & $\mathrm{n}$ & $\%$ & \\
\hline \multirow{4}{*}{$\begin{array}{l}\mathscr{9} \\
\stackrel{0}{\circ} \\
\stackrel{-}{-}\end{array}$} & \multirow{2}{*}{ Collor } & $1^{a}$ & 3 & 9,4 & 9 & 28,1 & 20 & 62,5 & 32 \\
\hline & & $2^{\mathrm{a}}$ & 12 & 19,7 & 26 & 42,6 & 23 & 37,7 & 61 \\
\hline & \multirow{2}{*}{ Lula } & $1^{\mathrm{a}}$ & 2 & 5,0 & 6 & 15,0 & 32 & 80,0 & 40 \\
\hline & & $2^{a}$ & 9 & 14,5 & 4 & 6,5 & 49 & 79,0 & 62 \\
\hline \multirow{2}{*}{ \& } & Cardoso & $1^{\mathrm{a}}$ & 11 & 28,9 & 13 & 34,2 & 14 & 36,9 & 38 \\
\hline & Lula & $1^{\mathrm{a}}$ & 7 & 29,2 & 9 & 37,5 & 8 & 33,3 & 24 \\
\hline \multirow{2}{*}{$\stackrel{\infty}{\circ}$} & Cardoso & $1^{\mathrm{a}}$ & 14 & 28,6 & 29 & 59,2 & 6 & 12,2 & 49 \\
\hline & Lula & $1^{\mathrm{a}}$ & 8 & 23,5 & 9 & 26,5 & 17 & 50,0 & 34 \\
\hline \multirow{4}{*}{ ণั } & \multirow{2}{*}{ Lula } & $1^{\mathrm{a}}$ & 4 & 19,0 & 3 & 14,3 & 14 & 44,7 & 21 \\
\hline & & $2^{a}$ & 5 & 19,2 & 7 & 26,9 & 14 & 53,9 & 26 \\
\hline & \multirow{2}{*}{ Serra } & $1^{\mathrm{a}}$ & 23 & 41,1 & 12 & 21,4 & 21 & 37,5 & 56 \\
\hline & & $2^{a}$ & 10 & 27,0 & 9 & 24,3 & 18 & 48,6 & 37 \\
\hline \multirow{5}{*}{ ஜ̊ํ } & \multirow{2}{*}{ Lula } & $1^{\mathrm{a}}$ & 5 & 17,2 & 10 & 34,5 & 14 & 48,3 & 29 \\
\hline & & $2^{a}$ & 14 & 38,9 & 3 & 8,3 & 19 & 52,8 & 36 \\
\hline & \multirow{2}{*}{ Alckmin } & $1^{\mathrm{a}}$ & 14 & 43,8 & 5 & 15,6 & 13 & 40,6 & 32 \\
\hline & & $2^{a}$ & 15 & 45,5 & 6 & 18,2 & 12 & 36,4 & 33 \\
\hline & TOTAL & & 150 & 24,6 & 160 & 26,2 & 300 & 49,2 & 610 \\
\hline
\end{tabular}

Hay aún una serie de tres spots en que las alianzas políticas de PT con diversos partidos pequeños aparecen en una sopa de letras. En ellos, un actor oye su estómago advertir para tan complicada mezcla de siglas partidistas, llevando que el "comensal” rechace la comida. Ese anuncio es la emulación de un comercial de la época en que el estómago también habla con su dueño. Es importante destacar la serie de anuncios en que la campaña de Collor hace la caricatura de la imagen negativa bastante trabajada por los adversarios vinculando el candidato de PRN a las elites. En todos los anuncios, hay una imagen en negro sobre fondo blanco, que es identificada de modo general por el narrador, para enseguida revelarse por entero y de modo preciso; en el primer momento, la insinuación lleva a las elites, pero luego se verifica una quiebra de 
expectativas, revelándose algo distinto, cercano al pueblo. La difundida idea (de hecho, real) de que el propietario de Red Globo daba soporte a la candidatura es descalificada con una caricatura que empieza con un texto que anuncia "El dueño de red que hizo alianza con Collor". En el segundo momento, cuando la imagen en negativo se pone iluminada, el dueño de la red es un pescador, lo que asocia el candidato con el pueblo trabajador. En otro spot de la serie, el narrador anuncia "enrolló la masa e hizo alianza con Collor”, para luego se mostrar un pizzaiolo preparando la masa de pizza, en cuanto el narrador completa: "más uno de los más de 20 millones de brasileños que hicieron alianza con Collor".

La mayoría de los mensajes de Lula en la campaña de 1989 adoptaron recursos simbólicos, algunas de ellas recurriendo a elementos lúdicos. Es el caso de un anuncio en que aparecen dos "cometas" en el aire. Los juguetes -tan conocidos en todo el paísen el principios están alejados, se van acercando y cuando están juntos se nota que en una hay la sílaba "LU" y en la otra la sílaba "LA", formando el nombre del candidato. En otro, se emula un comercial de jamón: en el mensaje original, un niño con los ojos vendados reconoce el mejor jamón tan sólo al tocarle los dedos; en el anuncio de Lula, un conocido humorista también con los ojos vendados va tentando aparatos de televisión en busca de la mejor opción. Primero rechaza la tele en que aparece el presidente Sarney, también hace lo propio con el aparato en que está Collor, donde añade un “¿quieres engañarme?” y enseguida se pone feliz y contento al llegar a la televisión en que está la imagen de Lula, cuando quita la venda y se pone entretenido a ver el candidato.

Esos mensajes simbólicos se utilizan de referencias ya presentes en el imaginario de la gente, ya sea un popular anuncio comercial, un mito, un juguete de niños, ya sea una distendida imagen como la que asociaba Collor a las elites. Esos recursos serán encontrados en las disputas siguientes. En 1994, la campaña de Cardoso celebra una fiesta por el cumple del precio del panecillo, había un mes sin cambiar de valor. Por supuesto, el spot es una referencia al éxito del plan Real.

En otro, utiliza un barquito de papel para decir como era antes del Real y después de la implantación del plan económico. Cuando se habla de la realidad anterior, con inflación y turbulencia en la economía, el barquito navega en aguas tormentosas; en el segundo momento, de economía estabilizada, aparece el barco de papel en aguas serenas, cuando el narrador añade en off: "Fernando Henrique, la economía en aguas tranquilas”. En la misma campaña, Lula usa anuncios como el que destaca que el gobierno que apoya Cardoso está generando empleo... en Inglaterra, Japón, Alemania y otros países, puesto que la política económica estimula la importación. Al final, fotos presentan personas de esos países dando "gracias" en sus lenguas al empleo generado 
en el extranjero -arigató, thanks, dank- y el narrador cierra el mensaje advirtiendo que "necesitamos de un presidente que hable la lengua del pueblo".

TABLA 6.13

Concreto vs simbólico en los spots sueltos

\begin{tabular}{|c|c|c|c|c|c|c|c|c|c|}
\hline \multicolumn{2}{|c|}{ Campaña* } & \multirow[t]{2}{*}{ Vuelta } & \multicolumn{2}{|c|}{ Concreto } & \multicolumn{2}{|c|}{ Reducionista } & \multicolumn{2}{|c|}{ Simbólico } & \multirow{2}{*}{$\begin{array}{c}\text { Total } \\
\mathrm{n}\end{array}$} \\
\hline & & & $\mathrm{n}$ & $\%$ & $\mathrm{n}$ & $\%$ & $\mathrm{n}$ & $\%$ & \\
\hline \multirow{2}{*}{$\stackrel{\infty}{\circ}$} & Cardoso & $1^{\mathrm{a}}$ & & & 10 & 66,7 & 5 & 33,3 & 15 \\
\hline & Lula & $1^{\mathrm{a}}$ & 2 & 13,3 & 10 & 66,7 & 3 & 20,0 & 15 \\
\hline \multirow{4}{*}{ ণั } & \multirow{2}{*}{ Lula } & $1^{\mathrm{a}}$ & 1 & 6,7 & 9 & 60,0 & 5 & 33,3 & 15 \\
\hline & & $2^{a}$ & 1 & 7,7 & 9 & 69,2 & 3 & 23,1 & 13 \\
\hline & \multirow{2}{*}{ Serra } & $1^{\mathrm{a}}$ & 2 & 12,5 & 6 & 37,5 & 8 & 50,0 & 16 \\
\hline & & $2^{\mathrm{a}}$ & 4 & 26,7 & 5 & 33,3 & 6 & 40,0 & 15 \\
\hline \multirow{4}{*}{ ஜ̊ } & \multirow{2}{*}{ Lula } & $1^{\mathrm{a}}$ & 5 & 23,8 & 9 & 42,9 & 7 & 33,3 & 21 \\
\hline & & $2^{a}$ & 8 & 36,4 & 11 & 50,0 & 3 & 13,6 & 22 \\
\hline & \multirow{2}{*}{ Alckmin } & $1^{a}$ & 3 & 23,1 & 7 & 53,8 & 3 & 23,1 & 13 \\
\hline & & $2^{a}$ & & & 6 & 60,0 & 4 & 40,0 & 10 \\
\hline & TOTAL & & 26 & 16,8 & 82 & 52,9 & 47 & 30,3 & 155 \\
\hline
\end{tabular}

En 1998, otras vez Cardoso recurriría a algunos anuncios simbólicos para enfatizar su diferencia respecto el adversario directo, Lula. En uno, el presidente es comparado al comandante de un Boeing. En ese anuncio, un actor vestido de piloto en una cabina de gran avión advierte que para ser comandante de un Boeing es necesario preparación y muchas horas de vuelos, igual que un "comandante del país" necesita tener mucha experiencia sobre todo en épocas de turbulencia. El texto hace referencia indirecta al hecho de Lula no contar con experiencia administrativa, a diferencia de Cardoso. En un otro anuncio, la campaña de PSDB destaca las realizaciones del presidente y luego advierte para el riesgo de retroceso. Simbólicamente, la imagen utilizada para transmitir esa idea es el cambio de un automóvil, que pasa de una marcha a otra a cada realización descripta por el narrador:

"Primeiro, Fernando Henrique criou o Real. Segundo, derrubou a inflação. Terceiro, fez resformas para modernizar o país. Fez grandes obras de infraestrutura e atraiu investimentos. Agora é hora de gerar emprego. E nós vamos 
decidir se queremos continuar em frente ou se vamos dar marcha a ré... Marcha à ré, não. Avança Brasil. Fernando Henrique presidente" 25.

Además de posicionar a Cardoso como realizador, resalta la imagen del opositor como un paso atrás. En ese mismo año, la publicidad de Lula vuelve a utilizar personajes de la televisión y conocidos anuncios comerciales como atajo simbólico. En uno, la comediante Cristina Pereira descalifica la publicidad de Cardoso: "Presidente, habla para la gente de la publicidad que nadie cree en ese Brasil que aparece en la televisión”, dice la actriz, mirando a la cámara. En otro, el mensaje es la emulación de un comercial de banco que destaca los beneficios generados por un tipo de aplicación financiera. En el mensaje electoral, un actor sugiere que la gente aplique en la "cuenta 13.0oo", porque rinde mucho más en empleo, salud, educación. El 13.000 es el número de la cuenta de la campaña de Lula, donde el simpatizante puede depositar sus donaciones.

En 2002, tanto la campaña de Lula como la de Serra hacen uso de la comunicación simbólica. En un intento de movilizar la gente y fortalecer la campaña, la publicidad de Lula presenta un spot en que el cliente de una peluquería mira el corte del pelo. Cuando el peluquero pone un espejo a las espaldas del cliente, este puede ver un cartel de Lula colgado en la tienda y entonces se ríe, aprobando. En narrador añade: "Hay mil y una maneras de ayudar la campaña de Lula. Invente una", repitiendo el eslogan de un conocido chocolate de la multinacional Nestlé. El simbolismo es todavía más fuerte en el anuncio en que las mujeres embarazadas son asociadas al nuevo Brasil que Lula va posibilitar. Por su parte, Serra exhibe un mensaje en que intenta atribuir a la falta de firmeza y preparo del petista la decisión de Lula en no participar de todos los cinco debates propuestos por emisoras de TV. La imagen que el vídeo presenta es de una mano que intenta coger un jabón que siempre resbala. En el texto, se utiliza el verbo “escorregar”, que es sinónimo de resbalar, pero que también tiene el sentido popular de esquivarse para eludir los retos importantes:

"Quando perguntam quantos empregos vai criar, Lula escorrega. Quando perguntam sobre economia, Lula escorrega. Vai ver é por isso que Lula não quer mais debates. Lá, ele não pode escorregar" 26 .

${ }^{25}$ En español: "Primeiro, Fernando Henrique creó el Real. Segundo, derrumbó la inflación. Tercero, hizo reformas para modernizar el país. Hizo grandes obras de infra-estructura e atrajo investimentos. Ahora es hora de generar empleo. $Y$ nosotros vamos decidir si deseamos seguir adelante o si vamos dar marcha atrás... Marcha atrás, no. Avanza Brasil. Fernando Henrique presidente". 
Los mensajes simbólicos son la parte más sustantiva de las campañas brasileñas, donde la busca de un clima positivo y simpático parece estar muy por encima de la preocupación con discursos concretos y propuestas acabadas. Esa tendencia a la simplificación se hace todavía más fuerte cuando se nota que los mensajes reducionistas sumados a los simbólicos representan casi tres cuartas partes del total de los bloques de programas. Los anuncios reducionistas son aquellos que, cuando enfocan un asunto, lo hacen desde un abordaje superficial, apelando más a los sentimientos que a la razón. Un ejemplo es un spot de Lula en 2002 en que destaca que "no basta dar el pez; es necesario enseñar a pescar", para entonces decir que Brasil necesita de planificación de largo plazo. El mensaje se pone en la generalización y se atrapa al sentido del dicho chino. Nada más, siquiera una idea de la tal planificación.

A pesar de la tendencia por el lenguaje simbólico o reducionista, se puede decir que la opción por mensajes concretos -cuando hay algo de palpable, sea un dato estadístico, una situación real minuciosamente presentada o la propuesta elaborada- puede ser el resultado de un momento político dado que exige un tipo de estrategia. Esto se puede ver en la campaña de Lula en 2006, que en la primera vuelta tuvo un 17,2\% de anuncios con contenido concreto, pasando a más que el doble en la segunda: un 38,9\%. La diferencia está relacionada a la decisión de utilizar una serie de mensajes en que se hace referencias a las acciones del gobierno Lula y las compara con los gobiernos anteriores, como en el spot "Quadrilha": el anuncio destaca en número de bandas criminales desarticulada en el gobierno de Lula, muy por encima de los datos referentes a los gobiernos de PSDB.

Entre los bloques de programas, no hay cambios significativos de una vuelta a otra, los mensajes concretos con una media cercana a un $25 \%$. Las otras tres cuartas partes se dividen entre mensajes reducionistas y simbólicos, con una media un poco más alta de los mensajes simbólicos en las segundas vueltas que en las primeras. Entre los spots sueltos, la opción por un lenguaje simplificado que funcione como atajo hacia la mente del elector sigue la tendencia predominante, pero ahora con mayor presencia de mensajes reducionistas. Los anuncios simbólicos representan un 30,3\% del total, en cuanto los reducionistas suman más de la mitad: un 52,9\% (Tabla 6.13). En los anuncios sueltos, los mensajes con abordaje concreto tienen todavía menos presencia, representando tan solo el 16,8\%. Todas las campañas, excepto la de Serra en 2002, presentan elevados índices de mensajes reducionistas. Tanto en la primera como en la

\footnotetext{
${ }^{26}$ En español: “Cuando preguntam cuantos empleo va a generar, Lula se esquiva. Cuando preguntan sobre economía, Lula se esquiva. Va a ver es por eso que Lula no quiere más debates. Allí, él no puede esquivarse"
} 
segunda vuelta, la campaña de Serra se pone por abajo del $40 \%$ de mensajes reducionistas, índice que es compensado por los mayores índices registrados entre los spots sueltos.

La amplia presencia de mensajes reducionistas quizá esté asociada al papel de información desempeñado por las campañas. En Brasil, excepto en el caso de 1989, las campañas publicitarias no han logrado producir gran influencia en la agenda mediática, que suele tener una pauta aparte (Miguel, 2004). En general, hay el silencio sobre la mayor parte de los temas tratados en los mensajes electorales, tanto en los spots de enfoque más serio como en los negativos o con un contenido irónico. Así, si bien la publicidad no influye significativamente en el establecimiento de la agenda de los medios, los mensajes sueltos en grande medida sí cumplen la función de información periodística, aunque una información superficial, dirigida por la intención principal de generar simpatía, confianza en las posibilidades de la candidatura y percepción (es decir, imagen) del candidato.

Es curioso notar el comportamiento de las candidaturas de PSDB en ese campo: normalmente más formales e incluso más tendientes a abordajes concretos, en los spots sueltos los tucanos recurren con más intensidad a los anuncios simbólicos o reducionistas. Cardoso y Alckmin no utilizaron anuncios sueltos guiados por el enfoque concreto, en cuanto Serra dio ese tratamiento a tan sólo 12,5\% de los mensajes de la primera vuelta. En la misma campaña, Serra exhibe un 50\% de spots simbólicos en la primera vuelta y un 40\% en la segunda. Si en la primera ronda de 2006 Alcmkin exhibe $23 \%$ de anuncios simbólicos, en la segunda el número sube a $40 \%$.

\subsection{El predominio de la emoción como estrategia política}

La comunicación publicitaria tiene en los mensajes emocionales una de las estrategias más utilizadas con el objetivo de persuadir al consumidor. La eficacia está en que, delante de productos que se asemejan en las características generales, la creación de estímulos afectivos facilitan la diferenciación anhelada por toda marca (López-Vázquez, 2007). En la publicidad electoral pasa lo mismo, sobre todo cuando las ofertas políticas son pautadas en las encuestas sobre las demandas de la gente, volviendo poco distintas las proposiciones más sustantivas de los diversos partidos y candidatos. Si bien en muchos sistemas los partidos no suelen ofrecer muchas posibilidades de diferenciación -como en el caso de Brasil- y las propuestas siguen un mismo guión, la importancia de las referencias personales tienden a crecer, importancia que se hace todavía mayor cuando se establece un vínculo emocional. Este pasa a ser un camino recorrido por las 
campañas profesionales, acorde con la premisa de Rees (1995) según la cual una sonrisa tiene mucho más poder de conquista que un rebuscado discurso político.

Lo que pasa es que el elector cultiva fuerte desconfianza respecto los discursos y propuestas políticas, de ahí prefiriendo votar no en las ideas sino en las persona. En ese sentido, los mensajes con un tono emocional humanizan el candidato y ofrecen un efectivo diferencial, puesto que establece una relación más allá de las construcciones racionales (Mendonça, 2001). La sonrisa en el candidato o sus mensajes son parte de ese concepto que apunta a una publicidad que apuesta por el clima agradable, capaz de hacer sentirse bien al elector delante del mensaje, asociando las buenas sensaciones al candidato. Y las campañas brasileñas siguen ese rumbo, con claro enfoque emocional, presentes en tres cuartas partes de los mensajes de los bloques de programas y en casi dos tercios de los spots sueltos (Tabla 6.14).

El tono racional se pone aparte incluso cuando los mensajes tratan de asuntos complejos, como el paro o las deficiencias en la sanidad. Son especialmente representativos de ese enfoque los ya citados spots de la campaña de Lula en 2002 sobre la sanidad -cuando el deficiente servicio encontrado en los hospitales públicos es relacionado a la dura experiencia de la muerte de la primera esposa- y la crisis del empleo en los astilleros de Río de Janeiro. En los dos casos, está presente un recurso común en la televisión brasileña, particularmente en el periodismo de TV Globo, que utiliza el caso particular para evidenciar los problemas más generales. Ese recurso, además de simplificar el entendimiento, permite la "humanización" y así la emocionalización de los problemas.

$\mathrm{Al}$ enfocar el problema de la sanidad, la campaña de Lula toma como particularización la experiencia del mismo candidato, que llora al hablar de la pérdida de la mujer y del niño que no llega a nacer, y atribuye la tragedia a los precarios servicios en el área de sanidad pública. En el caso de los astilleros, la individualización se da a través del relato de experiencias de trabajadores que perdieron el empleo por la decisión de la estatal Petrobrás de contratar en el extranjero la construcción de la nueva plataforma de extracción del crudo. Esas experiencias, tanto la de Lula como de los ex obreros de los astilleros, hacen visible en la piel de la gente los problemas que el mensaje trae. Es decir, no es sólo un frío dato estadístico que dice que miles de personas perdieron el puesto de trabajo. Es mucho más, puesto que el drama se revela por entero en el operario que habla de sus dificultades, retratado dramáticamente en situaciones de dificultades en su casa, en imágenes que a través del slow motion amplia la dimensión de lo humano y de lo emocional. 
La campaña de Lula de 2002 es la más emotiva de todas, seguida de cerca por la del mismo Lula en 2006 y por la de Collor en 1989. La emotividad es un rasgo de PT desde su fundación, cuando se propuso a hacer una política distinta de los partidos tradicionales caracterizados por un lenguaje rebuscado; un rasgo que estuvo presente ya en la primera campaña presidencial, aún cuando el candidato no se sometía a muchas de las orientaciones de la coordinación de publicidad (Paiva, 2005). La intención estética de las viñetas electrónicas, el humor de muchos de los anuncios, la presencia de artistas cantando el jingle y alegres vídeoclips están presentes en la primera campaña de Lula y seguirá así en las demás. Incluso en 1994, la campaña del PT va a presentar alto índice de emocionalización, aunque sea el más bajo de todas las cinco candidaturas presentadas por el partido. Reflejo directo de la legislación, los spots de tono emocional representan $58,3 \%$ del total de aquél año; en ninguna de las otras cuatro campañas ese índice fue menor que $72 \%$.

TABLA 6.14

El tono emocional de los mensajes en los bloques de programas y spots sueltos

\begin{tabular}{|c|c|c|c|c|c|c|c|c|c|c|c|c|}
\hline \multicolumn{2}{|c|}{ Campaña* } & \multirow{3}{*}{ Vuelta } & \multicolumn{5}{|c|}{ Bloques de programas } & \multicolumn{5}{|c|}{ Spots sueltos* } \\
\hline & & & \multicolumn{2}{|c|}{ Racional } & \multicolumn{2}{|c|}{ Emocional } & \multirow{2}{*}{$\frac{\text { Total }}{\mathrm{n}}$} & \multicolumn{2}{|c|}{ Racional } & \multicolumn{2}{|c|}{ Emocional } & \multirow{2}{*}{$\begin{array}{c}\text { Total } \\
\mathrm{n} \\
\end{array}$} \\
\hline & & & $\mathrm{n}$ & $\%$ & $\mathrm{n}$ & $\%$ & & $\mathrm{n}$ & $\%$ & $\mathrm{n}$ & $\%$ & \\
\hline \multirow{4}{*}{ 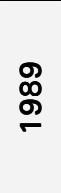 } & \multirow{2}{*}{ Collor } & $1^{\mathrm{a}}$ & 2 & 6,3 & 30 & 93,7 & 32 & & & & & \\
\hline & & $2^{a}$ & 15 & 24,6 & 46 & 75,4 & 61 & & & & & \\
\hline & \multirow{2}{*}{ Lula } & $1^{\mathrm{a}}$ & 5 & 12,5 & 35 & 87,5 & 40 & & & & & \\
\hline & & $2^{\mathrm{a}}$ & 13 & 21,0 & 49 & 79,0 & 62 & & & & & \\
\hline \multirow{2}{*}{ ১্ } & Cardoso & $1^{\mathrm{a}}$ & 16 & 42,1 & 22 & 57,9 & 38 & & & & & \\
\hline & Lula & $1^{\mathrm{a}}$ & 10 & 41,7 & 14 & 58,3 & 24 & & & & & \\
\hline \multirow{2}{*}{$\stackrel{\infty}{\sigma}$} & Cardoso & $1^{\mathrm{a}}$ & 24 & 49,0 & 25 & 51,0 & 49 & 7 & 46,7 & 8 & 53,3 & 15 \\
\hline & Lula & $1^{\mathrm{a}}$ & 9 & 26,5 & 25 & 73,5 & 34 & 10 & 66,7 & 5 & 33,3 & 15 \\
\hline \multirow{4}{*}{ ญ̊ } & \multirow{2}{*}{ Lula } & $1^{\mathrm{a}}$ & 3 & 14,3 & 18 & 85,7 & 21 & 1 & 6,7 & 14 & 93,3 & 15 \\
\hline & & $2^{a}$ & 2 & 7,7 & 24 & 93,3 & 26 & 1 & 7,7 & 12 & 92,3 & 13 \\
\hline & \multirow{2}{*}{ Serra } & $1^{\mathrm{a}}$ & 22 & 39,3 & 34 & 60,7 & 56 & 3 & 18,8 & 13 & 81,8 & 16 \\
\hline & & $2^{a}$ & 17 & 45,9 & 20 & 54,1 & 37 & 5 & 33,3 & 10 & 66,7 & 15 \\
\hline \multirow{5}{*}{ ஜ̊ } & \multirow{2}{*}{ Lula } & $1^{a}$ & 2 & 6,9 & 27 & 93,1 & 29 & 11 & 52,4 & 10 & 47,6 & 21 \\
\hline & & $2^{a}$ & 10 & 27,8 & 26 & 72,2 & 36 & 10 & 45,4 & 12 & 54,6 & 22 \\
\hline & \multirow{2}{*}{ Alckmin } & $1^{\mathrm{a}}$ & 6 & 18,8 & 26 & 81,2 & 32 & 3 & 23,1 & 10 & 76,1 & 13 \\
\hline & & $2^{a}$ & 7 & 21,2 & 26 & 78,8 & 33 & 2 & 20,0 & 8 & 80,0 & 10 \\
\hline & TOTAL & & 163 & 26,7 & 447 & 73,3 & 610 & 53 & 34,2 & 102 & 65,8 & 155 \\
\hline
\end{tabular}


En 2002 la campaña petista alcanza el mayor nivel de emocionalización no sólo por los cambios de Lula y del partido, sino también por la presencia en el comando de las acciones de comunicación y marketing del consultor Duda Mendonça, que siempre se caracterizó por trasportar las intencionalidades estratégicas de las campañas al campo emocional. Lo hizo así con candidatos de perfiles tan distintos como Miguel Arraes y Paulo Maluf. En 1998, Arraes -histórico líder de las izquierdas-, fue transformado en un dócil patriarca del Estado de Pernambuco, así como Maluf se vio involucrado en una relación de amor con la ciudad de São Paulo en que la marca de campaña era un corazón y el jingle sencillamente repetía que "São Paulo es Paulo" (Mendonça, 2001). Por supuesto, el Lula de 2002 es la evolución gradual de años de cambio en el candidato y el partido, pero que se transforma en permanente sonrisa en las manos de Mendonça, una maestro en hacer la política del corazón. En esa campaña es que el ex metalúrgico radical se metamorfosea en el "Lulinha paz e amor" [Lulita paz y amor] y que el casi belicoso rojo de las disputas anteriores da paso al blanco de la paz y la concordia (Rocha, 2004).

En 2006, otra vez el tono emocional es predominante a pesar de que en la segunda vuelta cediera espacio a los ataques al PSDB que en la mayor parte de los casos recurre a argumentos más bien racionales y concretos. El cambio de una vuelta a otra repite la estrategia de Collor en 1989, que en la primera vuelta es racional en tan sólo 6,3\% de los mensajes. En la segunda ronda la racionalidad sube a un cuarto de los mensajes, a pesar de algunos ataques conserva el tono emocional, como en los spots en los que el estómago habla con un hombre presto a comer una complicada sopa de letras. La racionalidad está presente en otros mensajes de ataque, como en los spots criticando las administraciones del PT o los que relatan el conflicto entre partidarios de Collor y Lula en Río Grande del Sur.

La emocionalización es parte importante en el esfuerzo de movilización de la gente en torno de las candidaturas. No es casual que las campañas brasileñas tengan como una de sus características la musicalidad, traducida en los alegres jingles que ocupan importante espacio de la publicidad electoral en la televisión ${ }^{27}$. Como ya se anotó antes, los vídeoclips basados en los jingles suman 14,1\% de los spots de los bloques, mensajes llenos de tono emocional.

La mayor presencia de un enfoque racional en los spots sueltos pueden ser atribuidos a la misma necesidad de las campañas en cumplir la función de información. Por supuesto, los bloques también tienen esa misma necesidad, pero juntos son obligados a

\footnotetext{
27 La destacada presencia de las músicas de campaña en las presidenciales brasileñas es enfatizada en el análisis del investigador uruguayo Luis Costa Bonino, que comenta los jingles de las campañas de 2002. Ver análisis en http://costabonino.com/brasil.htm.
} 
intensificar el tono emocional no sólo por el objetivo de movilizar a partir de una relación afectuosa sino también por la necesidad de hacer de los bloques un programa atractivo capaz de atrapar la atención del espectador. Además, la mayor presencia del tono racional en los anuncios sueltos no quita protagonismo a los mensajes emocionales, que solamente tienen presencia menos avasalladora.

\subsection{La sofisticación técnica}

Según Norris (1999), los factores tecnológicos son determinantes para la comprensión de los cambios en las campañas electorales, donde las nuevas tecnologías de la comunicación tiene especial relevancia. Entre las características que la autora destaca en las campañas postmodernas/profesionales están los nuevos canales de distribución de los mensajes, que establecen un nuevo modo de interlocución con el votante. En un paralelo con el campo específico de la televisión, se puede decir que la profesionalización se manifiesta en el uso de recursos tecnológicos de última generación traducidos en spots sofisticados, con efectos de ordenador y procesos de edición de imágenes que buscan producir impacto específicos junto al espectador.

En las presidenciales brasileñas, la sofisticación tiene relevancia desde la elección de 1989, sin embargo la evolución no es constante, puesto que asociada a tres factores principales: la disponibilidad de determinados recursos técnicos en el momento de la elección, la capacidad financiera de las campañas para acceder a tales recursos y la legislación que regula la competencia y puede (o no) establecer límites al uso de los avances tecnológicos. Son referenciales las campañas de 1989 y 1994, la primera sin ningún límite al uso de recursos técnicos, la segunda con la más amplia limitación entre las cinco elecciones analizadas. No es casual que la campaña de Lula en 1994 no cuente siquiera con un único spot sofisticado, reflejo tanto de las rígidas reglas para aquella disputa como del bajo presupuesto a la disposición del petista (Tabla 6.15): en aquél año, dos tercios de los mensajes de Lula tenían recursos técnicos simples.

Para la clasificación de los spots, fueron considerados simples los mensajes que ofrecen recursos de edición triviales, como los cortes simple entre imágenes o los que contienen efectos visuales disponibles en cualquiera aparato de edición, como el "efecto cortina" en que una imagen empuja la otra para fuera del vídeo, pasando a ocupar todo el campo visual. Los "medianamente sofisticados" ofrecen algunos recursos técnicos, pero sin gran sofisticación, como el slow motion y la fusión. Por otra parte, son considerados sofisticados los que utilizan recursos de mayor riqueza técnica, recurriendo a los efectos de ordenador. También se incluyen en esa clasificación aquellos que exigen compleja producción en el momento de la filmación. Un ejemplo de ello en la primera campaña 
fue el spot de Collor en el Monte Pascoal, sitio del descubrimiento de Brasil: para llevar a cabo la filmación, fue necesario el desplazamiento de un amplio equipo con grúas y carriles para movilización de la cámara. En 2002, Lula hizo amplio uso de la sofisticación donde es representativo la viñeta de apertura, cuya filmación exigió la construcción de un amplio escenario representando una sala de trabajo y cámaras que se desplazaban para producir la idea de dinamismo y grandeza.

La paradoja entre poder o no utilizar un recurso y tenerlos o no a la disposición se puede evidenciar en el conocido efecto Morph ${ }^{28}$ : en 1989 el recurso no estaba disponible en el mercado y siquiera campañas adineradas como la de Collor podían usarlo; en 1994, el Morph ya se hiciera popular, pero la legislación no permitía su uso por las campañas pues era considerado un trucaje capaz de alterar la realidad. A pesar de la indisponibilidad de algunos recursos técnicos en la campaña de 1989, se puede encontrar rasgos de sofisticación tanto en la comunicación de Collor -por ejemplo, en el spot que despinta y luego vuelve a colorear la bandera nacional o en el que el tren atropella los obstáculos negativos que se ponen en el camino- como en la de Lula, especialmente en las viñetas electrónicas emulando el visual de TV Globo. Es de notarse que en la publicidad electoral del petista en la primera vuelta, casi no hay sofisticación mediana: o son las viñetas de alta sofisticación (responsables por el $45 \%$ de mensajes con esa clasificación) o los spots casi todos con recursos sencillos conducentes con el limitado presupuesto de la campaña de Lula. En la comunicación de Collor, son pocos los mensajes con alta sofisticación pero el presupuesto permitió la constitución de un equipo de profesionales capaces de ofrecer mediana sofisticación en la mitad de los mensajes, por delante de los mensajes con simple tratamiento técnico.

La diferencia es que las viñetas, producidas con antelación, pueden recibir mayor cuidado técnico, lo que se hace más difícil en los spots producidos en el curso de la campaña, dificultad que sólo se puede eludir cuando se cuenta con grande estructura de producción. Collor contaba con amplia estructura -de ahí los 50\% de spots con mediana sofisticación en la primera vuelta - y Lula, no. La campaña de 1989 presenta el mayor índice de mensajes con producción simple, reflejo de la indisponibilidad de algunos recursos técnicos. Se va a encontrar una media mayor (un 66,7\%) en la campaña de Lula en 1994, cuando además del bajo presupuesto hay las limitaciones de la legislación. El índice de mensajes sencillas en la campaña de Cardoso también es elevado (44,7\%), pero significativamente menor que el presentado por el petista, puesto que los recursos financieros pudieron garantizar la formación de un amplio equipo de

\footnotetext{
${ }^{28}$ El Morph el un efecto de ordenador que permite la fusión de imágenes. Por ese recurso, se puede fusionar la imagen de un candidato con la de otra persona (como Hitler) o incluso con un animal (por ejemplo, un perro). El efecto se puso conocido en fines de 1991 quando Michael Jackson lo utilizó en el vídeoclip Black or White.
} 
profesionales capaces de superar parte de las limitaciones legales a través de producciones con algún nivel de sofisticación, a pesar de vídeos limitados a los estudios.

La planificación de largo plazo también influye en el nivel de sofisticación. Las dos campañas con planificación de corto plazo -Lula en 1998 y Alckmin en 2006presentan bajo índice de spots sofisticados. La razón es que la falta de una planificación consistente impide la producción de spots con estrategias más claras, obligando a los ajustes estratégicos en el curso de la disputa que llevan a vídeos con menor nivel de cuidado técnico puesto que el tiempo entre producir y exhibir pasa a ser menor. La campaña de Alckmin es particularmente ejemplar, obligándose a buscar un rumbo cuanto a la identificación del candidato que pasó de Alckmin a Geraldo y enseguida a Geraldo Alckmin. Los cambios afectaban los spots de identificación de la campaña, los impresos y de material de soporte de los mitines. En la televisión, el resultado era la pérdida de sofisticación. El índice de mensajes sofisticadas de la primera vuelta de Alckmin fue de un 25\%, menor incluso que los 26\% de la campaña de Cardoso ocho años antes.

TABLA 6.15

La sofisticación técnica de los mensajes en los bloques de programas

\begin{tabular}{|c|c|c|c|c|c|c|c|c|c|}
\hline \multicolumn{2}{|c|}{ Campaña* } & \multirow[t]{2}{*}{ Vuelta } & \multicolumn{2}{|c|}{ Simple } & \multicolumn{2}{|c|}{ Mediano } & \multicolumn{2}{|c|}{ Sofisticado } & \multirow{2}{*}{$\begin{array}{c}\text { Total } \\
\mathrm{n}\end{array}$} \\
\hline & & & $\mathrm{n}$ & $\%$ & $\mathrm{n}$ & $\%$ & $\mathrm{n}$ & $\%$ & \\
\hline \multirow{4}{*}{$\begin{array}{l}\text { : } \\
\stackrel{0}{\circ} \\
\stackrel{-}{-}\end{array}$} & \multirow{2}{*}{ Collor } & $1^{\mathrm{a}}$ & 13 & 40,6 & 16 & 50,0 & 3 & 9,4 & 32 \\
\hline & & $2^{a}$ & 37 & 60,6 & 20 & 32,8 & 4 & 6,6 & 61 \\
\hline & \multirow{2}{*}{ Lula } & $1^{\mathrm{a}}$ & 20 & 50,0 & 2 & 5,0 & 18 & 45,0 & 40 \\
\hline & & $2^{a}$ & 31 & 50,0 & 21 & 33,9 & 10 & 16,1 & 62 \\
\hline \multirow{2}{*}{ హ) } & Cardoso & $1^{\mathrm{a}}$ & 17 & 44,7 & 16 & 42,1 & 5 & 13,2 & 38 \\
\hline & Lula & $1^{\mathrm{a}}$ & 16 & 66,7 & 8 & 33,3 & & & 24 \\
\hline \multirow{2}{*}{ ๑ } & Cardoso & $1^{\mathrm{a}}$ & 8 & 16,3 & 28 & 57,1 & 13 & 26,6 & 49 \\
\hline & Lula & $1^{\mathrm{a}}$ & 17 & 50,0 & 15 & 44,1 & 2 & 5,9 & 34 \\
\hline \multirow{4}{*}{ ণ్రి } & \multirow{2}{*}{ Lula } & $1^{\mathrm{a}}$ & & & 4 & 19,0 & 17 & 81,0 & 21 \\
\hline & & $2^{a}$ & 3 & 11,5 & 8 & 30,8 & 15 & 57,7 & 26 \\
\hline & \multirow{2}{*}{ Serra } & $1^{\mathrm{a}}$ & 8 & 14,3 & 28 & 50,0 & 20 & 35,7 & 56 \\
\hline & & $2^{a}$ & 15 & 40,5 & 17 & 46,0 & 5 & 13,5 & 37 \\
\hline \multirow{4}{*}{ ஜ } & \multirow{2}{*}{ Lula } & $1^{\mathrm{a}}$ & 5 & 17,2 & 4 & 13,8 & 20 & 69,0 & 29 \\
\hline & & $2^{a}$ & 8 & 22,2 & 10 & 27,8 & 18 & 50,0 & 36 \\
\hline & \multirow{2}{*}{ Alckmin } & $1^{a}$ & 5 & 15,6 & 19 & 59,4 & 8 & 25,0 & 32 \\
\hline & & $2^{a}$ & 6 & 18,2 & 19 & 57,6 & 8 & 24,2 & 33 \\
\hline & TOTAL & & 209 & 34,3 & 235 & 38,5 & 166 & 27,2 & 610 \\
\hline
\end{tabular}

Fuente: elaboración propia 
No es casual que las dos últimas campañas de Lula presentan los mayores índices de sofisticación entre todas las analizadas. En 2002, los mensajes sofisticados de la primera vuelta alcanza un $81 \%$, cuando no hay ningún mensaje simple. En 2006, ese índice fue de $69 \%$ también en la primera vuelta. En los dos casos, las campañas tienen planificación de largo plazo y no sufren atropellos legales o de disputa interna, como en el caso de la campaña de Lula en 1994 o la de Serra en 2002. Es revelador que todo el posicionamiento de imagen de PT y su candidato de cara a las presidenciales de 2002 estaba establecido con bastante antelación: las preocupaciones de alianzas y de soporte profesional de la comunicación encontrados en las municipales de 2000 eran la anticipación de las presidenciales de dos años después. Hay que recordar que los vídeos exhibidos por PT en marzo y abril de 2002 ya contenían todos los marcos del posicionamiento del candidato que estarían en los mensajes electorales a partir de agosto. No hubo cambio de estrategias.

El factor tiempo relacionado a los ajustes de estrategias parece justificar que las segundas vueltas siempre presenten un nivel más bajo de sofisticación: al pasaren al segundo turno de votación, los candidatos necesitan ajustarse al nuevo escenario competitivo que no siempre es vislumbrado en la planificación previa. Sin duda Color habría adoptado una estrategia distinta en la segunda vuelta si su adversario en la tanda final fuese Leonel Brizola o Mário Covas. Contra Lula, enfatizó los problemas enfrentados por las administraciones del PT, posicionamiento que no cabría en el caso de Covas, reconocido por la buena administración como alcalde de São Paulo. La indefinición de escenario hace que muchos de los spots de la segunda vuelta sean producidos en el último momento y así carentes de los cuidados técnicos dispensados a la mayoría de los mensajes de la primera vuelta. Eso pasa con las campañas de Lula y Serra en 2002, y de Lula y Alckmin en 2006: hay la necesidad de producción de vídeos con objetivos estratégicos que se impusieran en el paso de una vuelta a otra, y la calidad técnica casi siempre pasa factura. En la primera vuelta de 2002, la campaña de Serra pasa del 14,3\% al 40,5\% de spots simples, en cuanto la de Lula sale de no tener ningún mensaje simple a un 11,5\%. En 2006, los mensajes de PT pasan de $17 \%$ a $22 \%$ de una vuelta a otra, en cuanto los de Alckmin pasan de 15,6\% a 18,2\%. En las diez campañas, las primeras vueltas suman $29 \%$ de spots simples, diez puntos abajo del índice para las segundas vueltas $(39,2 \%)$. Los mensajes con recursos técnicos sofisticados pasan de $30,1 \%$ en la primera ronda a $23,5 \%$ en la segunda.

En cuanto a los spots sueltos, en general presentan mayor sofisticación que los mensajes de los bloque de programas (Tabla 6.16). La media de mensajes simples es de $18,1 \%$ poco más de la mitad del 33,3\% encontrado entre los bloques de programas. La 
sofisticación, que está en 37,4\% en los bloques, es de 48,4\% de los anuncios sueltos. La explicación puede estar en la lógica que dirige los bloques, con un cierto tono periodístico y que se preocupa en dar resonancia a los acontecimientos. Los bloques suelen repercutir en el noticiario de la prensa o de la televisión, fenómeno encontrado en todas las campañas. Ese tipo de preocupación no está presente en los anuncios sueltos, que tienen un formato más estrechamente vinculado al formato de la publicidad comercial, cortos y de lenguaje directo, más atento al posicionamiento y a la imagen del candidato que al mismo carácter informativo encontrado en los bloques

TABLA 6.16

La sofisticación técnica de los mensajes en los spots sueltos

\begin{tabular}{|c|c|c|c|c|c|c|c|c|c|}
\hline \multicolumn{2}{|c|}{ Campaña* } & \multirow[t]{2}{*}{ Vuelta } & \multicolumn{2}{|c|}{ Simple } & \multicolumn{2}{|c|}{ Mediano } & \multicolumn{2}{|c|}{ Sofisticado } & \multirow{2}{*}{$\begin{array}{c}\text { Total } \\
\mathrm{n}\end{array}$} \\
\hline & & & $\mathrm{N}$ & $\%$ & $\mathrm{n}$ & $\%$ & $\mathrm{n}$ & $\%$ & \\
\hline \multirow{2}{*}{ \% } & Cardoso & $1^{\mathrm{a}}$ & 5 & 33,3 & 9 & 60,0 & 1 & 6,7 & 16 \\
\hline & Lula & $1^{\mathrm{a}}$ & 15 & 100 & & & & & 15 \\
\hline \multirow{4}{*}{ ชิ } & \multirow{2}{*}{ Lula } & $1^{\mathrm{a}}$ & & & 1 & 6,7 & 14 & 93,3 & 15 \\
\hline & & $2^{\mathrm{a}}$ & & & 6 & 46,2 & 7 & 53,8 & 13 \\
\hline & \multirow{2}{*}{ Serra } & $1^{\mathrm{a}}$ & 5 & 31,2 & 5 & 31,2 & 6 & 37,5 & 16 \\
\hline & & $2^{a}$ & & & 9 & 60,0 & 6 & 40,0 & 15 \\
\hline \multirow{4}{*}{ ஜ } & \multirow{2}{*}{ Lula } & $1^{a}$ & & & 5 & 23,8 & 16 & 76,2 & 21 \\
\hline & & $2^{a}$ & & & 6 & 27,3 & 16 & 72,7 & 22 \\
\hline & \multirow{2}{*}{ Alckmin } & $1^{\mathrm{a}}$ & 4 & 30,8 & 4 & 30,8 & 5 & 38,4 & 13 \\
\hline & & $2^{\mathrm{a}}$ & & & 6 & 60,0 & 4 & 40,0 & 10 \\
\hline & TOTAL & & 29 & 18,7 & 51 & 32,9 & 75 & 48,4 & 155 \\
\hline
\end{tabular}

Es de notar entre los anuncios sueltos el elevadísimo número de mensajes sofisticados en la campaña de Lula en 2002, en la que el posicionamiento de principio de año es mantenido en la primera y segunda vuelta. Sin cambios significativos en el escenario competitivo, los spots producidos con antelación son los que son llevados al aire. En 2006, la sofisticación también es elevada, aunque un poco más abajo, sobre todo delante de la necesidad de producción de algunos mensajes como respuesta a los hechos -el escándalo del Dossier, por ejemplo- que dictaron el rumbo del final de la disputa. En 2002, José Serra, atrapado por los problemas internos y con el inesperado riesgo de no pasar a la segunda vuelta, fue obligado a crear mensajes de última hora como forma de ajustar los anuncios al cambiante momento político. Eso justifica el índice tan bajo de mensajes sofisticados en la comunicación del tucano. 


\subsection{Los efectos cognitivos}

La sofisticación técnica de los mensajes es uno de los caminos que las campañas profesionales recorren con el propósito de reafirmar sus intencionalidades estratégicas, puesto que ciertos signos pueden llevar el espectador a hacer una lectura particular de los anuncios electorales. Cada elemento de un mensaje influye en el contenido. Los colores, por ejemplo, tienen implicaciones en el refuerzo de determinado posicionamiento, como es el caso de Lula en 2002, que cambió el tradicional rojo de PT por el blanco que traducía la idea de conciliación y paz, todo lo contrario de la percepción de radicalismo y enfrentamiento de las primeras campañas petistas (Rocha, 2004). En ese caso, el profesionalismo está en la elección de un color que encaje con el posicionamiento pretendido, que bien podría ser al revés, con la adopción de un color más caliente para intentar reverter la percepción de apatía ${ }^{29}$.

La quiebra del ritmo natural de los imágenes es uno de los recursos técnicos más utilizados para establecer un nuevo código de lectura respecto el que se presenta en el vídeo. La interferencia sobre el tempo natural crea en los mensajes otro tiempo, subjetivo y de naturaleza psicológica, interfiriendo en las sensaciones del espectador (Bonásio, 2002). La secuencia y el ritmo de edición de las imágenes por si mismos establecen un nuevo contenido, más bien un simulacro de la realidad que es presentado al espectador. Una imagen normal puede no enfatizar como se desea los aspectos distintivos del candidato o de su mensaje, pero la misma imagen presentada con un otro ritmo suele redimensionar el contenido o incluso añadir nuevos contenidos al mensaje. La imagen del abrazo del candidato en un simpatizante en la calle tiene distinta fuerza cognitiva cuando presentadas en ritmo normal o en slow motion.

El slow amplia el dramatismo y la posibilidad de emocionalización del mensaje, efecto que se queda limitado cuando se utiliza el tiempo normal; es un efecto que se ajusta a la medida de campañas basadas en la imágenes, en que las sensaciones respecto a los candidatos tienen especial trascendencia. Por otra parte, las ediciones rápida suelen pasar la idea de dinamismo. La edición fragmentada es una secuencia rápida de imágenes, concentrando un grande volumen de información visual en un mismo tiempo, al revés del slow, que amplia el tiempo de la acción. En la edición fragmentada, el dinamismo y la secuencia frenética de imágenes impone un lenguaje que Oliveira

\footnotetext{
${ }^{29}$ Un color per si no significa profesionalismo, sino un aspecto de la estrategia. Luego de la derrota de 2004, como estrategia de partido de oposición involucrado en manifestaciones y protestas callejeras, el PP español cambió su color de referencia del azul al naranja, presente en las municipales de 2007. Pero volvió a cambiar para el azul de cara a las generales de 2008, quizá intentando rescatar la imagen de moderación.
} 
(2005) llama postmoderna por traducir el estilo postmoderno de consumo: rápido, efímero e desechable.

El slow motion ha sido utilizado en larga medida desde las primeras presidenciales brasileñas, en cuanto la fragmentación está presente sobre todo en las últimas, como un lenguaje que se popularizó en últimos años. El slow está más asociado a los intentos de humanización del mensaje, ya sea centrando en la figura del candidato presentado en el emocionalizado contacto con la gente, ya sea enfocando temas a partir de las personas. Por otra parte, la edición fragmentada en la práctica no existe en la campaña de 1989, restringida básicamente a las viñetas. Más allá de las características de apertura de los programas electorales y la firma visual del candidato, este recurso va estar presente especialmente en las dos últimas campañas.

En las primeras presidenciales, los spots que incluyen la quiebra de ritmo como recurso cognitivo representan poco menos de un tercio del total para las dos vueltas, pero con situaciones distintas por campaña: en Collor, fueron $12,5 \%$ y $23 \%$ en la la primera y segunda vuelta, respectivamente, en contra $52,5 \%$ y $35,5 \%$ en el caso de Lula (Tabla 6.17). En la primera vuelta de la campaña del petista, sin embargo, la alta incidencia de mensajes con lenguaje fragmentado es resultado del gran número de viñetas electrónicas utilizadas para producir la sensación de dinamismo y modernidad en el programa. Aparte las viñetas, se encuentra el uso del slow motion en los vídeoclips del jingle y imágenes de los mítines. Los mensajes con declaraciones del candidato y reportajes sobre temas o caminadas del candidato tienen edición muy sencilla, acorde las limitaciones técnicas da la época y sobre todo el bajo presupuesto.

En las campañas siguientes, tal recurso crece. La sofisticación va a estar presente sobre todo en 2006, cuando las ediciones con quiebra de ritmo representan 64,6\%, variando del $51,5 \%$ de la campaña de Alckmin en la segunda vuelta al $75,9 \%$ de la campaña de Lula en primera vuelta. Entre los spots sueltos de aquél año, se encuentra promedio todavía más elevado, un 72,7\% de ediciones con ritmo alterado. De hecho, de todas las campañas analizadas, sólo la de Collor en 1989 y la de Lula en 1994 presentan índices por debajo de los 30\%. De las dos últimas disputas presidenciales, solamente la la campaña de Serra en la segunda vuelta va presentar menos de un tercio de ediciones con la quiebra de ritmo, distante del promedio general de las diez campañas, que es de un 43,9\%. El bajo índice de Serra es reflejo de la postura del candidato, recurriendo a las declaraciones en tono profesoral, verificado tanto en la primera como en la segunda vuelta.

El alto índice de esos recursos cognitivos evidencia la preocupación en las intenciones estratégicas de los mensajes, a la vez que revela importante rasgo profesional. Es decir, 
los recursos técnicos utilizados se vinculan a las estrategias abrazadas por cada campaña. Si bien es cierto que el slow busca destacar rasgos humanos y por lo tanto vinculados a las personas, ello explica el alto índice de ese recurso en la publicidad electoral de Alckmin: del 65,6\% correspondientes a los mensajes con imagen en ritmo alterado en la primera vuelta, el slow motion está presente en 59,4\% y la fragmentación en $6,2 \%$. Son mensajes que buscan consolidar la imagen del poco conocido candidato, hablando de su trayectoria personal. También habla de sus realizaciones, pero desde la perspectiva de la gente beneficiada por tales hechos. Incluso la viñeta de apertura cuenta con el candidato caminando en "cámara lenta".

TABLA 6.17

Los efectos cognitivos en los bloques de programas y spots Sueltos

\begin{tabular}{|c|c|c|c|c|c|c|c|c|c|c|c|c|}
\hline \multirow{3}{*}{\multicolumn{2}{|c|}{ Campaña* }} & \multirow{3}{*}{ Vuelta } & \multicolumn{5}{|c|}{ Bloques de programas } & \multicolumn{5}{|c|}{ Spots sueltos* } \\
\hline & & & \multicolumn{2}{|c|}{ Normal } & \multicolumn{2}{|c|}{ Alterado } & \multirow{2}{*}{$\frac{\text { Total }}{\mathrm{n}}$} & \multicolumn{2}{|c|}{ Normal } & \multicolumn{2}{|c|}{ Alterado } & \multirow{2}{*}{$\begin{array}{c}\text { Total } \\
\mathrm{n}\end{array}$} \\
\hline & & & $\mathrm{n}$ & $\%$ & $\mathrm{n}$ & $\%$ & & $\mathrm{n}$ & $\%$ & $\mathrm{n}$ & $\%$ & \\
\hline \multirow{4}{*}{ 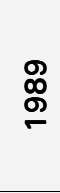 } & \multirow{2}{*}{ Collor } & $1^{\mathrm{a}}$ & 28 & 87,5 & 4 & 12,5 & 32 & & & & & \\
\hline & & $2^{a}$ & 47 & 77,0 & 14 & 23,0 & 61 & & & & & \\
\hline & \multirow{2}{*}{ Lula } & $1^{\mathrm{a}}$ & 19 & 47,5 & 21 & 52,5 & 40 & & & & & \\
\hline & & $2^{a}$ & 40 & 64,5 & 22 & 35,5 & 62 & & & & & \\
\hline \multirow{2}{*}{ హ) } & Cardoso & $1^{\mathrm{a}}$ & 17 & 44,7 & 21 & 55,3 & 38 & & & & & \\
\hline & Lula & $1^{\mathrm{a}}$ & 18 & 75,0 & 6 & 25,0 & 24 & & & & & \\
\hline \multirow{2}{*}{$\stackrel{\infty}{\infty}$} & Cardoso & $1^{a}$ & 27 & 55,1 & 22 & 44,9 & 49 & 7 & 46,7 & 8 & 53,3 & 15 \\
\hline & Lula & $1^{a}$ & 22 & 64,7 & 12 & 35,3 & 34 & 15 & 100 & & & 15 \\
\hline \multirow{4}{*}{ ঠิ } & \multirow{2}{*}{ Lula } & $1^{\mathrm{a}}$ & 8 & 38,1 & 13 & 61,9 & 21 & 7 & 46,7 & 8 & 53,3 & 15 \\
\hline & & $2^{a}$ & 14 & 53,8 & 12 & 46,2 & 26 & 7 & 53,8 & 6 & 46,2 & 13 \\
\hline & \multirow{2}{*}{ Serra } & $1^{\mathrm{a}}$ & 31 & 55,4 & 25 & 44,6 & 56 & 9 & 56,3 & 7 & 43,7 & 16 \\
\hline & & $2^{a}$ & 25 & 67,6 & 12 & 32,4 & 37 & 2 & 13,3 & 13 & 86,7 & 15 \\
\hline \multirow{5}{*}{ ஜ̊ } & \multirow{2}{*}{ Lula } & $1^{\mathrm{a}}$ & 7 & 24,1 & 22 & 75,9 & 29 & 5 & 23,8 & 16 & 76,2 & 21 \\
\hline & & $2^{a}$ & 12 & 33,3 & 24 & 66,7 & 36 & 4 & 18,2 & 18 & 81,8 & 22 \\
\hline & \multirow{2}{*}{ Alckmin } & $1^{\mathrm{a}}$ & 11 & 34,4 & 21 & 65,6 & 32 & 6 & 46.1 & 7 & 53,9 & 13 \\
\hline & & $2^{a}$ & 16 & 48,5 & 17 & 51,5 & 33 & 3 & 30,0 & 7 & 70,0 & 10 \\
\hline & TOTAL & & 342 & 56,1 & 268 & 43,9 & 610 & 65 & 41,9 & 90 & 58,1 & 155 \\
\hline
\end{tabular}

Fuente: elaboración propia

* El uso de los spots sueltos en las presidenciales empieza con la elección de 1998.

También la campaña de Lula en 2002 presenta alto índice de slow motion en las dos vueltas, reflejo de un discurso -que tiene que ver no sólo con el candidato sino con el mismo consultor Duda Mendonça- emocional y en general basado en las experiencias de la gente. En la primera vuelta, 57,1\% de los spots utilizaban el slow, y 4,8\% la edición fragmentada. En la segunda vuelta, todos $\operatorname{los} 46,2 \%$ con ritmo alterado utilizan la 
edición lenta. Un ejemplo es el ya citado vídeo de Lula en 2002 sobre la crisis de los astilleros de Río de Janeiro: el mensaje humaniza el problema del paro al utilizar casos particulares, y lo hace de un modo emocional tanto por el tono dramático de las experiencias retratadas como principalmente al usar el slow motion para ampliar el tiempo y la angustia del trabajador sin empleo. Es como si, al usar ese recurso técnico, estableciese un discurso paralelo, generando un nuevo discurso.

En 2006, el uso de la edición rápida por el candidato de PT es muy significativo: 17,3\% en la primera vuelta y $30,6 \%$ en la segunda, media que entre los anuncios sueltos alcanza el 40\% y el 38,1\% para primera y segunda vueltas. Tienen aplicación especialmente en los mensajes que hablan de las realizaciones del gobierno Lula, y más aún de las obras de infraestructura, como reformas de puertos y carreteras. La dinámica aplicada a esos mensajes son especialmente evidentes en anuncios sueltos titulados "Cubo", que enfocan obras del gobierno. En 15 segundos, la secuencia de imágenes y narración parecen pasar la idea de que es necesario ser rápido para hablar de tantas realizaciones de una administración tan dinámica.

\subsection{Objetividad de los mensajes por encima de todo}

A principios de la década de 1940, el publicitario estadounidense Rosser Reeves, director de la agencia Ted Bates, creó un nuevo concepto que cambiaría los mensajes de la publicidad comercial en el inmediato posguerra y después llegaría al campo político. La pequeña revolución era resumida en tres letras: USP, sigla en inglés para Unique Selling Proposition [propuesta única de venda] y indicaba que para tener más efectividad los mensajes necesitarían concentrar todo su empeño en una sola idea. En 1952, Bates y Reeves serían los responsables por la paradigmática campaña del general Dwight Eisenhower, llevando para la comunicación el concepto de simplificación de mensajes que asocia la objetividad a la mayor asimilación de la idea que se desea pasar al público (Maarek, 2005).

Más de medio siglo después, la simplificación de los mensajes es destacada como uno de los rasgos de las campañas contemporáneas (Rees, 1995), considerándose que al elector -cada vez más alejado de la política y inmerso en una vida estresada que desestima las reflexiones complejas- le va bien una comunicación directa; una comunicación que no le exija pensar demasiado, reduciendo el coste de decisión. La objetividad es un requisito de una campaña mediatizada, sobre todo cuando los mensajes buscan alcanzar públicos amplios y heterogéneos. En la planificación de las campañas actuales, la simplificación de los mensajes va más allá de un spot, mas bien involucrando todo el posicionamiento del candidato, centrando el foco general de la 
campaña a un número lo menor posible de temas o asociaciones. Las campañas estadounidenses ofrecen dos ejemplos que ya son considerados clásicos: las campañas de elección de Reagan, en 1980, y sobre todo la de Bill Clinton, en 1992.

Si la campaña de Eisenhower inauguró la preocupación de una idea central para cada spot, Reagan casi reduce todo el discurso electoral al tema del "estado mínimo", solo restando intachable las cuestiones de seguridad nacional. En 1992, la unique proposition en la campaña de Clinton fue la situación de la economía estadounidense, resultando en la célebre frase "es la economía, estúpido" que resumen toda la estrategia del candidato. En el caso de las campañas brasileñas, la grande mayoría de los spots siguen esa regla de oro, centrando los mensajes en un único tema, aunque esa avasalladora ventaja no se encuentre en los bloques de programas, donde la mitad enfoca más de un tema a la vez. Además, incluso cuando el candidato tiene claramente un enfoque central en la campaña -la moralización con Collor 1989, el Real de Cardoso 1994, el cambio de Lula 2002 y el empleo de Serra 2002- los candidatos exhiben programas sobre temas clásicos, como educación, sanidad o seguridad, importantes en un país donde hay grandes carencias en los servicios públicos esenciales.

Pero es de notar que el foco central en un sólo tema o idea va más allá del spot aislado, muchas veces ocupando todo el bloque de programa. De los 80 bloques analizados, 40 eran monotemáticos, así se consideran aquellos bloques en que había una única idea central en los diversos mensajes, como mucho complementado por los efectos de pasaje entre spots o por el jingle de campaña. Otros 35 tratan de dos ideas y 5 de tres (Tabla 6.18). El enfoque puede ser todo dedicado a la consolidar la percepción sobre el mismo candidato, como lo hace la campaña de PT en 1989, con un programa centrado exclusivamente en la trayectoria de Lula. En 2002, el mismo Lula elige un tema por programa, en general anunciado por el mismo candidato en la apertura del bloque publicitario, luego secuenciado por el equipo de políticos y técnicos responsables por la elaboración del programa de gobierno en el área destacado.

El foco monotemático tiene relación con el tiempo de los programas electorales de cada candidato. Eso justifica que los programas con un solo enfoque estén más presentes en las primeras vueltas que en las segundas: excepto en el caso de Serra en 2002, el tiempo de los candidatos en la primera vuelta es siempre menor que el la segunda, cuando cada candidato dispone de dos bloques diarios de 10 minutos de publicidad electoral, independiente de la representación de su partido o coalición que lo apoya. En casos como Lula en 2002, el tiempo de la segunda vuelta es casi el doble de la primera. El bloque corto facilita el tratamiento único. Además, las segundas vueltas suelen presentar una doble estrategia, fortaleciendo la imagen y propuestas del candidato a la vez que busca descalificar el opositor ahora claramente identificado. 
La incidencia de programas con un único enfoque, que en las primeras vueltas tiene promedio de $50 \%$, baja a $40 \%$ en la segunda. Los programas con tres ideas están presentes solamente en las segundas vueltas: Lula y Collor en 1989 y Alckmin en 2006. Son programas que buscan fortalecer la propia imagen del candidato al destacar su trayectoria; atacan el adversario desde referencias personales, y también intentan crear condiciones específicas de movilización de la gente, sea estimulando a las donaciones de dinero para la campaña o enfocando un tema del programa de gobierno. El promedio de mensajes con dos ideas también sube un poco, del $44 \%$ en la primera vuelta hacia al $46,7 \%$ en segunda, cuando $13,3 \%$ son mensajes con tres ideas.

TABLA 6.18

La propuesta única en los bloques de programas ( $n^{\circ}$ de bloques)

\begin{tabular}{|c|c|c|c|c|c|}
\hline \multicolumn{2}{|c|}{ Campaña } & \multirow{2}{*}{$\frac{\text { Vuelta }}{1^{\mathrm{a}}}$} & \multirow{2}{*}{$\begin{array}{c}\text { Uno só enfoque } \\
2\end{array}$} & \multirow{2}{*}{$\frac{2 \text { ideas o temas }}{3}$} & \multirow[t]{2}{*}{3 ideas o temas } \\
\hline \multirow{4}{*}{$\begin{array}{l}\text { வ } \\
\infty \\
\text { ஸ }\end{array}$} & \multirow[t]{2}{*}{ Collor } & & & & \\
\hline & & $2^{a}$ & 1 & 3 & 1 \\
\hline & \multirow[t]{2}{*}{ Lula } & $1^{\mathrm{a}}$ & 2 & 3 & \\
\hline & & $2^{a}$ & & 3 & 2 \\
\hline \multirow{2}{*}{ ণั } & Cardoso & $1^{\mathrm{a}}$ & 3 & 2 & \\
\hline & Lula & $1^{\mathrm{a}}$ & 3 & 2 & \\
\hline \multirow{2}{*}{ 足 } & Cardoso & $1^{\mathrm{a}}$ & 4 & 1 & \\
\hline & Lula & $1^{\mathrm{a}}$ & 2 & 3 & \\
\hline \multirow{4}{*}{ ָ̊ } & \multirow{2}{*}{ Lula } & $1^{\mathrm{a}}$ & 3 & 2 & \\
\hline & & $2^{a}$ & 3 & 2 & \\
\hline & \multirow{2}{*}{ Serra } & $1^{\mathrm{a}}$ & 3 & 2 & \\
\hline & & $2^{a}$ & 2 & 3 & \\
\hline \multirow{5}{*}{$\stackrel{\circ}{\stackrel{ }{\circ}}$} & \multirow{2}{*}{ Lula } & $1^{\mathrm{a}}$ & 4 & 1 & \\
\hline & & $2^{a}$ & 4 & 1 & \\
\hline & \multirow{2}{*}{ Alckmin } & $1^{\mathrm{a}}$ & 2 & 3 & \\
\hline & & $2^{a}$ & 2 & 2 & 1 \\
\hline & $\overline{\text { TOTAL }}$ & & 40 & 36 & 4 \\
\hline
\end{tabular}

Fuente: elaboración propia.

El enfoque de los spots aislados refuerza la percepción de que el tiempo de los mensajes tiene influencia sobre el foco centralizado de los anuncios. En los anuncios sueltos, un 97,4\% de los mensajes tiene una sola idea, que tanto puede referirse al candidato, al adversario o aún sobre un tema. Los mensajes con más de una idea están en las campañas de los tucanos José Serra y Geraldo Alckmin (Tabla 6.19). Un ejemplo es el anuncio de campaña de Serra en la segunda vuelta, cuando explora la decisión de Lula de no participar en los debates propuestos por algunas emisoras de televisión. A la vez 
que intenta crear un clima por la realización de más debates (que genere la confrontación y la comparación entre los candidatos), Serra destaca la decisión de Lula con el propósito de desgastar el candidato de PT. Al abrazar esa estrategia, el tucano busca reforzar la idea de un Lula sin preparación para el puesto de presidente. Y lo hace desde un anuncio de 30 segundos que enfoca los imprescindibles compromisos internacionales de un presidente, que para defender los interés nacionales se verá obligado a enfrentar personalidades como los presidentes de Estados Unidos y Francia, o los primeros ministros de Inglaterra y Alemania. El texto destaca eses compromisos, resaltando que a esos “debates” Lula no podrá falta.

El spots adopta ideas distintas (ausencia de los debates y relaciones internacionales), pero que se suman en la asociación pretendida por el candidato de PSDB: Lula no quiere debate porque no tiene preparación; y si no está preparado para enfrentar a Serra, ¿como hará cuando se establezca la necesidad de defender los intereses brasileños frente a los mandatarios de las principales potencias mundiales? Es una forma indirecta que la campaña de Serra utilizó para reavivar en la gente la baja escolaridad de Lula, que en otras campañas fue tan explotada.

TABLA 6.19

Objetividad de los mensajes, en los bloques y spots sueltos

\begin{tabular}{|c|c|c|c|c|c|c|c|c|c|c|c|c|}
\hline \multicolumn{2}{|c|}{ Campaña* } & \multirow{3}{*}{ Vuelta } & \multicolumn{5}{|c|}{ Bloques de programas } & \multicolumn{5}{|c|}{ Spots sueltos* } \\
\hline & & & \multicolumn{2}{|c|}{1 idea } & \multicolumn{2}{|c|}{ + 1 idea } & \multirow{2}{*}{$\frac{\text { Total }}{\mathrm{n}}$} & \multicolumn{2}{|c|}{1 idea } & \multicolumn{2}{|c|}{ + 1 idea } & \multirow{2}{*}{$\frac{\text { Total }}{\mathrm{n}}$} \\
\hline & & & $\mathrm{n}$ & $\%$ & $\mathrm{n}$ & $\%$ & & $\mathrm{n}$ & $\%$ & $\mathrm{n}$ & $\%$ & \\
\hline \multirow{4}{*}{$\begin{array}{l}\stackrel{9}{0} \\
\text { Ф } \\
-\end{array}$} & \multirow{2}{*}{ Collor } & $1^{\mathrm{a}}$ & 27 & 84,4 & 5 & 15,6 & 32 & & & & & \\
\hline & & $2^{a}$ & 56 & 91,8 & 5 & 8,2 & 61 & & & & & \\
\hline & \multirow{2}{*}{ Lula } & $1^{\mathrm{a}}$ & 39 & 97,5 & 1 & 2,5 & 40 & & & & & \\
\hline & & $2^{a}$ & 62 & 100 & & & 62 & & & & & \\
\hline \multirow{2}{*}{ హ্ } & Cardoso & $1^{\mathrm{a}}$ & 37 & 97,4 & 1 & 2,6 & 38 & & & & & \\
\hline & Lula & $1^{\mathrm{a}}$ & 23 & 95,8 & 1 & 4,2 & 24 & & & & & \\
\hline \multirow{2}{*}{ 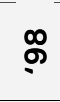 } & Cardoso & $1^{\mathrm{a}}$ & 46 & 93,9 & 3 & 6,1 & 49 & 15 & 100 & & & 15 \\
\hline & Lula & $1^{\mathrm{a}}$ & 32 & 94,1 & 2 & 5,9 & 34 & 15 & 100 & & & 15 \\
\hline \multirow{4}{*}{ ชิ } & \multirow{2}{*}{ Lula } & $1^{\mathrm{a}}$ & 19 & 90,5 & 2 & 9,5 & 21 & 15 & 100 & & & 15 \\
\hline & & $2^{a}$ & 22 & 84,6 & 4 & 15,4 & 26 & 13 & 100 & & & 13 \\
\hline & \multirow{2}{*}{ Serra } & $1^{\mathrm{a}}$ & 50 & 89,3 & 6 & 10,7 & 56 & 15 & 93,7 & 1 & 6,2 & 16 \\
\hline & & $2^{a}$ & 29 & 78,4 & 8 & 21,4 & 37 & 14 & 93,3 & 1 & 6,6 & 15 \\
\hline \multirow{4}{*}{ ஜ̊ } & \multirow{2}{*}{ Lula } & $1^{a}$ & 25 & 86,2 & 4 & 13,8 & 29 & 21 & 100 & & & 21 \\
\hline & & $2^{a}$ & 32 & 88,8 & 4 & 11,1 & 36 & 22 & 100 & & & 22 \\
\hline & \multirow{2}{*}{ Alckmin } & $1^{\mathrm{a}}$ & 25 & 78,1 & 7 & 21,9 & 32 & 12 & 92,3 & 1 & 7,7 & 13 \\
\hline & & $2^{a}$ & 25 & 75,8 & 8 & 24,2 & 33 & 9 & 90,0 & 1 & 10,0 & 10 \\
\hline & TOTAL & & 549 & 90,0 & 61 & 10,0 & 210 & 151 & 97,4 & 4 & 2,6 & 155 \\
\hline
\end{tabular}

Fuente: elaboración propia

* El uso de los spots sueltos en las presidenciales empieza con la elección de 1998. 
Entre los mensajes de los bloques de programas, el porcentual de anuncios con un solo enfoque es muy elevado, en una proporción de nueve en cada diez spots. La campaña donde hay mayor relevancia es en la de Alckmin, en 2006, con más del 20\% de los mensajes con dos ideas en cada una de las dos vueltas. En la segunda vuelta de Serra, en 2002, también pasa de los 20\%, quizá reflejo de la perspectiva de derrota apuntada por todas las encuestas, haciendo que la campaña busque alcanzar diversos públicos y temas a la vez. El mismo razonamiento se puede utilizar para Alckmin que por casi toda la primera vuelta vio amenazada incluso la posibilidad de ir a la segunda fase de la disputa, puesto que la intención de votos en Lula siempre estuvo muy cerca de los 50\% de los votos válidos. Y en la segunda vuelta, Alckmin nunca llegó a presentar reales perspectivas de victoria.

A pesar de esos índices en la comunicación de Serra y Alckmin que se salen del patrón general, ni siquiera en esos dos casos hay quiebra de la objetividad de los mensajes. En este aspecto, las campañas brasileñas atienden al principio de la Propuesta Única de Venta tan cara a las estrategias de la publicidad.

\subsection{La negatividad de los mensajes}

La negatividad es uno de los rasgos de las campañas contemporáneas en sistemas como el estadounidense donde las encuestas evidencian la condena de la gente hacia ese tipo de publicidad pero que los estrategas la siguen utilizando por considerarla fundamental sobre todo en campañas muy disputadas. En los cálculos de los estrategas, la condena de la negatividad manifiesta por el elector no impide que la información de los anuncios de ataque sean retenidos por los votantes (Devlin, 1995). La publicidad negativa es una de las más visibles características de las disputas estadounidenses, acompañando la comunicación de los candidatos a lo largo de todo el siglo XX (Ansolabehere y Iyengar, 1997; Jamieson, 1992). La publicidad de ataque se hace más intensa en las últimas dos décadas a punto de que algunas candidaturas utilicen tales mensajes en casi dos terceras partes de los spots electorales. En 1992, la estrategia de Clinton para enfrentar a George Bush fue sostenida sobre todo en los mensajes negativos, que sumaron 63\% del total. En 2004, nada menos del $72 \%$ de los spots llevados al aire por George W. Bush George eran anuncios negativos (Devlin, 2005).

La publicidad electoral sucia también está presente de modo significativo en diferentes sistemas, como el brasileño o de Europa occidental. Sin embargo, la presencia se da en niveles distintos de la avalancha negativa de Estados Unidos. En las presidenciales 
francesas de 1988, los mensajes de ataque sumaron 25\% del total, pero ninguno con críticas directas al opositor, más bien enfocando aspectos partidistas o de políticas públicas (Johnston, 1991). En la realidad brasileña, la presencia de mensajes negativos es en cierta medida todavía más bajo que el patrón francés -pero sí hay ataques personales al oponente-, sin duda reflejo del factor cultural que rechaza la campaña sucia y de la legislación que permite al candidato atacado el derecho de contestar al agresor en el espacio que debería ser utilizado por éste. En los bloques de programas, tan sólo 17,1\% de los mensajes tienen enfoque negativo, pero entre los spots sueltos cobra alguna fuerza, saltando a una media de 29\% (Tabla 6.20).

TABLA 6.20

La negatividad de los mensajes en los bloques de programas y spots sueltos

\begin{tabular}{|c|c|c|c|c|c|c|c|c|c|c|c|c|}
\hline \multicolumn{2}{|c|}{ Campaña* } & \multirow{3}{*}{ Vuelta } & \multicolumn{5}{|c|}{ Bloques de programas } & \multicolumn{5}{|c|}{ Spots sueltos* } \\
\hline & & & \multicolumn{2}{|c|}{ Positivo } & \multicolumn{2}{|c|}{ Negativo } & \multirow{2}{*}{$\frac{\text { Total }}{\mathrm{n}}$} & \multicolumn{2}{|c|}{ Positivo } & \multicolumn{2}{|c|}{ Negativo } & \multirow{2}{*}{$\begin{array}{c}\text { Total } \\
\mathrm{n}\end{array}$} \\
\hline & & & $\mathrm{n}$ & $\%$ & $\mathrm{n}$ & $\%$ & & $\mathrm{n}$ & $\%$ & $\mathrm{n}$ & $\%$ & \\
\hline \multirow{4}{*}{$\begin{array}{l}\text { \& } \\
\text { o } \\
\square\end{array}$} & \multirow{2}{*}{ Collor } & $1^{\mathrm{a}}$ & 26 & 81,2 & 6 & 18,8 & 32 & & & & & \\
\hline & & $2^{a}$ & 41 & 67,2 & 20 & 32,8 & 61 & & & & & \\
\hline & \multirow{2}{*}{ Lula } & $1^{\mathrm{a}}$ & 35 & 87,5 & 5 & 12,5 & 40 & & & & & \\
\hline & & $2^{a}$ & 51 & 82,3 & 11 & 17,7 & 62 & & & & & \\
\hline \multirow{2}{*}{ Ð } & Cardoso & $1^{\mathrm{a}}$ & 36 & 94,7 & 2 & 5,3 & 38 & & & & & \\
\hline & Lula & $1^{\mathrm{a}}$ & 17 & 70,8 & 7 & 29,2 & 24 & & & & & \\
\hline \multirow{2}{*}{ 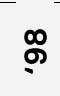 } & Cardoso & $1^{\mathrm{a}}$ & 48 & 98,0 & 1 & 2,0 & 49 & 15 & 100 & & & 15 \\
\hline & Lula & $1^{\mathrm{a}}$ & 25 & 73,5 & 9 & 26,5 & 34 & 9 & 60,0 & 6 & 40,0 & 15 \\
\hline \multirow{4}{*}{ ชิ } & \multirow{2}{*}{ Lula } & $1^{\mathrm{a}}$ & 18 & 65,7 & 3 & 14,3 & 21 & 15 & 100 & & & 15 \\
\hline & & $2^{a}$ & 23 & 88,5 & 3 & 11,5 & 26 & 13 & 100 & & & 13 \\
\hline & \multirow{2}{*}{ Serra } & $1^{\mathrm{a}}$ & 43 & 76,8 & 13 & 23,2 & 56 & 9 & 56,3 & 7 & 43,7 & 16 \\
\hline & & $2^{a}$ & 24 & 64,9 & 13 & 35,1 & 37 & 10 & 66,7 & 5 & 33,3 & 15 \\
\hline \multirow{4}{*}{ ஜ̊ } & \multirow{2}{*}{ Lula } & $1^{a}$ & 28 & 96,6 & 1 & 3,4 & 29 & 18 & 85,7 & 3 & 14,3 & 21 \\
\hline & & $2^{a}$ & 33 & 91,7 & 3 & 8,3 & 36 & 12 & 54,5 & 10 & 45,6 & 22 \\
\hline & \multirow{2}{*}{ Alckmin } & $1^{\mathrm{a}}$ & 28 & 87,5 & 4 & 12,5 & 32 & 4 & 30,8 & 9 & 69,2 & 13 \\
\hline & & $2^{a}$ & 30 & 90,9 & 3 & 9,1 & 33 & 5 & 50,0 & 5 & 5,0 & 10 \\
\hline & $\overline{\text { TOTAL }}$ & & 506 & 82,9 & 104 & 17,1 & 510 & 110 & 71,0 & 45 & 29,0 & 155 \\
\hline
\end{tabular}

Fuente: elaboración propia.

* El uso de los spots sueltos empieza con la elección de 1998

Aún así, es de notar que no hay un patrón en el uso de los anuncios negativos siquiera en un mismo candidato: en 1994, los mensajes negativos de la campaña de Lula superaron el 29\%, mientras en 2006 se pone en sólo 3,4\% en la primera vuelta y en $8,3 \%$ en la segunda. La decisión de utilizar anuncios de ataque está asociado sobre todo a la situación de cada candidato, que lleva a la adopción de determinadas estrategias: los que presentan gran perspectiva de victoria en la primera vuelta o que cuentan con 
un sitio cierto en la segunda ronda suelen no utilizar ese tipo de mensaje. Es lo que pasa con la campaña de Collor, las dos de Cardoso y las de Lula en 2002 y 2006. En tales casos, el uso de propaganda negativa puede ser una forma de generar animosidades con segmentos potencialmente aliados en la decisiva segunda vuelta.

En la elección de 1994, la campaña de Cardoso tuvo tan sólo 2 mensajes negativos (5,3\%). En 1998, la negatividad está presente en uno sólo spot (2\%) de los bloques de programas y en ningún de los spots sueltos. En 2002, ninguno de los anuncios sueltos de la publicidad de Lula en las dos vueltas son negativos; en los bloques, hay algo de ataque especialmente al gobierno (14,3\% y 11,5\%), pero sin un tono agresivo como en la campaña de 1994. Los bloques de programa petistas serían más positivos en 2006 (los mensajes negativos alcanzaron $3,4 \%$ y $8,3 \%$ en la primera y segunda vuelta, respectivamente), aunque los ataques van estar muy presentes en los anuncios sueltos, principalmente en la segunda vuelta, cuando 45,6\% presentaron enfoque negativo. Ese cambio es estratégicamente explicable: en la primera vuelta, Lula y el gobierno de PT fueron duramente criticado en la prensa y también en la publicidad de Alckmin, a razón de los escándalos de corrupción. En la primera fase, la campaña de Lula tuvo como principal estrategia silenciar sobre los escándalos, especialmente el que reveló la compra por dirigentes de PT y asesores del presidente de un falso dossier para ser usado en contra el candidato de PSDB.

El silencio respecto ese último escándalo es apuntado como una de las razones para que Lula no hubiera ganado ya en la primera vuelta: sectores más esclarecidos, especialmente de la clase media, exigían explicaciones y, como no las tenían, votaron en contra el candidato de PT como un voto de castigo ${ }^{30}$. A finales de la primera fase, la campaña de Lula utiliza algunos anuncios negativos, que van estar muy presentes en la segunda vuelta en dura comparación que muchas veces crea asociaciones especulativas hacia el opositor. Si la publicidad de Alckmin atacaba Lula y PT por los escándalos, la campaña petista centra la atención en hacer su defensa atacando con más dureza al opositor. Es particularmente duro el spot titulado "Quadrilha" [banda], en que la formación de bandas del crimen organizado es presentado como si fuera una creación de los gobiernos de PSDB. En un tono espectacular propio de programas policíacos, la imagen es de policiales al estilo de las películas de acción: caminan a pasos firmes como en el cine, accionan las pistolas o metralletas y van encerrando los delincuentes en la cárcel, culminando con el enganche del candado en las rejas. El texto no habla directamente del gobierno de PSDB, pero hace referencia a "gobiernos anteriores, además de referirse a "ellos" como los responsables por las bandas criminales. Es decir, el texto no es explícito pero sí evidente:

30 Sobre el comportamiento electoral en el final de la primera vuelta de 2006, ver el análisis de diversos expertos en http://www1.folha.uol.com.br/folha/brasil/ult96u85116.shtm/. 
"Das 75 quadrilhas desarmadas pela Polícia Federal, 61 foram formadas em governos anteriores. Operação Vampiro, quadrilha armada em 1993; desarmada em 2004 no governo Lula. Operação Anaconda, quadrilha armada em 1997; desarmada no final de 2003 por Lula. Operação Sanguessuga, quadrilha formada em 2001; desarmada por Lula em 2006. Eles armam, Lula desarma" ${ }^{1}$.

Se puede notar que es el tipo de spot que autores como Devlin (2005) llaman de anuncios de contraste. Sin embargo, a pesar de la comparación el tono que predomina es la crítica, con un ataque además de directo lleno de insinuaciones malévolas: "ellos arman, Lula desarma" es como se vinculase la formación de bandas criminales a una deliberada política de la administración de PSDB.

La lógica que asocia mayor negatividad al riesgo de no pasar a la segunda vuelta sólo no se verifica en la primera vuelta de Lula en 1989, cuando de hecho disputaba con Leonel Brizola (PDT) el pasaje a la segunda fase electoral. A pesar de eso, nunca atacó a Brizola. Es de se destacar que Brizola era una de las primeras alternativas en las posibilidades de apoyos para una segunda vuelta, por la ubicación de PDT en el campo de la izquierda, tal y cómo PT. Atacar el candidato de PDT podría cerrar las puertas al apoyo en la fase final. Es distinto lo que pasa con la campaña de Serra en 2002, cuando el riesgo de no pasar a la segunda vuelta hace que utilice publicidad negativa, pero no contra Lula sino contra Ciro Gomes (PPS), el candidato que en el inicio de la campaña creció en la intención de votos y se acercó al liderazgo en manos del candidato de PT. La publicidad de Serra atacó Gomes sobre todo en los spots sueltos, con resultados efectivos: luego del bombardeo que sufrió, el candidato de PPS perdió grande número de electores, acabando por fin en el cuarto puesto, también tras el candidato de PSB, Antony Garotinho. Por supuesto, decisiones como las de Serra están basadas en datos de encuestas, un rasgo de la profesionalización.

Las segundas vueltas suelen tener una mayor presencia de mensajes negativas, lo que se justifica por ser el momento decisivo, sin posibilidad de una otra oportunidad; es el momento del todo o nada y los candidatos recurren a todas las alternativas. Entre los 355 mensajes exhibidos en los bloques de programas de las cinco primeras vueltas, tan sólo un 13,5\% (48 spots) eran publicidad de ataque, en contra de los 21,2\% de las

\footnotetext{
31 En una traducción libre, el anuncio dije: "De las 75 bandas desarmadas por la Policía Federal, 61 fueron formadas en gobiernos anteriores. Operación Vampiro, , banda armada en 1993; desarmada en 2004 en el gobierno Lula. Operación Anaconda, bandas armada en 1997; desarmada en fines de 2003 por Lula. Operación Sanguijuela, bandas formada en 2001; desarmada por Lula en 2006. Ellos arman, Lula desarma". Las operaciones citadas son referentes a esquemas criminales desmontados y de amplio conocimiento público.
} 
segundas vueltas. En el caso de los spots sueltos, son negativos un 26,3\% de los anuncios de la primera vuelta, índice que sube al 33,3\% en la segunda.

La comparación revela también la tendencia a utilizar los anuncios sueltos como el espacio para los ataques, lo que sólo no se verifica en las campañas de Cardoso en 1998 y en la de Lula en 2002, candidaturas que tuvieron el cuidado de no ofrecer alternativas de discursos a los opositores. Atacar seria llamar a la escena adversarios que luchaban contra la inminente derrota. Los candidatos que ven la necesidad de atacar -caso de Lula en 1998, Serra en 2002 y Alckmin en 2006- dedican importante espacio de los spots sueltos a la propaganda negativa. En el caso de Lula, 40\% de esos anuncios eran de ataque a Cardoso o al gobierno, lo que da igual, puesto que el candidato de PSDB era también el presidente de la República.

En la primera vuelta de 2002, un 23,2\% de los mensajes de Serra en los bloques eran anuncios de ataque, índice que es del 43,7\% entre los anuncios sueltos. En la segunda vuelta, Serra equilibra la distribución de ataques: $32,4 \%$ en los bloques, 33,3\% en los mensajes sueltos, pero ya era el momento del todo o nada. Con Alckmin pasa algo distinto por lo menos en la segunda vuelta: en la primera fase de la campaña, los mensajes negativos en los bloques suman un 12,5\% en contra elevadísimos 69,2\% de los spots sueltos. Sin embargo, en la segunda vuelta el ataque corresponde tan sólo a 9,1\% de los bloques en cuanto se mantienen en $50 \%$ en el casos de los anuncios sin horario fijo. Aunque muy expresivos, los índices de la segunda vuelta son menores, lo que quizá se explique por el hecho de Alckmin tener al alcance de la visión la derrota en el primero escrutinio, obligando a que lanzara mano de toda la artillería disponible.

La constatación de una u otra campaña de más intensa publicidad de ataque no esconde la percepción de las campañas brasileñas como de negatividad entre baja y mediana. La baja negatividad en general es desestimada por la legislación que contempla el derecho de respuesta en el espacio del que ataca. En cuanto la mayor negatividad encontrada entre los spots sueltos, está de acuerdo con la cultura política que de modo general rechaza la publicidad negativa. Atacar en los anuncios sueltos reduce el vínculo explícito entre el mensaje y el responsable por el mensaje, cosa que no pasa en el caso de los spots de ataque dentro de los bloques, claramente vinculado al candidato dueño del bloque. Además, los mensajes en horarios no fijos tienen la ventaja de alcanzar un elector que no está previamente motivado a consumir los anuncios electorales, como lo hacen los que deliberadamente se ponen por delante de la tele para acompañar los bloques de programas. 



\section{La cuantificación del nivel profesional}

\section{Resumen}

El índice de profesionalización presenta dos comportamientos distintos, según la dimensión analizada. Por una parte, la dimensión organizativa registra índices muy variados por campaña, donde tienen especial influencia los factores endógenos, la realidad particular de cada partido; el comando partidistas, la participación de los miembros y la relación con los grupos de interés tienen gran importancia en la profesionalización. Por otra parte, los factores exógenos, con influencia cercana sobre las diversas campañas, llevan a una variación más pequeña entre los índices registrados por las campañas. Tal fenómeno se debe atribuir primero a la intención de los partidos de optimizar la respuestas a las acciones comunicacionales, con ofertas discursivas que pueden ser asociadas con objetivos esencialmente electorales. Además, la madurez de la industria de comunicación asegura a los diversos competidores condiciones mínimas producción de mensajes modernas, pautadas en lenguaje simbólico y orientada hacia una cultura de amplio consumo mediático. 

Los indicadores de profesionalización de las campañas brasileñas detallados en los dos capítulos anteriores revelan dos situaciones distintas: por una parte, una cierta uniformidad -o por lo menos una disparidad no tan acentuada- en el uso de los recursos de la comunicación electoral por las diversas candidaturas; por otra parte, condiciones muy diferentes respecto a la forma de organización de las campañas. El índice de profesionalización entre los factores organizativos varía, en una escala de o a 2, del muy bajo o,1 de la campaña de Lula en 1989 hasta el bastante elevado 1,6 del mismo Lula, en 2006 (Tabla 7.1); por tanto, se da una diferencia de 15 décimas entre el menor y el mayor índice. En cuanto al índice de profesionalización en la dimensión comunicacional, la variación es significativamente más pequeña: del 1,0 alcanzado por la candidatura petista en 1994 hasta el 1,7 otra vez de PT, en 2006 (Tabla 7.2), la diferencia se estrecha tan sólo a siete décimas.

Esa aparente contradicción revela cómo los factores sistémicos y partidistas pueden impactar de modo distinto sobre las dimensiones organizativa y comunicacional. La evaluación de las campañas brasileñas apuntan hacia una mayor influencia de los factores partidistas sobre los indicadores organizativos, donde los elementos del sistema producen menor impacto. A la vez, los factores sistémicos -comunes a todos los competidores- actúan más intensamente sobre las dimensiones comunicacionales, lo que explica parcialmente la menor variación de esos indicadores entre una campaña y otra. Por un lado, las rígidas reglas de control de los espacios mediáticos destinados a la publicidad electoral establecen límites que afectan de modo algo semejante a todos los candidatos; por otro, las condiciones que cercan cada candidatura -por ejemplo, pertenecer a un partido de masas o ser soportada por capital intensivo- interfieren de manera significativa en el modo de organización de las campañas.

\subsection{El índice de profesionalización en la dimensión organizativa}

A través de los indicadores de la Tabla 7.1, se puede ver las diferencias organizativas de una campaña a otra. La trayectoria de PT es extraordinariamente reveladora de los cambios en las campañas de un mismo partido, ofreciendo a la vez la peor y la mejor organización. En una misma campaña, los extremos son las disputas de 1989 y 2002, la primera como la más acentuada distancia organizativa entre adversarios, en cuanto la segunda ofrece el cuadro de más igualdad, aunque el 2006 también presente una situación de importante equilibrio. 
Collor tuvo en 1989 una campaña que se convirtió en referencia, con rasgos absolutamente novedosos, a partir de una planificación de largo plazo, fuerte soporte financiero de los grupos de interés y uso de amplios recursos técnicos (sondeos, media training, telemarketing. El índice organizativo de la campaña de Collor es de 1,2, que no logrará ser superado en las dos campañas siguientes, a pesar de la modernización que implicó en la incorporación de novedades tecnológicas como Internet. La organización traducía toda la esencia de la campaña, estructurada sin la necesidad de dar satisfacción sino al candidato y su pequeño grupo de acólitos, puesto que PRN es tan sólo una sigla formalmente establecida para dar sustentación legal a una candidatura que nace de un proyecto exclusivamente personal. Así, se quedó enteramente libre para estructurar la campaña como consideraba más adecuado: pudo contratar consultores, desarrollar la planificación entre las cuatros paredes del despacho y contratar empresas de encuestas, operadoras de telemarketing y gestora de datos informatizados. Si la campaña de Collor presenta importante grado de profesionalización, para el momento en que se desarrolló era vista como un verdadero fenómeno comunicacional.

En el mismo año, la campaña de Lula representa todo lo contrario, apenas contando con referencias profesionales, como revela un índice de tan sólo 0,1. El único rasgo medianamente profesional es la planificación desarrollada en un medio plazo, aunque estaba más enfocada en las estrategias políticas del partido que en los interés electorales inmediatos. Con fuerte centralidad de la estructura partidista y bajo presupuesto basado en las donaciones de la militancia, la fortaleza de la primera campaña de PT es la participación de los afiliados y simpatizantes. La presencia de consultores suena a sacrilegio, quedando en manos militantes las riendas de la publicidad y del marketing. Los sondeos y grupos focales son un lujo que la campaña no pudo tener, tampoco recursos aún menos usados como los bancos de datos informatizados y los servicios de telemarketing.

En las dos disputas siguientes, PT mantendrá una organización de campaña basada en la estructura partidista, con fuerte presencia de los miembros, como bien revela la ausencia de consultores sin vínculo con la vida del partido. Los primeros intentos de profesionalización fuero tímidos y enseguida frenados por las discusiones ideológicas intensas a consecuencia de las muchas tendencias que convivían en el seno del partido. En principios de la década de 1990 y la mirada puesta en 1994, se establece una planificación de largo plazo, los grupos de interés empiezan a tener alguna relevancia en el presupuesto y el candidato pasa a tener en cuenta los entrenamientos para encarar los medios y en especial la tele, cosa a que se había negado en 1989. Sin embargo, los avances hacia la profesionalización de la organización de campaña son limitados, traducidos en un índice que alcanza tan sólo 0,3, muy por debajo del o,9 
registrado en el mismo año por la campaña de Cardoso. Si el PT conservaba el comando colectivo, bajo las estrictas normas partidistas, PSDB realizó una campaña en la que el partido existe, pero en menor medida. El comando central estaba formado por personas del partido -aunque más vinculadas al candidato que al partido- pero los consultores del mercado fueron los responsables del marketing y la publicidad.

Tabla 7.1

El nivel de profesionalización en la organización de campañas

\begin{tabular}{|c|c|c|c|c|c|c|c|c|c|c|}
\hline & \multicolumn{2}{|c|}{1989} & \multicolumn{2}{|c|}{1994} & \multicolumn{2}{|c|}{1998} & \multicolumn{2}{|c|}{2002} & \multicolumn{2}{|c|}{2006} \\
\hline & COL & LUL & CAR & LUL & CAR & LUL & LUL & SER & LUL & ALC \\
\hline Comando centralizado & 2 & 0 & 1 & 0 & 1 & 1 & 1 & 1 & 1 & 1 \\
\hline Presença de consultores & 2 & 0 & 1 & 0 & 1 & 0 & 2 & 1 & 2 & 2 \\
\hline Planificación & 2 & 1 & 1 & 2 & 2 & 0 & 2 & 2 & 2 & 0 \\
\hline Fuente de financiación & 2 & 0 & 2 & 1 & 2 & 1 & 2 & 2 & 2 & 2 \\
\hline Sondes y focus group & 2 & 0 & 2 & 0 & 2 & 0 & 2 & 2 & 2 & 2 \\
\hline $\begin{array}{l}\text { Media training y } \\
\text { entrenamiento de equipe }\end{array}$ & 2 & 0 & 2 & 1 & 2 & 1 & 2 & 2 & 2 & 2 \\
\hline Site interactivo & 0 & 0 & 0 & 0 & 1 & 1 & 2 & 2 & 2 & 2 \\
\hline Uso del e-mail & 0 & 0 & 0 & 0 & 0 & 0 & 2 & 2 & 2 & 2 \\
\hline Intranet & 0 & 0 & 0 & 0 & 0 & 0 & 1 & 1 & 2 & 2 \\
\hline SMS (fica) & 0 & 0 & 0 & 0 & 0 & 0 & 0 & 0 & 2 & 2 \\
\hline Banco de datos & 1 & 0 & 0 & 0 & 0 & 0 & 1 & 1 & 1 & 1 \\
\hline Telemarketing & 2 & 0 & 1 & 0 & 1 & 0 & 1 & 1 & 1 & 1 \\
\hline Uso de satélite & 0 & 0 & 0 & 0 & 0 & 0 & 0 & 0 & 0 & 0 \\
\hline Militancia pagada & 2 & 0 & 2 & 0 & 2 & 0 & 1 & 2 & 2 & 2 \\
\hline TOTAL & 17 & 1 & 12 & 4 & 14 & 4 & 19 & 19 & 23 & 21 \\
\hline $\begin{array}{l}\text { La profesionalización en } \\
\text { la organización }\end{array}$ & 1,2 & 0,1 & 0,9 & 0,3 & 1,0 & 0,3 & 1,4 & 1,4 & 1,6 & 1,5 \\
\hline
\end{tabular}

Fuente: Elaboración propia.

La campaña de 1998 fue casi la repetición de la anterior para los dos partidos, incluso repitiendo los mismos candidatos, Cardoso y Lula. Una de las novedades -más de la sociedad que de los partidos per se- es el surgimiento de la Internet como recurso de campaña, siendo esta la primera vez que reciben alguna atención de los estrategas. En el ámbito particular, PT da un paso adelante y otro atrás: retrocede en la planificación de corto plazo, resultado de los cambios internos en curso, pero avanza al poder ofrecer por primera vez un comando central que, a pesar de compuesto por miembros partidistas, unifica el mando en un pequeño núcleo que reduce el asambleísmo de las estructuras anteriores. El índice de profesionalización organizativo es el mismo $(0,3)$ de la disputa anterior. PSDB mejora un poco -el índice pasa de 0,9 al 1,0-, pero ni 
siquiera logra alcanzar la estructura profesional de la campaña de Collor realizada nueve años antes. La campaña tucana es de largo plazo, el soporte financiero sigue siendo de los grupos de interés y los sondeos y los grupos focales son base de las decisiones estratégicas.

La nueva década va a traer importante evolución. En 2002, el índice organizativo registra un salto grande respecto de 1998, cuando tanto la campaña de Lula como la de Serra van a superar la organización alcanzada por Collor 13 años antes. En relación a la campaña de Cardoso de cuatro años antes, la estructura organizativa que da soporte a la de Serra repite la predisposición tucana a una amplia profesionalización, además con la incorporación de las nuevas tecnologías de comunicación, en especial las que facilitan la interacción con los electores. Las páginas webs son el ejemplo más fuerte, puesto que en esa campaña tiene alto nivel de utilización, así como los correos electrónicos y la intranet con mediana importancia en la estructura interna. La organización en la campaña de Serra alcanza un índice de 1,4, cuatro décimas por encima de la anterior de PSDB.

Sin duda, la campaña del 2002 va ofrecer el cambio más significativo de las campañas brasileñas: PT repite el candidato de las disputas anteriores, pero las condiciones de campaña son muy distintas, empezando por un presupuesto que supera a la competencia. El índice de 0,3 registrado en 1994 y 1998 es superado por la organización de 2002, que presenta un índice profesional de 1,4. Los cambios están en diversos indicadores: el comando sigue dirigido por miembros del partido, pero por primera vez la coordinación de comunicación y marketing pasa a manos de los consultores outsiders. Es más: Duda Mendonça disfruta de una autonomía inusual incluso para otros partidos. La principal fuente de financiación pasa a ser los grupos de interés, responsables de la mayor parte del presupuesto petista. El dinero deja de ser un problema y se puede ver el amplio uso de recursos como los sondeos y grupos focales, además de la utilización del correo electrónico y del telemarketing para comunicación con diversos públicos. La web se firma como un instrumento fundamental de diálogo con el elector.

El dinero tampoco es un problema en la campaña de Serra, con estrecha relación con lo grupos de interés. El candidato de PSDB mantiene la tradición del partido, con robusta estructura profesional, presencia de consultores externos, amplio abanico de instrumentos de evaluación del cuadro competitivo y recursos tecnológicos de última generación. Como en el caso de la campaña de Lula, la Internet tiene un papel destacado en las estrategias del candidato tucano en un esfuerzo de acercamiento al elector. El índice profesional en la organización es de 1,4, el mismo de la campaña del Partido de los Trabajadores. 
Las presidenciales de 2002 parecen establecer la amplia profesionalización como una regla, alcanzando a los dos principales candidatos en disputa; no es más "cosa de uno", como en las tres primeras disputas. La elección de 2006 confirma ese cambio, encontrándose destacada profesionalización en la estructura organizativa tanto de Lula como de Alckmin, ambas registrando índice superior a la de 2002, merced de la incorporación de nuevos recursos, o por lo menos la intensificación de algunos de eses instrumentos, como el SMS que apenas existía cuatro años antes. Las dos últimas presidenciales también parecen consolidar la orientación electoral de los principales partidos. Verdad que esa orientación estaba presente desde la primera presidencial, aunque PT conservase algunas prácticas más allá del interés electoral. Desde 2002, sin embargo, parece predominar la máxima, tan cara al marketing político, según la cual feo es perder.

La evolución es coherente con el tiempo y la caracterización de cada partido y condiciones de cada candidatura. El PT de 1989 que logra tan sólo el o,1 en el índice de organización es un partido que se caracteriza como partido de masas, con estructura interna determinante en los rumbos de la organización en cada momento, incluso en las campañas. La estructura de campaña de Collor en el mismo año -de amplia profesionalización para aquél momento- es el reflejo de un partido profesional electoral en su esencia: personalista, electoralista, sin participación de miembros y estrechamente vinculado a los grupos de interés. Las campañas de PSDB y las últimas de PT son las campañas de partidos que toman en cuenta las bases sí, pero que se estructuran según objetivos electorales inequívocos, buscando actuar dentro de un modelo profesional que tiene como objetivo la mayor eficacia en cada elección, es decir, que busca ante todo la conquista del mayor número posible de votos, aunque para ello sea necesario la flexibilización de alianzas y la estrecha relación con grupos de interés.

\subsection{El índice de profesionalización en la dimensión comunicacional}

Desde la primera disputa por la presidencia de Brasil, la dimensión comunicacional apunta hacia una profesionalización que va de mediana a alta. El nivel más abajo es en 1994, cuando la campaña de Lula registra un índice de 1,0 y la de Cardoso de 1,1. Son índices más bajos que los encontrados en 1989, reflejo de los cambios en la legislación: en la segunda elección, las reglas del juego indujeron las campañas a algunos formatos que entre otras cosas redujeron en parte el tono emocional, siempre muy amplio en un sistema donde el personalismo está por encima de casi todo y la construcción de relaciones afectivas es fundamental a la consolidación de las imágenes de los políticos. Ya en 1989, tanto la campaña de PT como la de PRN presentaron importantes recursos 
profesionales en área de la comunicación. El índice de la campaña de Collor fue de 1,5 en cuanto el líder de PT se puso cerca, con 1,3 (ver la Tabla 7.2). Los señales de la comunicación profesional están evidenciados en las altas dosis de personalización (incluso en el caso de la publicidad petista), en el lenguaje que en muchos momentos recurre al simbolismo, la aparatosa producción de algunos spots y la significativa presencia de recursos técnicos como el slow motion.

Las campañas de 1994 y 1998 presentan índices menores que las demás, posiblemente a razón de dos motivos: primero, la rígida legislación que en 1994 imponía algunas limitaciones a las acciones comunicacionales; segundo, el hecho de que el índice traduce en las dos campañas las acciones de una sola vuelta, puesto que no hubo segundo turno en esa disputa, vencida ya en la primera ronda por Cardoso. Como se ha subrayado en el capítulo 6, las primeras vueltas suelen reforzar ciertas tendencias, como la menor negatividad en los contenidos de los mensajes. Además, las dificultades organizativas de PT -sobre todo por el bajo presupuesto de 1998- implica una menor sofisticación técnica.

Tabla 7.2

El nivel de profesionalización en la comunicación de las campañas

\begin{tabular}{|c|c|c|c|c|c|c|c|c|c|c|}
\hline & \multicolumn{2}{|c|}{1989} & \multicolumn{2}{|c|}{1994} & \multicolumn{2}{|c|}{1998} & \multicolumn{2}{|c|}{2002} & \multicolumn{2}{|c|}{2006} \\
\hline & $\mathrm{COL}$ & LUL & CAR & LUL & CAR & LUL & LUL & SER & LUL & ALC \\
\hline Personalismo & 2 & 1 & 2 & 2 & 2 & 2 & 2 & 2 & 2 & 2 \\
\hline Foco en la imagen & 2 & 2 & 1 & 1 & 2 & 1 & 2 & 2 & 2 & 2 \\
\hline Profundidad de los spots & 2 & 1 & 1 & 1 & 1 & 1 & 2 & 1 & 2 & 1 \\
\hline Enfoque nacional & 2 & 2 & 2 & 2 & 2 & 2 & 2 & 2 & 2 & 2 \\
\hline Segmentación & 0 & 0 & 0 & 0 & 0 & 0 & 0 & 0 & 0 & 0 \\
\hline Simbolismo & 2 & 2 & 1 & 1 & 1 & 1 & 2 & 1 & 2 & 1 \\
\hline Emocionalización & 2 & 2 & 1 & 1 & 1 & 2 & 2 & 2 & 2 & 2 \\
\hline Sofisticación técnica & 1 & 1 & 1 & 0 & 2 & 0 & 2 & 2 & 2 & 2 \\
\hline Efectos cognitivos & 0 & 1 & 1 & 0 & 1 & 0 & 2 & 1 & 2 & 2 \\
\hline Objetividad & 2 & 2 & 2 & 2 & 2 & 2 & 2 & 2 & 2 & 2 \\
\hline Publicidad negativa & 1 & 0 & 0 & 1 & 0 & 1 & 0 & 2 & 1 & 1 \\
\hline TOTAL & 16 & 14 & 12 & 11 & 13 & 12 & 17 & 16 & 19 & 16 \\
\hline $\begin{array}{l}\text { La profesionalización en } \\
\text { la comunicación }\end{array}$ & 1,5 & 1,3 & 1,1 & 1,0 & 1,2 & 1,1 & 1,6 & 1,5 & 1,7 & 1,5 \\
\hline
\end{tabular}

Los índices de profesionalización vuelven a crecer en las campañas de 2002 y 2006, incluso superando el registrado por la publicidad de Collor. La comunicación llevada al 
aire por la campaña de Lula alcanza un índice de 1,6 en 2002 y 1,7 en la elección siguiente, un poco por encima del 1,5 registrado en las campañas de Serra y Alcmkin. Como resultado de la misma evolución tecnológica se puede encontrar mayor presencia de los efectos con intención cognitiva: sin duda la edición fragmentada es un lenguaje poco presente en la primera presidencial, cuando la estrella de eses efectos fueron las ediciones lentas; la edición rápida es, como señala Oliveira (2005), un lenguaje posmoderno y pasa a ser parte de la cultura de consumo desde mediados de la década de 1990. Verdad que también se puede advertir que hay señales que apuntan en sentido contrario a los marcos de las campañas profesionales, como un poco más de profundidad en los spots de Serra y Alckmin, a diferencia de la superficialidad defendida por autores como Rees (1995). Esa característica adoptada por PSDB es un poco parte del historial del mismo partido, con un origen programático. Además, es reforzada por el formato de los programas muy amplios ya desde la primera vuelta -9 minutos y medio para Alckmin y casi 11 minutos para Serra-, obligando a abordajes algo más hondos en los spots. Ello estará presente no sólo en esas dos campañas sino también en la de Cardoso en 1998, cuando el tucano tuvo más de 12 minutos de programas en la primera y única vuelta.

Las pequeñas variaciones quedan sujetas a las opciones particulares de cada partido y candidato, a veces opciones desesperadas, como la significativa presencia de negatividad en la campaña de PSDB en 2002, cuando José Serra peleaba para mantener la competitividad desde la primera vuelta. El carácter del candidato también tiene algún impacto, como la emocionalización en todas las campañas de Lula, incluso en la primera donde eludía la sonrisa pero no dejada de subrayar la relación personal con los trabajadores. En la publicidad de Serra, el simbolismo mucha veces es atropellado por el tono expositivo que recordaba más el profesor universitario que el político que busca conquistar el voto de un elector poco politizado. Lo mismo pasa con los mensajes de Gerald Alckmin, que abdican del simbolismo por la descripción de las obras realizadas por el candidato cuando en el gobierno de São Paulo.

Una cierta uniformidad en el nivel de profesionalización en el área de comunicación puede ser explicada especialmente por dos factores: primero, la ya madura industria de la comunicación que ofrece las condiciones efectivas a la profesionalización; segundo, las candidaturas se dejan guiar por el interés electoral cuyo éxito se mide en número de votos. En ese sentido, la adopción de una comunicación de mercado se hace necesaria, de ahí la amplia presencia de técnicas y lenguajes que son comunes a la industria de la publicidad o de la televisión, dos campos donde Brasil ofrece ricas experiencias, reconocidas en el ámbito internacional desde principios de la década de 1970. Además, rehusar una comunicación en patrones de la televisión y publicidad comerciales es estar en contra de la cultura de consumo de los medios: en Brasil, la sofisticación técnica 
hace parte del cotidiano de la gente, acostumbrada a ver telenovelas y anuncios por diversas horas diarias.

La opción por la mediatización en los mismos patrones de la publicidad comercial no se va encontrar solamente en las candidaturas que apenas cuentan, como son ejemplos el extrema izquierda Partido Socialista de los Trabajadores Unificados, PSTU; o el PMN, que en 1998 dio resguardo legal a la candidatura del ultraderecha coronel del aire retirado Ivan Frota. En esos casos, son partidos en que siquiera hay presupuesto: la campaña en la práctica se resume a la acción de televisión, lo que es facilitado por la legislación que garantiza espacio a los candidatos, incluso para aquellos partidos sin ninguna representación en el Congreso ${ }^{1}$. Por supuesto, en una realidad como la estadounidense, en que el espacio es comprado y representa el item con más gastos de las campañas, candidaturas como las del PSTU o del PMN tendría pocas posibilidades de presentarse o por lo menos ocupar espacios de TV como lo hacen. El presupuesto de PSTU ni siquiera cubriría el costo de exhibición de un comercial de 30 segundos en cadena nacional. Además, es evidente que tales "campañas" no tienen un efectivo foco electoral, ni siquiera preocupadas con la elección de una bancada. Quieren tan sólo un espacio para la defensa de algunas ideas, a bajo coste, puesto que la legislación les asegura.

El acceso gratuito de las candidaturas a los medios, garantizado por la legislación, quita un poco del poder efectivo de la estructura organizativa -especialmente cuanto a la financiación, es decir, la disponibilidad de dinero- respecto de la dimensión comunicacional. La posibilidad de acceso gratuito no crea un vínculo directo entre profesionalización de la organización y de la comunicación como en la realidad estadounidense. La parte más cara -el espacio de TV- está garantizado, independientemente si la campaña tiene amplio soporte financiero, como la de Collor

\footnotetext{
1 En una mirada hacia la campaña de José Maria Almeida en 2002 y de Ivan Frota en 1998 se encontró un índice muy bajo de profesionalización en el área comunicacional. La campaña de Frota alcanzó un 0,4 de índice de profesionalización, aún así por encima del 0,3 de Almeida. En la publicidad del candidato de PTSU, el discurso es partidista, tanto que el cartel que aparece en el inicio y el final del mensaje electoral destaca la sigla y el 16, número que el elector debe registrar en la urna electrónica para optar por esa candidatura. El nombre del candidato aparece tan sólo en letras pequeñas, sin referencia en jingle o logomarca. El mensaje siempre enfoca temas como la deuda externa, el paro o la explotación capitalista. El tono es racional, sin espacio para emocionalización. Coincide con la publicidad de PT, PSDB o PRN en el enfoque nacional, además de un poco de objetitividad y espacio mediano a publicidad de ataque al gobierno o al sistema. El máximo de simbología es eslogan "contra burguês, vote $16^{\prime \prime}$ (en contra el gurgués, vota el 16). En el caso de Ivan Frota, hay además un poco de personalismo, puesto que un cartel que abre el mensaje destaca el candidato, no el partido. La investigación no tiene como evaluar la estructura organizativa, puesto que esas campañas no hacen parte del corpus de estudio. Pero se supone que sencillamente no existen, como revelan las declaraciones de despesas: la campaña de José Maria en 2002 tuvo gastos de 8.212 reales (en valores de hoy, tan sólo 3.208 euros); por su parte, Ivan Frota dijo a la Justicia electoral que no tuvo recaudación tampoco despesas. No se sabe como pudo producir sus programas de TV, por más sencillo que fuesen.
} 
en 1989, o si depende del apoyo de los simpatizantes, como pasó con la campaña de Lula en el mismo año.

\section{7•3. El índice global de profesionalización de las campañas brasileñas}

El índice global de profesionalización, que reúne los indicadores organizativos y comunicacionales, apunta hacia una variación significativa, aunque no tan elástica como cuando se analiza específicamente la organización de campaña: la diferencia es de once décimas entre los extremos (Tabla 7.3). Los menores niveles son encontrados en las tres primeras campañas de Lula, todas con un índice de 0,6 , por tanto una campaña de baja profesionalización. Las otras tres primeras campañas (una de Collor y dos de Cardoso) presentan índice de mediana profesionalización, aún que en el caso del candidato de PRN se registró un índice de 1,3, muy cerca de la tercia parte superior clasificada como de alta profesionalización. Cardoso registra índices globales de 1,0 y 1,1, posicionándose poco arriba del centro de la escala de o a 2.

La evidencia más clara es sin duda el nivel de profesionalización experimentado por PT, toda vez que en 2002 presentó un índice más que el doble del encontrado en sus tres campañas anteriores, lo que se sostiene en otros trabajos de investigación realizado hasta el momento (Paiva, 2005). Además de una comunicación que se perfecciona en las técnicas de persuasión del elector, el candidato de PT puede contar con el soporte de una estructura también con alto grado de profesionalización. El índice global en la campaña del petista en aquel año fue de 1,4. En la siguiente, el índice será todavía más elevado, alcanzando el impresionante 1,7. Las dos campañas de PSDB mantienen un nivel equivalente: 1,4 para Serra en 2002 y 1,5 para Alckmin cuatro años después. Los indicadores para las diez campañas analizadas presentan una evolución hacia una estructura con más recursos profesionales, coherente con la evolución de la sociedad y con la literatura (Norris, 1999; LeDuc et al, 2001; Gibson y Römmele, 2001) que ve en la campaña profesional un fenómeno de la década de 1990.

Los datos refuerzan la importancia de los factores internos de los partidos en el proceso de profesionalización de las campañas. El cambio en el PT ha sido evidente, desde un partido de masas a un partido más pragmático y con rasgos de partido profesional electoral, buscando en los consultores y en las estrategias electoralistas el éxito electoral. La Tabla 7.3 muestra que el vencedor de cada campaña fue siempre el que tenía el mayor índice global, asociando el éxito electoral con la profesionalización. Esto no significa que los resultados de una elección son una sencilla operación matemática que suma los indicadores de organización y los de comunicación. Si así fuera, la disputa de 2002 tendría como resultado un empate entre Lula y Serra, quienes tuvieron 
campañas que se equivalen en la suma de las dos dimensiones analizadas. El proceso de selección de representantes públicos es un complejo juego que involucra diversos factores, entre ellos las condiciones particulares de la disputa en cada momento. En ello, la profesionalización se revela como un importante instrumento, contribuyendo en gran medida para el éxito electoral, especialmente por el hecho de que una campaña profesionalizada puede siempre leer de modo más eficaz los señales emitidos por la situación de cada momento, así como también conocer mejor las expectativas y demandas del elector.

TABLA 7.3

El nivel global de profesionalización en las campañas brasileñas

\begin{tabular}{lc|c|c|c|c|c|c|c|c|c}
\hline & \multicolumn{2}{c}{1989} & \multicolumn{2}{c}{1994} & \multicolumn{2}{c}{1998} & \multicolumn{2}{c}{2002} & \multicolumn{2}{c}{2006} \\
\hline & COL & LUL & CAR & LUL & CAR & LUL & LUL & SER & LUL & ALC \\
\hline Organizativos & 17 & 1 & 12 & 4 & 14 & 3 & 19 & 19 & 23 & 21 \\
\hline Comunicacional & 16 & 14 & 12 & 11 & 13 & 12 & 17 & 16 & 19 & 16 \\
\hline Total & 33 & 15 & 24 & 15 & 27 & 15 & 37 & 35 & 42 & 37 \\
\hline $\begin{array}{l}\text { Índice global de } \\
\text { profesionalización }\end{array}$ & 1,3 & 0,6 & 1,0 & 0,6 & 1,1 & 0,6 & 1,4 & 1,4 & 1,7 & 1,5 \\
\hline
\end{tabular}

Fuente: Elaboración propia.

La decisión del elector respecto a las candidaturas es resultado de un conjunto de factores donde la publicidad electoral es uno entre muchos, aunque uno de los más importantes. Al optar por uno u otro candidato, el ciudadano está manifestando un vínculo de representación que traduce la confianza en el político (Paramio, 1997). Sin embargo, la confianza se edifica desde referencias como el partido, las relaciones construidas en torno a las candidaturas y sobre todo el mismo candidato como persona que encarna sentimientos y expectativas. La campaña puede "inventar" un candidato casi desconocido, como hizo con Collor en 1989, pero tendrá mucha dificultad si intenta crear identificación con un candidato marcado por referencias negativas -por ejemplo, el mismo Collor luego de los escándalos que resultaron en su renuncia a la Presidencia-. Es decir, el nivel de profesionalización de la campaña es importante pero no es todo, puesto que necesita tener sintonía con el entorno real e imaginario.

En 2002, las campañas de Lula y Serra presentaron indicadores equivalentes pero resultados significativamente diferentes. Lula pudo hacer toda la campaña sin grandes problemas de estrategia, en un escenario -crisis económica, gobierno desgastado, 
adversario enfrentado con aliados- que le era muy favorable. Bastante diversa era el escenario particular que enmarcaba la campaña de Serra, empezando por la condición de candidato de un gobierno que se agotaba, con índices de aprobación muy bajos. A pesar de contar con una estructura profesional y una comunicación de un nivel evidentemente profesional, las condiciones que formaban el contexto competitivo eran desfavorables al candidato de PSDB. Los dos casos hacen recordar lo sostenido por Bowler y Farrel (1992), para quienes las campañas son fruto de su tiempo y lugar. Es decir, las campañas son fruto de un conjunto de condiciones generales que afectan a todos, pero que produce condiciones diferenciadas respecto cada competidor. En 1994, las condiciones de la coyuntura favorecieron a PSDB, obligando PT a adoptar estrategias desesperadas. En 2002 pasa al revés: la coyuntura crea problemas para la campaña de PSDB, dejando a PT el campo abierto hacia la victoria.

\section{CUADRO 7.1}

Distribución de los índices de profesionalización de las campañas

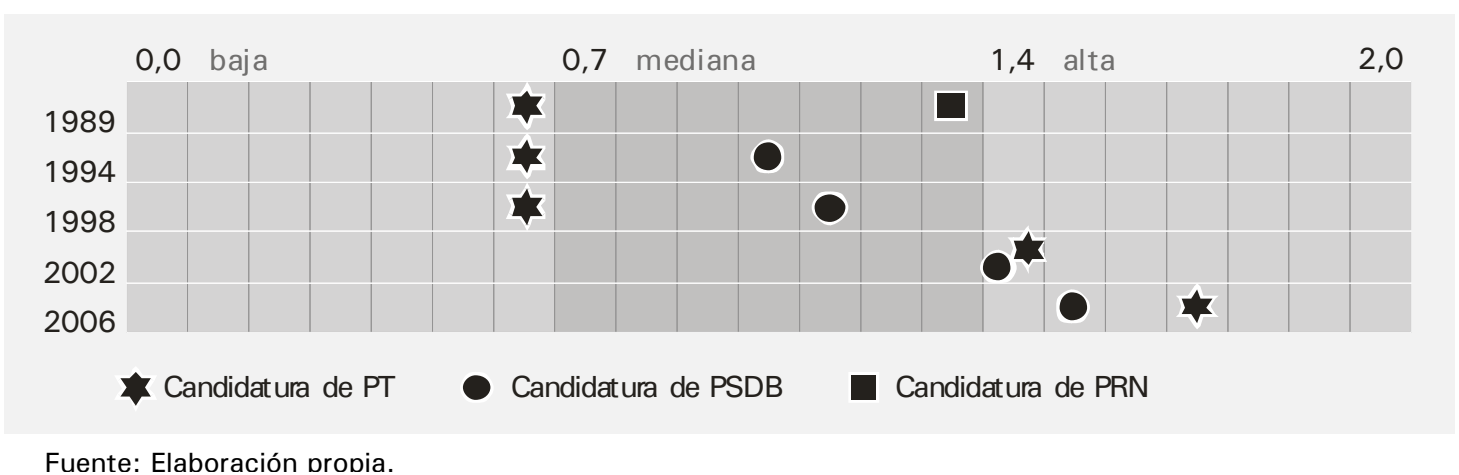

Fuente: Elaboración propia.

La Figura 7.1 ofrece una visión más clara de la evolución de las campañas brasileñas, distribuidas en las tres clasificaciones generales: hay tres en la primera columna de baja profesionalización, precisamente las tres primeras campañas de PT; luego otras tres en el tramo mediano, la de Collor y las dos de Cardoso; por fin son cuatro en la franja que corresponde a las campañas con alto nivel profesional, donde están las cuatro campañas de la actual década. En una visión general, se puede decir que hay sí importante grado de profesionalización de las campañas en Brasil, aunque diversos aspectos particulares del sistema local resulten decisivos para que esa profesionalización no sea aplastante. De las cuatro campañas en la franja de alta profesionalización, tres están con índices del inicio de esa franja; solamente la de Lula en 2006 presenta un índice realmente elevado, ocupando el medio de la franja de alta profesionalización; es un nivel que puede ser de algún modo comparable a los patrones del modelo estadounidense. 
En resumen, las campañas del Brasil contemporáneo presentan un alto índice de profesionalización que no es todavía más intenso por factores específicos de la realidad local, como las limitaciones legales y rasgos culturales. Algunas variables pueden ser tanto un estímulo como un freno a la profesionalización. Las reglas del juego son un ejemplo de ello. El sistema de lista abierta favorece al personalismo en las elecciones en todos los niveles, culminando en las presidenciales, cuando las candidaturas son más que todo alianzas de actores, poniendo los liderazgos regionales en el centro de la atención de las candidaturas. La financiación privada también es un estímulo extraordinario, en especial para los partidos con objetivos electoralistas que buscan el apoyo de los grupos de interés como soporte financiero. El dinero es la clave para otras acciones de naturaleza profesional, empezando por la contratación de expertos para las distintas áreas y la adquisición de instrumentos y servicios tecnológicos de última generación.

Sin embargo, las reglas del juego también imponen condiciones que reducen el ímpetu hacia la profesionalización. Un ejemplo es el rígido control que la legislación impone al acceso de los partidos a los medios, es decir, a la televisión y la radio. La ley establece orientación incluso para la cobertura periodística en radio y TV, además de limitar la participación de los candidatos. Otra limitación implica en los mismos formatos de los mensajes: si alguna candidatura desear llevar al aire un documental de 30 minutos como lo hizo la campaña de Bush en 2004, en Estados Unidos- no tendrá esa posibilidad. Primero porque no es posible comprar espacio; segundo, por que los tiempos son definidos según la representación de los partidos.

El sistema de partidos también ha contribuido a la personalización: altamente fragmentado y sin reglas que impidan el transfuguismo, el discurso de campaña al fin y al cabo se resume al mismo candidato. Por su parte, el sistema de medios favorece a la mediatización, además de imponer un hábito de consumo de medios en que predomina un lenguaje más ajustado a las prácticas profesionales: simbolismo, sofisticación técnica, recursos cognitivos y simplificación. La cultura política a la vez que favorece el personalismo tan característico de las campañas profesionales, también limita la publicidad negativa, otro marco de la profesionalización.

Además de todo ello, hay que reconocer que como fruto de su tiempo, las campañas brasileñas se encaminan hacia la profesionalización por la propia modernización de la sociedad. La campaña de Collor en 1989 naturalmente no podía utilizar nuevos canales de distribución de mensajes -como Internet- sencillamente porque ellos no estaban disponibles. En algunos casos, hay un pequeño retraso en la profesionalización en relación a Estados Unidos. El uso de la Internet, que pasa a tener amplio uso a partir de la reelección de Clinton en 1996, en Brasil sólo va tener uso realmente significativo en 
las elecciones de 2002. Sin embargo, hay situación al revés, como la mediatización más allá de los programas periodísticos: Collor utiliza programas de entretenimiento tres años antes de Clinton descubrir los talk shoows. 

Conclusiones 

En los capítulos precedentes se buscó evidenciar los rasgos principales de las campañas electorales en Brasil, según el marco teórico de la profesionalización de la política. Se pudo notar los rasgos generales de las campañas y aquellos que están presentes más en una que otra. A través de un índice, fue posible la cuantificación capaz de apuntar el nivel de profesionalización, que en general es significativo, sobre todo en las dos últimas elecciones, cuando las cuatro candidaturas presentaron índices que se posicionan en una franja alta, alcanzando un patrón en muchos puntos comparables a las campañas estadounidenses, el referencial profesional. En medio de esa innegable profesionalización, también se pudo notar algunos rasgos muy particulares de las campañas brasileñas, explicables por factores sistémicos y partidistas propios de la realidad brasileña.

Las hipótesis abrazadas por esta investigación encuentran validez en los resultados del análisis de las diez campañas que componen el corpus del estudio. La hipótesis general H1 es plenamente confirmada, en un destacado nivel de profesionalización que se materializa en las campañas más recientes, con la planificación estratégica, alto nivel de mediatización, amplio soporte financiero, el distendido uso de instrumentos de evaluación del escenario competitivo y la sofisticación de los mensajes electorales tanto en técnica como en lenguaje.

La hipótesis H2 también se confirma, al considerar la importancia de la madura industria de comunicación brasileña (en especial los sectores de TV y publicidad) como un primer paso avanzado que favorece a la profesionalización: desde la década de 1970 esos dos sectores presentan capacidad competitiva internacional, con el uso de sofisticados recursos de producción de programas y anuncios, lenguaje moderno y instrumentos de evaluación como sondeos y grupos focales capaces de orientar la actuación en el mercado competitivo. Tan pronto se restablece la democracia, esa experiencia va ser incorporada a la vida política en general y a las campañas en particular.

Las posibilidades abiertas por la experiencia del sector de comunicación, sin embargo, no pueden ser ampliamente utilizado en todas las disputas presidenciales, puesto que las reglas electorales imponen límites a las formas y contenidos de los mensajes. Es la confirmación también de la H3, evidenciada sobre todo en la campaña de 1994, cuando algunos recursos quedan prohibidos y quita un poco de la riqueza técnica común en el sector de comunicación. La legislación también impone límites a la publicidad negativa, en niveles muy por debajo de la realidad estadounidense. También el factor cultural -y ahí está la H4- inhibe la publicidad sucia, puesto que la gente suele no aceptar ese tipo de expediente. El rechazo a la negatividad se resume en la regla informal de la política 
brasileña según la cual aquél que es atacado suele perder votos, pero el que ataca no siempre los gana.

La altísima personalización de las campañas puede parecer confirmar las teorías sobre la profesionalización, que apuntan la centralidad de las personas como la consecuencia de la creciente mediatización de la sociedad de mano de la pérdida de fuerza de los partidos. Aunque Brasil puede ser calificado como una sociedad mediatizada, esa regla no se encaja del todo en la realidad brasileña, donde la personalización es anterior a la mediatización misma, sencillamente porque -como resaltan las $\mathrm{H}_{5}$ y $\mathrm{H} 6$ - los partidos siempre han contado poco en el diálogo y la representación de la ciudadanía. La excepción de PT como una organización disciplinada y con importante grado de identificación confirma la regla general en que la gente suele identificar el poder político con personas; estas funcionan como el canal de acceso a lo que es público.

En resumen, las campañas electorales brasileñas son la suma de las contradicciones y las tradiciones del país. Entre las contradicciones están la convivencia de realidades absolutamente desencontradas. Por una parte un país moderno, tecnológicamente avanzado y con alto nivel de calificación profesional encontrado en sectores como las comunicaciones y concentrado en núcleos urbanos más pujantes como São Paulo, Rio de Janeiro, Belo Horizonte, Salvador y Porto Alegre. Por otra, un país empobrecido y con bajo nivel educacional, esparcido por el Brasil profundo del extenso interior, cuya modernidad es una mirada limitada a la pantalla de televisión, donde los culebrones llevan la falsa sensación de vivir otra vida, de riqueza, belleza y felicidad. Las tradiciones están en prácticas como el clientelismo que afianza el poder de los caciques de los rincones del país y establecen ciertas reglas que las campañas no pueden olvidar so pena de agredir una regla informalmente institucionalizada y así reducir las posibilidades de éxito.

Los hallazgos que evidencian el cómo y porqué son las campañas electorales en Brasil no pueden limitarse a las constataciones más bien descriptivas o incluso explicativas. Y aquí se abre una nueva pauta de investigación: es fundamental buscar comprender las ventanas que tales hallazgos abren como perspectiva para la comprensión de las campañas mismas y del funcionamiento de la democracia. En cuanto a la democracia, es fundamental la comprensión de las campañas como una fase imprescindibles a las elecciones, cuando se desarrolla la etapa que además de esencial en la selección de gobernantes y de políticas públicas, funciona como legitimación del sistema, en un pacto entre la política y la ciudadanía. Es que ninguna democracia puede ser considerada como tal si no hay un proceso electoral limpio, libre, transparente, con regularidad definida y posibilidades amplias de participación tanto para votantes como para votados. Si la campaña (abierta, transparente, equilibrada en las condiciones de competencia) es imprescindible a las elecciones libres y limpias, y si éstas son fundamentales a la democracia, por consiguiente las campañas desempeñan un papel 
fundamental en el funcionamiento de las democracias. $\mathrm{Y}$ el perfeccionamiento de las campañas representará perfeccionar la misma democracia.

Si se tiene claro que la definición de las reglas del juego interfieren en la conformación de las campañas, haciéndolas más o menos profesionalizadas. Así hace falta comprender que papel juega la profesionalización en la calidad de la democracia. En esa reflexión, el primero que precisa ser comprendido es si la evolución hacia la profesionalización significa por sí misma una evolución en los procesos democráticos. Como resaltado en el marco teórico, la idea de profesionalización se asocia más a la idea de efectividad de las acciones de campaña con la intención de optimizar el resultado electoral. Es decir, si la gente no utiliza la identificación partidista o la pertenencia a grupos sociales como orientadores de las decisiones a la hora de votar, entonces cabe a los partidos buscar nuevos recursos que garanticen la participación de la gente en el proceso político. De ahí el uso de mensajes enfocados en la imagen, spots que buscan el encantamiento como estrategia para creación de vínculos, aunque vínculos que muchas veces se limitan a una elección. Sin embargo, la constatación de que los proceso de acercamiento al elector cambiaron, no significa decir necesariamente que el cambio fue para mejor. Por ejemplo, ¿contribye más a la calidad de la democracia la personalización que un debate centrado en las propuestas de políticas públicas ofrecidas por el partido? O, ¿̇cuál es la ventaja de una campaña centrada en la imagen sobre otra que prioriza la discusión de los temas?

Así, en conformidad con la literatura, la profesionalización debe ser entendida como el esfuerzo técnico -es decir, un conjunto de acciones científicamente sostenido- que asegura mayor eficacia a una campaña en la búsqueda del apoyo del elector y, así, de los objetivos políticos de las candidaturas. Pero no significa decir que esa participación es mejor o peor. En ese sentido, las campañas brasileñas ofrecen un claro avance en los instrumentos que vuelven más eficaces los esfuerzos de las candidaturas, pero hay elementos entre esos instrumentos de campaña que exigen una reflexión sobre el modo cómo están presentes. Un ejemplo es el modelo de financiación, parte público y parte privado. La financiación pública (a través del fondo partidista y de los espacios mediáticos gratuitos) abre la perspectiva hacia la publicidad electoral de candidaturas de pequeños partidos que en sistemas como el estadounidense no tendrían ninguna posibilidad de participación; es un instrumento de democratización. En cuanto la financiación privada, que abre espacio al protagonismo de los grupos de interés y a las donaciones que garantizan los recursos necesarios a la contratación de profesionales, carece de una discusión más profunda. Esa discusión no puede estar disociada de los problemas fiscales, cruciales en un país en que un tercio de la economía es registrada tan sólo en las contabilidades paralelas, un tema que no está presente en los debates actuales sobre la necesidad de cambios en el modelo de financiación de los partidos.

Al parecer, la financiación pública puede reducir el poder del dinero el las campañas, además de fortalecer los partidos, cuyo desempeño en la elección precedente sería la 
base de cálculo de los recursos de cada organización. Sin embargo, la realidad actual de Brasil hace sospechar que el simple cambio hacia un sistema de financiación únicamente pública no acabaría el problema porque la financiación privada seguiría, a través de la contabilidad paralela que está informalmente institucionalizada. El control de los gastos en las campañas muchas veces parece una simple obligación burocrática, como revela la prestación de cuentas del candidato de PMN a la presidencia en 1998, el brigadero Ivan Frota: sencillamente dijo a la Justicia que no recaudó nada y por tanto no tenía gastos a presentar, a pesar de haber cumplido algunos compromisos de agenda y de ocupar el espacio de televisión y radio con mensajes electorales. Como mínimo, esas acciones de campaña fueron costeadas por el dinero del propio candidato o del partido, necesitando el registro de la fuente del dinero. En el caso de los grandes partidos, el enmascaramiento de la contabilidad es técnicamente más ajustado aunque los valores no revelados son por cierto mucho más representativos.

Además, si las campañas son reflejo del entorno formal e informal, hace falta una mayor atención a los aspectos que facilitan la participación de candidatos sin ningún compromiso con la vida política del país. Quizá ese cambio empiece a establecerse ahora, cuando decisiones de la justicia fortalecen los vínculos partidistas al considerar que todo mandato pertenece a la organización partidista, no al individuo que fue votado. Aunque eso no implique en un automático cambio de contenido del discurso electoral hacia la discusión de temas y propuestas de políticas públicas, ciertamente ayudará a edificar mayor vínculo entre partido y político, luego resultando en cambios no sólo en las prácticas de campañas sino sobre todo en las acciones con impacto en la gobernabilidad. Sin duda, tales cambios pueden llevar a una mayor consistencia del proceso democrático.

La esperanza es que los hallazgos de la presente investigación se conviertan en una primera mirada hacia aspectos tan importantes para las democracias. Las campañas son, especialmente en América Latina, un momento de extraordinario valor simbólico, además de la importancia real de selección de gobernantes. El perfeccionamiento de ese proceso será un paso fundamental hacia democracias de más calidad. 
Bibliografía 

ABRAMo, C. (2004). Corrupção no Brasil: A perspectiva do setor privado. São Paulo: Kroll/Transparencia Internacional.

ABRANCHES, Sérgio H. H. (1988). "O presidencialismo de coalizão: o dilema institucional brasileiro”, en Dados, vol. 31, no 1.

AgranofF, R. (1976). The New Style in Election Campaigning. Boston: Halbrook.

Ailes, R. y Kraushar, J. (2001). Tú eres el mensaje. Paidós: Barcelona.

ALBUQUERQUE, A. (1995). "Querem roubar as cores da bandeira nacional! Collor e o uso dos símbolos nacionais no horário gratuito de propaganda eleitoral”, en FAUSTO NETO, A.; PORTO, S. y BRAGA, J. L. (orgs), Brasil: Comunicação, cultura \& política. Rio de Janeiro: Diadorim.

AlbuQuerque, A. (2003). "O Anfitrião Ausente: A televisão nos estudos sobre a propaganda política na televisão”, en Comunicação e Espaço Público, Ano IV, no 1 y 2, pp.94-105.

AlCÁntara, M. (1993) Gobernabilidad, crisis y cambio. Madrid: Centro de Estudios Constitucionales.

AlCÁNTARA, M. (1997). Las tipologías y funciones de los partidos políticos, en VV.AA. Curso de partidos políticos. Madrid: Akal. Madrid, pp. 37-57

ALCÁNTARA, M. (2004). ¿Instituciones o máquinas ideológicas? Origen, programa y organización de los partidos latinoameicanos. Barcelona.

AlCÁntara, M. (2006). Políticod y política en América Latina. Madrid: Siglo XXI.

AlCÁntara, M. (2006). Políticos y política en América Latina. Madrid.

Alcántara, M. (ed.) (1999). Sistemas Políticos de América Latina. Madrid: Tecnos, 2 vols.

AlCÁNtara, M. y BARAhona, E. M. (eds.) (2003) Política, dinero e institucionalización partidista en América Latina. México : Universidad Iberoamericana : Instituto Federal Electoral : Facultad Latinoamericana de Ciencias Sociales.

AlCÁntara, M. y Freidenberg, F. (eds.) (2003). Partidos Políticos en América Latina: Cono Sur. México.

AlCÁNTARA, Manuel (1994). Gobernabilidad, crisis y cambio. Madrid: Centro de Estudios Constitucionales.

ALDÉ, A. (2004). "As eleições de 2002 nos jornais”, en RUBIM, A. A. C. (org.), Eleições Presidenciais em 2002 no Brasil: Ensaios sobre Mídia, Cultura e Política. São Paulo: Hacker, pp. 106-128.

AlmeidA, J. (2004). "Serra e a mudança: um discurso fora do lugar de fala”, en RuBIM, A. A. C. (org.), Eleições Presidenciais em 2002 no Brasil: Ensaios sobre Mídia, Cultura e Política. São Paulo: Hacker, pp. 129-141.

Almeida, M. H. A. y CARNEIRO, L. P. (2003) Liderança local, democracia e políticas públicas no Brasil. En Revista OPINIÃO PÚBLICA, Campinas, Vol. IX, n 1, pp. 124-147.

Almond, G. A. y Verba, S. (1992). "La Cultura Política”, en VV.AA., Diez textos Básicos de Ciencia Política, Barcelona: Ariel, pp. 171-201.

AMARAL, K. (2006). "Getúlio Vargas: a propaganda ideológica na construção do líder e do mito”, en QueIroz, A. (org.), Na Arena do Marketing Político: Ideologia e propaganda nas campañas presidenciais brasileiras, São Paulo: Summus, pp.123-146. 
AMARAL, O. E. (2003). A Estrela nao é mais Vermelha: as mudanças do programa petista nos anos 90. São Paulo: Editora Garçoni.

Amorim Neto, O. (2006). Presidencialismo e Governabilidade nas Américas. Rio de Janeiro: Editora FGV.

ANDUIZA, E. (1999). ¿̇Indivíduos o sistemas?: las razones de la abstención en Europa Occidental. Madrid: CIS.

ANDUIZA, E. et allí. (1999). Metodología de la Ciencia Política. Madrid, Centro de Investigaciones Sociológicas.

ANDUIZA, E. y Bosch, A. (2004). Comportamiento político y electoral. Barcelona: Ariel.

Ansolabehere, S. y Iyengar, S. (1997). Going Negative: How Political Advertisements Shrink and Polarize the Electorate. New York: Free Press.

ARBESÚ, L. I. (1998). Mercadotecnía política. México: IFE.

ARCEO VACAS, J.L. (1982). Como ganar unas elecciones. Tratamiento teórico y práctico de la imagen de los políticos. Madrid : Fomento de Bibliotecas.

ARISTÓTELIS (1971). Retórica. Madrid. Instituto de Estudios Políticos.

ARREDONDO, Pablo. 1990. "Medios de comunicación y procesos electorales. El caso de los noticieros de televisión", en Comunicación y Sociedad, nº8, Universidad de Guadalajara.

AZEvEDO, C. B. (1995). A estrela partida ao meio: ambigüidades do pensamento petista. São Paulo: Editora Entrelinhas.

AzEvEDo, F. A. (2006). "Mídia e democracia no Brasil: relações entre o sistema de mídia e o sistema político", en Opinião Pública, v. 12, no 1, pp. 88-113.

BARRANCO, Francisco Javier (1997). Técnica de marketing político. México: Rei.

BEEVOR, A. (2003). Berlín, la caída: 1945. Barcelona: Crítica.

BELTRAO, L. (1980). Folkcomunicación. La comunicación de los marginalizados. São Paulo: Cortez.

BERRIO, J. (2000). La comunicación en democracia. Una visión sobre la opinión pública. Castellón. Universidad Jaime I. 2000.

BERROCAL, S. (1996). Comunicación política y televisión: definición de un marco teórico en la investigación electoral en televisión. Tesis doctoral presentada en la Universidad Complutense de Madrid.

BERROCAL, S. (2003b). La personalización de la política, en BERROCAL (comp.), Comunicación política en televisión y nuevos medios. Barcelona: Ariel, pp.55-79.

BERROCAL, S. (comp.) (2003). Comunicación política en televisión y nuevos medios. Barcelona. Ariel.

Blumenthal, S. (1982). The Permanent Campaign. New York: Simon and Schuster.

Blumer, J. y GuREVITCH, M. (1995). The Crisis of Public Communication. London. Routledge.

Blumer, J. y KaVanagh, D. (1999). "The Third Age of Political Communication: Influences and Features", en Political Communication, v. 16, $\mathrm{n}^{0} 3$, pp. 209-230.

BonÁsio, V. (2002). Televisão: manual de produção \& direção. Belo Horizonte: Leitura.

BONAVITA FEDERICO, Maria Elvira (1982). História da Comunicação - Rádio e TV no Brasil. Petrópolis: Vozes. 
BORRINI, A (2003). Cómo se vende un candidato. Un siglo de campañas políticas en la Argentina. Buenos Aires: La Crujía Ediciones/KAS.

BouRdieu, P (1990). “La opinión pública no existe” en Sociología y Cultura. México; Grijalbo.

BOWLER, S. y FARrell, D. (dir.) (1992). Electoral Strategies and Political Marketing. Londres: Macmillan.

BOWLER, S. Y FARRELL, D.M. y (eds.) (1992). Electoral Strategies and Political Marketing. New York: Macmillan.

BRAGA, J. L. (1991). O pasquim e os anos 7o. Brasilia: UnB.

BrickMANN, C. (1994). A vida é um palanque: segredos da comunicação política. Rio de Janeiro: Globo.

BRUNEAU, T. (1992) Elites and Democratic Consolidation in Latin America and Southern Europe. En HIGLEY, J. y GUNTHER, R., Elites and Democratic Consolidation in Latin America and Southern Europe, Cambridge: Cambridge University Press, Cap. 9, pp.257-281.

Buarque de Holanda, S. (1995). Raízes do Brasil. São Paulo: Cia das Letras.

BUCCI, E. (1996). Brasil em tempo de TV. São Paulo: Editempo.

BURBANO DE LARA, F. (2000). "Ecuador: cuando todos los equilibrios crujen”, en Anuario Social y Político de América Latina y El Caribe, $\mathrm{n}^{0} 3$.

CABRERA, J. R. (1995). Os Caminhos da Rosa: um estudo sobre a social-democracia no Brasil. Tesina de maestria presentada en la Unicamp, Campinas.

CAMPBELl, Angus et al. (1980). The American Voter. Chicago: Universty of Chicago.

CAMPMANY, J. (2005). El efecto ZP: 1000 días de campaña para llegar a La Moncloa. Madrid: Planeta.

CAmpos SAles, M. F. (1998). Da propaganda à presidência. Brasília: Senado Federal, edición facsimilar [original de 1908].

CANEL, M. J. (1999). Comunicación Política. Técnicas y estrategias para la sociedad de la información. Madrid: Tecnos.

CANEL, Maria José (2004). Cómo seguir una campaña electoral. Guía para ciudadanos, políticos y periodistas. Valencia: Tirant lo Blanch.

CAPARELLI, Sérgio (1982). Televisão e capitalismo no Brasil. Porto Alegre: L\&PM.

CAPDEVILA GÓMEZ, A. (2004). El discurso persuasivo: la estructura retórica de los espots electorales en televisión. Bellaterra: Universitat Autònoma de Barcelona.

CAPELATo, M. H. R. (1998). Multidões em Cena. Propaganda Política no Varguismo e no Peronismo. Campinas: Papirus.

CAPPELla, J. N. y JAMIESON, K. H. (1997): "Spiral of Cynicism: The Press and the Public Good, Nueva York, Oxford University Press.

CARAMANI, D. (2003). "The end of silent elections: The Birth of Electoral Competition, 1832-1915”, en Party Politics, v. 9., no.4 pp. 411-443.

CAREY, J. M. y REINHARDT, G. Y. (2003). "Impacto das Instituições Estaduais na Unidade das Coalizões Parlamentares no Brasil”, en Dados, vol. 44, n 4, pp. 773-804.

CARLOS FARA \& ASOCIADOS (2003): "Elección presidencial 2003: observaciones sobre los resultados electorales”. Buenos Aires: Carlos Fara \& Asociados. 
CARREIRÃO, Y. S. (2002). Identificação ideológica e voto para presidente. En Opinião Pública, Campinas,Vol.VIII, ${ }^{0}$ 1, pp.54-79.

CARREIRÃO, Y. S. (2002). A decisão do voto nas eleições presidenciais brasileiras. Rio de Janeiro: Fundação Getúlio Vargas.

CARREIRÃO, Y. S. y KINZO, M. D. (2004). "Partidos políticos, preferência partidária e decisão eleitoral no Brasil (1989/2002)”, en Dados, vol. 47, nº 1, pp. 131-167.

CARVALHO, J. M. (1997). "Mandonismo, Coronelismo, Clientelismo:uma discussão conceitual", en Dados, vol. 40, $\mathrm{n}^{\circ} 2$.

CARVAlHo, R. V. A. (2004). "Como se faz e desfaz um 'fenômeno eleitoral': o caso Roseana", en Rubim, A. A. C. (org.), Eleições Presidenciais em 2002 no Brasil: Ensaios sobre Mídia, Cultura e Política. São Paulo: Hacker, pp. 142-162.

CASAS ZAMORA, K.. (2003). "Subsidios electorales y financiamiento de campañas en Uruguay”, en Cuadernos CLAEH, vol. 28, n ${ }^{\circ}$ 86-87.

CASTRo SANTOS, M. H. (2004). A Nova Missão das Forças Armadas Latino-Americanas no Mundo Pós-Guerra Frita: o caso do Brasil, en Revista Brasileira de Ciências Sociais, Vol. $19, n^{\circ} .54$ - fevereiro.

CERVI, E. U. y Fuks, M. (2004). "Mídia Impressa e eleições para governador do Paraná em 2002”, en Cadernos da Escola de Comunicação da Unibrasil, v. 02, pp. 102-127.

CiCERón, Q. T. (1993): Breviario de Campaña Electoral (v.o. Comentatiorum Petitionis). Barcelona. Quaderns Cremá.

CoHeN, A. y WolfSFELD, G. (1995). "Overcoming Adversity and Diversity: The Utility of Television Political Advertising in Israel", en KAID, L. y HolTZ-BACHA, C. (Eds.), Political Advertising in Western Democracies: Parties and Candidates on Television, Newbury Park: Sage.

COLOMÉ, G. (2005): El príncipe en campaña. Barcelona. Ed. Mediterrania.

Colomé, J. M. (2001) Instituciones políticas. Barcelona: Ariel.

Colling, L. (2004). Os estudos sobre o Jornal Nacional nas eleições pós-ditadura e algumas reflexões sobre o papel desempenhado em 2002, en RUBIM, A. A. (org.) Eleições Presidenciais em 2002 no Brasil: Ensaios sobre mídia, cultura e política. São Paulo: Hacker Editores, pp.7-28.

Conti, M. S. (1999). Notícias do Planalto: a imprensa e Fernando Collor. São Paulo: Companhia das Letras.

Converse, P. (1964). "The Nature of Belief Systems in Mass Publics", en D. Apter (ed.), Ideology and Discontent. New Cork: Free Press.

Corte Real, V. K. (2004). Propaganda Republicana: Estratégias de Comunicação Política contra a monarquia brasileira. Ponencia presentada en el II Encontro Nacional da Rede Alfredo de Carvalho, Florianópolis, Abril.

CORZo FERnÁndEZ, S. (2002) Elites Políticas y Formación de redes en Latinoamérica. VII Congreso Internacional del CLAD sobre la Reforma del Estado y de la Administración Pública, Lisboa, Portugal, 8-11 Octubre.

Costa Bonino, L. (1994). Manual de Marketing Político. Montevideo: Fin de Siglo.

CostA, L. C. B. P (1978). Arraial e Coronel: Dois estudos de história social. São Paulo: Cultrix. 
CosTA, R. (2006). "Fernando Collor de Mello: encenações rituais do espetáculo político", en QueIROZ (org.), Na Arena do Marketing Político: Ideologia e propaganda nas campañas presidenciais brasileiras, São Paulo: Summus, pp.275-296.

CoTTA, M. (1988). "Parlamento y representación", en G. PASQUINO (comp.), Manual de Ciencia Política. Madrid: Alianza.

Cox, G. W. (2004). La coordinación estratégica de los sistemas electorales del mundo: haver que los vuetos cuenten. Barcelona: Gedisa.

CRESPO, I. (dir.) (2002). Las Campañas Electorales y sus Efectos en la decisión del votoVol. I. Valencia: Tirant lo Branch.

CRESPO, I. (ed.) (2003). Partidos, medios de comunicación y electores. Buenos Aires: Planeta.

CRESPO, Ismael (dir.) (2004). Las campañas electorales y sus efectos en la decisión del voto. VOL. II: La campaña electoral de 20oo: partidos, medios de comunicación y electores. Valencia. Tirant lo Blanch.

CRESPO, Ismael; MoRENO, Cristina; y DELGADO, Irene (2003). "El estudio de las campañas electorales”, en CRESPO (dir), Partidos, medios de comunicación y electores. Buenos Aires: Planeta, pp. 13-29.

CHAFFEE, S. H. (1981). "Mass media in political campaigns: An expanding role", en RICE y PIASLEY (Eds.), Public communication campaigns, pp. 181-198. Newbury Park: Sage.

CHAUí, M. (200o). Brasil: mito fundador e sociedade autoritária. São Paulo: Fundação Perseu Abramo.

D’AdAmo, O.; García Beaudoux, V. y Freidenberg, F. (2000). Medios de comunicación, efectos políticos y opinión pública. Una imagen, ¿vale más que mil palabras? Buenos Aires: Editorial de Belgrano.

D’Adamo, O.; García Beaudoux, V. y Freidenberg, F. (2007). Medios de Comunicación y opinión pública. Madrid: McGraw-Hill.

D’ARAÚJO, M. C. S. (1990). "Partidos Trabalhistas no Brasil: reflexoes atuais”. Estudos Históricos, v. 3, nº 6, pp. 196-206.

D’Ávila FILHo, P. M. (2000). "Democracia, Clientelismo e Cidadania: A Experiência do Orçamento Participativo no Modelo de Gestão Pública da Cidade de Porto Alegre”. Tese de Doutorado, Rio de Janeiro, IUPERJ. [Ver Capítulo "Tanto aqui, quanto lá ou alhures: o Clientelismo como fenômeno moderno"].

D’Elboux, Paulo César (2006). “José Sarney: você conhece o mapa da mina”, en A. QUEIROZ (org.), Na Arena do Marketing Político: Ideologia e propaganda nas campañas presidenciais brasileiras, São Paulo: Summus, pp.231-274.

DADER, J. L. (1998). Tratado de comunicación política, Primera parte. Madrid. Ed. Dader.

DADER, J. L. (1999). "Retórica mediática frente a cultura política autóctona: La encrucijada de la comunicación política electoral española entre la 'americanización' y el pluralismo democrático tradicional”, en $C I C, \mathrm{n}^{\circ} 4$, pp.63-87.

DADER, J. L. (2006): "Cibercomunicación y pseudoperiodismo en el 11M: Patologías de crisis en una democracia débil", en Comunicación y Pluralismo (Facultad de Comunicación Universidad Pontificia de Salamanca), $\mathrm{n}^{0}$ 1, pp.35-62.

DAHL, R. (1989). La Poliarquía. Madrid: Tecnos. 
Dalton, R. J. y Wattenberg, M. P. (eds.) (1993). Parties without Partisans: Political Change in Advanced Industrial Democracies. Oxford: Oxford University Press.

DEL Rey Morató, J. (1989). La Comunicación Política. Madrid: Eudema.

Del Rey Morató, J. (1997). Los Juegos de los Políticos: Teoría general de la información y comunicación política. Madrid: Tecnos.

DEL REY MORATó, J. (2007). Comunicación política, Internet y campañas electorales: de la teledemocracia a la ciberdemocr@cia. Madrid: Tecnos.

DELGAdo Sotillos, I. (2000). El comportamiento electoral municipal español, 1979-1995. Madrid: CIS.

DELLA CAVA, R. (1988). “The church and the abertura in Brazil, 1974-1985”. University of New York, Queens College, Working Paper \#114, noviembre.

DENVER, D.; HANDS, G. y FISHER, J. (2003). "Constituency Campaigning in Britain 19922001”, en Party Politics, vol. 9, n 5, pp.541-559.

Desposato, S. (2004). The Impact of Federalism on National Political Parties in Brazil. En Legislative Studies Quartelly, Vol. XXIX, pp. 259-285.

Devlin, P. (2005). "Contrasts in Presidential Campaign Commercials of 2004", en American Behavioral Scientist, $\mathrm{n}^{\circ}$ 49, pp. 279-313.

DEVLIN, P. (1995). "Political comercials in American presidential elections", en KAID, L. y Holtz-Bacha, C. (org.), Political Adverising in western democracies”. Londres: Sage, pp. 186-205.

Di TELA, T. S. (1996). "Perón y Vargas: vidas paralelas". Ponencia presentada en el Seminario Argentina-Brasil, PUC-Río de Janeiro, agosto.

DiAMOND, E. y BATES, S. (1984). The Spot: The Rise of Political Advertising on Television. Cambridge: MIT Press.

DíEz NicOlAS, J. y SEMETKO, H. A. (1995). "La televisión y las elecciones de 1993,. en MuÑoz Alonso, A. y RosPIR, J.I. (eds) Comunicación Política. Madrid: Universitas.

Dimenstein, G. y SouZA, J. (1994). A História Real. São Paulo: Brasiliense.

Diniz, E. (1982). Voto e máquina política, Patronagem e clientelismo no Rio de Janeiro. Rio de Janeiro: Paz e Terra.

DinIZ, E. (1988). Empresariado e Transição Política no Brasil: Problemas e perspectivas. En FlEISCHER, D. (org.), Da distensão à abertura: as eleições de 1982. Brasília: Editora UnB, pp. 159-184.

Dolan, Christopher J. (2004). 'Two Cheers for Negative Ads.' In Lights, Camera, Campaign!: Media, Politics and Political Advertising, ed. by David A. Schwartz. New York: Peter Lang Publishing.

Domenach, J. M. (s.f.). A Propaganda Política. São Paulo: Difusão Européia do Livro.

Downs, A. (1973). Teoría económica de la democracia. Madrid: Aguilar, 1973.

DREIFUSS, R. (1981). A Conquista do Estado: Ação política, poder e golpe de classe. Petrópolis: Vozes.

DUQUE, J. (2007). El liderazgo en los procesos políticos: una aproximación a los conceptos de liderazgo personalizado y liderazgo institucionalizado. Cali: Universidad de Cali.

Duverger, M. (2002). Los Partidos Políticos. México: FCE. 
ECHAZARRETA CARRION, J. y LOPEZ GARCÍA, G. (2000). "Manipulacion de las masas y propaganda en la Alemania nazi”. Ponencia presentada en el V Congreso de la Asociacion de Historia Contemporanea, Valencia, mayo.

Edelman, M. (1991): La Construcción del Espectáculo Político. Manantial, Buenos Aires.

ELSTER, J. (1985), "Rationality, morality and collective action", Ethics 96: 136-155

["Racionalidad, moralidad y acción colectiva", Zona Abierta 54-55: 43-67, 1990].

ELLuL, J. (1969). Historia de la Propaganda. Caracas: Monteavila.

ENEL, F. (1977). El Cartel. Lenguage, Funciones, Retórica. Valencia: Fernanado Torres.

ERWIN Leiser (1974). Nazi Cinema., Londres: Secker \& Warburg.

ESPAÑA, R. (2000). El cine de Goebbels, Madrid: Ariel.

ESPAÑA, Rafael (1998). "La guerra de celuloide: Goebbels vs. Hollywood, 1939-1941”, en Film-Historia, vol. VIII, ${ }^{\circ}$ 2-3, pp.187-223.

ESPAÑA, Rafael (2000). El cine de Goebbels. Madrid: Ariel.

Espíndola, R. (2003). Partidos, campañas y democratización en el Cono Sur de Latinoamérica, en AlCÁNTARa y BARAHONA, Política, Dinero e Institucionalización Partidista en Latino América Latina, México, Universidad Iberoamericana / Facultad Latinoamericana de Ciencias Sociales, pp. 159-192.

FARA, C. (2000). "Características del electorado argentino". En KONRAD ADENAUER, Acciones para una buena comunicación en campañas electorales. Cap. I. $1^{\text {a }}$ edición. Buenos Aires: Konrad-Adenauer.

FARA, C. (2002). "Características del electorado argentino". En FUndACIÓN KONRAD ADENAUER, Acciones para una buena comunicación en campañas electorales. Cap. I.. Buenos Aires: Konrad-Adenauer.

FARA, C. (ed.) (1997). Diseñando Estrategias. Buenos Aires: Fara \& Asociados.

FARA, C. (ed.) (2006). Manual de campaña electoral: marketing y comunicación política. Buenos Aires: Konrad Adenauer.

FARIAS, F. P. (2000). "Clientelismo e democracia capitalista: elementos para uma abordagem alternativa”, en Revista de Sociologia Política, Curitiba, nº 15, pp. 49-65.

FARRELl, D. M. (1996). "Campaign Strategies and Tactics", en LEDUC, NIEMI y NoRRIS, Comparing Democracies: elections and voting in global perspective. Londres: SAGE, pp.160-183.

FARRELl, D. M. y WeBb, P. (2004) "Los partidos políticos como organizadores de campañas”. Zona Abierta (108/109), pp. 67-109.

Fausto Neto, A. (1990) O presidente da televisão, en Comunicação \& Política, São Paulo, Vol. $9 \mathrm{n}^{\circ}$ 11: pp. 7-27.

Fausto Neto, A. (1994). O impeachment da Televisão. Rio de Janeiro: Diadorim.

Fausto Neto, A. (1994). "Vozes do Impeachment", en Matos (org.), Mídia, Eleições e Democracia: São Paulo, Scritta, pp.159-189.

Fausto Neto, A. y Verón, E. (2003). Lula Presidente. São Paulo: Hacker Editores.

Ferguson, C. (1997). "The Politics of Ethics and Elections", en Florida State University Law Review, vol. 24, pp.463-505.

FERNÁNDEZ MELlizo-Soto, M. (2001). "¿Para qué sirven las campañas electorales? Los efectos de la campaña electoral española de 1993". En REIS, $n^{\circ}$ 93, pp. 61-87. 
FERRARI Wolfenson, G. y MAZZINA, C (2001). "La democracia mediática y las bases del sistema republicano". En Contribuciones, ${ }^{0}$ 2/2001, pp. 7-17.

Fundación Getúlio VARgas, (2000). Dicionario Histórico-Bibliográfico Brasileiro. Rio de Janeiro: Fundaçao Getúlio Vargas.

Figueiredeo, N. L. y Figueiredo, R. (1990). Como ganhar uma eleição: lições de campanha e marketing político. São Paulo: Cultura Editores.

FIgUEIREDO, M.; ALDÉ, A.; DiAS, H.; y JORGE, V. L. (2000). "Estratégias de persuasão eleitoral em eleições majoritárias: uma proposta metodológica para o estudo da propaganda eleitoral", en Rubens FigueIREDO. (Org.). Marketing Político e Persuasão Eleitoral, Rio de Janeiro: Konrad Adenauer, 2000, pp. 147-203.

Figueiredo, A. y LimONGE, F. (1999). Executivo e Legislativo na nova ordem constitucional. São Paulo: Ed.FGV/FAPESP:1999

Figueiredo, A. y Limonge, F. (2002). "Incentivos Eleitorais, Partidos e Política Orçamentária”, en Dados, v. 45, nº 2, pp. 303-344.

FigueIREDo, N. (1994). Jogando para ganhar. São Paulo: Cultura Editores.

FigueIREDO, R. (org.) (1996). Marketing político e persuasão eleitoral. São Paulo: Fundação Konrad Adenauer.

Figueiredo, R. y Coutinho, C. (2003). “A eleiçao de 2002”, en Opiniao Pública, Campinas, v. IX, $n^{0} 2$, pp.93-117.

FigueiREDo, R. y Ribeiro, R. (1998). "La elección de 1998 en Brasil: la campaña de la reelección”, en PRIESS y TUESTA SOldevilla, Campañas electorales y medios de comunicación en América Latina. Buenos Aires, Ciedla y Konrad Adenauer.

FleISCHER, D. (1988b) As desventuras da engenharia política. En FlEISCHER (org.). Da distensão à abertura: as eleições de 1982. Brasília: Editora UnB, pp. 61-88.

FleISCHER, D. (org.) (1988). Da distensão à abertura: as eleições de 1982. Brasília: Editora UnB.

FrANCO, C. (2000). "Perú. Entre el proceso electoral y las incertidumbres del futuro", en Nueva Sociedad, $n^{o} 174$, pp. 15-24.

FREIDENBERG, F. (2003). Jama, caleta y camello. Las estrategias de Abdalá Bucaram y el PRE para ganar elecciones. Quito: Universidad Andina Simón Bolívar / Corporación Editorial Nacional.

Freidenberg, F. (2007). La Tentación Populista: una via al poder en América Latina. Madrid: Síntesis.

FRESTON, P. (1999). Protestantismo e democracia no Brasil. En Lusopedia, pp. 329-340.

FridKIn, K. L. y KenNeY, P. J (2004). “Do negative messages work?”, en American Politics Research.

FUNDACIÓN KONRAD ADENAUER (2002). Trastienda de una elección. Campaña presidencial Argentina 1999. Buenos Aires: Grupo Editorial Temas

GAGE, L. y MEYER, C. (1985). O filme publicitário. São Paulo: SSC\&B-Lintas Brasil.

GaLINDO, F. (1994): "Elecciones generales 1993, comunicación política y pluralismo informativo", Actas Cong. Int. Comunicación y Pluralismo, 1993. Univ. Pontificia de Salamanca.

Galindo, F. (1998). Fundamentos de comunicación política. Santiago de Compostela: Tórculo. 
García Beaudoux, V. y D’Adamo, O. (2006). "Comunicación Política y Campañas Electorales. Análisis de una herramienta comunicacional: el spot televisivo”. En Polis, vol. 2, $\mathrm{n}^{0}$ 2, pp.81-111.

García Beaudoux, V.; D’Adamo, O. y Slavinsky, G. (2005). Comunicación Política y Campañas Electorales: Estrategias en Elecciones Presidenciales. Barcelona: Gedisa.

GARCÍA JIMÉNEZ, J. (1993). Narrativa audiovisual. Madrid: Cátedra.

García Luengo, O. (2006). "E-activism: New Media and Political Participation in Europa", en Confines de Relaciones Internacionales y Ciencia Politica, $\mathrm{n}^{\circ}$ 4, pp. 59-71.

GARCÍA Luengo, Óscar (2005). "Media Malaise Revisited: Media Exposure and Political Activism in Europe”. En Central European Political Sciene Review, Vol. 6, No. 19, pp. $72-88$.

Garramone, G. (1985). "Effects of Negative Political Advertising: The Roles of Sponsor and Rebuttal”, en Journal of Broadcasting and Electronic Media, $\mathrm{n}^{0}$ 29, pp. 147-159.

GASPARI, Elio (2002). A ditadura escancarada. San Pablo: Cia. das Letras.

Gauthier, G., Gosselin, A. y Mouchon, J. (comps.) (1998). Comunicación y Política. Barcelona. Gedisa. 198.

GERSTLÉ, J. (ed.) (2005). La comunicación política. Santiago: LOM.

Gibson, R. y Rommele, A. (2001). "Changing Campaign Communications: A PartyCentered Theory of Professionalized Campaigning”, en Press/Politics, Vol. 6, $\mathrm{n}^{\mathrm{o}}$ 4, pp. 31-43.

Gíl García, G. y AlmazÁn, S. (2004). "Influencia de los gastos de campaña en los resultados de las elecciones federales de 1997”, en Espiral, vol. X, nº 29.

GILDER, G. (1996). A vida após a televisão. Rio de Janeiro: Ediouro.

GoMES, W. (2004). Transformaçoes da política na era da comunicaçao de massa. São Paulo: Ed. Paulus.

Graber, D. A. (1993). "Making Campaign News User Friendely: The lessons of 1992 and Beyond”, en American Behavioral Scientist, vol. 37, n. 2, pp.328-336.

Graham, R. (1997). Clientelismo e Política no Brasil do Século XIX. Rio de Janeiro: UFRJ Editora.

GRossi, E. (2006). "Jânio Quadros: as representações metafóricas da vassoura no imaginário popular", en QueIROZ (org.), Na Arena do Marketing Político: Ideologia e propaganda nas campañas presidenciais brasileiras, São Paulo: Summus, pp.185-202.

GuARESCHI, P. (1985). Comunicação e poder. Petrópolis: Vozes.

Guber, S. (1993). Cómo Ganar su Primera Elección: El Manual del Candidato. México: Publigrafics.

Guerra, A. (1984). Felipe González: de Suresnes a la Moncloa, de Alfonso Guerra. Madrid: Novatex.

Gugliano, A. A., y JEREZ, A. (1996). "Las elecciones brasileñas de 1994: ¿continuidad o cambio?”, en América Latina Hoy, Madrid, $\mathrm{n}^{0}{ }_{13}$, mayo.

Guzmán Mendoza, C. E. y Sena de Oliveira, E. (2001). "Brasil”, en Alcántara y Freidenberg (eds.), Partidos Políticos de América Latina: Cono Sur. Salamanca: Ediciones Universidad de Salamanca.

HABERMAS, J. (1987). Teoría de la acción comunicativa. Madrid: Taurus. 
HAIME, H. (1988). Votando Imágenes. Buenos Aires: Librería Editorial Tesis.

HERrero, J. C. y CONNOLlY-AHERn, C. (2004). "Origen y evolución de la propaganda política en la Espana democrática (1975-2000): análisis de las técnicas y de los mensajes en las elecciones generales del año 2000", en Doxa Comunicación, $\mathrm{n}^{0}$ 2, pp. 151-172.

Herreros Arconada, M. (1989). Teoría y técnica de la propaganda electoral : formas publicitarias. Barcelona: PPU.

HERZ, D. (1987). A História Secreta da Rede Globo. Porto Alegre: Tchê.

Hirschman, A.O. (1986), Interés privado y acción pública, México: Fondo de Cultura Económica, 1986 [Shifting involvements: private interest and public action, Princeton: Princeton University Press].

HoINEFF, Nelson (1991). TV em expansão: novas tecnologias, segmentação, abarangência e acesso na televisão moderna. Rio de Janeiro: Record.

HOLTZ-BACHA, C. (2002). "Campañas electorales en Alemania”, en PRIESS (Ed.), Relación entre política y medios. Propuestas alemanas en una perspectiva comparada. Buenos Aires: Temas, pp. 207-229.

HolTZ-BACHA, C. y Kaid, L. L. (1995). "A Comparative perspective on Political Advertising”, en KaID y Holtz-BACHA, Political Advertising in Western Democracies. Thousand Oaks: Sage, pp. 8-18.

Hoolbrook, T. (1996). Do Campaigns Matter? Londres: Sage.

InGHAM, Bernard (2003). The Wages of Spin: A Clear Case of Communications Gone Wrong. London: John Murray.

IYengaR, S. (1991). Is Anyone Responsible? How Television Frames Political Issues. Chicago: The University of Chicago Press.

Jahr Garcia, N. (s/f). Estado Novo, Ideologia e Propaganda Política: a legitimação do Estado autoritário perante as classes subalternas. São Paulo: Record. (disponible en http://www.ngarcia.org/nel/enovo/).

Jamieson, K. H. (1992). Dirty Politics: Deception, Distraction, and Democracy. Oxford: Oxford University Press.

Johnson, D. W. (2001). No Place for Amateurs: How Political Consultants are Reshaping American Democracy. New York: Routledge.

JOHNSTON, A. y GERSTLÉ, J. (1995). "The role of television broadcasts in promoting french presidential candidates", en HolTz-BACHA, C. y KAID, L. L., Western democracies: parties \& candidates on television. Thousand Oaks: Sage Publication.

Johnston, A. (1991). "Political broadcasts: An analysis of form, content, and style in presidential communication”, en KAID, L.; GERSTLÉ, J. y SANDERS, K., Mediated politics in two cultures: presidential campaigning in the United States and France. Londres: Sage, pp. 59-72.

Joslyn, R. (1980). “The Content of Political Spot Ads”, en Journalism Quarterly, nº 57, pp. 92-98.

JULIÁ, S. (1997). Los socialistas en la política española 1879-1982. Madrid: Taurus.

KAID, L. L. (1981). "Political Advertising", en Nimmo y SANDERS (eds.), Handbook of Political Communication, Beverly Hill: Sage, pp. 249-271. 
KAID, L. L. (1999). "Comparing and Contrasting the Styles and Effects of Political Advertising in European Democracies," en KAID (ed.), Television and Politics in Evolving European Democracies. Commack: Nova Science Publishers.

KAID, L. L. (ed.) (2004). Handbook of Political Communication Research. Mahwah: Erlbaum.

KAID, L. L. y Holtz-BACHA, C. (1995). "Political Advertising Across Cultures", en Kaid y Holtz-Bacha, Political Advertising in Western Democracies. Thousand Oaks: Sage, pp. 206-227.

KAID, L. L. y Holtz-Bacha, C. (dir.) (1995). Political Advertising in Western Democracies. Thousand Oaks: Sage.

KAID, L. L.; Gerstlé, J. y SANDERS, K. (1991). Mediated politics in two cultures: presidential campaigning in the United States and France. Londres: Sage.

KATZ, R. S. y MAIR, P. (2004). "El partido cartel: las transformaciones de los modelos de partidos y de la democracia de partidos". Zona Abierta, Madrid (108/109), Editorial Pablo Iglesias, pp. 7-41.

Kavanagh, D. (1995). Election Campaigning: The New Marketing of Politics. Oxford: Blackwell.

Kinzo, M. D. G. (1993). Radiografia do quadro partidário brasileiro. São Paulo: Fundação Konrad-Adenauer.

Kinzo, M. D. G. (2001). "A Democratização Brasileira: um balanço do processo político desde a transição", en São Paulo em Perspectiva, v. 15, nº 4, pp. 3-12.

KINZO, M. D. G. (2004). "Partidos, Eleições e Democracia no Brasil Pós-1985”. Em Revista Brasileira de Ciências Sociais, Vol. 19, n 54-fevereiro, pp. 23-41.

KIRCHHEIMER, O. (1980). "El camino hacia el partido de todo el mundo", en K. LENK y F. NEUMANn (eds.), Teoría y sociología crítica de los partidos políticos. Barcelona: Anagrama.

Kotler, P. y Kotler, N. (1999). "Political Marketing: Generating effetive candidates, campaigns and causes", en NEWMAN (ed.), Handbook of political marketing”. Thousand Oaks: Sage.

Kotler, P. (1978). Marketing para Organizações que não visam o lucro. São Paulo: Editora Atlas.

Krause, S. y CAMpos, I. (2006). "Los partidos políticos brasileños”, en Diálogo Político, v. 4-2006, pp. 41-72.

KROH, M. (2004). "Personal Voting: Individual and Contextual Determinants of Political Leadership". Paper presentado en el Gemeinsame Tagung des Arbeitskreises Interkultureller Demokratievergleich und der Ad-hoc-Gruppe Empirische Methoden der Politikwissenschaft,Universität Lüneburg.

KubitscheK, J. (1974). Meu caminho para Brasília: a escalada política. Rio de Janeiro: Bloch, vol. II.

KuntZ, R. y LuYTEn, J. (1982). Marketing Político: Manual de Campanha Eleitoral. Rio de Janeiro: Editora Global.

LACERDA, A. D. F. (2002). "O PT e a Unidade Partidária como Problema”, en Dados, v. 45, $\mathrm{n}^{0} 1$, pp.39-76. 
LAGO PEÑAS, I. (2005). El voto estratégico en las elecciones generales en España (1977200o): efectos y mecanismos causales en la explicación del comportamiento electoral. Madrid: CIS/Siglo XXI

LAMOUnier, B. (1989). Partidos e Utopia. O Brasil no Limiar dos anos 9o. São Paulo: Loyola.

LAVAREDA, A. (1991). A Democracia nas Urnas. Rio de Janeiro: Iuperj/Rio Grande.

Lazarsfeld, P.; Berelson, B. y Gaudet, H. (1944). The People's Coise: How the voter makes up his mind in a presidential campaign. New York: Columbia University Press.

LEAL, V. N. (1997) Coronelismo, enxada e voto : o município e o regime representativo no Brasil. Rio de Janeiro : Nova Fronteira.

LeDuc, L.; Niemi, R. y NorRis, P (eds.) (2001). Comparing Democracies 2. New Challenges in the Study of Elections and Voting. Londres: Sage.

LEONI, E. L. (2002). "Ideologia, Eleições e Eleitorado: Câmara dos Deputados e Consolidação Democrática”. Columbia University, Working Paper disponible en http://www.columbia.edu/ ell2002/lem.pdf.

LeVIne, D. (ed.). (1986). Religion and Political Conflict in Latin America. Chapel Hill: University of North Carolina Press.

LIMA JR., O. B. (1999). "Eleições presidenciais: Centralidade, contexto e Implicações”, en Revista Brasileira de Ciências Sociais, v. 14, no 40, pp. 11-30.

Lima JR., O. B. (1999). "Partidos, eleições e Poder Legislativo”, en Miceli, S. (org.), O que ler na ciência social brasileira (1970-1995). São Paulo: Sumaré.

LiMA, V. A. (1993). "CR-P: novos aspectos teóricos e implicações para a análise política”, en Comunicação \& Política, v. I , nº 3, pp. 95-106.

LimA, V. A. (1996). “Os mídias e o cenário de representação da política”, en Lua Nova, São Paulo, $n^{\circ} 38$.

Lima, V. A. (2001). Mídia: Teoria e Política. San Pablo: Fundação Perseu Abramo.

Limongi, F. y Figueiredo, A. (1995). "Os Partidos Políticos Na Câmara dos Deputados”, en Dados, v. 38, n. 3, p. 497-526

LippManN, W. (2003). La Opinión Pública. Madrid: Cuadernos de Langre.

LOPEZ GUERRA, L. (1977). Las campañas electorales: propaganda y política en la sociedad de masas. Barcelona: Ariel.

LÓPez Nieto, L. y Delgado Sotillos, I. (2000). Comportamiento Político. Sociología Electoral. Madrid: UNED.

LóPEZ VÁZqueZ, B. (2007). Publicidad Emocional. Estrategias creativas. Madrid: Esic Editorial.

LÓPEZ-ECOBAR, E.; LLAMAS, J. P. y REY, F.. (1996). "La agenda entre los medios: primero y segundo nivel”, en Comuncicación y Sociedad, v. IX, pp. 67-89.

LÓPEZ-Ecobar, E.; McCombs, M. y Rey, F. (1996). "La imagen de los candidatos: el segundo nivel de la agenda-setting”, en Comuncicación y Sociedad, v. IX, pp. 39-65.

LunTZ, F. I. (1988). Candidates, Consultants, and Campaigns: The Style and Substance of American Electioneering. Oxford: Basil Blackwell.

LUQUE, T. (1996). Marketing político. Barcelona: Ariel. 
LLERA RAMOS, F. (1982). Las elecciones políticas en la región castellanoleonesa. Valladolid: Ed. Ambito.

MAAREK, Ph. (2005). Marketing político y comunicación: Claves para una buena información política. (v.o. 1995). Barcelona. Paidos.

MacGinniss, J. (1970). Cómo se vende un presidente. Barcelona : Península, 1970

MACHADO, A. (1986). Rádios Livres: a reforma agrária no ar. São Paulo. Brasiliense.

MAINWARIng, S y SHUGART, M. S (1997). Presidentialism and Democracy in Latin America. Cambridge: Cambridge University Press.

MaInWARIng, S. (1990). Politicians, Parties and Electoral Systems: Brazil in Comparative Perspective, en Comparative Politics, Vol. 24, $\mathrm{n}^{\circ} 1$.

MAINWARING, S. (1999). "La durabilidad de la democracia en América Latina, 1940-1998", en Política y Gobierno, Vol. 2, pp. 315-363.

MAINWARING, S. y SCULLY, T. R. (1994). "A institucionalização dos sistemas partidários na América Latina”, en Dados, vol. 37, n⿳0 1.

Mainwaring, S.; Meneguello, R. y Power, T. (2000). Partidos Conservadores no Brasil Contemporâneo.Quem são, o que defendem, quem são suas bases. São Paulo: Paz e Terra: 2000

MAINWARING, S. (1990). “Brazil: Weak Parties, Feckless Democracy”. Paper presentado em el congreso de la APSA, San Francisco.

MANCINI, P. (1995). "Americanización y modernización. Breve história de la Campaña Electoral”, en MuÑOz, A. y Rospir, J. I. (eds.), Comunicación Política. Madrid: Universitas, pp.141-168

MANHEIM, J. B. (1984). “Can Democracy Survive Television?”, en Graber, D. (ed.), Media Power in Politics, Congressional Quarterly Press.

MANIN, B. (1997). "As metamorfoses do governo representativo", en Revista Brasileira de Ciencias Sociais, $\mathrm{n}^{0} 29$.

MANIN, B. (1998). Los principios del Gobierno Representativo. Madrid: Alianza.

MAQUIAVELO, N. (2000). El Príncipe. Madrid: Istmo.

MARAVALL, J. M. (2003). El control de los políticos. Madrid: Taurus.

MarCondes Filho, C. (1986). Política e imaginário nos meios de comunicação. São Paulo: Summus.

MARCONDES Filho, C. (1988). Televisão: a vida pelo vídeo. São Paulo: Moderna.

MARCONDES Filho, C. (1989). O Capital da Notícia. São Paulo: Ática.

MARKUn, P. (2004). O Sapo e o Príncipe: personagens, fatos e fábulas do Brasil contemporâneo. Rio de Janeiro, Objetiva, 2004.

MARTÍN SALGADO, L. (2002). Marketing político. Barcelona: Paidós.

MARTíneZ PANDIANI, G. (2000). "La irrupción del marketing político en las campañas electorales de América Latina”, Contribuciones, ${ }^{\circ}$ 2, pp.69-102, Buenos Aires: Konrad Adenauer/Ciedla.

Martínez Pandiani, G. (2001). Marketing Político, Campañas, Medios y Estrategias Electorales. Buenos Aires: Ugerman Editor.

MarTínez Silva, M. (1998). Manual de campaña política. México: Colegio Nacional de Ciencias Políticas. 
Martínez, A. y MÉNdez Lago, M. (eds.) (2000). Las elecciones al Parlamento Europeo de 1999. Valencia: Tirant lo Blanch.

MARTíNEZ, R. (ed.) (2004). La elección presidencial mediante doble vuelta en latinoamérica. Barcelona: ICPS

Mateos, A. (2004). "As atitudes políticas na Espanha, segundo uma estrutura dimensional indutiva”, em Opinião Pública, v.10, nº.1, pp.139-161.

Mateos, A. y Moral, F. (2006). Comportamiento electoral de los jóvenes españoles. Madrid: Instituto de la Juventud.

Matos, H. (org) (1994). Mídia, Eleições e Democracia. São Paulo: Scritta.

Mc NAIR, B. (1995). An Introduction to Political Communication. London: Routledge, 1995

McCombs, M. (1981). "The agenda-setting approach", en Nimmo y SANDERS (eds.), Handbook of Political Communication. Beverly Hills: Sage.

McCombs, M. (1996). "Influencia de las noticias sobre nuestras imágenes del mundo", en BRYANT y DOLF (eds.), Los efectos de los medios de comunicacción: Investigaciones y teorias. Barcelona: Paidós.

McCombs, M. (2005). Estableciendo la agenda. Barcelona: Paidós.

McCombs, M. y Shaw, D. L. (1972). “The Agenda-Setting Function of Mass Media”, en Public Opinion Quarterly, $\mathrm{n}^{\circ}$ 36, pp. 176-187.

McCombs, M. y Luna Pla, I. (eds.) (2003). Agenda-setting de los medios de comunicación. México: Universidad Iberoamericana/Universidad de Occidente.

McNAIR, B. (1995). An Introduction to Political Communication. Londres: Routledge.

MCQUAIL, D. (1979). Introducción a la teoría de la comunicación de masas. Barcelona: Paidós.

Melo, J. M. (1985). Comunicação: Teoria e Política. São Paulo: Summus..

MELo, J. M. (1994). "Eleições e meios de comunicação no Brasil. Análise do fenômeno Collor”. SP/Barcelona: USP, 1992.

Melo, C. R. F. (2000). Partidos e Migração Partidária na Câmara dos Deputados. En Dados, Rio de Janeiro, Vol. $43 \mathrm{n}^{\circ} 2$.

Melo, C. R. F. (2000). Retirando as Cadeiras do Lugar: Migração Partidária na Câmara dos Deputados (1985/1998). Belo Horizonte: UFMG.

Mellizo-Soto, M. F. (2001). “¿Para qué sirven las Campañas Electorales? - Los efectos de la campaña electoral española de 1993”. En REIS, nº 93, pp. 61-87.

MENDÉ, M. B. (2003). Campañas Electorales: La Modernización en América Latina, Casos de Argentina y México. México: Editorial Trillas, 2003.

MÉndez Lago, M. (2000). La estrategia Organizativa del Partido Socialista Obrero Español, 1975-1996. Madrid: CIS

MENDOnÇA, D. (2001). Casos \& Coisas. São Paulo: Editora Globo.

Mendonza, M y Oliveira, M. (2001). O Novo sindicalismo. Brasilia: Castelo.

Meneguello, R. (1989). PT, a formação de um partido (1979-1982). São Paulo: Paz e Terra.

Meneguello, R. (1997). “The Brazilian Electoral Behavior: The 1994 Presidential Election”, en International Journal of Social Science, n. 146, p. 627-641. 
Meneguello, Rachel (1998). Partidos e Governo no Brasil Contemporâneo (1985-1997). São Paulo: Paz e Terra.

Michels, R. (1991). Los partidos políticos: estudio sociológico de las tendencias oligárquicas de la democracia moderna. Buenos Aires: Amorrortu.

Miguel, L. F. (1999). "Mídia e Eleições: A Campanha de 1998 na Rede Globo”, en Dados, v. $42, n^{\circ} 2$.

Miguel, L. F. (2003). Mídia e vínculo eleitoral: a literatura internacional e o caso brasileiro. En Opinião Pública, Vol. X, $\mathrm{n}^{0}$ 1, pp. 91-111 (maio).

Miguel, L. F. (2004). "A Descoberta da Política: a campanha de 2002 na Rede Globo", en Rubim, A. A. (org.), Eleições Presidenciais em 2002 no Brasil: Ensaios sobre mídia, cultura e política. São Paulo: Hacker Editores, pp.91-105.

MoISÉs, J. A. (1990). “Eleições, participação e cultura política: mudanças e continuidades”, en Lua Nova, $\mathrm{n}^{0} 22$.

MoIsÉs, J. A. (1995). Os brasileiros e a democracia - bases sócio-políticas da legitimidade democrática. São Paulo: Ática, 1995.

MoIsÉs, J. A. (1997). “Cambio y Continuidades en la Cultura Política de los Brasileños”, en R. Winocur (comp.), Culturas Políticas a fin de siglo. Ciudad de Mexico: Juan Pablo Editor, pp. 77-125.

MOLINS, J. M. y OÑATE, P. (coords) (2006). Elecciones y comportamiento electoral en la España multinivel. Madrid: CIS

MonZón, C. (1996). Opinión pública, comunicación y política: la formación del espacio público. Madrid: Tecnos

Moraes, F. (1994). Chatô, o rei do Brasil. São Paulo: Cia das Letras.

Moreira Alves, M. (1998). Cultura e Ideologia: Jornalismo, Ética e Opinião Pública, en Rocha, E. (org.), Cultura e Imaginário. Rio de Janeiro: Mauad, pp. 127-169.

Morlino, L. (1994). "Problemas y Opciones en la Comparación", en G. SARTORI y L. MORLINO (comps.), La Comparación em las Ciencias Sociales, Madrid: Alianza, pp.13-28.

MORRIS, D. (2002). El Nuevo príncipe. Buenos Aires: El Ateneo.

MORRIS, D. (2002). Juegos de Poder. Ganar o perder: cómo juegan la partida los grandes líderes de la historia. Buenos Aires: El Ateneo.

MuÑoz Alonso, A. (org.) (1984). Las elecciones del cambio. Barcelona: Argos Vergara.

MuÑoz Alonso, A. y Rospir, J. I. (eds.) (1995). Comunicación Política. Madrid: Universitas.

MuÑoz Alonso, A. y RosPiR, J. I. (eds.). (1999). Democracia mediática y campañas electorales. Barcelona: Ariel.

Muñoz-Alonso, A.; Monzón, C.; Ropsir, R. I.; y DADER, J. L. (1992). Opinión Pública y Comunicación Política. Madrid: Eudema.

Muraro, H. (1991). Poder y comunicación. La irrupción del marketing y la publicidad en la política. Buenos Aires: Ediciones Letra Buena.

MURRAY, E. (1991). La construcción del espectáculo político. Buenos Aires: Manatial.

NASSER, M. C. Q. (2004). "Linguagem simbólica como ponte”, en Ciencias da ReligiãoHistória e Sociedade, ano 2, $\mathrm{n}^{\circ}$ 2, pp. 95-114. 
Natera, A. (2001). El liderazgo Político en la Sociedad Democrática. Madrid: Centro de Estudos Políticos e Constitucionais.

Negrine, R. M. y Lilleker, D. G. (2002). "The Professionalization of Political Communication: Continuities and Change in Media Practices", en European Journal of Political Communication, vol. 17, $\mathrm{n}^{\mathrm{O}}$ 3, pp.305-323.

Negrine, R. y Papathanassopoulos, S. (1996): "The 'Americanization' of Political Communication", en Press/Politics.

NeWMan, B. (1994). The Marketing of the President: political marketing as a campaign strategy. Thousand Oaks: Sage.

Nicolau, J. (2001). Falta de Fidelidade Partidária Anula Voto. En Jornal do Brasil, 10 de junho de 2001. Disponible en www.iuperj.br.

NiCOLAU, J. (2004). História do voto no Brasil. Rio de Janeiro: Jorge Zahar Editores.

Nimmo, D y Swanson, D. (1990). "The field of political communication", en Nimmo y SWANSON (ed.), New directions in political communications. Londres: Sage, pp. 7-47.

Nimmo, D. (1999). "The permanent campaign: Marketing as a Governing Tool", en B. Neuman (ED.), Handbook of Political Marketing, Thousad Oaks: Sage, pp.73-86.

Nimmo, D. y SANDERs, K (eds.) (1981). Handbook of Political Communication. Thousad Oaks: Sage.

Noblat, R.; Negreiros, J. y Dimenstein, G. (1985). O complô que elegeu Tancredo. Rio de Janeiro: Editora JB.Gilberto

Noelle-Neumann, E. (2002). La espiral del silencio. Opinión Pública: nuestra piel social. Barcelona. Paidós.

Nogueira, O. (1999). "Para Onde Caminha o Sistema Político Brasileiro?", en Parcerias Estratégicas, ${ }^{\circ}$ 6, pp. 68-79.

NOHLEN, D. (2004). Sistemas electorales y partidos políticos. México: FCE.

Norris, P. (2000). A Virtuous Circle: Political Communications in PostIndustrial Societies. Cambridge: Cambridge University Press.

NORRIS, P. (2001). "¿Un Circulo Virtuoso? El impacto de las comunicaciones políticas en las democracias post-industriales", en Revista Española de Ciencia Política, 4, pp.7-33.

NORRIS, P. (2004). "The evolution of election campaigns: Eroding political engagement?", paper presentado en la Conference sobre Comunicacción Política en el Siglo 21, en el St Margaret's College, University of Otago, New Zealand, enero.

Norris, P.; Curtice, J.; SANDERS, D.; SCAMmell, M. y SemetKo, H. A. (1999). On Message: Communicating the Campaign. LondRES: Sage.

NoRTH, D. (1993). Instituciones, Cambio Institucional y Desempeño Económico. México: Fondo de Cultura Económica.

O’DonNell, G. (1996). “Otra institucionalización”, en Política y Gobierno, v. III, nº 2, pp. 219-244

Oliveira, A. S. (2005). "Estética Pós-Moderna na Publicidade”, en Revista Famecos, vol. 1, $\mathrm{n}^{0} 13, \mathrm{pp} .113-120$.

OliveIRA, H. M. G. (2006). “Tancredo Neves: Muda Brasil! Volta a sorrir meu Brasil!”, en A. QUeIroz (org.), Na Arena do Marketing Político: Ideologia e propaganda nas campañas presidenciais brasileiras, São Paulo: Summus, pp.203-229. 
OliveIRA, M. J. C. (2003). "Gestão pública, comunicação e Cidadanía”, ponencia presentada en el XXVI Congresso Brasileiro de Ciências da Comunicação, Belo Horizonte, 2 al 6 de septiembre.

OLson, M. (1965). The logic of collective action, $2^{\mathrm{a}}$ ed. Cambridge: Harvard University Press [La lógica de la acción colectiva, México: Limusa, 1992].

ORo, A. P. (2003). "Organização eclesial e eficácia política: o caso da Igreja Universal do Reino de Deus”. En Civitas, v. 3, nº 1, pp. 97-109.

ORTRIWANO, Gisela Swetlana (1985). A informação no rádio: os grupos de poder e a determinação dos conteúdos. San Pablo : Summus, 1985.

PaIVA, D. A. P. (2005). La estrella viaja al centro: Cambio organizativo, moderación ideológica y profesionalización de las campañas electorales en el Partido de los Trabajadores (1989-2002). Tesina de Maestría en Estudios Latinoamericanos, del Institudo e Estudios de Iberoamérica, Universidad de Salamanca.

PaIVA, M. A. P. (1985) Direito político do sufrágio no Brasil(1822-1982). Brasília: Thesaurus.

PALETZ, D. (1997). “Campañas y Elecciones”, Cuadernos de Información y Comunicación (CIC), $\mathrm{n}^{\circ} 3$, pp. 205-228.

PALETZ, David L. (1998). The media in American politics. Nueva York: Longman.

Panebianco, A. (1990). Modelos de Partidos. Madri: Alianza.

Paniagua RoJano, F. J. (2004): Comunicación política y elecciones: Nuevas prácticas en el escenario español. Málaga: Asociación.

Paramio, L. (1997). "La sociedad desconfiada”. En Nexos, nº 29, pp. 63-67.

PARAmio, L. (1999). "Problemas de la consolidación democrática en América Latina en la década de los 90”. Documento de Trabajo 99-03. Madrid, Instituto de Estudios Sociales Avanzados.

PaRtido dos Trabalhadores (1998). Resoluções de Encontros e Congressos: 1979-1998. São Paulo: Editora Perseu Abramo.

PARTIDO DOS TRABALHADORES (2002). Trajetórias: das origens à vitória de Lula. São Paulo: Fundación Perseu Abramo.

PASQuino, G. (2003). "The New Campaign Politics in Southern Europe”, en Diamandouros y GunTher (eds.), Parties, Politics and Democracy in the New Southern Europe. London: John Hopkins University.

PAYNE, L. A. (1991). Industrialists, Labor Relations and The Transition to Democracy in Brazil. Kellogg Institute, Working Paper \# 158, abril.

Peiхото, C. A. (2000). "Coronel, enxada e voto", artigo digital disponible en http://www.iigov.org/dhial/?p=2_o2p

Pereira, C. y Mueller, B. (2006). "Partidos Fracos na Arena Eleitoral e Partidos Fortes na Arena Legislativa: A Conexão Eleitoral no Brasil”. En Dados, v. 46, no 4. pp. 735-771.

Pereira, C. y RenNó Jr., L. (2001). "O que é que o Reeleito Tem? Dinâmicas PolíticoInstitucionais Locais e Nacionais nas Eleições de 1998 para a Câmara dos Deputados”. En Dados, v. 44, ${ }^{\circ} 2$.

PÉREZ GarCíA, D. (2003): Técnicas de comunicación política. El lenguaje de los partidos. Madrid. Tecnos. 
PETERS, B. G. (2003). El nuevo institucionalismo: teoría institucional en ciencia política. Barcelona: Gedida.

PiColin, João Carlos (2006). "Peixe Vivo em Água Fria: Juscelino e a propaganda política”, en A. QueIroz (org.), Na Arena do Marketing Político: Ideologia e propaganda nas campañas presidenciais brasileiras, São Paulo: Summus, pp.147-183.

Pinto, J. N. (1989). Atrás do Palanque: bastidores das eleições 1989. São Paulo: Siciliano.

PiNTO, V. B. N. (1994). "Das estradas persas às rodovias da informação", en H. MATos (org.), Mídia, Eleições e Democracia: São Paulo, Scritta, pp. 1-11.

Pizzorno, A. (1989). "Algún otro tipo de alteridad: una crítica a las teorías de la elección racional", en Sistema, no 88 , pp. 27-42.

Plasser, F. (2000). "Proliferación mundial de técnicas americanas en campañas electorales”, Contribuciones, 2000, Año XVII, 2 (66), pp. 123-148.

PlaSSER, F. y PlASSER, G. (2002). La campaña global: Los nuevos gurúes del marketing político en acción. Buenos Aires: Temas Grupo Editorial.

Plasser, F.; Scheucher, C. ySenft, C. (1999). "Is There a European Style of Political Campaigning?”, en NEwMAN (ed.), Handbook of Political Marketing. Thousand Oaks: Sage, pp. 89-112.

PoRTo, M. P. (1995). "Telenovela e política: O CR-P da eleição presidencial de 1994", en Comunicação \& Política, Vol. 1, no 3, pp. 55-76.

PorTo, M. P. (2004). "A televisão e o primeiro turno das eleições presidenciais de 2002". En Rubim, A. A. C. (org.) Eleições Presidenciais em 2002 no Brasil: Ensaios sobre mídia, cultura e política. São Paulo: Hacker Editores, pp. 68-90.

PRIESS, F. (2000). "El marketing político y su incidencia en el éxito electoral - Una visión de la literatura más reciente". Contribuciones, $\mathrm{n}^{0} 2$, pp. 149-157.

Priess, F. y Thesing, J. (ed.) (1999). Globalización, democracia y medios de comunicación. Buenos Aires: Ciedla/Konrad Adenauer Stiftung.

Priess, F., y Tuesta Soldevilla, F. (ed.) (1999). Campañas electorales y medios de comunicación en América Latina, 2 Tomos. Buenos Aires: Ciedla/Konrad Adenauer.

QUeIROZ, A. (1998). "Voto, mídia e pesquisa: propaganda política no Brasil". En Comunicação \& Sociedade, São Bernardo do Campo: Umesp, PósCom, no 30, p.105140.

QUEIROZ, A. (2006b). "Ideologia e propaganda política na literatura latino-americana”, en A. QueIroz (org.), Na Arena do Marketing Político: Ideologia e propaganda nas campañas presidenciais brasileiras, São Paulo: Summus, pp.19-35.

QUEIROZ, A. (2006c). "Fernando Henrique Cardoso: as armas de sedução na propaganda política”, en A. QueIroz (org.), Na Arena do Marketing Político: Ideologia e propaganda nas campañas presidenciais brasileiras, São Paulo: Summus, pp.327338.

QueIROZ, A. (org.) (2006). Na Arena do Marketing Político: Ideologia e propaganda nas campañas presidenciais brasileiras. São Paulo: Summus.

RABENEICK, M. (1998). "Elecciones de fin de siglo en el Ecuador", Contribuciones vol. 15, $\mathrm{n}^{\mathrm{o}}$ 3, Buenos Aires: Fundación Konrad Adenauer, pp. 227-236.

RADUNSKI, P. (1983): Luchas electorales: la conducción moderna de la lucha electoral como comunicación política. Bonn. Institut für Internationale Solidritat. 
RAMONET, I. (1998): La tiranía de la comunicación. Madrid. Debate.

REES, L. (1995). Vende-se Política. São Paulo: Revan.

Reis, F.; Castelo Branco, R. y Martensen, R. L. (orgs) (1990). História da propaganda no Brasil. São Paulo: T.A Queiroz.

REIS, J. C. (1999). As Identidades do Brasil. Rio de Janeiro: FGV.

RENNÓ JR., L. (1999). "Instituições, cultura e lógica da desconfiança numa cidade brasileira”, en M. BAQUero (org.), Desafios da Democratização na América Latina, Porto Alegre: Editora UFGRS, pp. 103-132.

Reyes, A. y Munch, L. (1998). Comunicación y Mercadotecnia Política. México: Editorial Noriega.

RiBEIRO, P. J. F. (2007). "Las elecciones en Brasil: Comsolidación electoral del PT y reafirmación de la fuerza personal del presidente Lula". Ponencia presentada en el Simposio ESyP1, América Latina 2006 - balance de un año de elecciones, en el V Congreso Europeo CEISAL de Latinoamericanistas. Bruxelas, 11-14 de abril.

Ries, Al y Trout, Jack (1989). Posicionamento. São Paulo: Pioneira.

Roberts, K. y ARCE, M. (1998). "Neoliberalism and Lower-Class Voting Behavior in Peru", en Comparative Political Studies, v. 31, $\mathrm{n}^{0}$ 2, pp. 217-246.

Rocha, F. (2004). “O Homem vestido de herói”, en Scientia et Spes, Año 3, n o 6, pp.131152.

RochA, F. (2005). "La hipótesis de la americanización en la campaña electoral en Brasil 2002". Trabajo presentado en el $9^{\circ}$ Encuentro Español de Latinoamericanistas, realizado en Tordesillas, 26 al 28 de mayo de 2005.

Rocha, F. (2006). "La intermediación del voto”, en Apuntes Electorales, n ${ }^{\circ}$ 25, pp. 79-114.

Rodrigues, L. M. (2002). Partidos, Ideologia e Composição Social. Um Estudo das Bancadas Partidárias na Câmara dos Deputados. São Paulo: Edusp:2002

Rodriguez DíAZ, R. (2004). Teoría de la Agenda-Setting: aplicacióna la enseñanza universitaria. Aliance: Observatorio Europeo de Tendencias Sociales. Disponible en www.obets.ua.es.

RoMA, C. (2002). "Programa partidário e ação estratégica das lideranças: PT e PSDB em perspectiva comparada". Texto apresentado, en el $3^{\circ}$ Encontro Nacional da Associação Brasileira de Ciência Política (ABCP), en Rio de Janeiro.

RomA, C. (2004). A trajetória do PSDB na recente democracia brasileira. Boletim Conjuntura Política, v. 16, 17-19.

RomA, C. (2006). "Organizaciones de partidos en Brasil: el PT y el PSDB bajo perspectiva comparada”, en América Latina Hoy, $\mathrm{n}^{\circ}$ 44, pp. 153-184.

Romanini, M. G. (2006). "Prudente de Moraes: a visão singular como sustentáculo do fenômeno coletivo", en A. Queiroz (org.), Na Arena do Marketing Político: Ideologia e propaganda nas campañas presidenciais brasileiras, São Paulo: Summus, pp.99-122.

Romano, R. (1979). Brasil: Igreja contra Estado. São Paulo: Kairós.

Romero, A. (1979). Estrategia y Política en la era nuclear. Madrid: Tecnos.

RONCERO, M.T. (1998). "Antonio Banderas versus Julio Iglesias: la imagen de la política en prensa". Ponencia presentada en el II Workshop de Investigadores Audiovisuales. Facultad de Comunicación Audiovisual. Salamanca. 
RONCERO, M.T. y SAMPEDRO, V. F. (1998). "¿Noticias o carteles electorales?. Imagen política en prensa e info-propaganda", en Revista Latina de Comunicación Social, $\mathrm{n}^{0}$ 10, diponible en: http://www.lazarillo.com/latina/a/22salamanca/22sala.htm

Rosa E Silva, C. H. (1993). Mil dias de solidão. São Paulo: Mundo das Letras.

Rosenberg, S, Bohan, L., McCaffery, P y Harris, K. (1986). "The Image and the Vote: The Effect of Candidate Presentation on Voter Preference." American Journal of Political Science 30: 108-127.

Rospigliosi, F. (2000). "Fujimori y El Niño. Campaña reeleccionista en aguas turbias”, en Nueva Sociedad, no 154, pp. 6-13.

RosPIR, J. (1999). "La globalización de las campañas electorales”, en MuÑOZ-ALONSO, A. y RosPIR, J., Democracia mediática y campañas electorales, Madrid: Ariel, pp. 55-88.

Rounce, A. D. (2004). Political Actors' Perceptions of Public Opinion:Assessing the Impact of Opinion on Decision Making. Encuentro Anual de la Asociación Canadense de Ciencia Política, 3-5 de junio.

RUA, M. G. (1995). "Mídia, informação e política: a eleição presidencial brasileira de 1994", en Comunicação e Política, Rio de Janeiro, v. 1, n. 3, p. 77-94, abr.-jul.

Rubim, A. A. (1999). Comunicação, espaço público e eleições presidenciais. En Comunicação \& Política, São Paulo, Vol. 9, nº 2, pp. 7-23.

RuBim, A. A. (org.) (2004). Eleições Presidenciais em 2002 no Brasil: Ensaios sobre mídia, cultura e política. São Paulo: Hacker Editores.

Rubim, Antonio A. C. (2004). "Visibilidades e estratégias nas eleições presidenciais de 2002: política, mídia e cultura”. En RuBIM, A. A. C. (org.), Eleições Presidenciais em 2002 no Brasil: Ensaios sobre Mídia, Cultura e Política. San Pablo: Hacker, pp. 7-28.

Rubim, Antonio A. C. y AzEvedo, Fernando (1998). "Mídia e política no Brasil". En Lua Nova, $\mathrm{n}^{0} 43$, pp.189-216.

Rubim, A. C. (1994). "Mídia e Política: Transmissão de Poder”, en Matos, H. (org.), Mídia, Eleições e Democracia: São Paulo, Scritta, pp.31-52.

SABAto, L. (1981). The Rise of Political Consultants: New Ways of Winning Elections, Basic Books, New York, 1981.

Sabato, L. J. (1981). The Rise of Political Consultants: New Ways of Winning Elections. New York: Basic Books.

SÁDABA, T. (2003). "Los anuncios de los partidos en televisión: el caso de España", en BERROCAL (coord.), Comunicación política en televisión y nuevos medios. Madrid: Ariel, pp. 163-205.

SADEK, M. T. (1993) Sistema Partidário Brasileiro: a debilidade institucional. ICPS, Barcelona, Working Paper $\mathrm{n}^{\circ} 72$.

SALÀs DARRocha, J. T. (2004). "Brasil", en MARTínEZ, La elección presidencial mediante doble vuelta en latinoamérica. Barcelona: ICPS, pp. 99-138.

SALGADO, Lourdes Martín. Marketing político: arte y ciencia de la persuasión en democracia. $2^{\text {a }}$ edición. Barcelona, Paidós, 2002, pp. 199-209.

SAMPaIO, R. (2003) Propaganda de A a $Z, 3^{\mathrm{a}}$ ed. Rio de Janeiro: Campus.

SAMPEDRO, V. (2000). Opinión pública y democracia deliberativa. Medios, sondeos y urnas. Madrid: Istmo. 
SAMPEDRO, V. (ed.) (2003). La pantalla de las identidades. Medios de comunicación, políticas y mercados de identidad. Barcelona. Icaria.

SAMPEDRO, V. (ed.) (2005). 13-M Multitudes on-line. Madrid. Los libros de la Catarata.

SAmuels, D. (2001). "Money, Elections, and Democracy in Brazil." Latin American Politics and Society, v. 43, $\mathrm{n}^{\mathrm{O}} 2$, pp. 27-48.

SAmuels, D. (1999). "Incentives to Cultivate a Party Vote in a System Candidate-Centric Electoral System: Evidence From Brazil”, en Comparative Political Studies, v. 32 no 4 , pp. 487-518.

SAmuels, D. y ABRUcio, F. L. (2000). "Federalism and Democratic Transitions: The 'New' Politics of the Governors in Brazil”, en Publius: The journal of Federalism, v. 30, $\mathrm{n}^{\circ}$ 2, pp. 43-61.

SÁnchez Alonso, O. (2005). El servicio postvenda de la política. Salamanca: Publicaciones Universidad Pontificia de Salamanca.

SÁnchez-CuencA, I. (2004). Teoría de Juegos. Cuadernos Metológicos, $n^{o}$ 34. Madrid: CIS.

SANCHIS, J. L. (1996). Cómo se gana el Poder. Madrid Espasa/Calpe.

SANTA Rita, C. (2001). Batalhas Eleitorais: 25 anos de Marketing Político. São Paulo: Geração Editorial.

SANTANA, M. A. (1999) Entre a Ruptura e a Continuidade: visões da história do movimento sindical brasileiro. En Revista Ciência da Informação, Vol. 14, $\mathrm{n}^{\circ} 41$ (outubro), pp.103-120.

SANTIAGO BARNÉS, J. (2006). El político nace o se hace. Salamanca: Amarú.

SANTIAGO BARNÉs, J. (2007). La imagen del político.Madrid: Prósopon.

SARTORI, G. (1987). Partidos y Sistemas de Partidos. Madrid: Alianza

SARTORI, G. (1990). Homo Videns. Madrid: Taurus.

SARTORI, G. (1992). Elementos de teoría política. Madrid: Alianza.

SARTORI, G. (1994). “Comparación y Método Comparativo”, en SARTORI y MORLINO

(comps.), La Comparación en las Ciencias Sociales, Madrid: Alianza, pp.29-49.

SARTORI, G. y Morlino, L. (comps.) (1994). La Comparación em las Ciencias Sociales. Madrid: Alianza.

Scammell, M. y Semetko, H. (1995). "Political Advertising on Television: The British Experience". En KAID y HOLTZ-BACHA (eds.), Political Advertising in Western Democracies: Parties and Candidates on Television. London: Sage.

SCARROW, S. E.; WebB P. y FARRELl, D. (2004). "De la integración social a la competición electoral: la nueva distribución del poder en los partidos políticos”, en Zona Abierta, $\mathrm{n}^{\mathrm{o}}$ 108/109, pp. 111-146.

SCHEUfELE, D. A. (1999). "Framing as a theory of media effects", en Journal of Communication, New York, v. 49, $\mathrm{n}^{\mathrm{0}}$ 1, pp. 103-122.

SCHMUCler, H. y MATA, M. (coord) (1992). Política y comunicación. ¿Hay lugar para la política en la cultura mediática? Córdoba: Catálogos/UNC.

SERBIN, K. P. (1999). “The Catholic Church, Religious Pluralism, and Democracy in Brazil”. Kellogg Institute, \# 263, febrero. 
Side, J.; Grossman, M.; LiPsitZ, K.; y Trost, C. (2003). "Candidate Attacks and Voter Aversion: The Uncertain Link Between Negativity and Campaign Satisfaction". Berkeley: Berkeley University of California, WP 2003/3.

SilveirA, F. E. (2000). “A dimensão simbólica da escolha eleitoral”. En FiguEIREDo (org.). Marketing político e persuasão eleitoral. São Paulo: Fundação Konrad Adenauer.

SINGER, A. (1999). Esquerda e direita no eleitorado brasileiro. São Paulo: EDUSP.

SingER, A. (2001). O PT. São Paulo, Publifolha, 2001.

Singer, A. (org.) (1990). Sem medo de ser feliz. São Paulo: Scritta Editorial.

SOARES, G. A. D. (1981). A Formação dos Partidos Nacionais. En Fleischer, D. (org.), Os Partidos Políticos no Brasil, v. I.

SODRÉ, N. W. (1978). Historia da imprensa no Brasil. São Paulo: Mauad Editora.

SOlER SÁNCHEZ, M. (2001). Campañas electorales y Democracia en España. Castelló de la Plana: Publicaciones de la Universitat Jaume I.

SouZA, M. C. C. (1976). Estado e Partidos Políticos no Brasil (l930-1964) . São Paulo: AlfaOmega: 1976

Steffen, C. (2004). A Política nos espaços digitais: a campanha Presidencial de 2002 na Internet. Tesina de maestria presentada en la Universidad Valle de los Sinos (Unisinos), São Leopoldo.

Stromback, J. y Dimitrova, D. (2006). "Political and Media Systems Matter: A Comparison of Election News Coverage in Sweden and the United States", en The Harvard International Journal of Press/Politics, pp. 11-131

SWANSON, D. (1995). "El campo de la comunicación política. La democracia centrada en los medios", en A. MuÑoz-Alonso y J. I. RosPIR (eds.), Comunicación Política. Madrid: Universitas.

Swanson, D. K. y Nimmo, D. (1990). New Directions in Political Communications. Londres: Sage.

Swanson, D. L. y Nimmo, D. (eds.). (1990). New Directions in Political Communication - A resource Book. New Park: sage.

Swanson, D.L. y Mancini, P. (eds.) (1996). Politics, Media and Modern Democracy. An International Study of Innovations in Electoral Campaigning and Their Consequences. Londres: Praeguer.

TAAgePERA, R. y SHugarT, M. S. (1987). Seats and Votes: The Effects and Determinants of Electoral Systems. New Have: Yale University Press.

TAVARES (1988). Propaganda nos Impérios da Antiguidade. Lisboa: Presença.

TCHAKHotine, S. (1967). A mistificação das massas pela propaganda política. Rio de Janeiro: Civilização Brasileira.

Thesing, J. y PRIEss, F. (1999). Globalización, Democracia y Medios de Comunicación. Buenos Aires: Konrad - Adenauer.

THompson, John (2001). El escándalo politico. Poder y visibilidad en la era de los medios de comunicación. (v.o. 2000). Barcelona. Paidós.

ToCQueVille, A. (1990). La democracia en América. Madrid, Aguilar.

Torquato do Rego, G. (1985). Marketing Político e governamental. São Paulo: Summus. 
Trelles CruZ, M. E. (2006). "Medios de comunicación y gobernabilidad. Escenarios de interdependencia en la comunicación política”, en UNIrevista, Vol. 1, $\mathrm{n}^{\circ} 3$.

Trent, J. S. y Friedenberg, R. V. (2000) Political Campaign Communication. Principles and Practices. Londres: Praeger.

Tuesta Soldevilla, F. (1997). No Sabe/No Contesta. Encuestas Políticas y Medios. Lima: Universidad de Lima-Fundación Konrad Adenauer.

VALDEZ ZEPEDA, A. (2004). Campañas electorales inteligentes. Guadalajara: Universidad de Guadalajara.

VALDEZ ZEPEDA, A. (2006). El arte de ganar elecciones. México: Trillas

Valença, M. M. Patron-Client Relations and Politics in Brazil: An Historical Overview. Texto disponible

en: http://www.lse.ac.uk/collections/geographyAndEnvironment/pdf/rp58.pdf.

VAlLÉs, J. M. y Bosch, A. (1997). Sistemas electorales y gobierno representativo. Barcelona: Ariel.

VELASCO, J. C. (2003). "Patriotismo constitucional y republicanismo", Claves de razón práctica, $\mathrm{n}^{\mathrm{O}} 125$, pp. 33-40.

Ventura, Z. (1988) 1968 - O Ano que Não Terminou. Rio de Janeiro: Nova Fronteira.

VERdugo HidAlgo, E.. (20003). Estudio comparativo del análisis de las estrategias de persuasión en las campañas parlamentarias del Partido Popular de España en el 2000 y del Partido Demócrata Cristiano de Chile en el 2001. Tesis doctoral en la Universidad Diego Portales, Santiago.

VV.AA. (2002). La comunicación política. Transformación del espacio público. Monográfico de la Revista De Signis, $\mathrm{n}^{0}$ 2. Barcelona: Gedisa.

WAISBORD, Silvio (1995): El gran desfile. Campañas electorales y medios de comunicación en la Argentina. Editorial Sudamericana. Buenos Aires.

Weber, M. (1991). El Político y el Científico. Madrid. Alianza.

White, T. (1962). Como se faz um presidente da República. Belo Horizonte: Itatiaia.

Winocur, R. (2002). Ciudadanos mediáticos. La construcción de lo público en la radio. México: Gedisa.

Wolf, Mauro (1992). Teorias de Comunicação. Lisboa: Editorial Presença.

Wolton, D. (1996). Elogio do grande público: uma teoria crítica da televisão. São Paulo: Ática.

Wolton, Dominique (1999). Sobre la comunicación: Una reflexión sobre sus luces y sus sombras. Barcelona. Acento.

Wright Mills, C. (1964). Poder, Política y Pueblo. México: FCE.

WRING, D. 2002. "Images of Labour: The Progression and Politics of Party Campaigning in Britain”, en Journal of Political Marketing, v. $\mathrm{n}^{\circ} 1$. 


\section{Fontes on-line:}

Banco Central de Brasil: www.bcb.gov.br

BBC: http://news.bbc.co.uk/hi/spanish/latin_america.htm

Costa Bonino: http://costabonino.com/brasil.htm.

Folha de S. Paulo: www.folha.com.br

Instituo Vox Populi de Opinión Pública: www.voxpopuli.com.br

Instituto Data Folha de Opinión Pública: www.datafolha.com.br

Instituto Ibope de Opinión Pública: www.ibope.com.br

IUPERJ - Ver www.iuperj.br.

New York Times: www.nyt.com).

O Estado de S. Paulo : www.estadao.com.br

O Globo: www.oglobo.com.br

PSDB: www.psdb.org.br

PT: www.pt.org.br

Revista Época: www.epoca.com.br

Revista Isto É: www.istoe.com.br

Revista Veja : www.veja.com.br

Senado Federal: ww.senado.gov.br

Tribunal Superior Electoral: www.tse.gov.br).

TV Globo: www.globo.com 